FABRICIO GUSTAVO TARDIVO

ESTUDO DE ESQUEMAS ESTRUTURAIS E MODELAGEM DE TABULEIROS DE PONTES ESCONSAS 
FABRICIO GUSTAVO TARDIVO

\section{ESTUDO DE ESQUEMAS ESTRUTURAIS E MODELAGEM DE TABULEIROS DE PONTES ESCONSAS}

Dissertação apresentada à Escola Politécnica da Universidade de São Paulo para obtenção do título de Mestre em Engenharia.

Área de Concentração:

Engenharia de Estruturas

Orientador: Prof. Dr. Fernando Rebouças Stucchi 
Este exemplar foi revisado e corrigido em relação à versão original, sob responsabilidade única do autor e com a anuência de seu orientador.

São Paulo, 22 de janeiro de 2014.

Assinatura do autor

Assinatura do orientador

FICHA CATALOGRÁFICA

Tardivo, Fabricio Gustavo

Estudo de esquemas estruturais e modelagem de tabuleiros de pontes esconsas / F.G. Tardivo. - versão corr. -- São Paulo, 2014.

$162 \mathrm{p}$.

Dissertação (Mestrado) - Escola Politécnica da Universidade de São Paulo. Departamento de Engenharia de Estruturas e Geotécnica.

1.Tabuleiros de pontes I.Universidade de São Paulo. Escola Politécnica. Departamento de Engenharia de Estruturas e Geotécnica II.t. 


\section{RESUMO}

O presente trabalho se propôs a estudar os esquemas estruturais alternativos para pontes esconsas e avaliar as modelagens matemáticas possíveis através de softwares especializados, como o SAP2000 e STRAP2010, a fim de identificar as melhores soluções e modelos para cada caso. O objetivo foi o de aprimorar os modelos de cálculo, especialmente no que diz respeito à previsão das reações de apoio e das forças cortantes, ponto mais delicado de obras esconsas. O estudo baseou-se em soluções de superestrutura em laje e em grelha, com ou sem transversinas, com esconsidade variável entre zero e sessenta graus, eixo longitudinal reto, modeladas por barras e elementos finitos. Não foi objeto deste estudo a influência da meso e da infraestrutura dessas pontes nos esforços na superestrutura.

Palavras-chave: Pontes. Pontes esconsas. Tabuleiros. Esconsidade. 


\section{ABSTRACT}

The present work is proposed to study alternative structural schemes for skew bridges and to evaluate possible mathematical modeling through specialized software, such as SAP 2000 and STRAP2010, in order to identify the best solutions and models for each case. The aim was to improve the calculation models, especially with regard to the prediction of the support reactions and shear forces, most delicate point in skew bridges. The study was based on slab or grid, with or without transversal beams, superstructure solutions, with variable skew between zero and sixty degrees, straight longitudinal axis, modeled through bars and shell elements. It was not purpose of this study the influence of meso and infrastructure of the bridge on its superstructure.

Keywords: Bridges. Skew bridges. Slab deck. 


\section{LISTA DE ILUSTRAÇÕES}

Figura 1 - Ponte reta ortogonal

Figura 2 - Ponte esconsa 3

Figura 3 - Seção transversal de uma ponte em laje maciça .............................................. 4

Figura 4 - Principais indicadores de uma laje esconsa................................................. 5

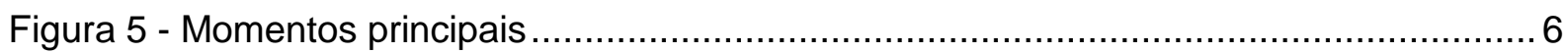

Figura 6 - Efeito dos espaçamentos entre aparelhos de apoio.......................................... 7

Figura 7 - Efeito da flexibilidade dos aparelhos de apoio ........................................... 8

Figura 8 - Exemplo de superfície de influência.......................................................... 9

Figura 9 - Seção transversal de uma ponte em grelha ................................................. 10

Figura 10 - Variações dos ângulos de esconsidade estudados...................................... 13

Figura 11 - Vista superior típica do tabuleiro de laje estudada ........................................ 14

Figura 12 - Seção transversal típica do tabuleiro de laje estudada .................................. 14

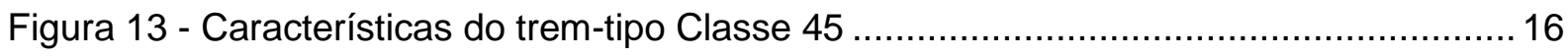

Figura 14 - Localização dos pontos de dimensionamento.......................................... 17

Figura 15 - Direção dos momentos principais ........................................................ 20

Figura 16 - Modelo matemático adotando apoios com restrição a translações ...................21

Figura 17 - Modelo matemático adotando molas que simulam os aparelhos de apoio.........22

Figura 18 - Locação e nomenclatura dos apoios estudados......................................... 35

Figura 19 - Vista superior típica do tabuleiro de grelha estudada .................................... 49

Figura 20 - Seção transversal típica do tabuleiro de grelha estudada ............................. 49

Figura 21 - Características da longarina............................................................ 50

Figura 22 - Características do trem-tipo Classe 45 e trem-tipo Classe 45 homogeneizado 51

Figura 23 - Modelo matemático adotando apoios com restrição a translações....................52

Figura 24 - Modelo matemático adotando molas que simulam os aparelhos de apoio ........53

Figura 25 - Estrutura sem transversinas de apoio .................................................. 54

Figura 26 - Estrutura sem transversinas de apoio ................................................. 54

Figura 27 - Balanço Longitudinal - 15ำ Figura 28 - Balanço Longitudinal $-60^{\circ} \ldots \ldots \ldots \ldots . . . .71$ 


\section{LISTA DE TABELAS}

Tabela 1 - Sinais para determinação da direção dos momentos principais .........................20

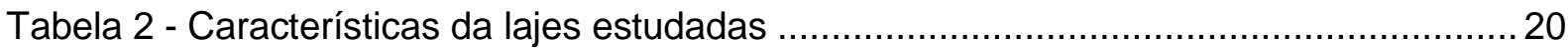

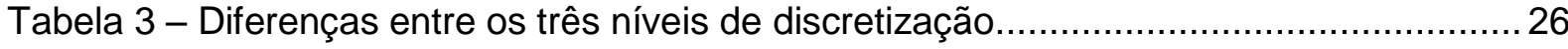

Tabela 4 - Erro devido ao carregamento indevido - ponto A ............................................ 28

Tabela 5 - Comparação entre discretização com elementos esconsos e retangulares........ 29

Tabela 6 - Momentos Principais - STRAP ................................................................. 30

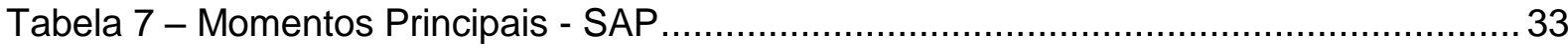

Tabela 8 - Solicitações e Momentos Principais - RUSCH …........................................ 33

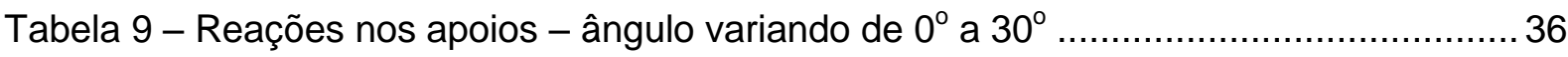

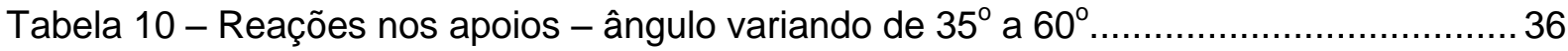

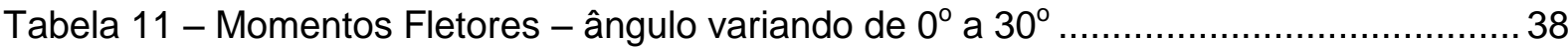

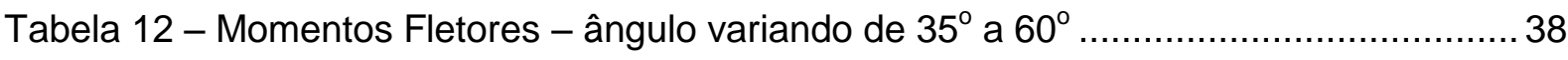

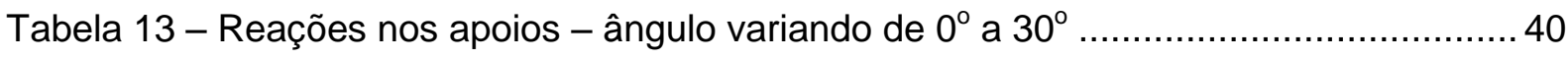

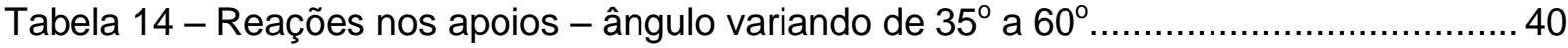

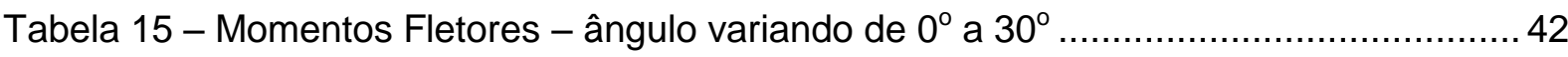

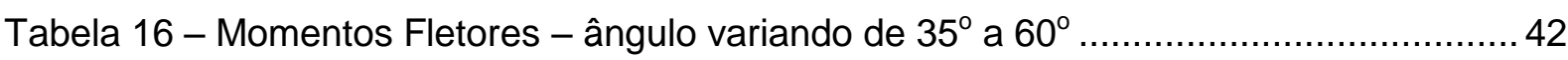

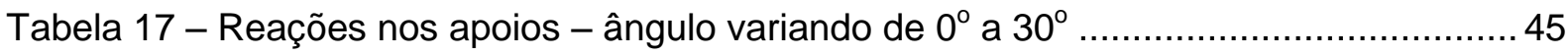

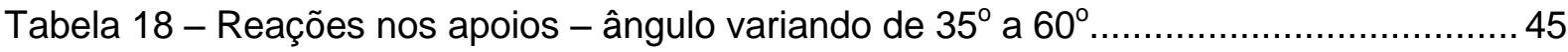

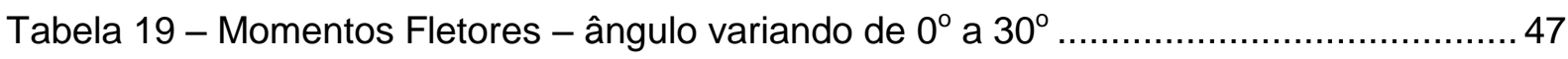

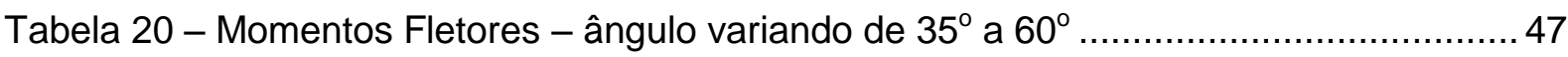

Tabela 21 - Características da lajes estudadas........................................................... 50

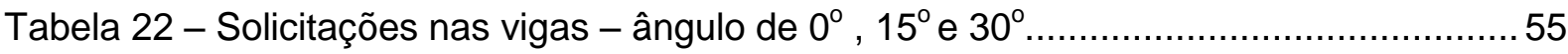

Tabela 23 - Solicitações nas vigas - ângulo variando de $45^{\circ}$ e $60^{\circ}$.................................. 55

Tabela 24 - Solicitações nas vigas - ângulo de $60^{\circ}$ com apoios flexíveis ..........................60

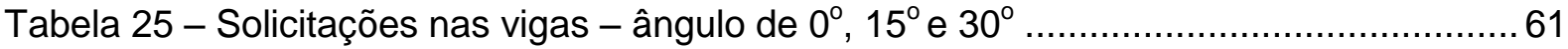


Tabela 26 - Solicitações nas vigas - ângulo variando de $45^{\circ}$ e $60^{\circ}$

Tabela 27 - Solicitações nas vigas - ângulo de 0ำ, 15ำ e 30ำ 66

Tabela 28 - Solicitações nas vigas - ângulo variando de $45^{\circ}$ e $60^{\circ}$ 66 


\section{SUMÁRIO}

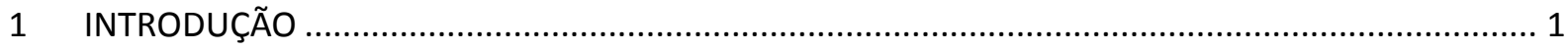

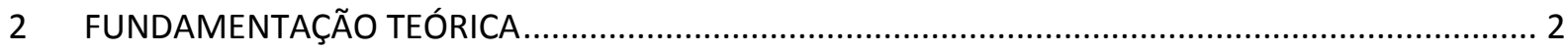

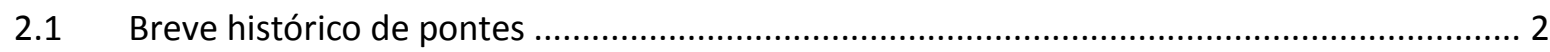

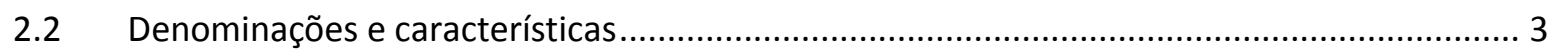

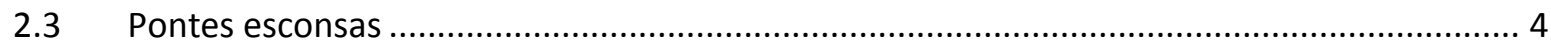

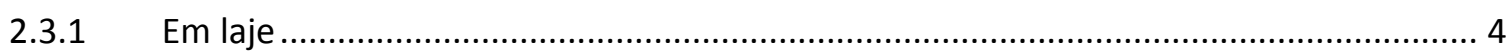

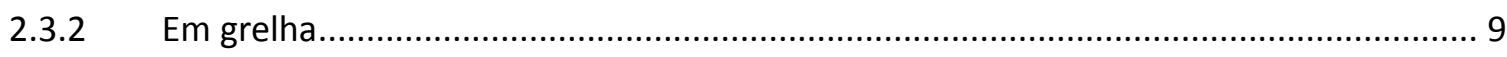

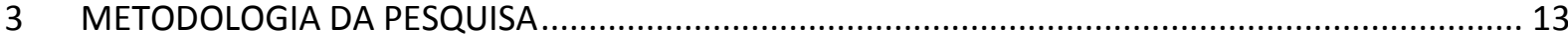

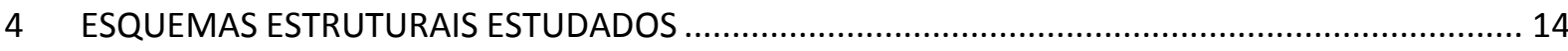

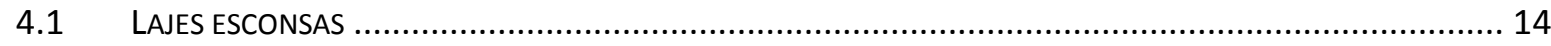

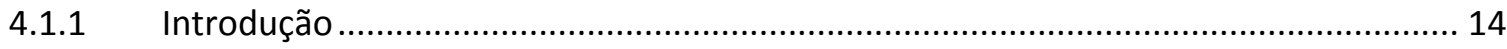

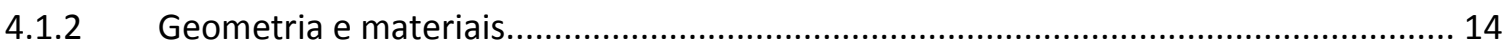

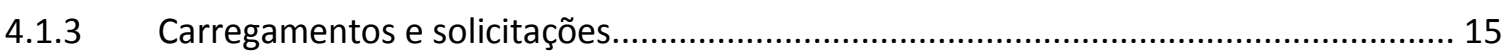

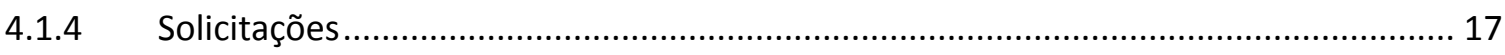

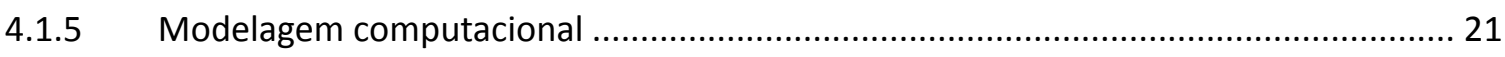

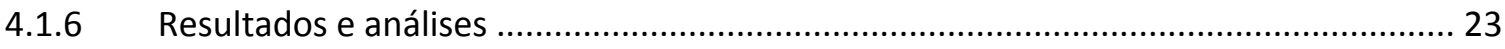

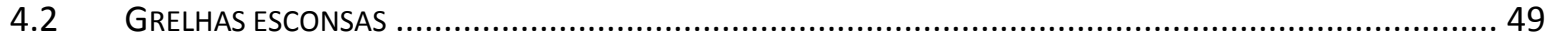

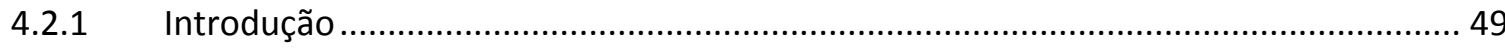

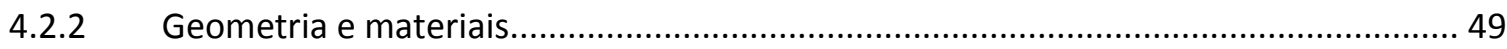

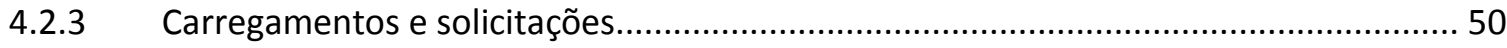

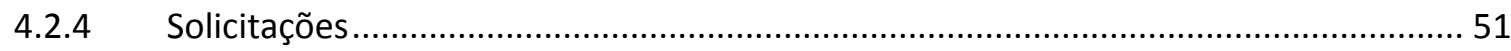

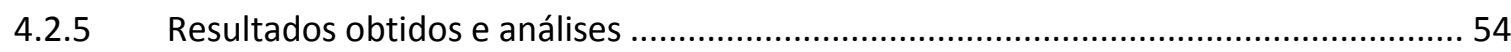

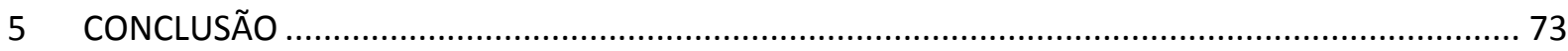

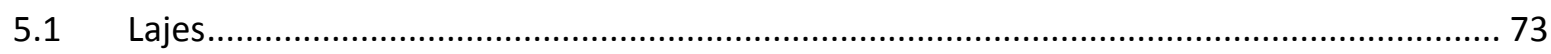

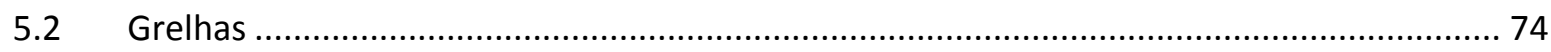

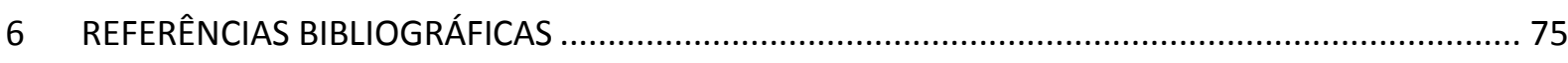

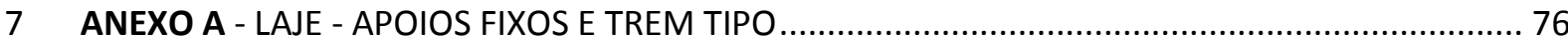

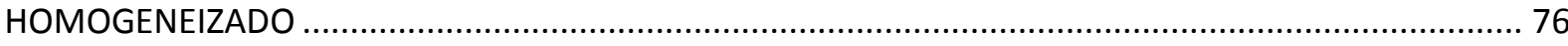

8 ANEXO B - LAJE - APOIOS FIXOS E SEM HOMOGENEIZAÇÃO …….......................................... 93

9 ANEXO C - LAJE - APOIOS FLEXIVEIS E SEM HOMOGENEIZAÇÃO ............................................ 108 


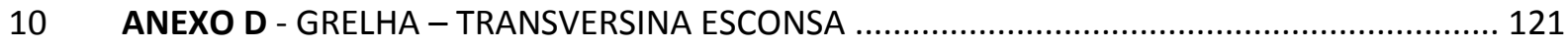

11 ANEXO E - GRELHA - TRANSVERSINA NORMAL A LONGARINA ........................................ 137

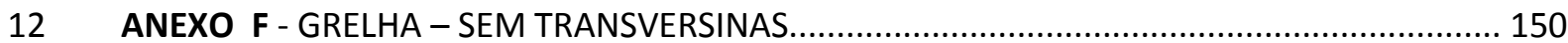




\section{INTRODUÇÃO}

Ponte é uma estrutura construída para vencer um obstáculo e estabelecer a continuidade de uma via de qualquer natureza. Neste trabalho, a via estudada é uma rodovia, mas poderia ser uma ferrovia, uma passagem de pedestres ou, até mesmo, uma hidrovia. Associa-se a denominação de "ponte" quando o obstáculo a ser transposto é constituido de um curso d’água, já quando o obstáculo é um vale ou uma via, nomea-se "viaduto".

Neste trabalho, as denominações não serão diferenciadas, de maneira que, ao se ler "pontes", deve-se considerar que pode tratar-se de um viaduto também.

No passado, o cálculo dos esforços nas pontes esconsas apresentava muitas dificuldades. Porém, com o avanço na capacidade de processamento dos computadores e com o desenvolvimento de programas de análise estrutural, esse problema foi minimizado. Assim, a solução esconsa se tornou mais usual e econômica, mas os resultados ainda dependem muito da solução escolhida e do modelo de cálculo adotado. Especialmente as reações de apoio e as forças cortantes variam muito dependendo do ângulo de esconsidade. O assunto ainda preocupa o meio técnico a ponto de, frequentemente, surgirem publicações sobre ele, como no recente Congresso da FIB, em Washington (1), e, embora menos frequentes, casos de ruptura de aparelhos de apoio ou vigas por força cortante em obras executadas.

Esta pesquisa tem por objetivo geral aprofundar o estudo dos esquemas estruturais de pontes esconsas com esconsidade variável de zero a sessenta graus, bem como a avaliação de modelos matemáticos utilizados para o cálculo de esforços solicitantes, procurando identificar:

- o efeito da esconsidade na obras em laje;

- o efeito das transversinas nas grelhas esconsas;

- as limitações de cada tipo estrutural em relação à esconsidade;

- as modelagens mais adequadas para cada caso. 


\section{FUNDAMENTAÇÃO TEÓRICA}

\subsection{Breve histórico de pontes}

Segundo Leonhardt (2), os materiais empregados na construção indica, de forma resumida, um histórico dos tipos de pontes na seguinte ordem cronológica:

a) Pontes de madeira - material empregado desde a Antiguidade. A ponte sobre o rio Reno, construida em 1758 utilizando madeira, apresenta vão de 118 metros.

b) Pontes de pedra - também empregado desde a Antiguidade na construção de pontes. Abóbodas de pedra foram construidas pelos romanos e chineses antes de Cristo. Na Idade Média, o vão de pontes construidas com ábobodas de pedra chegou a atingir 50 metros.

c) Pontes metálicas - No final do século XVIII surgiram as primeiras pontes metálicas em ferro fundido. $\mathrm{O}$ aço foi empregado a partir do desenvolvimento das ferrovias e já em 1850 foram construídas pontes em treliças de aço com 124 metros de vão.

d) Pontes de concreto - no inicio do século XX foram construidas as primeiras pontes em concreto simples em arco triarticulado. As primeiras pontes de concreto apareceram no início do século XX. A partir de 1912 iniciou-se a construção de pontes de viga e de pórtico em concreto armado com até 30 metros de vão. Já o concreto protendido começou a ser empregado com grande frequência após a Segunda Guerra Mundial, devido à necessidade de reconstruir uma grande quantidade de pontes destruidas em um curto período de tempo.

A partir de então, o desenvolvimento da construção das pontes se concentrou nos processos construtivos, como lajes, grelhas, caixão, balanços sucessivos, estaiadas e pênsil. 


\subsection{Denominações e características}

Varios elementos estruturais compõem uma ponte. Usualmente e segundo EI Debs (3), subdividimos estes elementos em:

a) Superestrutura: responsável pelo transporte longitudinal das cargas. Laje, transversina e longarinas são exemplos de elementos que fazem parte da superestrutura.

Neste trabalho tratou-se apenas de pontes com a superestrutura formada por tabuleiro em laje e em viga (grelha). Pontes em duas vigas, viga celular única, viga celular dupla, também são denominadas de ponte em viga. Existem também outros sistemas estruturais da superestrutura, como: ponte em pórtico, em arco, pênsil e estaiada.

b) Mesoestrutura: responsável pelo transporte vertical das cargas, como aparelhos de apoio, vigas travessas e pilares.

O aparelho de apoio é o elemento destinado a transmitir as reações de apoio da superestrutura para outro elemento da mesoestrutura ou diretamente para algum elemento da infraestrutura, permitindo determinados movimentos da superestrutura. Considerou-se o efeito da rigidez apenas dos aparelhos de apoio neste trabalho.

c) Infraestrutura: recebe as cargas dos aparelhos de apoio e as transmite ao solo, através de fundação direta, blocos sobre estacas, estacões, tubulões, etc. Não levou-se em consideração o efeito da infraestrutura neste estudo.

Esconsidade é o complemento do ângulo formado pelo eixo longitudinal da ponte e o eixo do encontro. Em função desse ângulo, pode-se dividir as pontes em retas ortogonais (quando esse ângulo é $0^{\circ}$ ) e esconsas (quando esse ângulo é diferente de $0^{\circ}$ ).

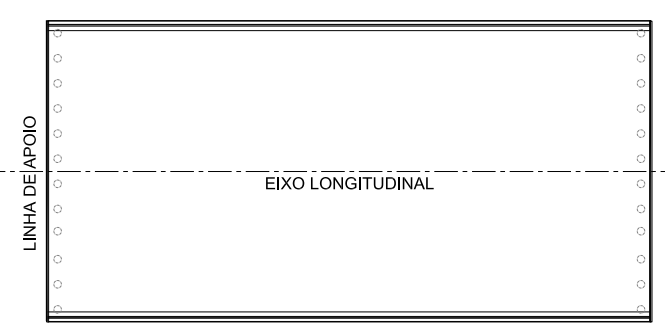

Figura 1 - Ponte reta ortogonal

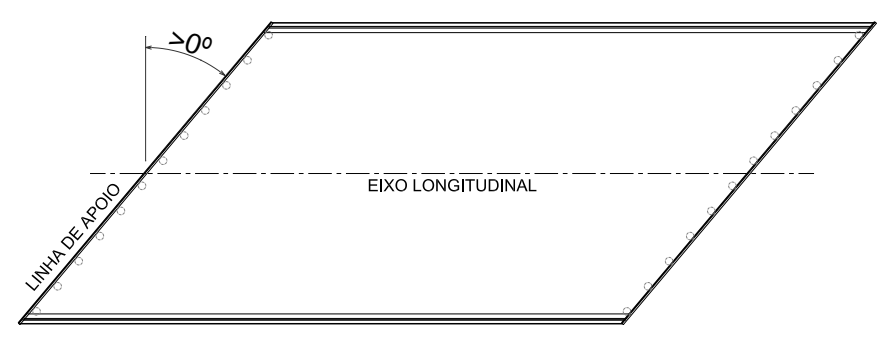

Figura 2 - Ponte esconsa 


\subsection{Pontes esconsas}

\subsubsection{Em laje}

A ponte em laje é um dos esquemas estruturais mais simples de superestrutura. A estrutura principal e o tabuleiro se confundem em uma única peça, de grande simplicidade de execução, tanto para formas quanto para armações, além de garantir uma boa distribuição transversal de esforços. Em contrapartida, a seção transversal, no caso de ser maciça, apresenta um elevado consumo de concreto e, consequentemente, elevado peso próprio.

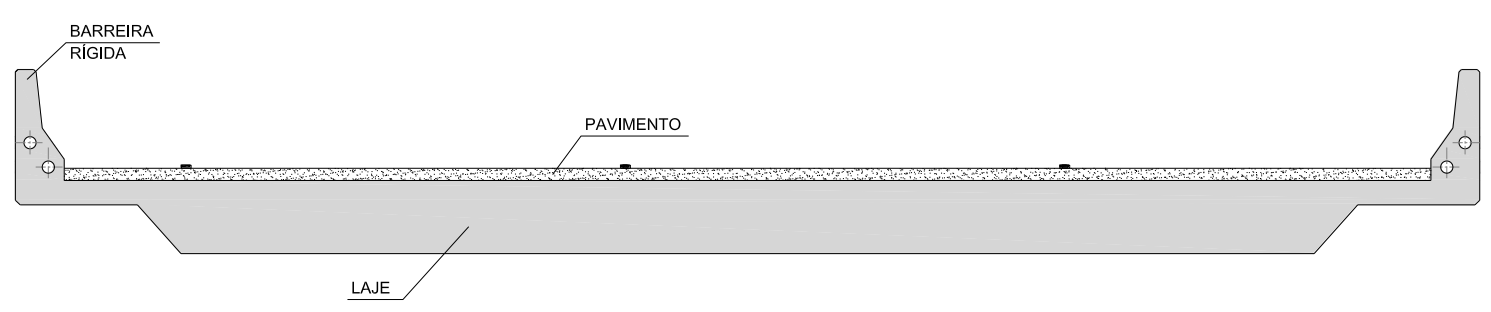

Figura 3 - Seção transversal de uma ponte em laje maciça

A seção em laje maciça é indicada para pontes de vãos pequenos e especialmente indicada para pontes esconsas ou com largura variável. Segundo Leonhardt (2), elas podem chegar a $20 \mathrm{~m}$ de vão em tramo único ou $30 \mathrm{~m}$ em contínuo.

Conforme a descrição de Matar (4), a laje maciça é a solução ideal para cruzamentos esconsos. Isso porque ela transmite as cargas aplicadas ao apoio pelo caminho mais curto, permitindo menor altura estrutural.

Atualmente, os esforços solicitantes não apresentam grandes problemas para serem determinados, graças ao auxílio de softwares de elementos finitos, que permitem determinar superfícies de influência dos deslocamentos e dos esforços solicitantes, além das reações de apoio. O cálculo de solicitações é realizado pela teoria das placas, isótropa ou ortótropa, com rigidez longitudinal e transversal iguais. No caso das lajes maciças, escopo deste trabalho, também serão utilizadas para cálculo as tabelas de Rüsch (5). 
Os valores que influenciam de uma maneira mais intensa no dimensionamento de lajes esconsas estão representados na figura abaixo.

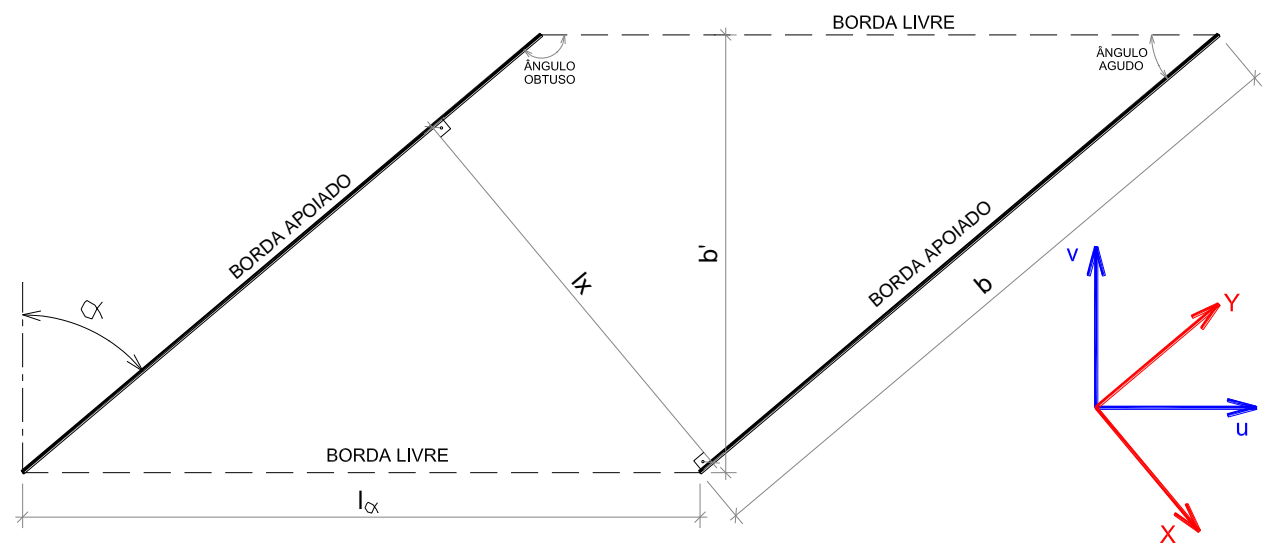

Figura 4 - Principais indicadores de uma laje esconsa

Na qual:

b - largura do tabuleiro na esconsidade, paralela à borda apoiada.

b'- largura do tabuleiro na normal, perpendicular à borda livre.

$\mathrm{I}_{\alpha}$ - comprimento do tabuleiro, paralelo à borda livre.

$\mathrm{I}_{\mathrm{x}}$ - comprimento do tabuleiro, perpendicular à borda apoiada.

$\alpha$ - ângulo de esconsidade.

u,v - sistema de coordenadas, considerando o eixo "u" paralelo à borda livre, coincidentemente ao sentido do tráfego.

$\mathrm{x}, \mathrm{y}$ - sistema de coordenadas, considerando o eixo "y" paralelo à borda apoiada.

Para a solicitação de flexão, é preciso determinar os momentos principais $\mathrm{m} 1$ e m2 e suas direções. Esses são obtidos a partir dos momentos mx, my, mxy, mu, mv e muv, que, por sua vez, são obtidos de superfícies de influência existentes nas tabelas de Rüsch (5) e são diferentes para diferentes tipos de carregamentos, ou por elementos finitos. 


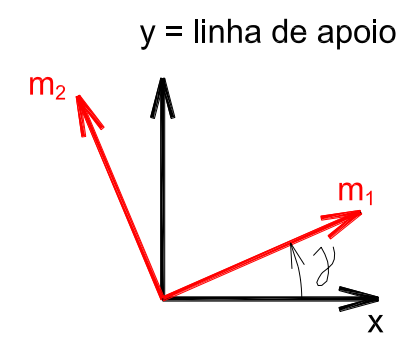

Figura 5 - Momentos principais

Nas lajes esconsas, existe o momento principal negativo m2, que aparece junto ao canto obtuso e que tem grande influência no valor e na distribuição das reações de apoio. Por ter um valor alto, que aumenta ainda mais com a esconsidade, esse momento provocaria, no caso de apoio linear rígido resistente à tração, elevada compressão na extremidade do apoio correspondente ao ângulo obtuso e tração no outro extremo. Leonhardt (2) cita que, em uma das primeiras grandes pontes em laje esconsa, um aparelho de apoio de aço reforçado, colocado junto ao canto obtuso, se rompeu.

Considerando apoios isolados e igualmente espaçados, o segundo aparelho de apoio junto ao canto obtuso apresentará um esforço de tração relativamente alto, como normalmente os apoios não resistem à tração (aparelhos de apoio tipo neoprene por exemplo) e, caso não ocorra seu escorregamento, pode haver redução da compressão no primeiro aparelho de apoio junto ao canto obtuso.

Como foi descrito por Matar (4) e demonstrado na modelagem a seguir, a compressão concentrada junto ao canto obtuso se torna menor quando se tem aparelhos de apoio individuais espaçados e flexíveis. As reações de apoio, próximas ao ângulo obtuso, são maiores à medida que a quantidade de aparelhos de apoio e sua rigidez aumentam.

A fim de evitar elevada pressão e os grandes momentos nos cantos obtusos de lajes muito esconsas, se projetam os aparelhos de apoio com as seguintes características:

a) Aparelhos de apoio individuais bastante espaçados.

b) Aparelhos de apoio individuais tipo "neoprene".

A primeira solução foi pesquisada por Leonhardt (2). O efeito favorável de grandes espaçamentos entre aparelhos de apoio está demonstrado em Leonhardt (2) e na figura 6. Comparando-se à reação de apoio $A 1$, as ordenadas máximas diminuem de $+1,8$ para $+1,1$ e de $-0,3$ para $-0,2$ quando se adotam quatro aparelhos de apoio em vez de 12. As superfícies de influência mostram também que podem 
surgir forças de levantamento, especialmente na extremidade no apoio de ângulo agudo.

Em 1964, A. Mehmel demonstrou a influência favorável de uma pequena flexibilidade do aparelho de apoio. O resultado foi representado por Leonhardt (2) e na figura 7 abaixo.

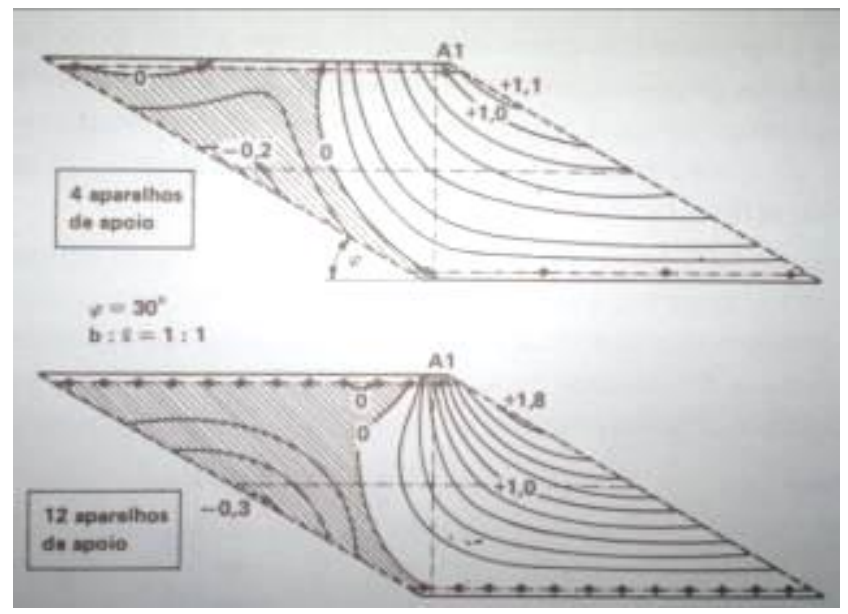

Figura 6 - Efeito dos espaçamentos entre aparelhos de apoio Fonte:Leonhardt (2)

As forças cortantes determinantes para o dimensionamento da capacidade resistente se obtêm a partir das reações de apoio. Para julgar se é necessário adotar armadura de cisalhamento, se determinam as tensões a uma distância de h/2 da face do aparelho de apoio. No caso de lajes de concreto armado, pode ser necessário adotar estribos nas zonas próximas aos apoios, principalmente nos cantos obtusos.

Modernamente, em consequência do avanço da capacidade de processamento dos computadores e do desenvolvimento de softwares especializados, pode-se utilizar o Método dos Elementos Finitos (MEF) para determinação dos esforços solicitantes nas lajes. Mesmo com esse facilitador, devese ter uma atenção especial à pesquisa das superfícies de influência e posições críticas de carga.

Dependendo das características e das condições de contorno de uma laje discretizada em EF, o carregamento de uma determinada região pode aliviar os esforços críticos que se está procurando.

A figura 8 abaixo apresenta uma superfície de influência onde se busca o momento máximo no ponto 4 de uma laje bi-engastada. Caso seja carregada a área 
com valores negativos, o valor no ponto 4 não será máximo, ou seja, se se carregar toda a laje (pode-se imaginar que, quanto mais carga, maior o esforço) não será encontrado o valor máximo do ponto 4.

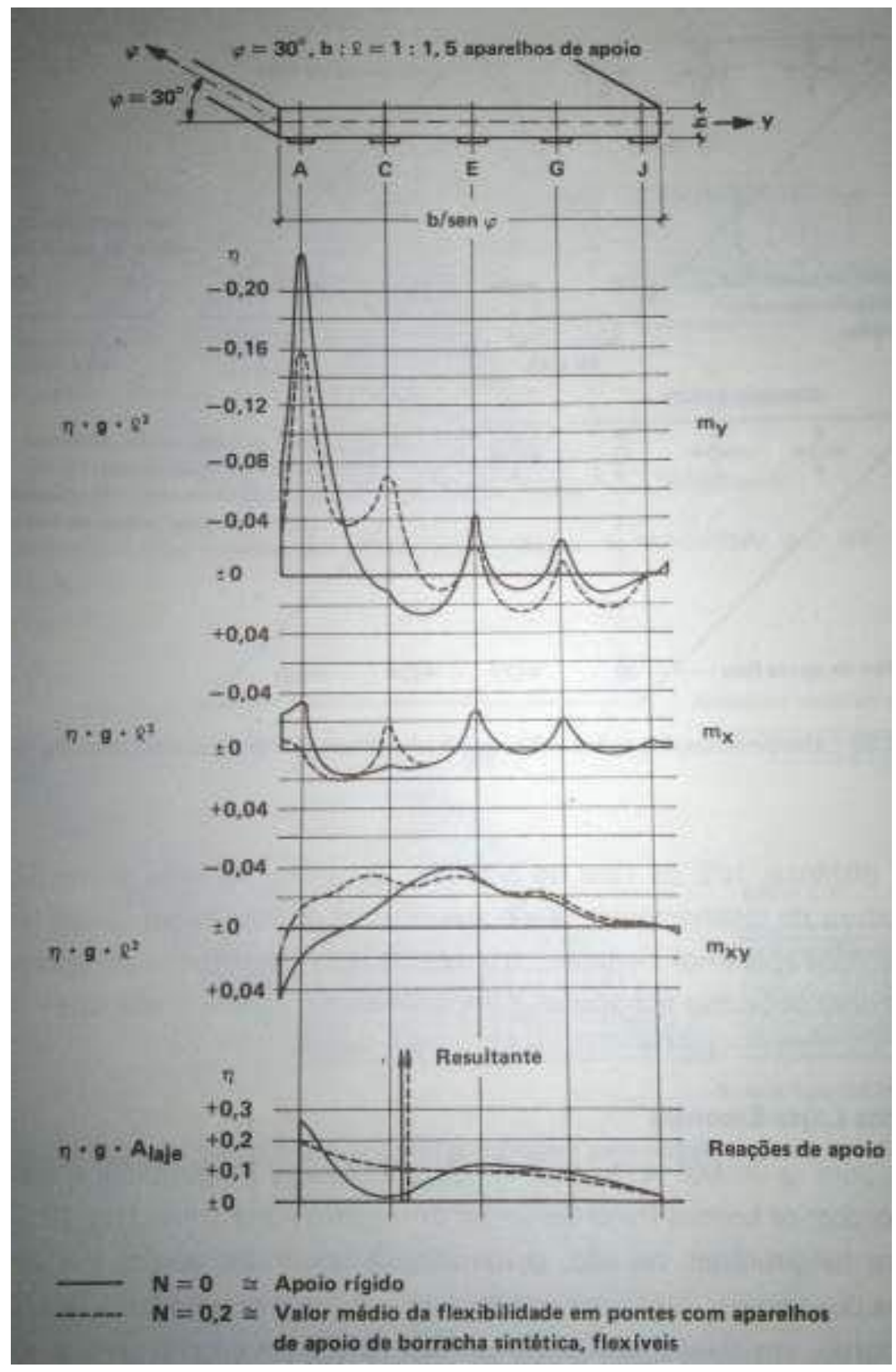

Figura 7 - Efeito da flexibilidade dos aparelhos de apoio Fonte:Leonhardt (2) 
Os softwares utilizados neste estudo apresentam um recurso de busca dessas superfícies de influência. São criadas faixas para as cargas móveis, onde se indica o "passo" (de quantos em quantos metros o carregamento será trocado de posição) e uma rotina interna realiza inúmeras combinações buscando a área de carregamento crítico para cada ponto do tabuleiro discretizado.

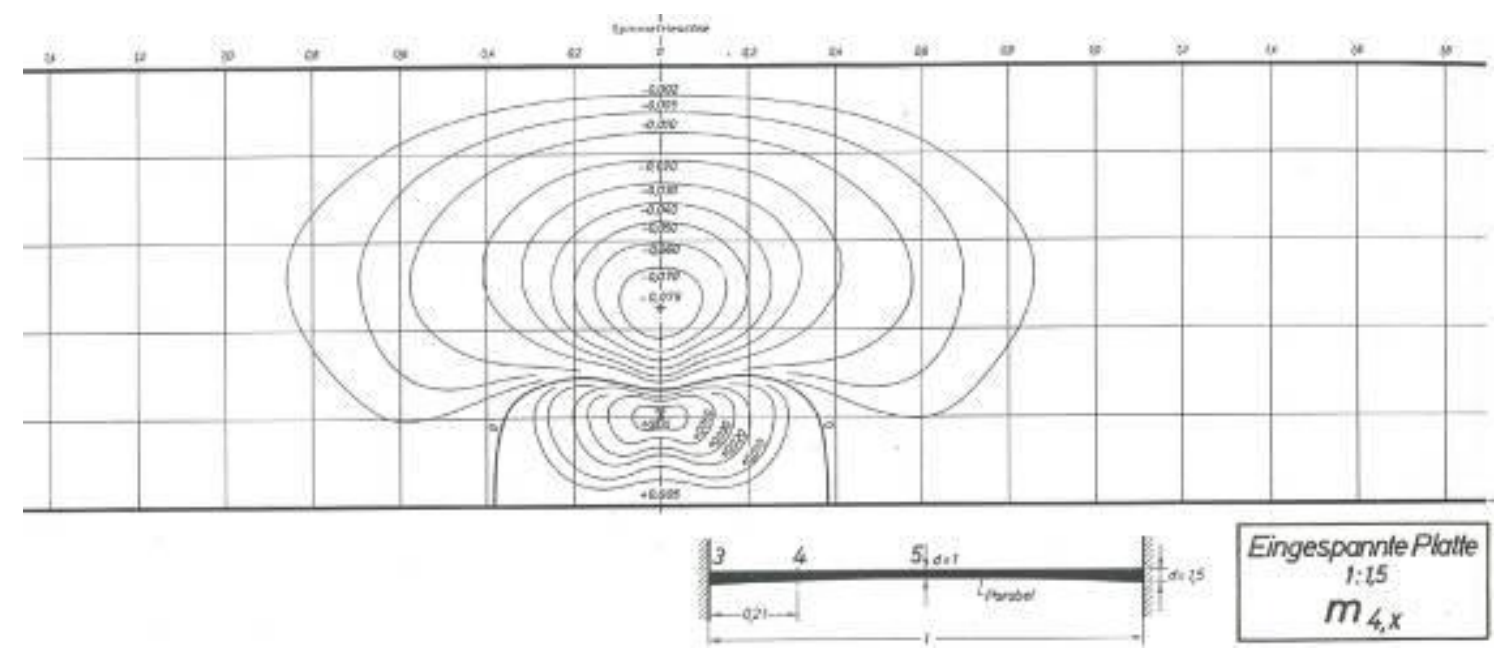

Figura 8 - Exemplo de superfície de influência

\subsubsection{Em grelha}

A utilização de tabuleiros de vigas múltiplas de concreto armado ou protendido em pontes é extremamente difundida no Brasil em função das vantagens econômicas e construtivas dessa solução.

As vigas "T", "I" e "U" são formas de seção transversal mais usadas especialmente para absorver momentos fletores positivos, caso corriqueiro nas estruturas usuais. A laje constitui o tabuleiro da ponte e o banzo comprimido da longarina, já o banzo tracionado se concentra na parte inferior da alma.

Almas delgadas são preferidas, mas devem ser suficientes para resistir às tensões principais de compressão inclinadas (forças cortantes). Transversinas nos apoios são necessárias para absorção dos esforços transversais, dos momentos de torção e para a troca dos aparelhos de apoio. 


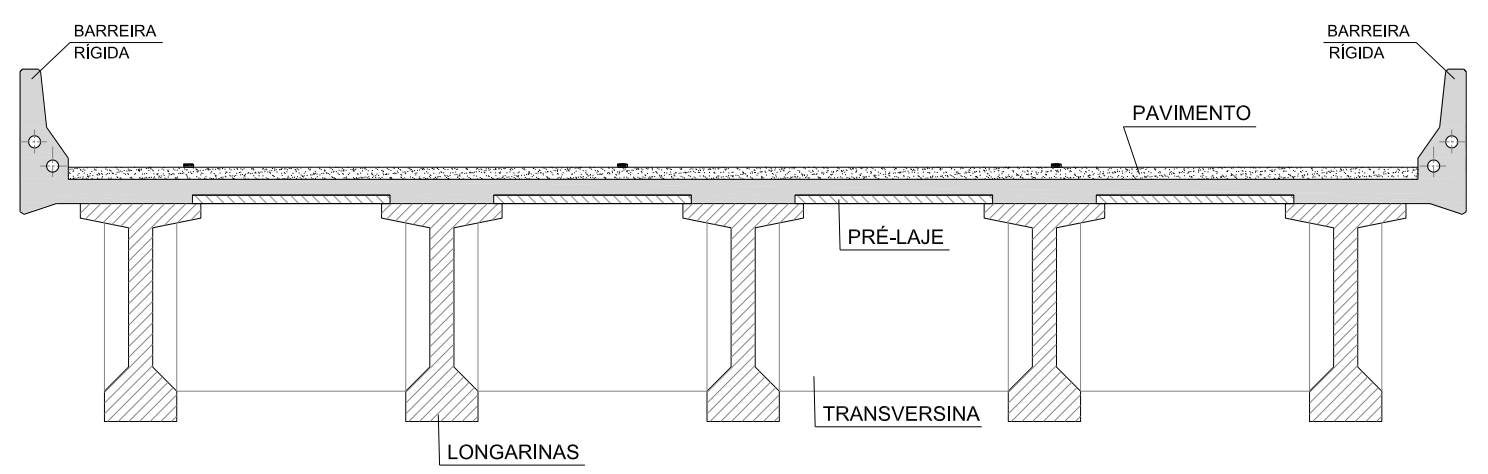

Figura 9 - Seção transversal de uma ponte em grelha

Usualmente, obras constituídas por longarinas com ângulo de esconsidade de $0^{\circ}$ a $30^{\circ}$ são calculadas e dimensionadas aproximando-as a obras retangulares. Mesmo nesses casos, o apoio extremo do canto obtuso deve ser dimensionado para um acréscimo de carga. A armadura da laje é disposta em forma de leque na extremidade, ocasionando uma maior concentração de armadura no canto obtuso, cobrindo o engastamento de extremidade na transversina de apoio.

Quanto mais esconsa, maiores os momentos de torção nas almas, que são maiores quanto maior for a relação de rigidez à torção e rigidez à flexão das longarinas. Analisando isoladamente o Estado Limite Último, os momentos de torção não são críticos, já que, em consequência da fissuração, seus valores são reduzidos (não se aplica no caso de vigas protendidas). No Estado Limite de Serviço, esses momentos podem provocar o aparecimento de fissuras que devem ser devidamente verificadas.

Leonhardt (2) sugere não se adotar transversina de apoio muito rígida, a fim de evitar elevados momentos de torção. Neste trabalho, serão estudadas novas disposições das transversinas para esse mesmo fim.

A análise estrutural desse tipo de obra é efetuada usualmente em duas etapas. Na primeira delas, se desenvolve a análise da superestrutura separando-a dos demais elementos integrantes do conjunto estrutural: meso e infraestrutura. $\mathrm{Na}$ etapa de análise da superestrutura, faz-se, em geral, nova simplificação. Assimila-se o modelo estrutural da grelha formada por longarinas e transversinas a um modelo menos rigoroso, representado por vigas biapoiadas. Para que essa assimilação seja feita, se aplicam métodos variados, por meio dos quais são determinadas as parcelas de carregamento correspondentes a cada uma das longarinas. 
Em função da sua elevada hiperestaticidade, a análise do comportamento estrutural de grelhas constituiu-se no passado em uma tarefa complexa para os projetistas. Isso motivou o desenvolvimento de diversos processos simplificados de cálculo manual para obras retas. Abaixo, segue um breve histórico dos métodos simplificados, descrito no artigo de Alves (6).

- 1893: Zschetzsche desenvolveu um trabalho baseado no método das forças, mas sem grandes aplicações práticas devido às complexidades do cálculo numérico.

- 1912: Arnstein também não obteve sucesso, desenvolvendo trabalho com a mesma base de Zschetzsche. Kögler apresentou algumas conclusões específicas mais importantes através do estudo de uma ponte. Já Lossier, diferentemente dos trabalhos anteriores, apresentou um trabalho baseando-se na teoria de vigas contínuas sobre apoios elásticos.

-1914: Huber aplicou pela primeira vez a teoria de placas ortotrópicas para a resolução do problema. Através de pesquisas experimentais, Saliger, Frank e Knorr contribuíram para o melhor conhecimento do assunto.

-1922: Thullie, considerou transversinas com rigidez infinita para resolução de problemas de grelhas.

-1925: Petermann também apresentou dificuldades devido à complexidade do cálculo numérico ao adotar os momentos dos nós da grelha como incógnitas.

-1926: Faltus conseguiu bons resultados para a distribuição de cargas no meio do vão, representando todas as transversinas como uma única.

-1927: Bleich e Melan apresentaram um sitema de equações diferenciais parciais, desprezando a rigidez à torção dos elementos da grelha.

-1928: Gennter incluiu as rigidez à torção no estudo anterior, mas, também devido à complexidade numérica, não obteve uma resolução prática.

-1930: Ostenfeld obteve um sistema de equações, considerando cada nó como apoio indeslocável. Krall, desenvolveu um trabalho sobre repartição transversal de cargas.

-1940: Leonhardt iniciando o trabalho em 1938 para grelhas biapoiadas, desenvolveu o conhecido "Método de Leonhardt" também para grelhas engastadas e contínuas, desprezando a torção e considerando a laje como parte colaborante na inércia das vigas. 
-1940: Courbon e Engesser desenvolveram o chamado "Método de EngesserCourbon", para distribuição transversal para grelhas constituídas por transversinas com rigidez infinita.

-1946: Guyon continuou o estudo de Huber para grelhas compostas por elementos sem rigidez à torção, assimilando a grelha a uma placa ortotrópica.

-1950: Junto com o Andrä, Leonhardt aperfeiçoou seu método. Massonet incluiu a rigidez à torção nos estudos de Guyon, finalizando o "Método dos Coeficientes de Distribuição Transversal de Guyon- Massonet".

-1955: Rowe aprimorou o método de Guyon- Massonet, introduzindo a influência do coeficiente de Poisson.

-1965: Barés amplitou o estudo anterior

-1956: Homberg e Weinmeister realizaram um estudo sem considerar efeitos de torção.

-1962: Homberg e Trenks apresentaram um trabalho no qual os efeitos de torção foram incluídos. 


\section{METODOLOGIA DA PESQUISA}

Foram modeladas, através do SAP2000 e do STRAP2010, pontes esconsas com os seguintes esquemas estruturais: com esconsidade variável de zero a sessenta graus, incremento de cinco graus no caso de pontes em laje e de quinze graus e no caso de grelha, com ou sem transversinas de apoio.

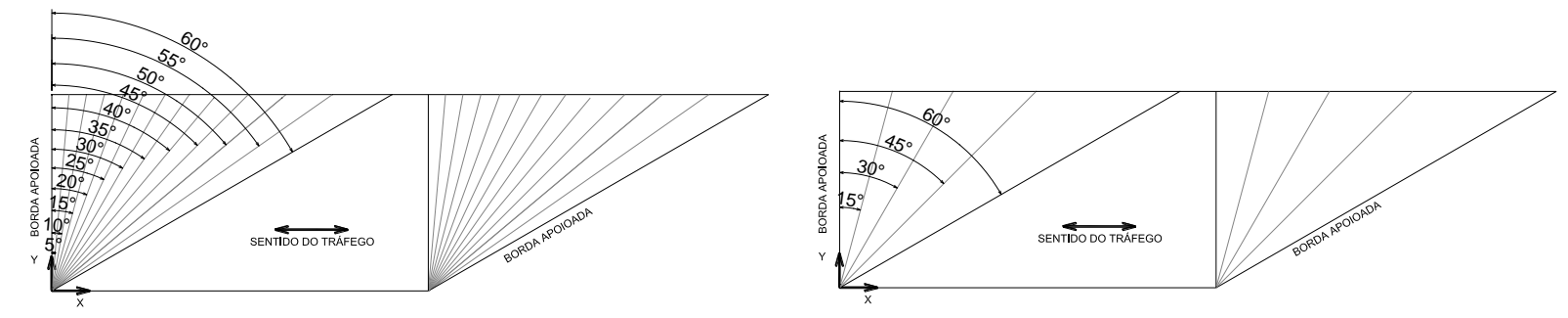

Figura 10 - Variações dos ângulos de esconsidade estudados

Para a execução deste trabalho, foi fundamental o domínio da ferramenta computacional. Essa modelagem foi comparada entre os softwares adotados e com resultados obtidos nas tabelas de Rüsch (5), a fim de identificar as melhores soluções e modelos para cada caso. 


\section{ESQUEMAS ESTRUTURAIS ESTUDADOS}

\subsection{LAJES ESCONSAS}

\subsubsection{Introdução}

Utilizaram-se dois métodos para o cálculo dos esforços solicitantes em lajes esconsas: tabelas de Rüsch (5) para cálculo de placas oblíquas de pista de pontes rodoviárias e o método dos elementos finitos através da modelagem computacional nos programas SAP2000 e STRAP2010. A descrição do levantamento das solicitações bem como suas particularidades serão tratadas a seguir.

\subsubsection{Geometria e materiais}

\subsubsection{Características geométricas}

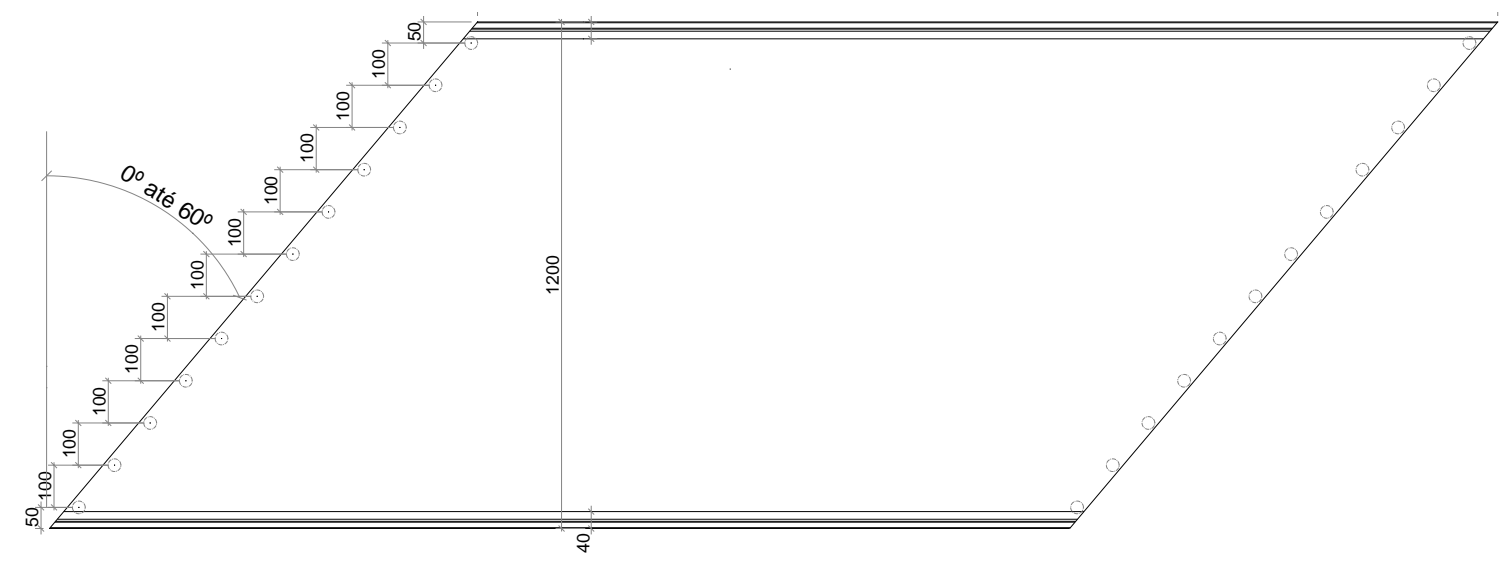

Figura 11 - Vista superior típica do tabuleiro de laje estudada

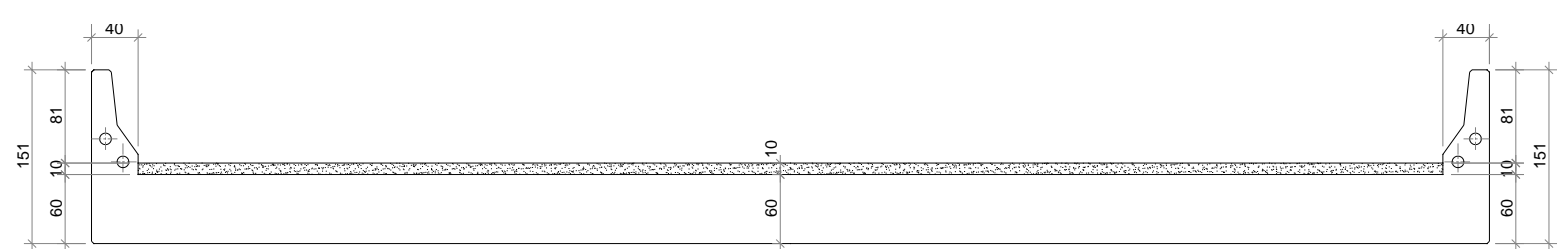

Figura 12 - Seção transversal típica do tabuleiro de laje estudada 


\subsubsection{2_Materiais}

Concreto $\mathrm{p} /$ Superestrutura

$$
\mathrm{f}_{\mathrm{ck}}=30 \mathrm{MPa}
$$

Apoios fixos indeslocáveis e apoios flexíveis simulando Neoprene Dureza Shore A60.

\subsubsection{Carregamentos e solicitações}

\subsubsection{Cargas permanentes}

Peso Próprio - considerando o $\gamma_{c}=25,0 \mathrm{kN} / \mathrm{m}^{3}$

Pavimentação $=0,10 \mathrm{~m} \times 24,0 \mathrm{kN} / \mathrm{m}^{3}=2,40 \mathrm{kN} / \mathrm{m}^{2}$

Recapeamento $=2,00 \mathrm{kN} / \mathrm{m}^{2}$

Barreira rígida $=2,42 \mathrm{~m}^{2} \times 25,0 \mathrm{kN} / \mathrm{m}^{3} / 0,40 \mathrm{~m}=15,1 \mathrm{kN} / \mathrm{m}^{2}$ (distribuídos em $40 \mathrm{~cm}$ )

\subsubsection{Cargas móveis}

Optou-se por utilizar o trem-tipo Classe 45, descrito na NBR-7188 (7) e largamente utilizado, e por não espraiar as cargas das rodas no plano médio da laje. Considerou-se que essa ação provocaria pequenas alterações nos resultados dos esforços, mas não influenciaria sua comparação. 


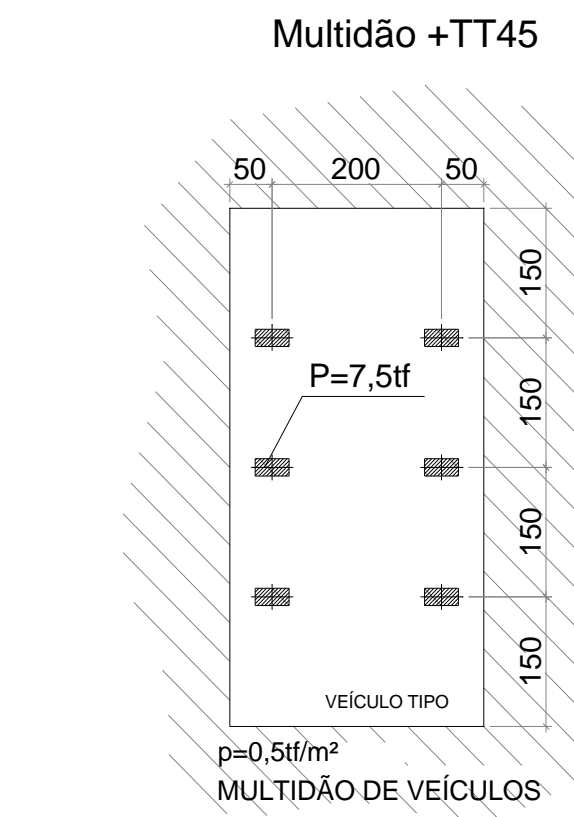

Figura 13 - Características do trem-tipo Classe 45

Coeficiente de Impacto

A expressão prevista na NBR7187 (8) é a seguinte:

$$
\varphi=1,4-0,007 \times l \quad \text { Eq. } 1
$$

Na qual: I é a distância entre apoios no sentido do tráfego.

No caso a ser estudado, placas oblíquas livremente apoiadas, pode-se ficar em dúvida se se supor que o $|=|$ la ou $I=\mid x$, sendo que o segundo valor é mais desfavorável. Para placas muito estreitas, certamente é determinante o valor de la, já, para placas largas, o valor é Ix. A expressão que indica um valor intermediário pode ser encontrada em Rüsch (5) e está descrita a seguir.

$$
l=l_{\alpha} \times\left[1-\frac{b}{l_{\alpha}} \times(1-\operatorname{sen} \alpha)\right] \geq l_{x} \quad \text { Eq. } 2
$$




\subsubsection{Solicitações}

\subsubsection{Tabelas de Rüsch}

Servem como base para o dimensionamento de placas oblíquas de vão único, apoiadas bilateralmente, que constituem a estrutura principal de uma ponte.

Na prática, o dimensionamento à flexão da laje limita-se a poucos pontos, cujos valores usualmente são os que apresentam seus valores máximos.

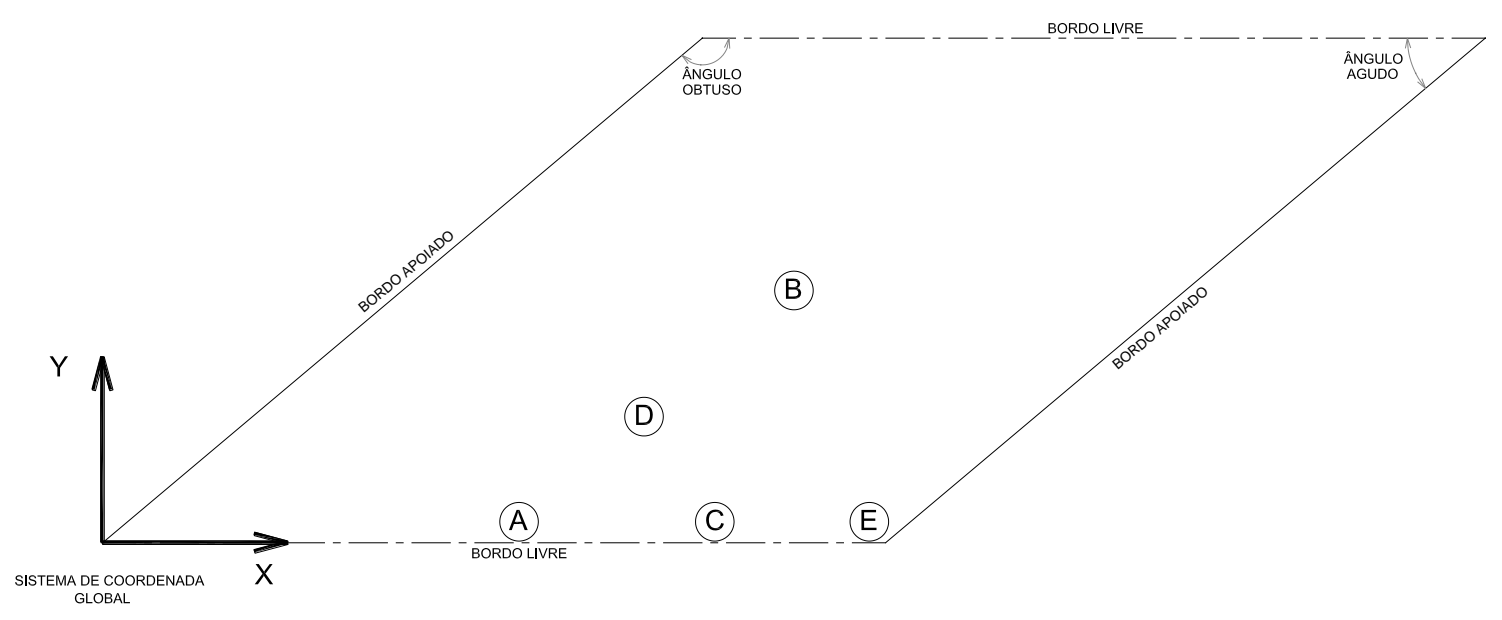

Figura 14 - Localização dos pontos de dimensionamento

A posição dos pontos de dimensionamento examinados está representada na figura acima e, segundo Rüsch (5), esses pontos representam os valores extremos dos momentos principais:

A - Ponto que apresenta o maior momento fletor positivo no vão junto ao bordo livre para cargas móveis.

B - Ponto que apresenta o maior momento fletor positivo no vão central.

C - Ponto em que ocorre o maior momento fletor positivo em consequência de carga permanente.

D - Valor intermediário entre A e B, importante para o melhor detalhamento da variação da armadura.

E - Ponto que apresenta maior momento fletor negativo junto ao canto de ângulo obtuso. Esse momento tem o plano de ação aproximadamente perpendicular à bissetriz do ângulo obtuso. 
Rüsch (5) descreve cada momento principal nas tabelas através dos coeficientes determinantes para as suas três componentes, momentos nas duas direções ortogonais e momento de torção. Nas tabelas de dimensionamento para placas retangulares usuais, a indicação de momentos de torção é dispensada. Para placas oblíquas, a direção principal dos momentos principais, no entanto, diverge sensivelmente da direção das coordenadas e varia mais intensamente com a posição da carga do que no caso das placas retangulares. Além disso, também a direção da armadura, em geral, não coincide com a direção dos momentos principais.

Serão demonstradas a seguir as principais informações necessárias para a determinação de momentos fletores atuantes na laje, utilizando as tabelas de Rüsch:

a) Cargas permanentes - a influência de uma carga distribuída uniformemente sobre toda a placa é calculada pela seguinte expressão:

$$
M=k \cdot g \cdot l_{x}^{2}(\mathrm{tf} \cdot \mathrm{m} / \mathrm{m}) \quad \text { Eq.3 }
$$

Na qual:

k - coeficiente dos momentos para carga unitária e estão compilados na tabela 12 na Parte B das tabelas de Rüsch;

$\mathrm{g}$ - carga uniformemente distribuída em tf. $\mathrm{m}^{2}$;

$I_{x}-$ ver figura 1 .

b) Cargas móveis - os coeficientes dos momentos contidos nas tabelas valem para uma carga unitária, devendo-se ainda serem acrescidos dos fatores de carga correspondentes à classe da ponte. Neste trabalho, foram estudadas pontes Classe 45, ou seja, veículos de $450 \mathrm{kN}$ ( $75 \mathrm{kN}$ por roda), acrescidos de uma carga uniforme distribuída de $5 \mathrm{kN} / \mathrm{m}^{2}$ no restante da via principal do tabuleiro, excluindo-se os possíveis passeios.

Além disso, as cargas situadas na via principal devem ser multiplicadas pelo coeficiente de impacto $\varphi$, descrito no item anterior. 
Para a classe considerada neste projeto, os momentos fletores decorrentes do tráfego de veículos são determinados pela expressão:

$$
M=\varphi \cdot P \cdot M_{L}+\varphi \cdot p \cdot M_{P}+p^{\prime} \cdot M_{P}^{\prime}(\mathrm{tf} . \mathrm{m} / \mathrm{m}) \quad \text { Eq.4 }
$$

Na qual:

$\mathrm{P}$ - carga que representa a roda do veículo (7,5tf para Classe 45).

$\mathrm{p}$ - carga uniformemente distribuída na frente e atrás do veículo $\left(5 \mathrm{tf} / \mathrm{m}^{2}\right.$ para Classe 45).

$p^{\prime}$ - carga uniformemente distribuída na via lateral ( $5 t \mathrm{t} / \mathrm{m}^{2}$ para Classe 45$)$.

$M_{L}$ - coeficientes dos momentos indicados na tabela decorrentes da compressão da roda do veículo.

$M_{P}$ - coeficientes dos momentos indicados na tabela para carga uniforme na frente e atrás do veículo.

$M_{P}^{\prime}$ - coeficientes dos momentos indicados na tabela para carga uniforme na via lateral.

$\varphi$ - coeficiente de impacto descrito no item anterior e desprezado neste estudo.

Com as componentes dos momentos calculados da maneira descrita acima, devem ser determinados o valor e a direção dos momentos principais.

Para o dimensionamento de placas oblíquas, em geral são calculadas e sobrepostas as componentes $M_{x}, M_{y}$, e $M_{x y}$ e $M_{u}, M_{v}$, e $M_{u v}$ que surgem nos diversos pontos de incidência e casos de carga. Para os casos de carga mais desfavoráveis, são então calculados os momentos principais $M_{\Perp}$ e $M_{\|}$da seguinte maneira:

$$
M_{I, I}=\frac{M x+M y}{2} \pm \sqrt{\left(\frac{M x-M y}{2}\right)^{2}+M x y^{2}} \quad \text { Eq.5 }
$$

Já a direção é calculada pela expressão abaixo:

$$
\operatorname{tg} 2 \gamma=\frac{2 M x y}{M x-M y} ; \quad \operatorname{tg} 2 \gamma=\frac{2 M u v}{M u-M v} \quad \text { Eq. } 6
$$


Com valor de $\operatorname{tg} 2 y$ somente determinou-se o valor de tabela $y_{0}$ sempre positivo. Esse valor deve ser utilizado para a determinação do ângulo real com o auxílio dos sinais utilizados no denominador e numerador da expressão anterior, devendo-se proceder da seguinte forma:

\begin{tabular}{|c|c|c|}
\hline \multicolumn{2}{|c|}{ Sinal } & Ângulo \\
\hline Mxy ou Muv & $(\mathrm{Mx}-\mathrm{My})$ ou (Mu-Mv) & $\gamma$ \\
\hline+ & + & $\gamma=\gamma_{0}$ \\
\hline+ & - & $\gamma=\pi / 2-\gamma_{0}$ \\
\hline- & - & $\gamma=\pi / 2+\gamma_{0}$ \\
\hline- & + & $\gamma=\pi-\gamma_{0}$ \\
\hline
\end{tabular}

Tabela 1 - Sinais para determinação da direção dos momentos principais

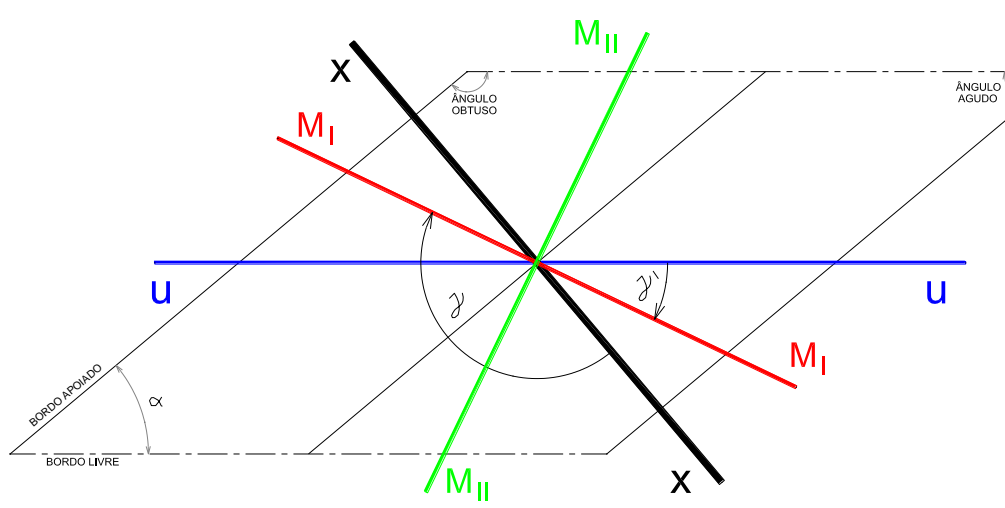

Figura 15 - Direção dos momentos principais

Resumo das características e coeficientes:

\begin{tabular}{|c|c|c|c|c|c|c|c|c|c|c|}
\hline $\boldsymbol{\alpha}$ & $\mathbf{b}^{\prime}$ & $\mathbf{b}$ & \multirow{2}{*}{$\mathbf{b} / \mathbf{\alpha}$} & $\mathbf{l}$ & $\mathbf{l}$ & $\mathbf{e}$ & $\mathbf{g}$ & $\mathbf{T T}$ & $\mathbf{q}$ & \multirow{2}{*}{$\boldsymbol{\varphi}$} \\
\cline { 1 - 5 }$(\mathbf{9})$ & $(\mathrm{m})$ & $(\mathrm{m})$ & & $(\mathrm{m})$ & $(\mathrm{m})$ & $(\mathrm{m})$ & $\left(\mathrm{kN} / \mathrm{m}^{2}\right)$ & $(\mathrm{kN})$ & $\left(\mathrm{kN} / \mathrm{m}^{2}\right)$ & \\
\hline 0 & 12.0 & 12.00 & 1.00 & 12.0 & 12.00 & 0.60 & 19.40 & 450.0 & 5.0 & 1.316 \\
\hline 5 & 12.0 & 12.05 & 1.00 & 12.0 & 12.00 & 0.60 & 19.40 & 450.0 & 5.0 & 1.316 \\
\hline 10 & 12.0 & 12.19 & 1.00 & 12.2 & 12.00 & 0.60 & 19.40 & 450.0 & 5.0 & 1.316 \\
\hline 15 & 12.0 & 12.42 & 1.00 & 12.4 & 12.00 & 0.60 & 19.40 & 450.0 & 5.0 & 1.316 \\
\hline 20 & 12.0 & 12.77 & 1.00 & 12.8 & 12.00 & 0.60 & 19.40 & 450.0 & 5.0 & 1.316 \\
\hline 15 & 12.0 & 12.42 & 1.00 & 12.4 & 12.00 & 0.60 & 19.40 & 450.0 & 5.0 & 1.316 \\
\hline 25 & 12.0 & 13.24 & 1.00 & 13.2 & 12.00 & 0.60 & 19.40 & 450.0 & 5.0 & 1.316 \\
\hline 30 & 12.0 & 13.86 & 1.00 & 13.9 & 12.00 & 0.60 & 19.40 & 450.0 & 5.0 & 1.316 \\
\hline 35 & 12.0 & 14.65 & 1.00 & 14.6 & 12.00 & 0.60 & 19.40 & 450.0 & 5.0 & 1.316 \\
\hline 40 & 12.0 & 15.66 & 1.00 & 15.7 & 12.00 & 0.60 & 19.40 & 450.0 & 5.0 & 1.316 \\
\hline 45 & 12.0 & 16.97 & 1.00 & 17.0 & 12.00 & 0.60 & 19.40 & 450.0 & 5.0 & 1.316 \\
\hline 50 & 12.0 & 18.67 & 1.00 & 18.7 & 12.00 & 0.60 & 19.40 & 450.0 & 5.0 & 1.316 \\
\hline 55 & 12.0 & 20.92 & 1.00 & 20.9 & 12.00 & 0.60 & 19.40 & 450.0 & 5.0 & 1.316 \\
\hline 60 & 12.0 & 24.00 & 1.00 & 24.0 & 12.00 & 0.60 & 19.40 & 450.0 & 5.0 & 1.316 \\
\hline
\end{tabular}

Tabela 2 - Características da lajes estudadas 


\subsubsection{Modelagem computacional}

As solicitações foram obtidas com o axílio dos programas computacionais STRAP2010 e SAP2000. Utilizando elementos de geometria plana, ambos os programas elaboram a malha de elementos finitos e calculam os esforços e deslocamentos para cada elemento, disponibilizando seus resultados em mapa de contorno (gráficos) e/ou por tabelas.

Por facilidade de manusear os programas e devido aos modelos não apresentarem significativo número de elementos (tempo de processamento reduzido) definiu-se a laje com elementos de casca. Conforme descrito em Soriano (9), casca é um sólido em que a espessura é muito menor do que as dimensões de sua superfície e está submetida a efeitos de flexão e de membrana. O efeito de flexão é semelhante ao de placa (flexão transversal) e o efeito de membrana se refere a deformações da superfície neste mesmo plano.

O carregamento dos modelos deu-se apenas com cargas verticais e com os apoios restritos apenas na translação vertical (z), resultando em deformações nulas ao longo de sua superfície (não havendo o efeito de membrana).

A laje foi dividida em malha. No caso do STRAP, priorizaram-se elementos retangulares, com faces paralelas aos eixos globais, mas, em consequência da geometria, se fez necessária a utilização de elementos triangulares, já para o SAP2000 foram utilizados elementos esconsos que acompanham a esconsidade da laje. Os elementos apresentam lados de aproximadamente $50 \mathrm{~cm}$ de comprimento.

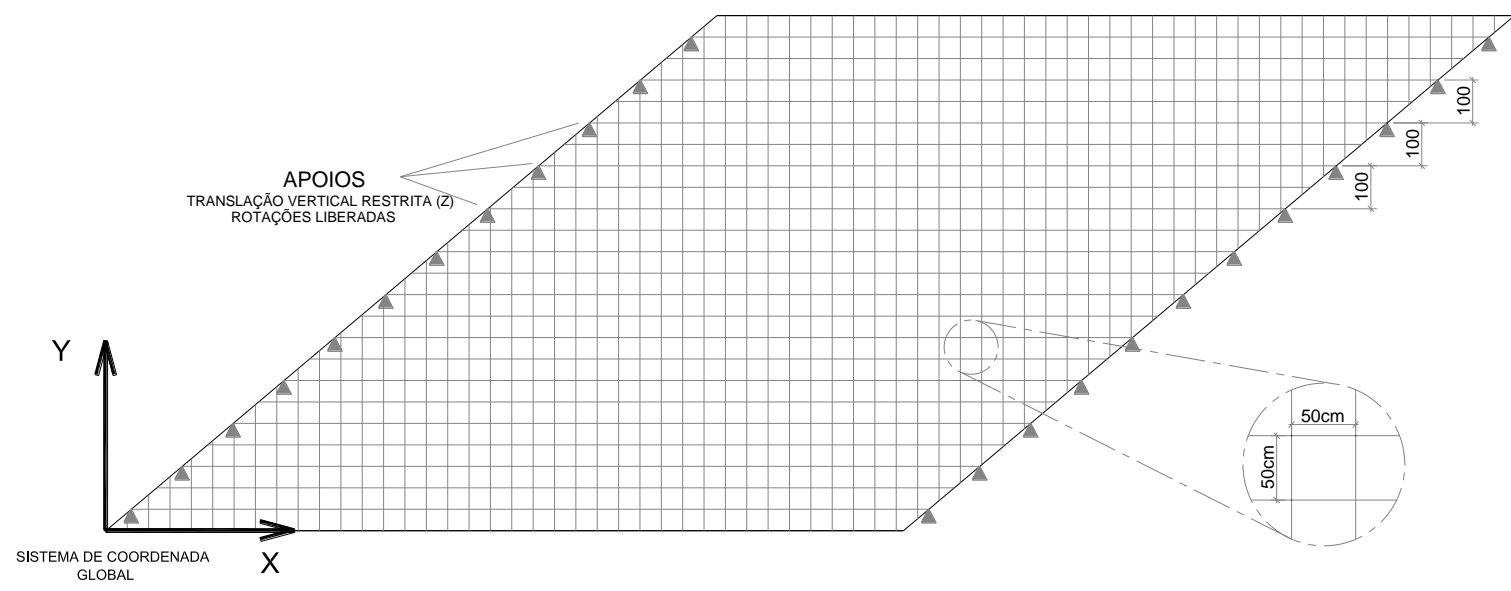

Figura 16 - Modelo matemático adotando apoios com restrição a translações 
As cargas permanentes foram aplicadas diretamente nos elementos na direção " $z$ ". No caso das cargas móveis, ao invés de se determinar o mapa de influência para cada ponto, foram consideradas as cargas percorrendo todo o tabuleiro, a fim de se determinar a envoltória de máximos e mínimos de todos os pontos. No caso das cargas de multidão $\left(5,0 \mathrm{kN} / \mathrm{m}^{2}\right)$ criou-se faixas na extensão do tabuleiro, com 1,0m de largura, uma ao lado da outra. Para a consideração do TT45, as faixas criadas foram de $3,0 \mathrm{~m}$ de largura, podendo as mesmas se sobreporem, e tomando o cuidado de sempre haver apenas um TT45 nas combinações.

Inicialmente os apoios, tipo neoprene fretado, foram simulados como apoios articulados perfeitos, ou seja, restringindo apenas a translação em " $z$ " e liberando as rotações. Considerou-se o espaçamento de 1,0m entre os mesmo, resultando em 12 apoios discretos por borda apoiada, sendo que o primeiro e o últimos foram posicionados a 50m de distância da borá livre.

Para uma distribuição de esforços mais realista, se substituíram os apoios fixos por molas que simplificadamente representam as características de rigidez do aparelho de apoio - kv=100.000kN/m (nulo no caso de tração). Este valor não representa um neoprene específico, pois devido a esconsidade, existe uma variação nas reações de apoio o que resultaria em varios tipos de aparelhos de apoio e consequentemente vários coeficiente de mola. $\mathrm{O}$ valor de rigidez adotado representa um aparelho de apoio que deslocaria $1 \mathrm{~cm}$ na vertical quando aplicado uma carga de compressão de $1.000 \mathrm{kN}$.

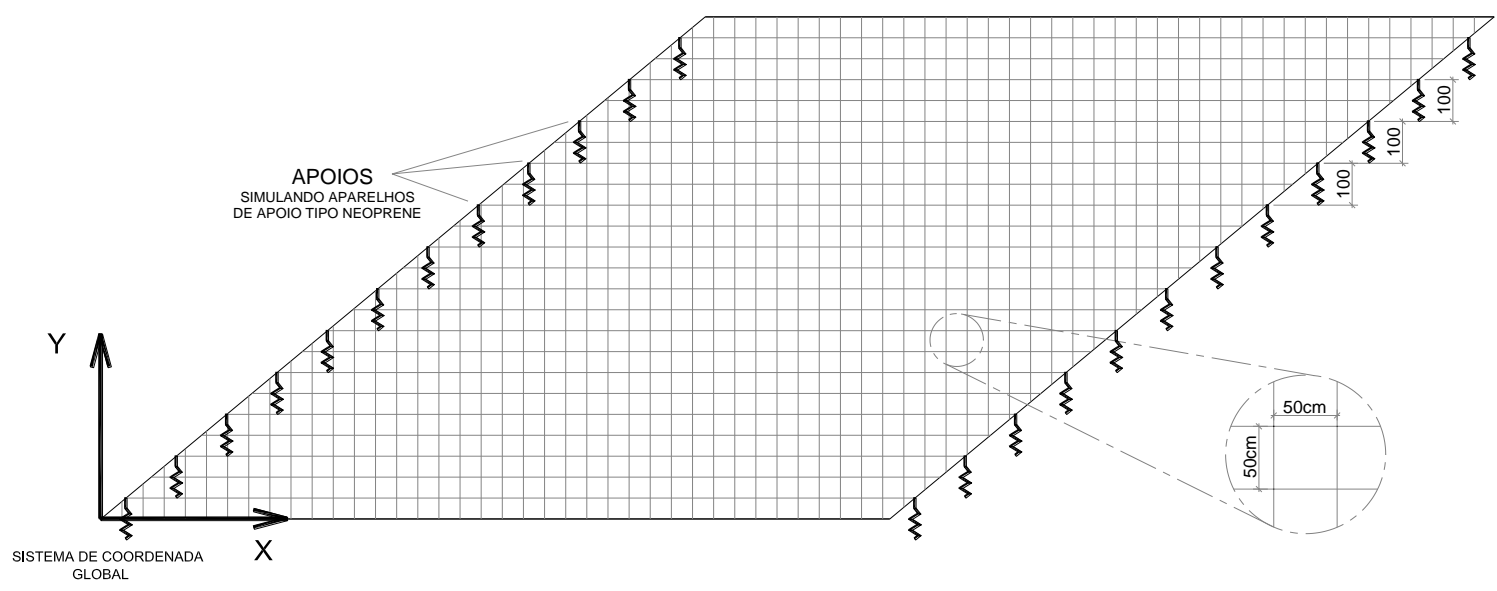

Figura 17 - Modelo matemático adotando molas que simulam os aparelhos de apoio 


\subsubsection{Resultados e análises}

A seguir serão apresentadas várias verificações no sentido de validar os modelos estudados e comparar os resultados para entender melhor 0 comportamento e a divergência entre eles.

4.1.6.1 Discretização da malha de elementos finitos para laje com esconsidade de $45^{\circ}$

\section{Elementos com $25 \mathrm{~cm}$ de lado:}

\section{Momentos fletores}

Permanente:

Longitudinal $(\mathrm{x})$

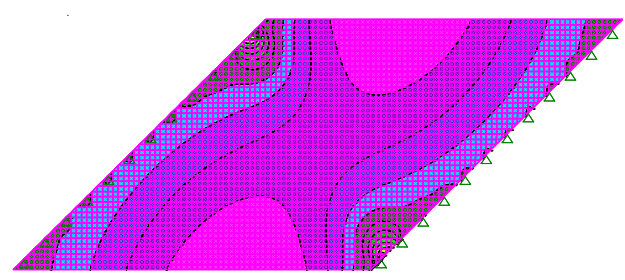

Móvel:

Longitudinal mínimo (x)

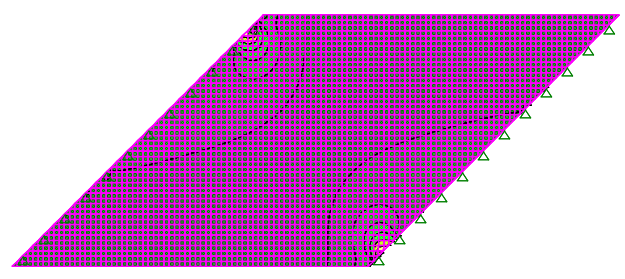

Transversal mínimo (y)

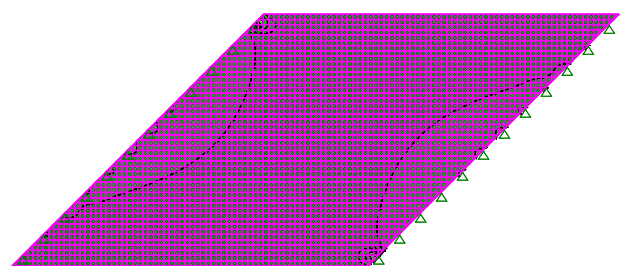

Transversal (y)
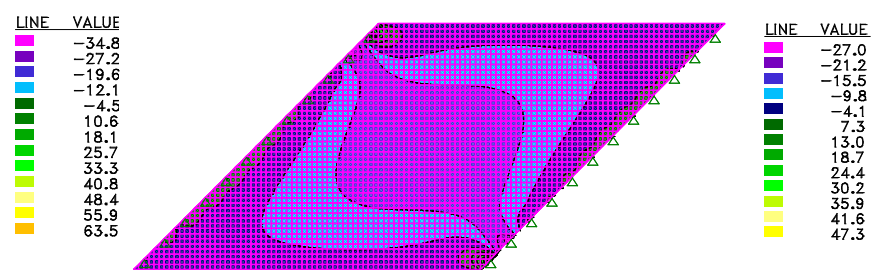

Longitudinal máximo (x)
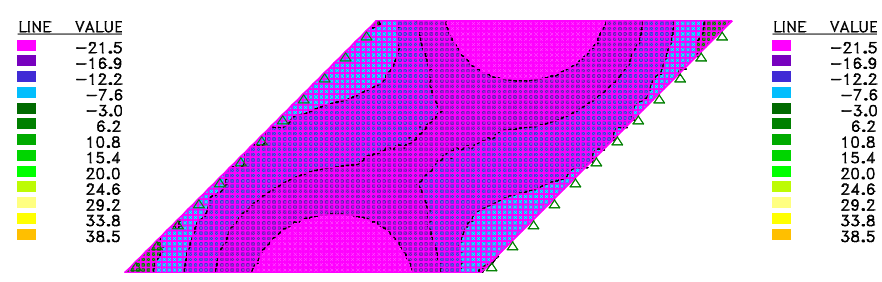

Transversal máximo (y)

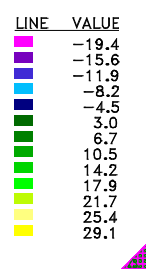


Reações nos apoios

Permanente:

Móvel:
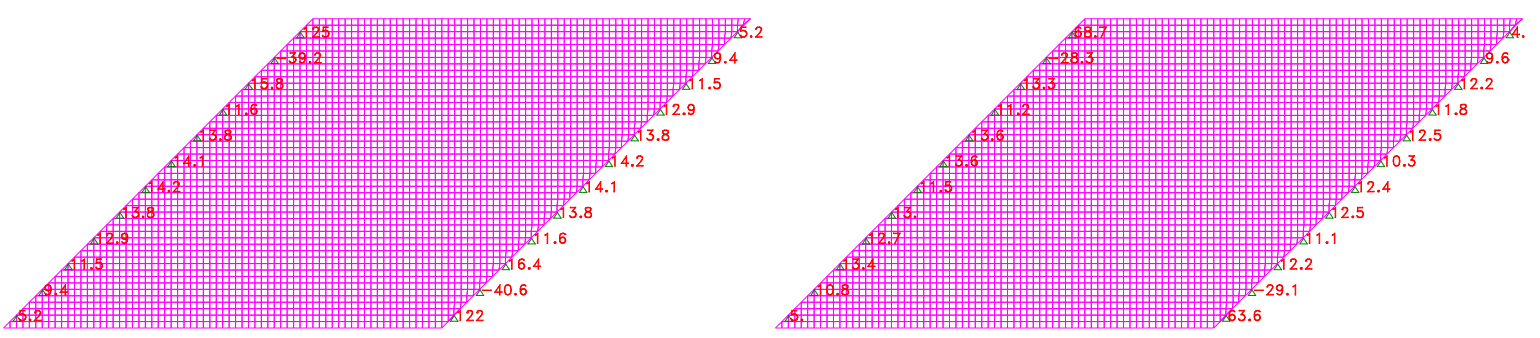

Elementos com $50 \mathrm{~cm}$ de lado:

\section{Momentos fletores}

Permanente:

Longitudinal $(\mathrm{x})$

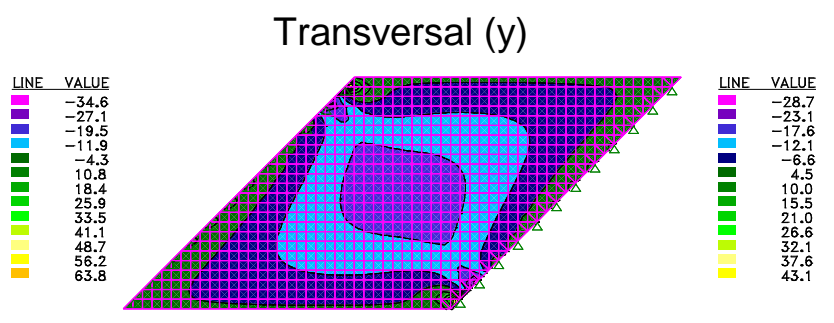

Móvel:

Longitudinal Mínimo (x)

Longitudinal Máximo (x)
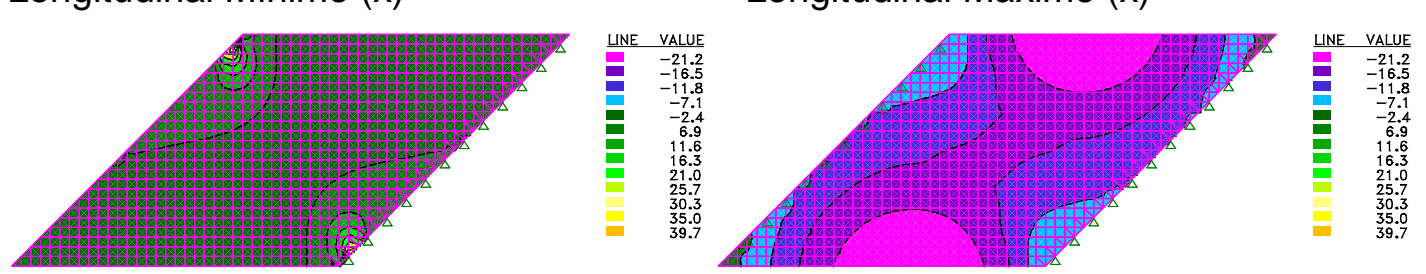
Transversal Mínimo (y)

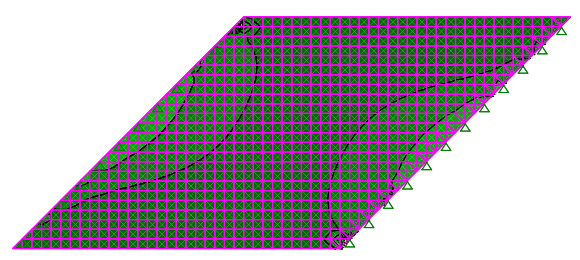

Transversal Máximo (y)

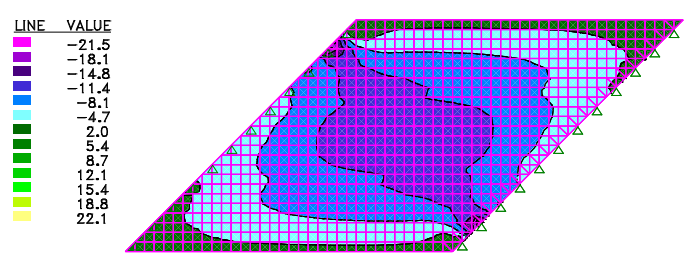

Reações nos apoios

Permanentes

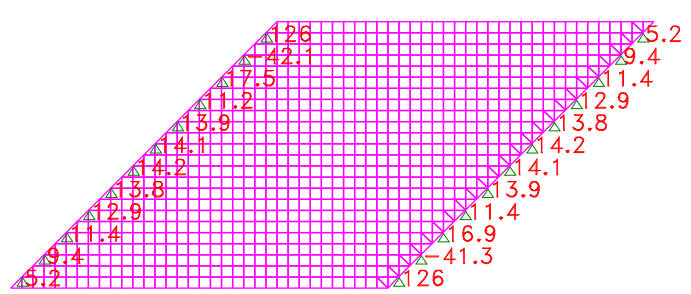

Envoltória das acidentais

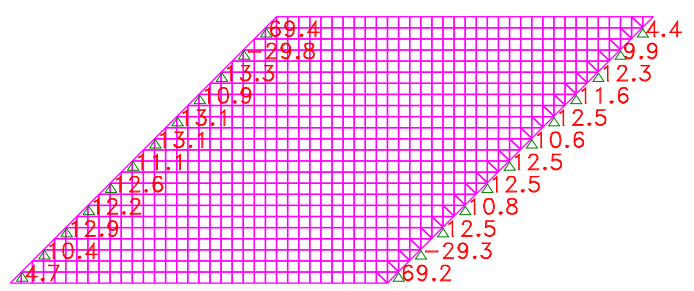

\section{Elementos com $100 \mathrm{~cm}$ de lado:}

\section{Momentos fletores}

Permanente:

Longitudinal $(\mathrm{x})$

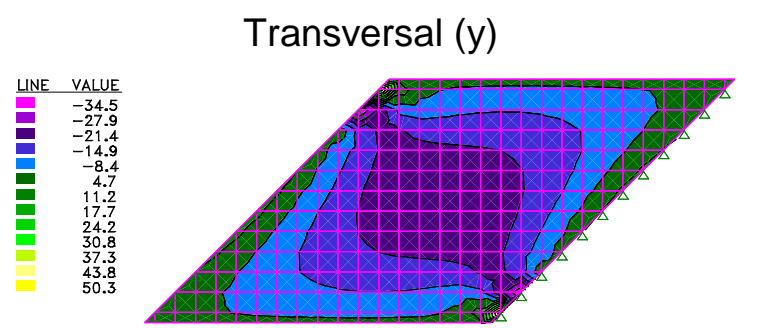


Móvel:

Longitudinal Mínimo (x)

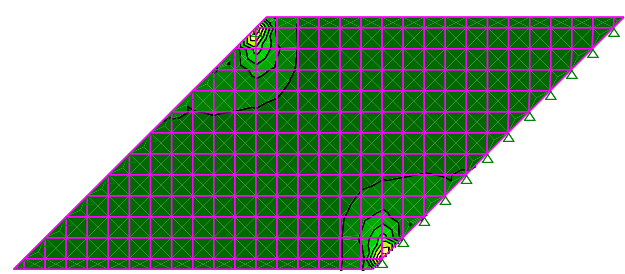

Transversal Mínimo (y)

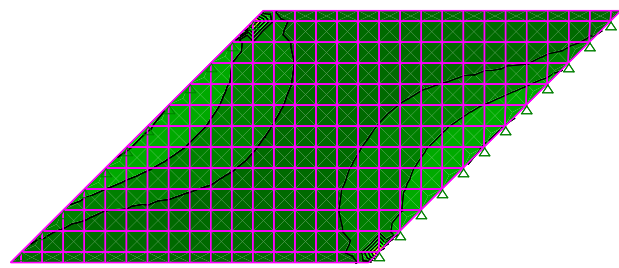

Longitudinal Máximo (x)
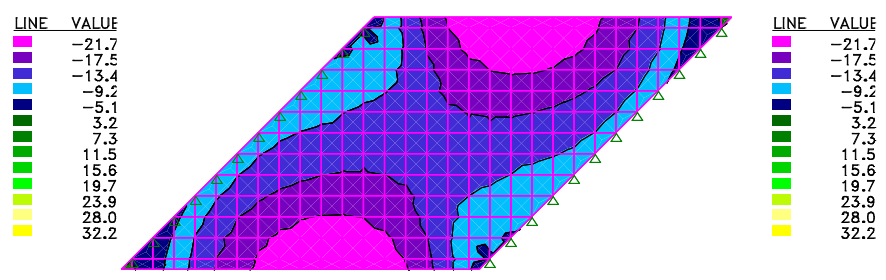

Transversal Máximo (y)

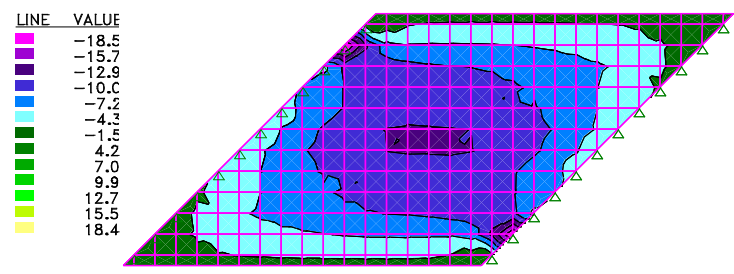

\section{Reações nos apoios}

Permanentes

Envoltória das acidentais
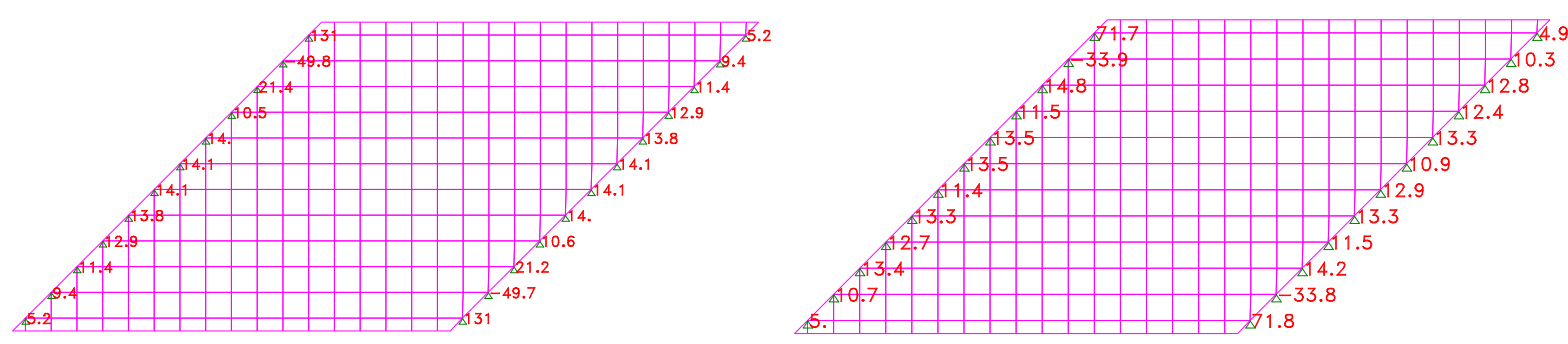

Comparação

\begin{tabular}{|c|c|c|c|c|c|c|}
\hline \multirow{3}{*}{ Modelos } & \multicolumn{4}{|c|}{ Momento Fletor (kN.m) } & \multicolumn{2}{|c|}{ Reações (kN) } \\
\hline & \multicolumn{2}{|c|}{ Permanente } & \multicolumn{2}{|c|}{ Móvel } & Permanente & Móvel \\
\hline & long. (x) & transv. (y) & long. $(x)$ & transv. (y) & \multicolumn{2}{|c|}{ Canto Obtuso } \\
\hline $25 \mathrm{~cm}$ & 348 & 155 & 215 & 118 & 1250 & 687 \\
\hline $50 \mathrm{~cm}$ & 346 & 156 & 215 & 115 & 1260 & 694 \\
\hline $100 \mathrm{~cm}$ & 345 & 155 & 217 & 129 & 1310 & 717 \\
\hline$\%(25-50)$ & $-0.58 \%$ & $0.64 \%$ & $0.00 \%$ & $-2.61 \%$ & $0.79 \%$ & $1.01 \%$ \\
\hline$\%(50-100)$ & $-0.29 \%$ & $-0.65 \%$ & $0.92 \%$ & $10.85 \%$ & $3.82 \%$ & $3.21 \%$ \\
\hline
\end{tabular}

Tabela 3 - Diferenças entre os três níveis de discretização 
4.1.6.2 Diferença nos resultados conforme superficie de influência

Todo tabuleiro carregado com a carga de multidão:

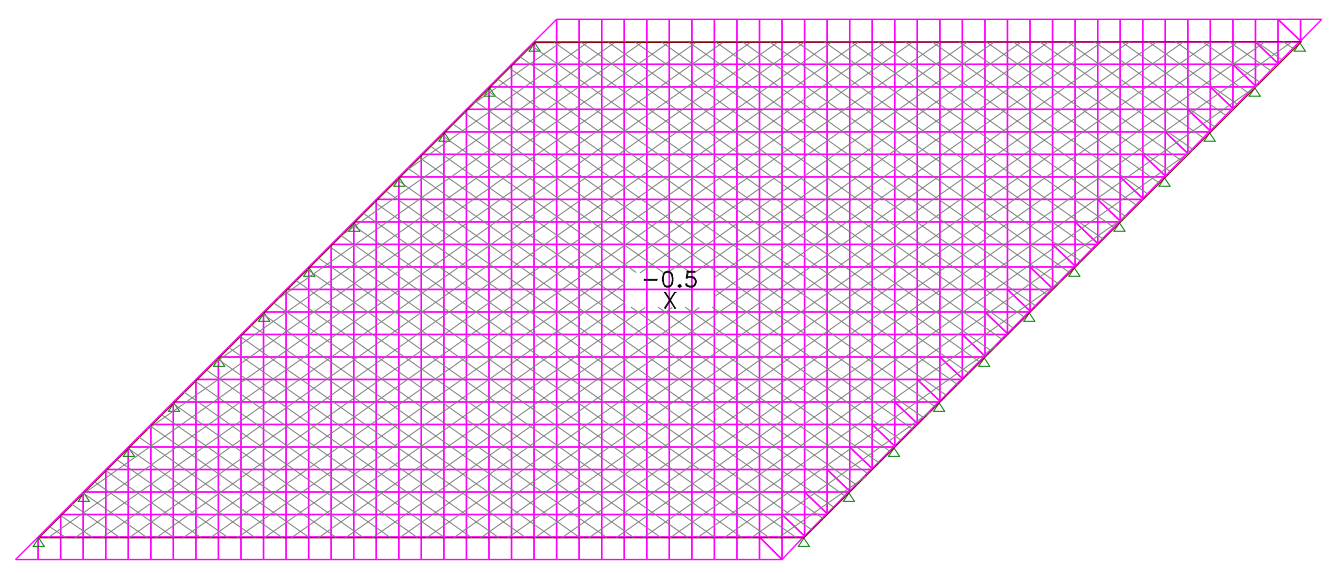

Longitudinal ( $\mathrm{x}$ )
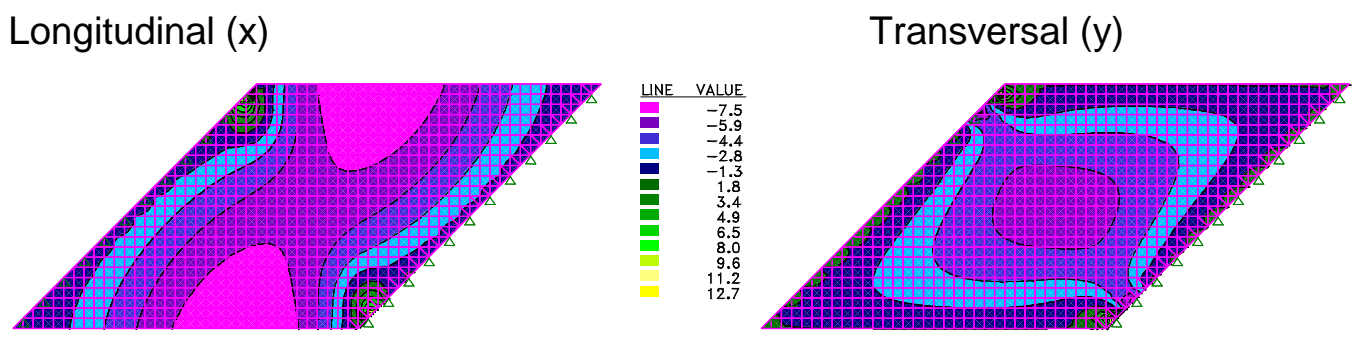

LINE $\quad$ VALUE
-5.53
-4.43
-3.33
-2.23
-2.13
-1.13
1.08
2.18
3.28
4.38
5.48
6.59
67.69
7.79
8.79

Reações

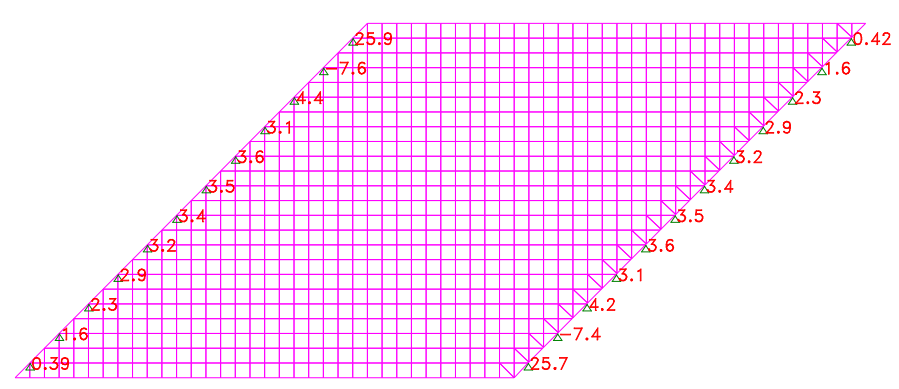


Carregado com a superficie de influência para para o ponto A:

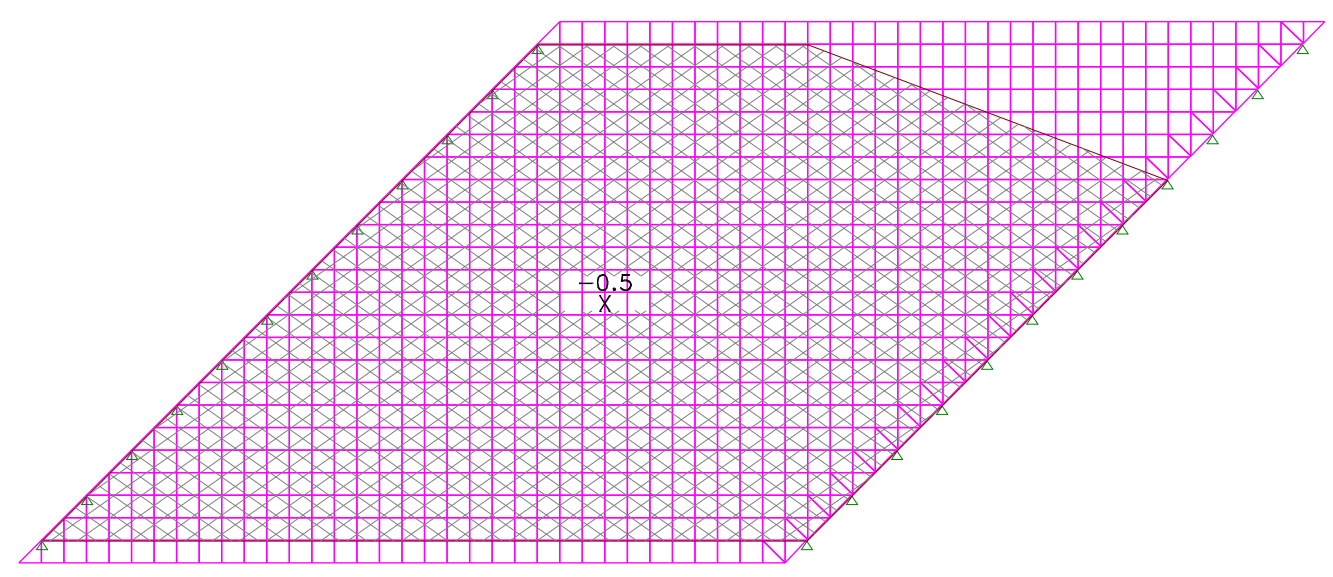

Longitudinal (x)

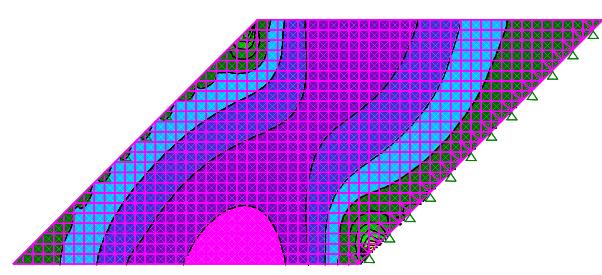

Transversal $(\mathrm{y})$

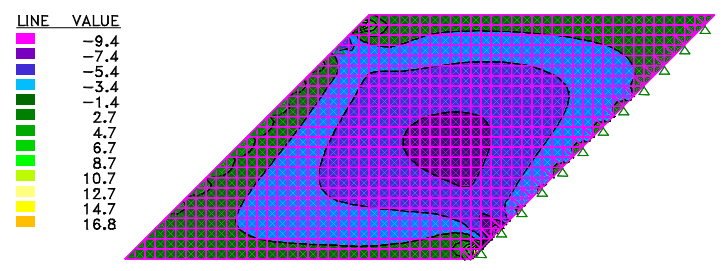

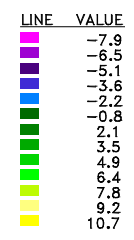

Reações

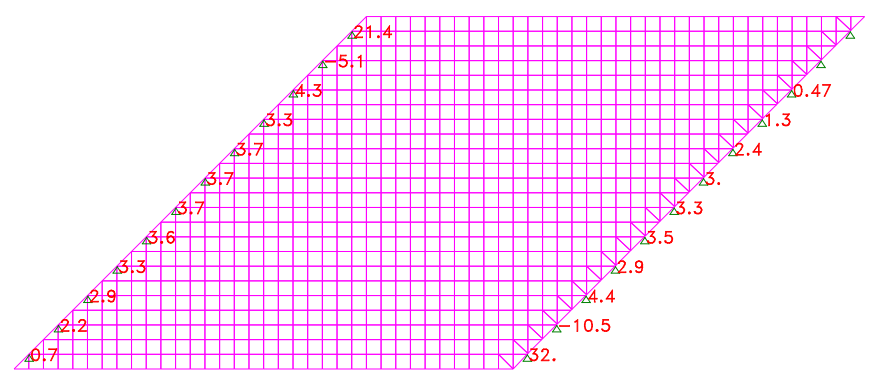

\section{Comparação}

\begin{tabular}{|l|c|c|c|}
\hline \multirow{2}{*}{ Tipo de Carregamento } & \multicolumn{2}{|c|}{ Momento Fletor (kN.m) } & Reações (kN) \\
\cline { 2 - 4 } & long. $(\mathrm{x})$ & transv. $(\mathrm{y})$ & Canto Obtuso \\
\hline Todo Tabuleiro & 75 & 55.3 & 257 \\
\hline Superfície de Influência & 94 & 79 & 320 \\
\hline \% de erro & $-20 \%$ & $-30 \%$ & $-20 \%$ \\
\hline
\end{tabular}

Tabela 4 - Erro devido ao carregamento indevido - ponto $\mathrm{A}$ 


\subsubsection{Modelagem com elementos esconsos (STRAP)}

\section{Momentos fletores}

Permanente:

Longitudinal $(\mathrm{x})$

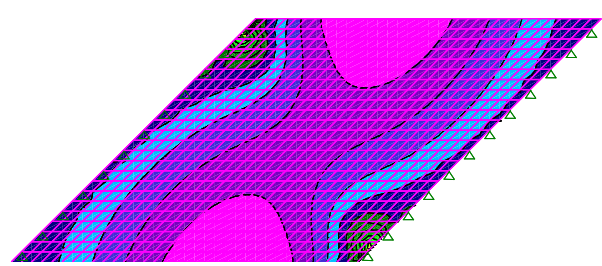

Móvel

Longitudinal Mínimo (x)

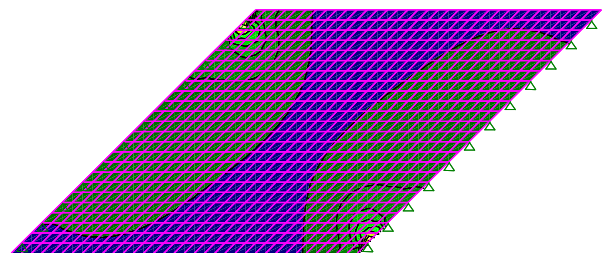

Transversal Mínimo (y)

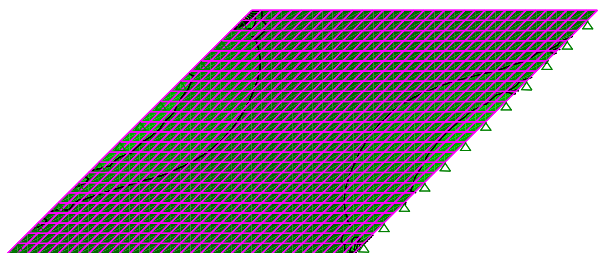

Transversal (y)

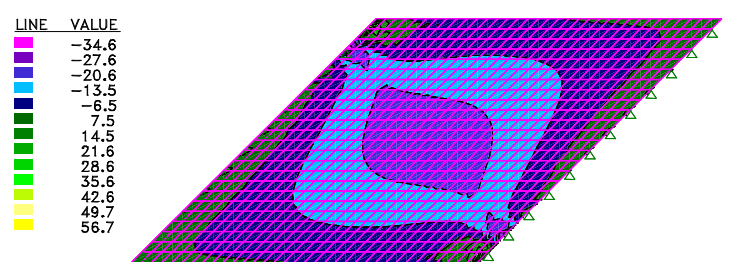

Longitudinal Máximo (x)

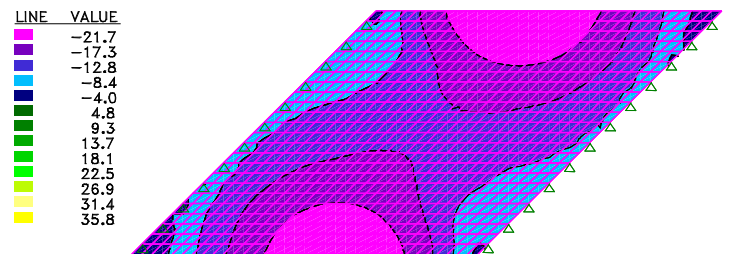

Transversal Máximo (y)

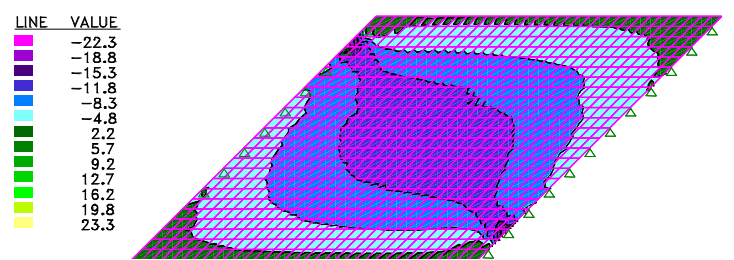

LINE VALUE
-22.3
-18.8
-15.3
-11.8
-8.3
-4.8
2.2
5.7
9.2
12.7
16.2
19.8
23.3

\section{Reações nos apoios}

Permanentes

Envoltória das acidentais
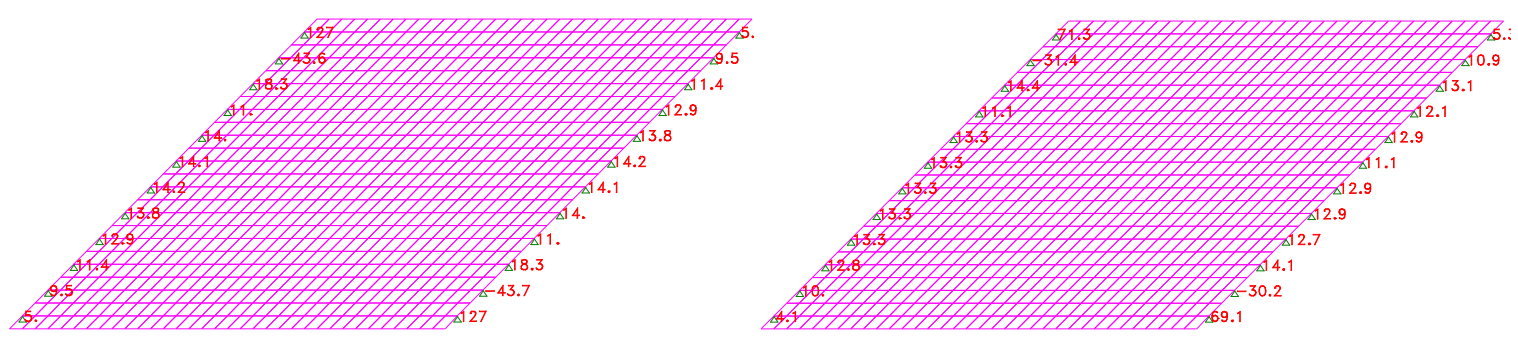

\section{Comparação}

\begin{tabular}{|l|c|c|c|c|c|c|}
\hline \multirow{2}{*}{ Modelos } & \multicolumn{4}{|c|}{ Momento Fletor (kN.m) } & \multicolumn{2}{c|}{ Reações (kN) } \\
\cline { 2 - 7 } & \multicolumn{2}{|c|}{ Permanente } & \multicolumn{2}{c|}{ Móvel } & Permanente & Móvel \\
\cline { 2 - 7 } & long. (x) & transv. (y) & long. (x) & transv. (y) & \multicolumn{2}{c|}{ Canto Obtuso } \\
\hline Elementos Esconsos & 346 & 157 & 217 & 117 & 1270 & 691 \\
\hline Elementos Retangulares & 346 & 156 & 215 & 115 & 1260 & 694 \\
\hline Diferença (\%) & $0.00 \%$ & $-0.64 \%$ & $-0.93 \%$ & $-1.74 \%$ & $-0.79 \%$ & $0.43 \%$ \\
\hline
\end{tabular}

Tabela 5 - Comparação entre discretização com elementos esconsos e retangulares 
4.1.6.4 Resultados da modelagem no STRAP para laje com esconsidade de 45ํㅡㄴ

\section{Momentos fletores}

Permanente:

Longitudinal $(\mathrm{x})$

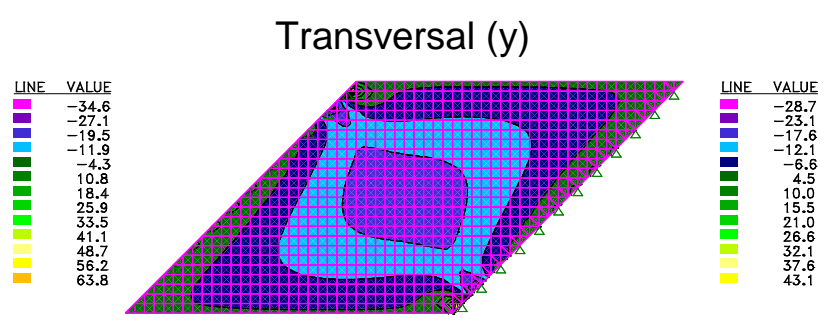

Móvel:

Longitudinal Mínimo (x)
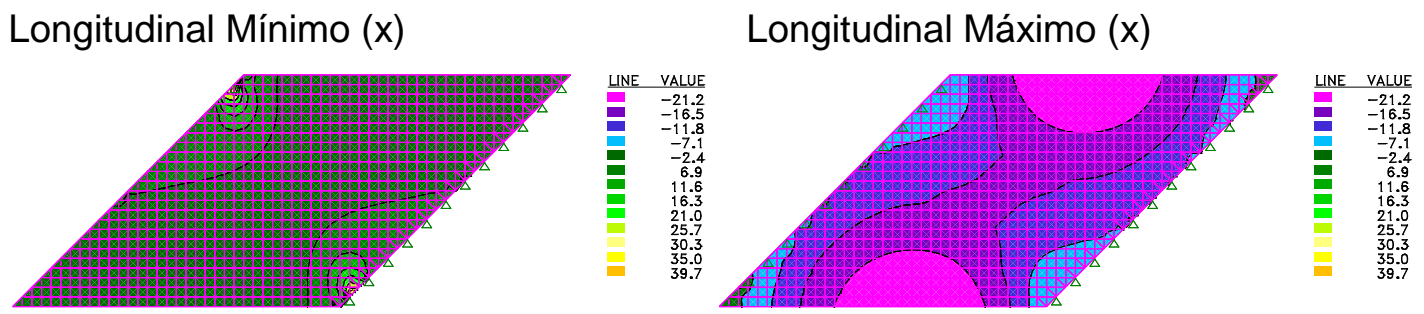

Transversal Mínimo (y)
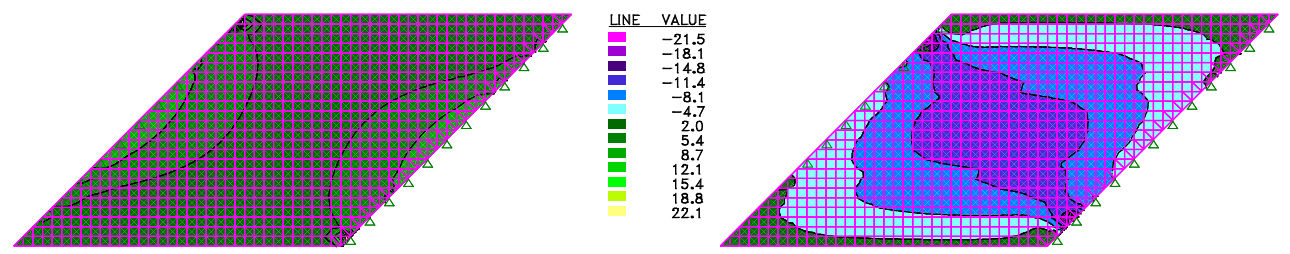

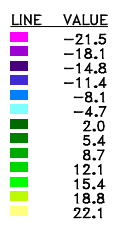

\section{Reações nos apoios}

Permanentes

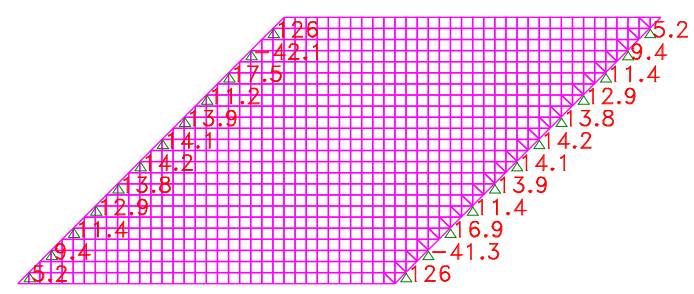

Envoltória das acidentais

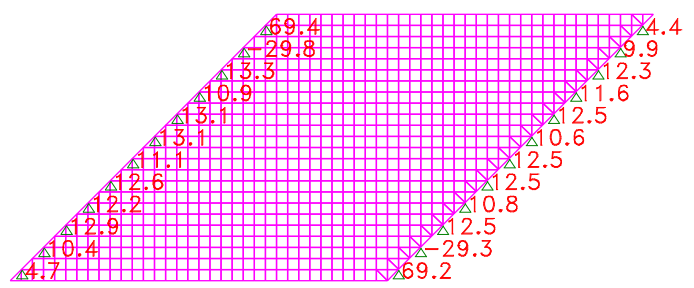

Momentos Principais:

\begin{tabular}{|c|c|c|c|c|c|c|c|c|c|c|c|c|c|c|c|c|}
\hline \multicolumn{17}{|c|}{ STRAP } \\
\hline \multirow{2}{*}{\multicolumn{2}{|c|}{ Momentos Principais }} & \multicolumn{3}{|c|}{ Ponto $\mathrm{A}$} & \multicolumn{3}{|c|}{ Ponto B } & \multicolumn{3}{|c|}{ Ponto C } & \multicolumn{3}{|c|}{ Ponto D } & \multicolumn{3}{|c|}{ Ponto E } \\
\hline & & $\mathrm{Mx}$ & My & Mxy & $\mathrm{Mx}$ & My & Mxy & $\mathrm{Mx}$ & My & Mxy & $\mathrm{Mx}$ & $\mathrm{My}$ & Mxy & $\mathrm{Mx}$ & $\mathrm{My}$ & Mxy \\
\hline \multicolumn{2}{|c|}{ Máximos } & 53.68 & 2.04 & -13.79 & 35.46 & 24.60 & -21.78 & 55.35 & 2.11 & -18.73 & 42.87 & 18.13 & -20.53 & 9.55 & -2.61 & -24.01 \\
\hline \multicolumn{2}{|c|}{ Mínimos } & 32.44 & 1.13 & -20.99 & 22.94 & 14.28 & -30.30 & 34.32 & 1.15 & -28.10 & 27.64 & 10.07 & -30.26 & -2.58 & -3.99 & -35.90 \\
\hline \multirow{3}{*}{ STRAP - Max } & $M_{1}(t f . m / m)$ & \multicolumn{3}{|c|}{57.13} & \multicolumn{3}{|c|}{52.48} & \multicolumn{3}{|c|}{61.28} & \multicolumn{3}{|c|}{54.47} & \multicolumn{3}{|c|}{28.24} \\
\hline & $M_{11}$ (tf.m/m) & \multicolumn{3}{|c|}{-1.41} & \multicolumn{3}{|c|}{7.58} & \multirow{2}{*}{\multicolumn{3}{|c|}{$\frac{-3.82}{-17.56}$}} & \multirow{2}{*}{\multicolumn{3}{|c|}{$\begin{array}{c}\frac{6.53}{-29.46} \\
-\end{array}$}} & \multicolumn{3}{|c|}{-21.29} \\
\hline & Ângulo $\left({ }^{\circ}\right)$ & \multicolumn{3}{|c|}{-14.05} & \multirow{2}{*}{\multicolumn{3}{|c|}{$\frac{-38.00}{49.22}$}} & & & & & & & & & \\
\hline \multirow{3}{*}{ STRAP - Min } & $M_{1}$ (tf.m/m) & \multirow{2}{*}{\multicolumn{3}{|c|}{$\begin{array}{r}42.97 \\
-9.40\end{array}$}} & & & & \multicolumn{3}{|c|}{50.36} & \multicolumn{3}{|c|}{50.36} & \multicolumn{3}{|c|}{$\begin{array}{c}-3.89 \\
32.63\end{array}$} \\
\hline & $M_{11}$ (tf.m/m) & & & & \multicolumn{3}{|c|}{-12.00} & & & \multicolumn{3}{|c|}{-39.19} \\
\hline & Ângulo ( ${ }^{\circ}$ ) & \multicolumn{3}{|c|}{-26.64} & \multicolumn{3}{|c|}{-40.93} & \multicolumn{3}{|c|}{$\begin{array}{l}-14.90 \\
-29.72\end{array}$} & \multicolumn{3}{|c|}{$\frac{-12.65}{-36.91}$} & & -44.44 & \\
\hline
\end{tabular}


4.1.6.5 Resultados da modelagem no SAP2000 para laje com esconsidade de 45ํㅜ Permanente $\mathrm{x}$

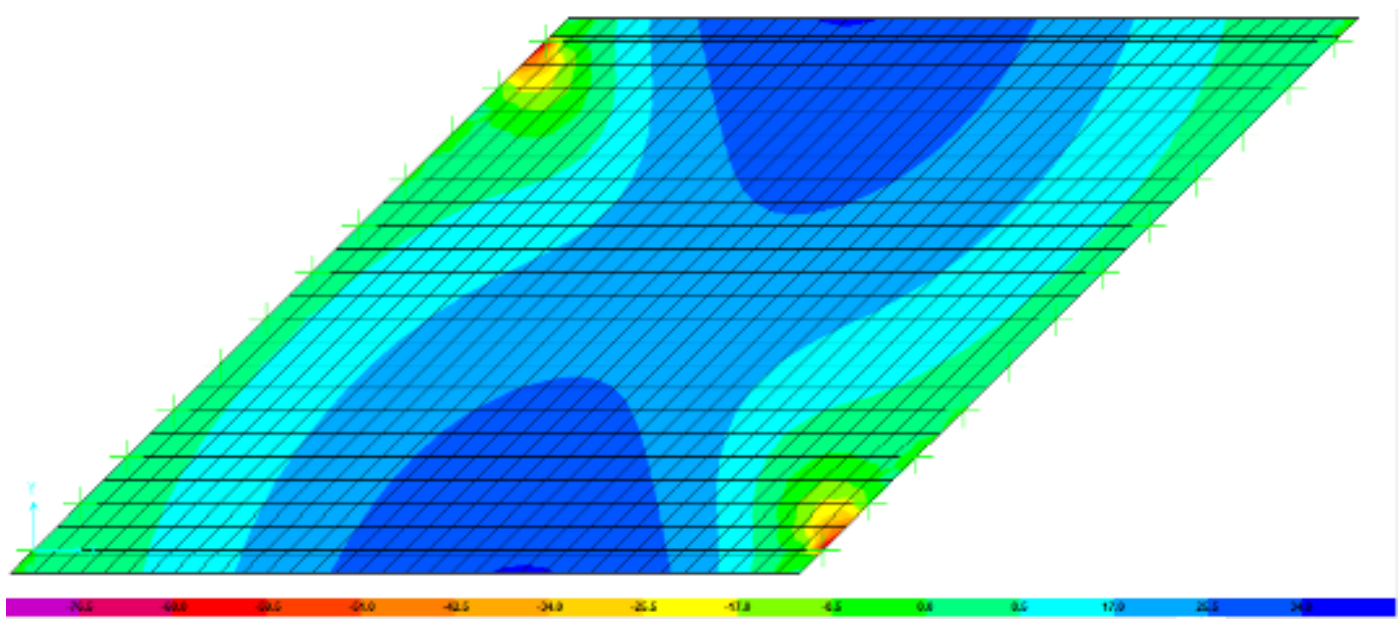

Permanente y

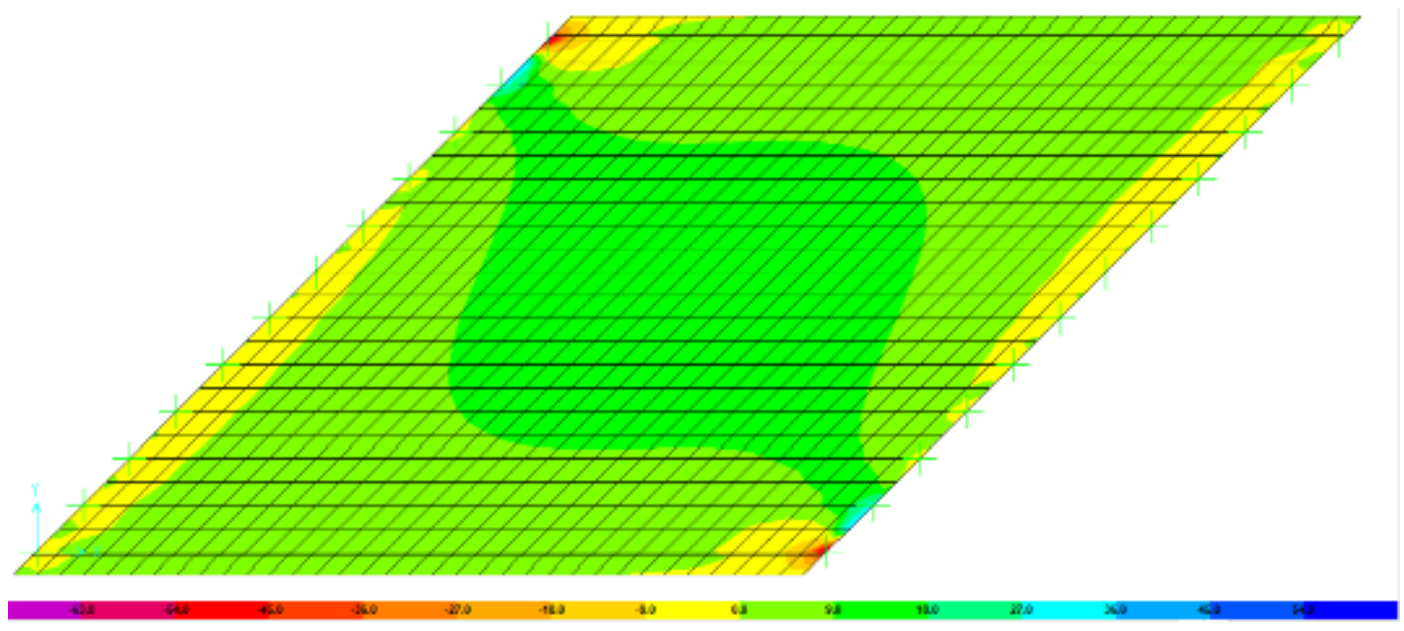

Envoltória Mínima x

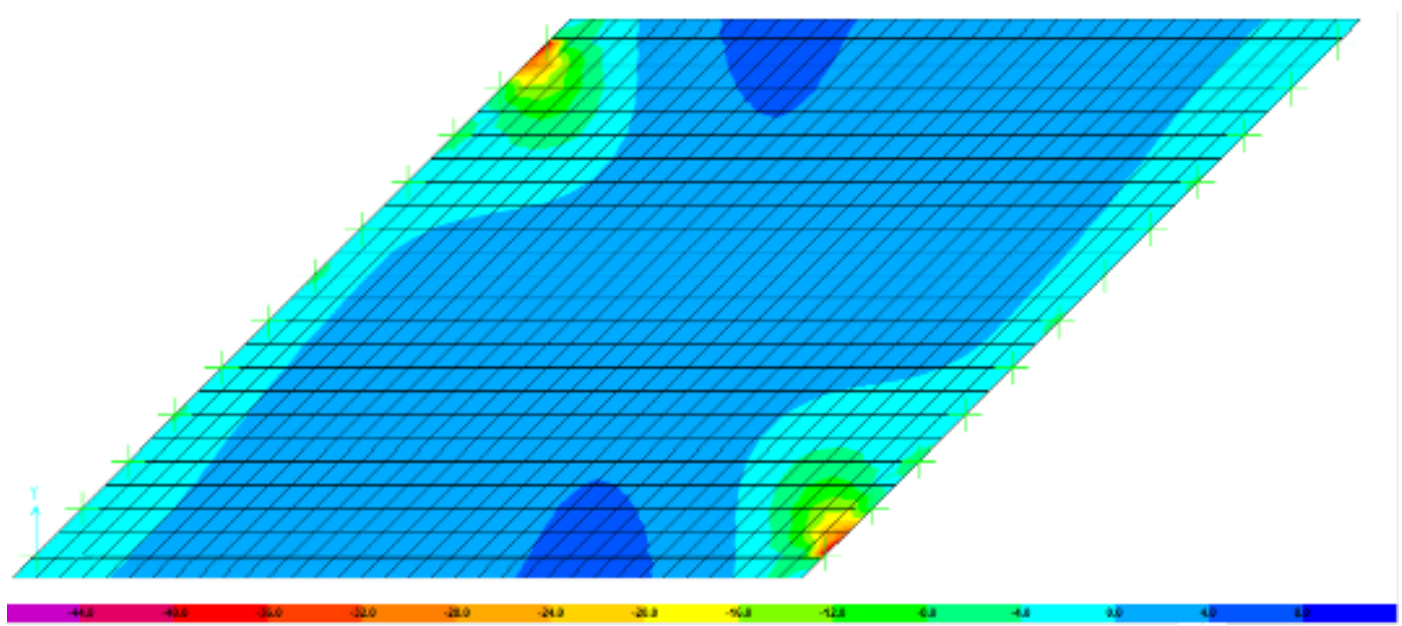


Envoltória Máxima x

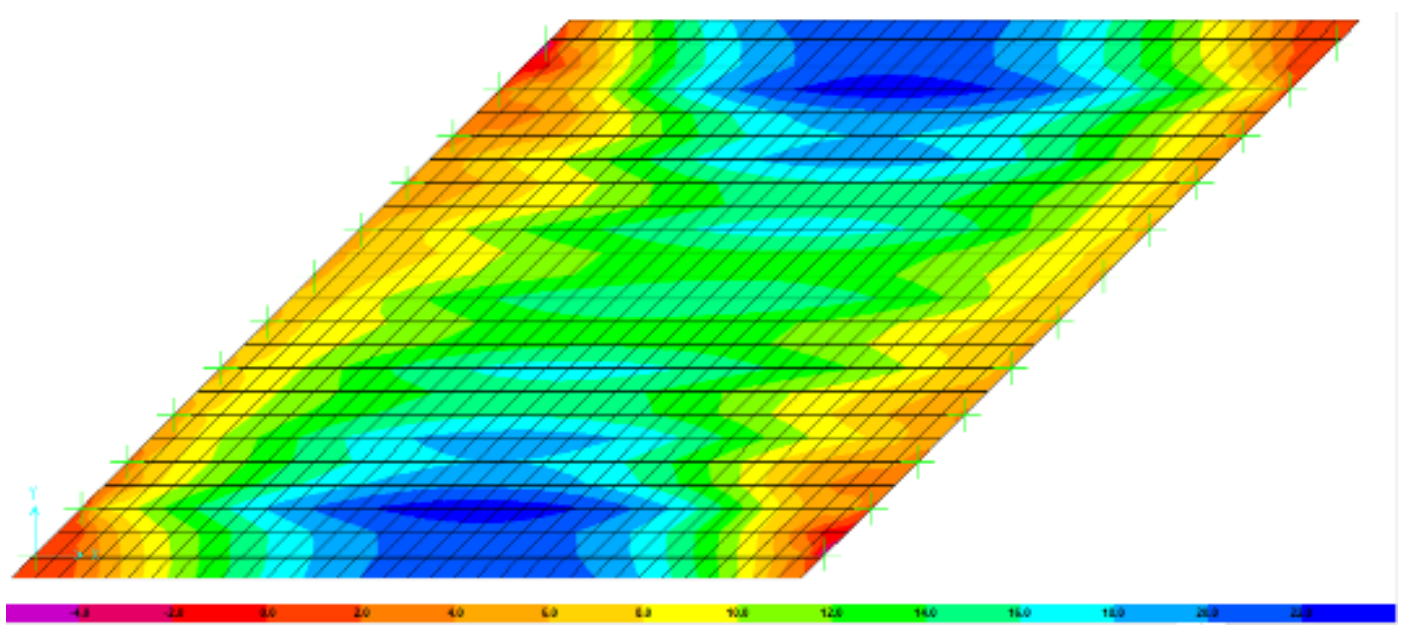

Envoltória Mínima y

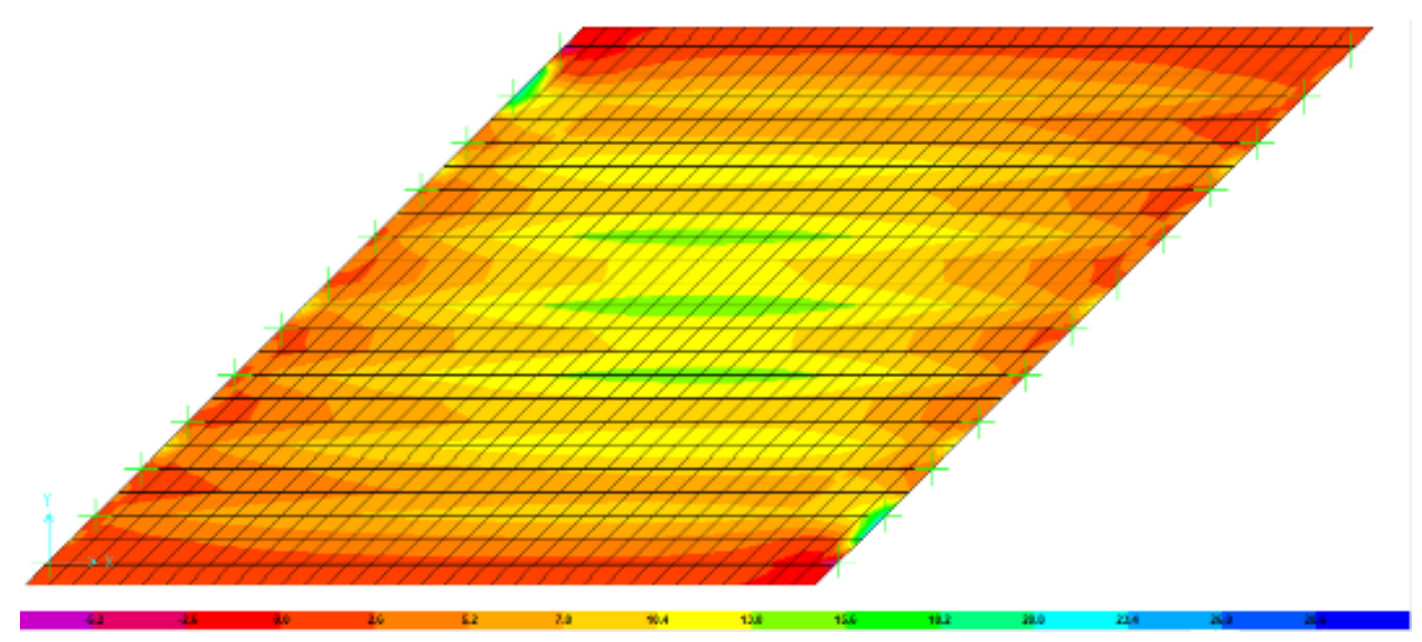

Envoltória Máxima y

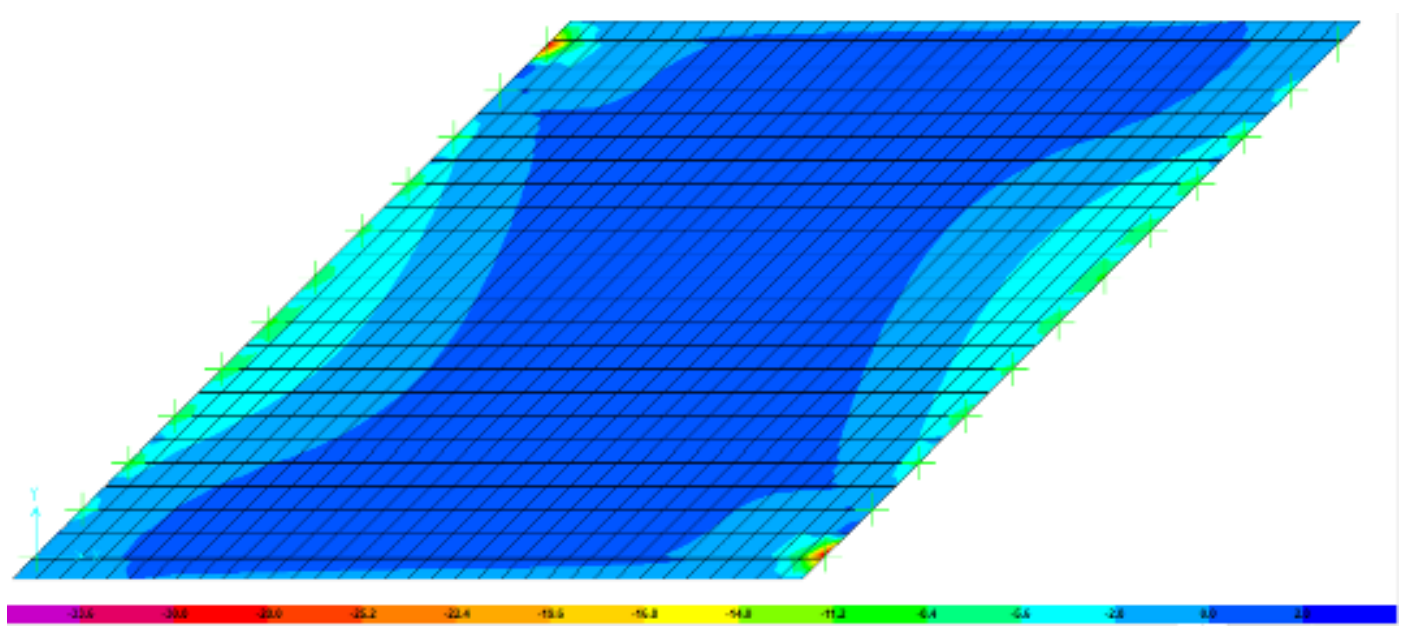


Momentos Principais:

\begin{tabular}{|c|c|c|c|c|c|c|c|c|c|c|c|c|c|c|c|c|}
\hline \multicolumn{17}{|c|}{ SAP } \\
\hline \multirow{2}{*}{\multicolumn{2}{|c|}{ Momentos Principais }} & \multicolumn{3}{|c|}{ Ponto A } & \multicolumn{3}{|c|}{ Ponto B } & \multicolumn{3}{|c|}{ Ponto C } & \multicolumn{3}{|c|}{ Ponto D } & \multicolumn{3}{|c|}{ Ponto $\mathrm{E}$} \\
\hline & & $\mathrm{Mx}$ & My & Mxy & $\mathrm{Mx}$ & My & Mxy & $\mathrm{Mx}$ & My & Mxy & $M x$ & My & Mxy & $\mathrm{Mx}$ & My & Mxy \\
\hline \multicolumn{2}{|c|}{ Máximos } & 52.18 & 4.01 & -14.45 & 39.20 & 28.76 & -24.77 & 54.83 & 4.38 & -20.65 & 41.15 & 19.11 & -22.06 & 9.26 & -5.22 & -23.79 \\
\hline \multicolumn{2}{|c|}{ Mínimos } & 33.98 & 2.43 & -18.80 & 26.63 & 16.00 & -29.90 & 37.76 & 2.56 & -26.98 & 30.52 & 12.17 & -28.40 & -0.59 & -6.85 & -32.70 \\
\hline \multirow{3}{*}{ SAP - Max } & $M_{1}$ (tf.m/m) & \multicolumn{3}{|c|}{56.18} & \multicolumn{3}{|c|}{59.29} & \multicolumn{3}{|c|}{62.20} & \multicolumn{3}{|c|}{54.79} & \multicolumn{3}{|c|}{26.88} \\
\hline & $M_{11}$ (tf.m/m) & \multicolumn{3}{|c|}{0.01} & \multicolumn{3}{|c|}{8.66} & \multicolumn{3}{|c|}{-2.99} & \multicolumn{3}{|c|}{5.47} & \multicolumn{3}{|c|}{-22.85} \\
\hline & Ângulo ( ${ }^{\circ}$ ) & \multirow{2}{*}{\multicolumn{3}{|c|}{$\frac{-15.48}{42.74}$}} & \multirow{2}{*}{\multicolumn{3}{|c|}{$\frac{-39.05}{51.69}$}} & \multicolumn{3}{|c|}{-19.65} & \multicolumn{3}{|c|}{-31.73} & \multicolumn{3}{|c|}{-36.53} \\
\hline \multirow{3}{*}{ SAP - Min } & $M_{1}(t f . m / m)$ & & & & & & & \multirow{2}{*}{\multicolumn{3}{|c|}{$\begin{array}{l}52.37 \\
-12.05\end{array}$}} & \multicolumn{3}{|c|}{51.20} & \multicolumn{3}{|c|}{29.13} \\
\hline & $M_{11}$ (tf.m/m) & \multicolumn{3}{|c|}{-6.34} & \multicolumn{3}{|c|}{-9.05} & & & & \multicolumn{3}{|c|}{-8.50} & & -36.56 & \\
\hline & Ângulo ( ${ }^{\circ}$ ) & \multicolumn{3}{|c|}{-25.00} & \multicolumn{3}{|c|}{-39.96} & \multicolumn{3}{|c|}{$\frac{-12.05}{-28.44}$} & & -36.05 & & & -42.27 & \\
\hline
\end{tabular}

Tabela 7 - Momentos Principais - SAP

\subsubsection{Resultados da Tabela de Rüsh para laje com esconsidade de 45ำ}

\begin{tabular}{|c|c|c|c|c|c|c|c|c|c|c|c|c|c|c|c|c|}
\hline \multirow{2}{*}{\multicolumn{2}{|c|}{ Momentos Fletores }} & \multicolumn{3}{|c|}{ Ponto $\mathrm{A}$} & \multicolumn{3}{|c|}{ Ponto B } & \multicolumn{3}{|c|}{ Ponto $\mathrm{C}$} & \multicolumn{3}{|c|}{ Ponto D } & \multicolumn{3}{|c|}{ Ponto $\mathrm{E}$} \\
\hline & & $\mathrm{Mu}$ & Muv & $\mathrm{Mv}$ & $\mathrm{Mx}$ & My & Mxy & $\mathrm{Mu}$ & Muv & $\mathrm{Mv}$ & $\mathrm{Mx}$ & My & Mxy & $\mathrm{Mx}$ & My & $\mathrm{Mxy}$ \\
\hline \multirow{9}{*}{ PERMANENTE } & $k_{\text {pista }}$ & 0.108 & 0.043 & 0.000 & 0.135 & -0.005 & -0.018 & 0.119 & 0.071 & 0.000 & 0.131 & 0.006 & -0.025 & 0.062 & -0.080 & 0.014 \\
\hline & $M_{p}(t f . m / m)$ & 30.17 & 12.01 & 0.00 & 37.71 & -1.40 & -5.03 & 33.24 & 19.83 & 0.00 & 36.60 & 1.68 & -6.98 & 17.32 & -22.35 & 3.91 \\
\hline & $k_{\text {barreira } 1}$ & -0.670 & -0.160 & 0.000 & 0.040 & 0.220 & 0.030 & -0.440 & -0.340 & 0.000 & 0.000 & 0.420 & 0.420 & -0.470 & 1.000 & -0.500 \\
\hline & $k_{\text {barreira } 2}$ & 0.070 & 0.050 & 0.000 & 0.040 & 0.220 & 0.020 & 0.070 & 0.040 & 0.000 & 0.090 & 0.050 & -0.040 & 0.030 & -0.070 & 0.020 \\
\hline & $M_{m b}(t f \cdot m / m)$ & 0.17 & 0.03 & -0.28 & -0.02 & -0.12 & -0.01 & 0.10 & 0.08 & -0.28 & -0.28 & -0.13 & -0.10 & 0.12 & -0.26 & 0.13 \\
\hline & $k_{\text {barreira } 1}$ & 0.320 & 0.090 & 0.000 & 0.110 & -0.080 & -0.030 & 0.270 & 0.170 & 0.000 & 0.200 & -0.060 & -0.100 & 0.170 & -0.360 & 0.140 \\
\hline & $k_{\text {barreira } 2}$ & 0.000 & 0.010 & 0.000 & 0.110 & -0.080 & -0.030 & 0.020 & 0.020 & 0.000 & 0.050 & -0.030 & -0.010 & 0.030 & 0.020 & -0.040 \\
\hline & $M_{a b}$ (tf.m/m) & 5.30 & 1.66 & 0.00 & 3.64 & -2.65 & -0.99 & 4.80 & 3.15 & 0.00 & 4.14 & -1.49 & -1.82 & 3.31 & -5.63 & 1.66 \\
\hline & Mp Total (tf.m/m) & 35.64 & 13.70 & -0.28 & 41.33 & -4.17 & -6.04 & 38.15 & 23.06 & -0.28 & 40.46 & 0.06 & -8.91 & 20.75 & -28.24 & 5.70 \\
\hline \multirow{4}{*}{$\operatorname{MAX} M_{1}$} & $k_{\pi}$ & 2.72 & 0.47 & 0.00 & 1.48 & 0.78 & -0.10 & 2.66 & 0.66 & 0.00 & 1.68 & 0.58 & -0.40 & 1.20 & -1.27 & 0.21 \\
\hline & $\mathrm{k}_{\text {MULT PRINGPAL }}$ & 2.78 & 1.22 & 0.00 & 2.27 & 0.04 & 0.08 & 2.45 & 2.63 & 0.00 & 2.72 & -0.59 & -0.49 & 1.45 & -5.37 & 2.17 \\
\hline & $k_{\text {MULT SECUNDÁRIA }}$ & 6.42 & 3.27 & 0.00 & 12.65 & -2.19 & -2.40 & 8.72 & 5.80 & 0.00 & 11.42 & 0.32 & -1.92 & 4.66 & -3.42 & -0.51 \\
\hline & $M(t f . m / m)$ & 25.00 & 5.77 & 0.00 & 18.56 & 4.78 & -1.91 & 25.54 & 9.17 & 0.00 & 19.67 & 4.22 & -4.21 & 12.06 & -13.92 & 2.41 \\
\hline \multirow{4}{*}{ MIN M $M_{\|}$} & $k_{\pi}$ & 0.00 & 0.00 & 0.00 & 0.67 & -0.45 & -0.13 & 0.00 & 0.00 & 0.00 & 1.14 & -0.50 & -0.25 & 0.69 & -1.92 & 0.80 \\
\hline & $\mathrm{k}_{\text {MULT PRINGPAL }}$ & 0.00 & 0.00 & 0.00 & 1.39 & -0.57 & -0.37 & 0.00 & 0.00 & 0.00 & 0.71 & -0.30 & -0.34 & 2.14 & -3.66 & 0.99 \\
\hline & $k_{\text {MULT SECUNDÁRAA }}$ & 0.00 & 0.00 & 0.00 & 6.41 & -2.44 & -0.84 & 0.00 & 0.00 & 0.00 & 4.18 & -0.98 & -0.25 & 3.14 & -3.64 & 0.54 \\
\hline & $\mathrm{M}(\mathrm{tf} \cdot \mathrm{m} / \mathrm{m})$ & 0.00 & 0.00 & 0.00 & 8.93 & -4.88 & -1.58 & 0.00 & 0.00 & 0.00 & 11.00 & -4.39 & -2.17 & 7.82 & -18.05 & 6.77 \\
\hline \multirow{4}{*}{ MAX M } & $k_{\pi}$ & 0.00 & 0.00 & 0.00 & 1.48 & 0.78 & -0.10 & 0.00 & 0.00 & 0.00 & 1.61 & 0.72 & -0.20 & 0.00 & 0.00 & 0.00 \\
\hline & $\mathrm{k}_{\text {MULT PRINCPAL }}$ & 0.00 & 0.00 & 0.00 & 1.02 & 0.28 & 0.09 & 0.00 & 0.00 & 0.00 & 1.54 & 0.33 & -0.10 & 0.00 & 0.00 & 0.00 \\
\hline & $\mathrm{k}_{\text {MULT SECUNDÁRIA }}$ & 0.00 & 0.00 & 0.00 & 5.05 & 1.65 & -0.84 & 0.00 & 0.00 & 0.00 & 4.96 & 1.36 & -1.63 & 0.00 & 0.00 & 0.00 \\
\hline & $M$ (tf.m/m) & 0.00 & 0.00 & 0.00 & 14.14 & 6.82 & -1.13 & 0.00 & 0.00 & 0.00 & 15.33 & 6.25 & -2.37 & 0.00 & 0.00 & 0.00 \\
\hline \multicolumn{17}{|c|}{ RUSCH } \\
\hline \multicolumn{2}{|c|}{ Momentos Principais } & \multirow{2}{*}{\multicolumn{3}{|c|}{$\frac{\text { Ponto A }}{66.33}$}} & \multicolumn{3}{|c|}{ Ponto B } & \multicolumn{3}{|c|}{ Ponto C } & \multicolumn{3}{|c|}{ Ponto D } & \multicolumn{3}{|c|}{ Ponto $\mathrm{E}$} \\
\hline \multirow{3}{*}{$\begin{array}{l}\text { PERM+SC } \\
\text { MAX M }\end{array}$} & $M_{1}$ (tf.m/m) & \multirow{2}{*}{\multicolumn{3}{|c|}{$\begin{array}{l}66.33 \\
-5.97\end{array}$}} & & \multirow{2}{*}{\multicolumn{3}{|c|}{77.11}} & \multicolumn{3}{|c|}{63.06} & \multicolumn{3}{|c|}{33.67} \\
\hline & $M_{11}$ (tf.m/m) & & & & & & & & & & & 1.34 & & & -43.02 & \\
\hline & Ângulo $\left({ }^{\circ}\right)$ & \multicolumn{3}{|c|}{-16.29} & & -37.50 & & & -22.61 & & & -32.42 & & & -38.90 & \\
\hline & $M_{1}$ (tf.m/m) & & 40.26 & & & 51.22 & & & 48.95 & & & 53.58 & & & 30.59 & \\
\hline MIN M & $M_{11}$ (tf.m/m) & & -4.90 & & & -10.01 & & & -11.08 & & & -6.45 & & & -48.31 & \\
\hline & Ângulo $\left({ }^{\circ}\right)$ & & -18.67 & & & -37.80 & & & -25.10 & & & -34.17 & & & -35.79 & \\
\hline & $M_{1}$ (tf.m/m) & & 40.26 & & & 56.42 & & & 48.95 & & & 58.23 & & & 21.41 & \\
\hline MAXM & $M_{11}$ (tf.m/m) & & -4.90 & & & 1.69 & & & -11.08 & & & 3.85 & & & -28.89 & \\
\hline & Ângulo $\left({ }^{\circ}\right)$ & & -18.67 & & & -37.42 & & & -25.10 & & & -32.75 & & & -38.45 & \\
\hline
\end{tabular}

Tabela 8 - Solicitações e Momentos Principais - RUSCH 
4.1.6.7 Comparação dos momentos principais para laje com esconsidade de $45^{\circ}$

A seguir, serão apresentados gráficos comparativos dos momentos principais nos cinco pontos (ver figura 14) para os três cálculos realizados: Tabelas de Rüsch (5), SAP2000 e STRAP, para a laje com esconsidade de $45^{\circ}$.

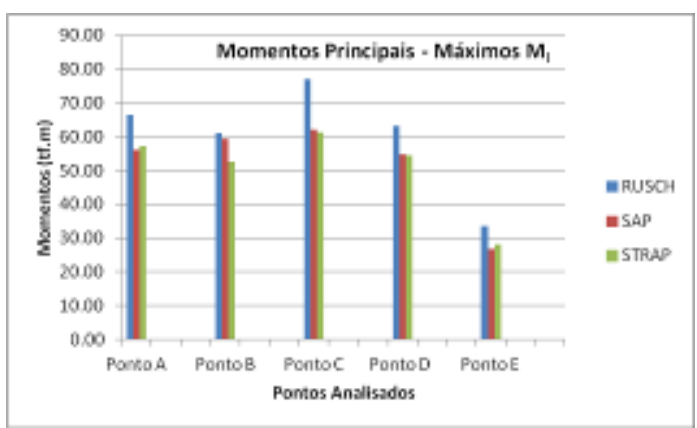

Momentos Máximos $\mathrm{M}_{1}$

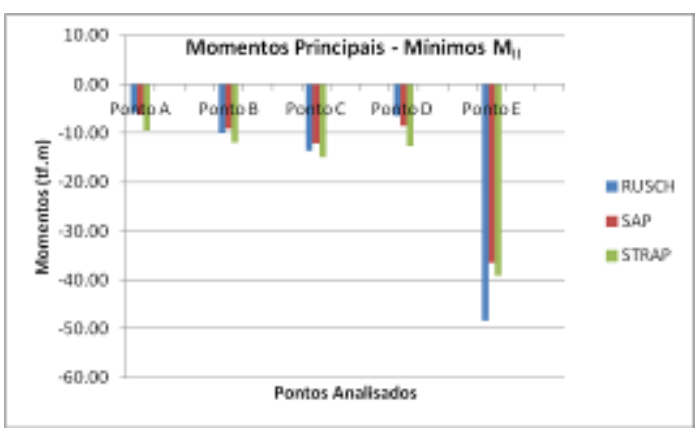

Momentos Mínimos MII

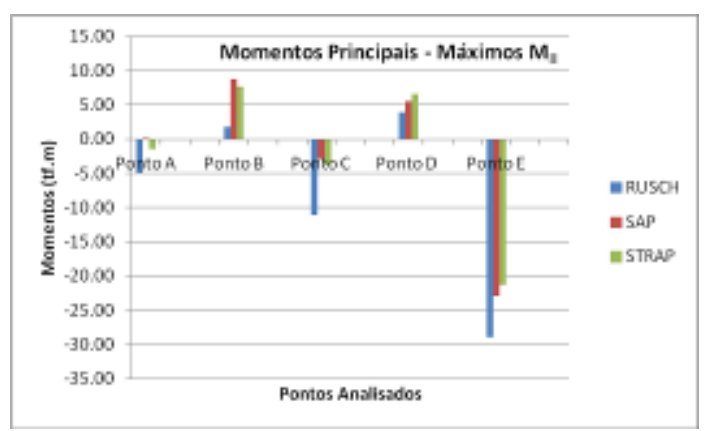

Momentos Máximos $\mathrm{M}_{\|}$

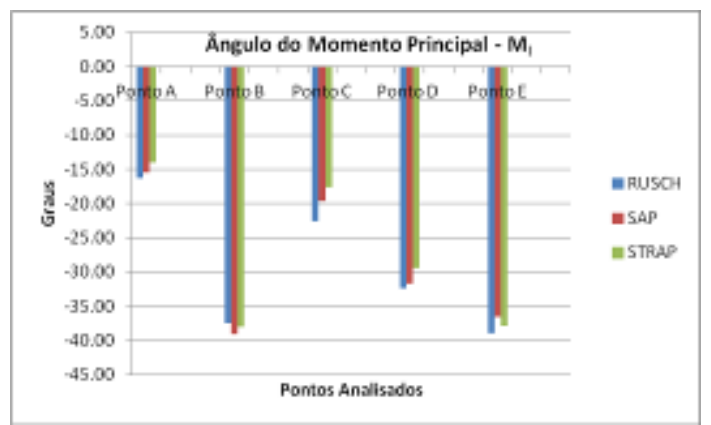

Ângulo do MI 
4.1.6.8 Comparação dos resultados para lajes com esconsidade variando de $0^{\circ}$ de $60^{\circ}$

A seguir serão apresentados resultados obtidos através das análises e das modelagens, ilustrando o que ocorre com os esforços à medida que o ângulo de esconsidade aumenta. Com o intuito de contribuir para o entendimento, os resultados serão apresentados em forma de tabelas e gráficos.

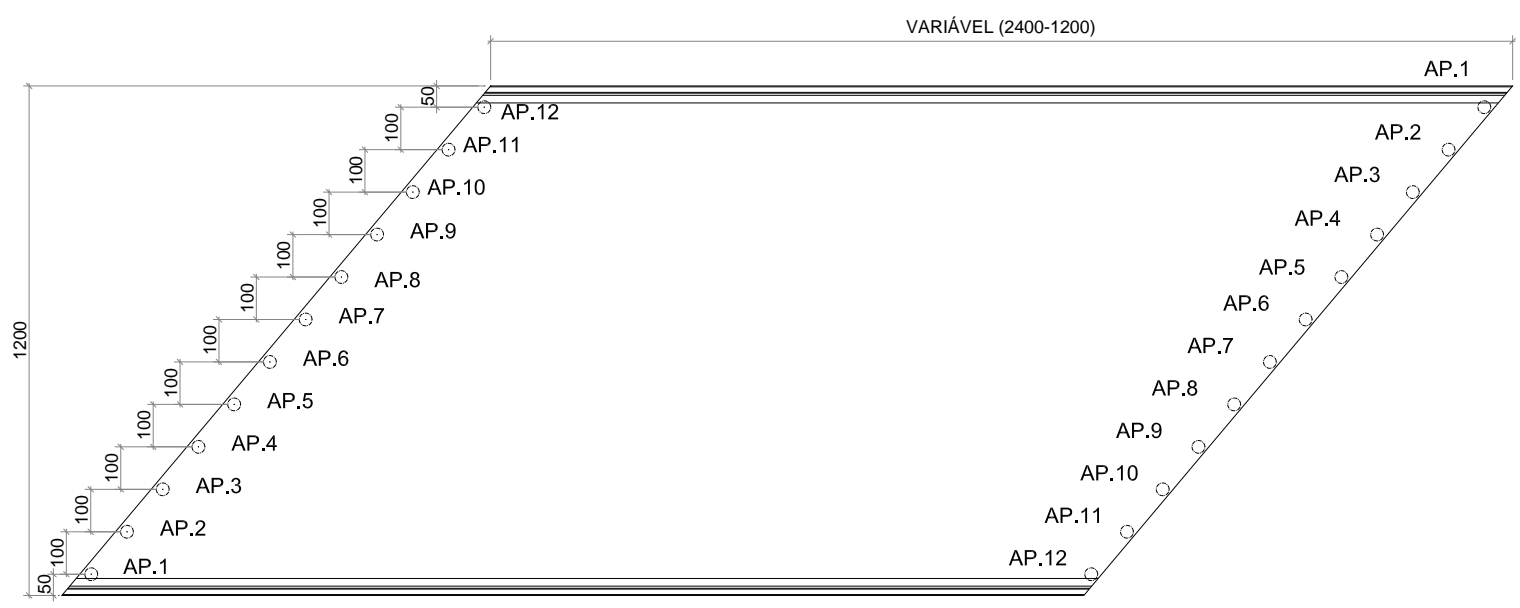

Figura 18 - Locação e nomenclatura dos apoios estudados

\subsection{TT homogeneizado}

As solicitações apresentadas nesta seção estão presentes no Anexo A, bem como as solicitações em diversos pontos da laje através de mapas de contorno.

Reações nos apoios em consequência de carga permanente e carga móvel com o ângulo de esconsidade variando de $0^{\circ}$ a $60^{\circ}$ considerando apoios restritos às translações. 


\begin{tabular}{|c|c|c|c|c|c|c|c|c|c|c|c|c|c|c|}
\hline \multirow{2}{*}{$\begin{array}{l}\text { Reação } \\
\text { máxima } \\
(\mathrm{kN})\end{array}$} & \multicolumn{2}{|c|}{$0^{\circ}$} & \multicolumn{2}{|c|}{$5^{\circ}$} & \multicolumn{2}{|c|}{$10^{\circ}$} & \multicolumn{2}{|c|}{$15^{\circ}$} & \multicolumn{2}{|c|}{$20^{\circ}$} & \multicolumn{2}{|c|}{$25^{\circ}$} & \multicolumn{2}{|c|}{$30^{\circ}$} \\
\hline & Perm. & Ac. & Perm. & Ac. & Perm. & Ac. & Perm. & Ac. & Perm. & Ac. & Perm. & Ac. & Perm. & Ac. \\
\hline AP.1 & 266 & 211 & 212 & 177 & 169 & 149 & 136 & 126 & 107 & 110 & 91 & 90 & 86 & 87 \\
\hline AP. 2 & 39 & 64 & 58 & 73 & 71 & 78 & 78 & 80 & 90 & 84 & 86 & 93 & 93 & 105 \\
\hline AP. 3 & 111 & 101 & 108 & 103 & 106 & 98 & 106 & 103 & 103 & 103 & 103 & 109 & 87 & 98 \\
\hline AP. 4 & 103 & 99 & 104 & 97 & 105 & 105 & 105 & 102 & 104 & 108 & 109 & 110 & 114 & 115 \\
\hline AP. 5 & 107 & 92 & 108 & 87 & 108 & 85 & 110 & 85 & 88 & 110 & 113 & 95 & 115 & 101 \\
\hline AP. 6 & 108 & 103 & 108 & 101 & 109 & 102 & 109 & 102 & 105 & 112 & 116 & 108 & 119 & 105 \\
\hline AP.7 & 108 & 103 & 109 & 105 & 109 & 107 & 111 & 103 & 105 & 111 & 113 & 111 & 118 & 112 \\
\hline AP. 8 & 107 & 92 & 107 & 96 & 108 & 95 & 108 & 100 & 105 & 113 & 115 & 111 & 118 & 112 \\
\hline AP.9 & 103 & 99 & 103 & 101 & 102 & 96 & 103 & 92 & 95 & 101 & 101 & 94 & 102 & 83 \\
\hline AP.10 & 111 & 101 & 113 & 100 & 116 & 108 & 120 & 108 & 112 & 126 & 131 & 115 & 140 & 115 \\
\hline AP.11 & 39 & 64 & 14 & 59 & -17 & -64 & -56 & -90 & -120 & -102 & -152 & -151 & -211 & -186 \\
\hline AP.12 & 266 & 211 & 330 & 249 & 404 & 292 & 490 & 339 & 391 & 588 & 695 & 446 & 816 & 504 \\
\hline
\end{tabular}

Tabela 9 - Reações nos apoios - ângulo variando de $0^{\circ}$ a $30^{\circ}$

\begin{tabular}{|c|c|c|c|c|c|c|c|c|c|c|c|c|}
\hline \multirow{2}{*}{$\begin{array}{c}\text { Reação } \\
\text { máxima } \\
\text { (kN) }\end{array}$} & \multicolumn{2}{|c|}{$35^{\circ}$} & \multicolumn{2}{|c|}{$40^{\circ}$} & \multicolumn{2}{|c|}{$45^{\circ}$} & \multicolumn{2}{c|}{$50^{\circ}$} & \multicolumn{2}{|c|}{$55^{\circ}$} & \multicolumn{2}{|c|}{$60^{\circ}$} \\
\cline { 2 - 15 } & Perm. & Ac. & Perm. & Ac. & Perm. & Ac. & Perm. & Ac. & Perm. & Ac. & Perm. & Ac. \\
\hline AP.1 & 66 & 67 & 58 & 56 & 52 & 47 & 46 & 38 & 42 & 34 & 39 & 30 \\
\hline AP.2 & 89 & 102 & 91 & 100 & 94 & 104 & 97 & 103 & 101 & 107 & 107 & 95 \\
\hline AP.3 & 105 & 113 & 109 & 121 & 114 & 129 & 125 & 138 & 134 & 148 & 146 & 131 \\
\hline AP.4 & 115 & 116 & 121 & 118 & 129 & 122 & 140 & 130 & 159 & 149 & 183 & 132 \\
\hline AP.5 & 121 & 109 & 127 & 115 & 138 & 126 & 153 & 139 & 175 & 158 & 204 & 149 \\
\hline AP.6 & 123 & 106 & 131 & 107 & 142 & 111 & 157 & 115 & 181 & 130 & 221 & 164 \\
\hline AP.7 & 123 & 121 & 131 & 125 & 141 & 131 & 156 & 138 & 180 & 154 & 216 & 163 \\
\hline AP.8 & 122 & 117 & 129 & 120 & 139 & 131 & 153 & 140 & 174 & 154 & 210 & 160 \\
\hline AP.9 & 103 & 106 & 109 & 99 & 112 & 109 & 121 & 121 & 138 & 139 & 164 & 129 \\
\hline AP.10 & 143 & 126 & 155 & 126 & 175 & 133 & 184 & 136 & 202 & 148 & 224 & 173 \\
\hline AP.11 & -313 & -241 & -335 & -254 & -421 & -298 & -482 & -328 & -577 & -367 & -663 & -458 \\
\hline AP.12 & 1000 & 592 & 1090 & 625 & 1260 & 694 & 1440 & 759 & 1650 & 833 & 1890 & 1360 \\
\hline
\end{tabular}

Tabela 10 - Reações nos apoios - ângulo variando de $35^{\circ}$ a $60^{\circ}$

A seguir, serão apresentadas em curvas sobrepostas representando as reações nos apoios para as diversas esconsidades estudadas e separando-as em carregamento permanente, envoltória das acidentais e soma dos dois carregamentos. 
Reações máximas em consequência de carregamento permanente:

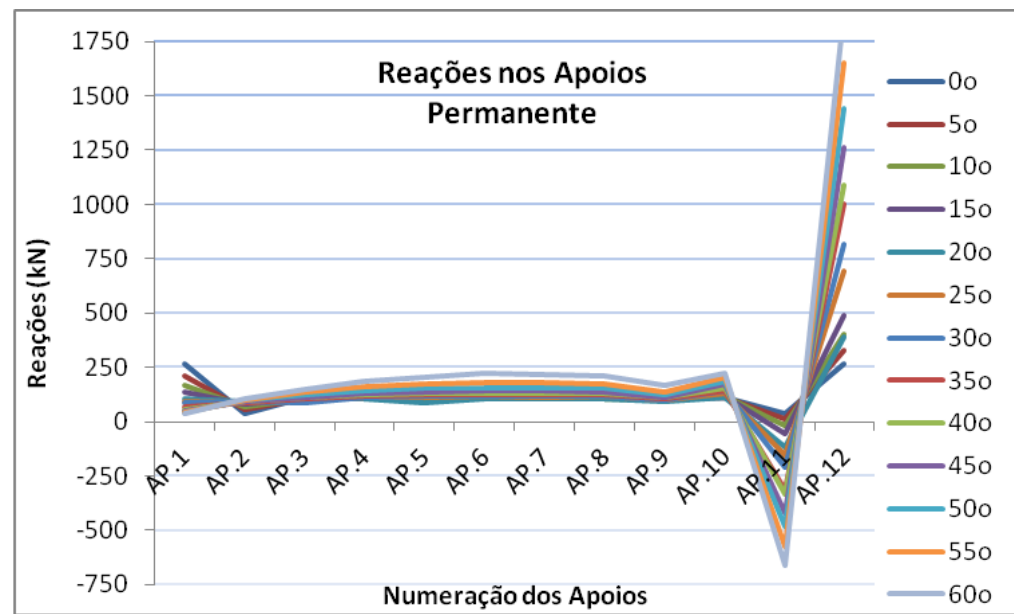

Reações máximas em consequência de carregamento móvel:

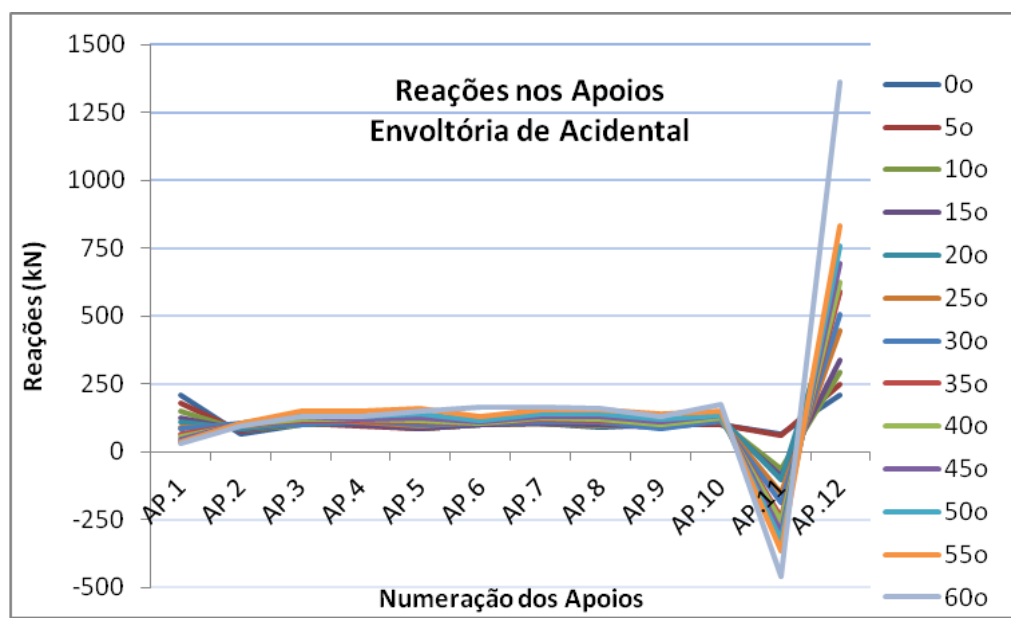

Somatória das reações permanentes e acidentais:

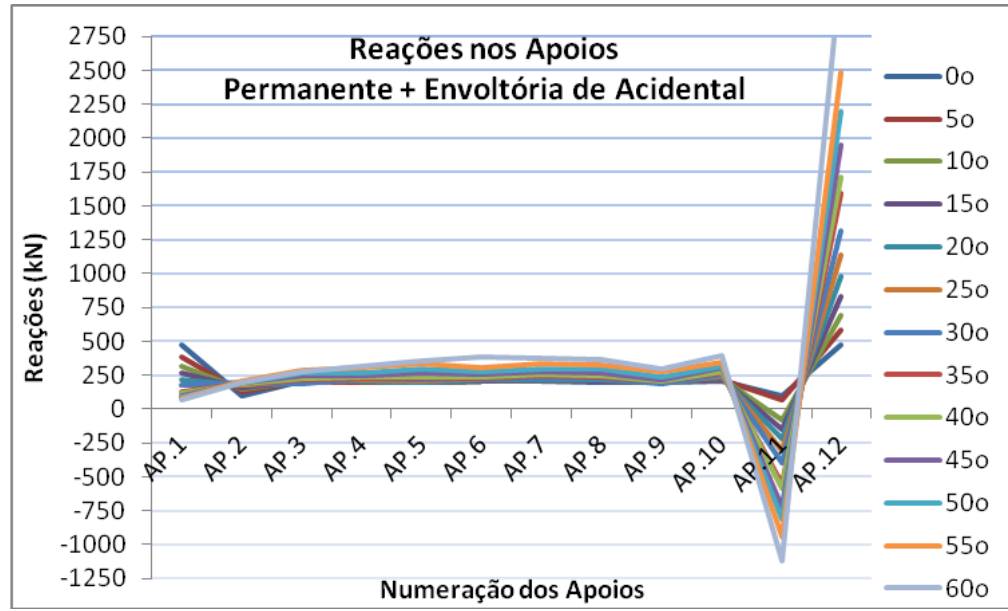


Nota-se que as curvas de $0^{\circ}, 5^{\circ}$ e $10^{\circ}$ estão bem próximas entre si, indicando que, até $10^{\circ}$ de esconsidade, se pode simplificar o cálculo para lajes ortogonais.

Momentos Fletores em consequência de carregamento permanente e móvel com o ângulo de esconsidade variando de $0^{\circ}$ a $60^{\circ}$ :

\begin{tabular}{|c|l|c|c|c|c|c|c|c|}
\hline \multicolumn{2}{|c|}{ Momen } & $0^{\circ}$ & $5^{\circ}$ & $10^{\circ}$ & $15^{\circ}$ & $20^{\circ}$ & $25^{\circ}$ & $30^{\circ}$ \\
\hline \multirow{5}{*}{ Permanente Fletores (kN.m/m) } & Long. vão (B) & 358 & 357 & 353 & 345 & 334 & 320 & 304 \\
\cline { 2 - 9 } & Long. borda livre (A) & 385 & 384 & 382 & 378 & 374 & 368 & 362 \\
\cline { 2 - 9 } & Transv. vão (B) & 47 & 49 & 53 & 56 & 68 & 79 & 93 \\
\cline { 2 - 9 } & Transv. borda livre (A) & 0 & 0 & 0 & 0 & 0 & 0 & 0 \\
\hline \multirow{5}{*}{ Acidental } & Long. vão (B) & 174 & 174 & 172 & 167 & 162 & 158 & 151 \\
\cline { 2 - 9 } & Long. borda livre (A) & 228 & 228 & 227 & 223 & 221 & 219 & 217 \\
\cline { 2 - 9 } & Transv. vão (B) & 65 & 66 & 67 & 68 & 72 & 76 & 81 \\
\cline { 2 - 9 } & Transv. borda livre (A) & 0 & 0 & 0 & 0 & 0 & 0 & 0 \\
\hline
\end{tabular}

Tabela 11 - Momentos Fletores - ângulo variando de $0^{\circ}$ a $30^{\circ}$

\begin{tabular}{|c|l|c|c|c|c|c|c|}
\hline \multicolumn{2}{|c|}{ Momentos Fletores (kN.m/m) } & $35^{\circ}$ & $40^{\circ}$ & $45^{\circ}$ & $50^{\circ}$ & $55^{\circ}$ & $60^{\circ}$ \\
\hline \multirow{5}{*}{ Permanente } & Long. vão (B) & 284 & 260 & 231 & 197 & 153 & 101 \\
\cline { 2 - 8 } & Long. borda livre (A) & 356 & 350 & 346 & 345 & 360 & 430 \\
\cline { 2 - 8 } & Transv. vão (B) & 107 & 126 & 145 & 165 & 188 & 212 \\
\cline { 2 - 7 } & Transv. borda livre (A) & 0 & 0 & 0 & 0 & 0 & 0 \\
\hline \multirow{5}{*}{ Acidental } & Long. vão (B) & 143 & 135 & 124 & 112 & 100 & 90 \\
\cline { 2 - 8 } & Long. borda livre (A) & 215 & 213 & 212 & 213 & 217 & 225 \\
\cline { 2 - 7 } & Transv. vão (B) & 87 & 93 & 100 & 107 & 115 & 123 \\
\cline { 2 - 7 } & Transv. borda livre (A) & 0 & 0 & 0 & 0 & 0 & 0 \\
\hline
\end{tabular}

Tabela 12 - Momentos Fletores - ângulo variando de $35^{\circ}$ a $60^{\circ}$

A seguir, serão apresentados em curvas sobrepostas representado os momentos fletores para as diversas esconsidades estudadas e separando-os em carregamento permanente, móvel e soma dos dois carregamentos.

Momentos Fletores em consequência de carregamento permanente - Ponto A e $B$, no sentido longitudinal e transversal (consideraram-se o sentido longitudinal, o eixo paralelo, faixa de tráfego e transversal, o normal ao longitudinal):

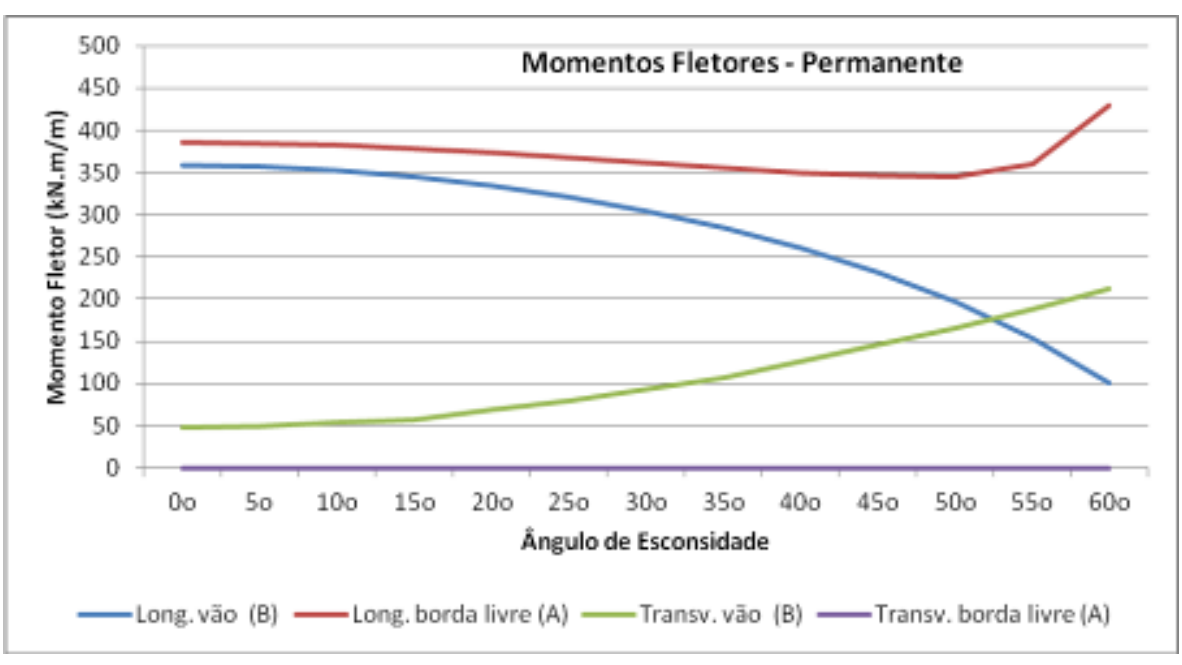


Momentos Fletores em consequência de carregamento móvel - Ponto A e B, no sentido longitudinal e transversal:

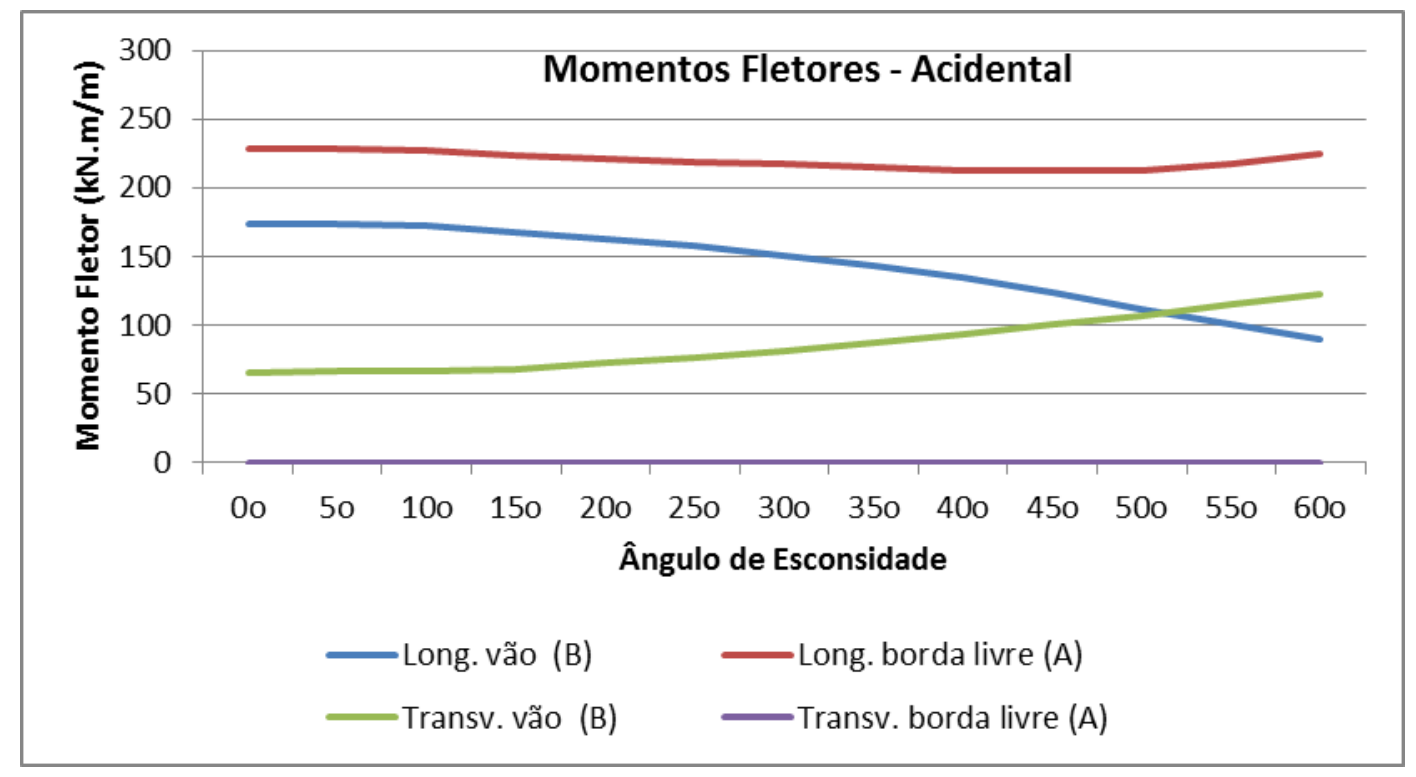

Momentos Fletores em consequência da somatória dos dois carregamentos acima descritos:

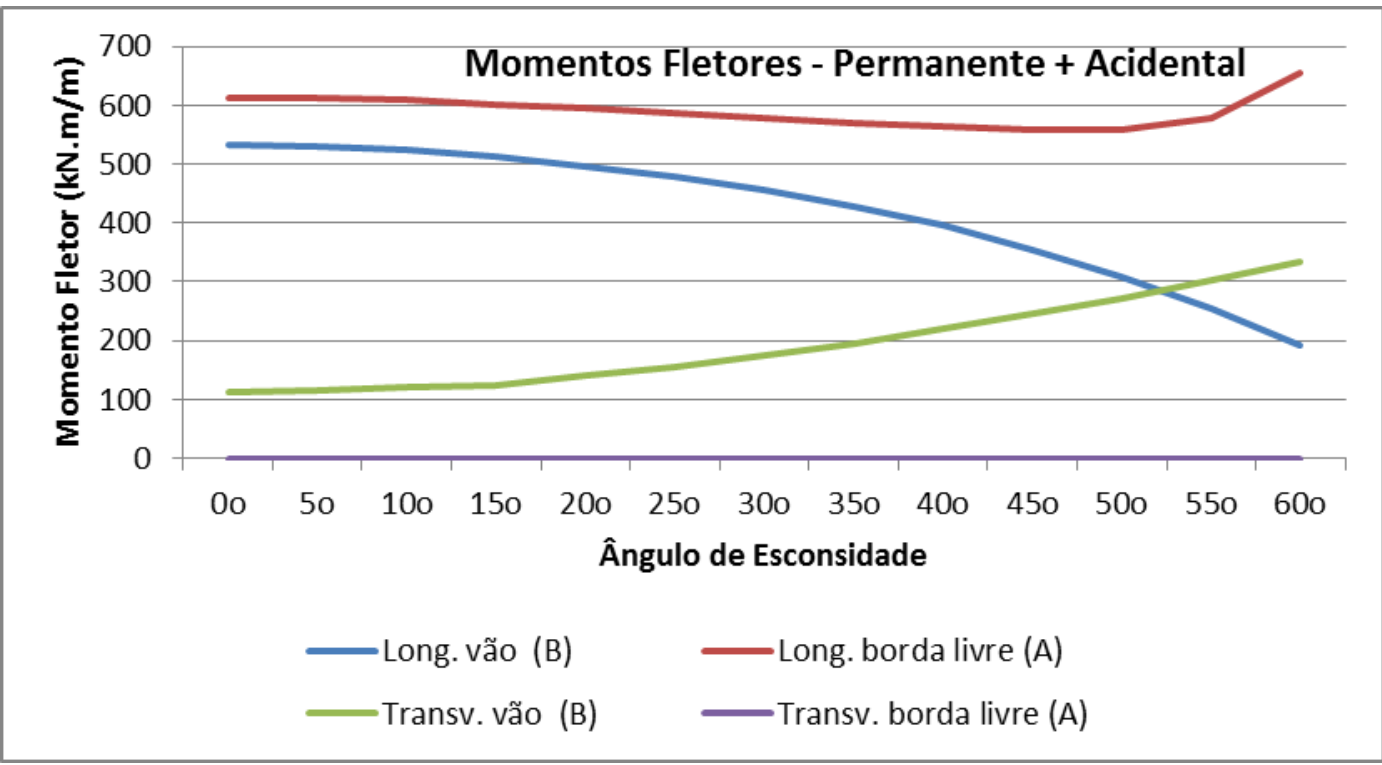




\subsection{TT sem homogeneização}

As solicitações apresentadas nesta seção estão presentes no Anexo B, bem como as solicitações em diversos pontos da laje através de mapas de contorno.

Reações nos apoios em consequência de carga permanente e carga móvel com o ângulo de esconsidade variando de $0^{\circ}$ a $60^{\circ}$ considerando apoios restritos às translações.

\begin{tabular}{|c|c|c|c|c|c|c|c|c|c|c|c|c|c|c|}
\hline \multirow{2}{*}{$\begin{array}{c}\text { Reação } \\
\text { máxima } \\
(\mathrm{kN})\end{array}$} & \multicolumn{2}{|c|}{$0^{\circ}$} & \multicolumn{2}{|c|}{$5^{\circ}$} & \multicolumn{2}{|c|}{$10^{\circ}$} & \multicolumn{2}{|c|}{$15^{\circ}$} & \multicolumn{2}{|c|}{$20^{\circ}$} & \multicolumn{2}{|c|}{$25^{\circ}$} & \multicolumn{2}{|c|}{$30^{\circ}$} \\
\hline & Perm. & Ac. & Perm. & Ac. & Perm. & Ac. & Perm. & Ac. & Perm. & Ac. & Perm. & Ac. & Perm. & Ac. \\
\hline AP.1 & 266 & 214 & 212 & 180 & 169 & 153 & 136 & 131 & 107 & 111 & 91 & 94 & 86 & 91 \\
\hline AP. 2 & 39 & 69 & 58 & 79 & 71 & 85 & 78 & 85 & 90 & 97 & 86 & 99 & 93 & 111 \\
\hline AP. 3 & 111 & 108 & 108 & 110 & 106 & 104 & 106 & 109 & 103 & 108 & 103 & 116 & 87 & 105 \\
\hline AP. 4 & 103 & 106 & 104 & 103 & 105 & 112 & 105 & 108 & 104 & 109 & 109 & 117 & 114 & 122 \\
\hline AP. 5 & 107 & 98 & 108 & 92 & 108 & 90 & 110 & 90 & 88 & 92 & 113 & 100 & 115 & 106 \\
\hline AP. 6 & 108 & 109 & 108 & 108 & 109 & 108 & 109 & 108 & 105 & 112 & 116 & 115 & 119 & 111 \\
\hline AP. 7 & 108 & 109 & 109 & 111 & 109 & 115 & 111 & 109 & 105 & 110 & 113 & 118 & 118 & 118 \\
\hline AP. 8 & 107 & 98 & 107 & 102 & 108 & 100 & 108 & 106 & 105 & 110 & 115 & 118 & 118 & 118 \\
\hline AP.9 & 103 & 106 & 103 & 108 & 102 & 102 & 103 & 96 & 95 & 101 & 101 & 100 & 102 & 86 \\
\hline AP.10 & 111 & 108 & 113 & 105 & 116 & 116 & 120 & 114 & 112 & 118 & 131 & 121 & 140 & 121 \\
\hline AP. 11 & 39 & 69 & 14 & 63 & -17 & -65 & -56 & -91 & -120 & -121 & -152 & -152 & -211 & -188 \\
\hline AP. 12 & 266 & 214 & 330 & 252 & 404 & 294 & 490 & 342 & 391 & 393 & 695 & 449 & 816 & 507 \\
\hline
\end{tabular}

Tabela 13 - Reações nos apoios - ângulo variando de $0^{\circ}$ a $30^{\circ}$

\begin{tabular}{|c|c|c|c|c|c|c|c|c|c|c|c|c|}
\hline $\begin{array}{c}\text { Reação } \\
\text { máxima } \\
\text { (kN) }\end{array}$ & \multicolumn{2}{|c|}{$35^{\circ}$} & \multicolumn{2}{|c|}{$40^{\circ}$} & \multicolumn{2}{|c|}{$45^{\circ}$} & \multicolumn{2}{|c|}{$50^{\circ}$} & \multicolumn{2}{|c|}{$55^{\circ}$} & \multicolumn{2}{|c|}{$60^{\circ}$} \\
\cline { 2 - 15 } & Perm. & Ac. & Perm. & Ac. & Perm. & Ac. & Perm. & Ac. & Perm. & Ac. & Perm. & Ac. \\
\hline AP.1 & 66 & 71 & 58 & 59 & 46 & 50 & 46 & 40 & 42 & 36 & 39 & 35 \\
\hline AP.2 & 89 & 108 & 91 & 104 & 97 & 108 & 97 & 107 & 101 & 112 & 107 & 119 \\
\hline AP.3 & 105 & 120 & 109 & 127 & 125 & 134 & 125 & 143 & 134 & 154 & 146 & 169 \\
\hline AP.4 & 115 & 122 & 121 & 123 & 140 & 127 & 140 & 134 & 159 & 155 & 183 & 178 \\
\hline AP.5 & 121 & 114 & 127 & 120 & 153 & 131 & 153 & 145 & 175 & 165 & 204 & 184 \\
\hline AP.6 & 123 & 112 & 131 & 112 & 157 & 115 & 157 & 119 & 181 & 133 & 221 & 159 \\
\hline AP.7 & 123 & 128 & 131 & 131 & 156 & 137 & 156 & 143 & 180 & 160 & 216 & 181 \\
\hline AP.8 & 122 & 123 & 129 & 125 & 153 & 137 & 153 & 145 & 174 & 160 & 210 & 186 \\
\hline AP.9 & 103 & 112 & 109 & 102 & 121 & 112 & 121 & 124 & 138 & 144 & 164 & 167 \\
\hline AP.10 & 143 & 132 & 155 & 132 & 184 & 138 & 184 & 140 & 202 & 154 & 224 & 171 \\
\hline AP.11 & -313 & -243 & -335 & -255 & -482 & -299 & -482 & -329 & -577 & -368 & -663 & -402 \\
\hline AP.12 & 1000 & 595 & 1090 & 628 & 1440 & 696 & 1440 & 761 & 1650 & 835 & 1890 & 914 \\
\hline
\end{tabular}

Tabela 14 - Reações nos apoios - ângulo variando de $35^{\circ}$ a $60^{\circ}$ 
A seguir, serão apresentadas em curvas sobrepostas representando as reações nos apoios para as diversas esconsidades estudadas e separando-as em carregamento permanente, envoltória das acidentais e soma dos dois carregamentos.

Reações máximas em consequência de carregamento permanente:

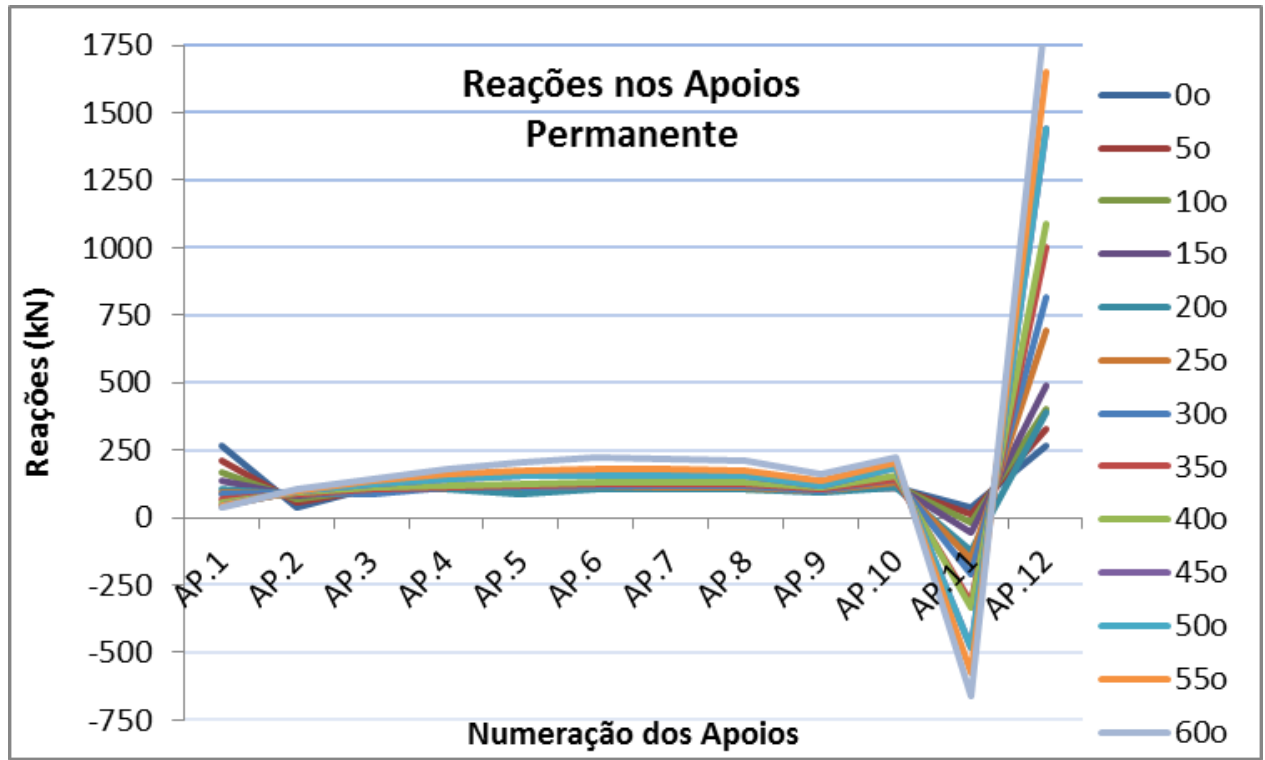

Reações máximas em consequência de carregamento móvel:

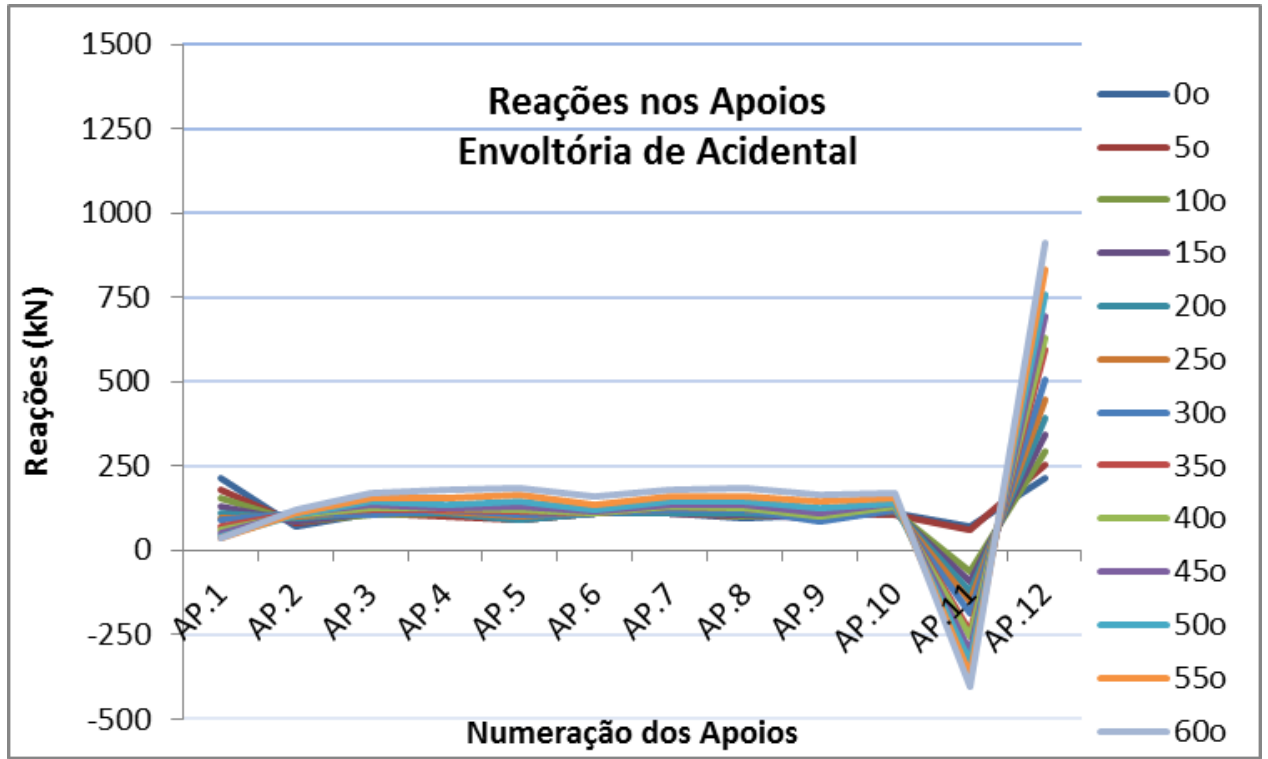


Somatória das reações permanentes e acidentais:

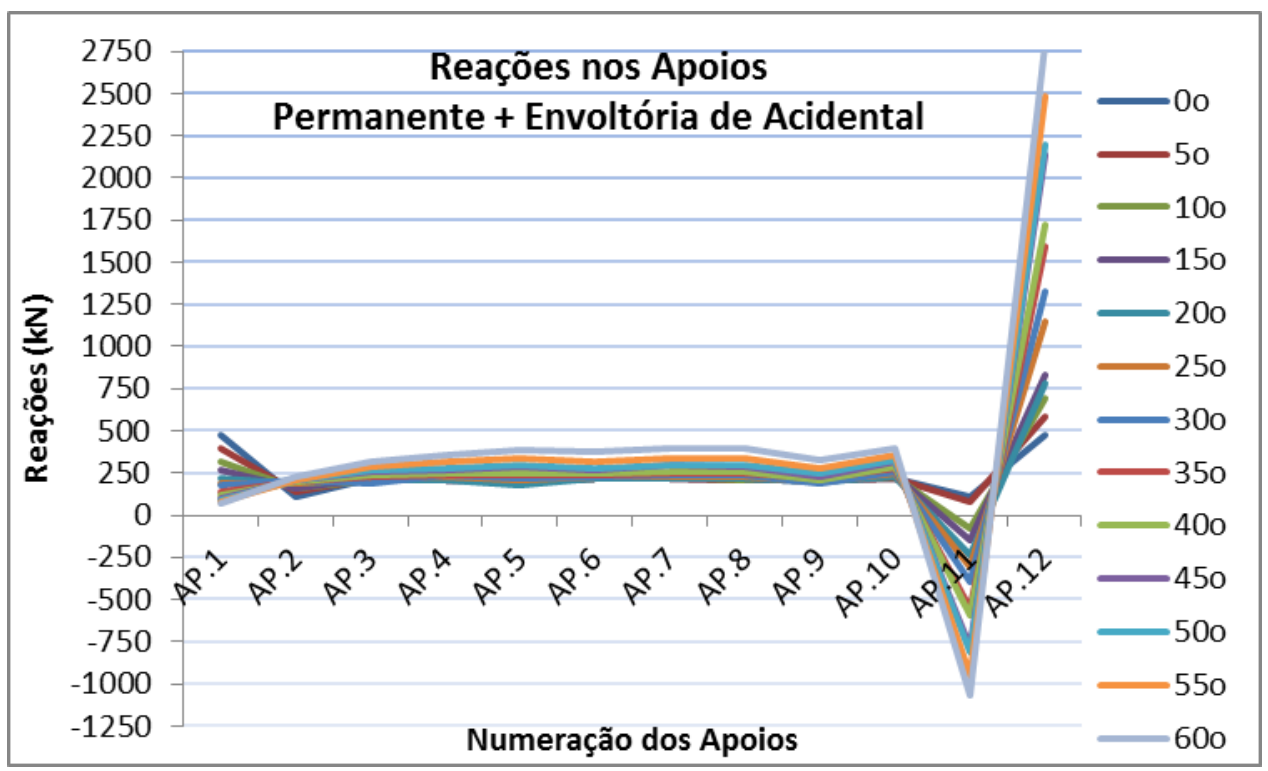

Nota-se que as curvas de $90^{\circ}, 85^{\circ}$ e $80^{\circ}$ estão bem próximas entre si, podendo significar que, até $10^{\circ}$ de esconsidade, se pode simplificar o cálculo para lajes ortogonais.

Momentos Fletores em consequência de carregamento permanente e móvel com o ângulo de esconsidade variando de $0^{\circ}$ a $60^{\circ}$ :

\begin{tabular}{|c|l|c|c|c|c|c|c|c|}
\hline \multicolumn{2}{|c|}{ Momentos Fletores (kN.m/m) } & $0^{\circ}$ & $5^{\circ}$ & $10^{\circ}$ & $15^{\circ}$ & $20^{\circ}$ & $25^{\circ}$ & $30^{\circ}$ \\
\hline \multirow{4}{*}{ Permanente } & Long. vão (B) & 358 & 357 & 353 & 345 & 334 & 320 & 304 \\
\cline { 2 - 9 } & Long. borda livre (A) & 385 & 384 & 382 & 378 & 374 & 368 & 362 \\
\cline { 2 - 9 } & Transv. vão (B) & 47 & 49 & 53 & 76 & 68 & 79 & 93 \\
\cline { 2 - 9 } & Transv. borda livre (A) & 0 & 0 & 0 & 0 & 0 & 0 & 0 \\
\hline \multirow{5}{*}{ Acidental } & Long. vão (B) & 178 & 177 & 175 & 169 & 164 & 161 & 154 \\
\cline { 2 - 9 } & Long. borda livre (A) & 233 & 232 & 231 & 227 & 224 & 224 & 221 \\
\cline { 2 - 9 } & Transv. vão (B) & 67 & 77 & 69 & 81 & 73 & 78 & 83 \\
\cline { 2 - 9 } & Transv. borda livre (A) & 0 & 0 & 0 & 0 & 0 & 0 & 0 \\
\hline
\end{tabular}

Tabela 15 - Momentos Fletores - ângulo variando de $0^{\circ}$ a $30^{\circ}$

\begin{tabular}{|c|l|c|c|c|c|c|c|}
\hline \multicolumn{2}{|c|}{ Momentos Fletores (kN.m/m) } & $35^{\circ}$ & $40^{\circ}$ & $45^{\circ}$ & $50^{\circ}$ & $55^{\circ}$ & $60^{\circ}$ \\
\hline \multirow{4}{*}{ Permanente } & Long. vão (B) & 284 & 260 & 231 & 197 & 153 & 101 \\
\cline { 2 - 7 } & Long. borda livre (A) & 356 & 350 & 346 & 345 & 360 & 430 \\
\cline { 2 - 8 } & Transv. vão (B) & 107 & 126 & 145 & 165 & 188 & 212 \\
\cline { 2 - 7 } & Transv. borda livre (A) & 0 & 0 & 0 & 0 & 0 & 0 \\
\hline \multirow{5}{*}{ Acidental } & Long. vão (B) & 146 & 137 & 127 & 115 & 105 & 93 \\
\cline { 2 - 8 } & Long. borda livre (A) & 219 & 216 & 216 & 217 & 221 & 229 \\
\cline { 2 - 7 } & Transv. vão (B) & 88 & 95 & 102 & 108 & 116 & 125 \\
\cline { 2 - 7 } & Transv. borda livre (A) & 0 & 0 & 0 & 0 & 0 & 0 \\
\hline
\end{tabular}

Tabela 16 - Momentos Fletores - ângulo variando de $35^{\circ}$ a $60^{\circ}$ 
A seguir, serão apresentados em curvas sobrepostas representando os momentos fletores para as diversas esconsidades estudadas e separando-os em carregamento permanente, móvel e soma dos dois carregamentos.

Momentos Fletores em consequência de carregamento permanente - Ponto $A$ e $B$, no sentido longitudinal e transversal (considerou-se o sentido longitudinal, o eixo paralelo, a faixa de tráfego e transversal, o normal ao longitudinal):

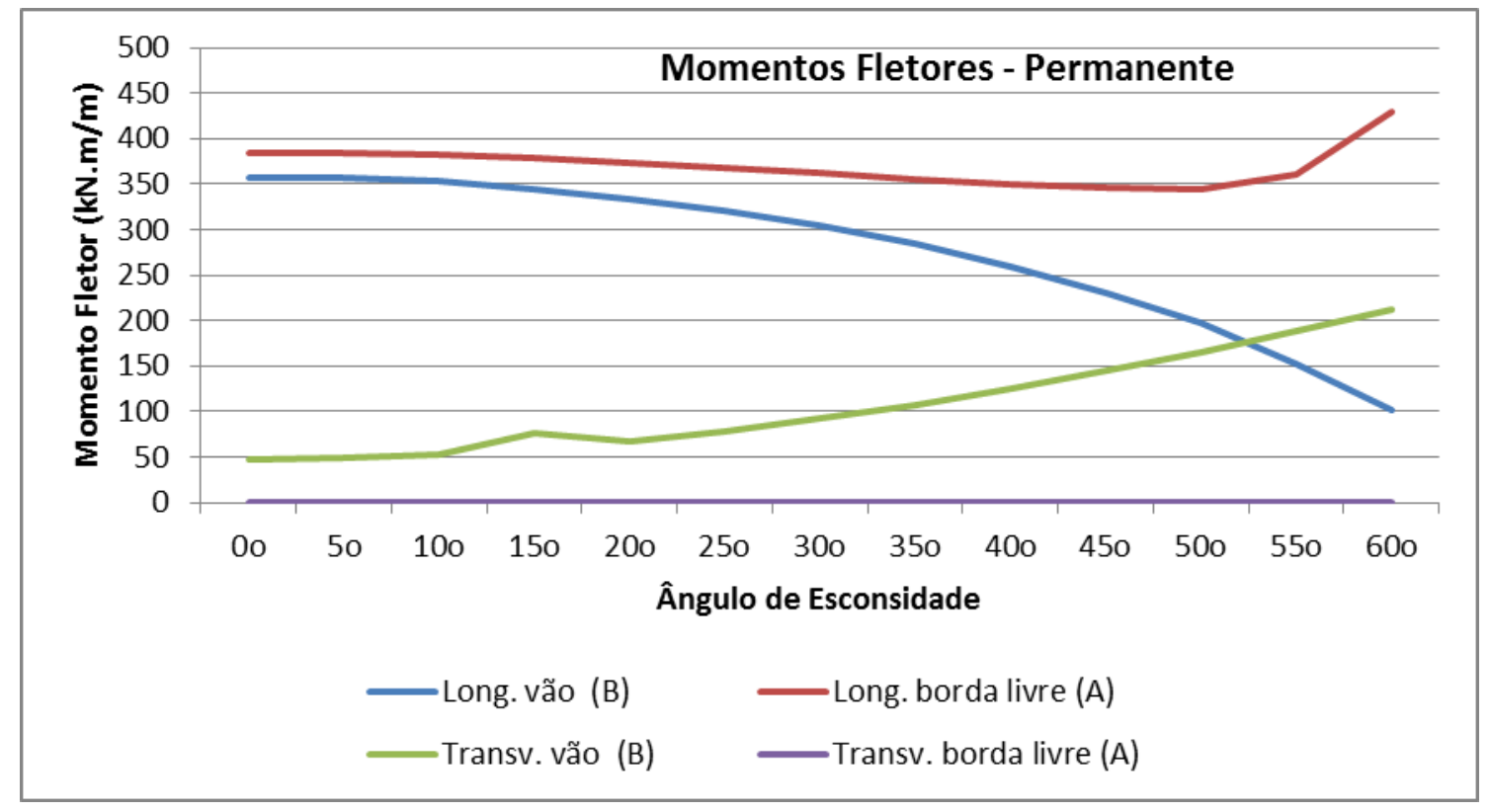

Momentos Fletores em consequência de carregamento móvel - Ponto A e B, no sentido longitudinal e transversal:

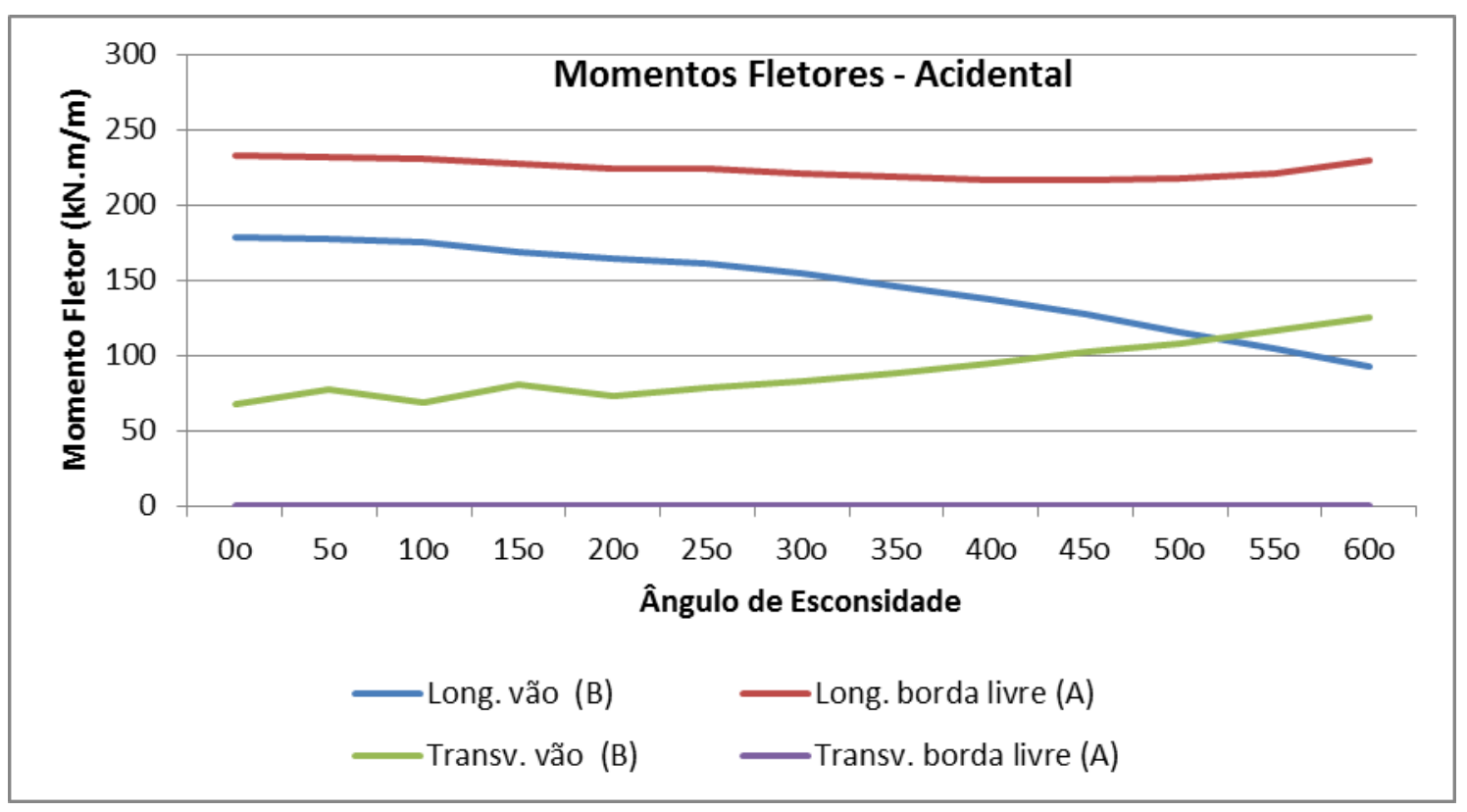


Momentos Fletores em consequência da somatória dos dois carregamentos acima descritos:

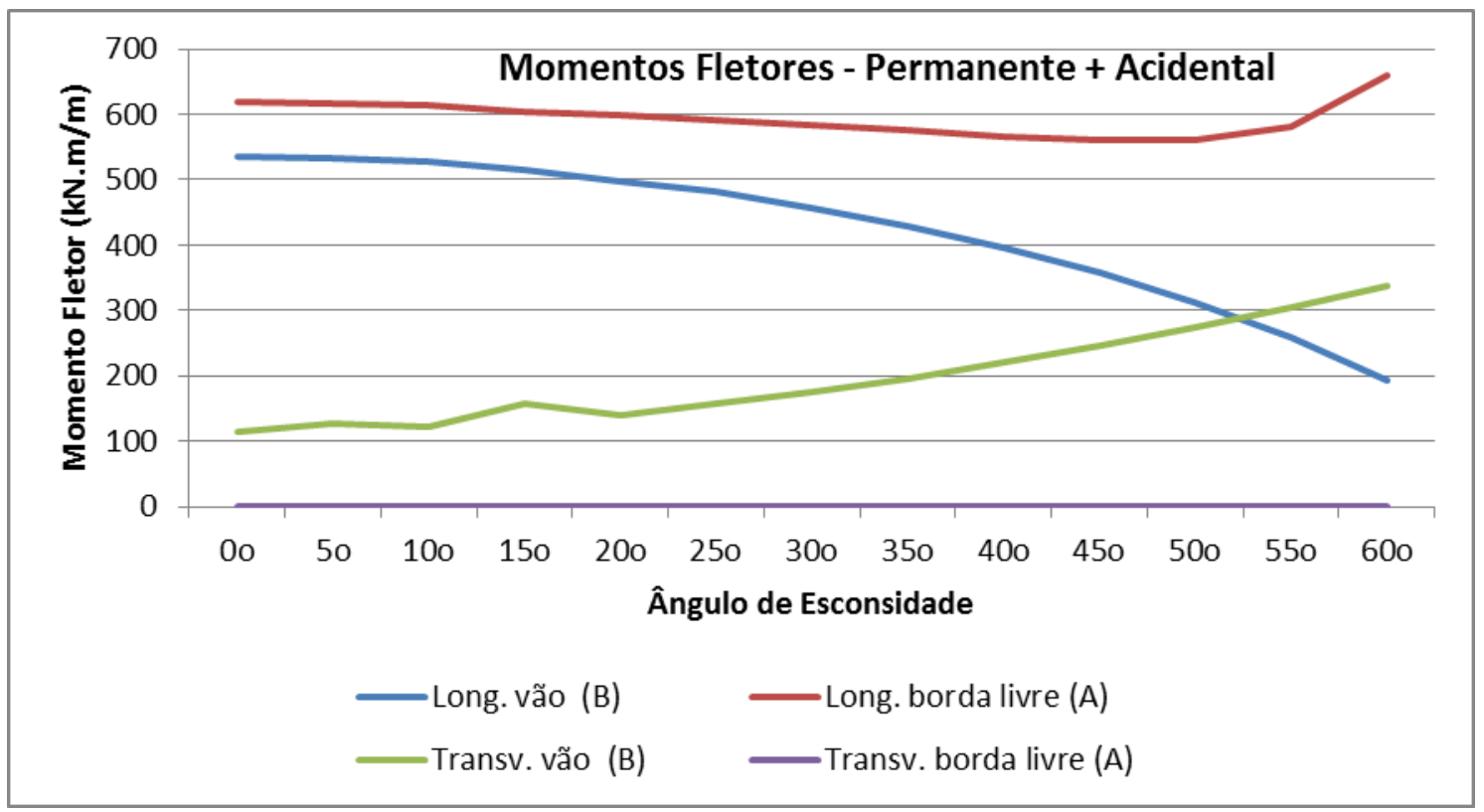

\subsection{Apoios flexíveis}

Substituíram-se os apoios fixos por molas equivalentes ao aparelho de apoio na alternativa de TT sem homogeneização. As solicitações apresentadas nesta seção estão presentes no Anexo C, bem como as solicitações em diversos pontos da laje através de mapas de contorno.

Reações nos apoios em consequência de carga permanente e carga móvel com o ângulo de esconsidade variando de $0^{\circ}$ a $60^{\circ}$ considerando apoios restritos às translações: 


\begin{tabular}{|c|c|c|c|c|c|c|c|c|c|c|c|c|c|c|}
\hline \multirow{2}{*}{$\begin{array}{c}\text { Reação } \\
\text { máxima } \\
\text { (kN) }\end{array}$} & \multicolumn{2}{|c|}{$0^{\circ}$} & \multicolumn{2}{|c|}{$5^{\circ}$} & \multicolumn{2}{|c|}{$10^{\circ}$} & \multicolumn{2}{|c|}{$15^{\circ}$} & \multicolumn{2}{|c|}{$20^{\circ}$} & \multicolumn{2}{|c|}{$25^{\circ}$} & \multicolumn{2}{c|}{$30^{\circ}$} \\
\hline & Perm. & Ac. & Perm. & Ac. & Perm. & Ac. & Perm. & Ac. & Perm. & Ac. & Perm. & Ac. & Perm. & Ac. \\
\hline AP.1 & 165 & 142 & 147 & 134 & 131 & 123 & 117 & 116 & 106 & 107 & 96 & 101 & 88 & 94 \\
\hline AP.2 & 137 & 113 & 127 & 109 & 117 & 102 & 109 & 99 & 103 & 93 & 98 & 93 & 94 & 89 \\
\hline AP.3 & 119 & 89 & 114 & 88 & 109 & 85 & 105 & 84 & 102 & 82 & 100 & 84 & 100 & 85 \\
\hline AP.4 & 109 & 78 & 106 & 76 & 104 & 78 & 103 & 75 & 102 & 75 & 103 & 77 & 104 & 79 \\
\hline AP.5 & 103 & 73 & 102 & 71 & 102 & 71 & 102 & 70 & 102 & 71 & 104 & 74 & 106 & 77 \\
\hline AP.6 & 101 & 77 & 91 & 70 & 104 & 78 & 98 & 73 & 102 & 73 & 104 & 75 & 107 & 77 \\
\hline AP.7 & 101 & 77 & 102 & 77 & 102 & 77 & 103 & 74 & 104 & 75 & 105 & 78 & 108 & 80 \\
\hline AP.8 & 103 & 73 & 105 & 75 & 106 & 74 & 107 & 73 & 109 & 75 & 111 & 78 & 113 & 79 \\
\hline AP.9 & 109 & 78 & 112 & 76 & 115 & 79 & 118 & 77 & 122 & 77 & 126 & 77 & 129 & 77 \\
\hline AP.10 & 119 & 89 & 126 & 89 & 132 & 89 & 140 & 89 & 148 & 91 & 156 & 95 & 164 & 97 \\
\hline AP.11 & 137 & 113 & 150 & 118 & 163 & 119 & 178 & 124 & 195 & 129 & 213 & 134 & 233 & 143 \\
\hline AP.12 & 165 & 142 & 186 & 150 & 210 & 159 & 238 & 168 & 269 & 182 & 306 & 199 & 349 & 217 \\
\hline
\end{tabular}

Tabela 17 - Reações nos apoios - ângulo variando de $0^{\circ}$ a $30^{\circ}$

\begin{tabular}{|c|c|c|c|c|c|c|c|c|c|c|c|c|}
\hline $\begin{array}{c}\text { Reação } \\
\text { máxima } \\
\text { (kN) }\end{array}$ & \multicolumn{2}{|c|}{$35^{\circ}$} & \multicolumn{2}{|c|}{$40^{\circ}$} & \multicolumn{2}{|c|}{$45^{\circ}$} & \multicolumn{2}{c|}{$50^{\circ}$} & \multicolumn{2}{|c|}{$55^{\circ}$} & \multicolumn{2}{|c|}{$60^{\circ}$} \\
\cline { 2 - 16 } & Perm. & Ac. & Perm. & Ac. & Perm. & Ac. & Perm. & Ac. & Perm. & Ac. & Perm. & Ac. \\
\hline AP.1 & 81 & 87 & 76 & 79 & 73 & 70 & 64 & 66 & 57 & 64 & 50 & 60 \\
\hline AP.2 & 92 & 86 & 92 & 84 & 84 & 93 & 95 & 85 & 99 & 89 & 104 & 92 \\
\hline AP.3 & 101 & 86 & 105 & 88 & 93 & 111 & 112 & 94 & 132 & 109 & 148 & 122 \\
\hline AP.4 & 108 & 80 & 114 & 86 & 93 & 123 & 136 & 102 & 155 & 116 & 180 & 132 \\
\hline AP.5 & 111 & 83 & 118 & 87 & 94 & 129 & 144 & 103 & 167 & 119 & 199 & 134 \\
\hline AP.6 & 111 & 79 & 119 & 81 & 87 & 129 & 145 & 98 & 169 & 110 & 202 & 128 \\
\hline AP.7 & 111 & 83 & 118 & 86 & 93 & 126 & 140 & 102 & 161 & 117 & 196 & 135 \\
\hline AP.8 & 116 & 83 & 120 & 85 & 92 & 126 & 136 & 102 & 150 & 116 & 178 & 136 \\
\hline AP.9 & 133 & 80 & 136 & 84 & 90 & 140 & 145 & 99 & 152 & 112 & 166 & 130 \\
\hline AP.10 & 175 & 100 & 185 & 105 & 105 & 190 & 197 & 109 & 203 & 117 & 205 & 126 \\
\hline AP.11 & 261 & 150 & 281 & 157 & 166 & 308 & 336 & 270 & 370 & 185 & 401 & 194 \\
\hline AP.12 & 409 & 238 & 460 & 264 & 297 & 534 & 627 & 337 & 748 & 391 & 903 & 457 \\
\hline
\end{tabular}

Tabela 18 - Reações nos apoios - ângulo variando de $35^{\circ}$ a $60^{\circ}$

A seguir, serão apresentadas em curvas sobrepostas representado as reações nos apoios para as diversas esconsidades estudadas e separando-as em carregamento permanente, envoltória das acidentais e soma dos dois carregamentos.

Reações máximas em consequência de carregamento permanente: 


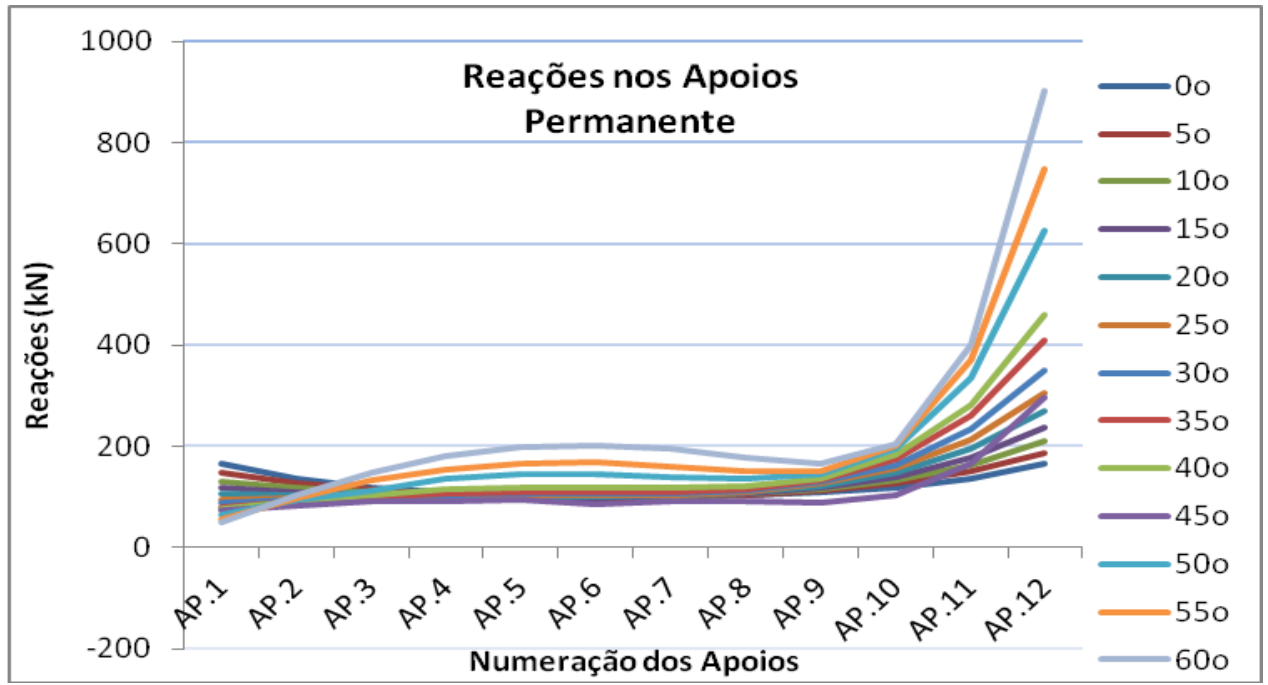

Reações máximas em consequência de carregamento móvel:

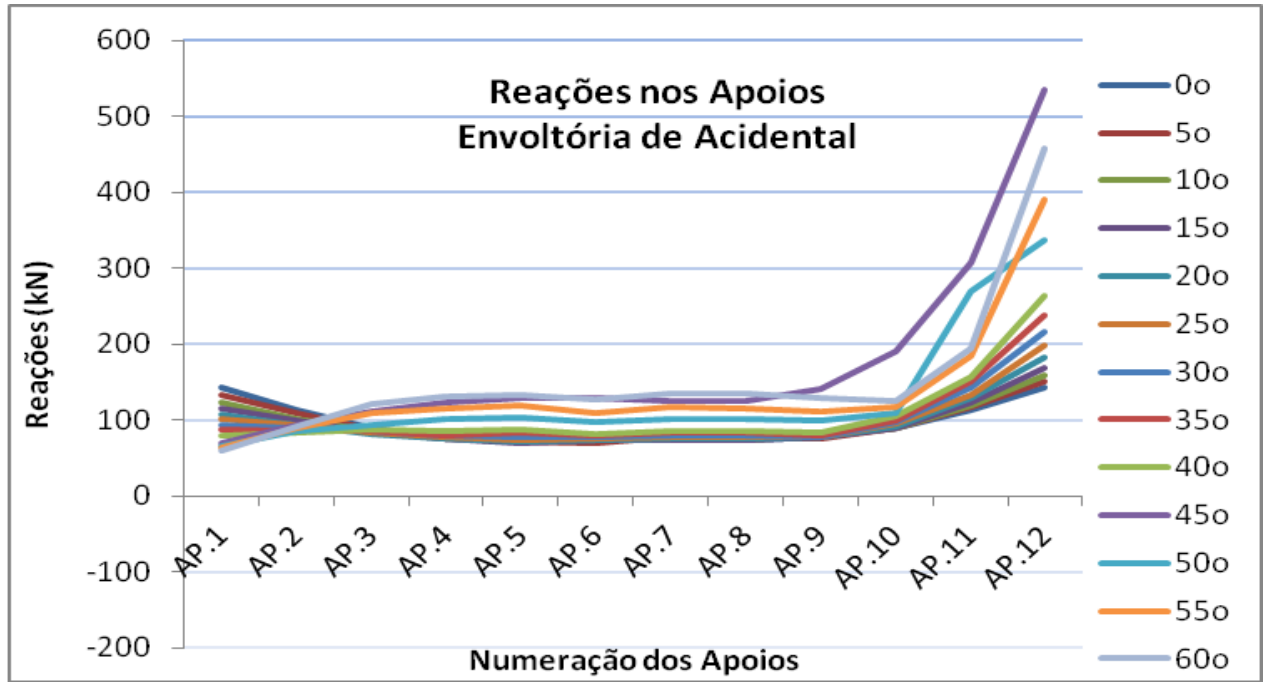

Somatória das reações permanentes e acidentais:

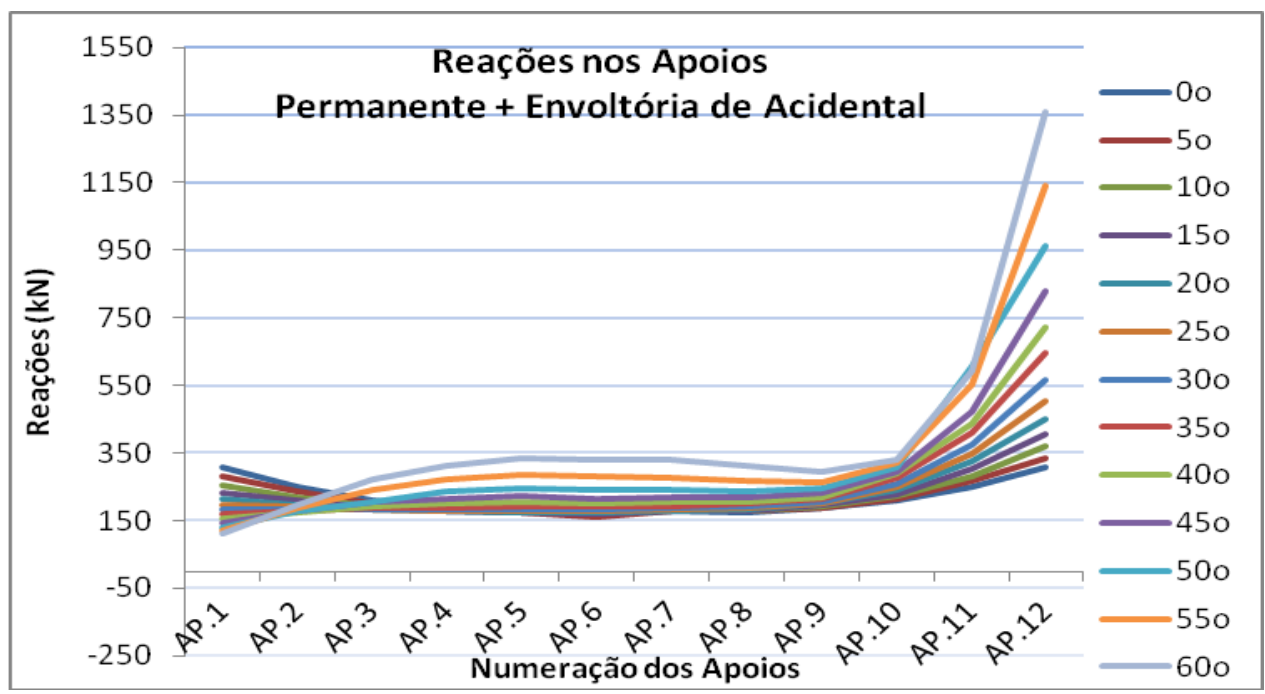


Momentos Fletores em consequência de carregamento permanente e móvel com o ângulo de esconsidade variando de $0^{\circ}$ a $60^{\circ}$ :

\begin{tabular}{|c|c|c|c|c|c|c|c|c|}
\hline Momen & tos Fletores (kN.m/m) & $0^{\circ}$ & $5^{\circ}$ & $10^{\circ}$ & $15^{\circ}$ & $20^{\circ}$ & $25^{\circ}$ & $30^{\circ}$ \\
\hline \multirow{6}{*}{ Permanente } & Long. vão (B) & 359 & 358 & 356 & 350 & 345 & 336 & 325 \\
\hline & Long. borda livre (A) & 381 & 381 & 380 & 378 & 377 & 374 & 372 \\
\hline & Long. obtuso (E) & 0 & 0 & -2 & -7 & -11 & -13 & -28 \\
\hline & Transv. vão (B) & 33 & 34 & 36 & 38 & 43 & 48 & 55 \\
\hline & Transv. borda livre (A) & 0 & 0 & 0 & 0 & 0 & 0 & 0 \\
\hline & Transv. obtuso (E) & -38 & -44 & -62 & -68 & -76 & -80 & -86 \\
\hline \multirow{6}{*}{ Acidental } & Long. vão (B) & 177 & 177 & 175 & 170 & 168 & 165 & 161 \\
\hline & Long. borda livre $(A)$ & 231 & 231 & 231 & 228 & 227 & 229 & 228 \\
\hline & Long. obtuso (E) & 0 & -4 & -12 & -23 & -33 & -38 & -56 \\
\hline & Transv. vão (B) & 71 & 71 & 71 & 72 & 74 & 77 & 79 \\
\hline & Transv. borda livre (A) & 0 & 0 & 0 & 0 & 0 & 0 & 0 \\
\hline & Transv. obtuso (E) & -36 & -38 & -39 & -41 & -43 & -44 & -48 \\
\hline
\end{tabular}

Tabela 19 - Momentos Fletores - ângulo variando de $0^{\circ}$ a $30^{\circ}$

\begin{tabular}{|c|c|c|c|c|c|c|c|}
\hline \multicolumn{2}{|c|}{ Momentos Fletores $(\mathrm{kN} . \mathrm{m} / \mathrm{m})$} & $35^{\circ}$ & $40^{\circ}$ & $45^{\circ}$ & $50^{\circ}$ & $55^{\circ}$ & $60^{\circ}$ \\
\hline \multirow{6}{*}{ Permanente } & Long. vão (B) & 312 & 295 & 277 & 253 & 223 & 182 \\
\hline & Long. borda livre (A) & 369 & 367 & 366 & 365 & 365 & 369 \\
\hline & Long. obtuso (E) & -45 & -58 & -85 & -112 & -208 & -246 \\
\hline & Transv. vão (B) & 63 & 72 & 82 & 94 & 107 & 124 \\
\hline & Transv. borda livre (A) & 0 & 0 & 0 & 0 & 0 & 0 \\
\hline & Transv. obtuso (E) & -98 & -117 & -125 & -158 & -190 & -203 \\
\hline \multirow{6}{*}{ Acidental } & Long. vão (B) & 155 & 148 & 141 & 133 & 124 & 115 \\
\hline & Long. borda livre $(\mathrm{A})$ & 228 & 228 & 230 & 233 & 240 & 249 \\
\hline & Long. obtuso (E) & -73 & -94 & -100 & -137 & -190 & -201 \\
\hline & \begin{tabular}{|l} 
Transv. vão (B) \\
\end{tabular} & 82 & 86 & 89 & 94 & 100 & 105 \\
\hline & Transv. borda livre (A) & 0 & 0 & 0 & 0 & 0 & 0 \\
\hline & Transv. obtuso (E) & -56 & -69 & -80 & -84 & -91 & -96 \\
\hline
\end{tabular}

Tabela 20 - Momentos Fletores - ângulo variando de $35^{\circ}$ a $60^{\circ}$

A seguir, serão apresentados em curvas sobrepostas representado os momentos fletores para as diversas esconsidades estudadas e separando-os em carregamento permanente, móvel e soma dos dois carregamentos.

Momentos Fletores em consequência de carregamento permanente - Ponto A e $B$, no sentido longitudinal e transversal (considerou-se o sentido longitudinal, o eixo paralelo, a faixa de tráfego e transversal, o normal ao longitudinal):

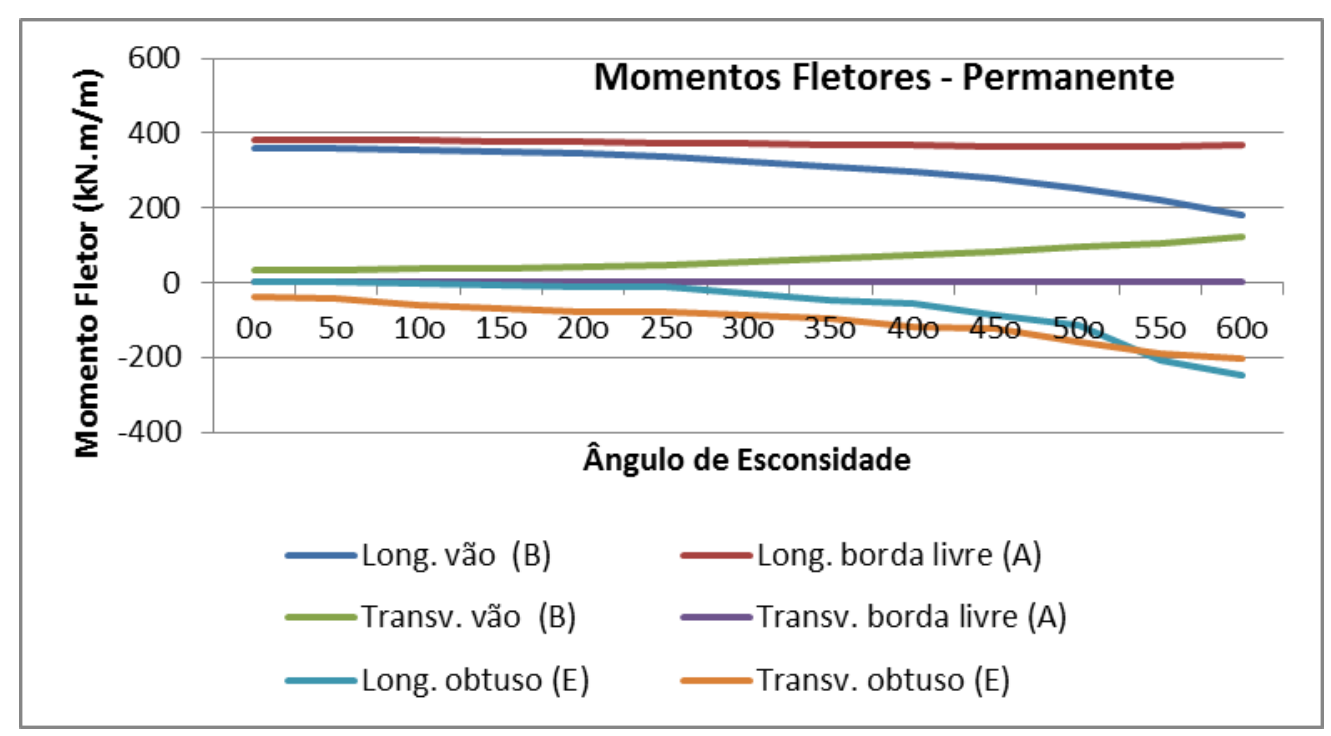


Momentos Fletores em consequência de carregamento móvel - Ponto A e B, no sentido longitudinal e transversal:

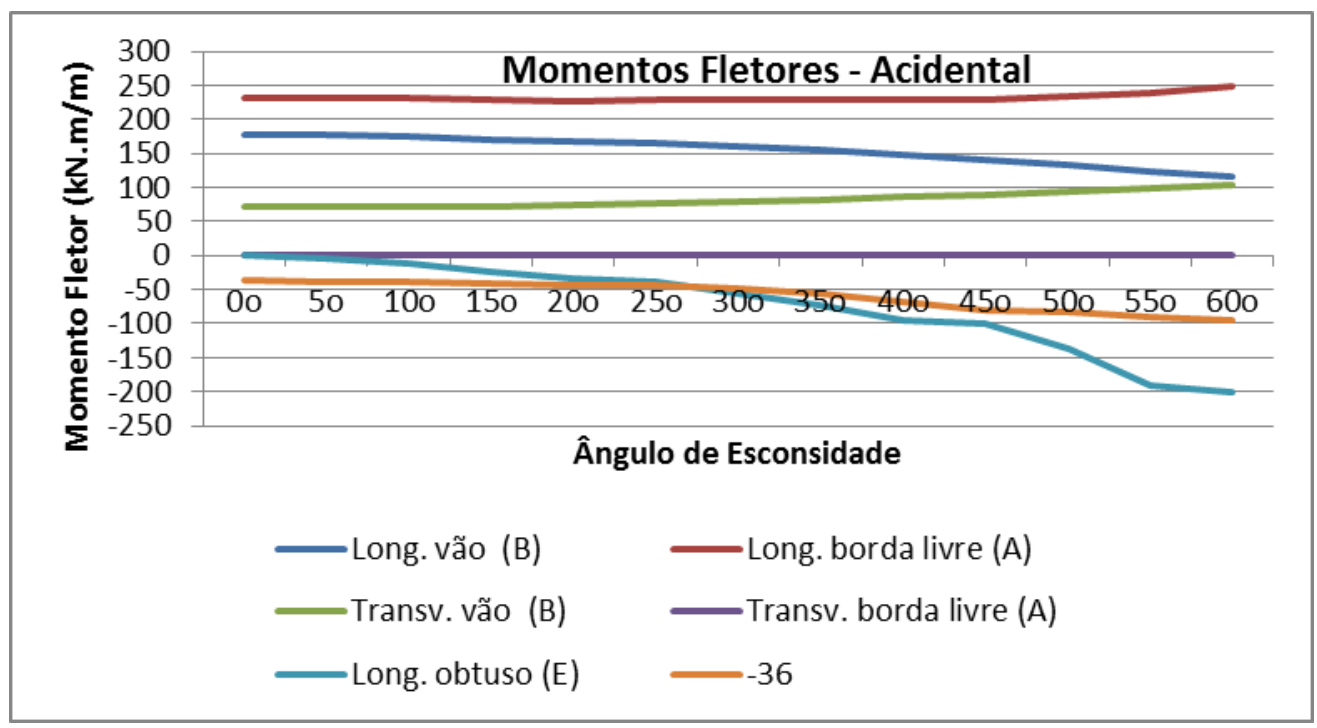

Momentos Fletores em consequência da somatória dos dois carregamentos acima descritos:

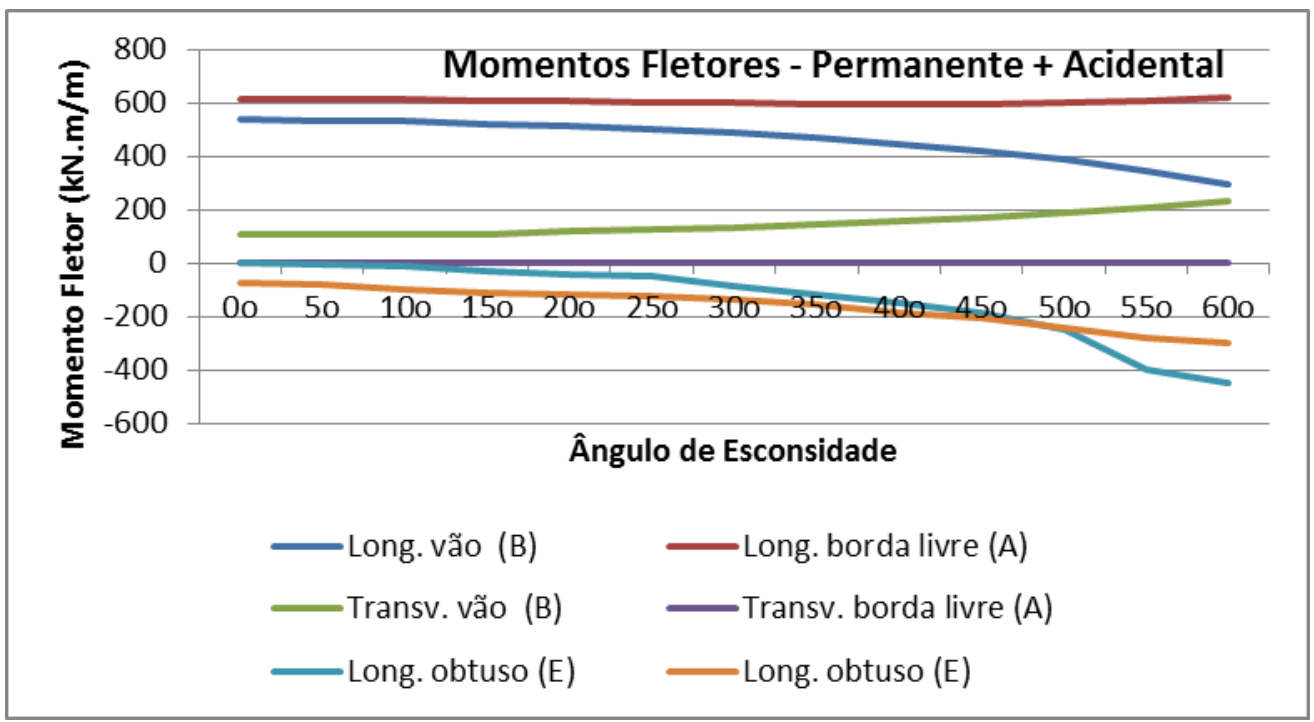

Como o detalhamento da estrutura é usualmente simplificado e, na maioria das vezes, por facilidade construtiva, a armadura é detalhada por faixas, resultam em áreas de aço maiores do que as necessárias. 


\subsection{GRELHAS ESCONSAS}

\subsubsection{Introdução}

Utilizou-se o método dos elementos finitos através da modelagem computacional no programa STRAP2010. Nos processamentos não foi considerado o "off set", ou seja, a laje está discretizada no centro de inércia da longarinas. A descrição do levantamento das solicitações bem como suas particularidades serão tratadas a seguir.

\subsubsection{Geometria e materiais}

\subsubsection{Características geométricas}

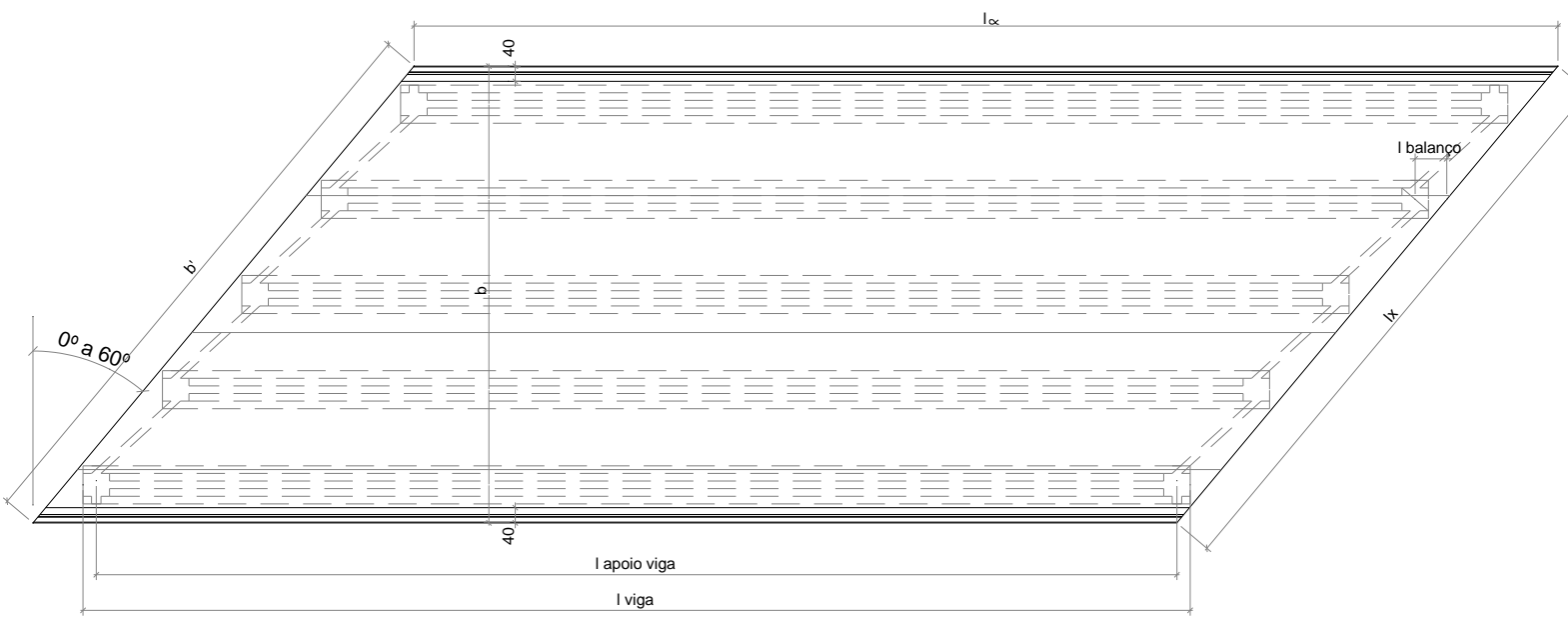

Figura 19 - Vista superior típica do tabuleiro de grelha estudada

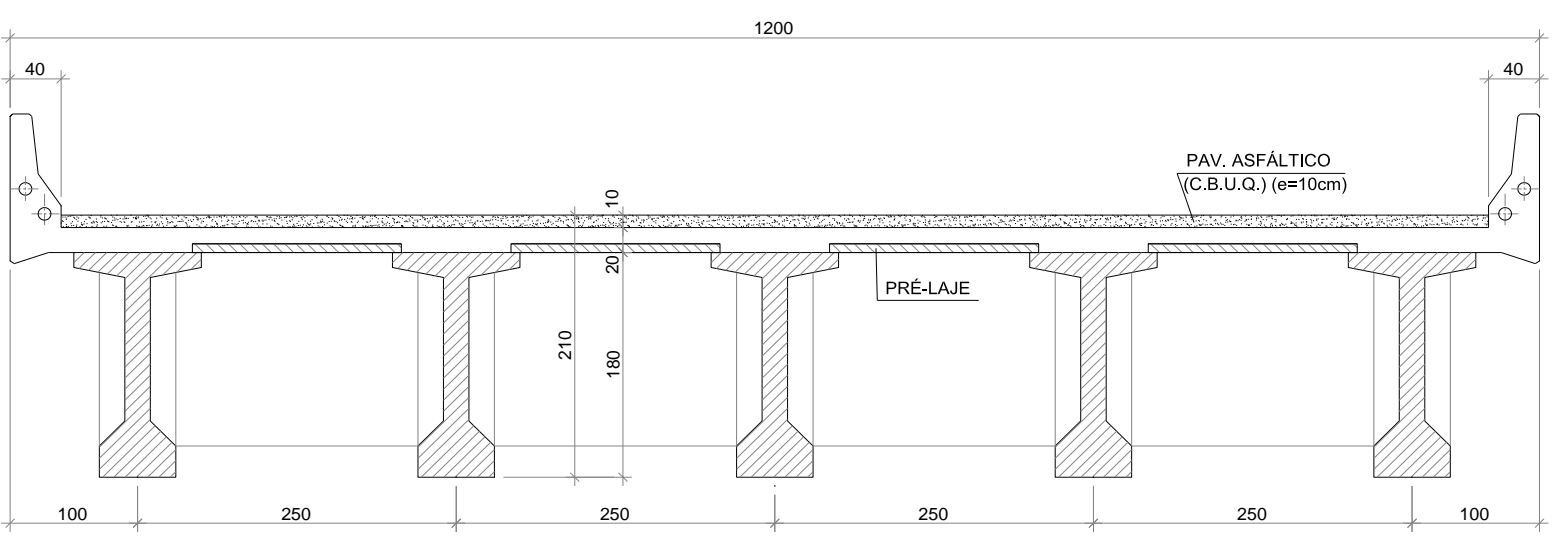

Figura 20 - Seção transversal típica do tabuleiro de grelha estudada 


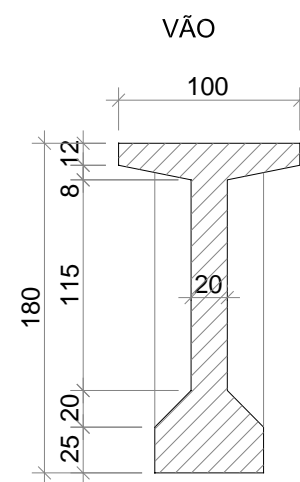

60
APOIO

100

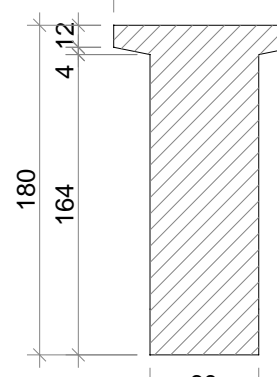

60

Figura 21 - Características da longarina

Resumo das características:

\begin{tabular}{|c|c|c|c|c|c|c|c|}
\hline $\boldsymbol{\alpha}$ & $\mathbf{b}^{\prime}$ & $\mathbf{b}$ & $\mathbf{l} \boldsymbol{\alpha}$ & $\mathbf{I x}$ & I apoio vigas & I vigas & dist. Apoio/borda \\
\hline$(\mathrm{o})$ & $(\mathrm{m})$ & $(\mathrm{m})$ & $(\mathrm{m})$ & $(\mathrm{m})$ & $(\mathrm{m})$ & $(\mathrm{m})$ & $(\mathrm{m})$ \\
\hline 0 & 12.0 & 12.00 & 29.35 & 29.35 & 27.02 & 29.25 & 1.17 \\
\hline 15 & 12.0 & 12.42 & 29.62 & 28.61 & 27.02 & 29.25 & 1.30 \\
\hline 30 & 12.0 & 13.86 & 29.94 & 25.93 & 27.02 & 29.25 & 1.46 \\
\hline 45 & 12.0 & 16.97 & 30.39 & 21.49 & 27.02 & 29.25 & 1.69 \\
\hline 60 & 12.0 & 24.00 & 31.18 & 15.59 & 27.02 & 29.25 & 2.08 \\
\hline
\end{tabular}

Tabela 21 - Características da lajes estudadas

\subsubsection{Materiais}

Concreto $\mathrm{p} /$ Superestrutura

$\mathrm{f}_{\mathrm{ck}}=30 \mathrm{MPa}$

Apoios fixos indeslocáveis e apoios flexíveis simulando Neoprene Dureza Shore A60

\subsubsection{Carregamentos e solicitações}

\subsubsection{Cargas permanentes}

Peso Próprio - considerando o $\gamma_{c}=25,0 \mathrm{kN} / \mathrm{m}^{3}$

Pavimentação $=0,10 \mathrm{~m} \times 24,0 \mathrm{kN} / \mathrm{m}^{3}=2,40 \mathrm{kN} / \mathrm{m}^{2}$

Recapeamento $=2,00 \mathrm{kN} / \mathrm{m}^{2}$

Barreira rígida $=2,42 \mathrm{~m}^{2} \times 25,0 \mathrm{kN} / \mathrm{m}^{3} / 0,40 \mathrm{~m}=15,1 \mathrm{kN} / \mathrm{m}^{2}$ (distribuídos em $40 \mathrm{~cm}$ ) 


\subsubsection{Cargas móveis}

Optou-se por utilizar o trem-tipo Classe 45, já que, atualmente, é o largamente utilizado, e por não espraiar as cargas das rodas no plano médio da laje. Considerou-se que essa ação provocaria pequenas alterações nos resultados dos esforços, mas não influenciaria a sua comparação.

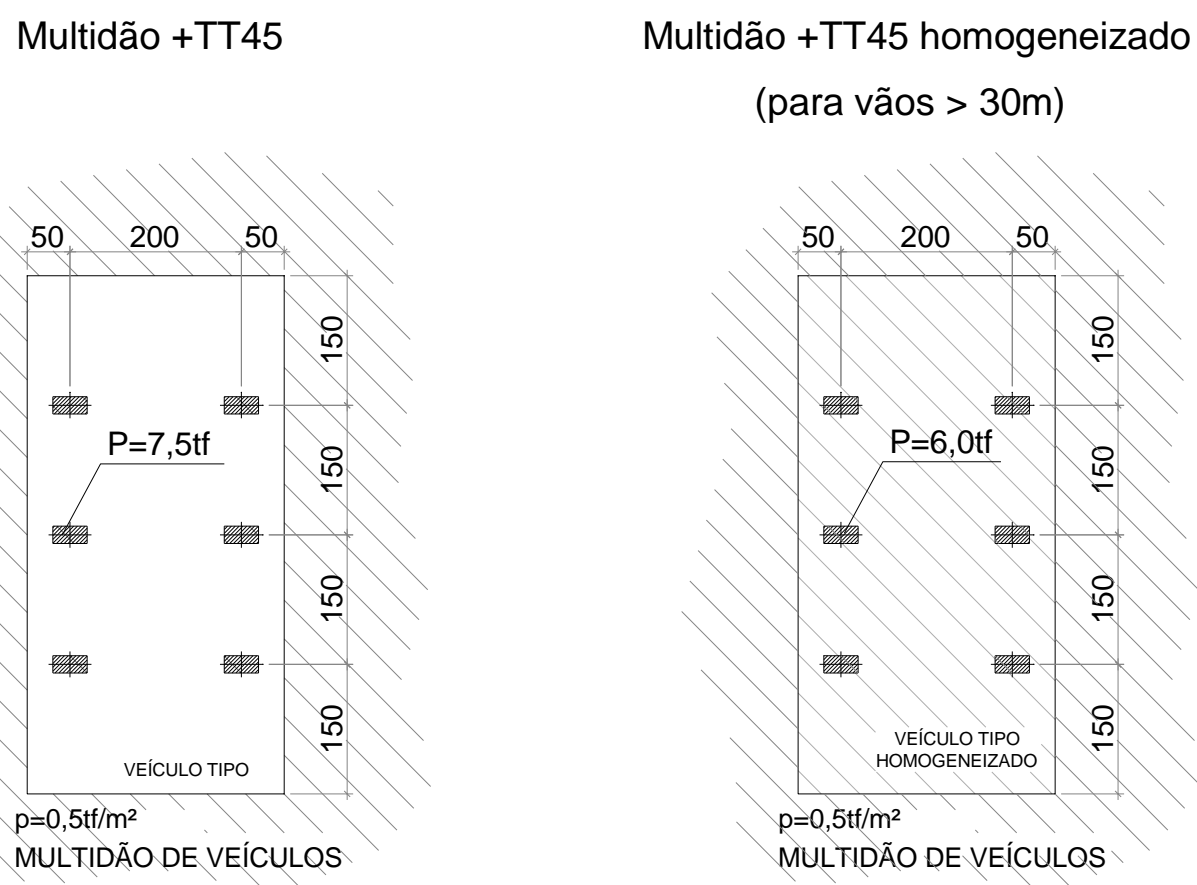

Figura 22 - Características do trem-tipo Classe 45 e trem-tipo Classe 45 homogeneizado

\subsubsection{Solicitações}

\subsubsection{Crítérios de cálculo}

Inicialmente se utilizou como base a recente publicação do Congresso da FIB, em Washington (1), que indica que alguns critérios de cálculo podem estar conservadores nas reações de apoio das vigas extremas e subestimando as reações nas vigas intermediárias de pontes esconsas contínuas.

Outros textos foram estudados, como os publicados no ARPN Journal of Engineering and Applied Sciences: "Effect on support reactions of T-beam skew 
bridge decks" (10) e "Effect of skew angle on behavior of simply supported R.C.Tbeam bridge decks" (11).

\subsubsection{2_Modelagem computacional}

A análise estática destes modelos foi realizada com o auxílio do programa computacional STRAP, discretizando as vigas como elementos de barra e a laje do tabuleiro com elementos de planos.

Por facilidade de manusear os programas e devido aos modelos não apresentarem significativo número de elementos (tempo de processamento reduzido) definiu-se a laje com elementos de casca. Conforme descrito em Soriano (9), casca é um sólido em que a espessura é muito menor do que as dimensões de sua superfície e está submetida a efeitos de flexão e de membrana. $O$ efeito de flexão é semelhante ao de placa (flexão transversal) e o efeito de membrana se refere a deformações da superfície neste mesmo plano.

O carregamento dos modelos deu-se apenas com cargas verticais e com os apoios restritos apenas na translação vertical (z), resultando em deformações nulas ao longo de sua superfície (não havendo o efeito de membrana).

A laje foi dividida em malha. No caso do STRAP, priorizaram-se elementos retangulares, com faces paralelas aos eixos globais, mas, em consequência da geometria, se fez necessária a utilização de elementos triangulares. Os elementos apresentam lados de aproximadamente $50 \mathrm{~cm}$ de comprimento, consequentemente, as vigas foram divididas com esse mesmo valor.

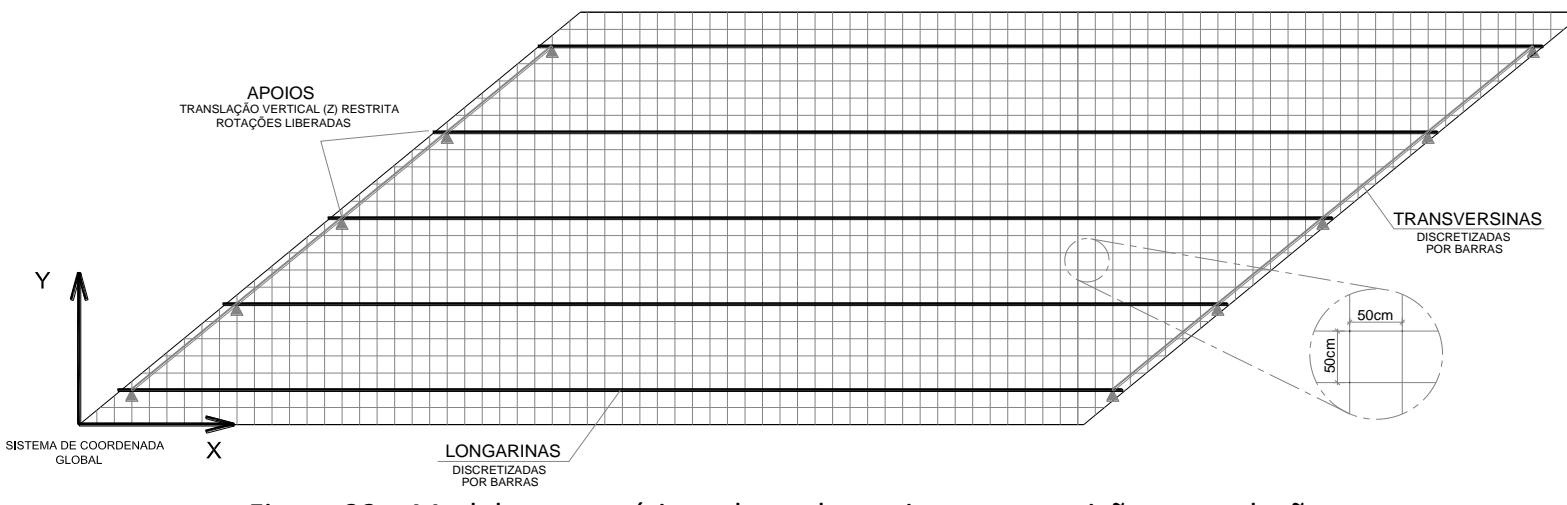

Figura 23 - Modelo matemático adotando apoios com restrição a translações

As cargas permanentes foram aplicadas diretamente nos elementos na direção "z". No caso das cargas móveis, ao invés de se determinar o mapa de 
influência para cada ponto, foram consideradas as cargas percorrendo todo o tabuleiro, a fim de se determinar a envoltória de máximos e mínimos de todos os pontos. No caso das cargas de multidão $\left(5,0 \mathrm{kN} / \mathrm{m}^{2}\right)$ criou-se faixas na extensão do tabuleiro, com 1,0m de largura, uma ao lado da outra. Para a consideração do TT45, as faixas criadas foram de $3,0 \mathrm{~m}$ de largura, podendo as mesmas se sobreporem, e tomando o cuidado de sempre haver apenas um TT45 nas combinações.

Inicialmente os apoios, tipo neoprene fretado, foram simulados como apoios articulados perfeitos, ou seja, restringindo apenas a translação em " $z$ " e liberando as rotações. Considerou-se o espaçamento de 1,0m entre os mesmo, resultando em 12 apoios discretos por borda apoiada, sendo que o primeiro e o último foram posicionados a $50 \mathrm{~m}$ de distância da borda livre.

Para uma distribuição de esforços mais realista, substituíram-se os apoios fixos por molas que simplificadamente representam as características de rigidez do aparelho de apoio $-\mathrm{kV}=100.000 \mathrm{kN} / \mathrm{m}$ (no caso das grelhas, nenhum apoio resultou em esforços de tração). Este valor não representa um neoprene específico, pois devido à esconsidade, existe uma variação nas reações de apoio o que resultaria em vários tipos de aparelhos de apoio e consequentemente vários coeficientes de mola. $\mathrm{O}$ valor de rigidez adotado representa um aparelho de apoio que deslocaria $1 \mathrm{~cm}$ na vertical quando aplicado uma carga de compressão de $1.000 \mathrm{kN}$.

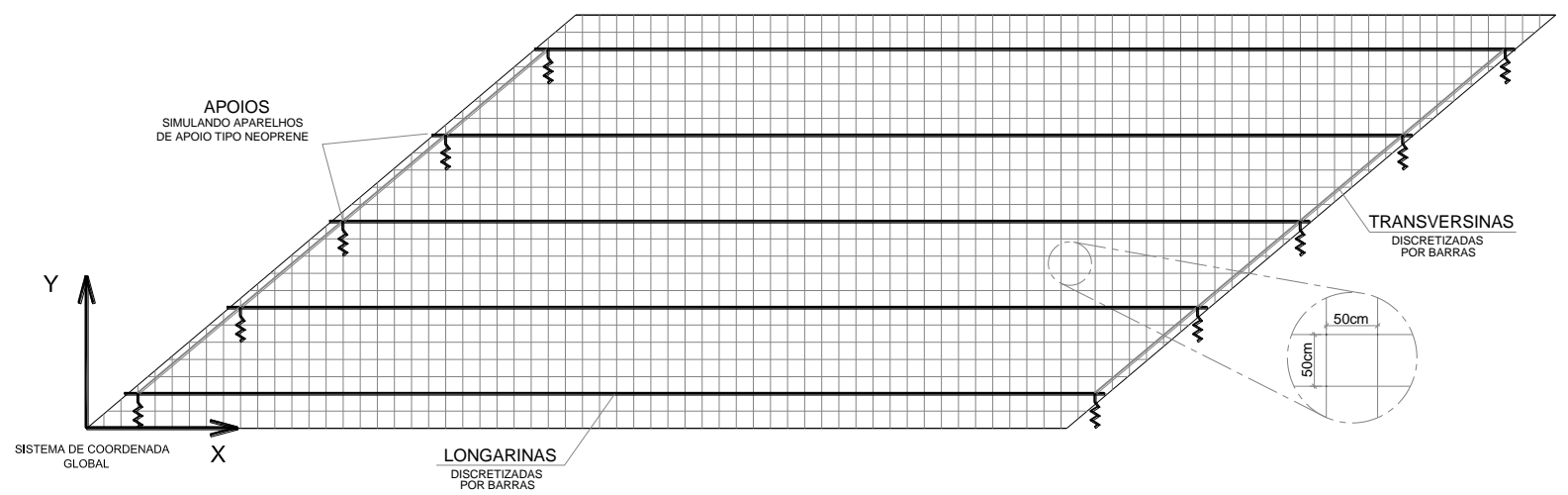

Figura 24 - Modelo matemático adotando molas que simulam os aparelhos de apoio 


\subsubsection{Resultados obtidos e análises}

Como foi descrito na recente publicação do Congresso da FIB, em Washington (1), alguns critérios de cálculo podem estar conservadores nas reações de apoio das vigas extremas e subestimando as reações nas vigas intermediárias de pontes esconsas contínuas.

Verificar o efeito das transversinas nas grelhas, a modelagem mais adequada para cada caso e descrever as vantagens e desvantagens do modelo matemático, são objetivos desta seção.

Para isso, além das características da estrutura descrita acima, será realizado o processamento dessa mesma estrutura sem a transversina no apoio e com a transversina na normal, conforme figuras abaixo.

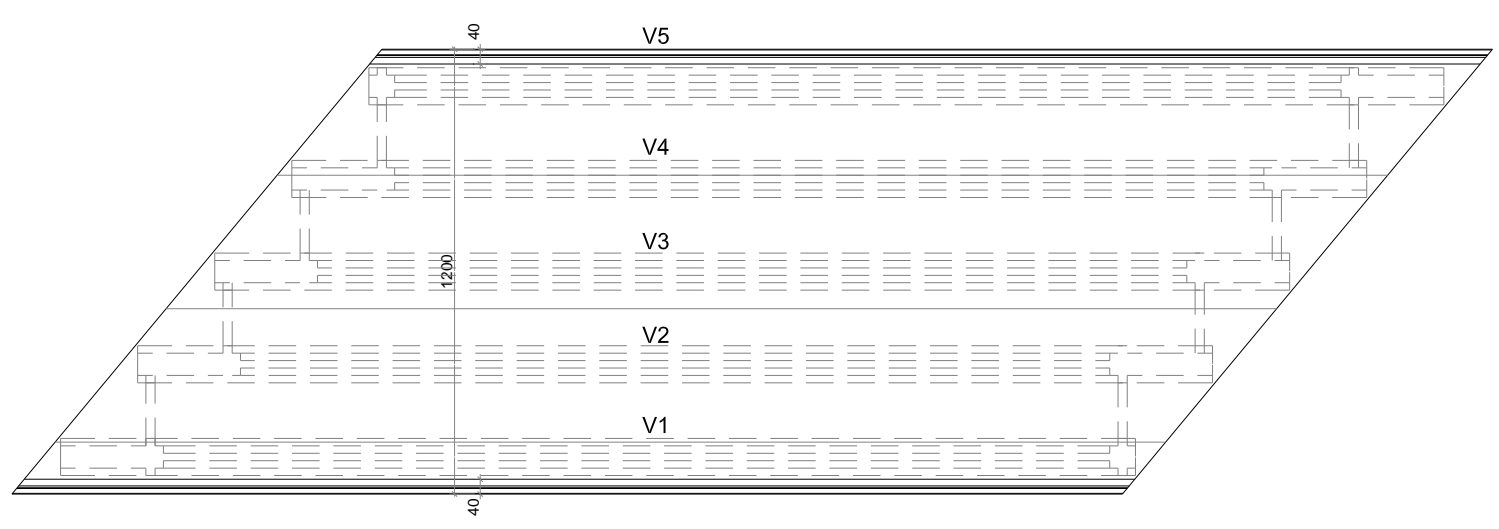

Figura 25 - Estrutura sem transversinas de apoio

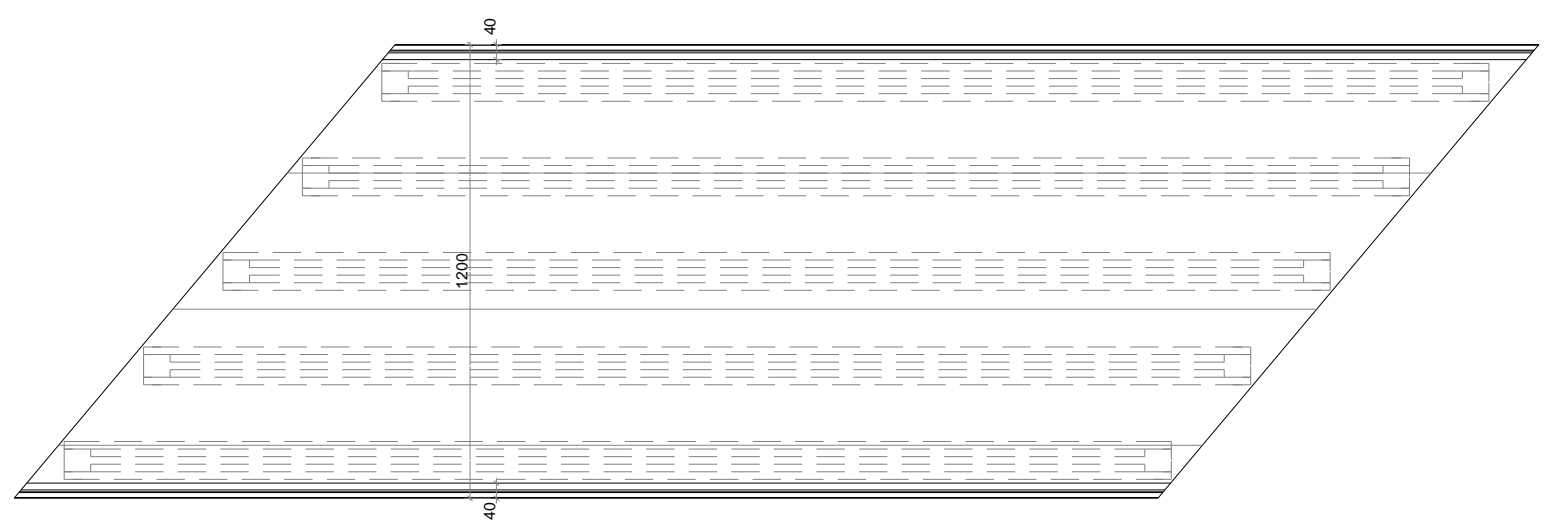

Figura 26 - Estrutura sem transversinas de apoio 


\subsubsection{Transversina esconsa}

As solicitações apresentadas nesta seção estão presentes no Anexo D e nas tabelas abaixo, indicando os momentos fletores, forças cortantes, momentos de torsão e reações nos apoios em consequência de carga permanente e carga móvel com o ângulo de esconsidade variando de $0^{\circ}$ a $60^{\circ}$, considerando apoios restritos às translações.

\begin{tabular}{|c|c|c|c|c|c|c|c|c|c|c|c|c|}
\hline \multicolumn{2}{|c|}{ Grau de Esconsidade } & \multicolumn{3}{|c|}{$0^{\circ}$} & \multicolumn{4}{|c|}{$15^{\circ}$} & \multicolumn{4}{|c|}{$30^{\circ}$} \\
\hline \multirow{2}{*}{\multicolumn{2}{|c|}{ Solicitações }} & Momento & Cortante & Reação & Momento & Cortante & Torção & Reação & Momento & Cortante & Torção & Reação \\
\hline & & (kN.m) & $(\mathrm{kN})$ & $(\mathrm{kN})$ & (kN.m) & $(\mathrm{kN})$ & (kN.m) & $(\mathrm{kN})$ & (kN.m) & $(\mathrm{kN})$ & (kN.m) & $(\mathrm{kN})$ \\
\hline \multirow{5}{*}{ Permanente } & V1 & 3730 & 538 & 654 & 3720 & 495 & 26 & 656 & 3710 & 498 & 30 & 661 \\
\hline & $\mathrm{V} 2$ & 3540 & 507 & 614 & 3520 & 496 & 8.3 & 623 & 3490 & 482 & 17 & 634 \\
\hline & V3 & 3490 & 503 & 619 & 3480 & 495 & 7.4 & 625 & 3440 & 477 & 16 & 633 \\
\hline & V4 & 3540 & 507 & 614 & 3520 & 493 & 8.3 & 616 & 3490 & 483 & 17 & 619 \\
\hline & V5 & 3730 & 538 & 654 & 3720 & 511 & 25 & 666 & 3710 & 547 & 30 & 686 \\
\hline \multirow{5}{*}{ Acidental } & V1 & 2320 & 333 & 396 & 2320 & 313 & 55 & 388 & 2300 & 295 & 57 & 379 \\
\hline & $\mathrm{V} 2$ & 2050 & 341 & 466 & 2040 & 335 & 54 & 460 & 2020 & 323 & 42 & 455 \\
\hline & V3 & 2080 & 344 & 459 & 2070 & 338 & 52 & 458 & 2050 & 327 & 36 & 459 \\
\hline & V4 & 2050 & 341 & 466 & 2040 & 338 & 54 & 469 & 2020 & 325 & 42 & 473 \\
\hline & V5 & 2320 & 333 & 396 & 2320 & 330 & 55 & 403 & 2300 & 349 & 51 & 412 \\
\hline
\end{tabular}

Tabela 22 - Solicitações nas vigas - ângulo de $0^{\circ}, 15^{\circ}$ e $30^{\circ}$

\begin{tabular}{|c|c|c|c|c|c|c|c|c|c|}
\hline \multicolumn{2}{|c|}{ Grau de Esconsidade } & \multicolumn{4}{|c|}{$45^{\circ}$} & \multicolumn{4}{|c|}{$60^{\circ}$} \\
\hline \multirow{2}{*}{\multicolumn{2}{|c|}{ Solicitações }} & Momento & Cortante & Torção & Reação & Momento & Cortante & Torção & Reação \\
\hline & & (kN.m) & $(\mathrm{kN})$ & (kN.m) & $(\mathrm{kN})$ & (kN.m) & $(\mathrm{kN})$ & (kN.m) & $(\mathrm{kN})$ \\
\hline \multirow{5}{*}{ Permanente } & V1 & 3700 & 479 & 50 & 680 & 3660 & 464 & 86 & 714 \\
\hline & $\mathrm{V} 2$ & 3410 & 460 & 28 & 656 & 3180 & 451 & 45 & 687 \\
\hline & V3 & 3360 & 456 & 26 & 653 & 3150 & 450 & 42 & 687 \\
\hline & V4 & 3410 & 465 & 28 & 631 & 3180 & 451 & 45 & 647 \\
\hline & V5 & 3700 & 544 & 42 & 711 & 3660 & 584 & 86 & 809 \\
\hline \multirow{5}{*}{ Acidental } & V1 & 2260 & 280 & 71 & 372 & 2180 & 295 & 84 & 368 \\
\hline & $\mathrm{V} 2$ & 1970 & 302 & 70 & 453 & 1830 & 288 & 73 & 460 \\
\hline & V3 & 1980 & 307 & 64 & 463 & 1820 & 287 & 73 & 476 \\
\hline & V4 & 1970 & 309 & 71 & 484 & 1830 & 278 & 75 & 496 \\
\hline & V5 & 2260 & 352 & 70 & 425 & 2180 & 267 & 84 & 452 \\
\hline
\end{tabular}

Tabela 23 - Solicitações nas vigas - ângulo variando de $45^{\circ}$ e $60^{\circ}$

A seguir, serão apresentados em curvas sobrepostas, representado os momentos fletores para as diversas esconsidades estudadas e separando-os em carregamento permanente, móvel e soma dos dois carregamentos.

Momentos Fletores em consequência de carregamento permanente: 


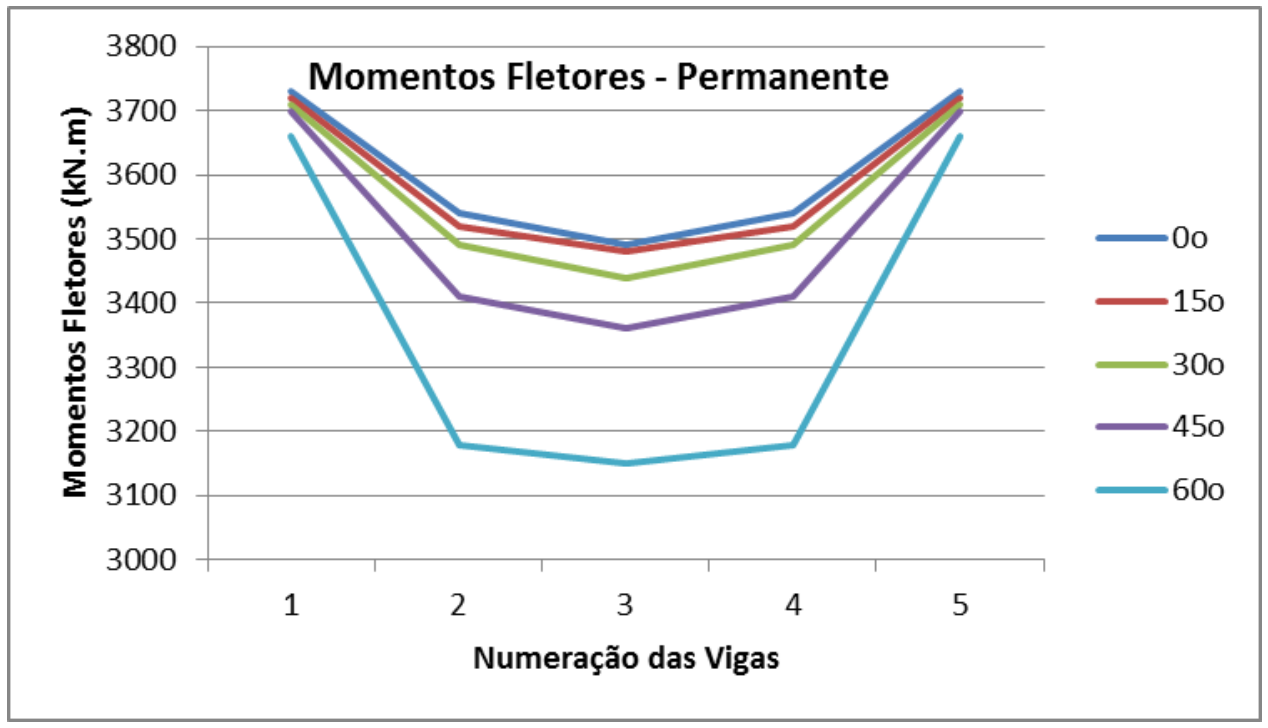

Momentos Fletores em consequência de carregamento móvel:

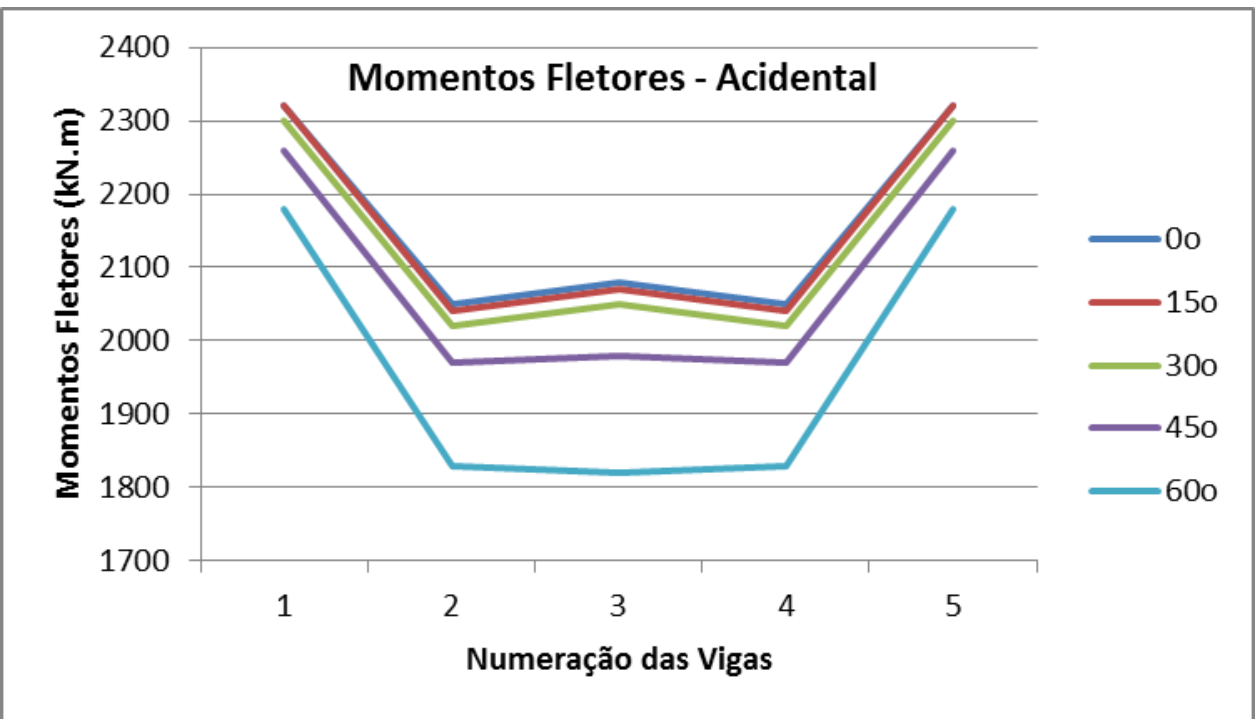


Somatória dos Momentos Fletores em consequência de cargas permanentes e acidentais.

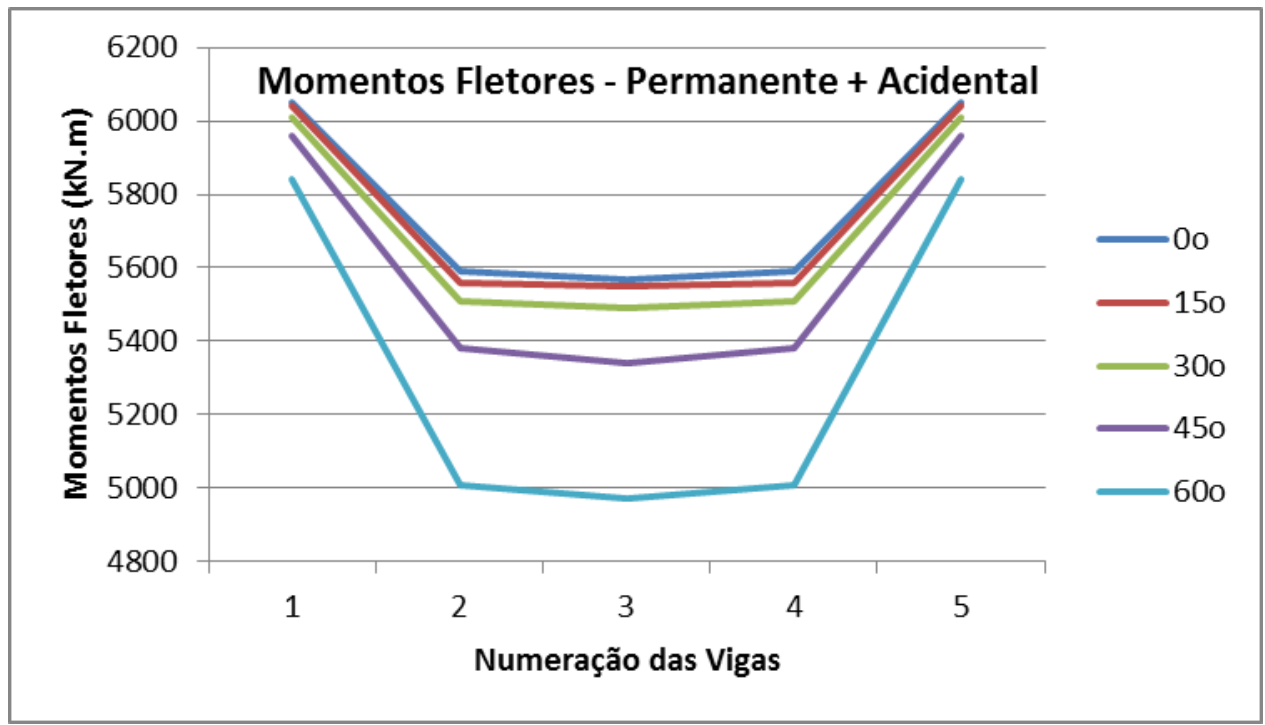

A seguir serão apresentadas em curvas sobrepostas representado as forças cortantes para as diversas esconsidades estudadas e separando-as em carregamento permanente, móvel e soma dos dois carregamentos.

Forças Cortantes em consequência de carregamento permanente:

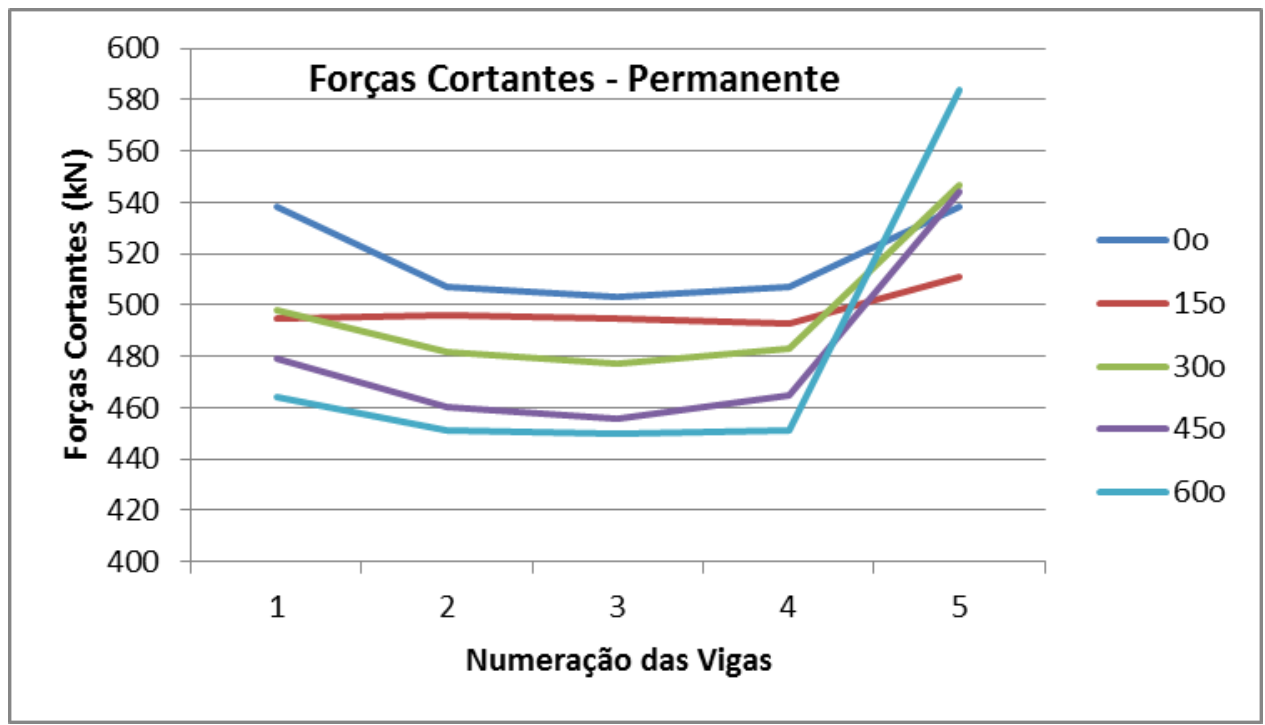


Forças Cortantes em consequência de carregamento móvel:

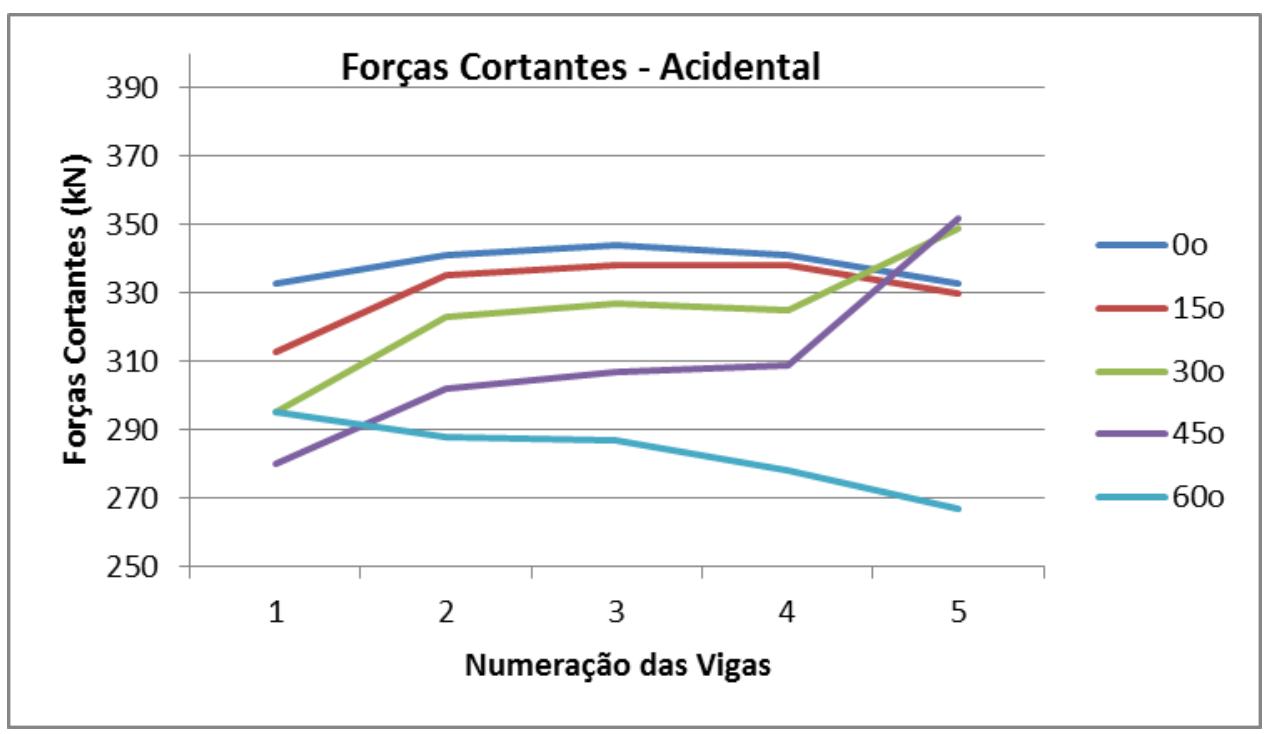

Somatória das Forças Cortantes em consequência de cargas permanentes e acidentais:

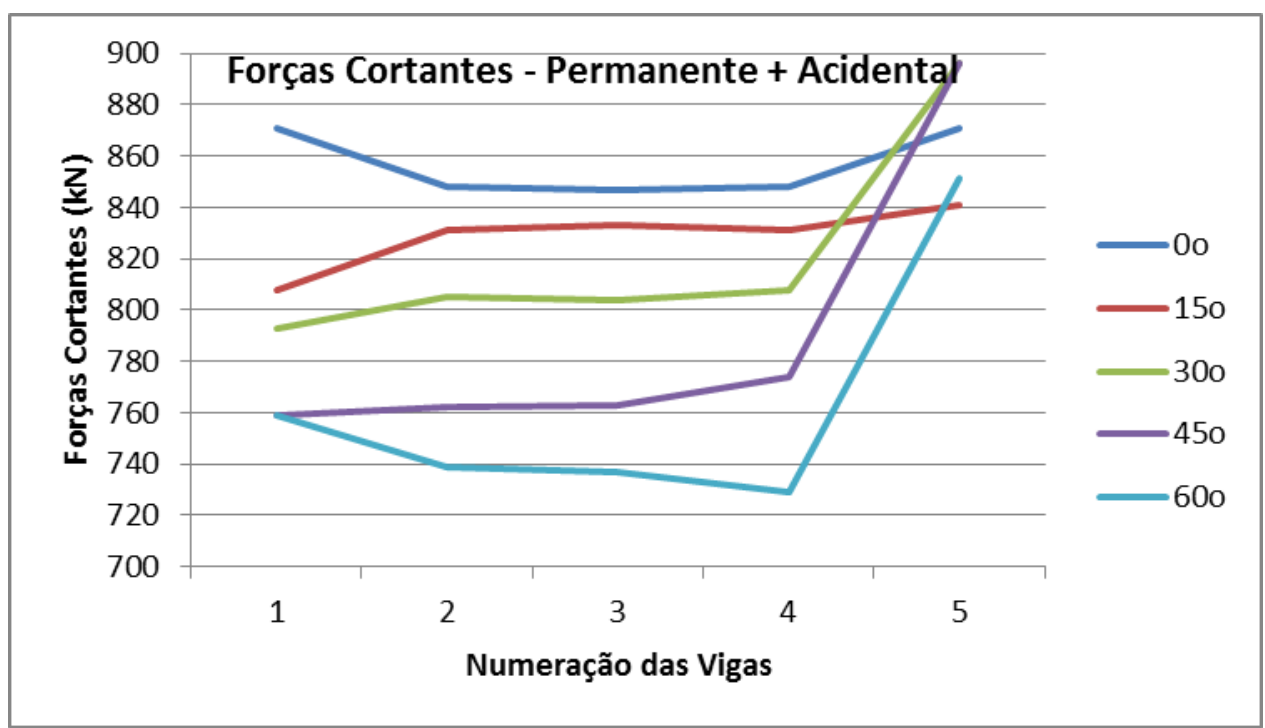

A seguir serão apresentadas em curvas sobrepostas representado as solicitações para as diversas esconsidades estudadas e separando-as em carregamento permanente, envoltória das acidentais e soma dos dois carregamentos. 
Reações máximas em consequência de carregamento permanente:

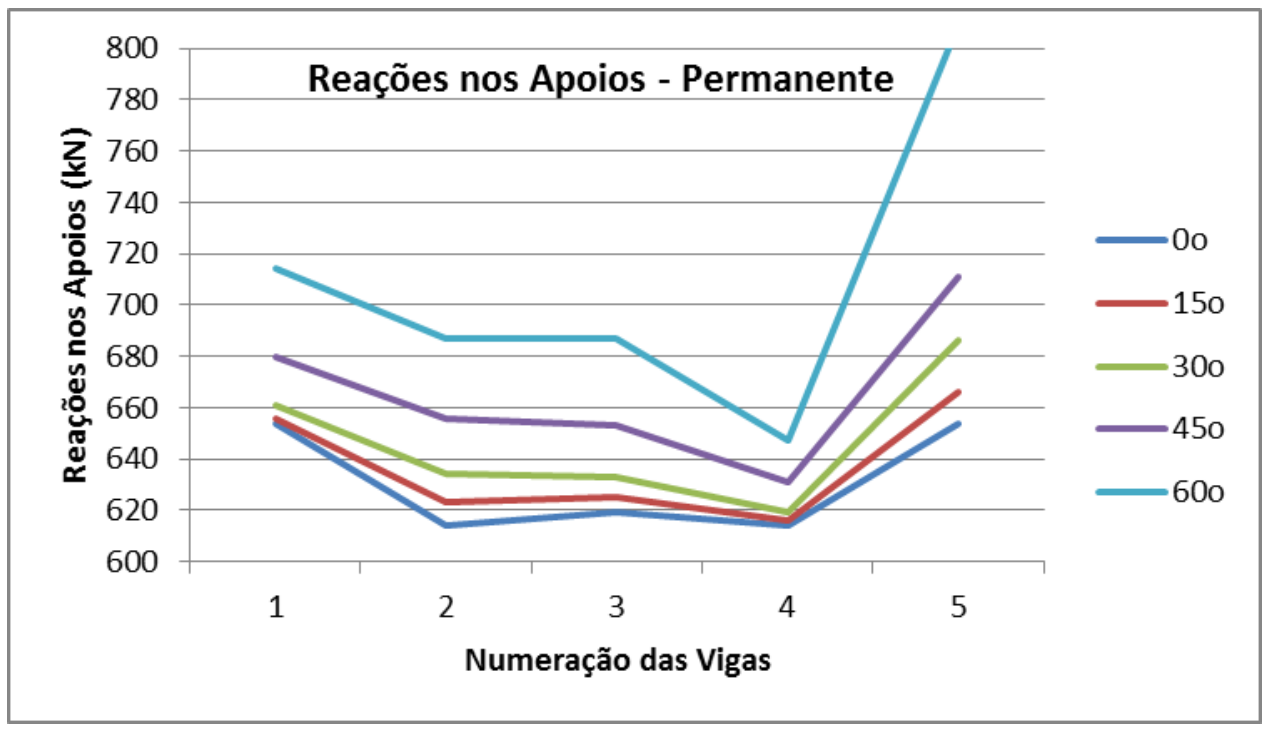

Reações máximas em consequência de carregamento móvel:

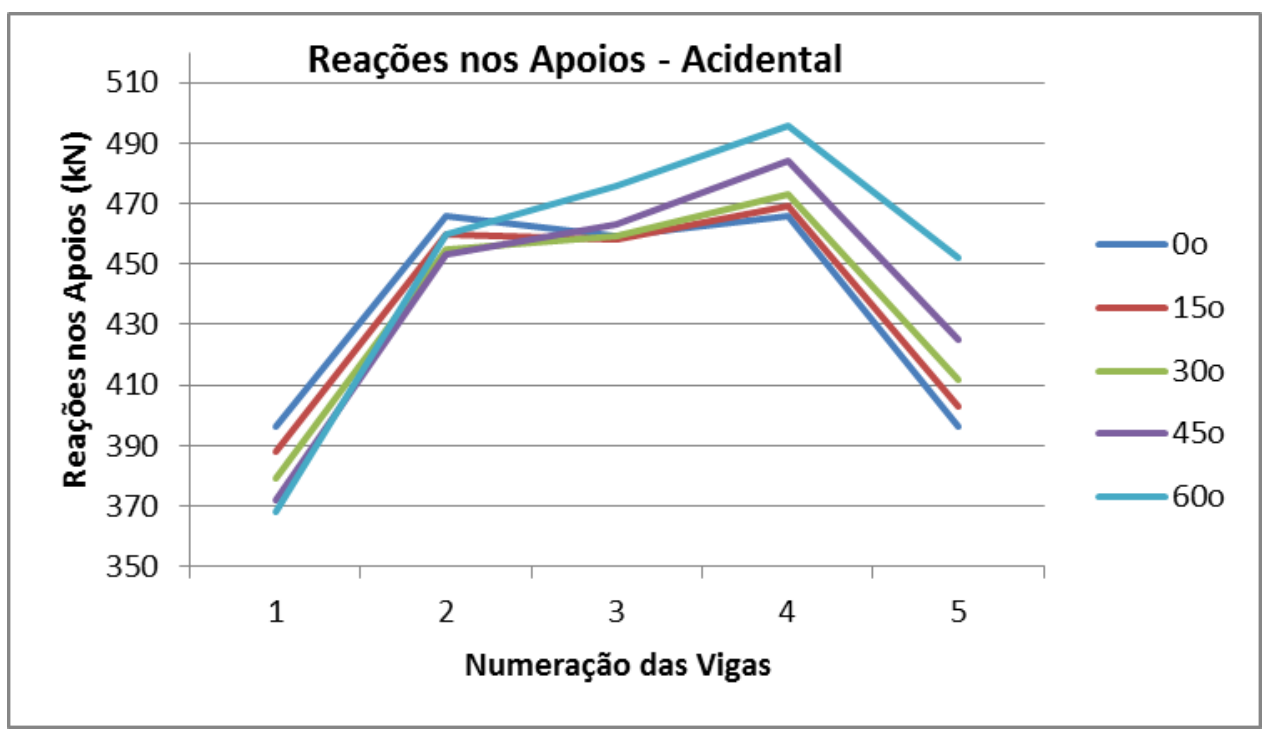

Somatória das reações permanentes e acidentais:

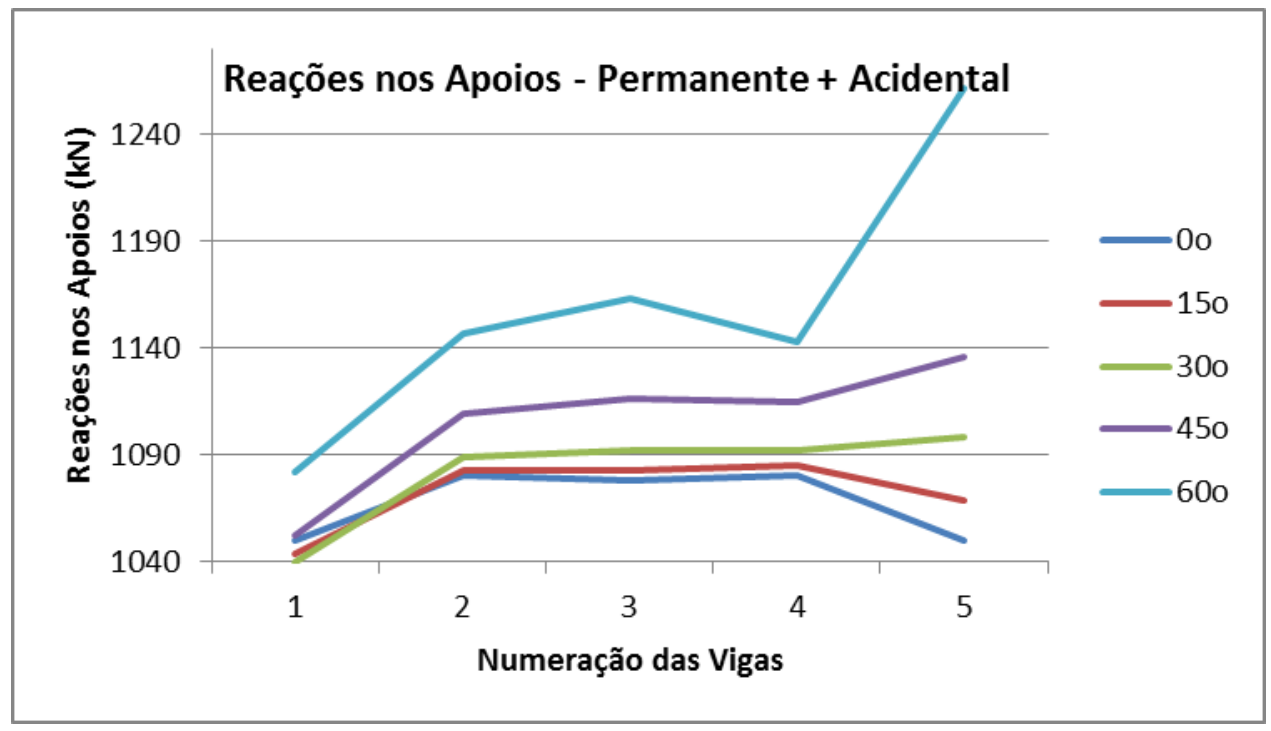




\subsubsection{Transversina esconsa com apoios flexíveis}

As solicitações apresentadas abaixo estão indicadas no final do Anexo D e nas tabelas abaixo, indicando os momentos fletores, forças cortantes, momentos de torção e reações nos apoios em consequência de carga permanente e carga móvel com o ângulo de esconsidade de $60^{\circ}$, considerando apoios flexíveis (molas).

\begin{tabular}{|c|l|c|c|c|c|c|c|c|c|c|}
\hline \multicolumn{2}{|c|}{$60^{\circ}$} & \multicolumn{3}{c|}{ Apoios Fixos } & \multicolumn{3}{c|}{ Apoios Flexíveis } & \multicolumn{3}{c|}{ Diferença } \\
\hline \multirow{3}{*}{ Solicitações } & Momento & Cortante & Reação & Momento & Cortante & Reação & Momento & Cortante & Reação \\
\cline { 2 - 11 } & $(\mathrm{kN.m})$ & $(\mathrm{kN})$ & $(\mathrm{kN})$ & $(\mathrm{kN} . \mathrm{m})$ & $(\mathrm{kN})$ & $(\mathrm{kN})$ & $\%$ & $\%$ & $\%$ \\
\hline \multirow{5}{*}{ Permanente } & V1 & 3660 & 464 & 714 & 3650 & 452 & 709 & $-0.27 \%$ & $-2.65 \%$ & $-0.71 \%$ \\
\cline { 2 - 12 } & V2 & 3180 & 451 & 687 & 3190 & 434 & 688 & $0.31 \%$ & $-3.92 \%$ & $0.15 \%$ \\
\cline { 2 - 11 } & V3 & 3150 & 450 & 687 & 3150 & 432 & 676 & $0.00 \%$ & $-4.17 \%$ & $-1.63 \%$ \\
\cline { 2 - 11 } & V4 & 3180 & 451 & 647 & 3190 & 466 & 694 & $0.31 \%$ & $3.22 \%$ & $6.77 \%$ \\
\cline { 2 - 11 } & V5 & 3660 & 584 & 809 & 3630 & 580 & 776 & $-0.83 \%$ & $-0.69 \%$ & $-4.25 \%$ \\
\hline \multirow{5}{*}{ Acidental } & V1 & 2180 & 295 & 368 & 2200 & 280 & 369 & $0.91 \%$ & $-5.36 \%$ & $0.27 \%$ \\
\cline { 2 - 11 } & V2 & 1830 & 288 & 460 & 1830 & 280 & 328 & $0.00 \%$ & $-2.86 \%$ & $-40.24 \%$ \\
\cline { 2 - 11 } & V3 & 1820 & 287 & 476 & 1820 & 276 & 346 & $0.00 \%$ & $-3.99 \%$ & $-37.57 \%$ \\
\cline { 2 - 11 } & V4 & 1830 & 278 & 496 & 1830 & 276 & 344 & $0.00 \%$ & $-0.72 \%$ & $-44.19 \%$ \\
\cline { 2 - 11 } & V5 & 2180 & 267 & 452 & 2190 & 275 & 424 & $0.46 \%$ & $2.91 \%$ & $-6.60 \%$ \\
\hline
\end{tabular}

Tabela 24 - Solicitações nas vigas - ângulo de $60^{\circ} \mathrm{com}$ apoios flexíveis 


\subsubsection{Transversina normal a longarina}

As solicitações apresentadas nesta seção estão presentes no Anexo E e nas tabelas abaixo, indicando os Momentos Fletores, Forças Cortantes, Momentos de Torção e Reações nos apoios em consequência de carga permanente e carga móvel com o ângulo de esconsidade variando de $0^{\circ}$ a $60^{\circ}$, considerando apoios restritos às translações.

\begin{tabular}{|c|c|c|c|c|c|c|c|c|c|c|c|c|}
\hline \multirow{3}{*}{\multicolumn{2}{|c|}{\begin{tabular}{|c|} 
Grau de Esconsidade \\
Solicitações
\end{tabular}}} & \multicolumn{3}{|c|}{$0^{\circ}$} & \multicolumn{4}{|c|}{$15^{\circ}$} & \multicolumn{4}{|c|}{$30^{\circ}$} \\
\hline & & Momento & Cortante & Reação & Momento & Cortante & Torção & Reação & Momento & Cortante & Torção & Reação \\
\hline & & (kN.m) & $(\mathrm{kN})$ & $(\mathrm{kN})$ & (kN.m) & $(\mathrm{kN})$ & (kN.m) & $(\mathrm{kN})$ & (kN.m) & $(\mathrm{kN})$ & (kN.m) & $(\mathrm{kN})$ \\
\hline \multirow{3}{*}{ Permanente } & V1 & 3730 & 538 & 654 & 3720 & 520 & 26 & 647 & 3720 & 535 & 30 & 657 \\
\hline & V3 & 3490 & 503 & 619 & 3480 & 517 & 13 & 620 & 3450 & 502 & 16 & 625 \\
\hline & V4 & 3540 & 507 & 614 & 3530 & 505 & 28 & 607 & 3500 & 488 & 17 & 610 \\
\hline \multirow{4}{*}{ Acidental } & V2 & 2050 & 341 & 466 & 2040 & 323 & 86 & 427 & 2010 & 326 & 39 & 436 \\
\hline & V3 & 2080 & 344 & 459 & 2070 & 328 & 85 & 450 & 2050 & 332 & 38 & 457 \\
\hline & V4 & 2050 & 341 & 466 & 2040 & 358 & 91 & 476 & 2010 & 354 & 37 & 473 \\
\hline & V5 & 2320 & 333 & 396 & 2310 & 327 & 48 & 429 & 2290 & 339 & 43 & 433 \\
\hline
\end{tabular}

Tabela 25 - Solicitações nas vigas - ângulo de $0^{\circ}, 15^{\circ}$ e $30^{\circ}$

\begin{tabular}{|c|c|c|c|c|c|c|c|c|c|}
\hline \multirow{3}{*}{\multicolumn{2}{|c|}{$\begin{array}{c}\text { Grau de Esconsidade } \\
\text { Solicitações }\end{array}$}} & \multicolumn{4}{|c|}{$45^{\circ}$} & \multicolumn{4}{|c|}{$60^{\circ}$} \\
\hline & & \multirow{2}{*}{\begin{tabular}{|c|} 
Momento \\
$(\mathrm{kN} . \mathrm{m})$ \\
\end{tabular}} & \multirow{2}{*}{$\begin{array}{c}\text { Cortante } \\
(\mathrm{kN}) \\
\end{array}$} & \multirow{2}{*}{$\begin{array}{c}\text { Torção } \\
\text { (kN.m) }\end{array}$} & \multirow{2}{*}{$\frac{\text { Reação }}{(\mathrm{kN})}$} & \multirow{2}{*}{\begin{tabular}{|c|} 
Momento \\
$(\mathrm{kN} . \mathrm{m})$ \\
\end{tabular}} & \multirow{2}{*}{\begin{tabular}{|c|} 
Cortante \\
$(\mathrm{kN})$
\end{tabular}} & \multirow{2}{*}{$\begin{array}{l}\text { Torção } \\
\text { (kN.m) }\end{array}$} & \multirow{2}{*}{$\begin{array}{c}\text { Reação } \\
(\mathrm{kN})\end{array}$} \\
\hline & & & & & & & & & \\
\hline \multirow{5}{*}{ Permanente } & V1 & 3730 & 530 & 48 & 673 & 3720 & 554 & 48 & 702 \\
\hline & V2 & 3440 & 506 & 28 & 653 & 3220 & 511 & 47 & 671 \\
\hline & V3 & 3380 & 489 & 27 & 634 & 3160 & 484 & 42 & 641 \\
\hline & V4 & 3440 & 468 & 28 & 616 & 3220 & 452 & 46 & 622 \\
\hline & V5 & 3730 & 536 & 39 & 714 & 3720 & 568 & 75 & 811 \\
\hline \multirow{5}{*}{ Acidental } & V1 & 2240 & 318 & 47 & 375 & 2180 & 321 & 48 & 370 \\
\hline & V2 & 1950 & 323 & 45 & 438 & 1810 & 337 & 60 & 451 \\
\hline & V3 & 1980 & 337 & 43 & 461 & 1810 & 334 & 60 & 471 \\
\hline & V4 & 1950 & 351 & 46 & 480 & 1810 & 357 & 62 & 484 \\
\hline & V5 & 2240 & 338 & 38 & 448 & 2180 & 346 & 50 & 474 \\
\hline
\end{tabular}

Tabela 26 - Solicitações nas vigas - ângulo variando de $45^{\circ}$ e $60^{\circ}$ 
A seguir, serão apresentados em curvas sobrepostas representado os momentos fletores para as diversas esconsidades estudadas e separando-os em carregamento permanente, móvel e soma dos dois carregamentos.

Momentos Fletores em consequência de carregamento permanente:

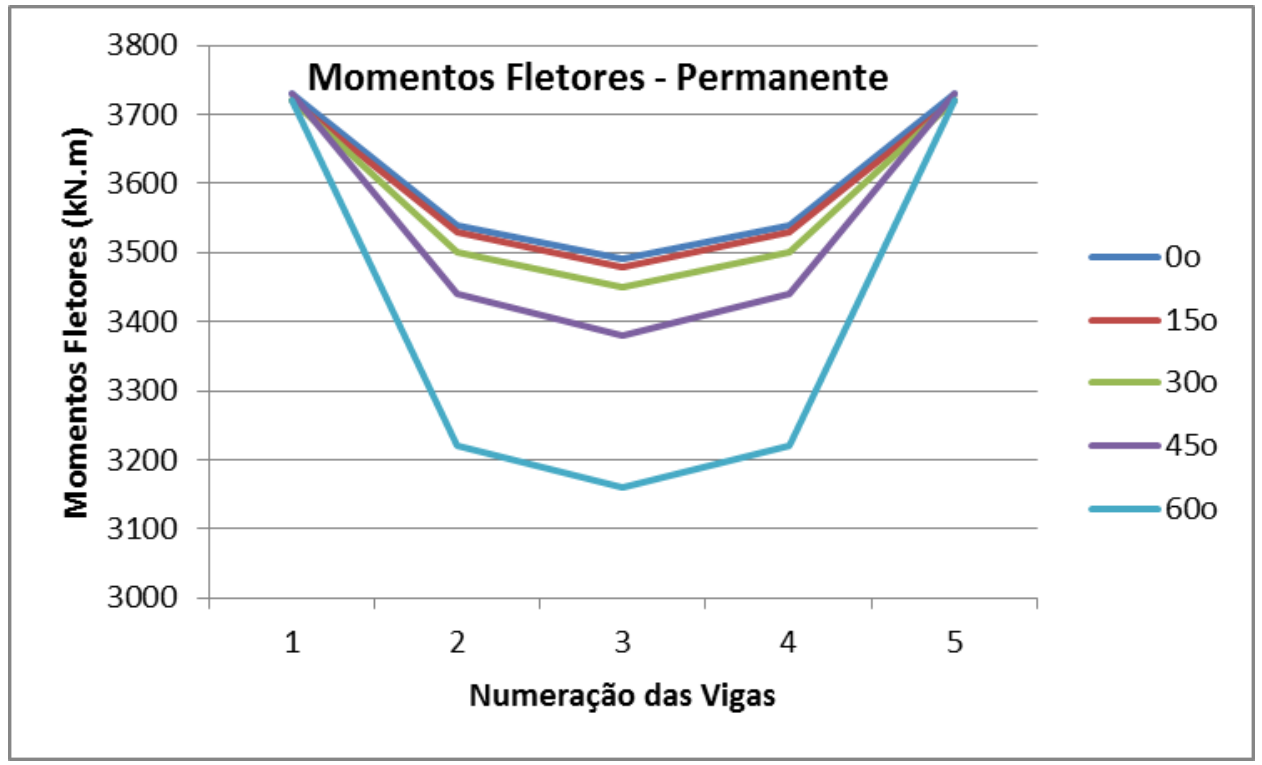

Momentos Fletores em consequência de carregamento móvel:

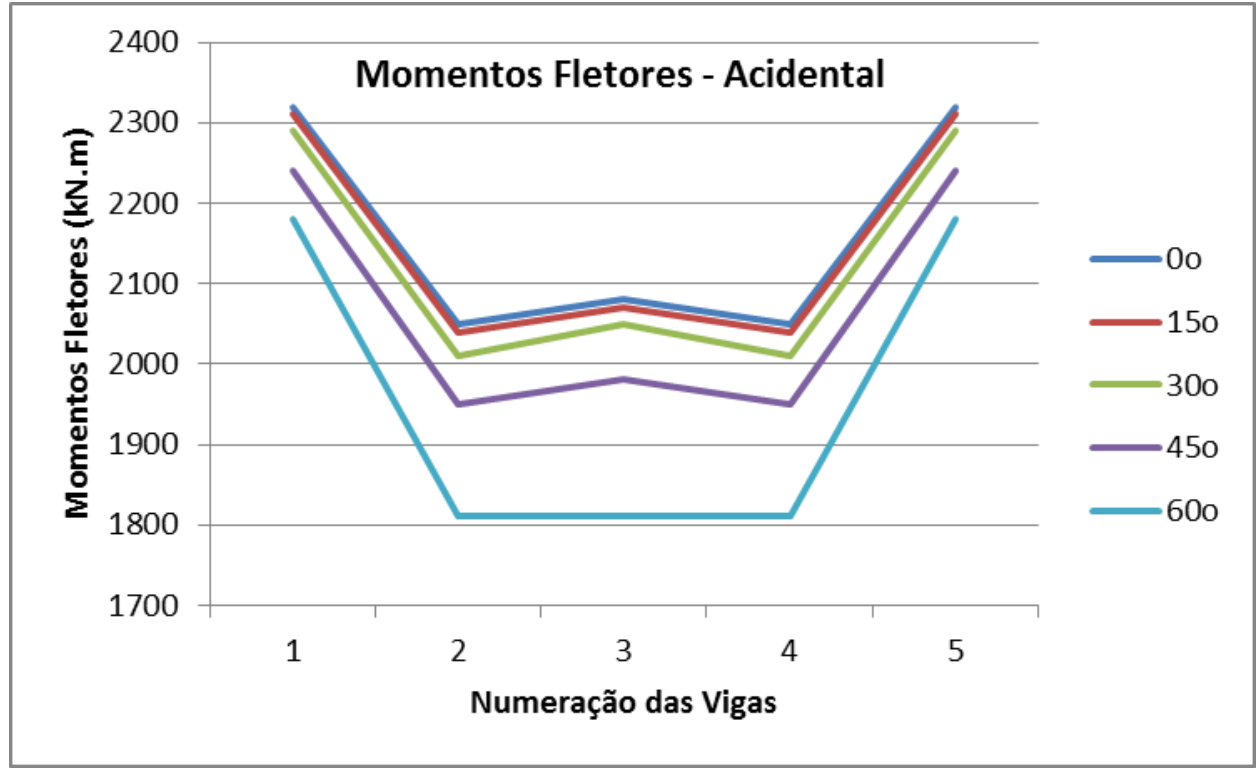


Somatória dos Momentos Fletores em consequência de cargas permanentes e acidentais:

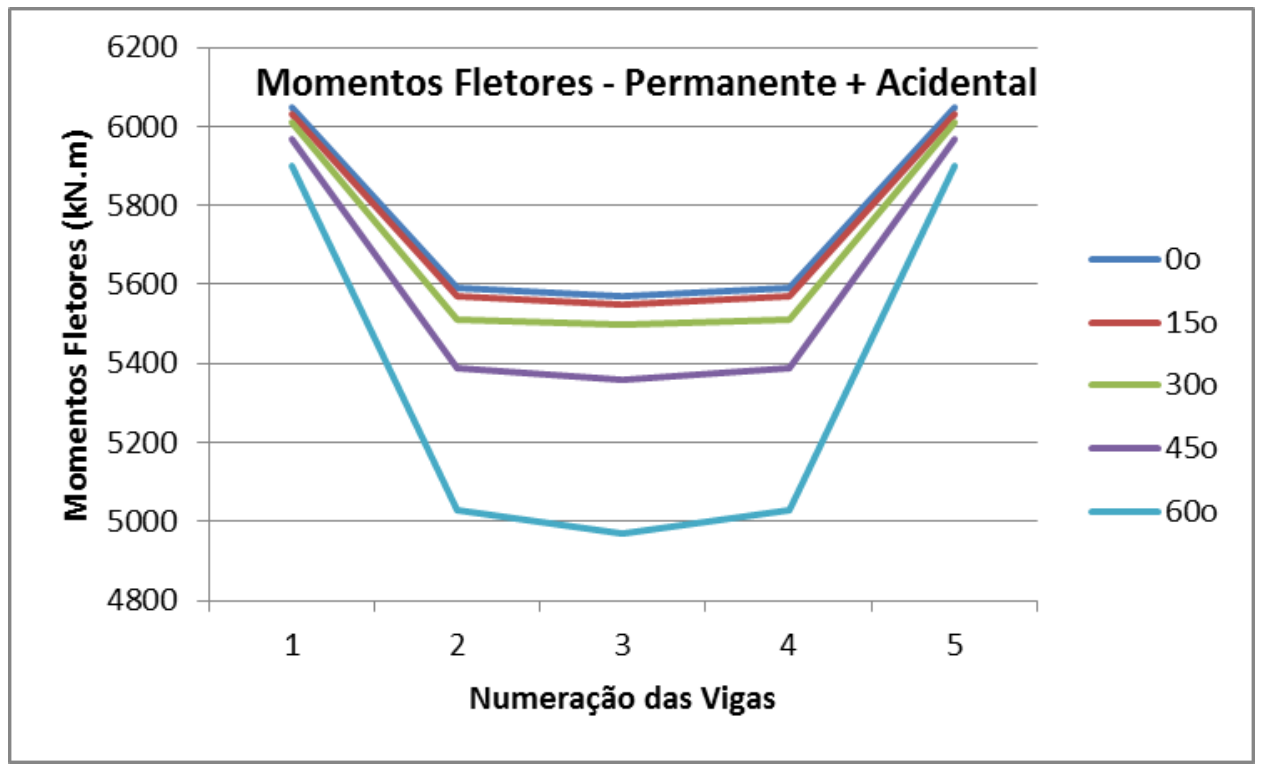

A seguir serão apresentadas em curvas sobrepostas representado as forças cortantes para as diversas esconsidades estudadas e separando-as em carregamento permanente, móvel e soma dos dois carregamentos.

Forças Cortantes em consequência de carregamento permanente:

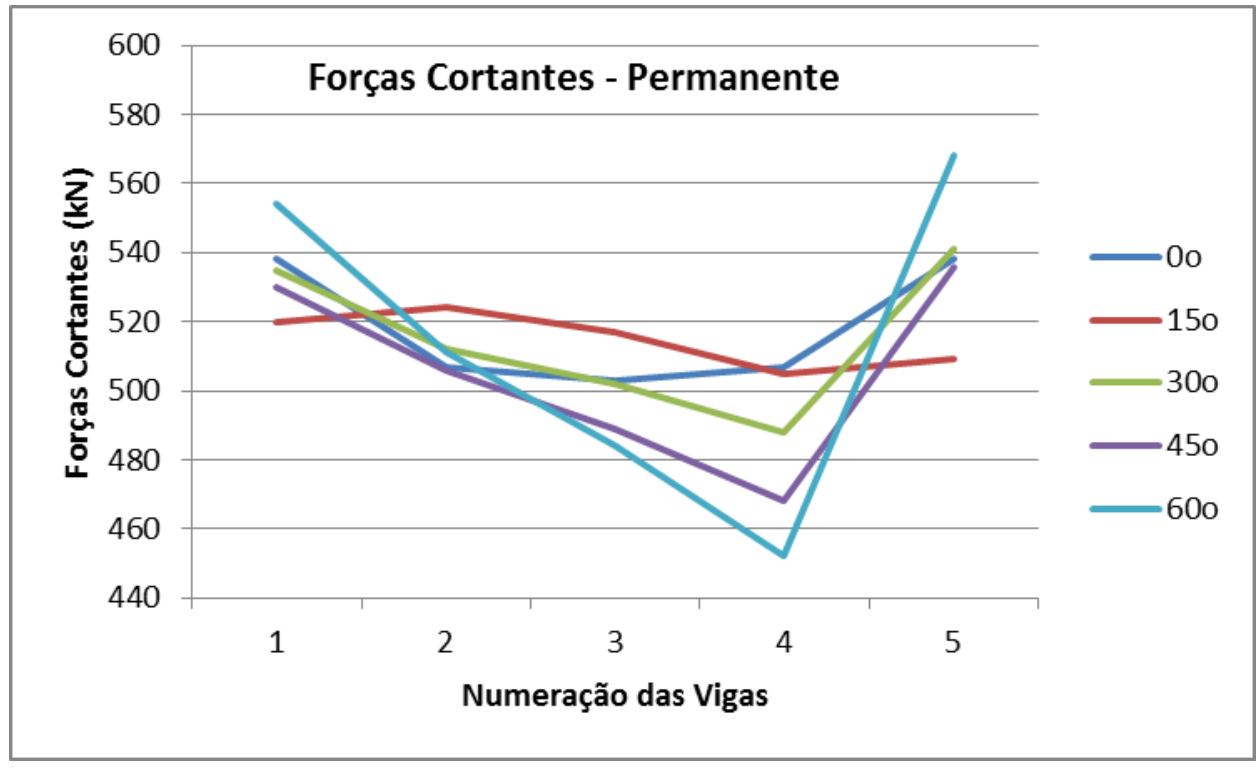


Forças Cortantes em consequência de carregamento móvel:

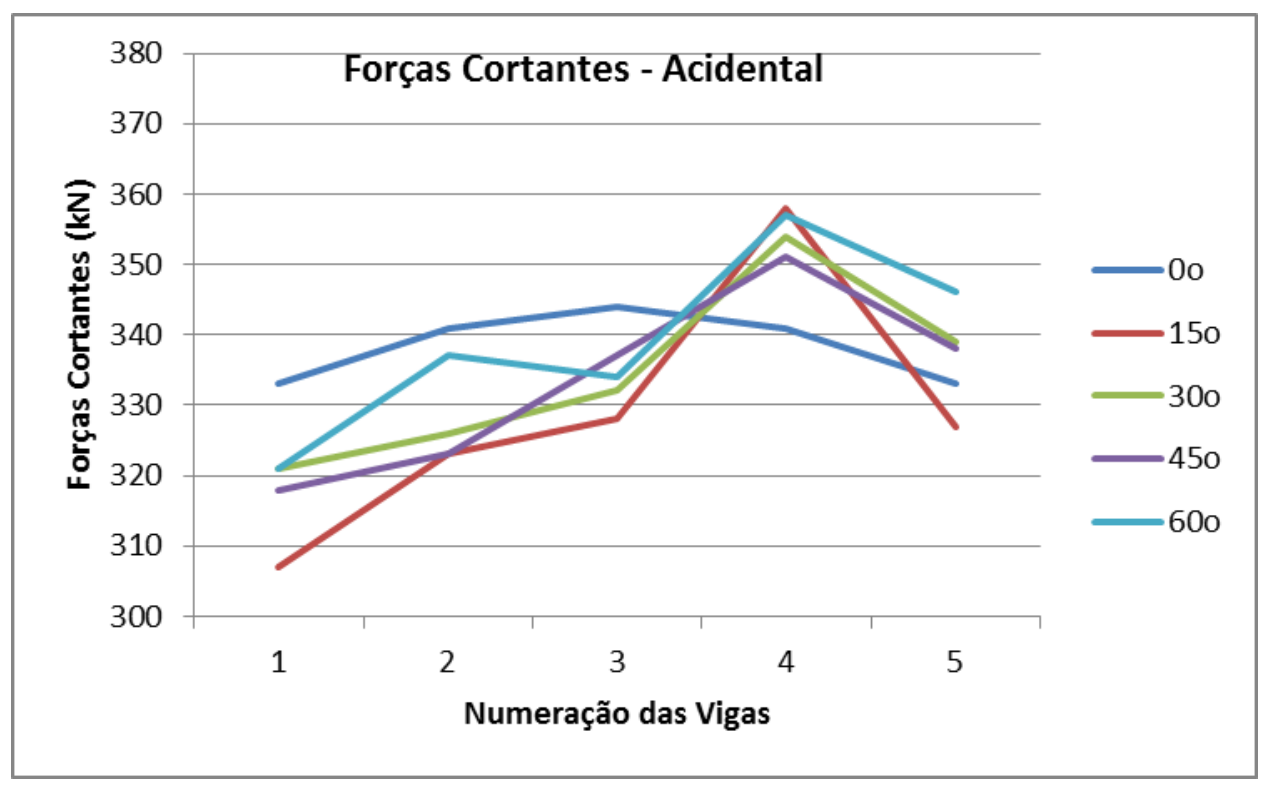

Somatória dos Forças Cortantes em consequência de cargas permanentes e acidentais:

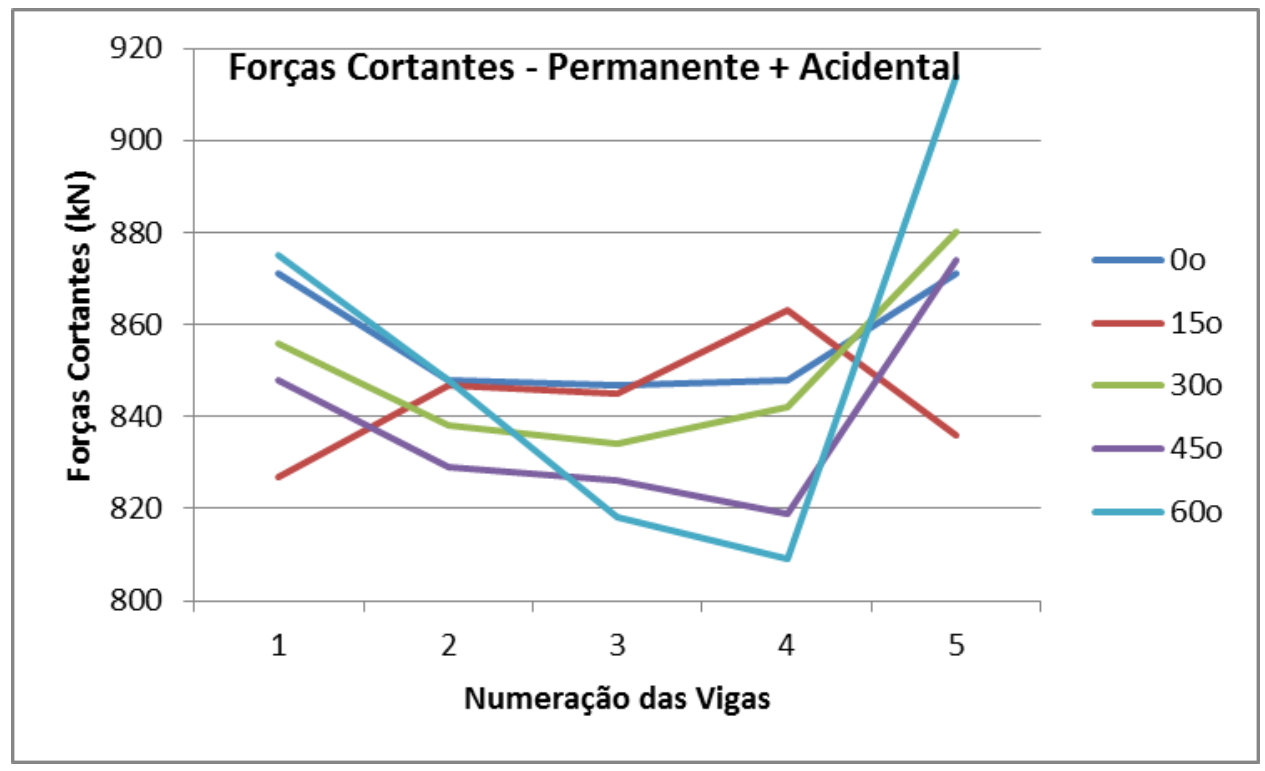

A seguir, serão apresentadas em curvas sobrepostas representado as solicitações para as diversas esconsidades estudadas e separando-as em carregamento permanente, envoltória das acidentais e soma dos dois carregamentos. 
Reações máximas em consequência de carregamento permanente:

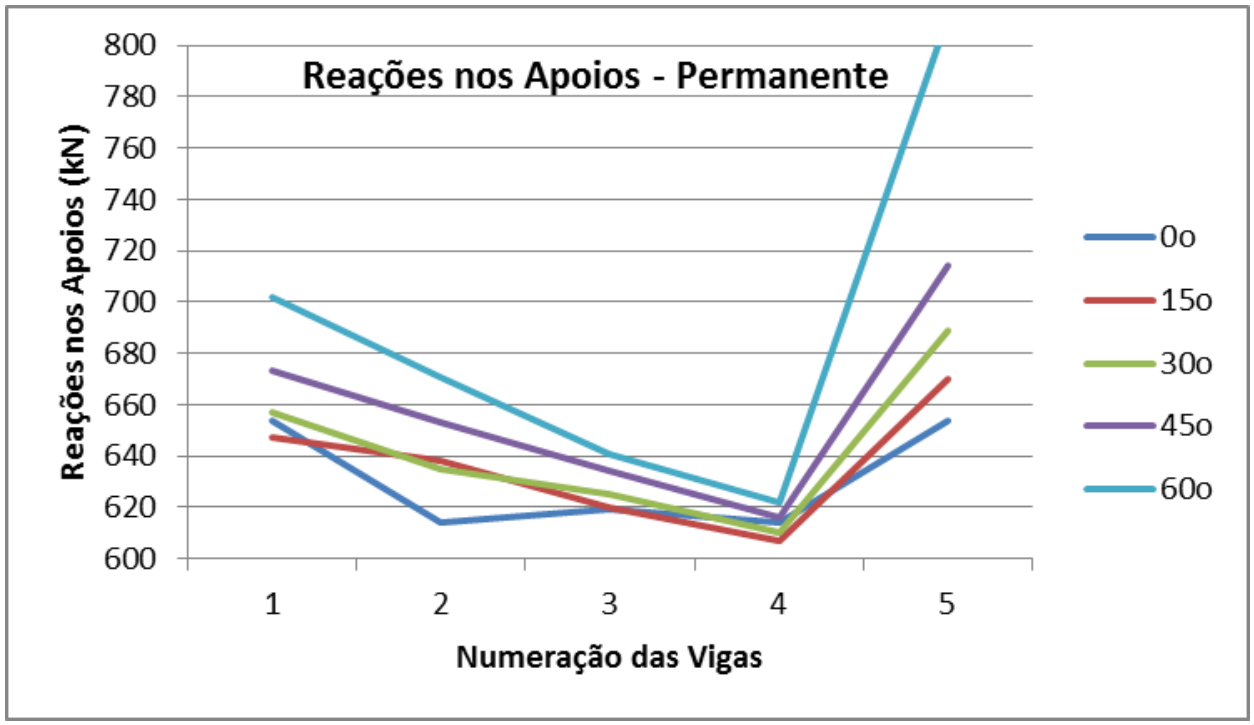

Reações máximas em consequência de carregamento móvel:

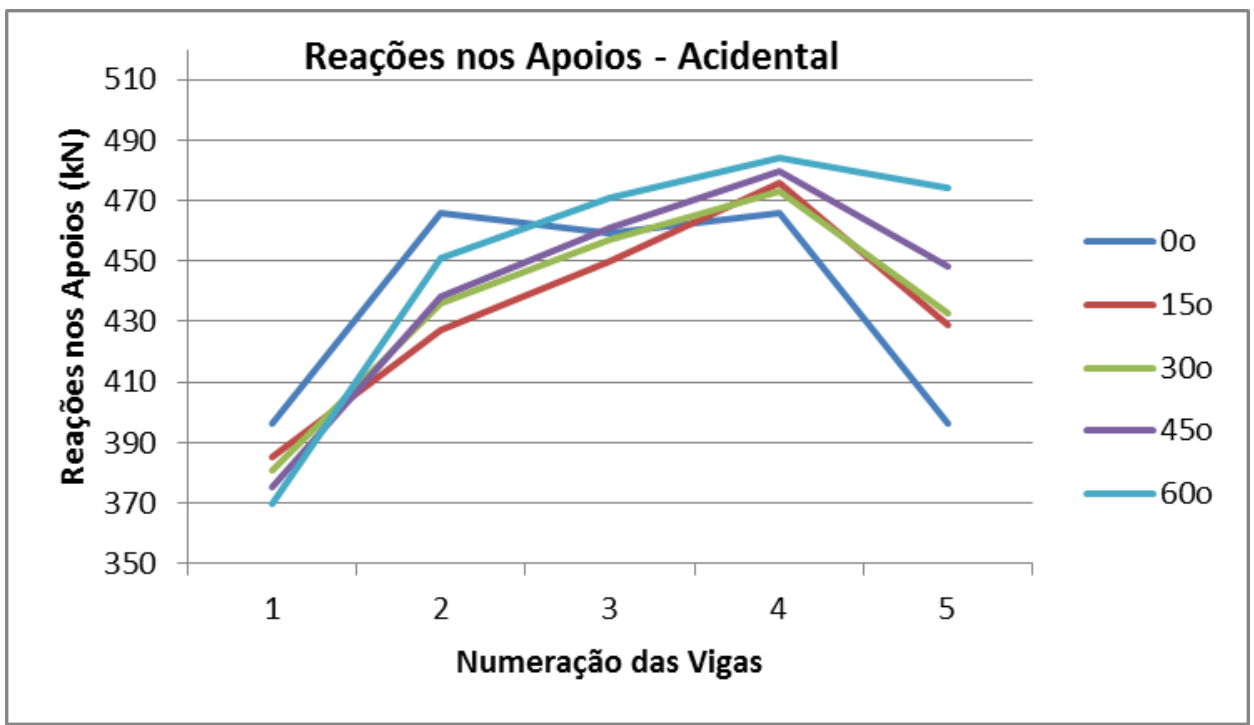

Somatória das reações permanentes e acidentais:

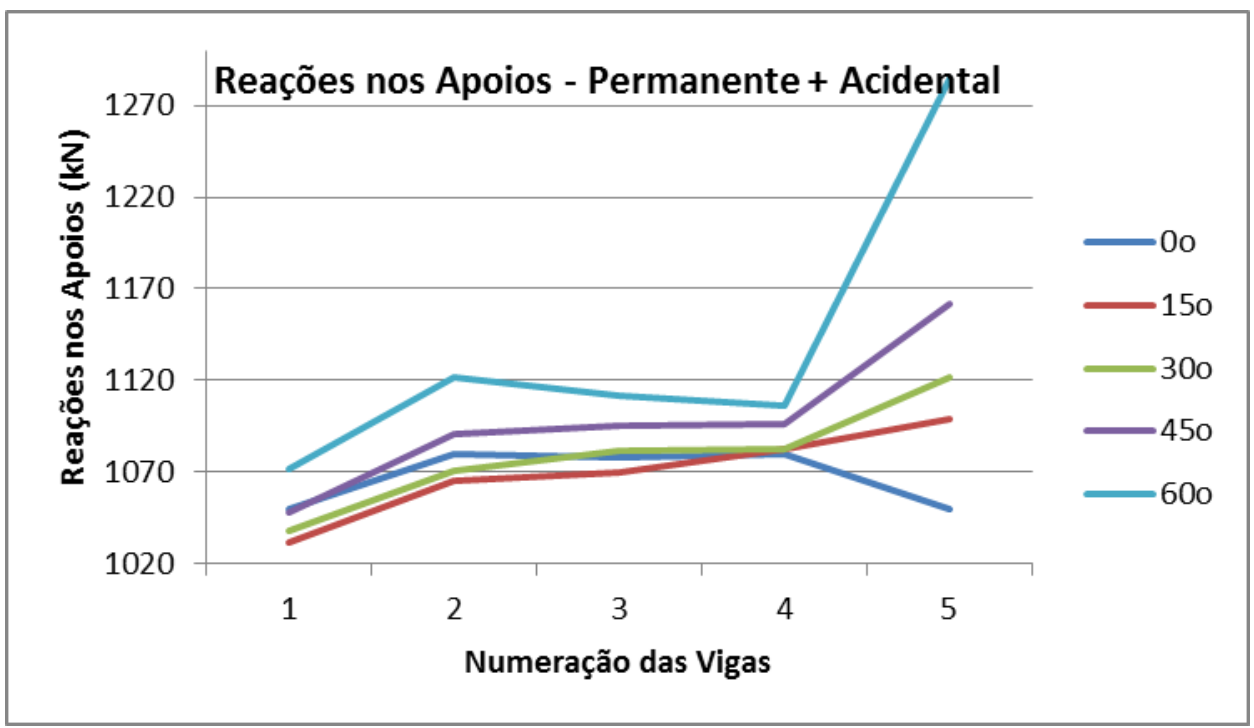




\subsubsection{Sem Transversina}

As solicitações apresentadas nesta seção estão presentes no Anexo F e nas tabelas abaixo, indicando os Momentos Fletores, Forças Cortantes, Momentos de Torsão e Reações nos apoios em consequência de carga permanente e carga móvel com o ângulo de esconsidade variando de $0^{\circ}$ a $60^{\circ}$, considerando apoios restritos às translações.

\begin{tabular}{|c|c|c|c|c|c|c|c|c|c|c|c|c|c|}
\hline \multirow{3}{*}{\multicolumn{2}{|c|}{$\begin{array}{c}\text { Grau de Esconsidade } \\
\text { Solicitações }\end{array}$}} & \multicolumn{4}{|c|}{$0^{\circ}$} & \multicolumn{4}{|c|}{$15^{\circ}$} & \multicolumn{4}{|c|}{$30^{\circ}$} \\
\hline & & \multirow{2}{*}{$\begin{array}{c}\text { Momento } \\
(\mathrm{kN} . \mathrm{m}) \\
\end{array}$} & \multirow{2}{*}{\begin{tabular}{|c|} 
Cortante \\
$(\mathrm{kN})$
\end{tabular}} & \multirow{2}{*}{$\begin{array}{l}\text { Torção } \\
\text { (kN.m) }\end{array}$} & \multirow{2}{*}{$\begin{array}{c}\text { Reação } \\
(k N)\end{array}$} & \multirow{2}{*}{\begin{tabular}{|c|} 
Momento \\
(kN.m) \\
\end{tabular}} & \multirow{2}{*}{\begin{tabular}{|c|} 
Cortante \\
$(\mathrm{kN})$ \\
\end{tabular}} & \multirow{2}{*}{$\begin{array}{l}\text { Torção } \\
\text { (kN.m) }\end{array}$} & \multirow{2}{*}{$\begin{array}{c}\text { Reação } \\
\text { (kN) }\end{array}$} & \multirow{2}{*}{\begin{tabular}{|c|} 
Momento \\
(kN.m)
\end{tabular}} & \multirow{2}{*}{\begin{tabular}{|c|} 
Cortante \\
$(\mathrm{kN})$
\end{tabular}} & \multirow{2}{*}{$\begin{array}{l}\text { Torção } \\
\text { (kN.m) }\end{array}$} & \multirow{2}{*}{$\begin{array}{c}\text { Reação } \\
(k N)\end{array}$} \\
\hline & & & & & & & & & & & & & \\
\hline \multirow{5}{*}{ Permanente } & V1 & 3730 & 548 & 5.8 & 644 & 3720 & 517 & 10 & 647 & 3720 & 529 & 18 & 651 \\
\hline & V2 & 3540 & 510 & 4.7 & 586 & 3520 & 508 & 8.5 & 593 & 3490 & 501 & 17 & 601 \\
\hline & V3 & 3480 & 513 & 0 & 597 & 3470 & 508 & 7.4 & 602 & 3430 & 498 & 16 & 607 \\
\hline & V4 & 3540 & 510 & 4.7 & 586 & 3520 & 502 & 8.5 & 587 & 3490 & 488 & 17 & 589 \\
\hline & V5 & 3730 & 548 & 5.8 & 644 & 3720 & 515 & 10 & 656 & 3720 & 552 & 18 & 673 \\
\hline \multirow{5}{*}{ Acidental } & V1 & 2340 & 340 & 24 & 396 & 2330 & 324 & 27 & 387 & 2320 & 327 & 30 & 379 \\
\hline & $\mathrm{V} 2$ & 2060 & 367 & 33 & 473 & 2050 & 363 & 34 & 467 & 2030 & 358 & 32 & 461 \\
\hline & V3 & 2100 & 364 & 29 & 465 & 2090 & 363 & 31 & 463 & 2060 & 360 & 30 & 463 \\
\hline & V4 & 2060 & 367 & 33 & 473 & 2050 & 373 & 36 & 474 & 2030 & 373 & 36 & 473 \\
\hline & V5 & 2340 & 340 & 24 & 396 & 2330 & 331 & 28 & 403 & 2320 & 351 & 30 & 411 \\
\hline
\end{tabular}

Tabela 27 - Solicitações nas vigas - ângulo de $0^{\circ}, 15^{\circ}$ e $30^{\circ}$

\begin{tabular}{|c|c|c|c|c|c|c|c|c|c|}
\hline \multirow{3}{*}{\multicolumn{2}{|c|}{$\begin{array}{c}\text { Grau de Esconsidade } \\
\text { Solicitações }\end{array}$}} & \multicolumn{4}{|c|}{$45^{\circ}$} & \multicolumn{4}{|c|}{$60^{\circ}$} \\
\hline & & \multirow{2}{*}{$\begin{array}{l}\text { Momento } \\
\text { (kN.m) }\end{array}$} & \multirow{2}{*}{$\begin{array}{c}\text { Cortante } \\
(\mathrm{kN})\end{array}$} & \multirow{2}{*}{$\begin{array}{l}\text { Torção } \\
\text { (kN.m) }\end{array}$} & \multirow{2}{*}{$\frac{\text { Reação }}{(k N)}$} & \multirow{2}{*}{$\frac{\text { Momento }}{(\mathrm{kN} . \mathrm{m})}$} & \multirow{2}{*}{\begin{tabular}{|c|} 
Cortante \\
$(\mathrm{kN})$ \\
\end{tabular}} & \multirow{2}{*}{$\begin{array}{l}\text { Torção } \\
\text { (kN.m) }\end{array}$} & \multirow{2}{*}{$\begin{array}{c}\text { Reação } \\
(\mathrm{kN}) \\
\end{array}$} \\
\hline & & & & & & & & & \\
\hline \multirow{5}{*}{ Permanente } & V1 & 3720 & 524 & 28 & 668 & 3700 & 549 & 53 & 696 \\
\hline & V2 & 3410 & 496 & 28 & 616 & 3180 & 508 & 46 & 635 \\
\hline & V3 & 3340 & 489 & 26 & 618 & 3110 & 492 & 42 & 631 \\
\hline & V4 & 3410 & 472 & 28 & 598 & 3180 & 468 & 46 & 611 \\
\hline & V5 & 3720 & 548 & 28 & 694 & 3700 & 586 & 53 & 778 \\
\hline \multirow{5}{*}{ Acidental } & V1 & 2290 & 318 & 39 & 371 & 2230 & 319 & 50 & 366 \\
\hline & $\mathrm{V} 2$ & 1970 & 354 & 36 & 455 & 1840 & 359 & 42 & 460 \\
\hline & V3 & 2000 & 362 & 32 & 465 & 1830 & 361 & 47 & 477 \\
\hline & V4 & 1970 & 376 & 36 & 477 & 1840 & 382 & 42 & 482 \\
\hline & V5 & 2290 & 354 & 34 & 425 & 2230 & 363 & 50 & 452 \\
\hline
\end{tabular}

Tabela 28 - Solicitações nas vigas - ângulo variando de $45^{\circ}$ e $60^{\circ}$ 
A seguir, serão apresentados em curvas sobrepostas representado os momentos fletores para as diversas esconsidades estudadas e separando-os em carregamento permanente, móvel e soma dos dois carregamentos.

Momentos Fletores em consequência de carregamento permanente:

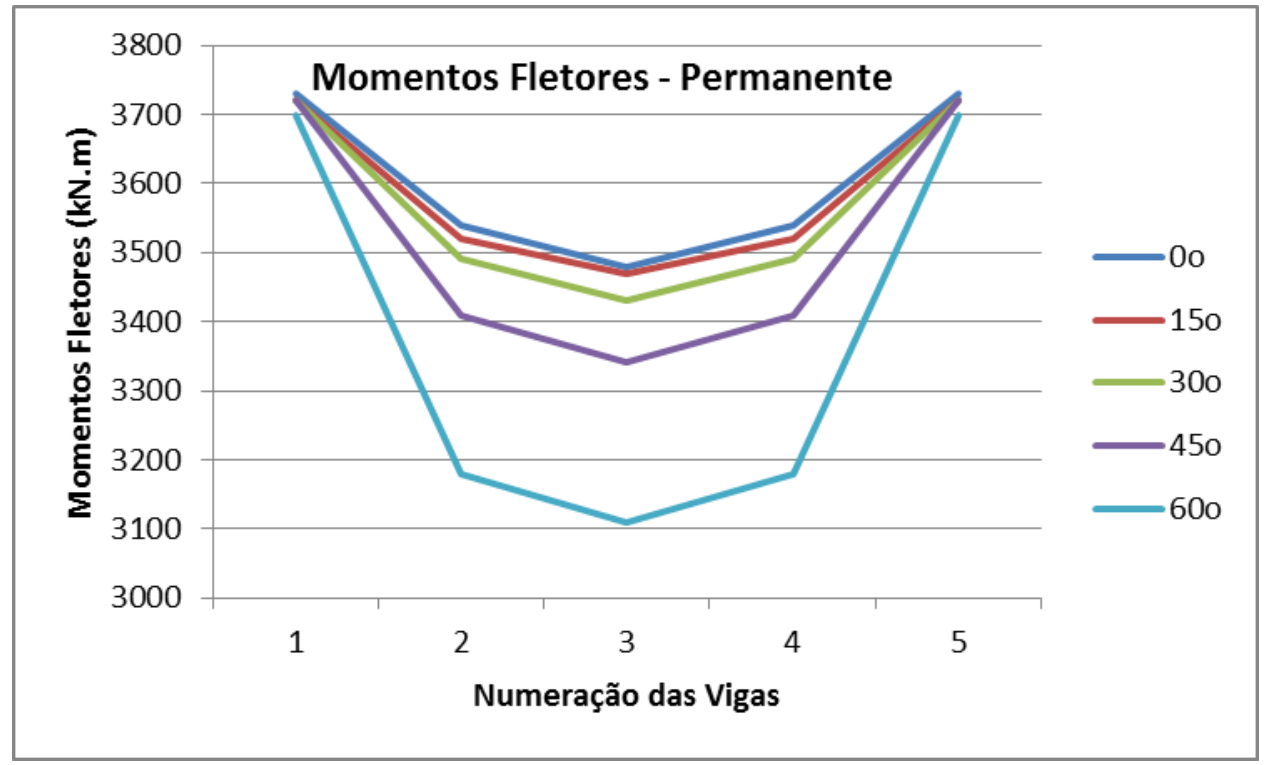

Momentos Fletores em consequência de carregamento móvel:

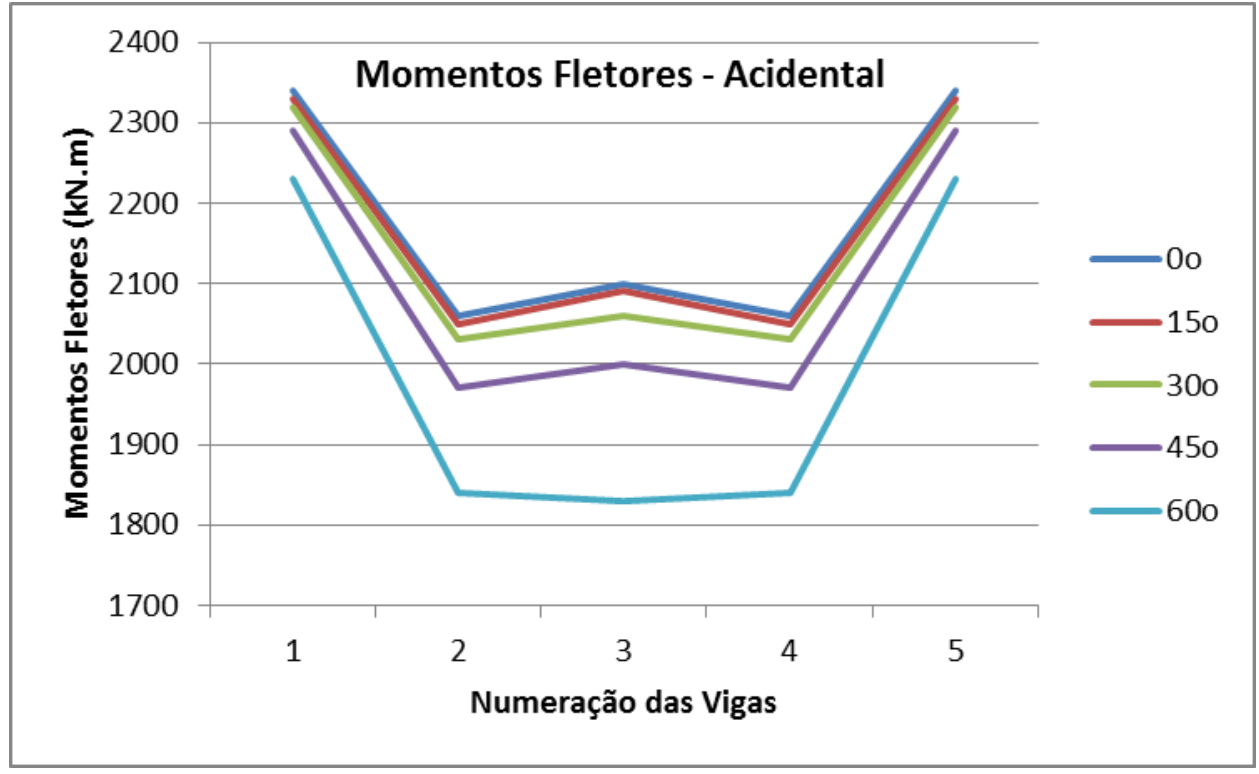


Somatória dos Momentos Fletores em consequência de cargas permanentes e acidentais:

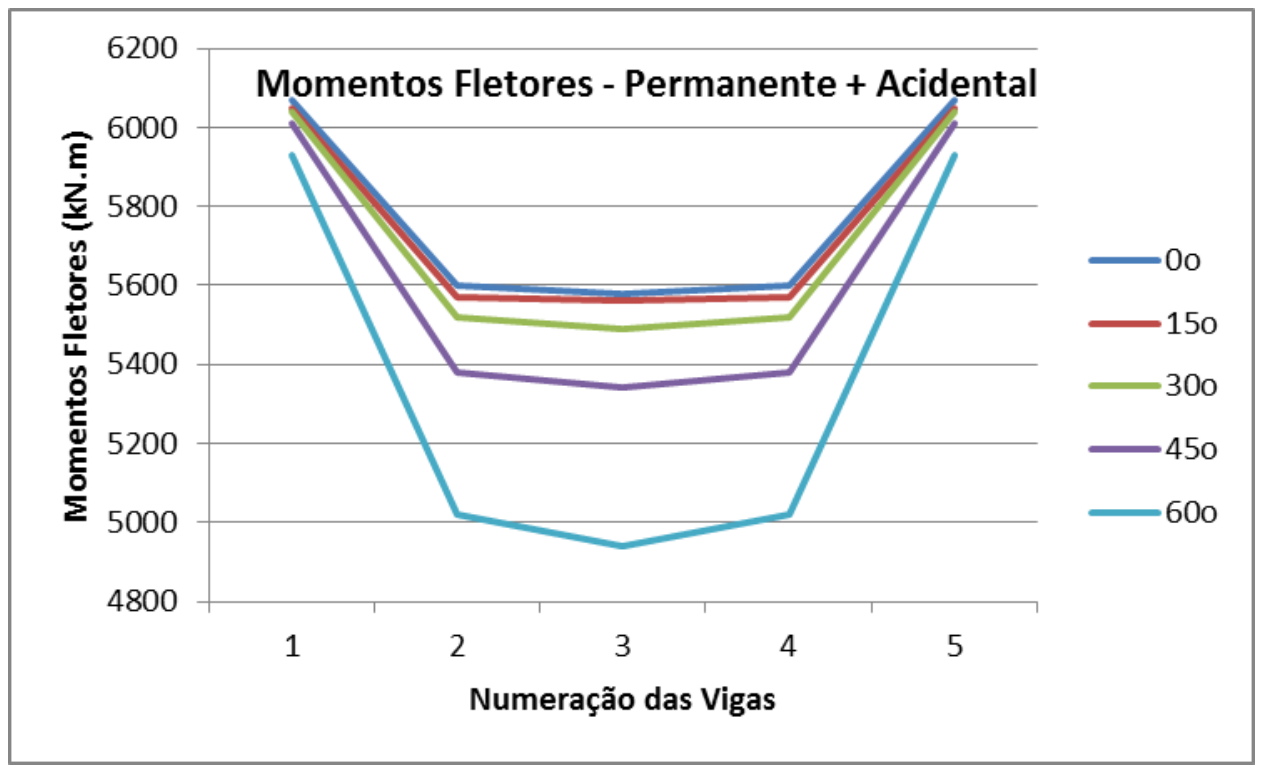

A seguir, serão apresentadas em curvas sobrepostas representado as forças cortantes para as diversas esconsidades estudadas e separando-as em carregamento permanente, móvel e soma dos dois carregamentos.

Forças Cortantes em consequência de carregamento permanente:

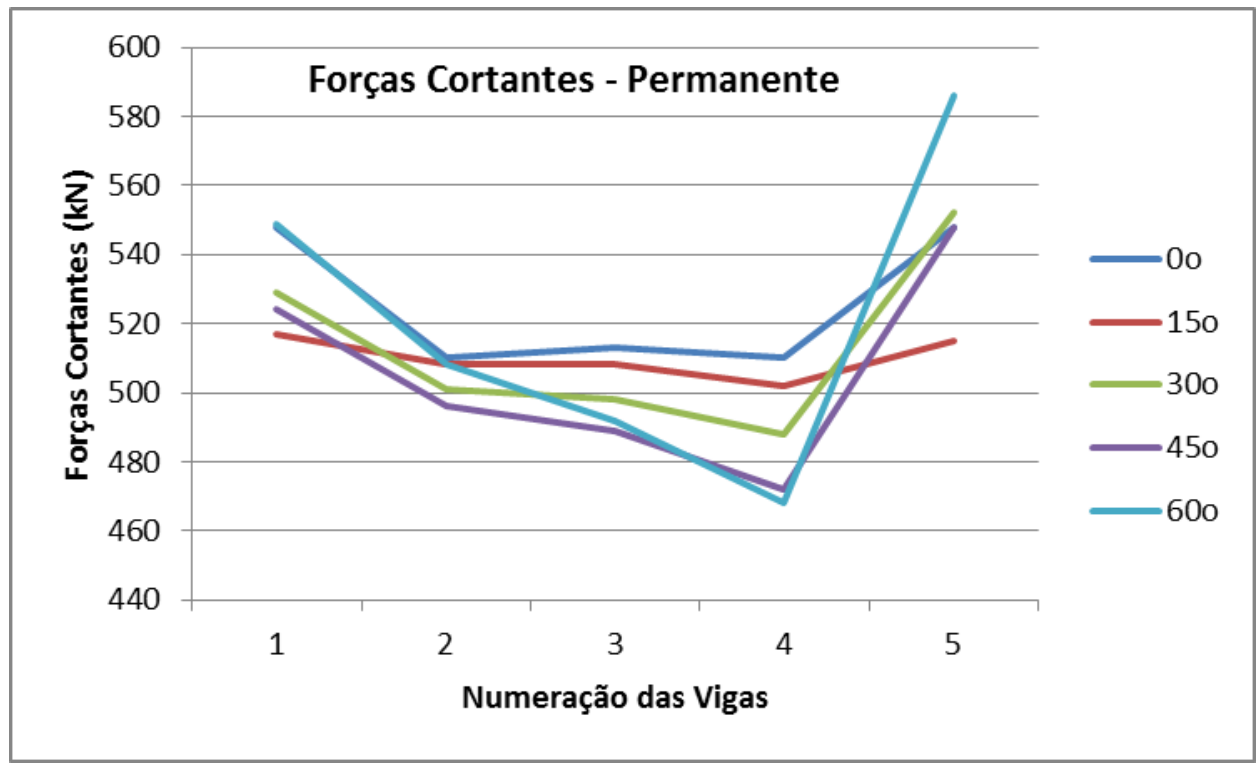


Forças Cortantes em consequência de carregamento móvel:

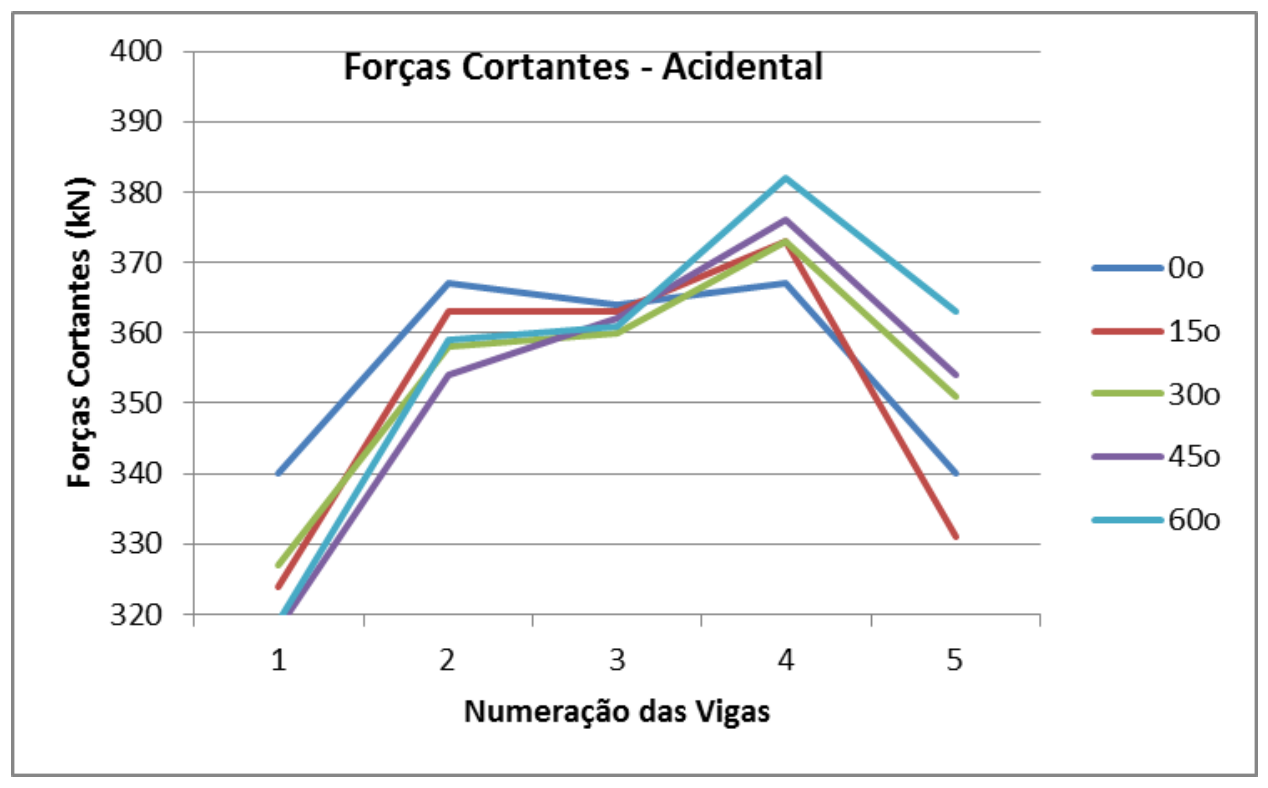

Somatória dos Forças Cortantes em consequência de cargas permanentes e acidentais:

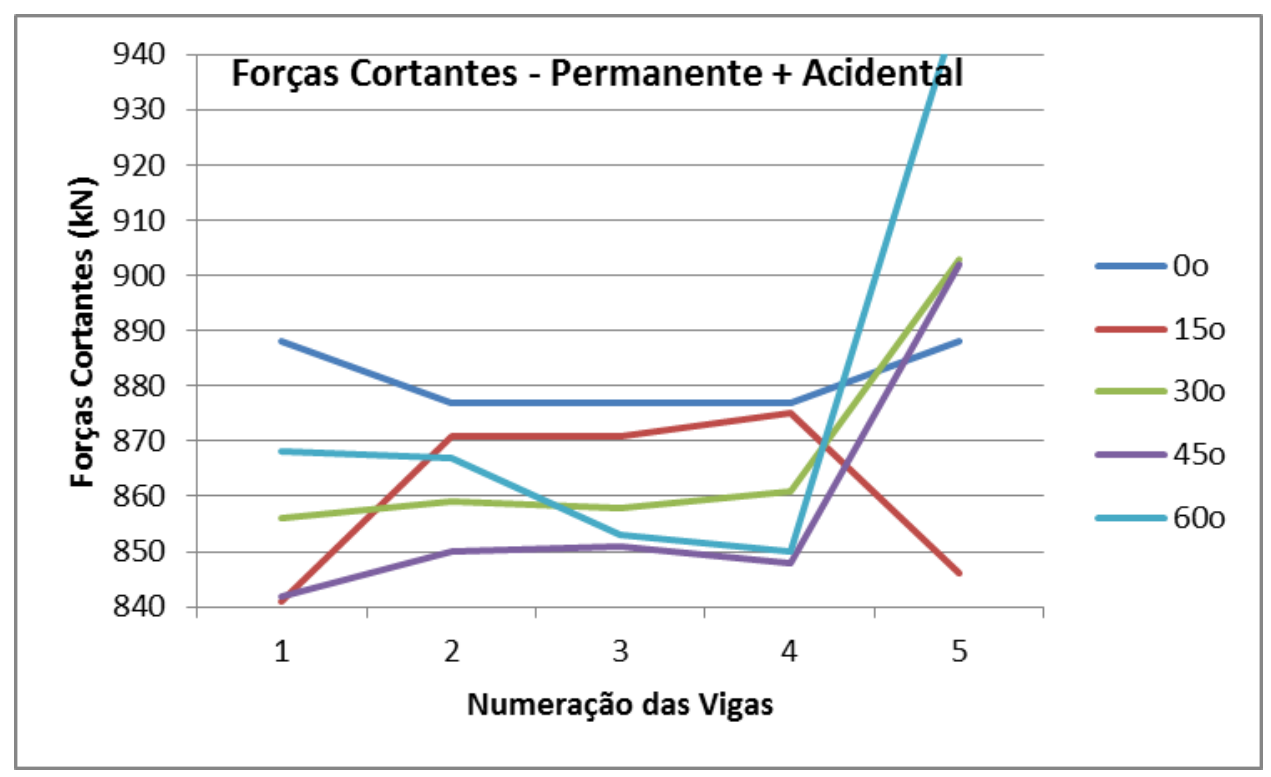

A seguir, serão apresentadas em curvas sobrepostas representado as solicitações para as diversas esconsidades estudadas e separando-as em carregamento permanente, envoltória dos acidentais e soma dos dois carregamentos. 
Reações máximas em consequência de carregamento permanente:

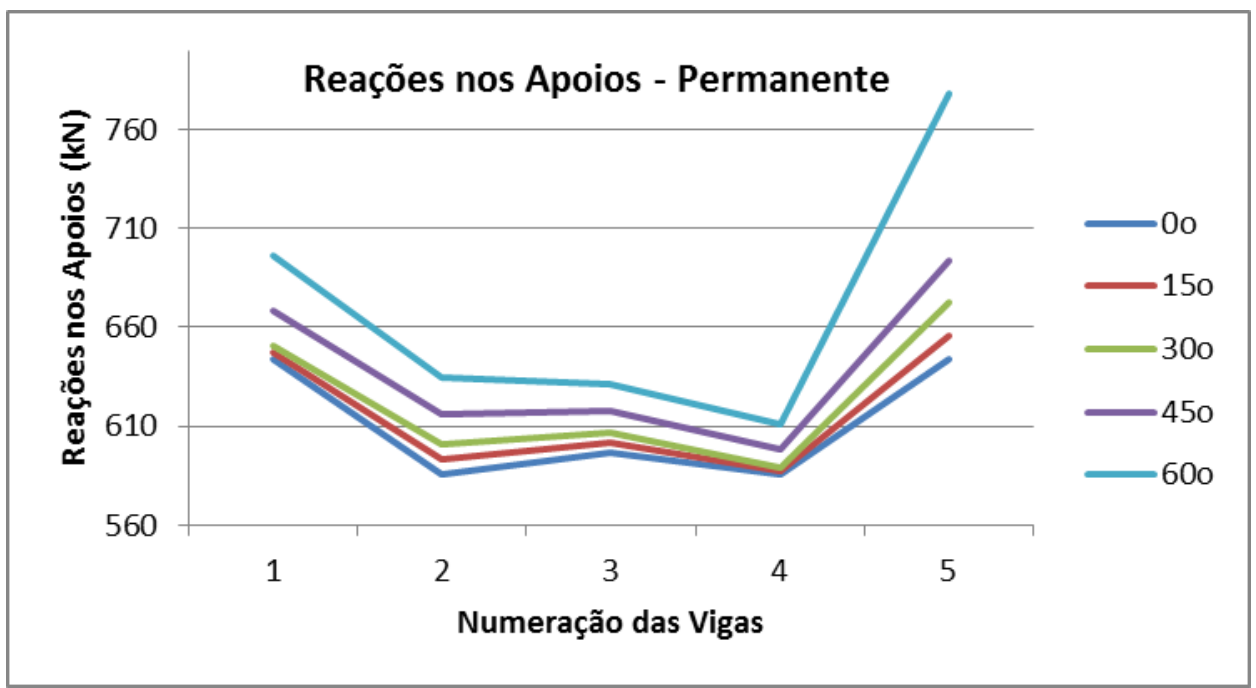

Reações máximas em consequência de carregamento móvel:

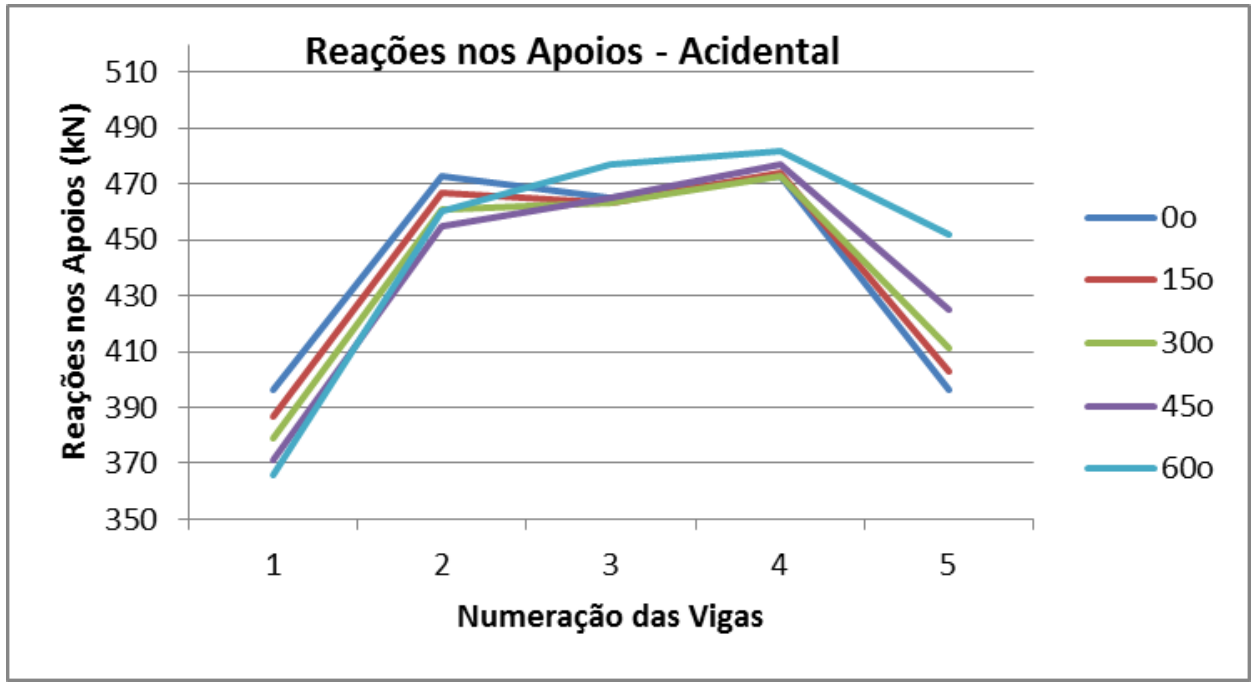

Somatória das reações permanentes e acidentais:

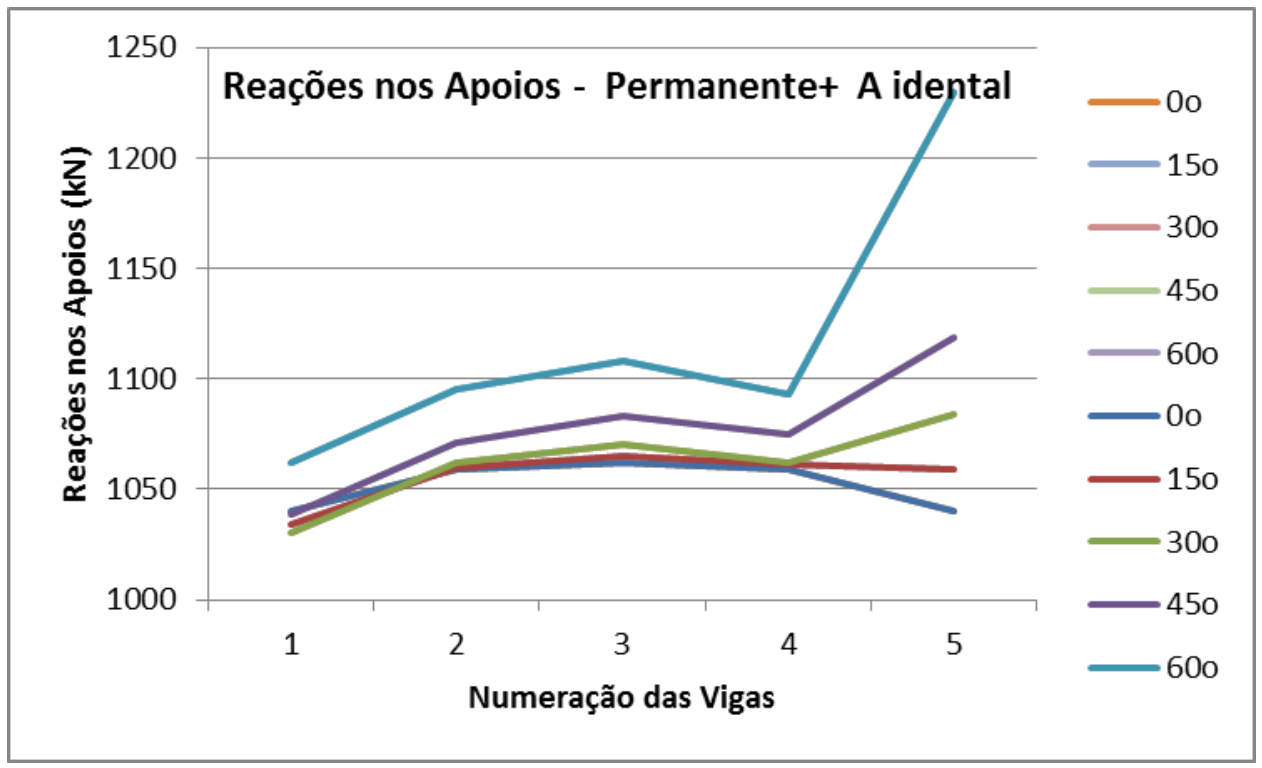




\subsubsection{Análise da redução do balanço longitudinal}

A escolha de adotar longarinas com o mesmo comprimento em todos os graus de esconsidade fez com que surgisse um balanço longitudinal em todas as longarinas e quanto maior o grau de esconsidade, maior o balanço.

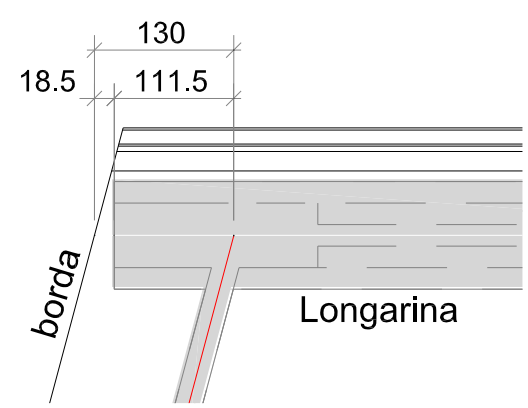

Figura 27 - Balanço Longitudinal - 15ำ

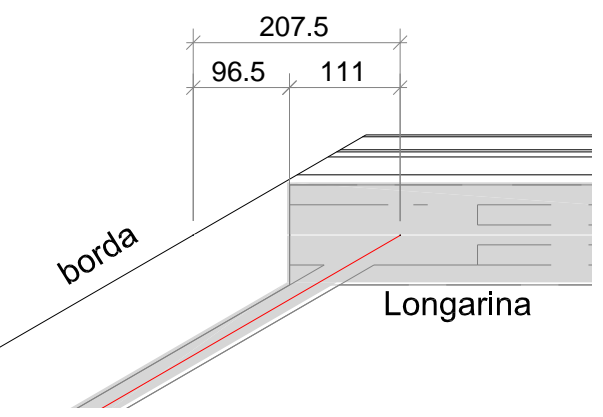

Figura 28 - Balanço Longitudinal $-60^{\circ}$

Ao comparar as soluções com transversina esconsa, transversina normal e sem tranversina, esperava-se uma maior diminuição no momento negativo e da força cortante junto ao canto de ângulo obtuso nesta ordem.

Com o intuito de verificar a interferência deste balanço longitudinal nos resultados, realizou-se o processamento da grelha com $60^{\circ}$ de esconsidade para os três modelos sem considerar o balanço. A seguir serão apresentados os diagramas de Momentos Fletores, Força Cortante e Momentos de Torção da longarina extrema.

Transversina esconsa

\section{Permanentes}
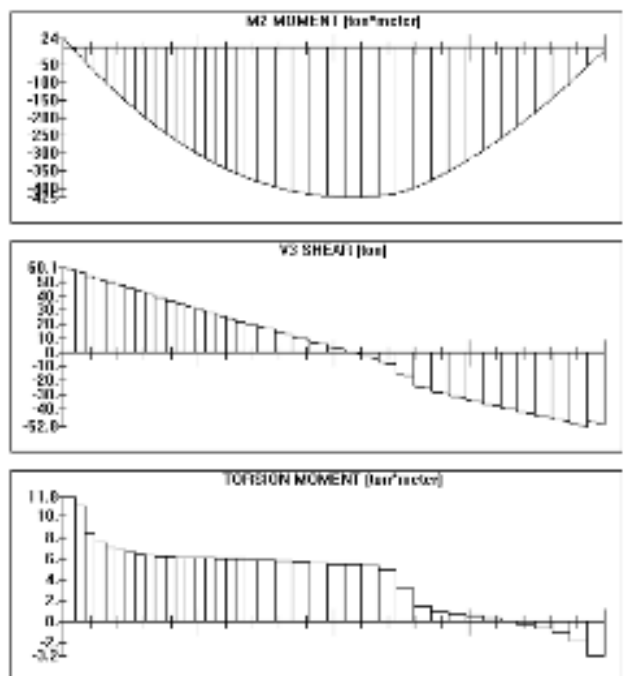

Envoltória das Acidentais

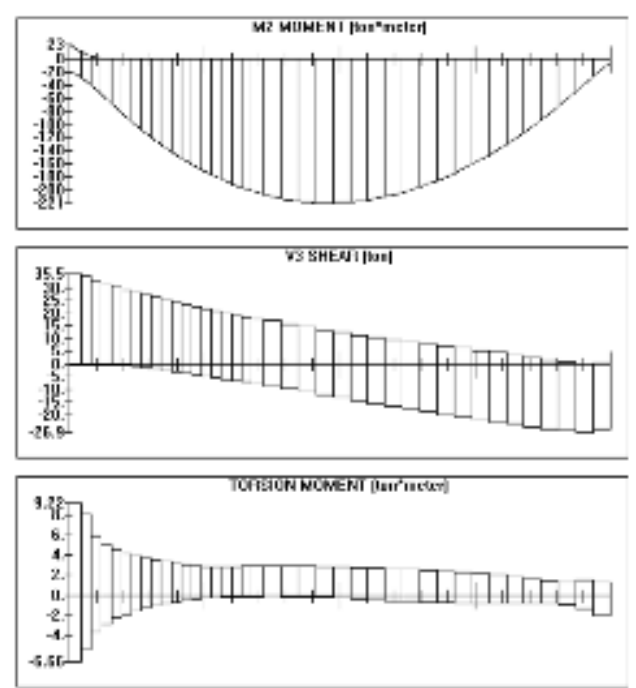


$\underline{\text { Transversina normal a longarina }}$

\section{Permanentes}
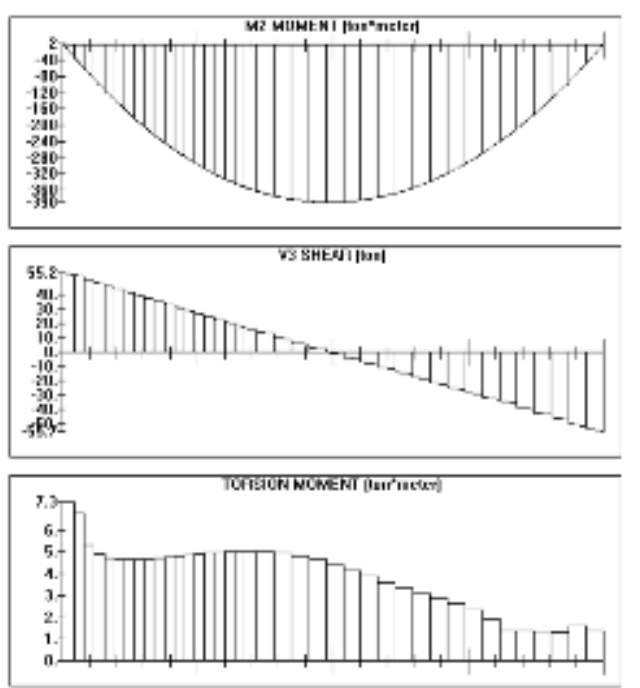

$\underline{\text { Sem transversina }}$

\section{Permanentes}
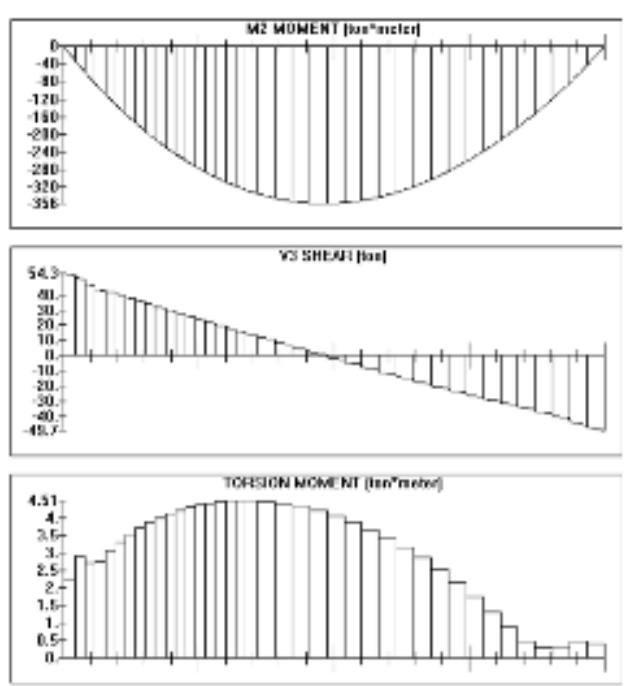

Envoltória das Acidentais
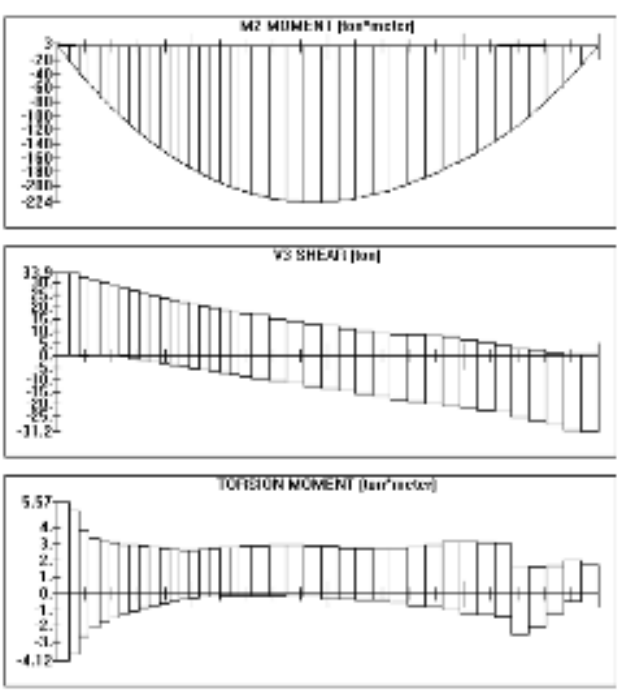

\section{Envoltória das Acidentais}

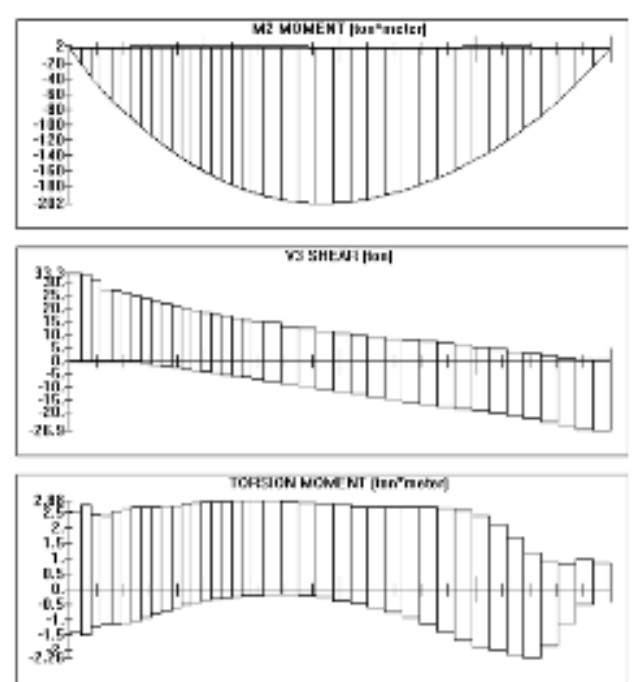




\section{CONCLUSÃO}

Vale ressaltar que as conclusões apresentadas a seguir são restritas aos casos estudados e apresentados neste texto: lajes com o mesmo valor de largura e extensão da borda livre (relação b/la $=1,0$ ) e grelhas com $12,0 \mathrm{~m}$ de largura e longarinas com $29,25 \mathrm{~m}$.

\section{$5.1 \quad$ Lajes}

No caso dos tabuleiros de pontes esconsas em laje, nos três métodos de cálculo analisados, observou-se uma pequena variação nos momentos principais, sendo que, no Rüsch, os valores se apresentam, na maioria dos casos, mais conservadores quando comparados com qualquer das duas modelagens em elementos finitos.

Sabe-se que as tabelas foram elaboradas através das deformações resultantes em ensaios com placas de gesso, que, mesmo possuindo valores de contração lateral (efeito de Poisson) próximos ao do concreto, podem resultar em divergências nos valores. Além disso, os equipamentos utilizados na época para medir as deformações não apresentavam a mesma precisão dos equipamentos utilizados atualmente.

Inicialmente pode-se imaginar que a determinação dos esforços solicitantes através da modelagem em elementos finitos resultará em uma estrutura mais econômica, mas vale ressaltar a importância de se discretizar e carregar o modelo de uma forma correta, sabendo que, carregar todo o tabuleiro com a carga móvel, levará às solicitações máximas.

Os gráficos acima apresentados demonstram que, mesmo carregando a estrutura da mesma maneira e utilizando o mesmo método de cálculo (elementos finitos), os resultados são próximos, mas diferentes, indicando que o software e o modo de discretização influenciam no resultado.

As análises realizadas também demonstram uma pequena variação dos esforços de $0^{\circ}$ a $10^{\circ}$ de esconsidade, indicando que, até $15^{\circ}$, o cálculo da laje pode ser simplificado para uma ponte reta (ortogonal). 


\subsection{Grelhas}

No caso dos tabuleiros de pontes esconsas em grelha, notou-se a diminuição dos momentos positivos e o aumento do momento negativo na viga junto ao canto obtuso, conforme o grau de esconsidade vai aumentando para os três casos estudados (transversina esconsa, transversina normal e sem transversina).

Observou-se também um acréscimo de aproximadamente $20 \%$ nas reações de apoio junto ao canto obtuso, justificando a preocupação com o dimensionamento do apoio nesta região.

Outro aspecto importante a ser destacado foi o aumento da força cortante da viga junto ao canto obtuso. Quanto maior o grau de esconsidade, maior a força cortante nesta região, quando comparada às vigas intermediárias.

Ao comparar as soluções com transversina esconsa, transversina normal e sem tranversina, esperava-se uma redução do efeito da esconsidade (aumento de momento negativo e acréscimo da cortante junto ao ângulo obtuso). Ocorre que, em consequência do grande balanço existente para fora do apoio até a borda (aproximadamente 2,0m), esse acréscimo não foi observado.

A análise do caso com esconsidade de $60^{\circ}$ sem balanço mostrou o resultado esperado. 
(1) HUO, X.S., ZHANNG, Q. Distribution of live load reaction at piers of skewed continuous prestressed concrete bridges. 3rd FIB International Congress, Washington, D.C., 2010.

(2) LEONHARDT, F. Construções de concreto. Rio de Janeiro: Editora Interciência, 1979. v. 4 e v. 6.

(3) EL DEBS, M.K.; TAKEYA, T. Introdução às pontes de concreto - texto provisório de apoio à disciplina SET412. Escola de Engenharia de São Carlos Universidade de São Paulo, São Carlos, 2007.

(4) MATAR, E. E., Pontes em laje. 1985. Dissertação (Mestrado) - Escola Politécnica, Universidade de São Paulo, São Paulo, 1985.

(5) $\mathrm{RÜSCH}, \mathrm{H}$., Berechnungstafeln für Schiefwinklige Fahrbahnplatten von Strassenbrücken. Berlin: Verlag von Withelm Ernst \& Sohn, 1967.

(6) ALVES, E.V.; ALMEIDA, S.M.F.; JUDICE, F.M.S. Métodos de análise estrutural de tabuleiros de pontes em vigas múltiplas de concreto protendido. Niterói: Engevista, 2004.

(7) ASSOCIAÇÃO BRASILEIRA DE NORMAS TÉCNICAS (ABNT). Carga móvel em ponte rodoviária e passarela de pedestres- NBR-7188. Rio de Janeiro, 1984.

(8) ASSOCIAÇÃO BRASILEIRA DE NORMAS TÉCNICAS (ABNT). Projeto e execução de pontes em concreto armado e protendido - NBR-7187. Rio de Janeiro, 1987.

(9) SORIANO, H. L.. Método de Elementos Finitos em Análise de Estruturas. São Paulo: Editora da Universidade de São Paulo, 2003.

(10) GUPTA, T.; MISRA, A. Effect on support reactions of T-beam skew bridge decks - ARPN Journal of Engineering and Applied Sciences, v. 2, 2007.

(11) HARBA, I. S. I. Effect of skew angle on behavior of simply supported R. C. T-beam bridge decks - ARPN Journal of Engineering and Applied Sciences, v. 6, 2011. 


\section{ANEXO A - LAJE - APOIOS FIXOS E TREM TIPO}

Atenção: O programa Strap apresenta sinais invertidos em relação à convenção, portanto, quando for apresentado um valor negativo (-) abaixo, refere-se ao momento fletor positivo (+). No caso de reações, o sinal (+) representa compressão e o sinal (-) representa tração.

\section{HOMOGENEIZADO}

Solicitações das Lajes com $0^{\circ}$ de esconsidade (tf e tf.m/m) Momentos Fletores

Permanente:

Longitudinal $(\mathrm{x})$

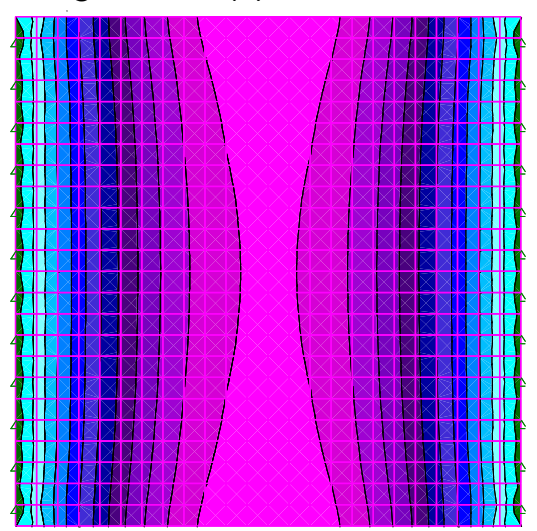

Longitudinal Mínimo (x)

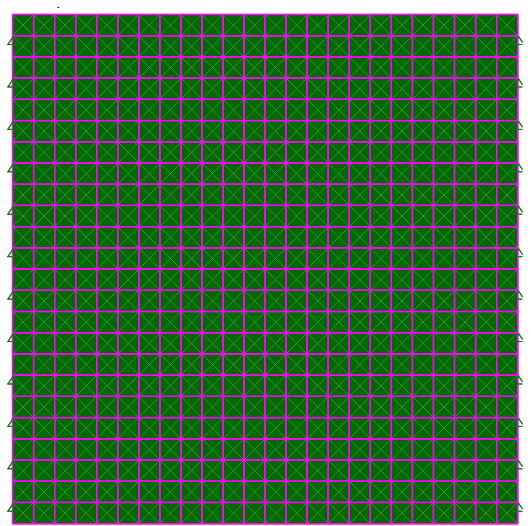

Transversal Mínimo (y)
Transversal (y)

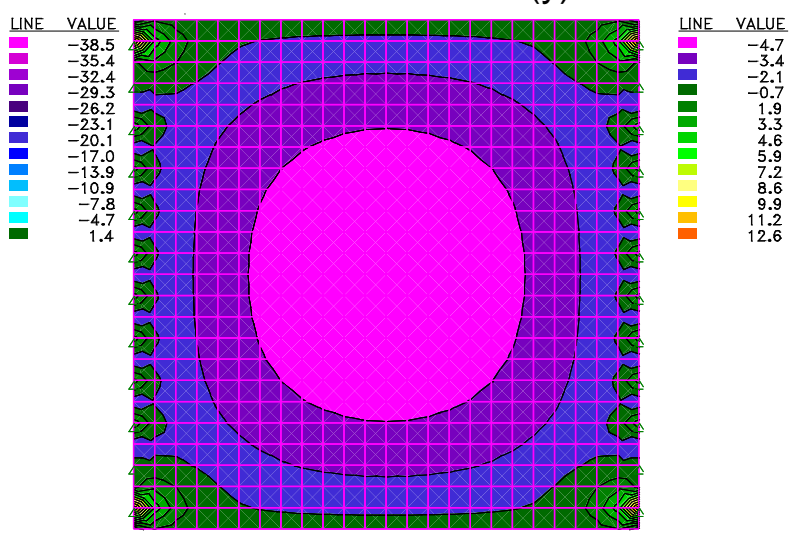

Longitudinal Máximo (x)

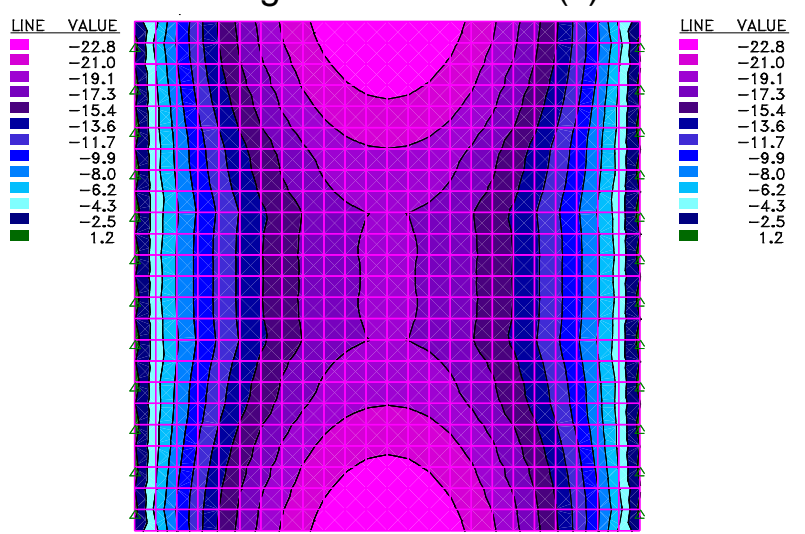

Tranversal Máximo (y) 


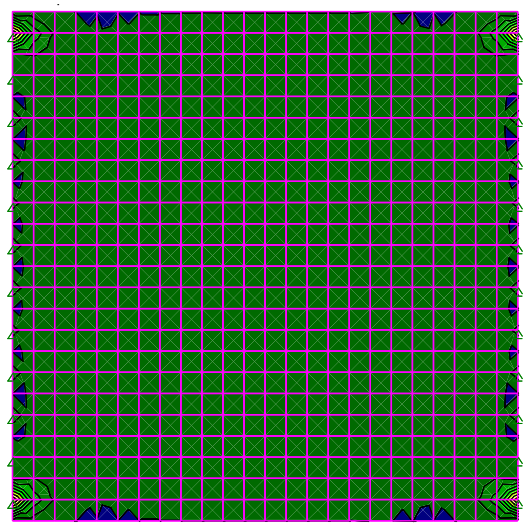

Reações nos Apoios

Permanentes

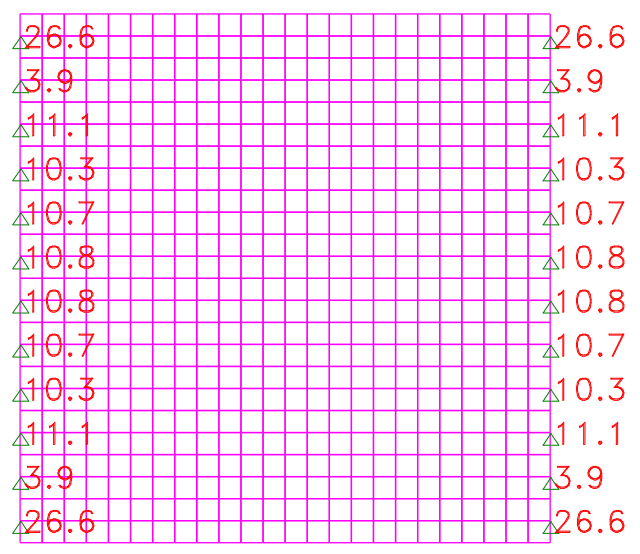

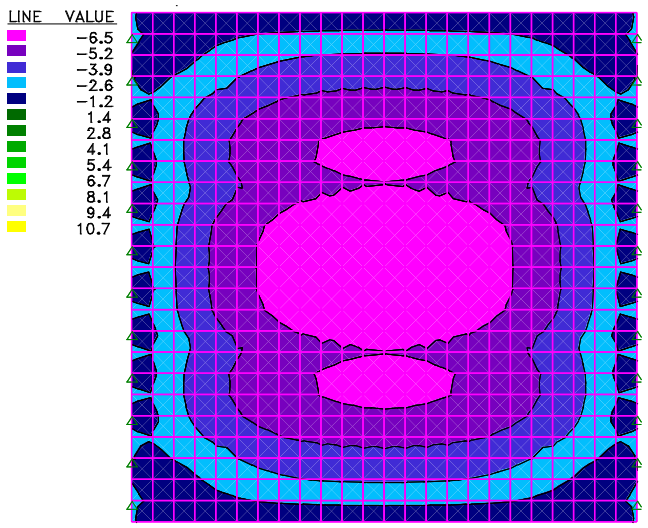

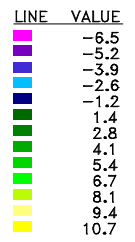

\section{Solicitações das Lajes com $5^{\circ}$ de esconsidade}

\section{Momentos Fletores}

\section{Permanente:}

Longitudinal $(\mathrm{x})$

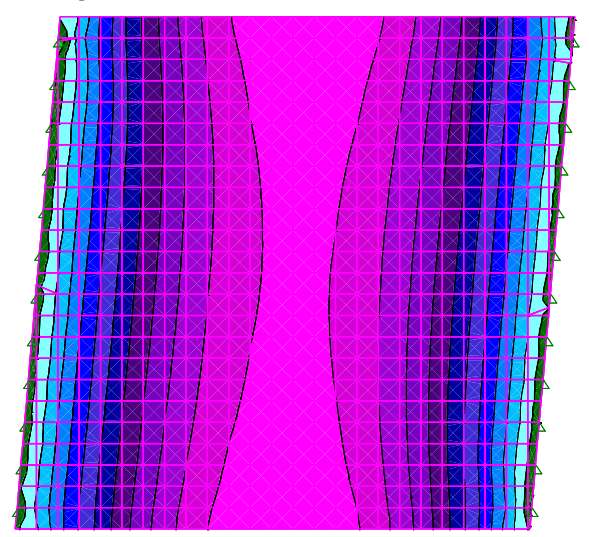

Longitudinal Mínimo (x)
Envoltória das acidentais

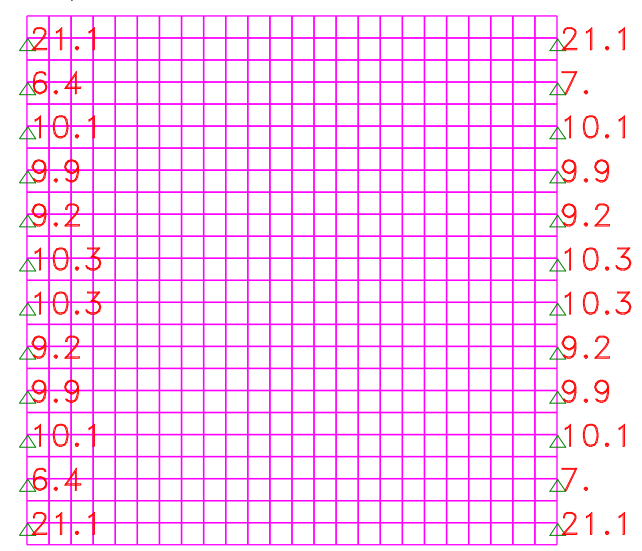



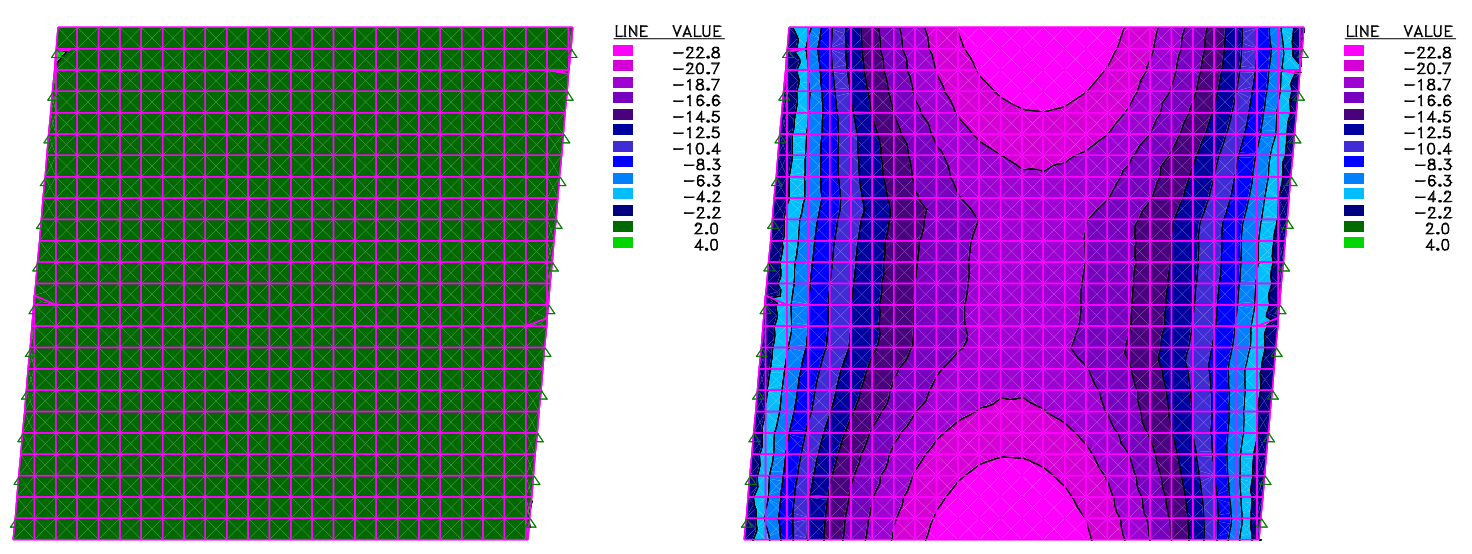
Transversal Mínimo (y)

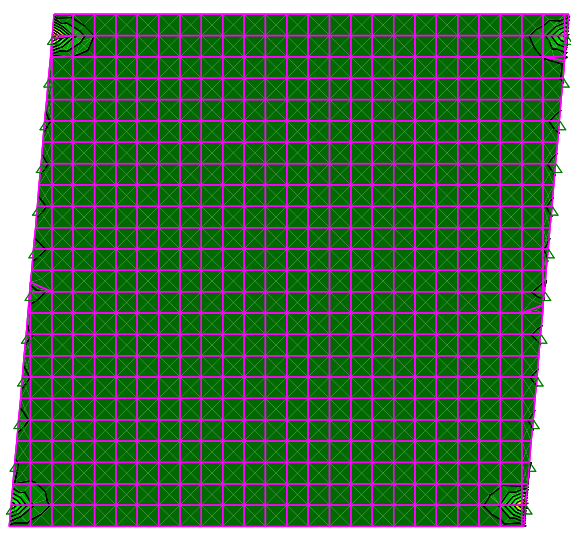

\section{Reações nos Apoios}

Permanentes

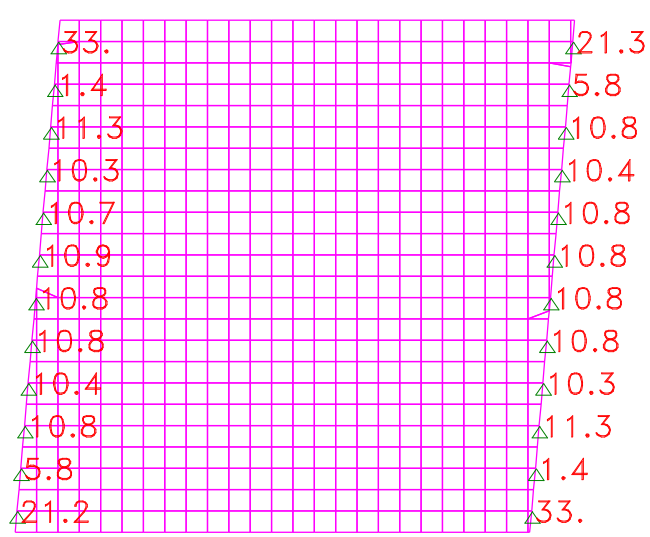

Tranversal Máximo (y)

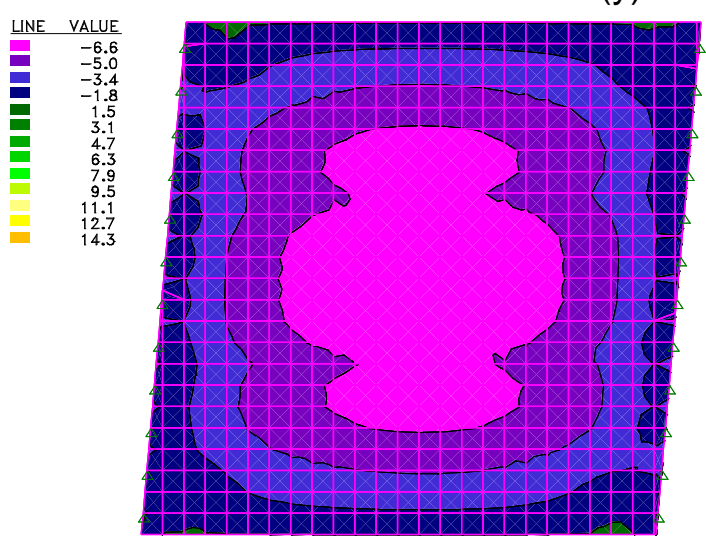

LINE VALUE
-6.6
-50
-3.4
-1.8
1.5
3.1
4.7
63
7.9
9.9
95
11.1
127
14.3
Envoltória das acidentais

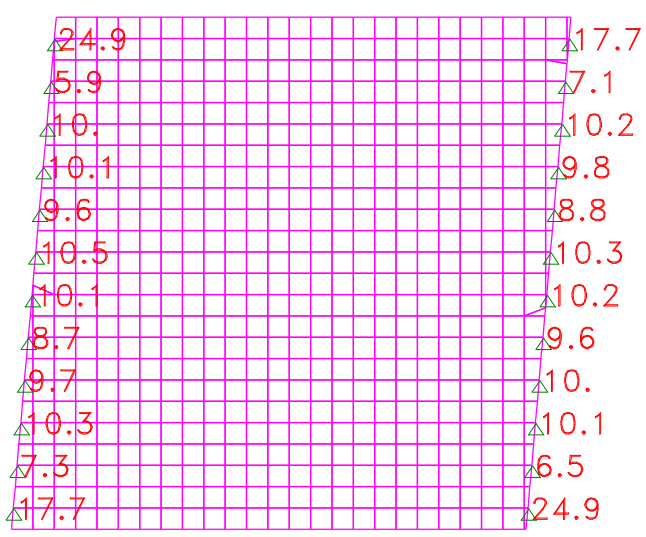


Solicitações das Lajes com $10^{\circ}$ de esconsidade

\section{Momentos Fletores}

Permanente:

Longitudinal $(x)$
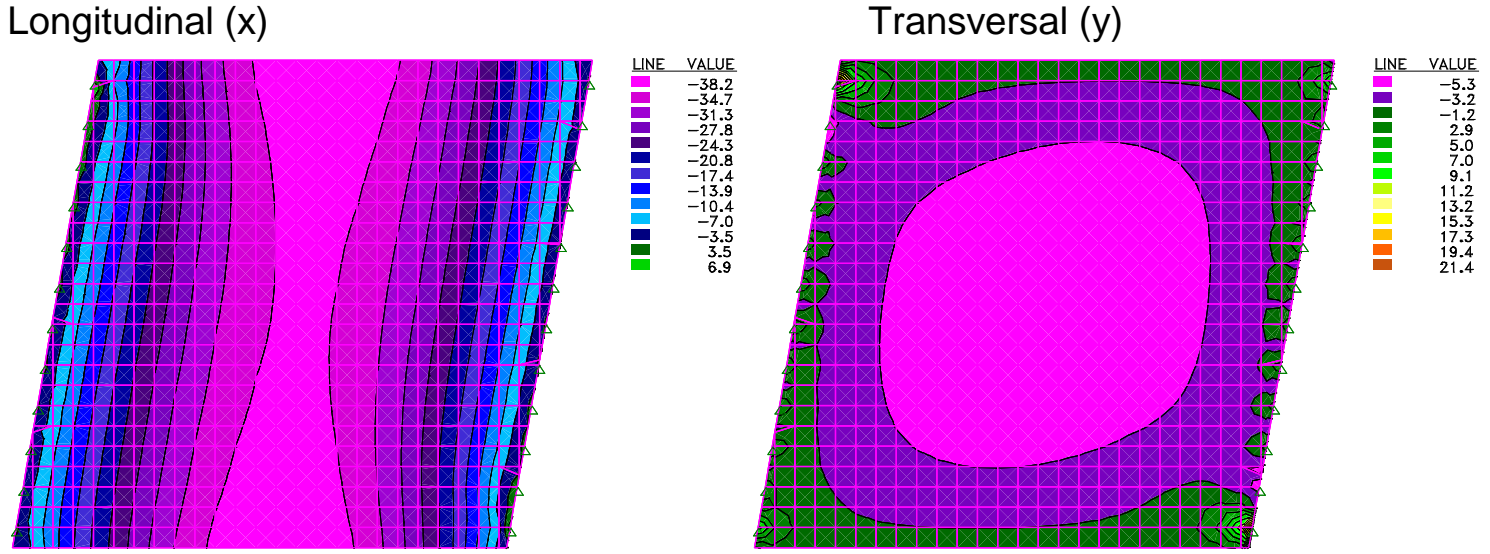

Longitudinal Mínimo (x)

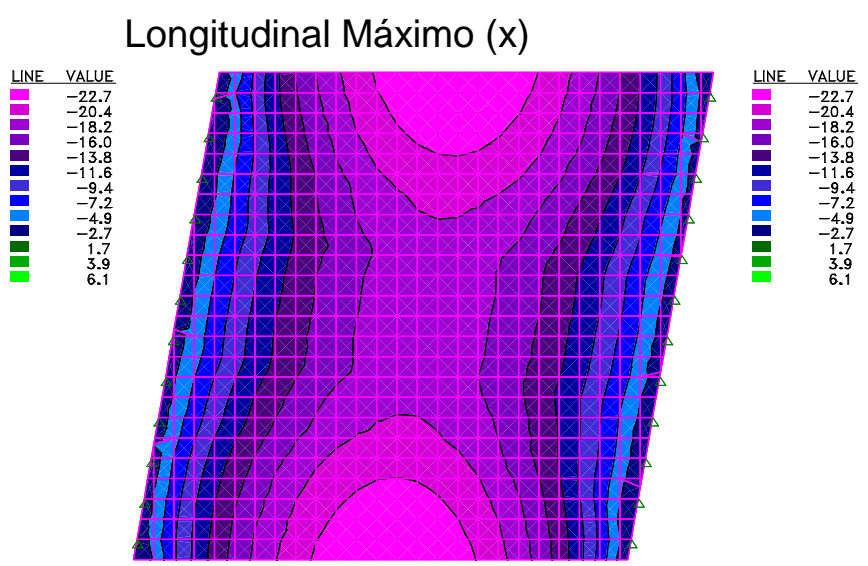

Transversal Mínimo (y)
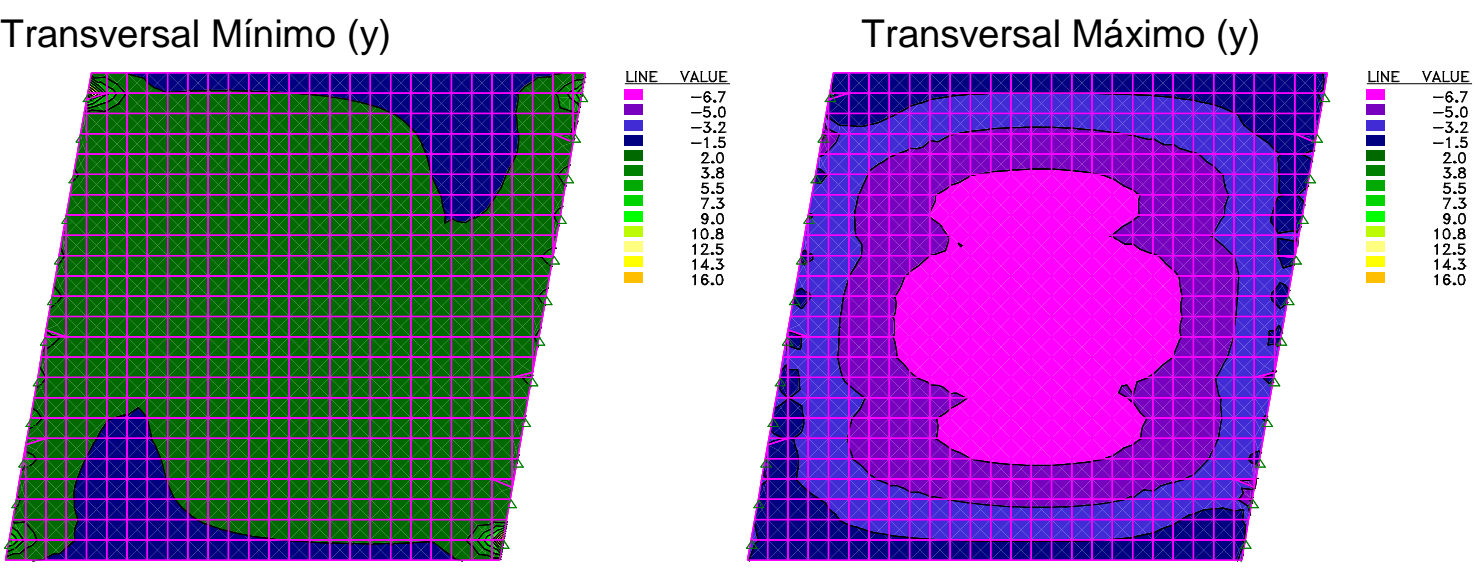


\section{Reações nos Apoios}

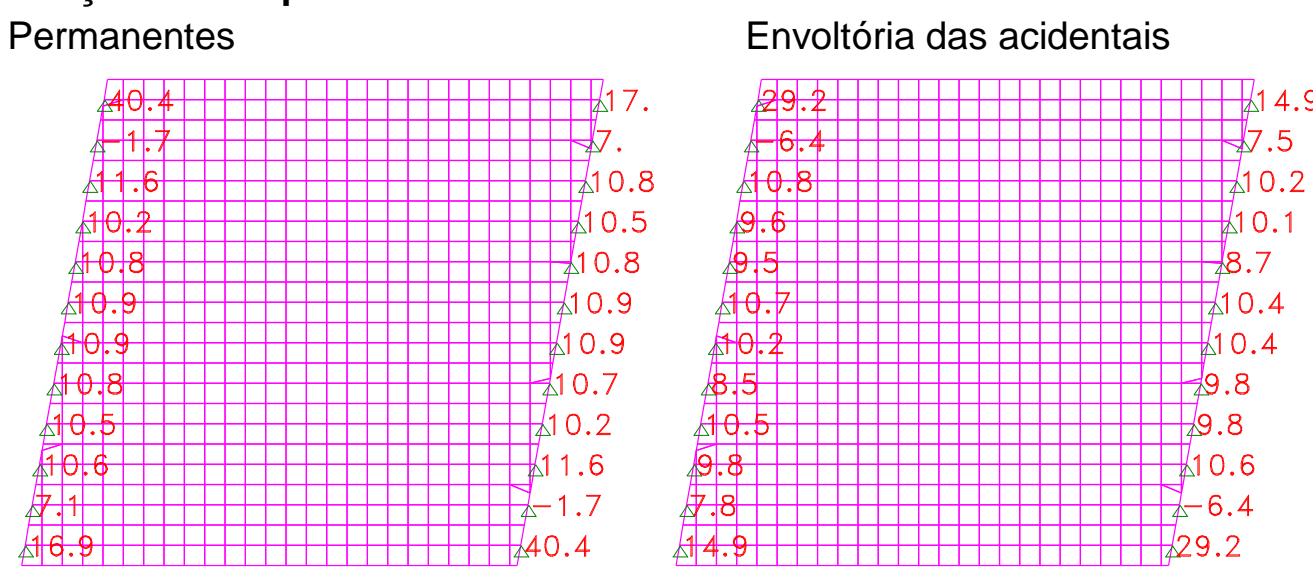

Solicitações das Lajes com $15^{\circ}$ de esconsidade

\section{Momentos Fletores}

Permanente:

Longitudinal $(x)$
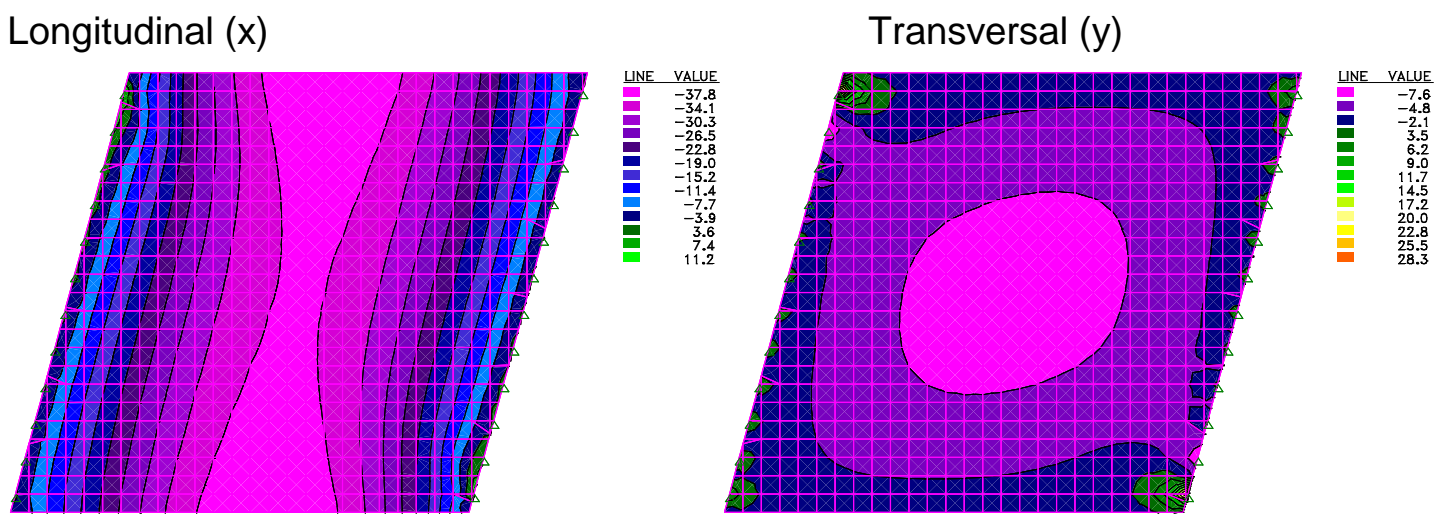

Longitudinal Mínimo (x)
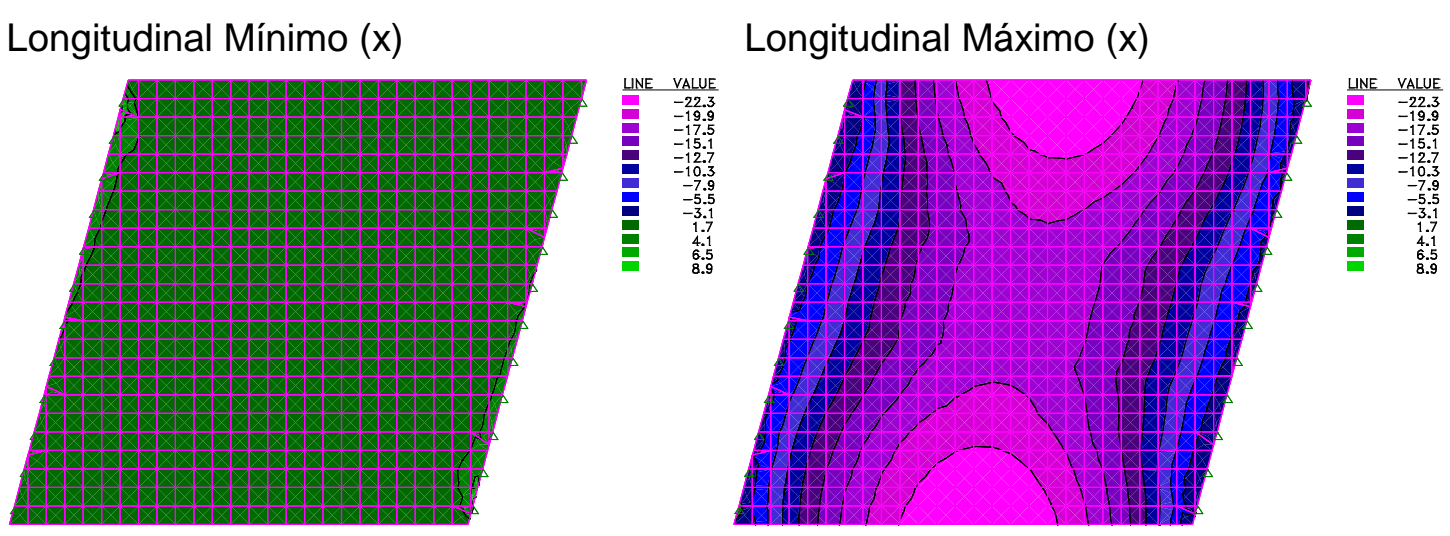
Transversal Mínimo (y)

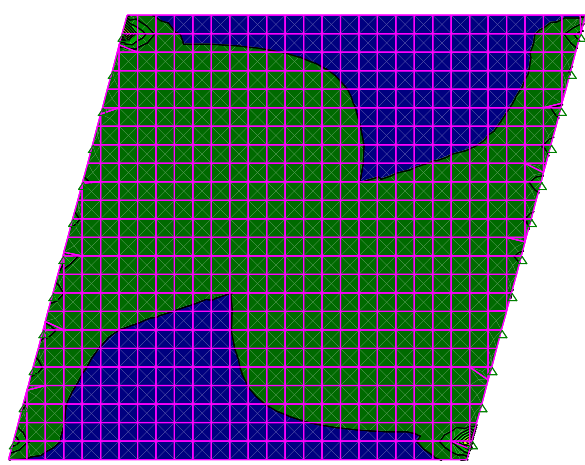

Reações nos Apoios

Permanentes

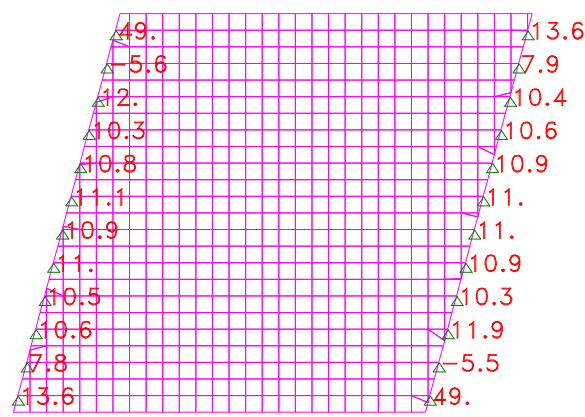

Transversal Máximo (y)

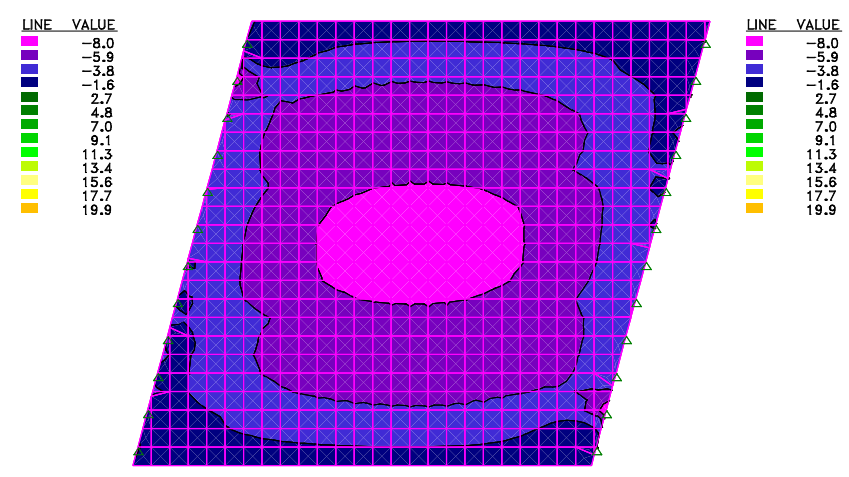

Envoltória das acidentais

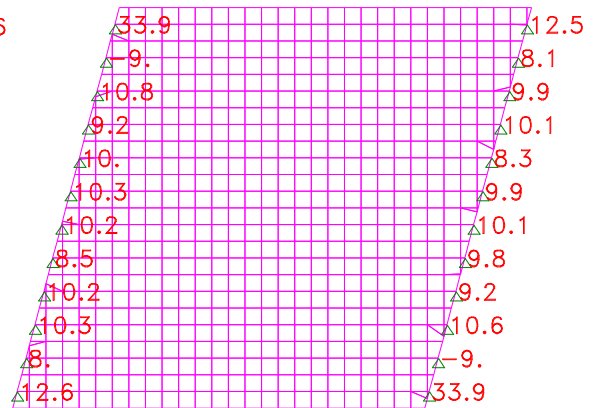


Solicitações das Lajes com $20^{\circ}$ de esconsidade

\section{Momentos Fletores}

Permanente:

Longitudinal $(x)$
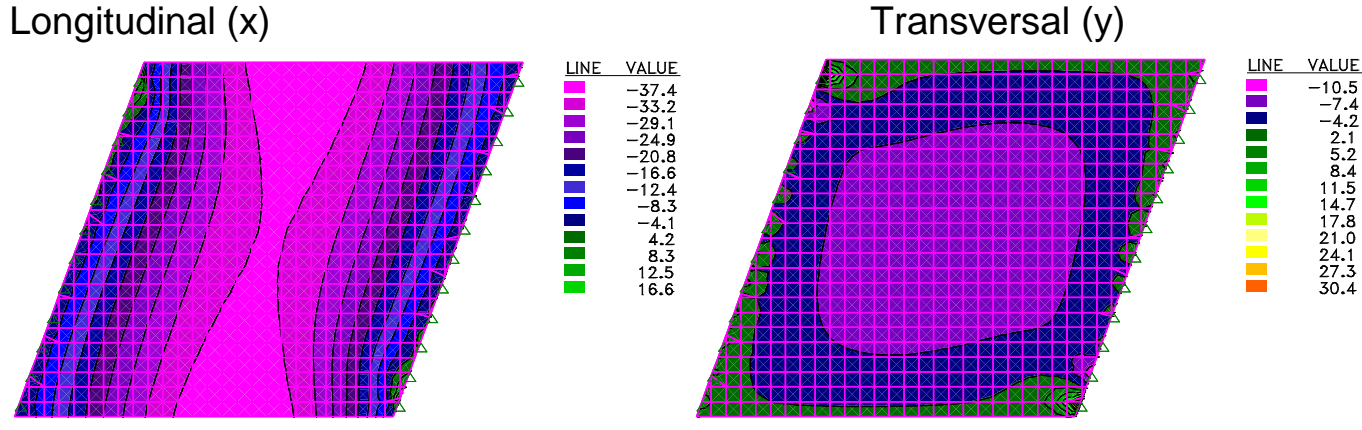

Longitudinal Mínimo (x)
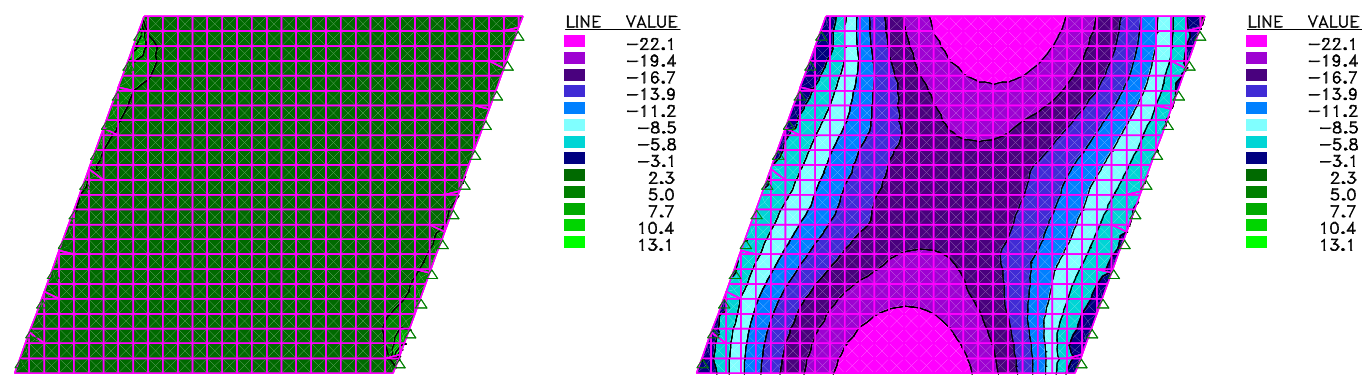

Transversal Mínimo (y)
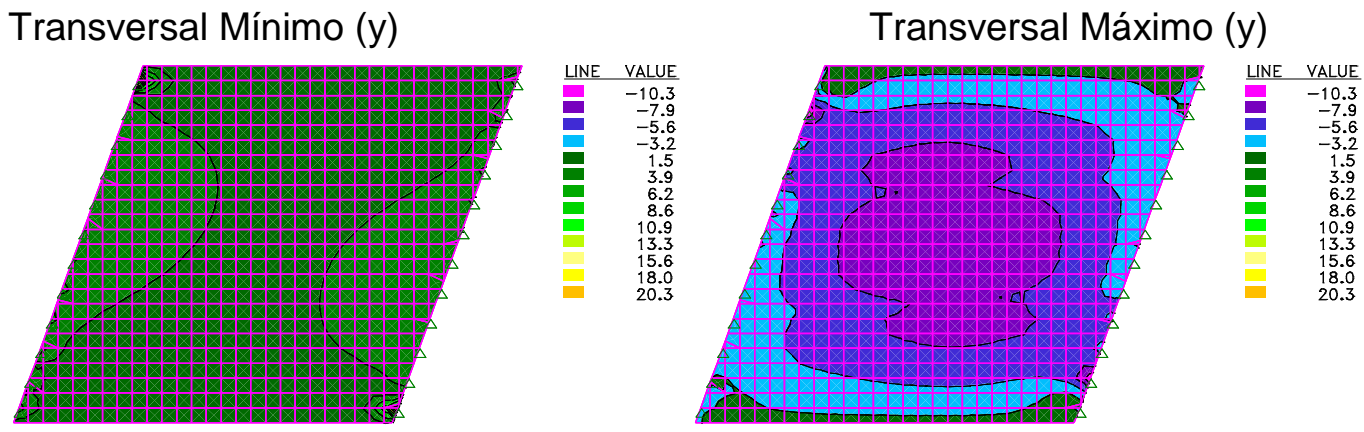

\section{Reações nos Apoios}

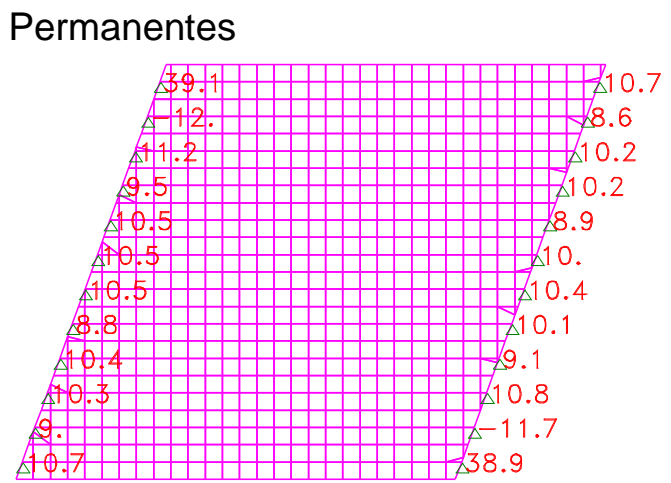

Envoltória das acidentais

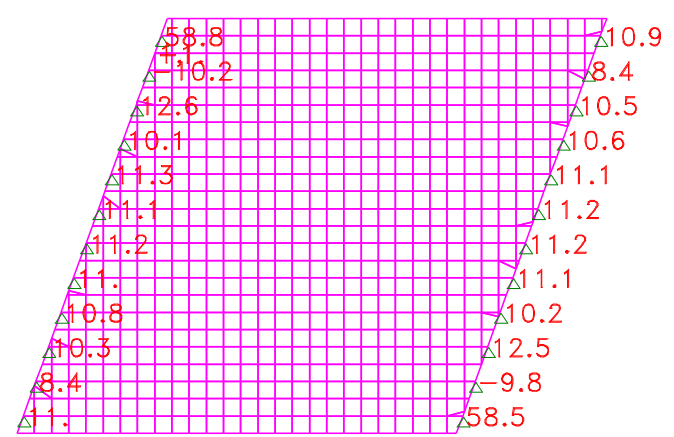


Solicitações das Lajes com $25^{\circ}$ de esconsidade

\section{Momentos Fletores}

Permanente:

Longitudinal $(\mathrm{x})$
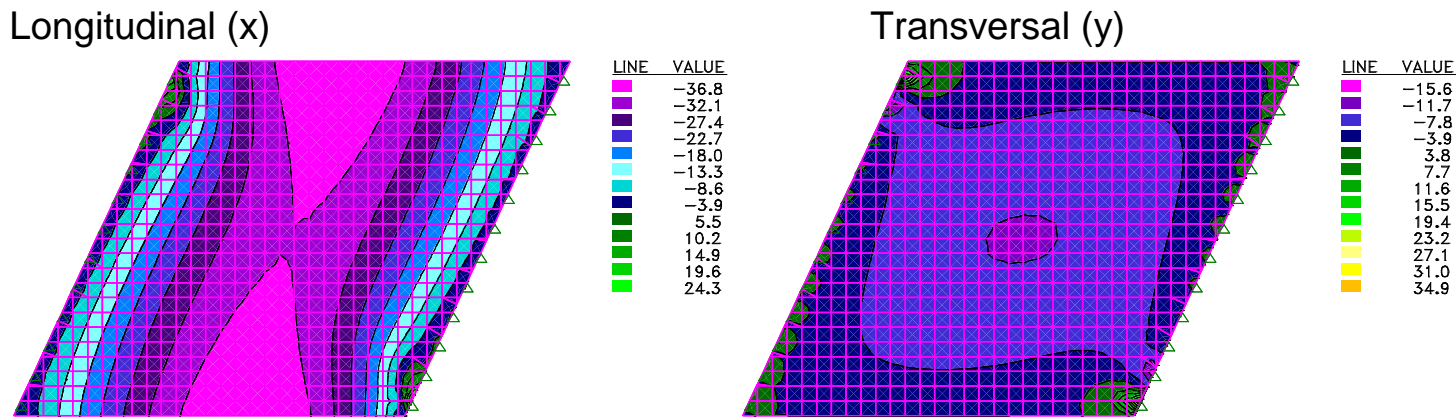

Longitudinal Mínimo (x)

Longitudinal Máximo (x)
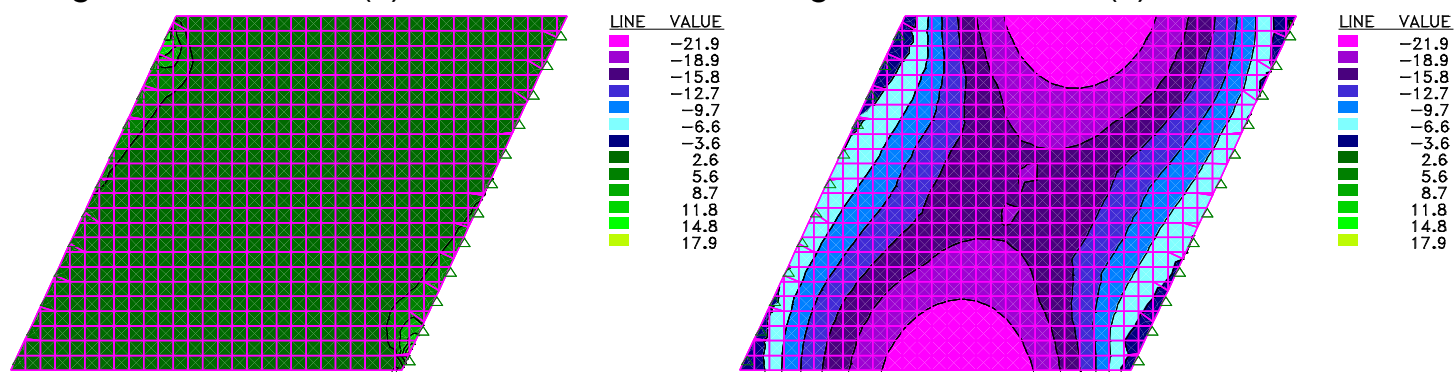

Transversal Mínimo (y)
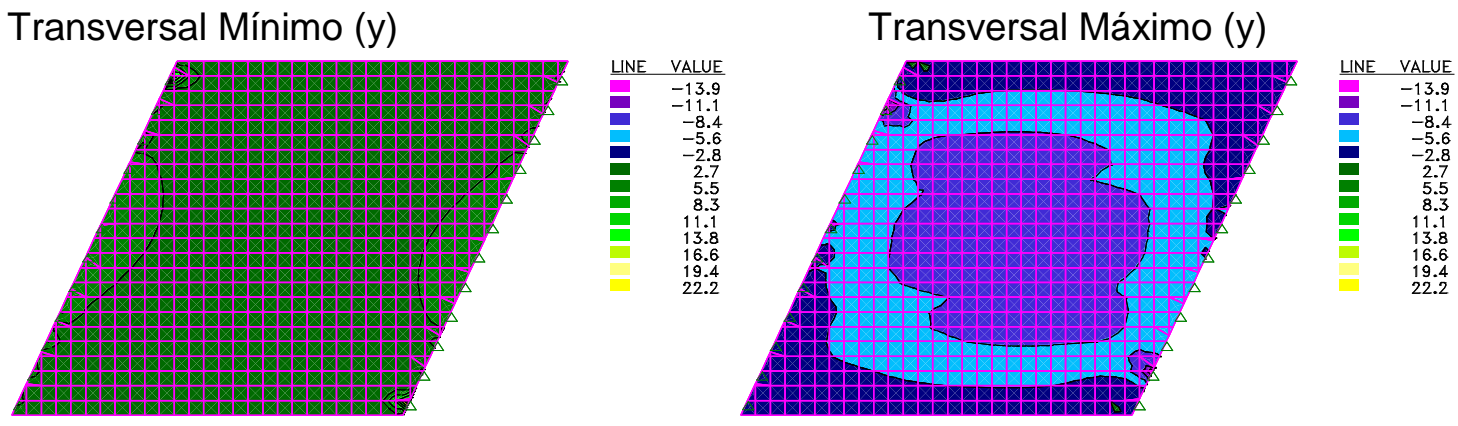

\section{Reações nos Apoios}

Permanentes

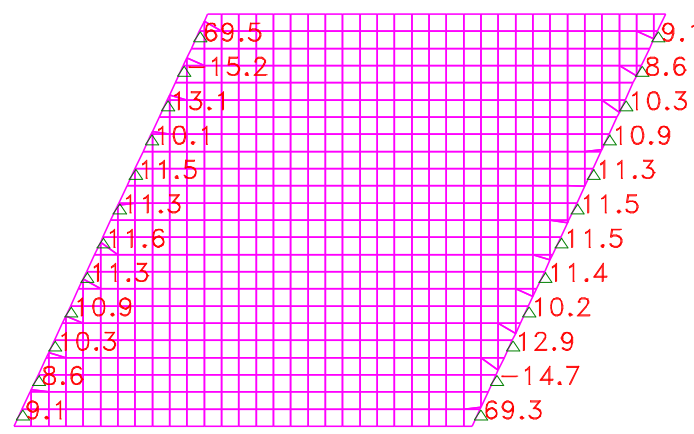

Envoltória das acidentais

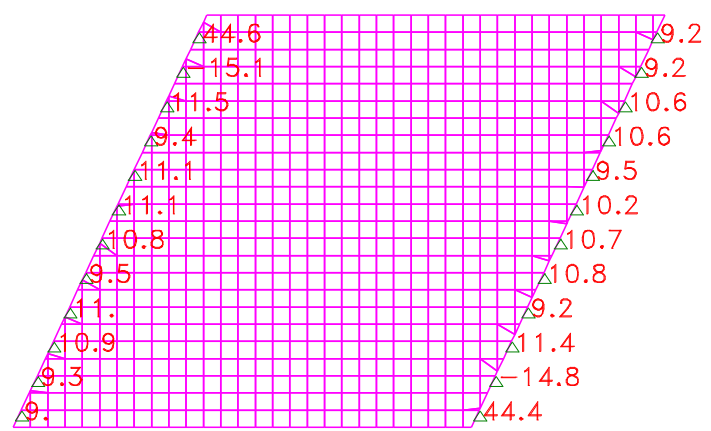


Solicitações das Lajes com $25^{\circ}$ de esconsidade

\section{Momentos Fletores}

Permanente:

Longitudinal $(\mathrm{x})$


Longitudinal Mínimo (x)

Longitudinal Máximo (x)
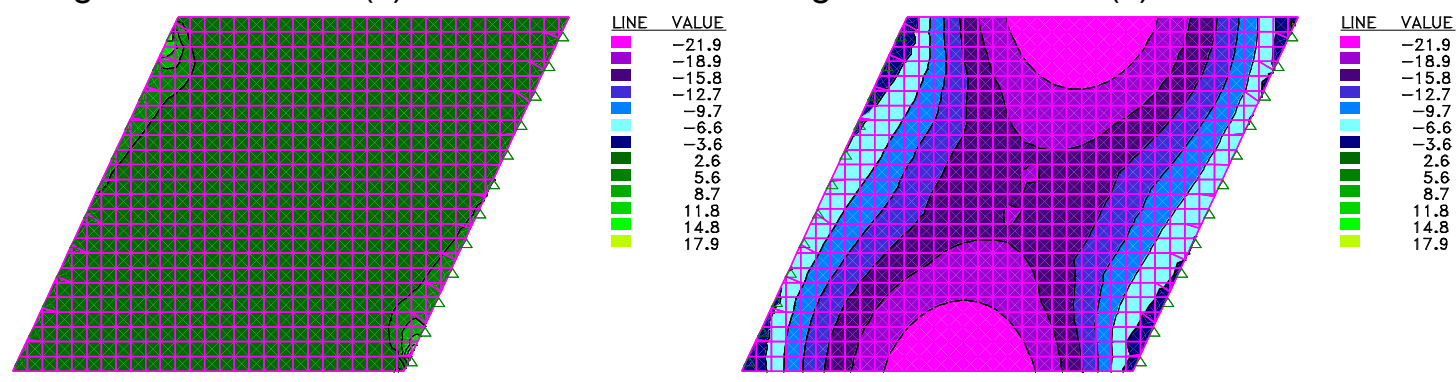

Transversal Mínimo (y)
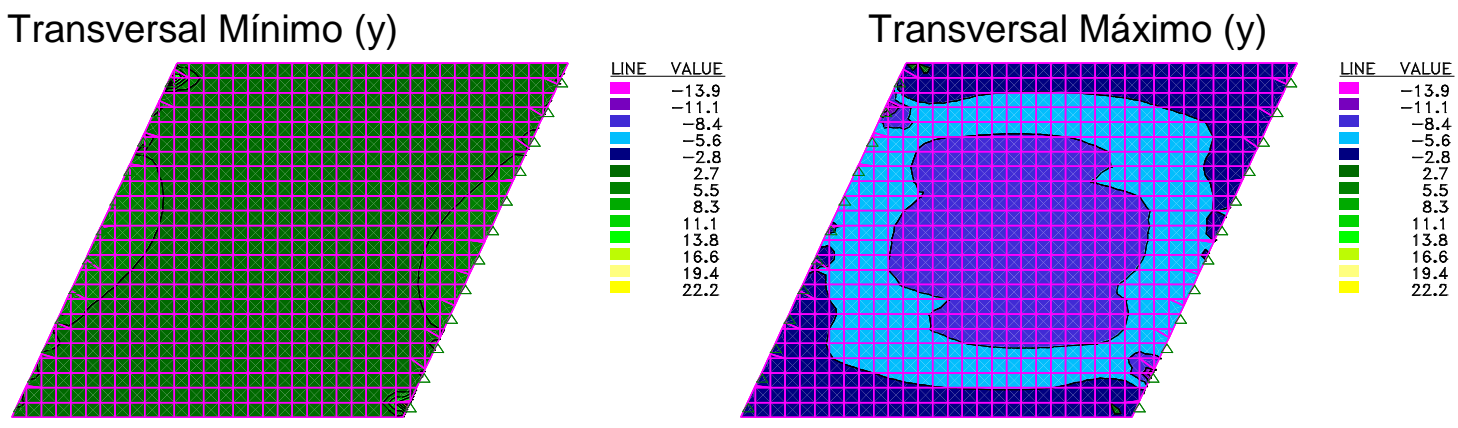

\section{Reações nos Apoios}

Permanentes

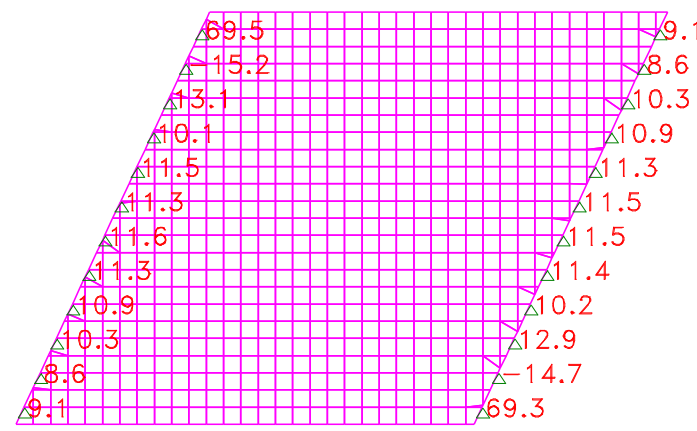

Envoltória das acidentais

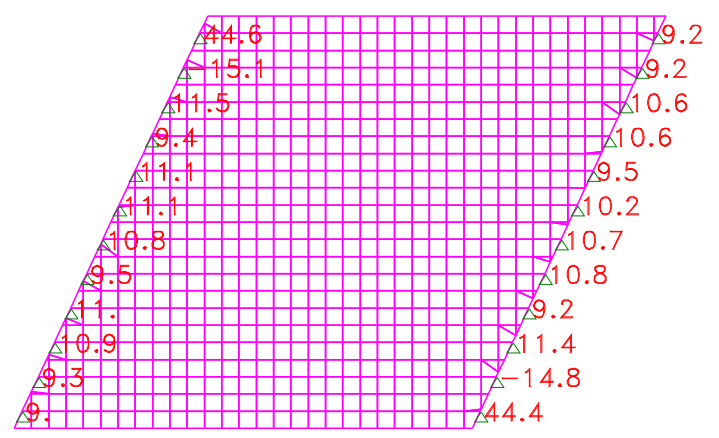


Solicitações das Lajes com $30^{\circ}$ de esconsidade

\section{Momentos Fletores}

Permanente:

Longitudinal $(\mathrm{x})$

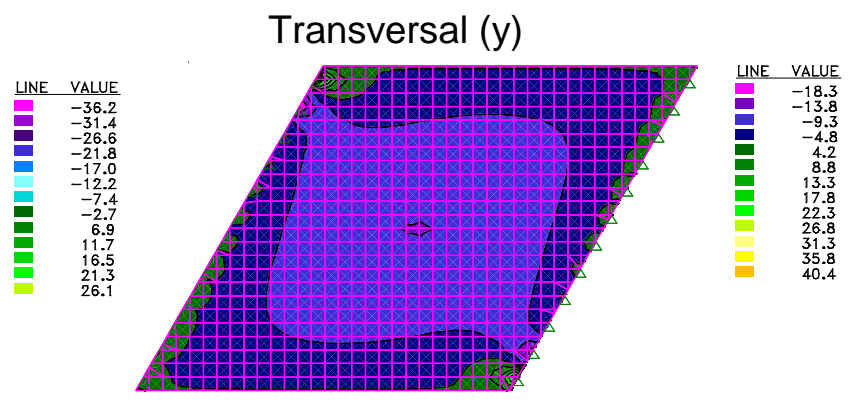

Longitudinal Mínimo (x)
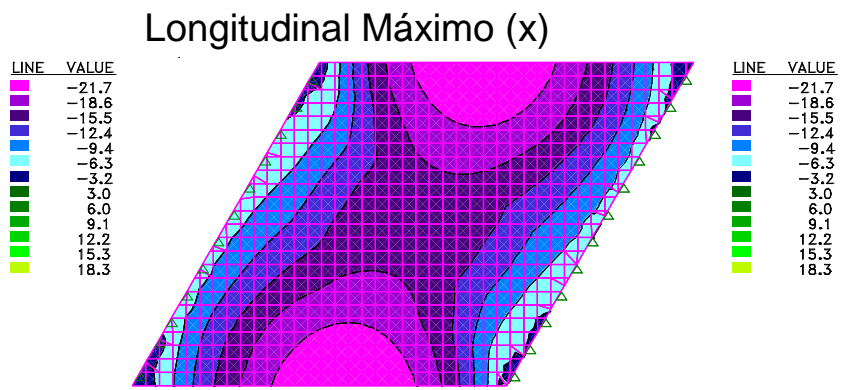

Transversal Mínimo (y)
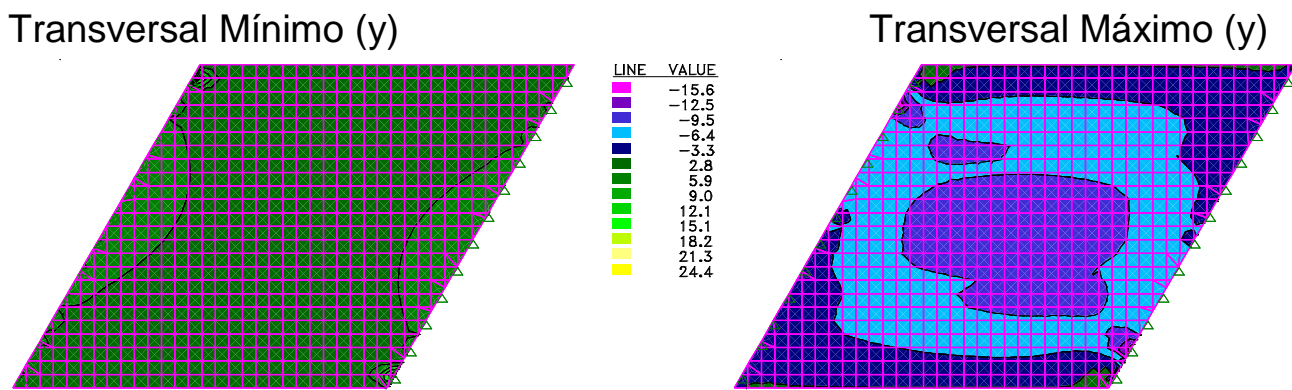

LINE
VALUE
-15.6
-12.5
-9.5
-6.4
-6.4
-3.3
2.8
59.9
9.0
12.1
151
18.2
21.3
24.4
2

\section{Reações nos Apoios}

Permanentes

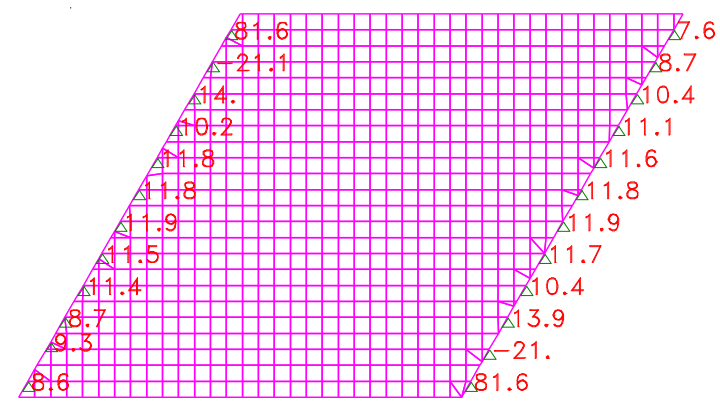

Envoltória das acidentais

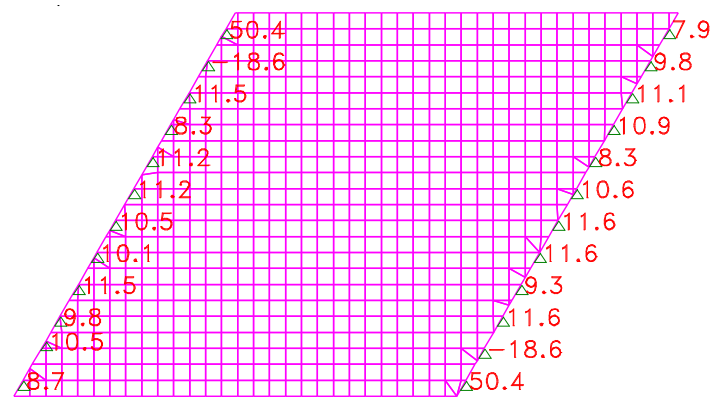


Solicitações das Lajes com $35^{\circ}$ de esconsidade

\section{Momentos Fletores}

Permanente:

Longitudinal $(\mathrm{x})$
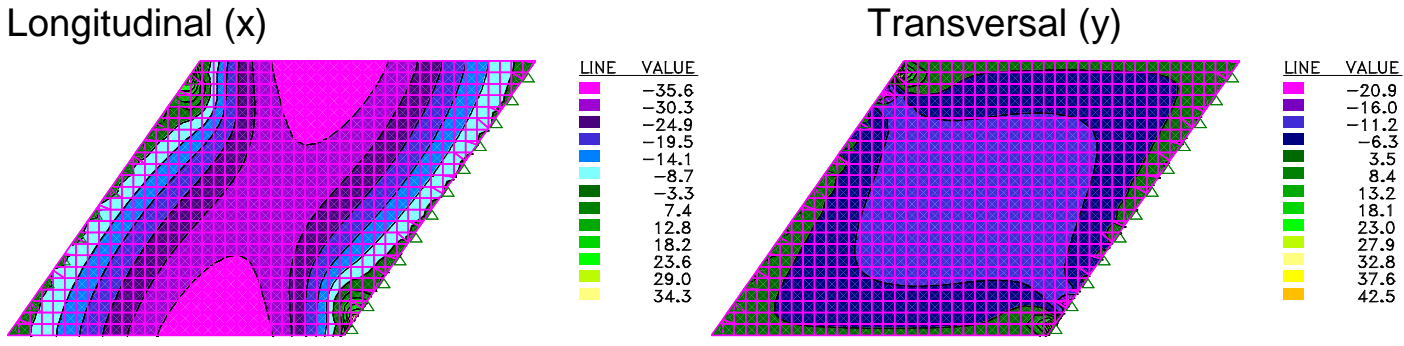

Longitudinal Mínimo (x)
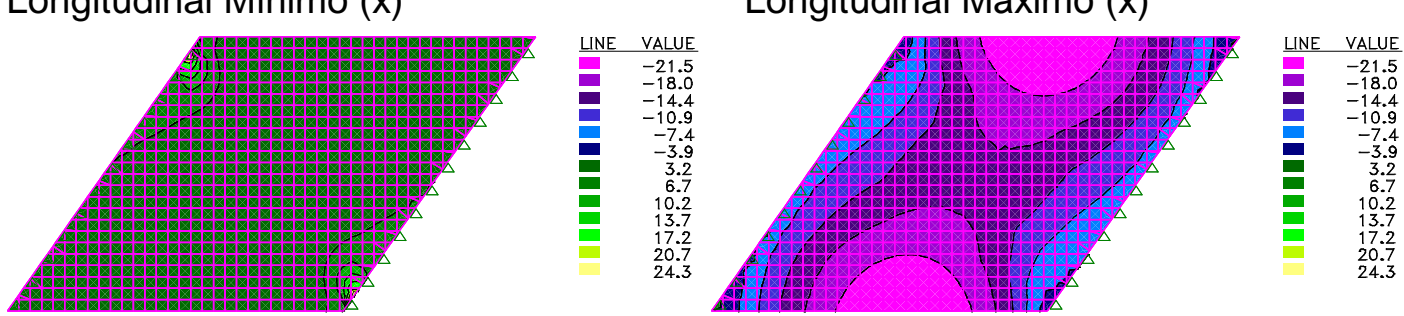

Transversal Mínimo (y)
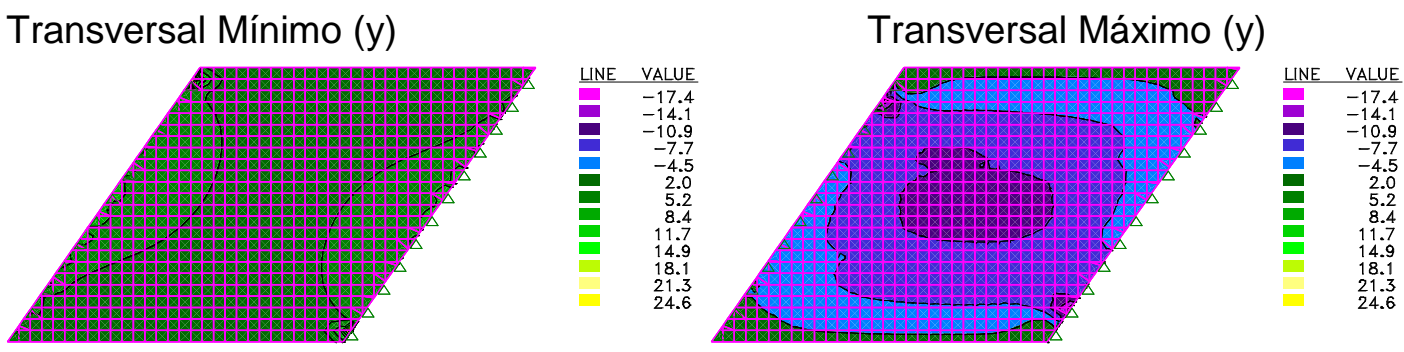

\section{Reações nos Apoios}

Permanentes

Envoltória das acidentais
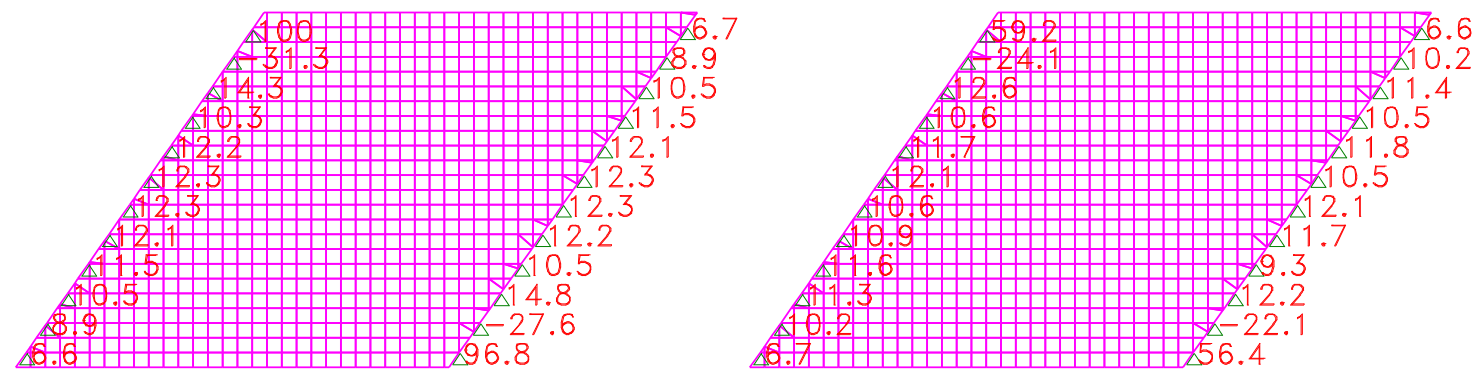
Solicitações das Lajes com $40^{\circ}$ de esconsidade

\section{Momentos Fletores}

Permanente:

Longitudinal $(\mathrm{x})$
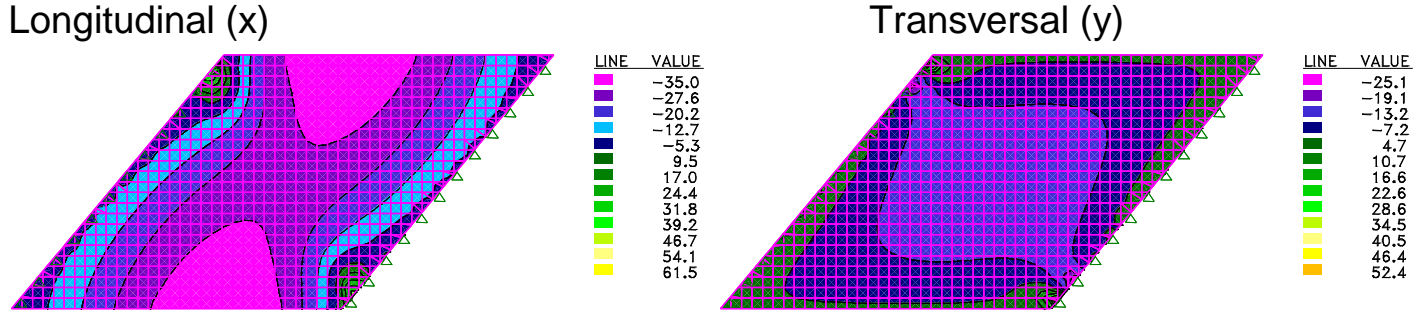

Longitudinal Mínimo (x)
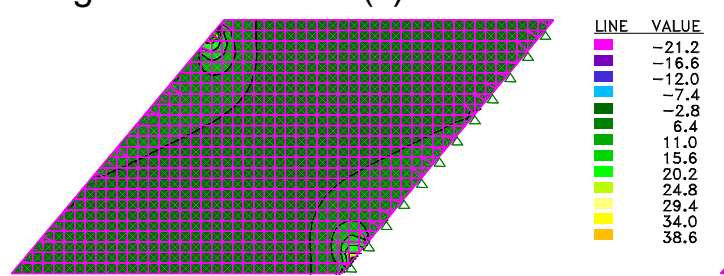

Longitudinal Máximo (x)

Transversal Mínimo (y)
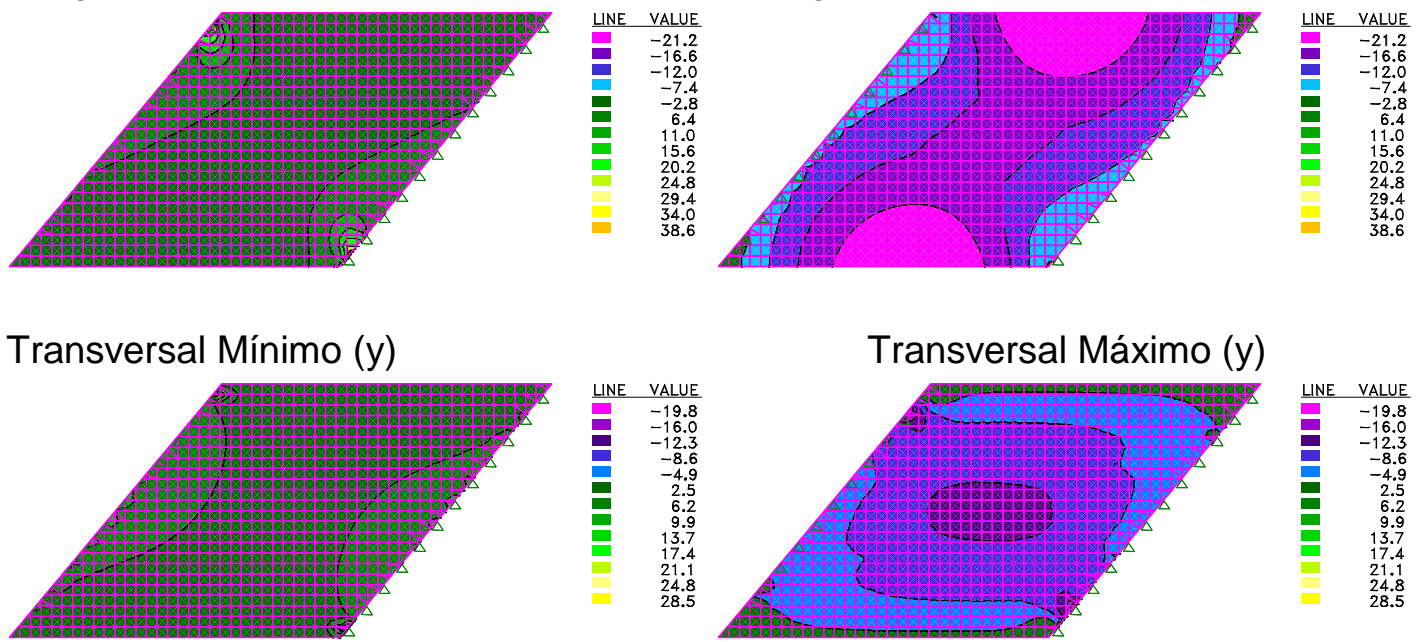

\section{Reações nos Apoios}

Permanentes

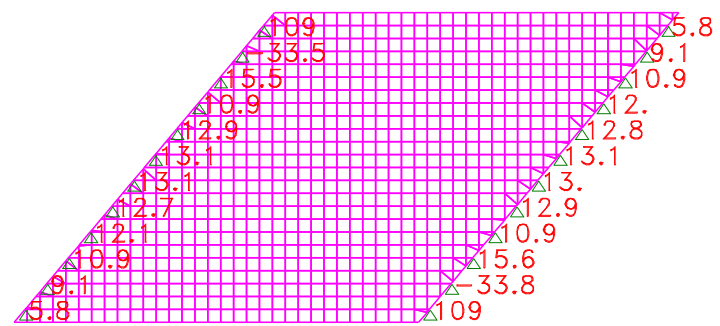

Envoltória das acidentais

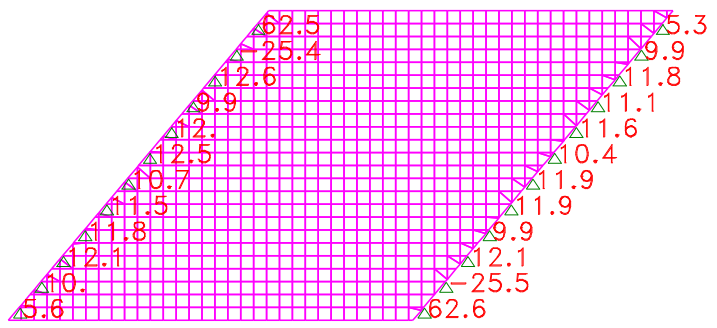


Solicitações das Lajes com $45^{\circ}$ de esconsidade

\section{Momentos Fletores}

Permanente:

Longitudinal $(\mathrm{x})$
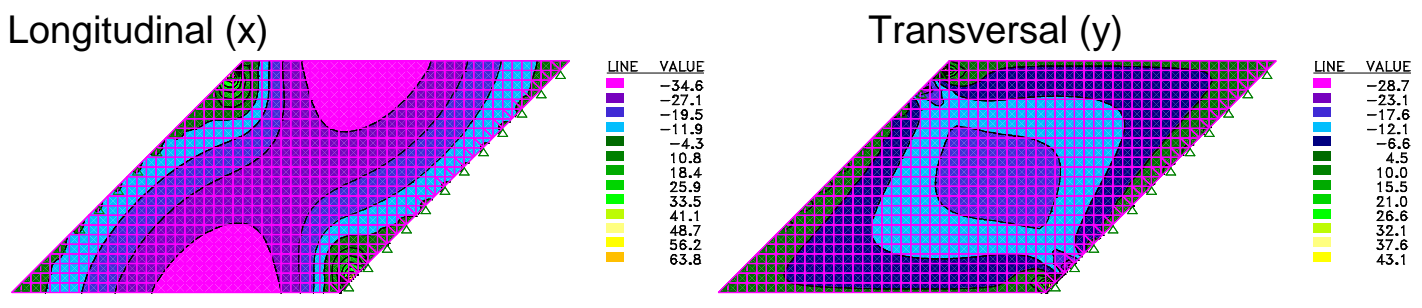

Longitudinal Mínimo (x)
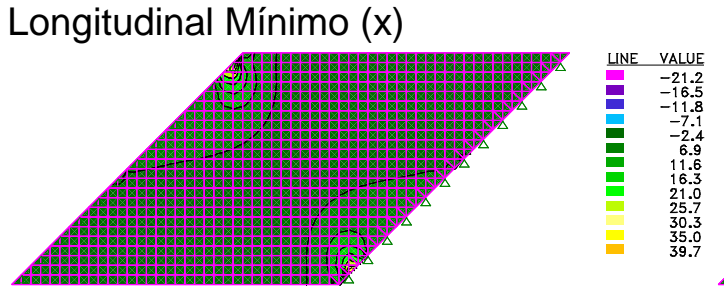

Longitudinal Máximo (x)

Transversal Mínimo (y)
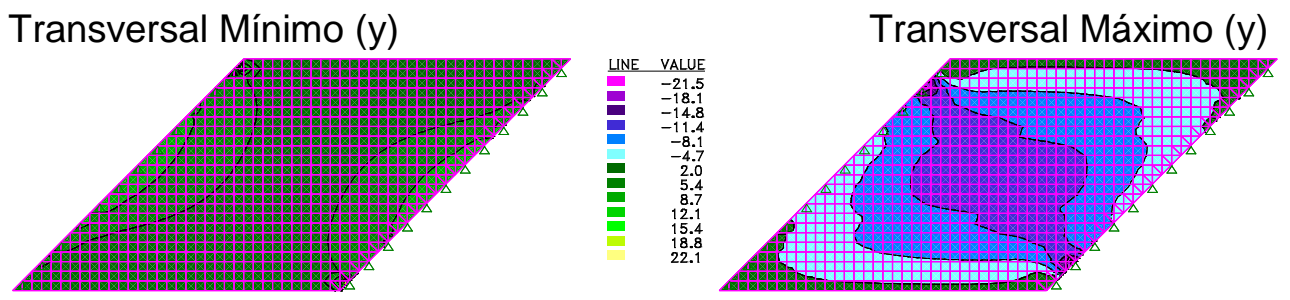

LINE VALUE
-21.5
-18.1
-14.8
-11.4
-8.1
-47
2.0
5.4
8.7
121
15.4
18.8
22.1

\section{Reações nos Apoios}

Permanentes

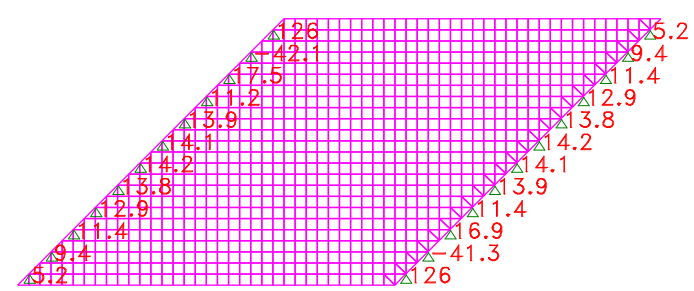

Envoltória das acidentais

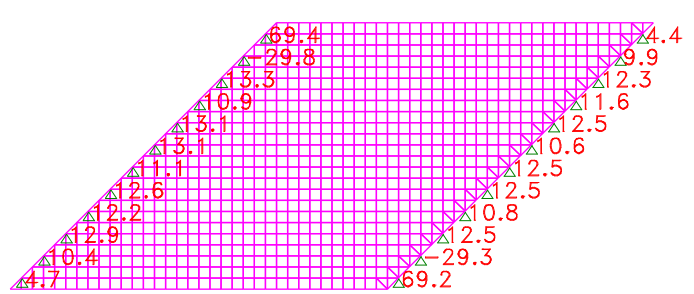


Solicitações das Lajes com $50^{\circ}$ de esconsidade

\section{Momentos Fletores}

Permanente:

Longitudinal $(\mathrm{x})$
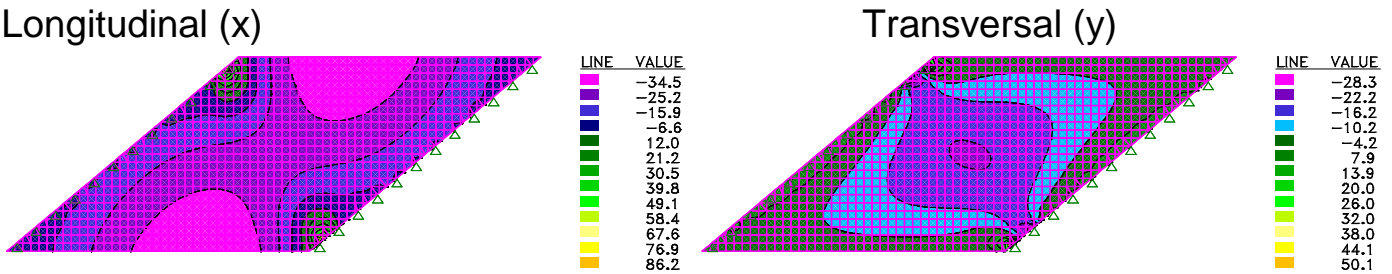

Longitudinal Mínimo (x)
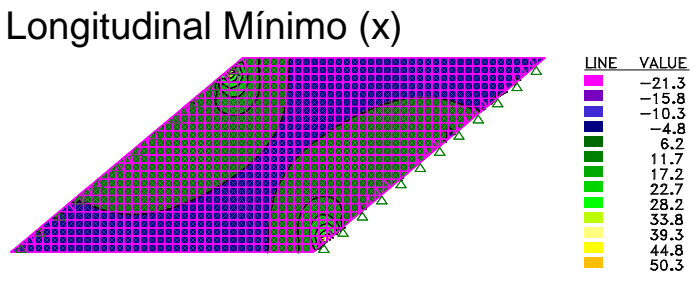

Longitudinal Máximo (x)

Transversal Mínimo (y)
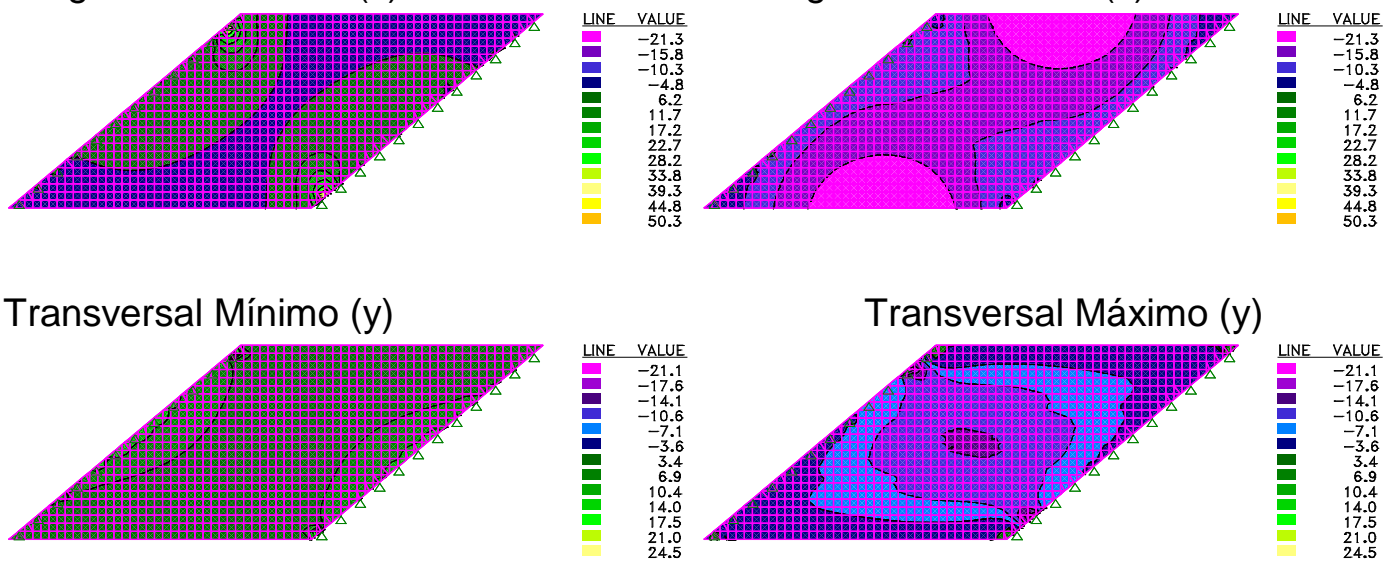

Reações nos Apoios

Permanentes

Envoltória das acidentais
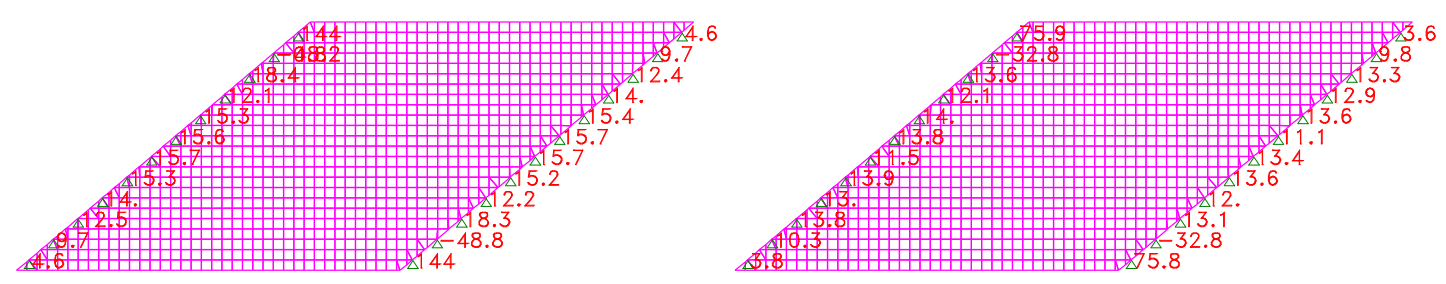
Solicitações das Lajes com $55^{\circ}$ de esconsidade

\section{Momentos Fletores}

Permanente:

Longitudinal $(\mathrm{x})$
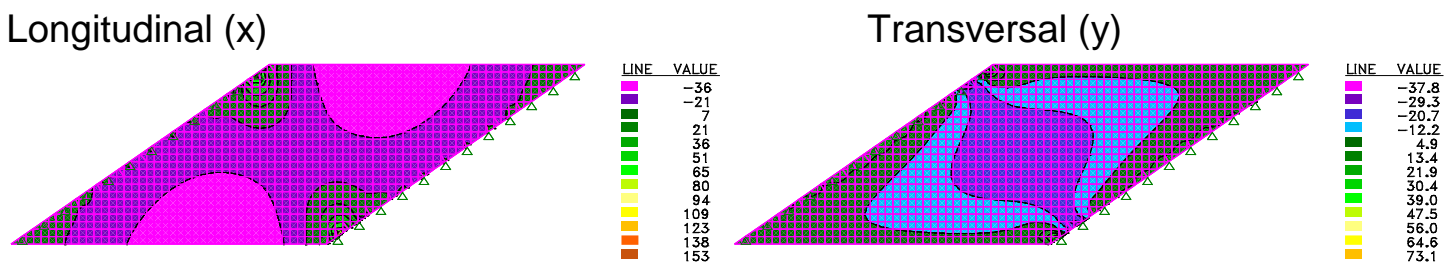

Longitudinal Mínimo (x)

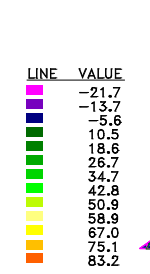

Longitudinal Máximo (x)
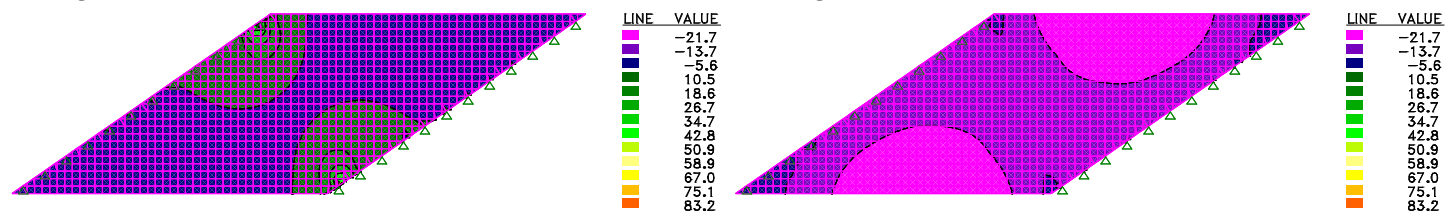

Transversal Mínimo (y)
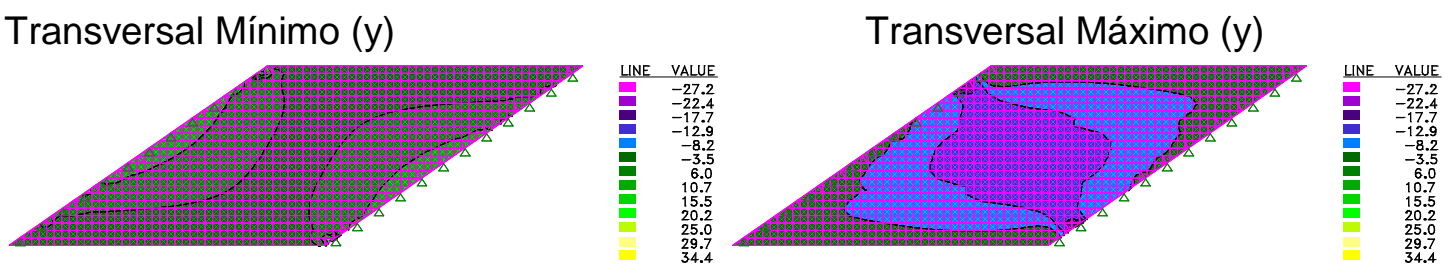

\section{Reações nos Apoios}

Permanentes

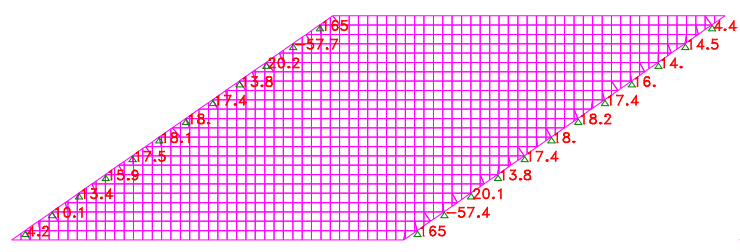

Envoltória das acidentais

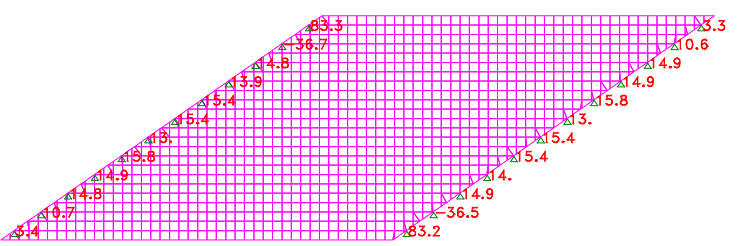


Solicitações das Lajes com $60^{\circ}$ de esconsidade

\section{Momentos Fletores}

Permanente:

Longitudinal $(\mathrm{x})$
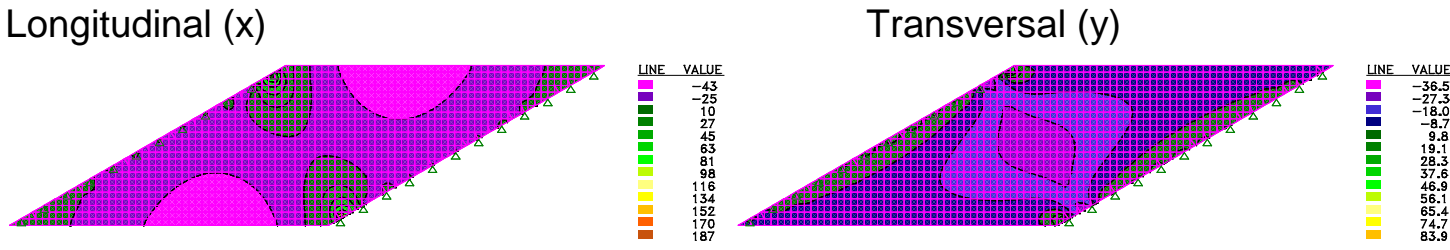

Longitudinal Mínimo (x)
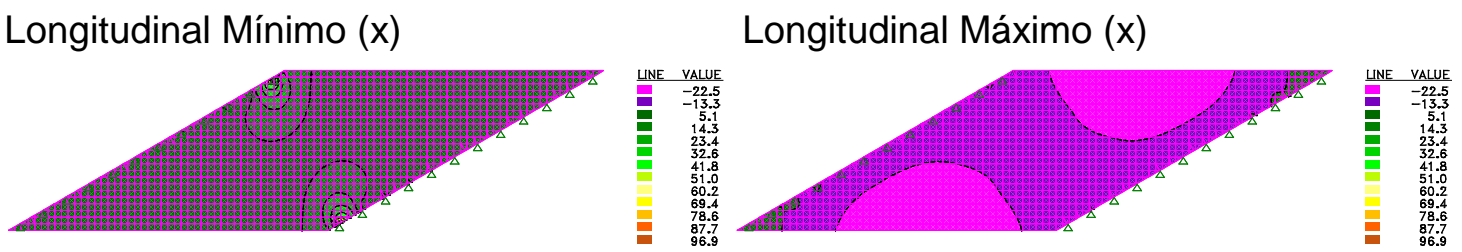

Transversal Mínimo (y)

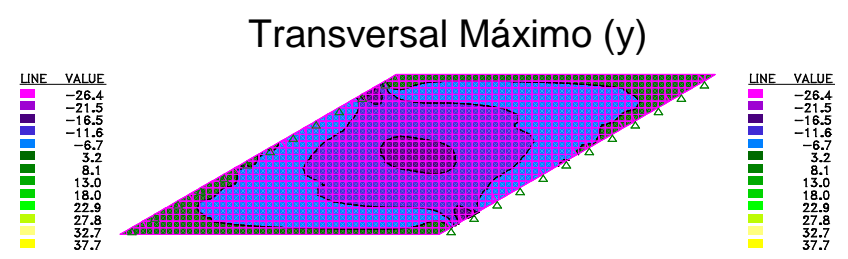

\section{Forças Cortantes}

Permanentes

Envoltória das acidentais
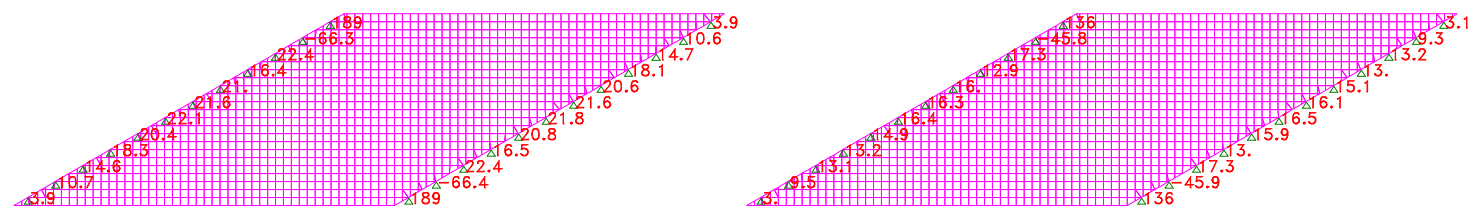


\section{ANEXO B - LAJE - APOIOS FIXOS E SEM HOMOGENEIZAÇÃO}

Solicitações das Lajes com $0^{\circ}$ de esconsidade Momentos Fletores

Permanente:

Longitudinal $(\mathrm{x})$
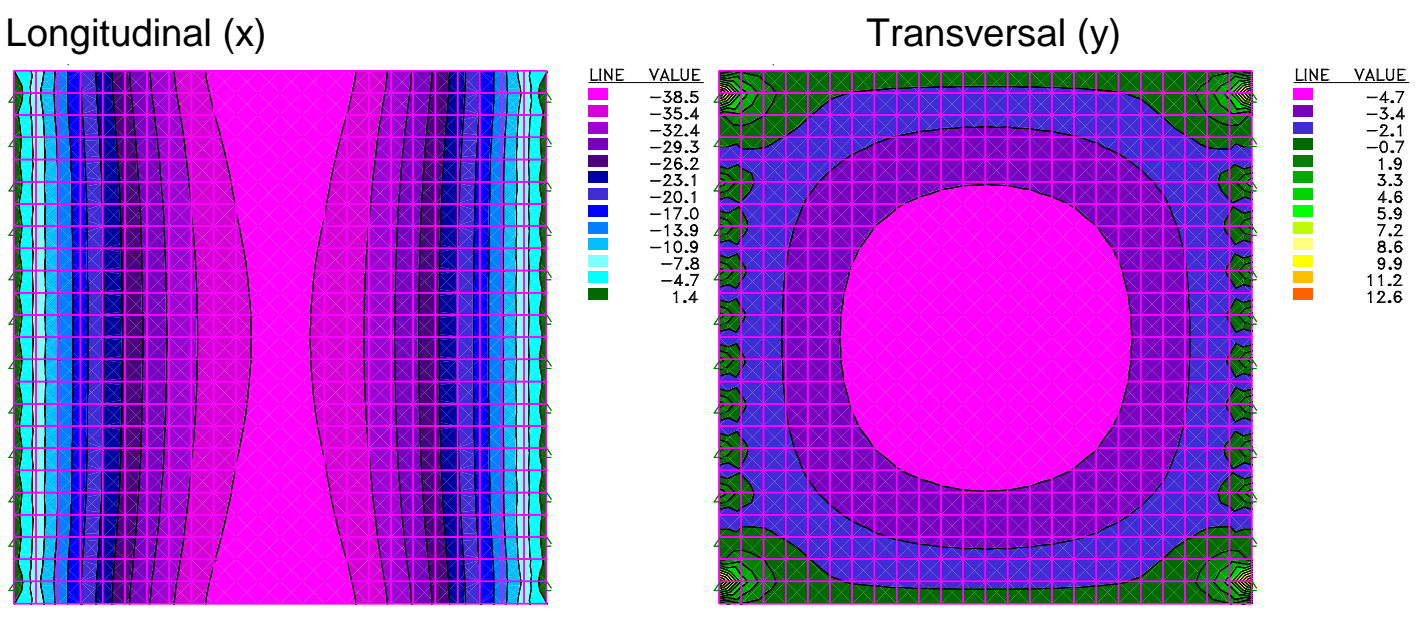

Longitudinal Mínimo (x)

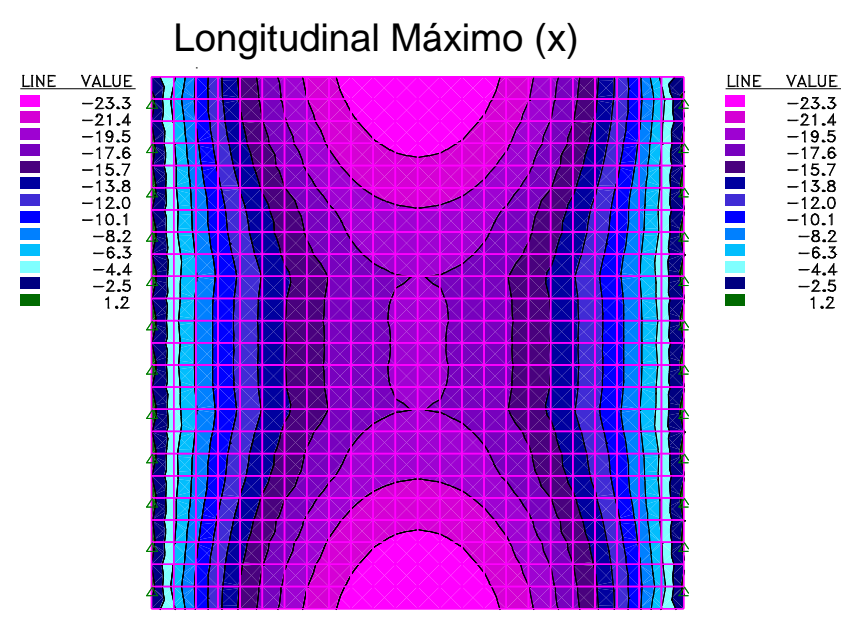

Transversal Mínimo (y)

Tranversal Máximo (y)
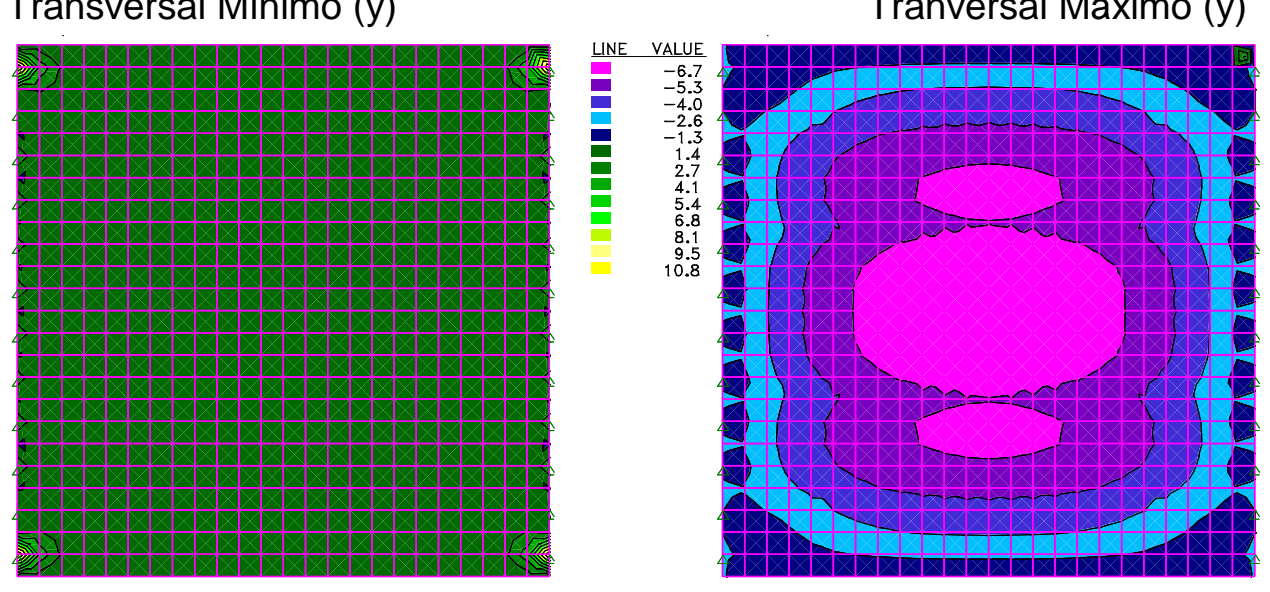

LINE VALUE
-6.7
-5.3
-4.0
-2.6
-1.3
14
2.7
41
5.4
6.8
8.1
95
10.8 
Reações nos Apoios

Permanentes

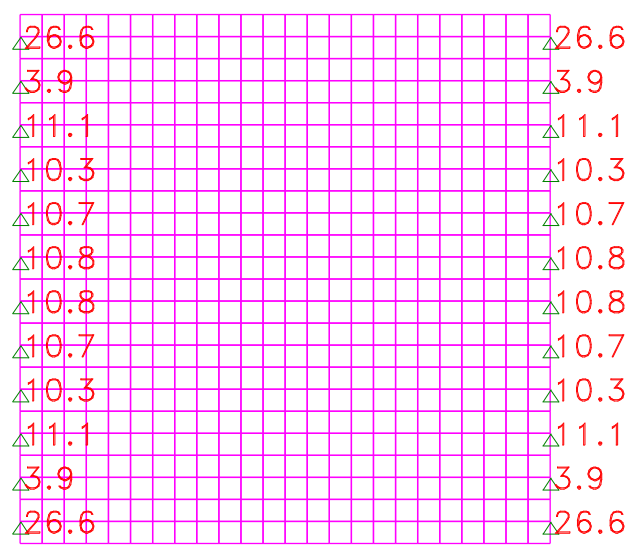

Envoltória das acidentais

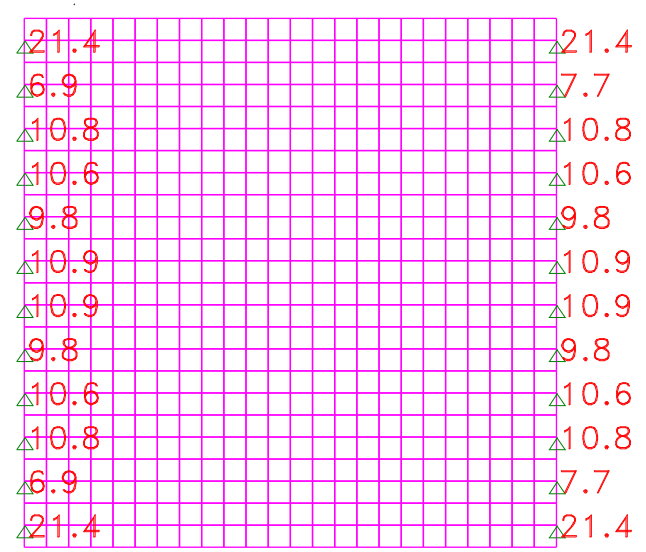

Solicitações das Lajes com $5^{\circ}$ de esconsidade

\section{Momentos Fletores}

Permanente:

Longitudinal $(\mathrm{x})$

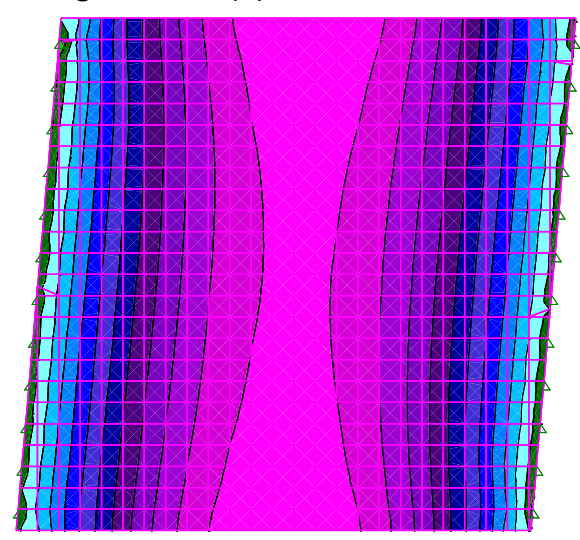

Longitudinal Mínimo (x)

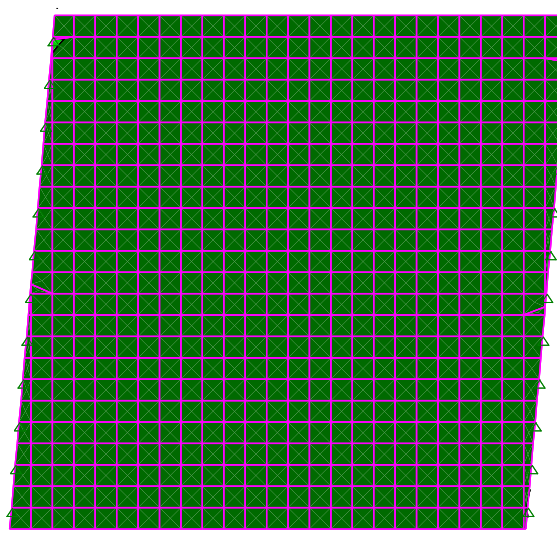

Transversal (y)

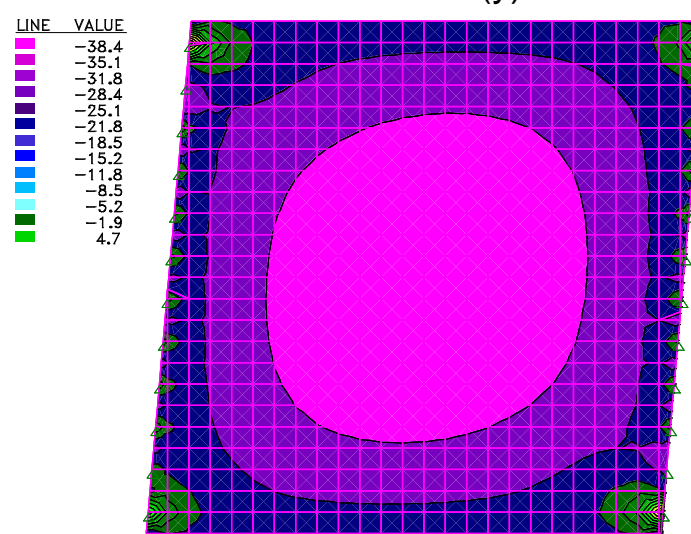

Longitudinal Máximo (x)

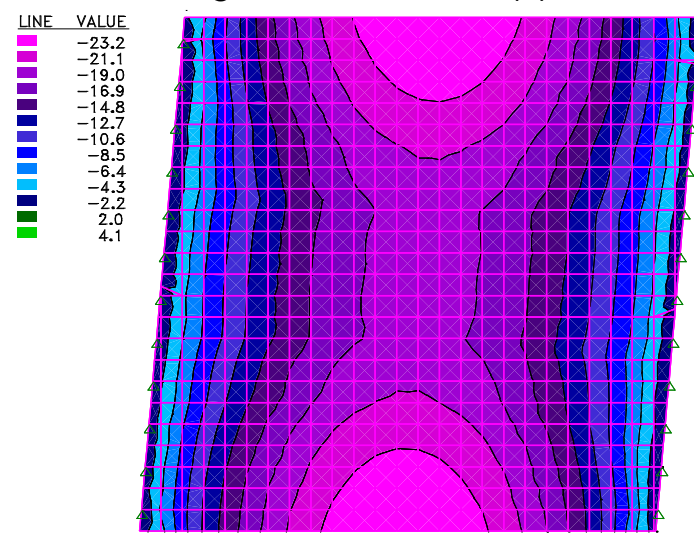

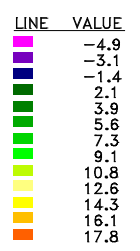

\begin{tabular}{r} 
LINE $\quad$ VALUE \\
\hline-23.2 \\
-21.1 \\
-19.0 \\
-16.9 \\
-14.8 \\
-12.7 \\
-10.6 \\
-85 \\
-6.4 \\
-4.3 \\
-2.2 \\
2.0 \\
4.1 \\
4.1
\end{tabular} 
Transversal Mínimo (y)

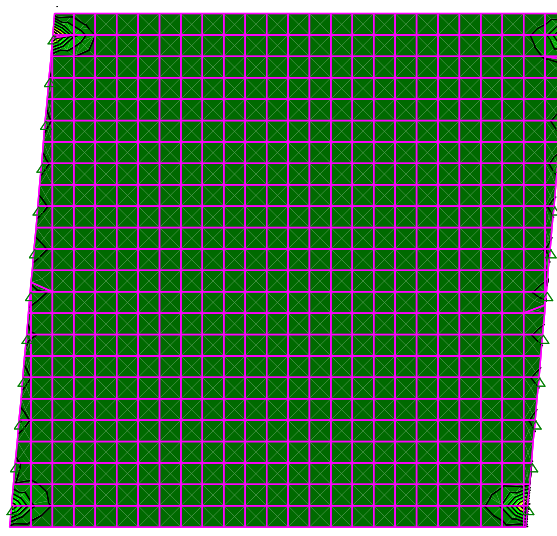

\section{Reações nos Apoios}

Permanentes

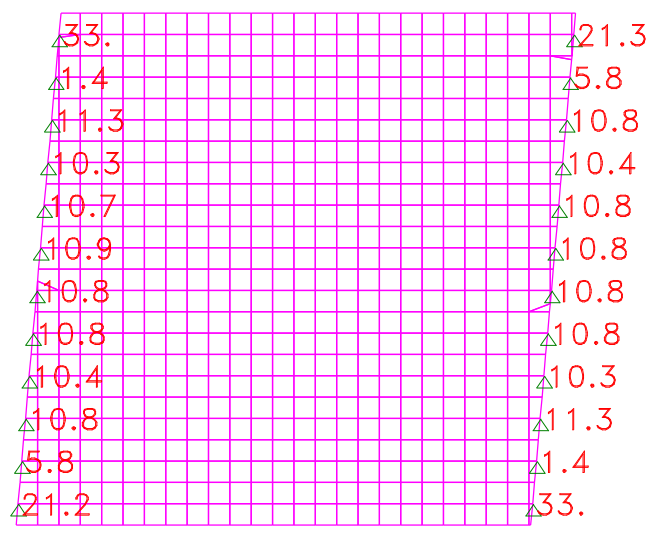

Transversal Máximo (y)

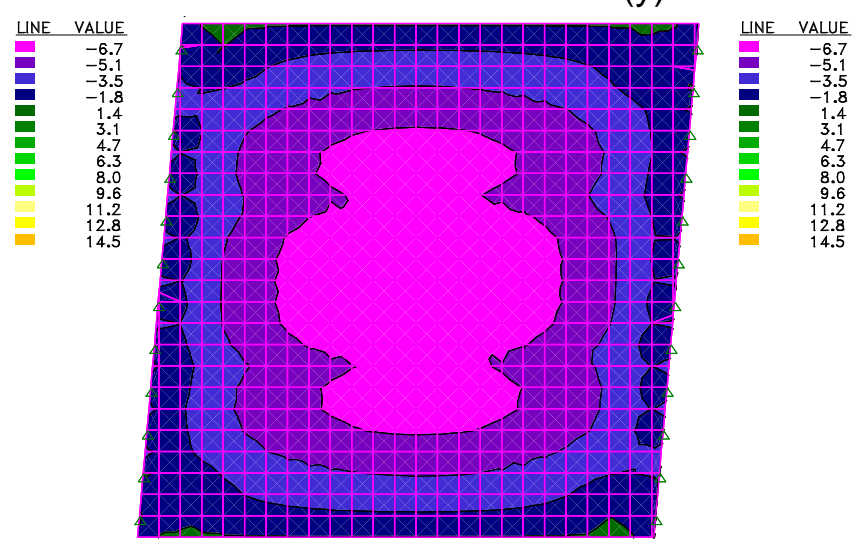

Envoltória das acidentais

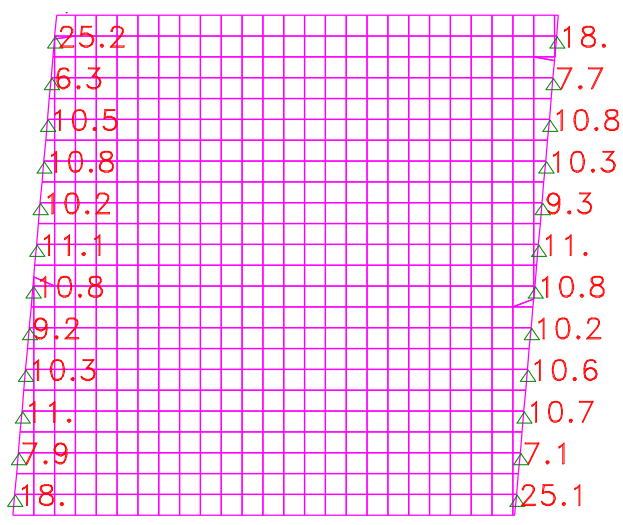


Solicitações das Lajes com $10^{\circ}$ de esconsidade

\section{Momentos Fletores}

Permanente:

Longitudinal $(x)$

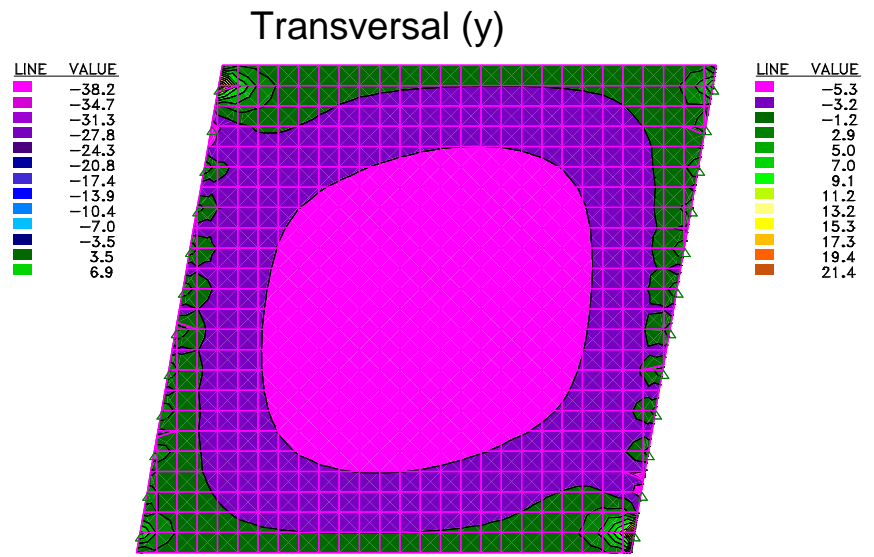

Longitudinal Mínimo (x)
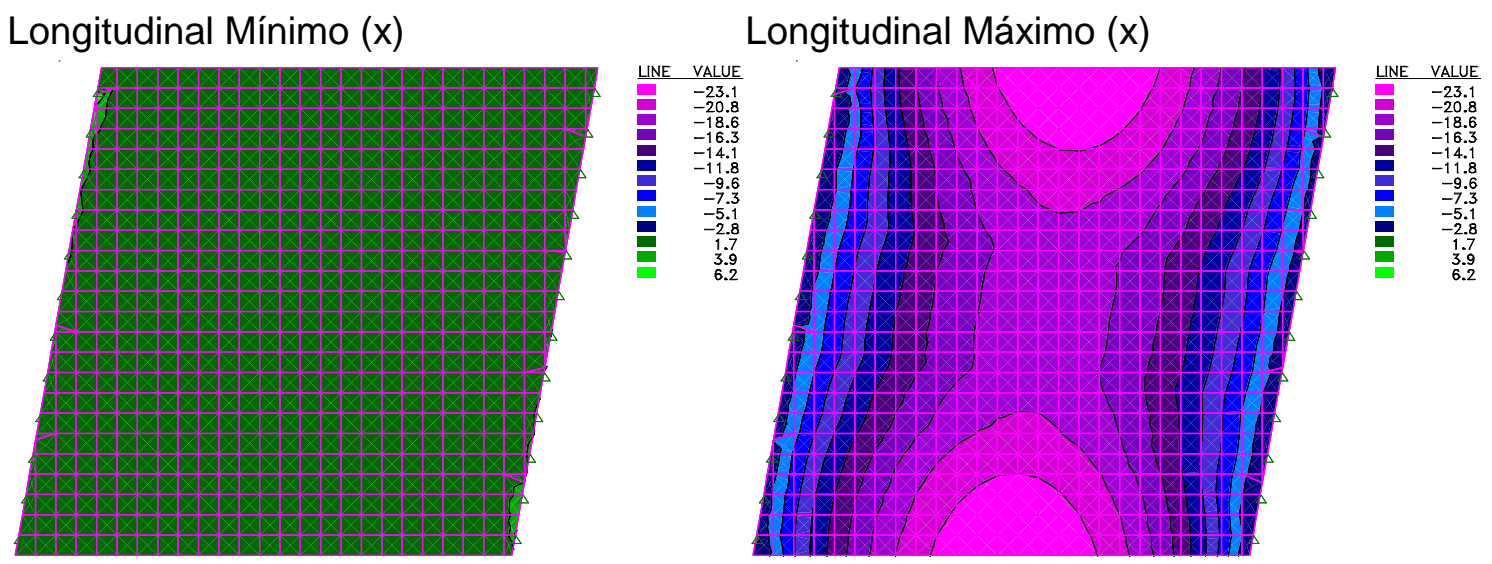

Transversal Mínimo (y)

Transversal Máximo (y)
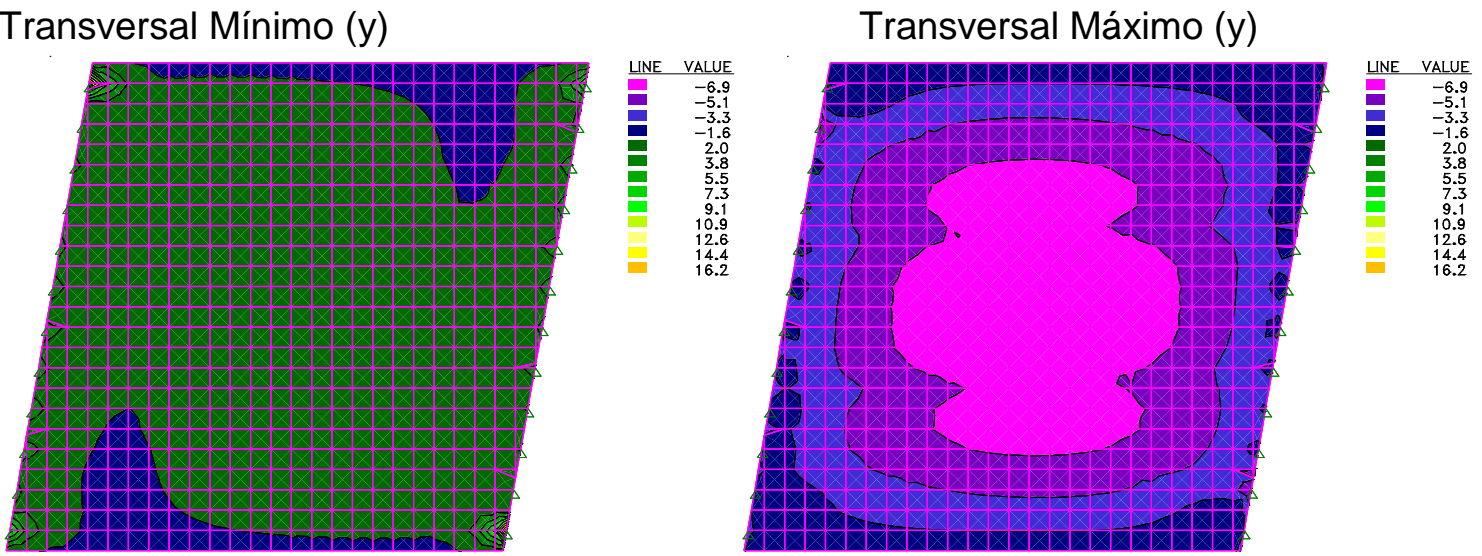


\section{Reações nos apoios}

Permanentes

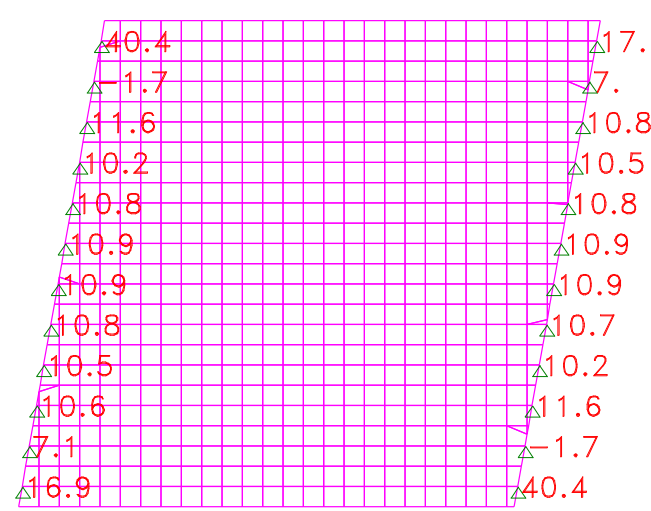

Envoltória das acidentais

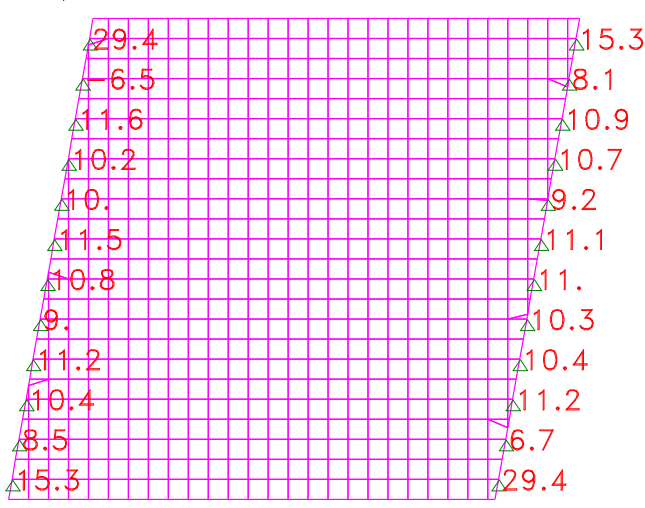

Solicitações das Lajes com $15^{\circ}$ de esconsidade

\section{Momentos Fletores}

Permanente:

Longitudinal $(\mathrm{x})$

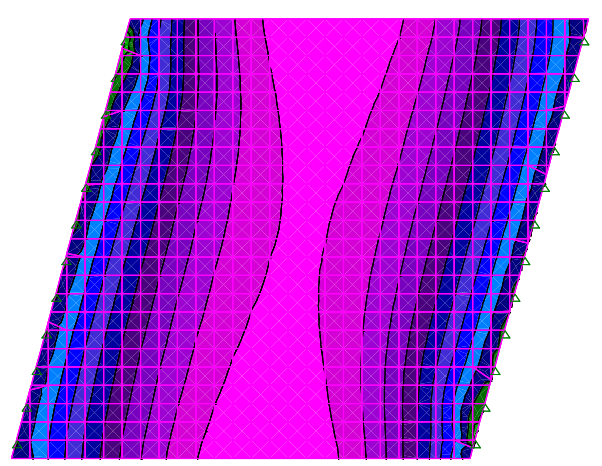

Longitudinal Mínimo (x)

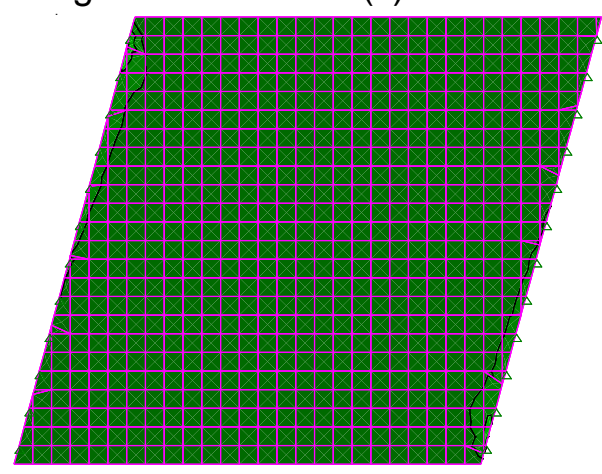

Transversal $(\mathrm{y})$
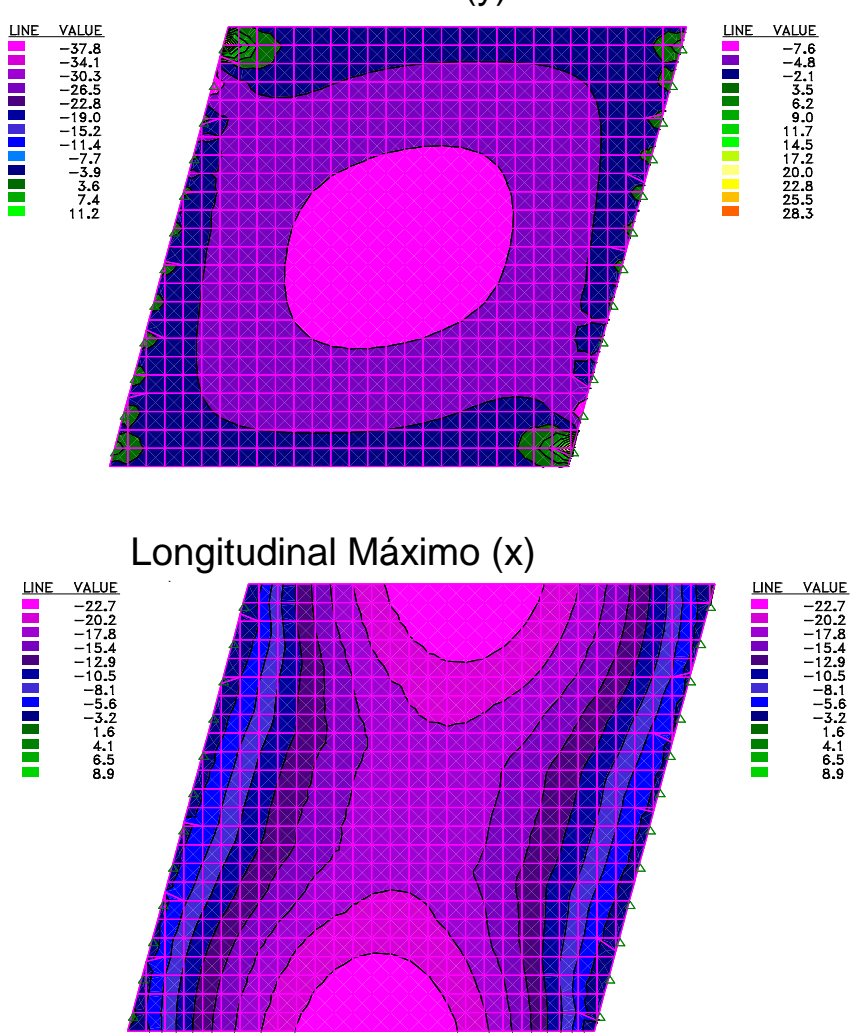
Transversal Mínimo (y)

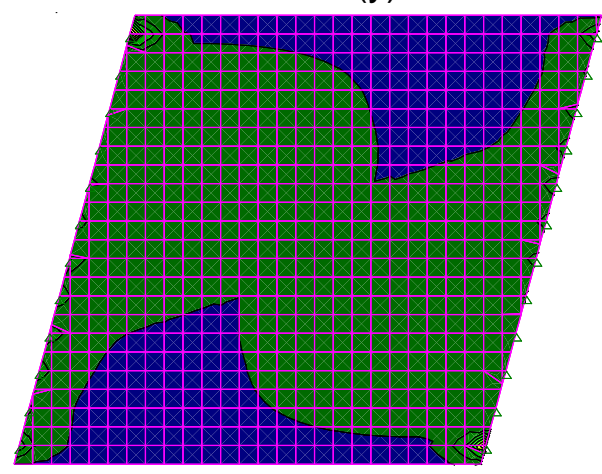

Reações nos Apoios

Permanentes

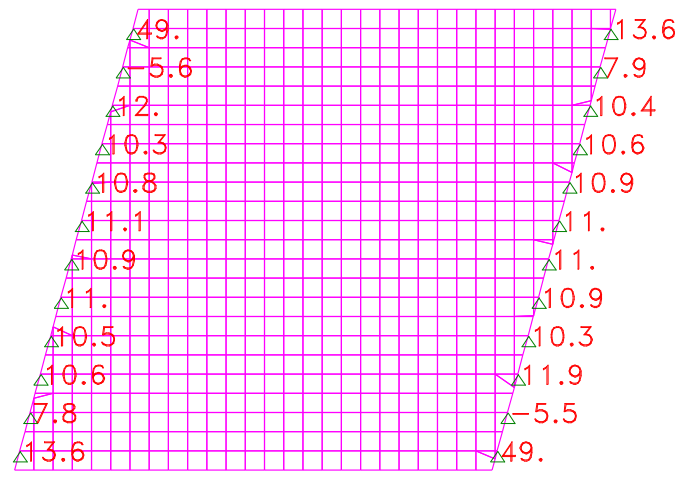

Transversal Máximo (y)

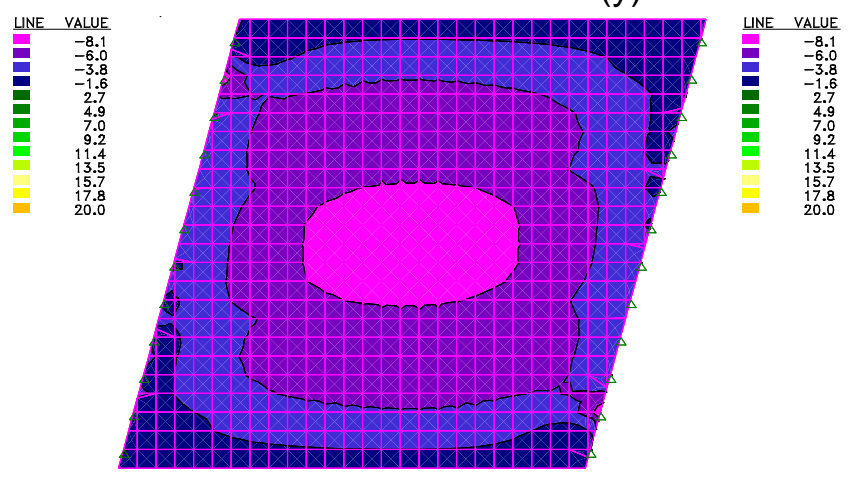

Envoltória das acidentais

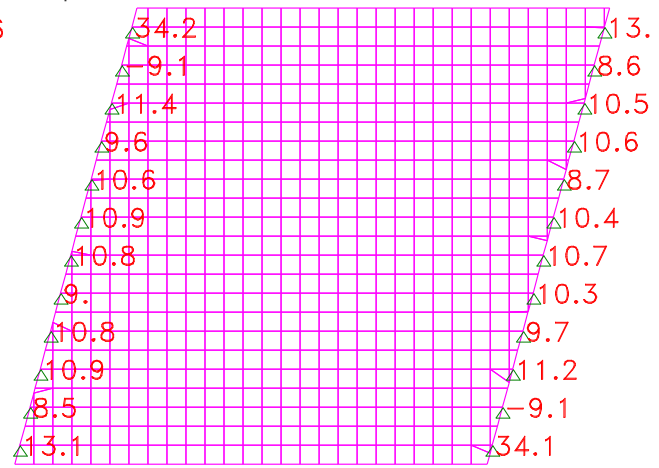


Solicitações das Lajes com $20^{\circ}$ de esconsidade

\section{Momentos Fletores}

Permanente:

Longitudinal (x)
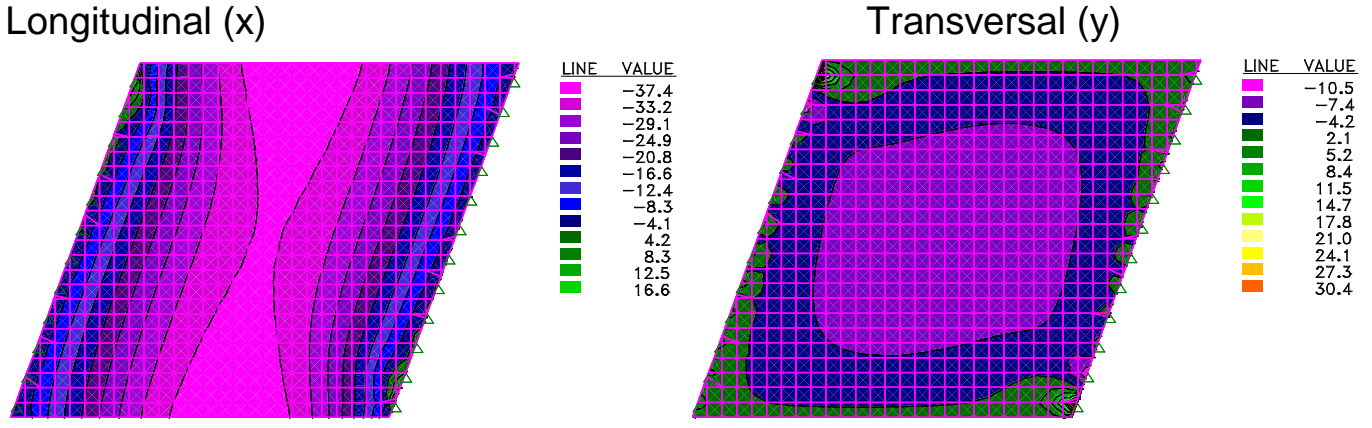

Longitudinal Mínimo (x)

Longitudinal Máximo (x)
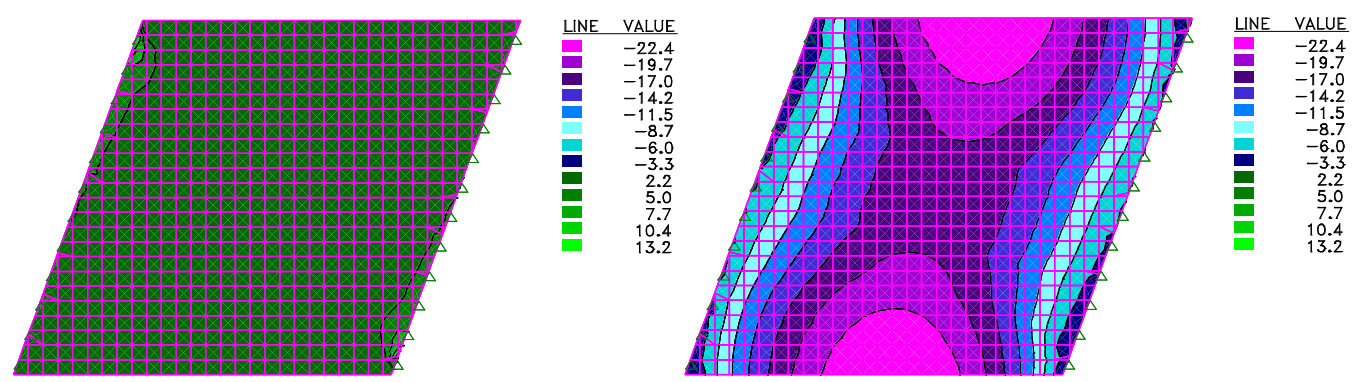

Transversal Mínimo (y)

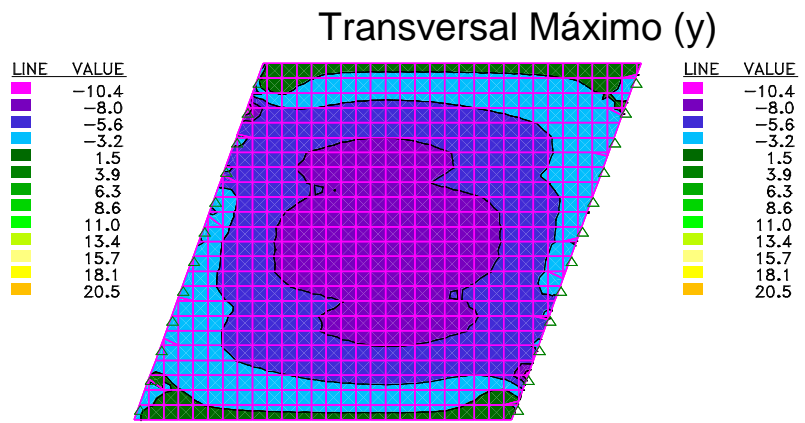

\section{Reações nos Apoios}

Permanentes

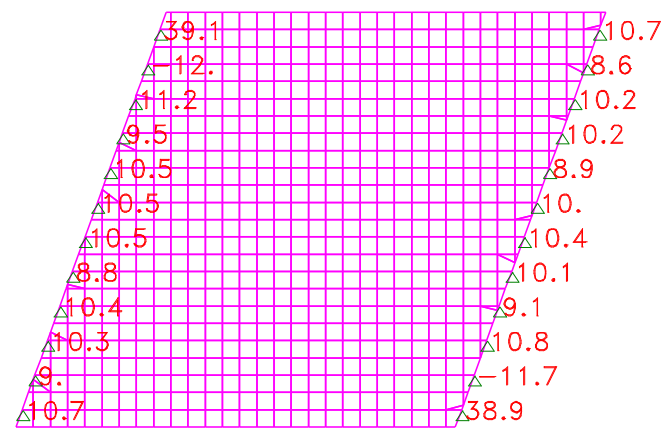

Envoltória das acidentais

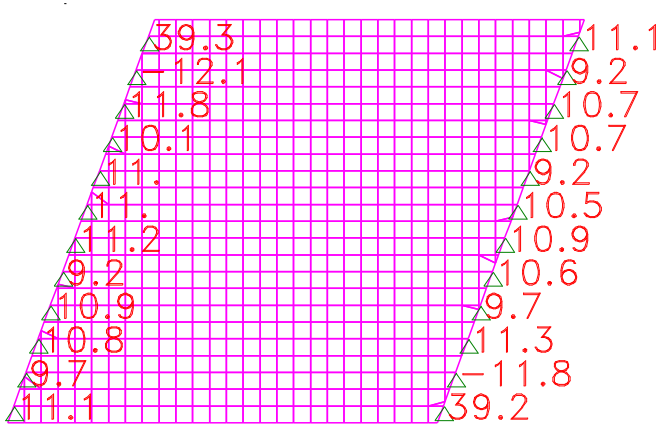


Solicitações das Lajes com $25^{\circ}$ de esconsidade

\section{Momentos Fletores}

Permanente:

Longitudinal $(\mathrm{x})$

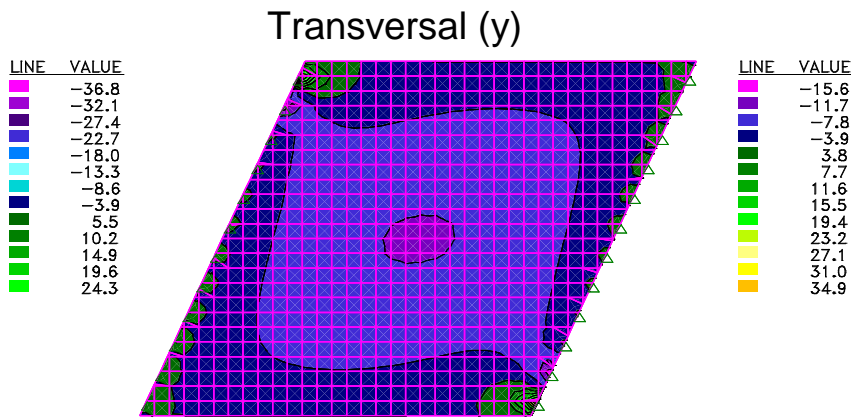

Longitudinal Mínimo (x)
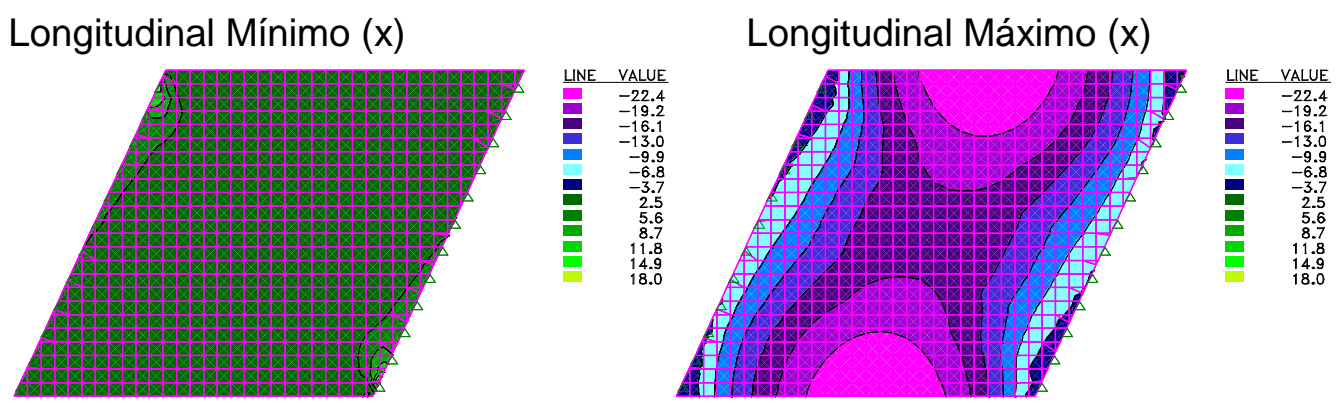

Transversal Mínimo (y)
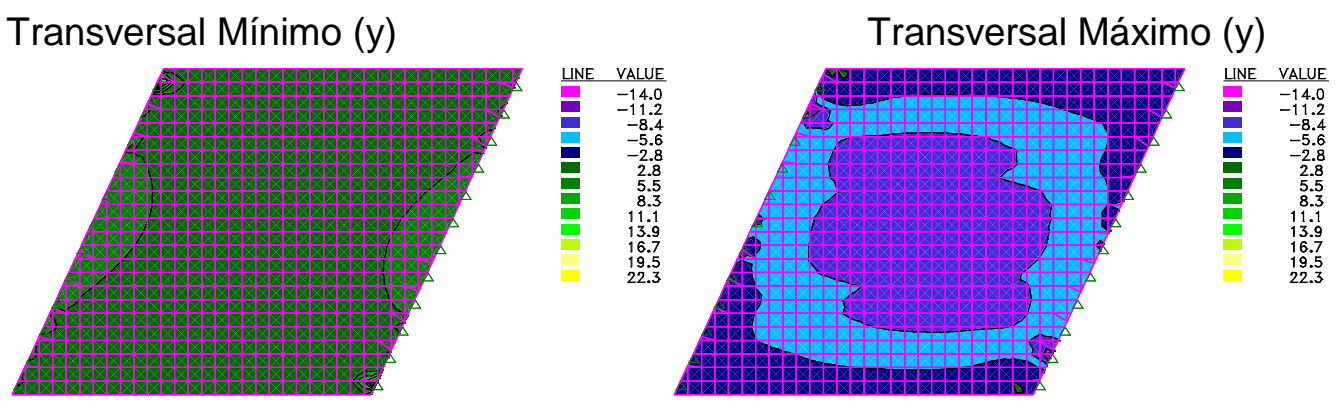

\section{Reações nos Apoios}

Permanentes

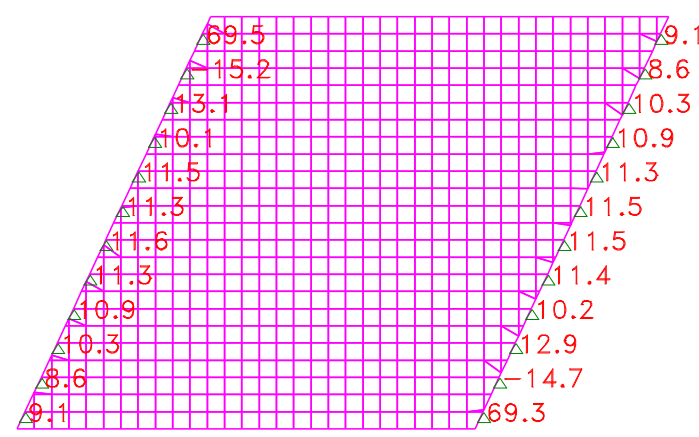

Envoltória das acidentais

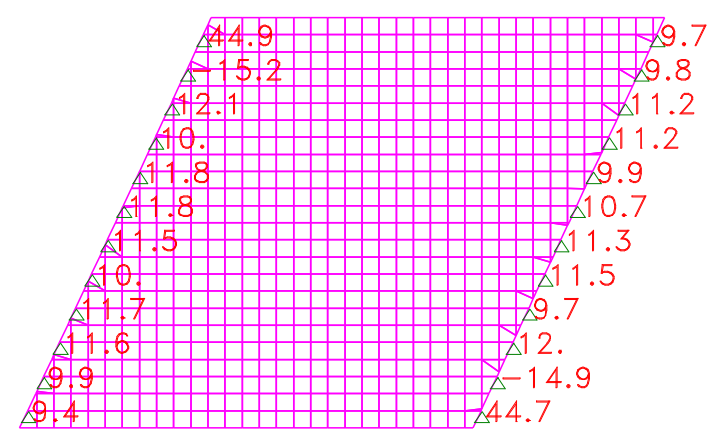


Solicitações das Lajes com $30^{\circ}$ de esconsidade

\section{Momentos Fletores}

Permanente:

Longitudinal $(\mathrm{x})$
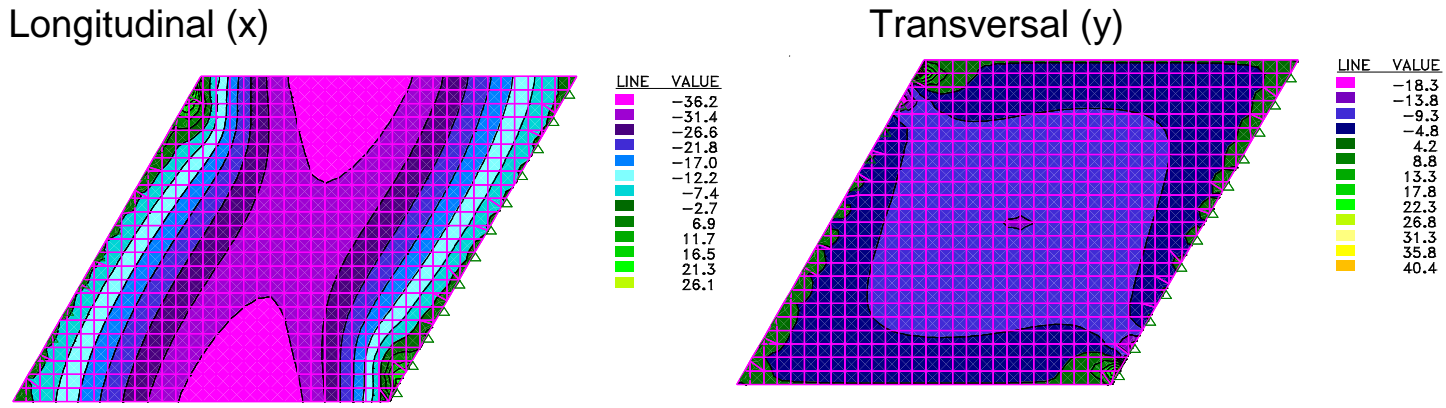

Longitudinal Mínimo (x)
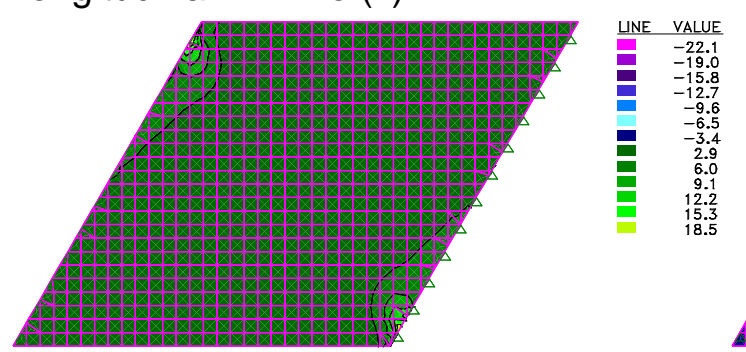

Longitudinal Máximo (x)

Transversal Mínimo (y)
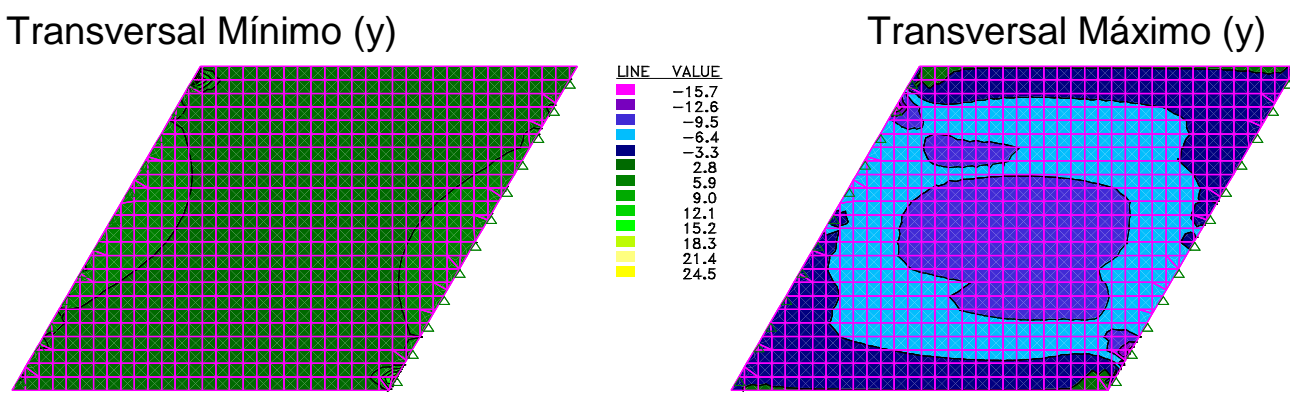

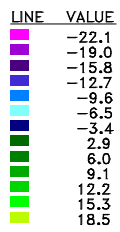

\section{Reações nos Apoios}

Permanentes

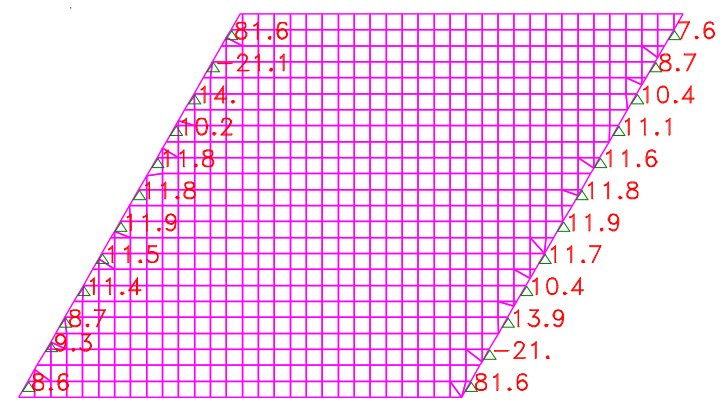

\section{Envoltória das acidentais}

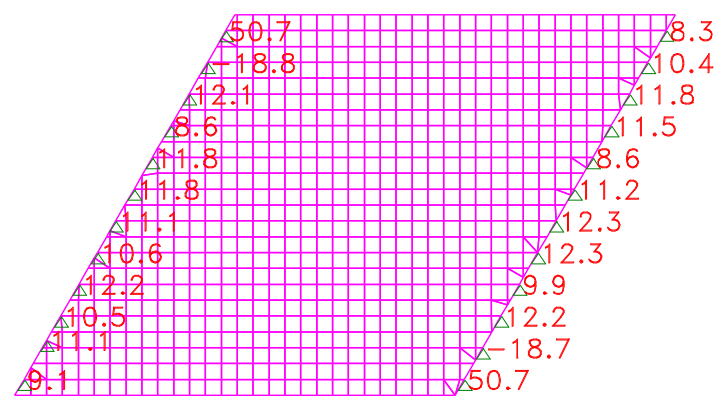


Solicitações das Lajes com $35^{\circ}$ de esconsidade

\section{Momentos Fletores}

Permanente:

Longitudinal $(\mathrm{x})$
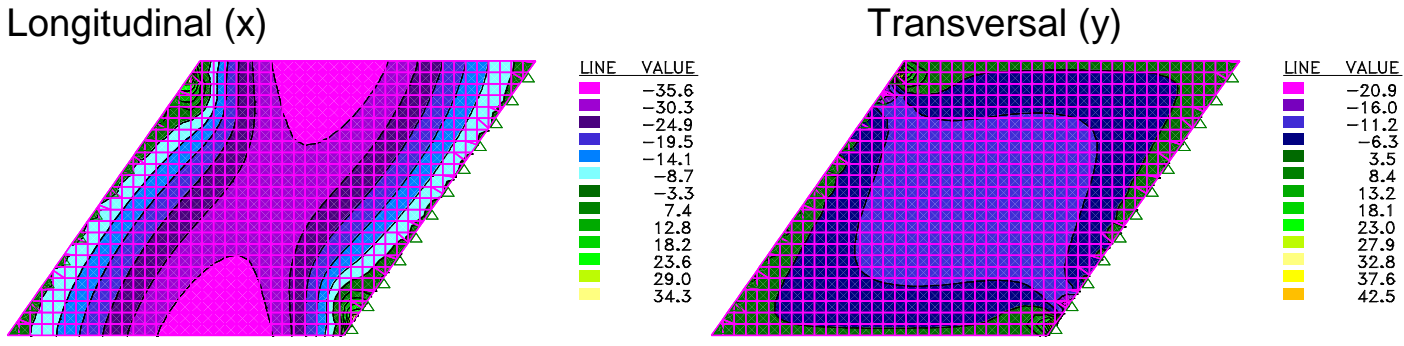

Longitudinal Mínimo (x)
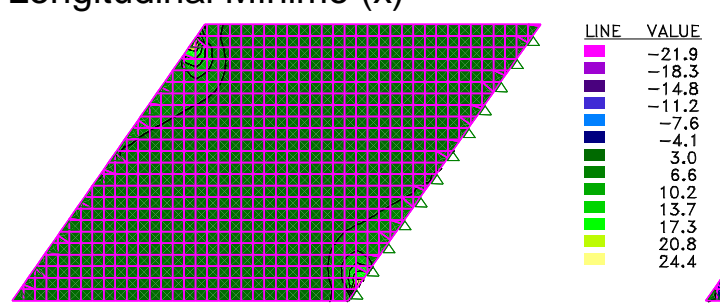

Longitudinal Máximo (x)

Transversal Mínimo (y)
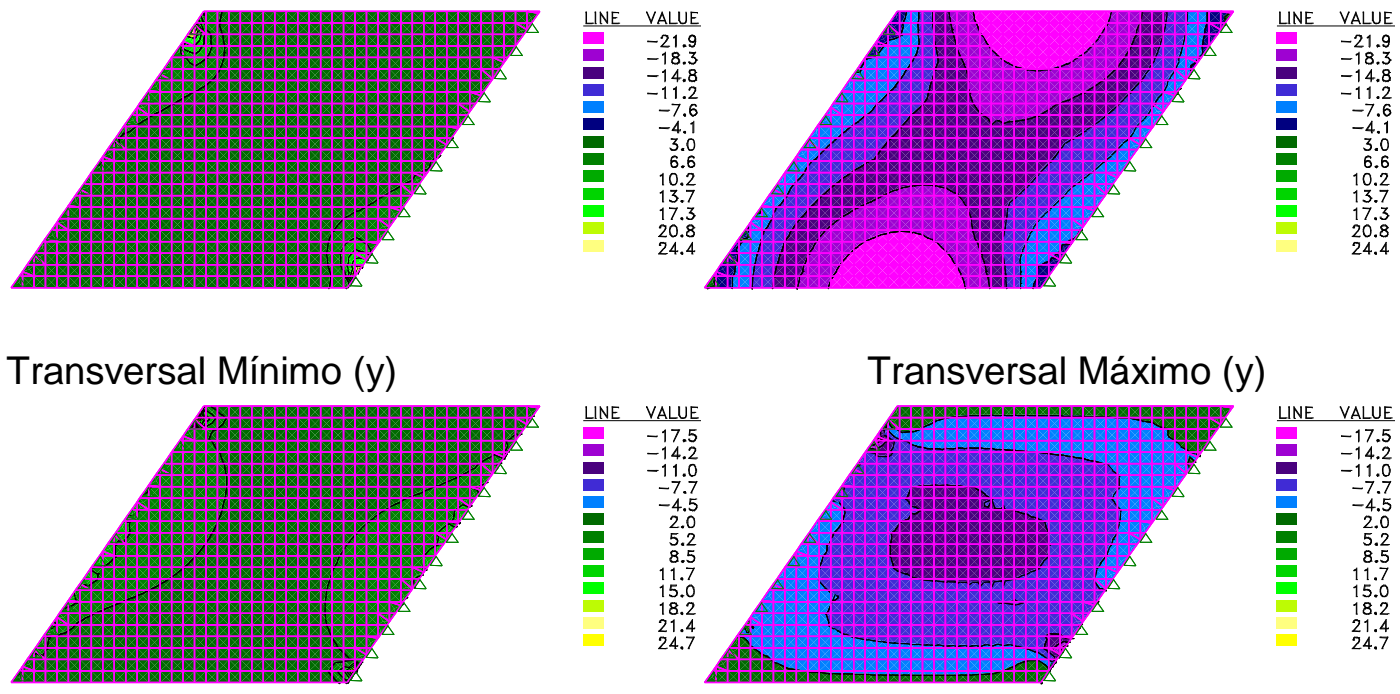

\section{Reações nos Apoios}

Permanentes

Envoltória das acidentais
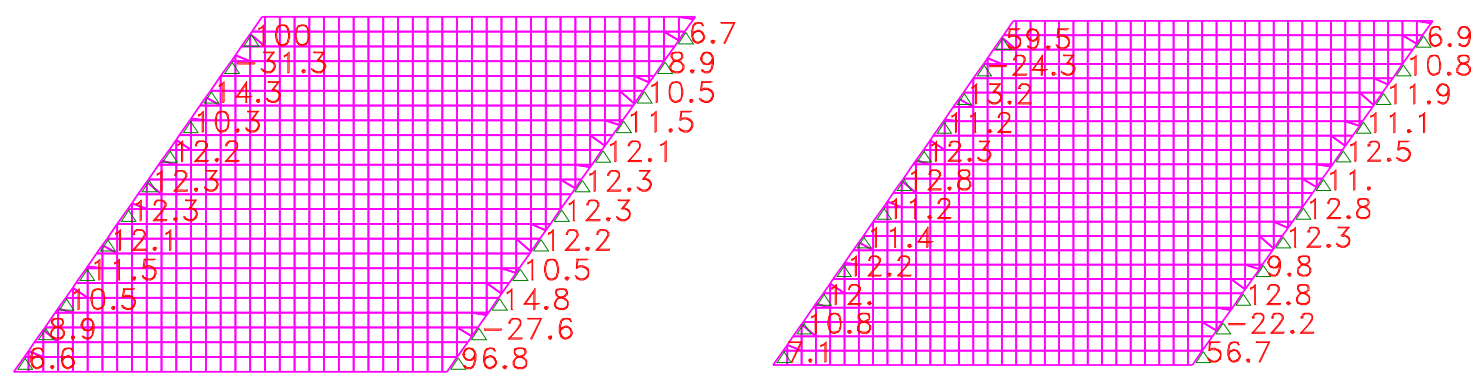
Solicitações das Lajes com $40^{\circ}$ de esconsidade

\section{Momentos Fletores}

Permanente:

Longitudinal $(\mathrm{x})$

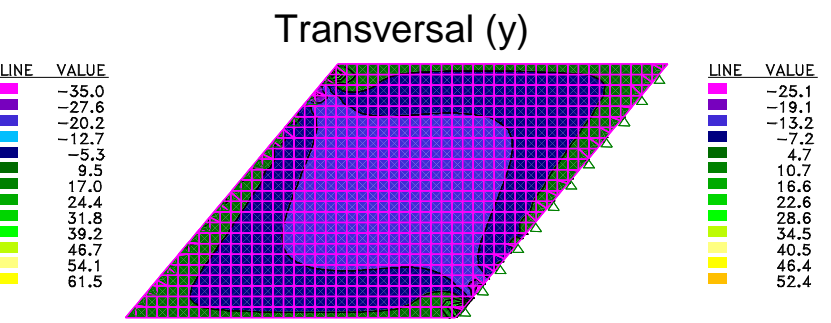

Longitudinal Mínimo (x)
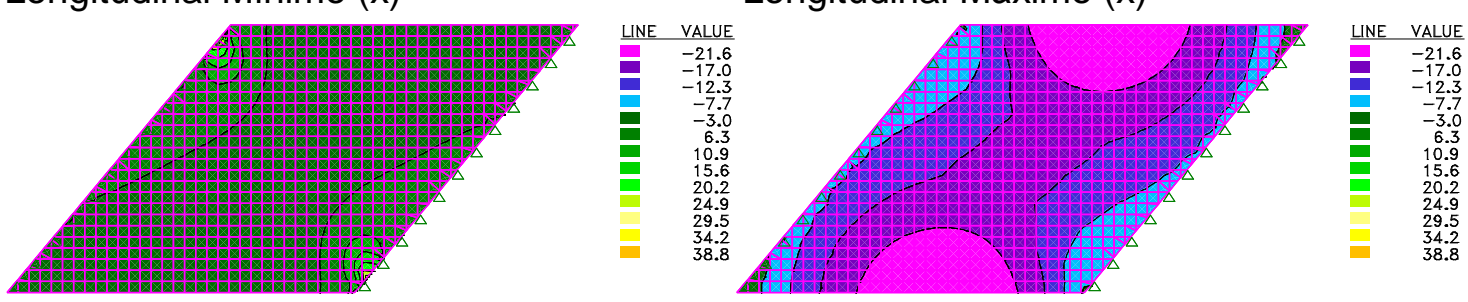

Transversal Mínimo (y)
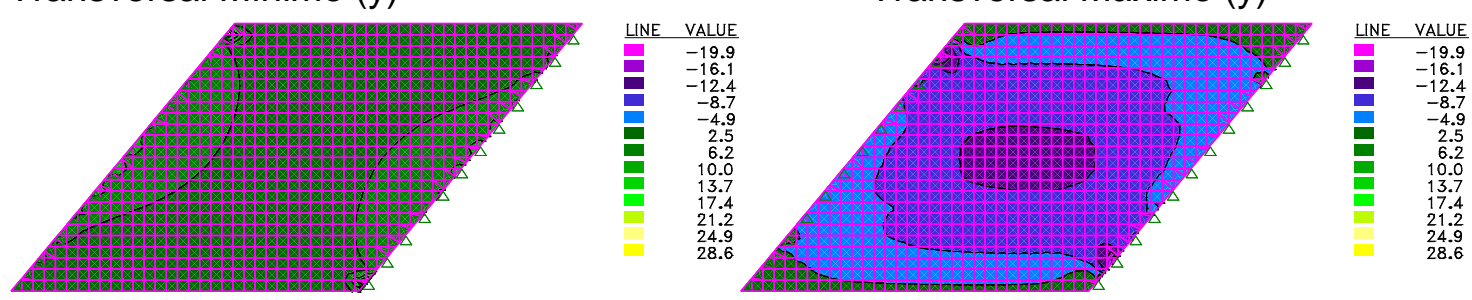

\section{Reações nos Apoios}

Permanentes

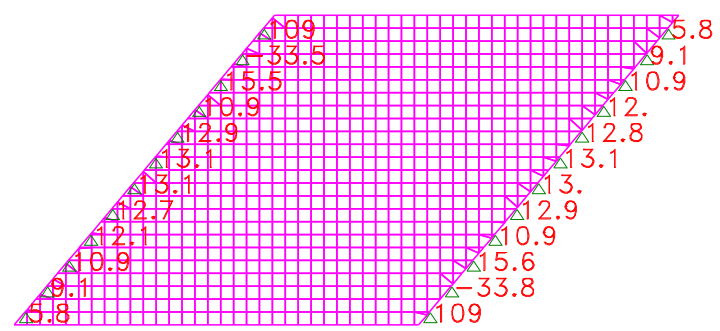

Envoltória das acidentais

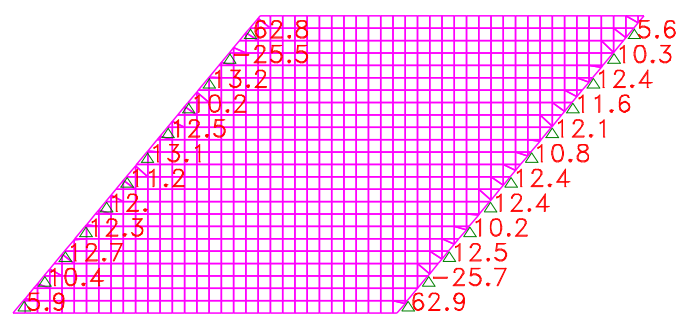


Solicitações das Lajes com $45^{\circ}$ de esconsidade

\section{Momentos Fletores}

Permanente:

Longitudinal $(\mathrm{x})$
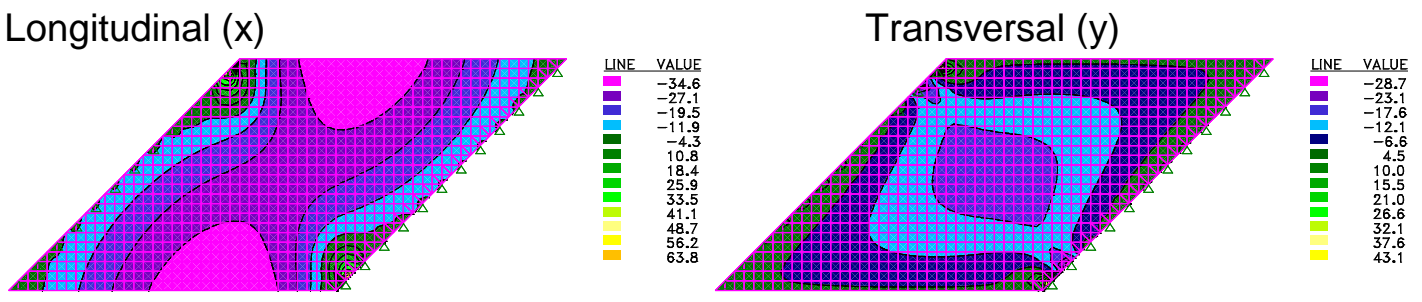

Longitudinal Mínimo (x)
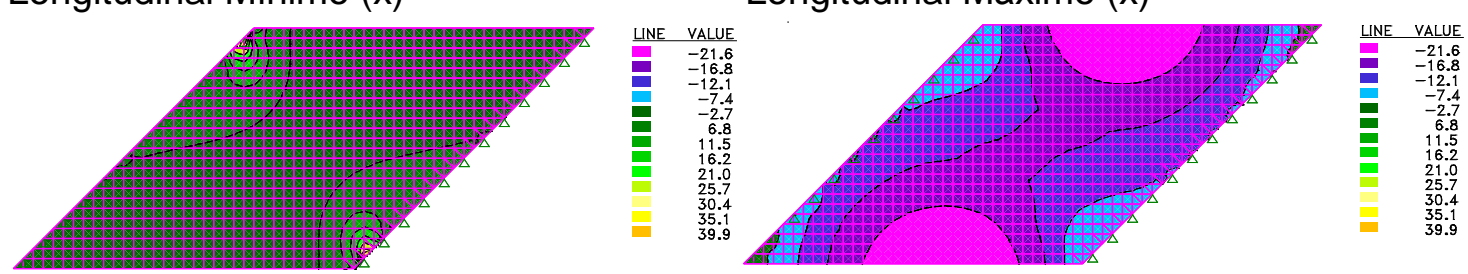

Transversal Mínimo (y)
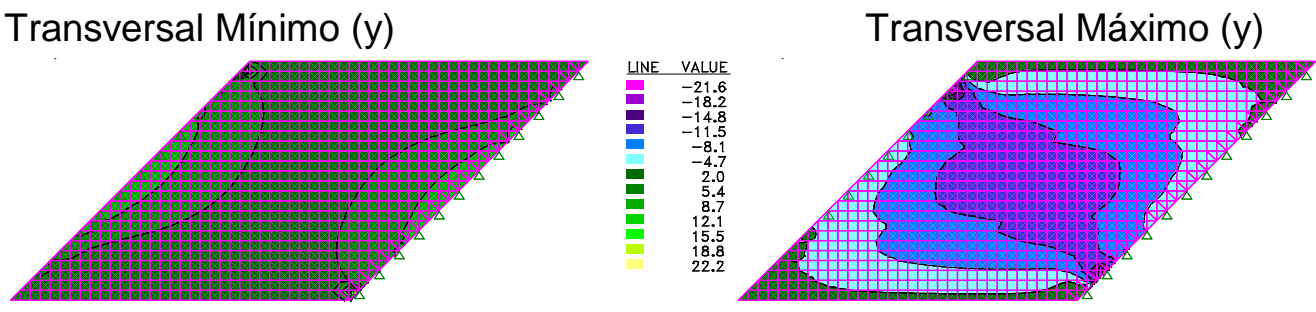

\begin{tabular}{r} 
LIME VALUE \\
\hline-21.6 \\
-18.2 \\
-14.8 \\
-11.5 \\
-8.1 \\
-4.7 \\
2.0 \\
5.4 \\
8.7 \\
12.1 \\
15.5 \\
18.8 \\
22.2 \\
\end{tabular}

\section{Reações nos Apoios}

Permanentes

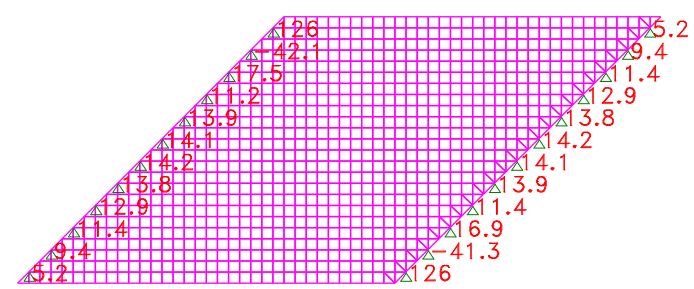

Envoltória das acidentais

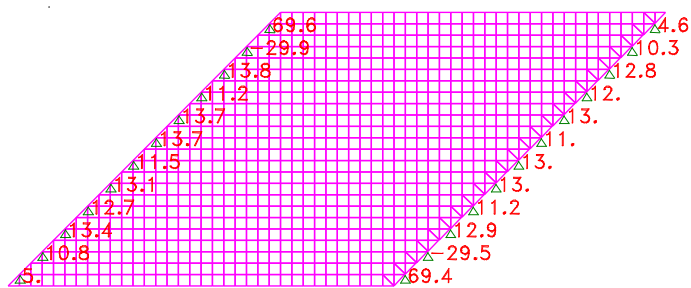


Solicitações das Lajes com $50^{\circ}$ de esconsidade

\section{Momentos Fletores}

Permanente:

Longitudinal $(\mathrm{x})$
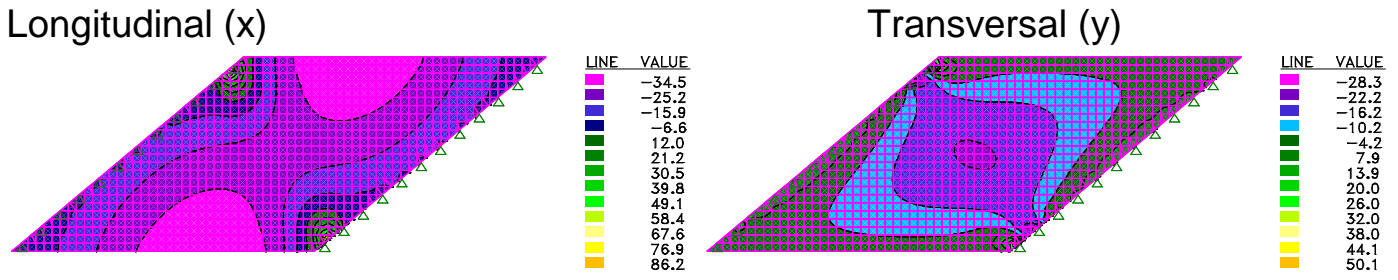

Longitudinal Mínimo (x)
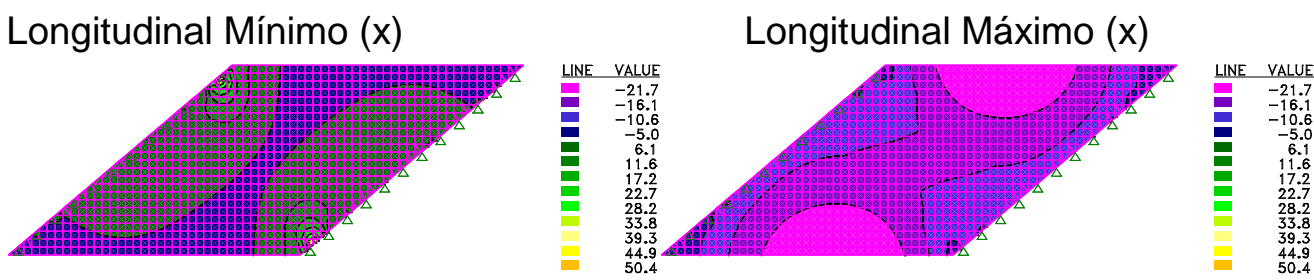

Transversal Mínimo (y)
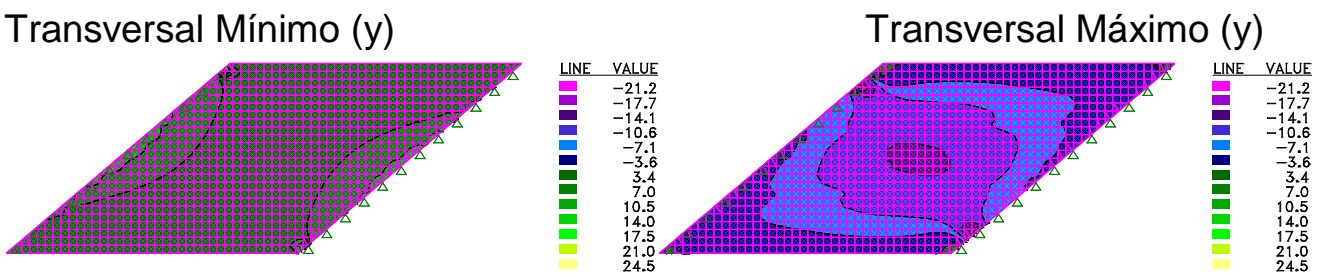

Reações nos Apoios

Permanentes

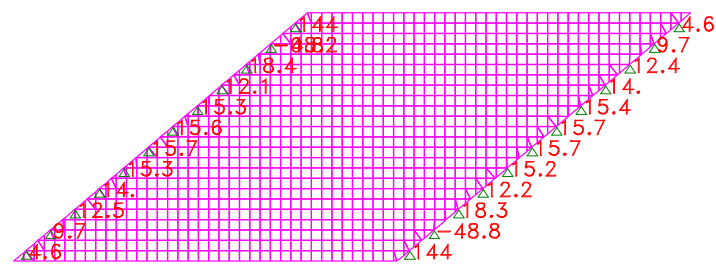

Envoltória das acidentais

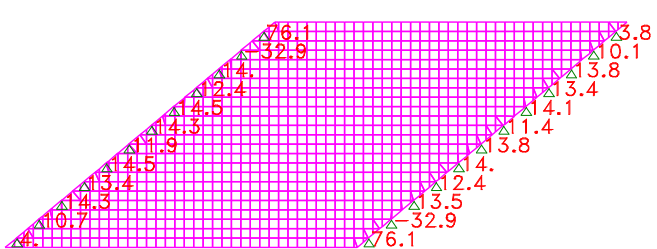


Solicitações das Lajes com $55^{\circ}$ de esconsidade

\section{Momentos Fletores}

Permanente:

Longitudinal $(\mathrm{x})$

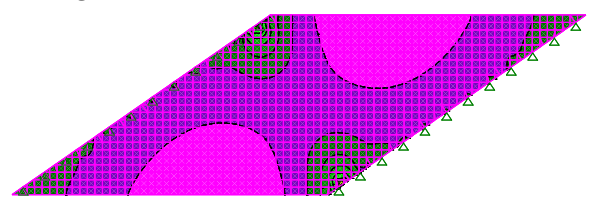

Longitudinal Mínimo (x)

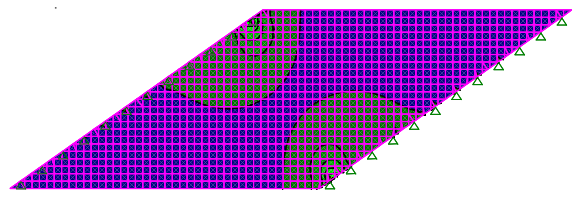

Transversal Mínimo (y)

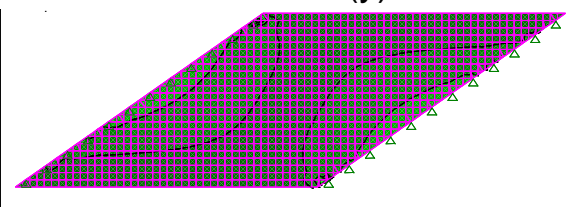

Transversal (y)

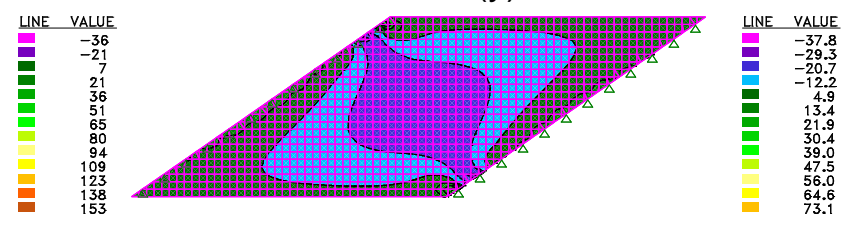

Longitudinal Máximo (x)

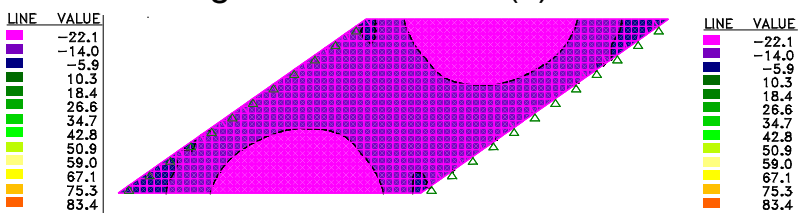

Transversal Máximo (y)

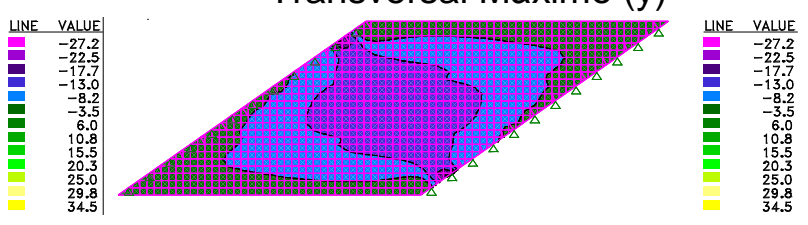

\section{Reações nos Apoios}

Permanentes

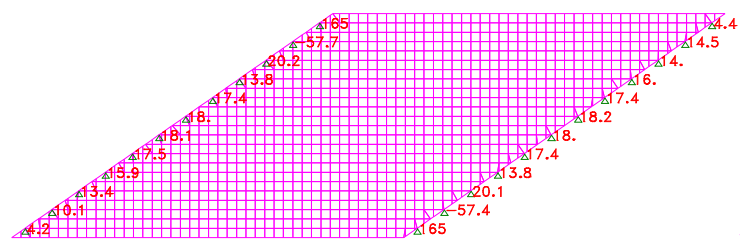

Envoltória das acidentais

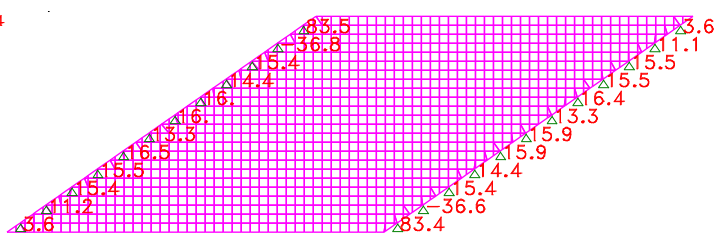


Solicitações das Lajes com $60^{\circ}$ de esconsidade

\section{Momentos Fletores}

Permanente:

Longitudinal $(\mathrm{x})$

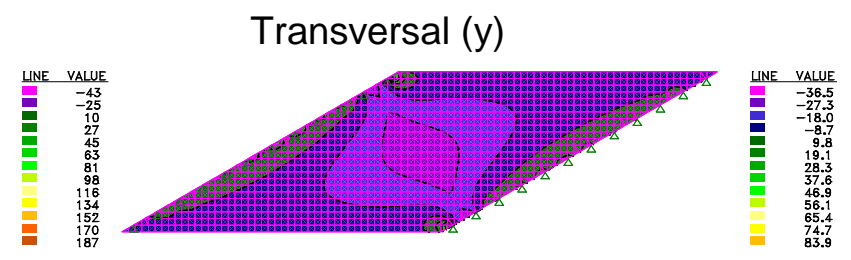

Longitudinal Mínimo (x)

Longitudinal Máximo (x)
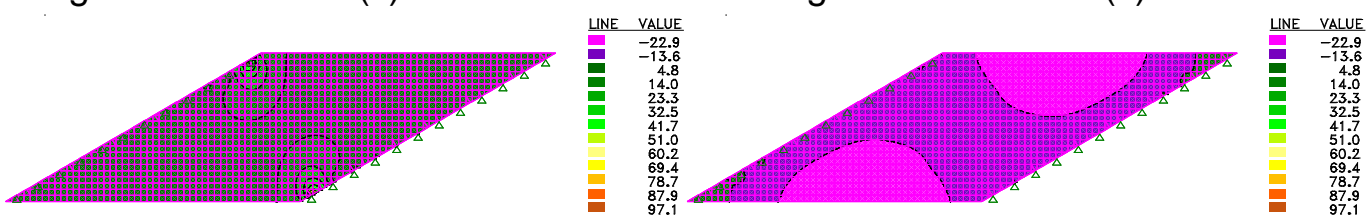

Transversal Mínimo (y)

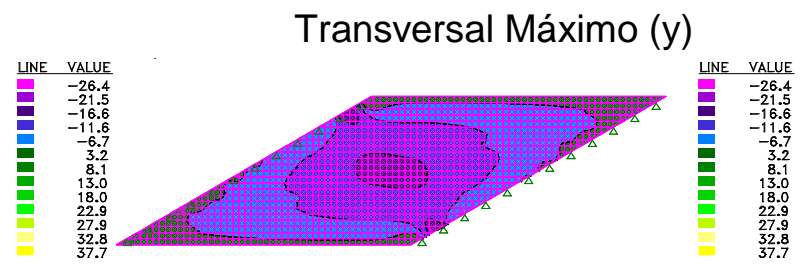

Reações nos Apoios

Permanentes

Envoltória das acidentais
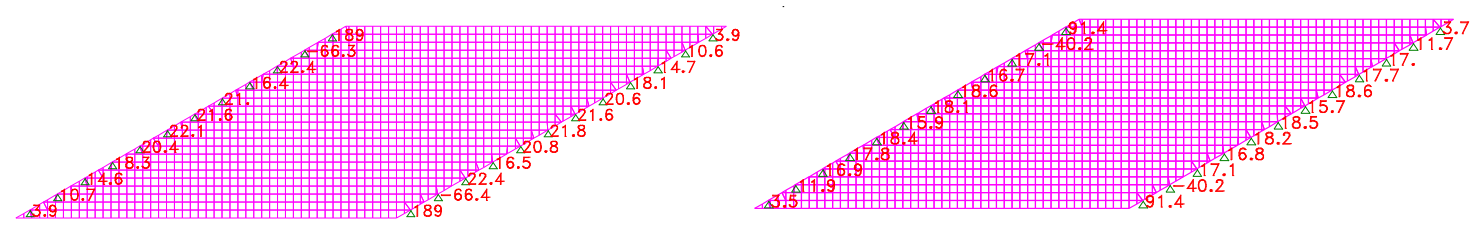


\section{ANEXO C - LAJE - APOIOS FLEXIVEIS E SEM HOMOGENEIZAÇÃO}

\section{Solicitaç̃es das lajes com $0^{\circ}$ de esconsidade}

\section{Momentos Fletores}

Permanente:

Longitudinal $(\mathrm{x})$

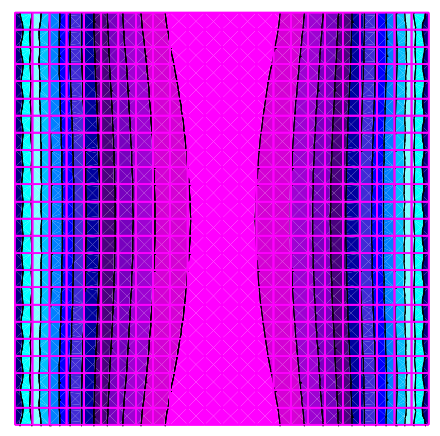

Longitudinal Mínimo (x)

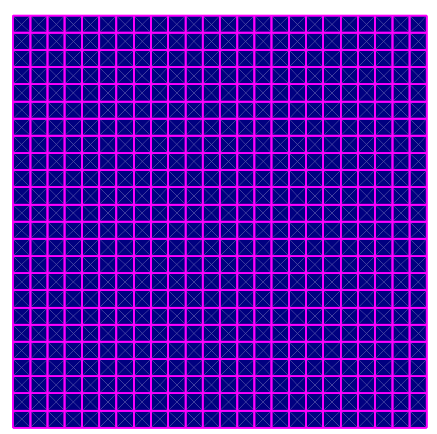

Transversal Mínimo (y)

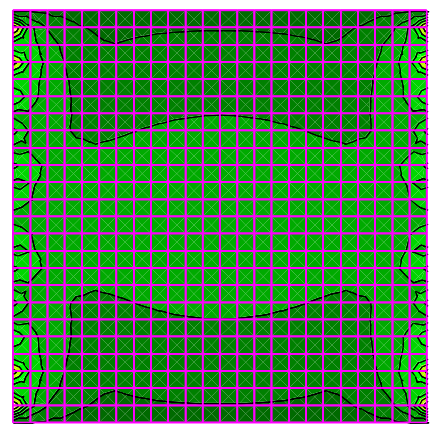

Reações nos Apoios

Permanentes
Transversal (y)
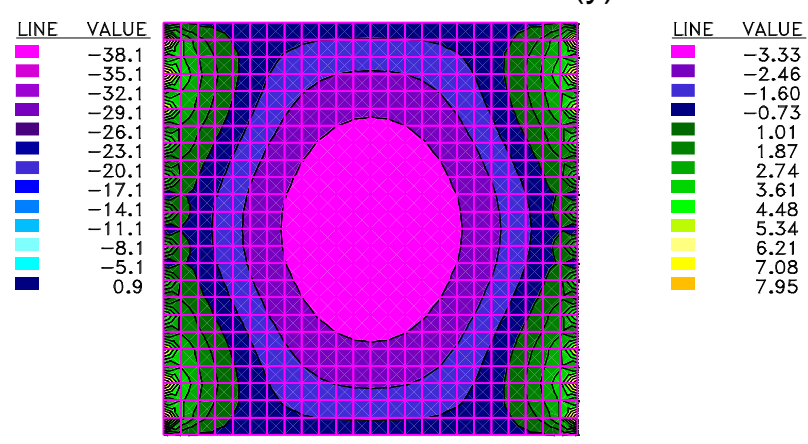

Longitudinal Máximo (x)
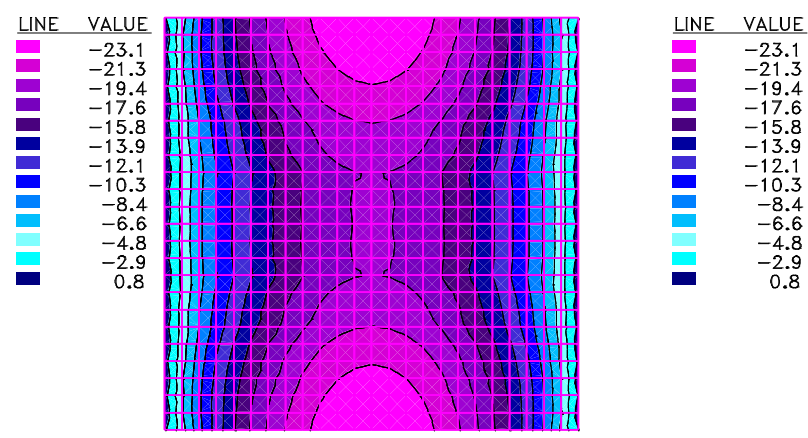

Tranversal Máximo (y)

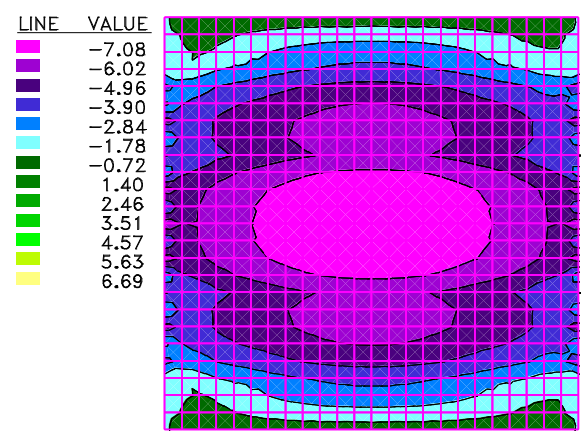

LINE VALUE
-7.08
-6.02
-4.96
-3.90
-2.84
-1.78
-0.72
1.40
2.46
3.51
4.57
5.63
6.69

Envoltória das acidentais 

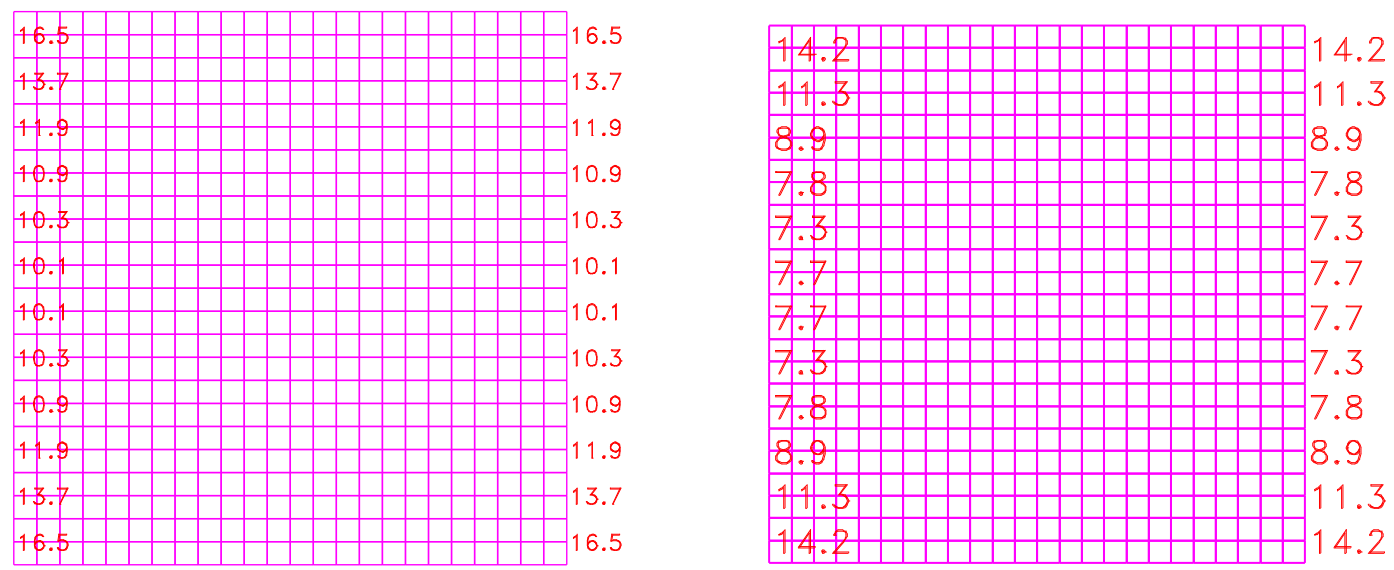

\section{Solicitacões das lajes com $5^{\circ}$ de esconsidade} Momentos Fletores

Permanente:

Longitudinal $(\mathrm{x})$

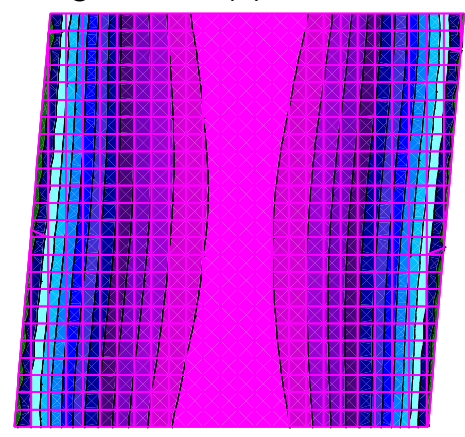

Longitudinal Mínimo (x)

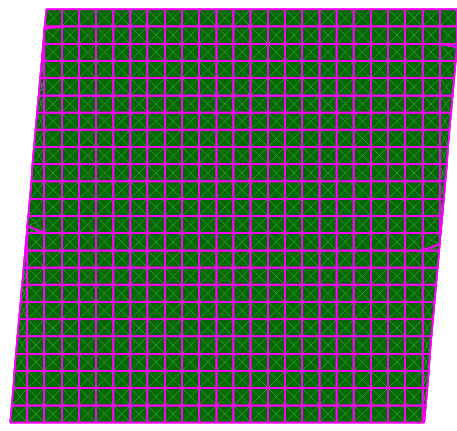

Transversal Mínimo (y)

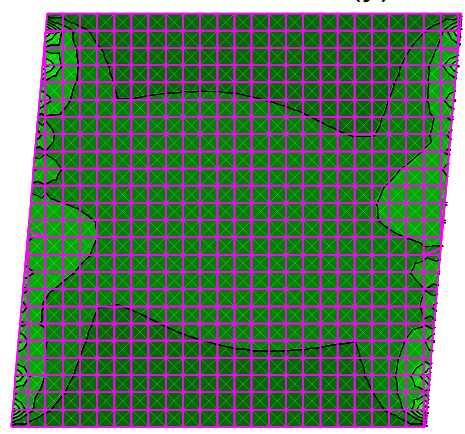

Transversal (y)
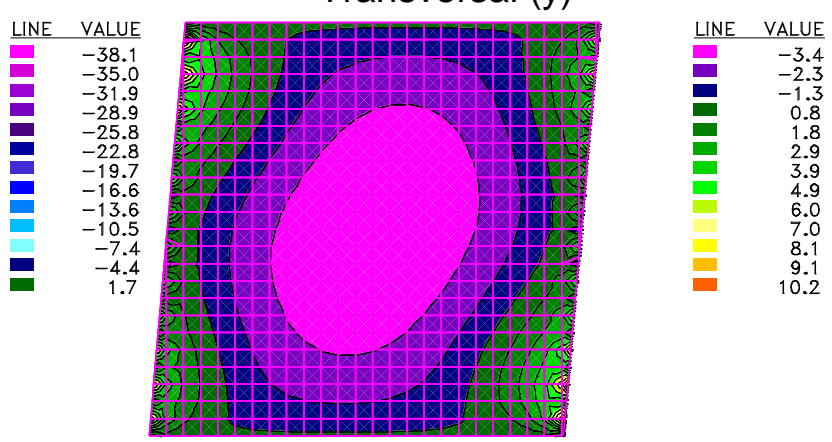

Longitudinal Máximo (x)
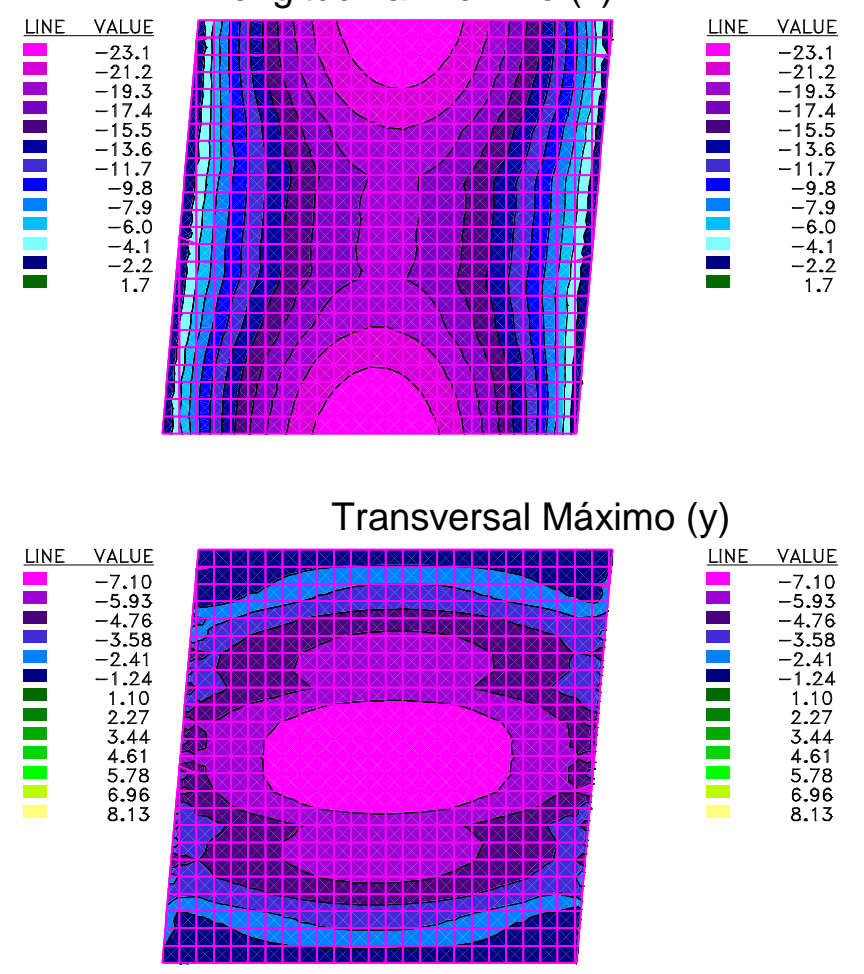
Reações nos Apoios
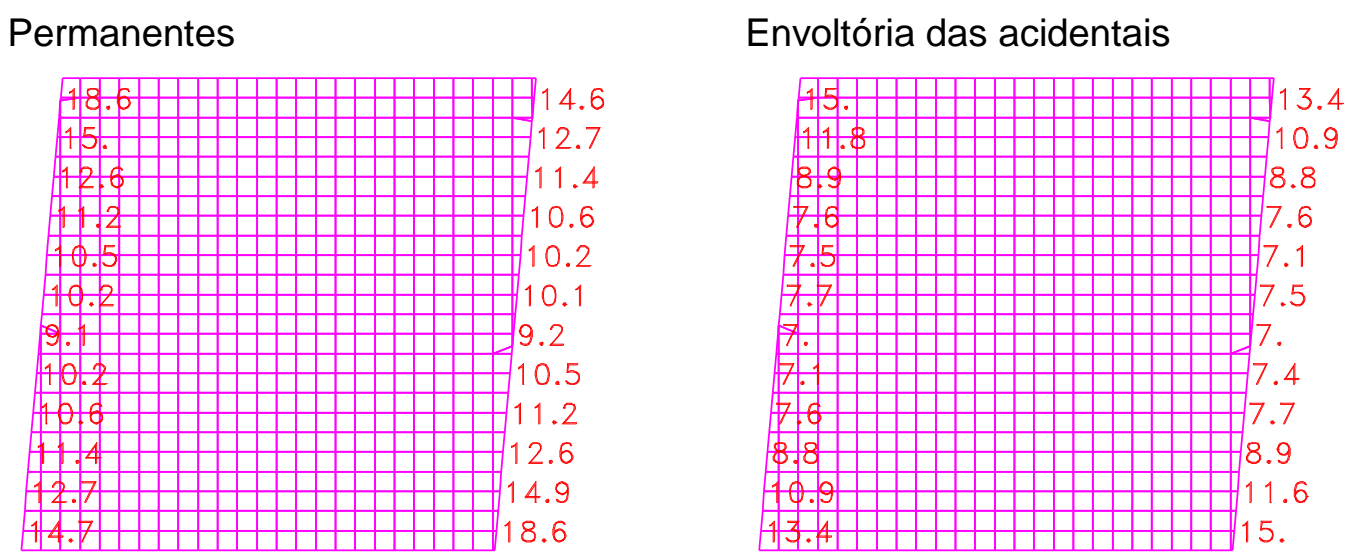

\section{Solicitacões das lajes com $10^{\circ}$ de esconsidade}

\section{Momentos Fletores}

Permanente:

Longitudinal (x)

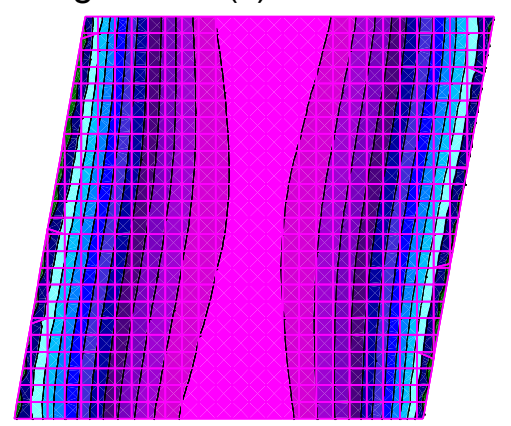

Longitudinal Mínimo (x)

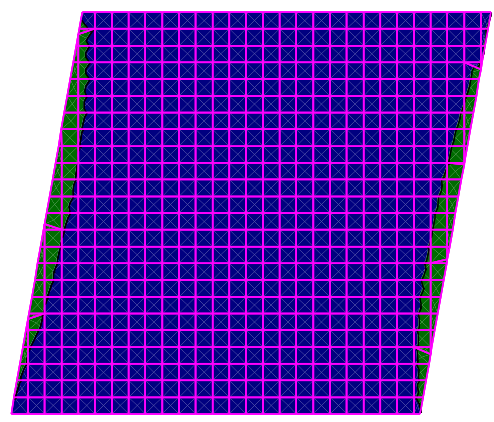

Transversal Mínimo (y)

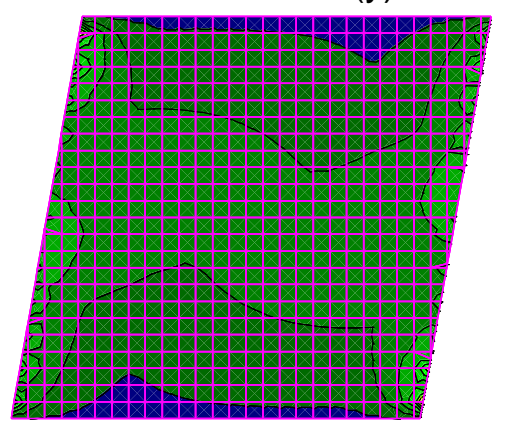

Transversal $(\mathrm{y})$

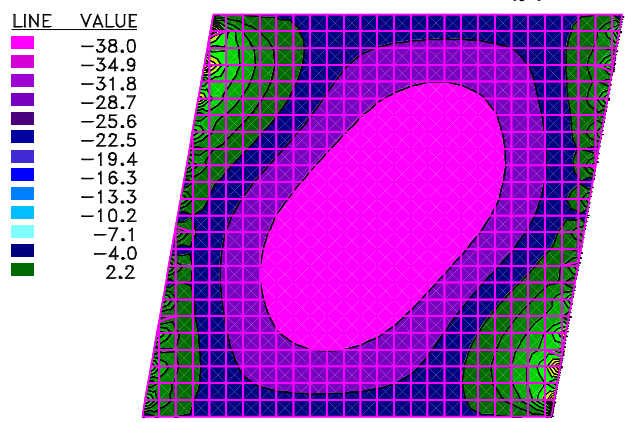

LINE VALUE
-3.6
-2.4
-1.2
1.2
2.4
3.6
4.8
6.0
7.2
8.4
9.6
10.8
12.0
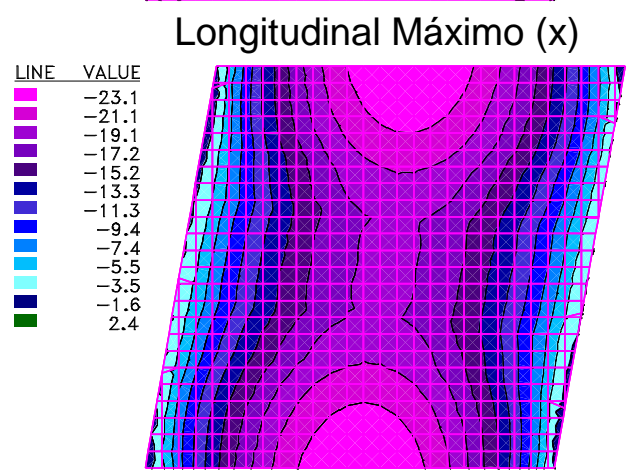

LINE VALUE
-23.1
-21.1
-19.1
-17.2
-15.2
-13.3
-11.3
-9.4
-7.4
-5.5
-3.5
-1.6
2.4

Transversal Máximo (y)

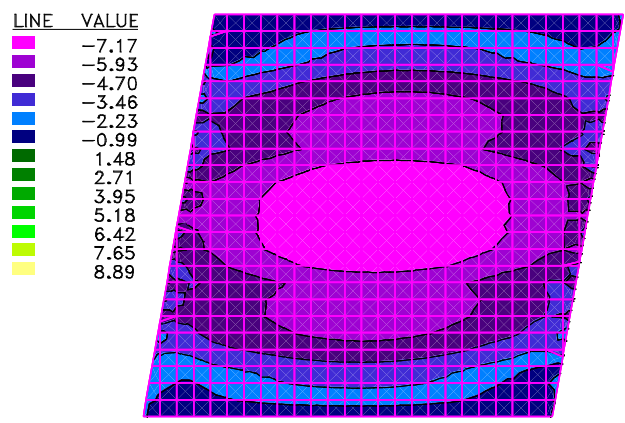

LINE VALUE
-7.17
-5.93
-4.70
-3.46
-2.23
-0.99
1.48
2.71
3.95
5.18
6.42
7.65
8.89 


\section{olicitações das lajes com $15^{\circ}$ de esconsidade}

\section{Momentos Fletores}

Permanente:

Longitudinal $(\mathrm{x})$

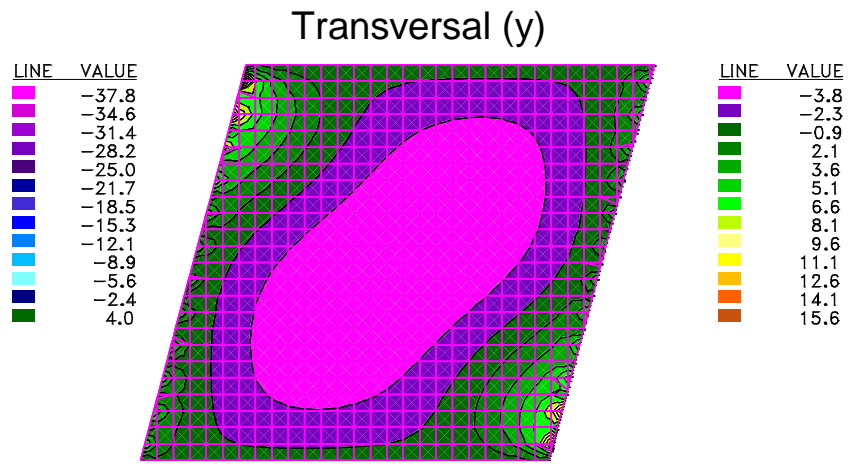

Longitudinal Mínimo (x)
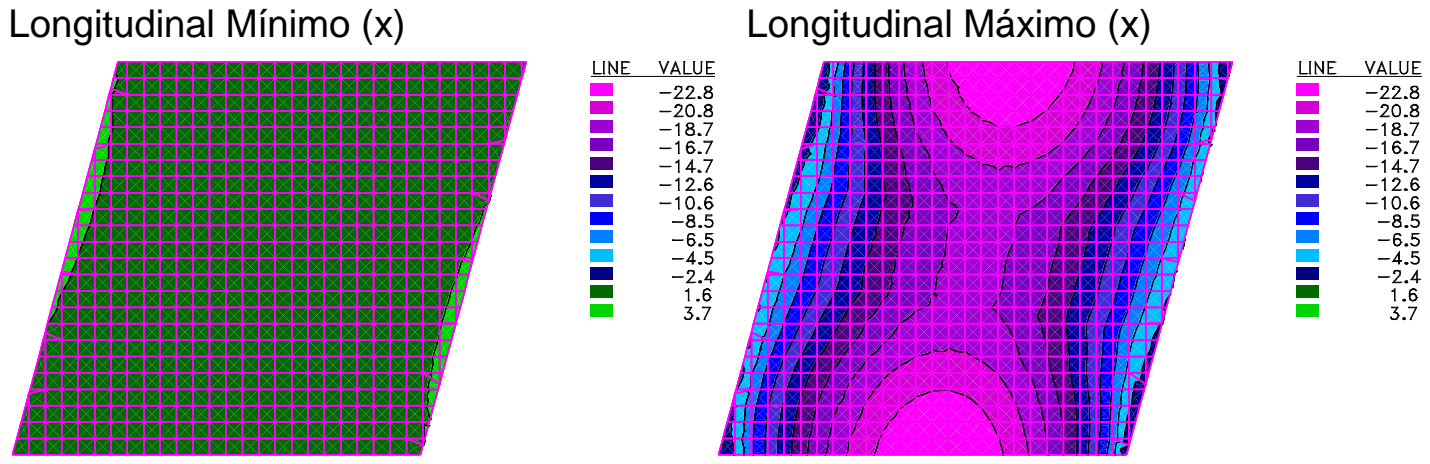

Transversal Mínimo (y)
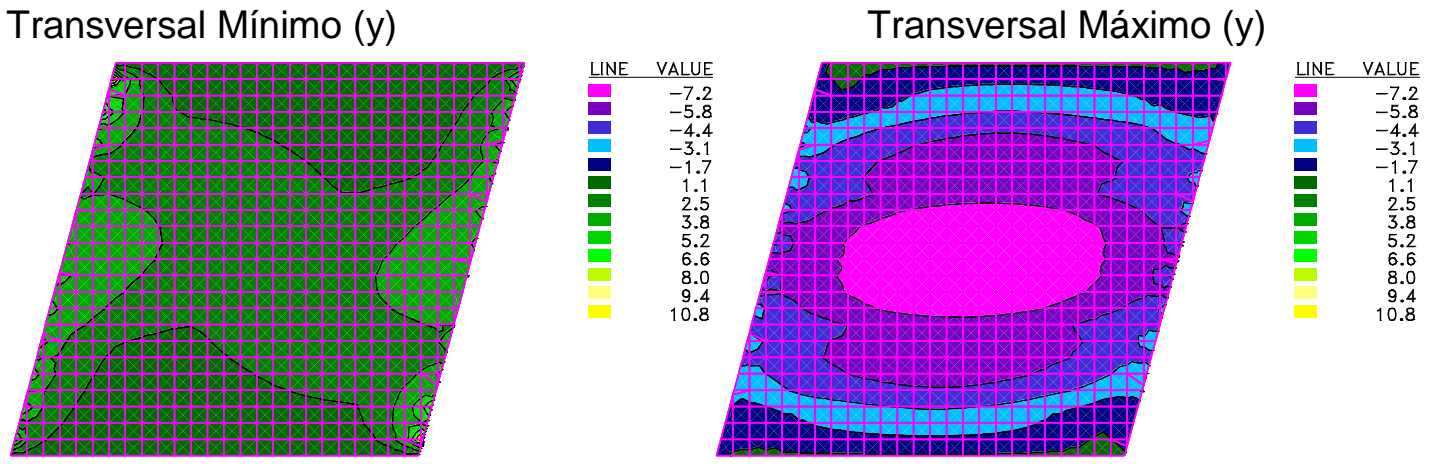

Reações nos Apoios

Permanentes

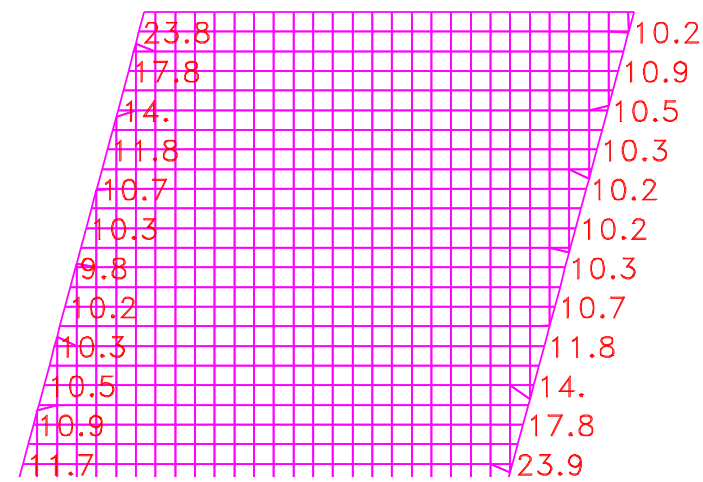

Envoltória das acidentais

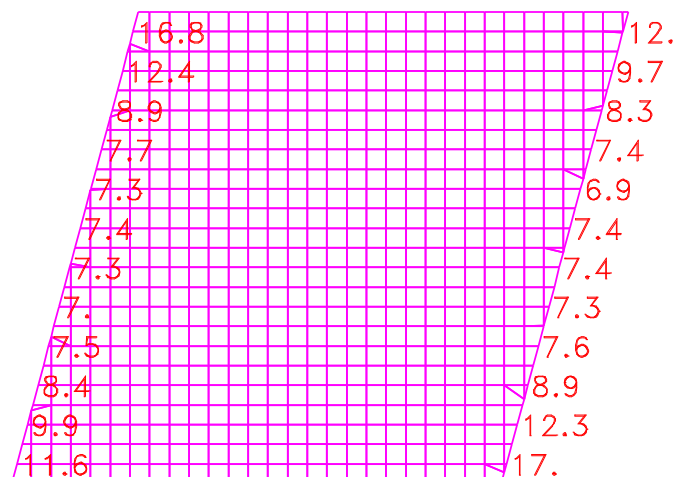




\section{Solicitacões das lajes com $20^{\circ}$ de esconsidade}

\section{Momentos Fletores}

Permanente:

Longitudinal ( $\mathrm{x}$ )
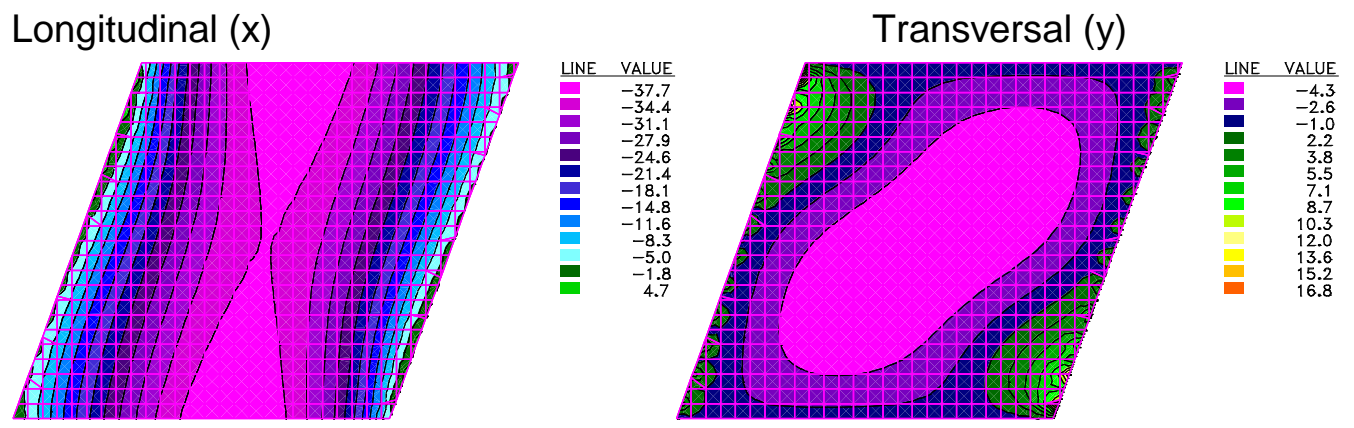

Longitudinal Mínimo (x)
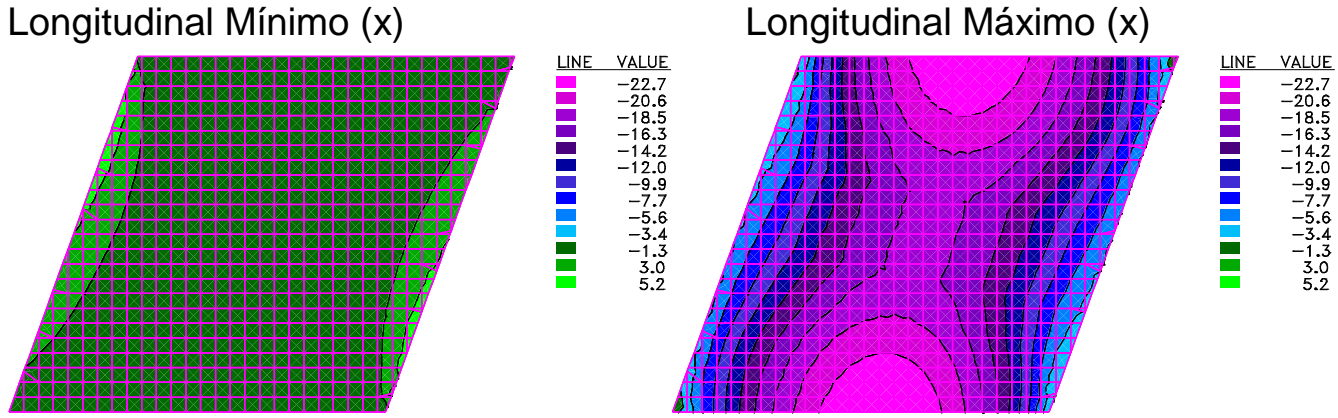

Transversal Mínimo (y)

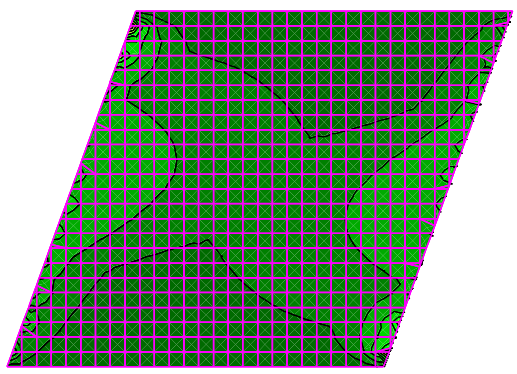

Transversal Máximo (y)

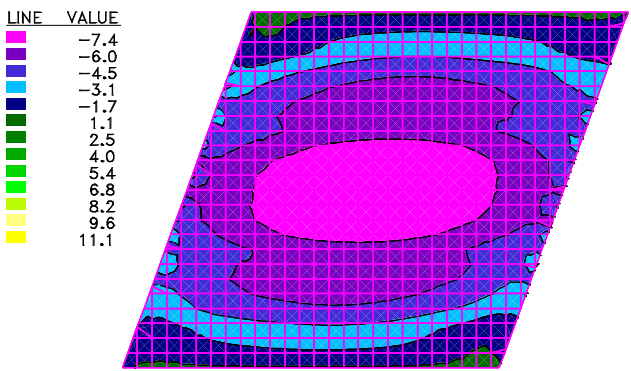

VALUE
-7.4
-6.0
-4.5
-3.1
-1.7
1.1
2.5
4.0
5.4
6.8
8.2
9.6
11.1

\section{Reações nos Apoios}

Permanentes

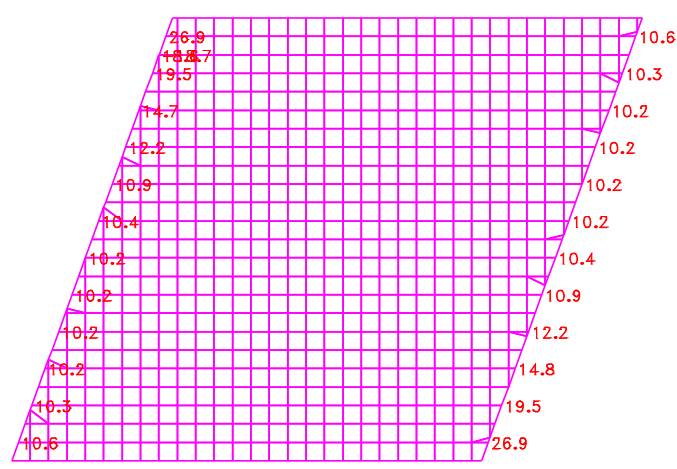

Envoltória das acidentais

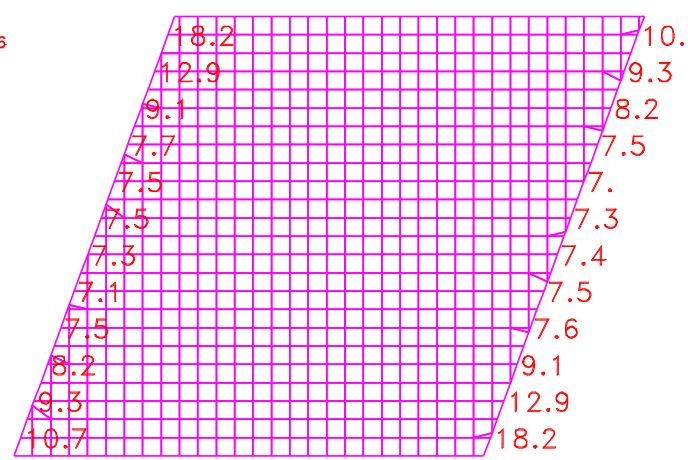




\section{Solicitacões das lajes com $25^{\circ}$ de esconsidade}

\section{Momentos Fletores}

Permanente:

Longitudinal $(\mathrm{x})$
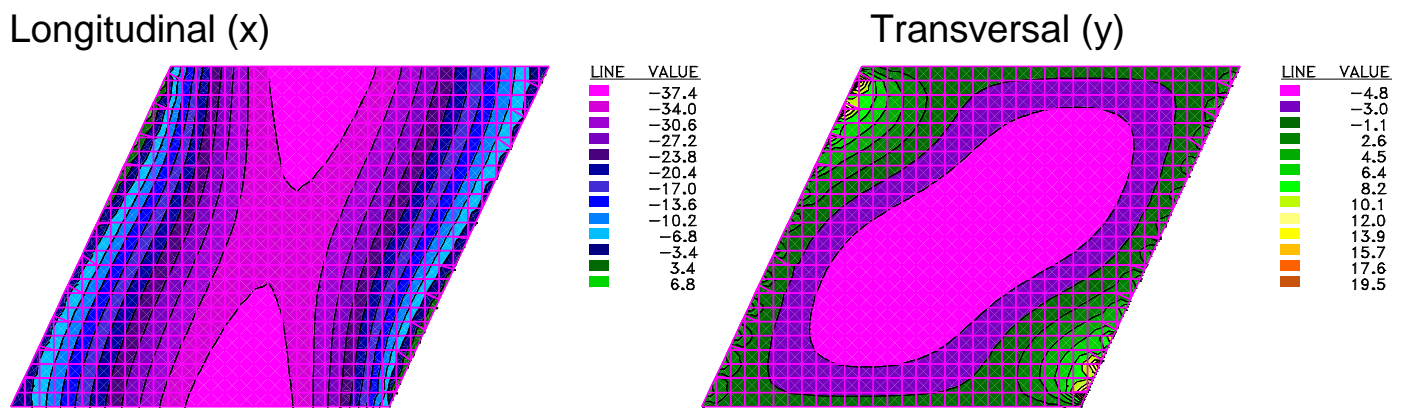

Longitudinal Mínimo (x)
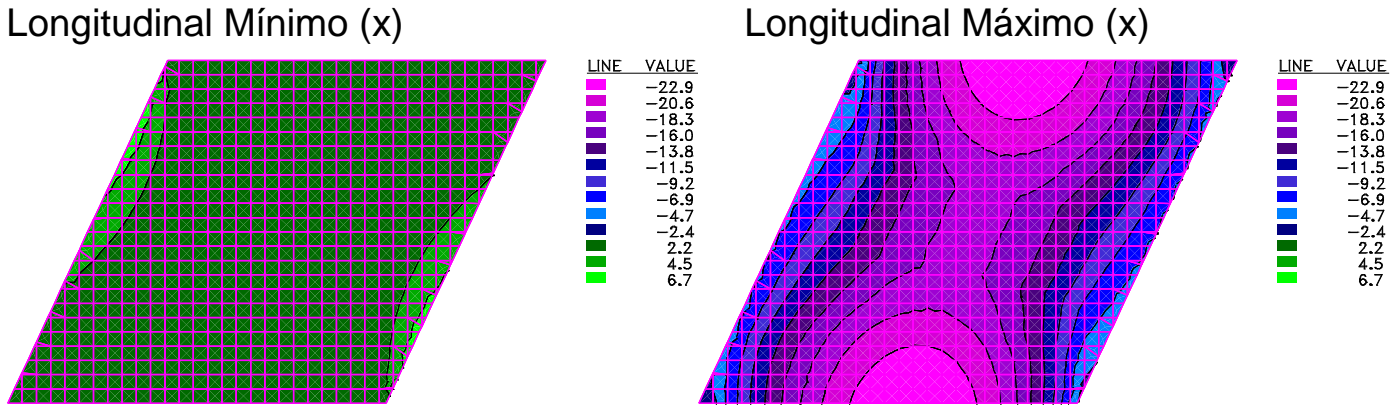

Transversal Mínimo (y)
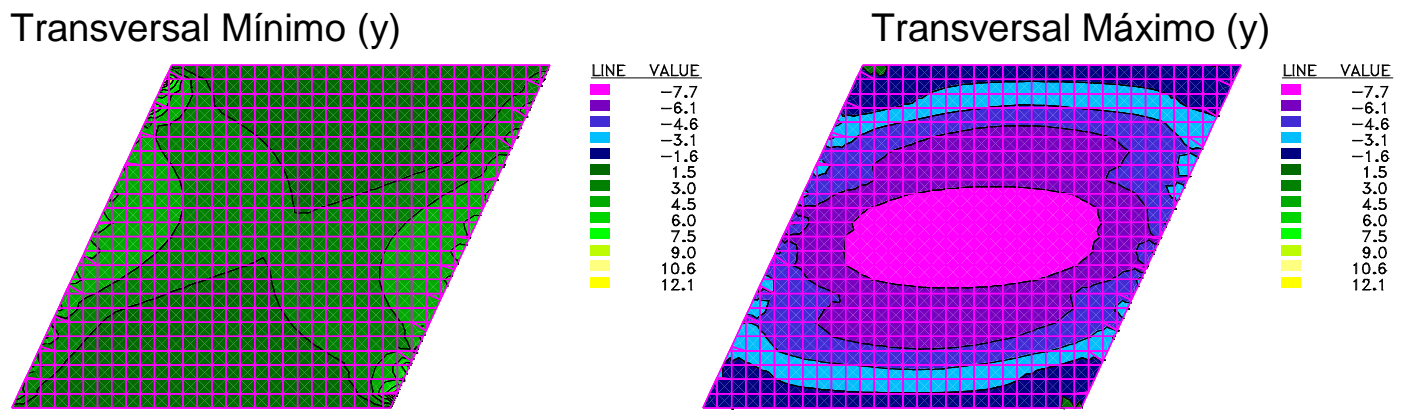

\section{Reações nos Apoios}

Permanentes

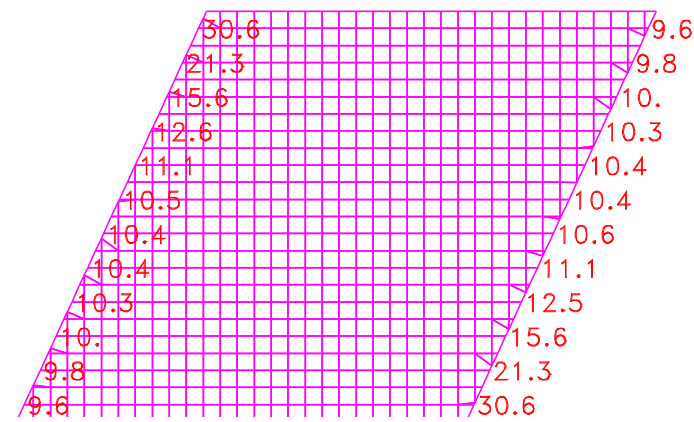

Envoltória das acidentais

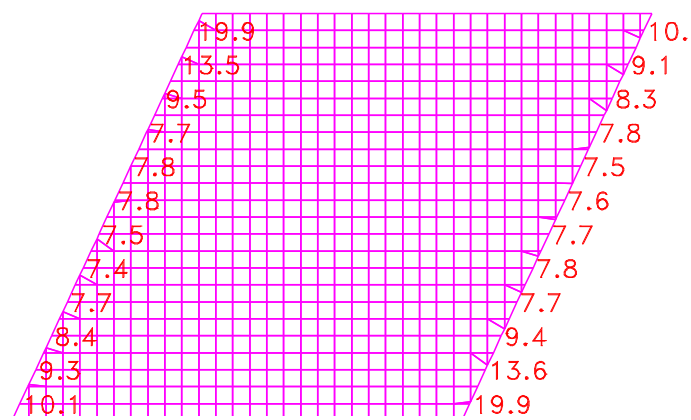




\section{Solicitacões das lajes com $30^{\circ}$ de esconsidade}

\section{Momentos Fletores}

Permanente:

Longitudinal $(\mathrm{x})$
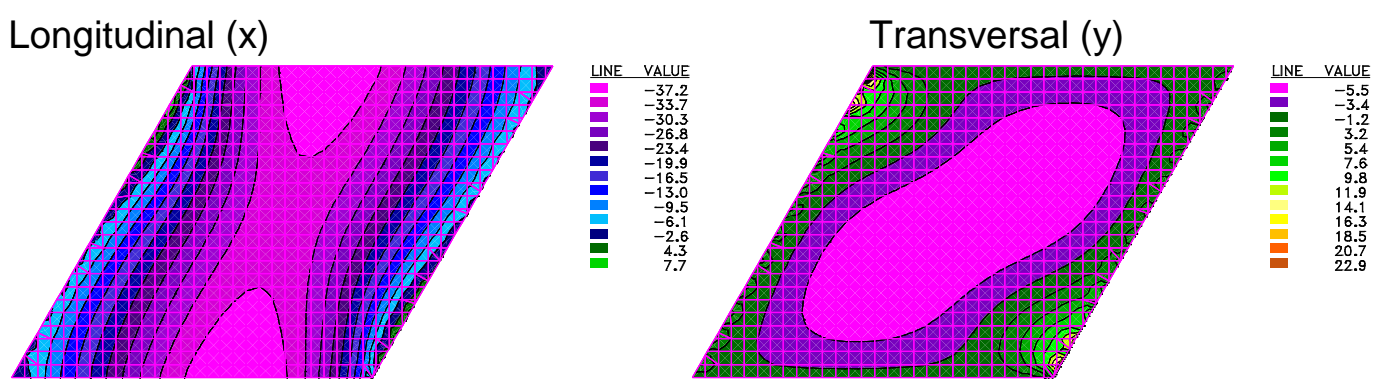

Longitudinal Mínimo (x)
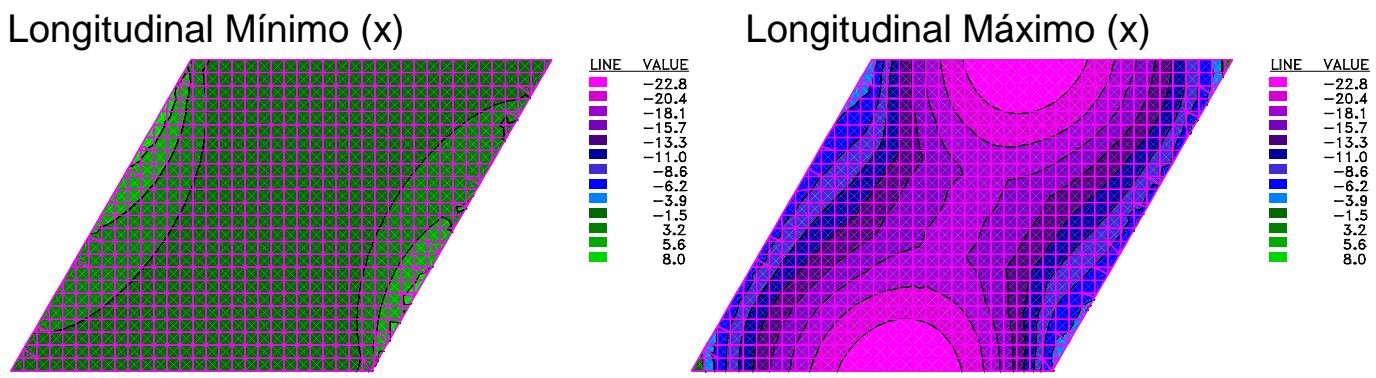

Transversal Mínimo (y)
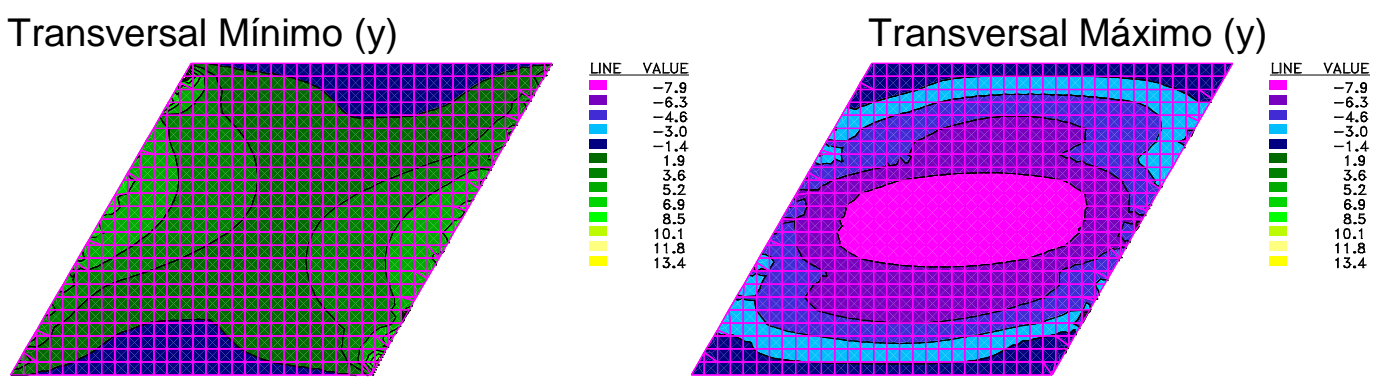

\section{Reações nos Apoios}

Permanentes

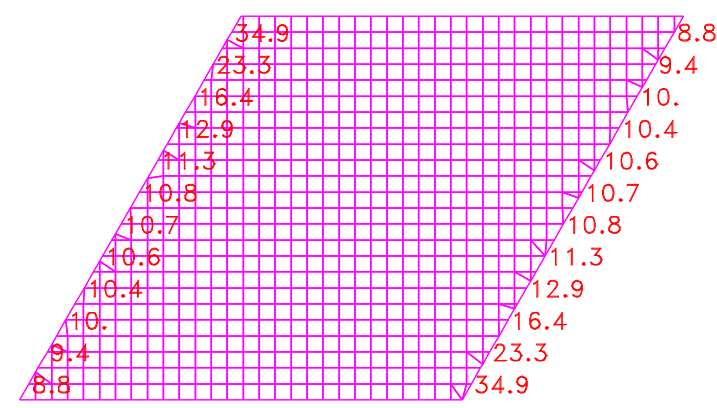

Envoltória das acidentais

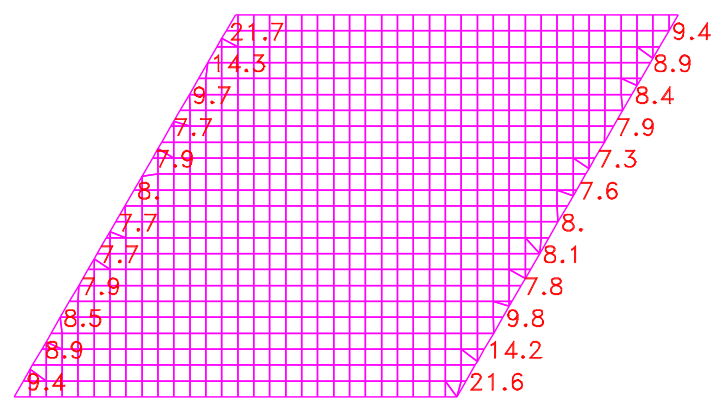




\section{Solicitacões das lajes com $35^{\circ}$ de esconsidade}

\section{Momentos Fletores}

Permanente:

Longitudinal $(x)$

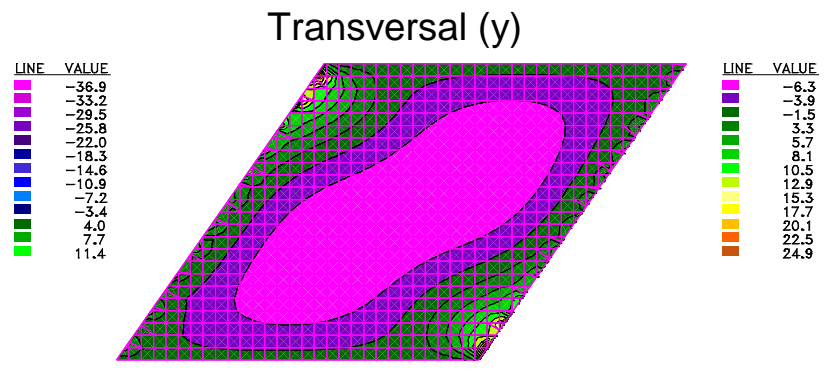

Longitudinal Mínimo (x)

Longitudinal Máximo (x)
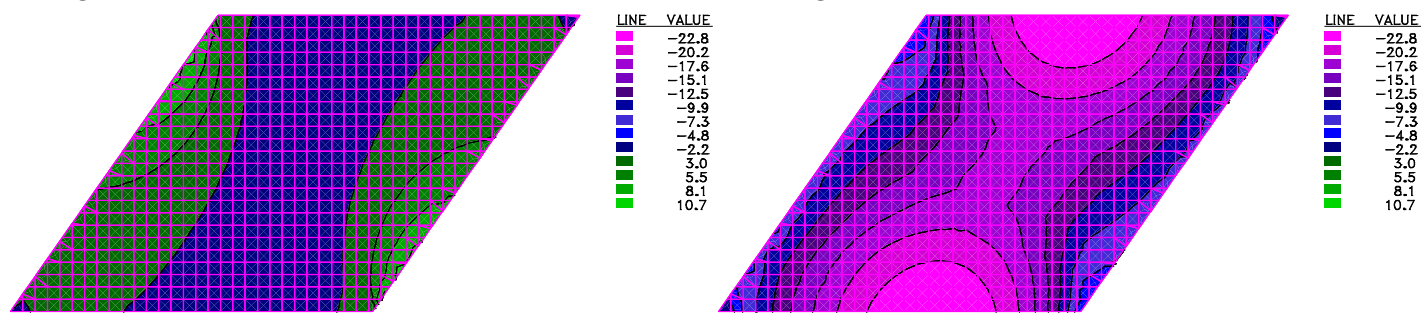

Transversal Mínimo (y)
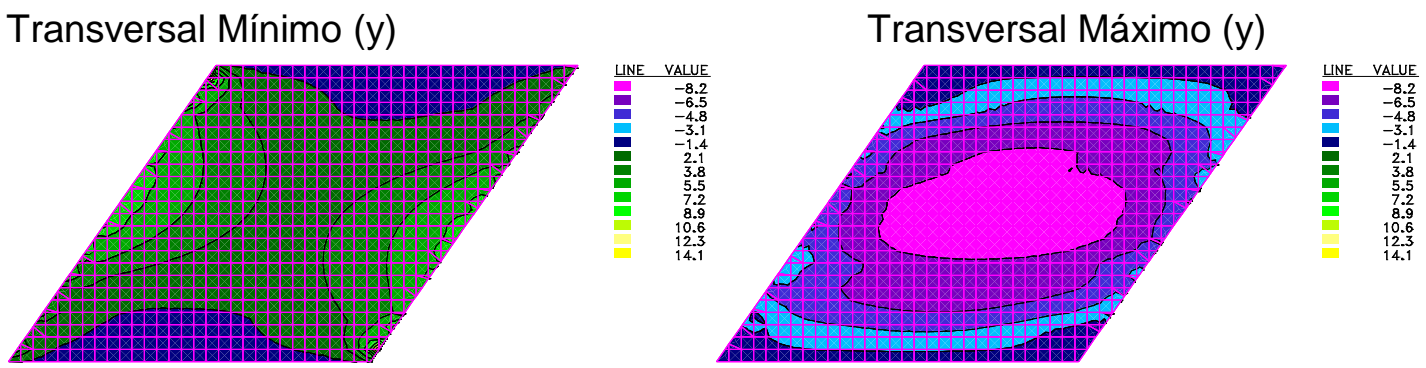

\section{Reações nos Apoios}

Permanentes

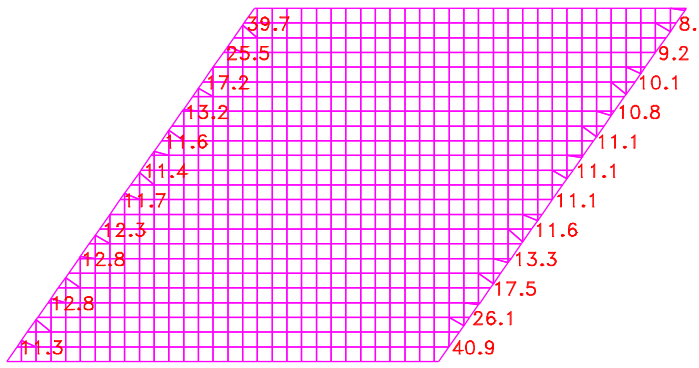

Envoltória das acidentais

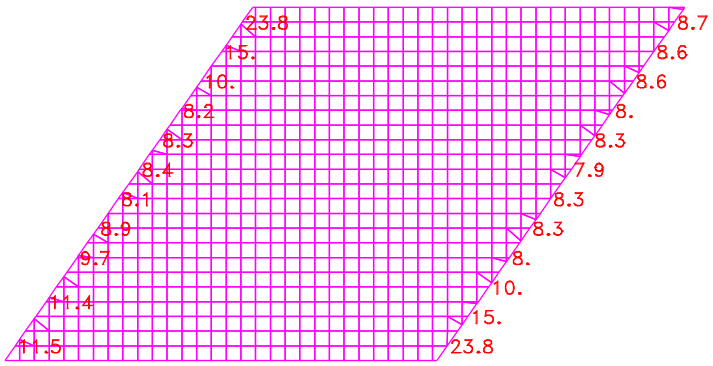




\section{Solicitacões das lajes com $40^{\circ}$ de esconsidade}

\section{Momentos Fletores}

Permanente:

Longitudinal $(\mathrm{x})$
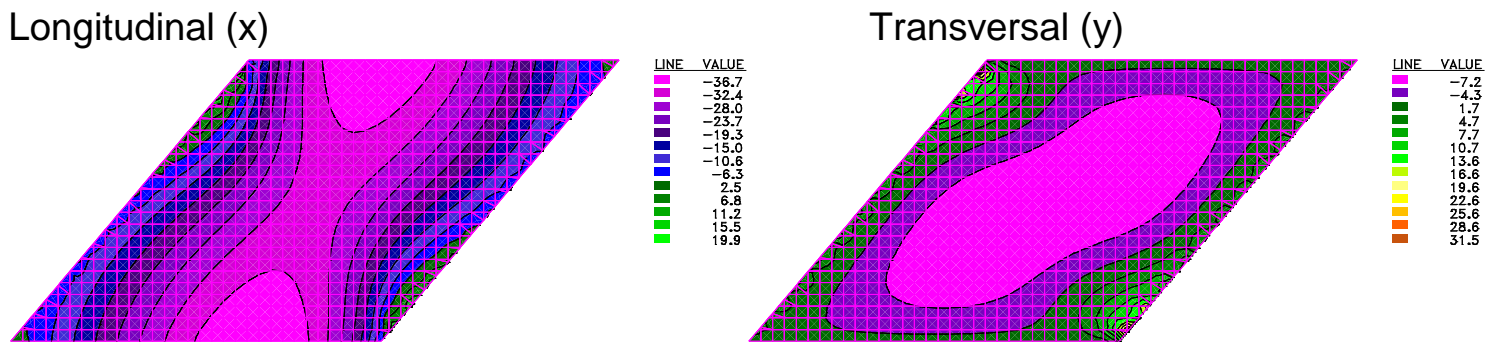

Longitudinal Mínimo (x)

Longitudinal Máximo (x)
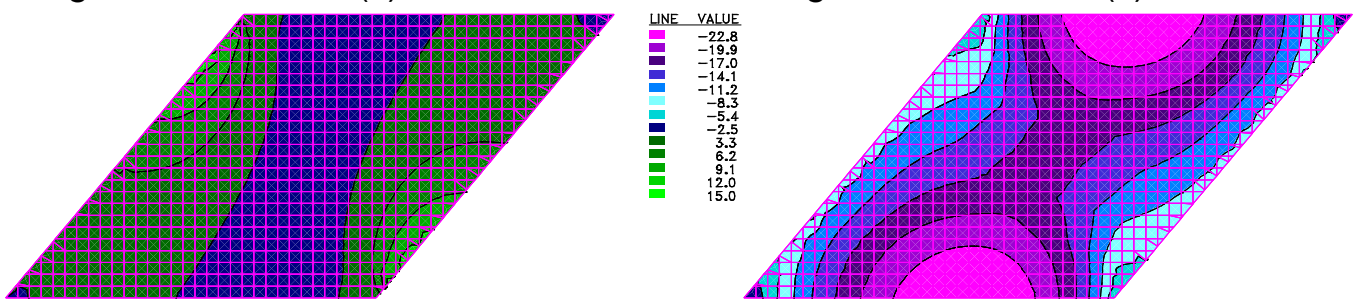

\begin{aligned} LINE VALUE \\ \hline -22.8 \\ -19.9 \\ -17.0 \\ -14.1 \\ -1.1 \\ -8.3 \\ -5.3 \\ -2.4 \\ -2.5 \\ 3.3 \\ 6.2 \\ 9.1 \\ 12.0 \\ 15.0\end{aligned}

Transversal Mínimo (y)
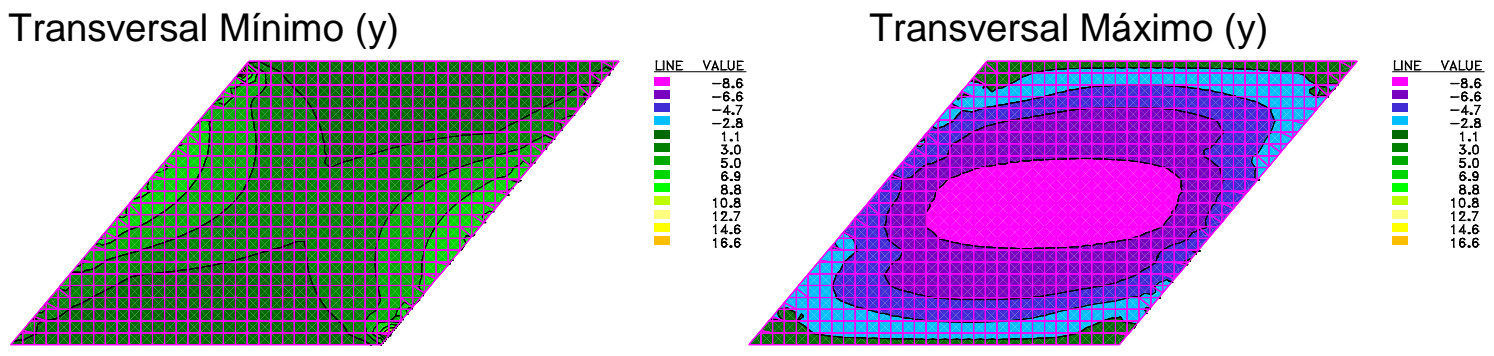

Reações nos Apoios

Permanentes

Envoltória das acidentais
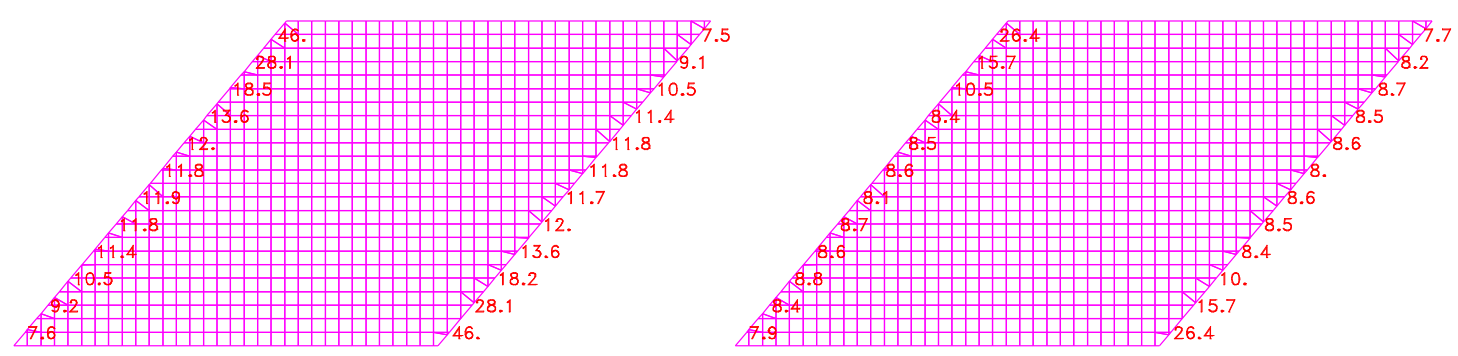


\section{Solicitacões das lajes com $45^{\circ}$ de esconsidade}

\section{Momentos Fletores}

Permanente:

Longitudinal $(\mathrm{x})$

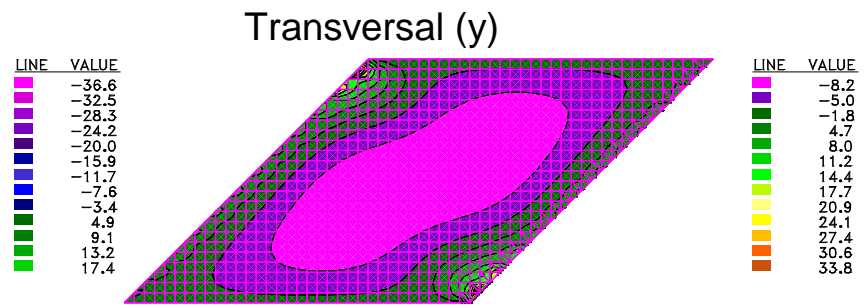

Longitudinal Mínimo (x)
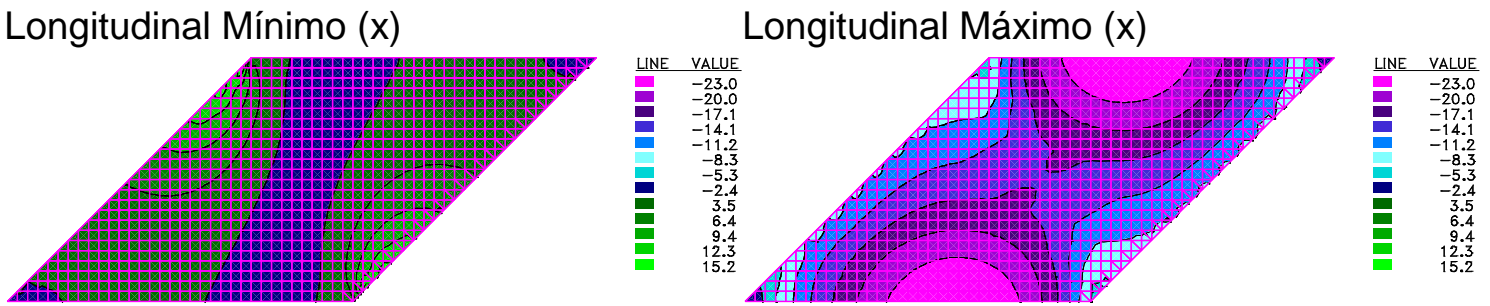

Transversal Mínimo (y)
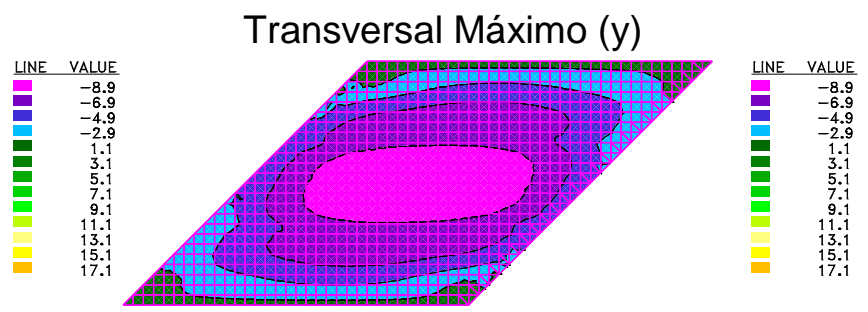

\section{Reações nos Apoios}

Permanentes

Envoltória das acidentais
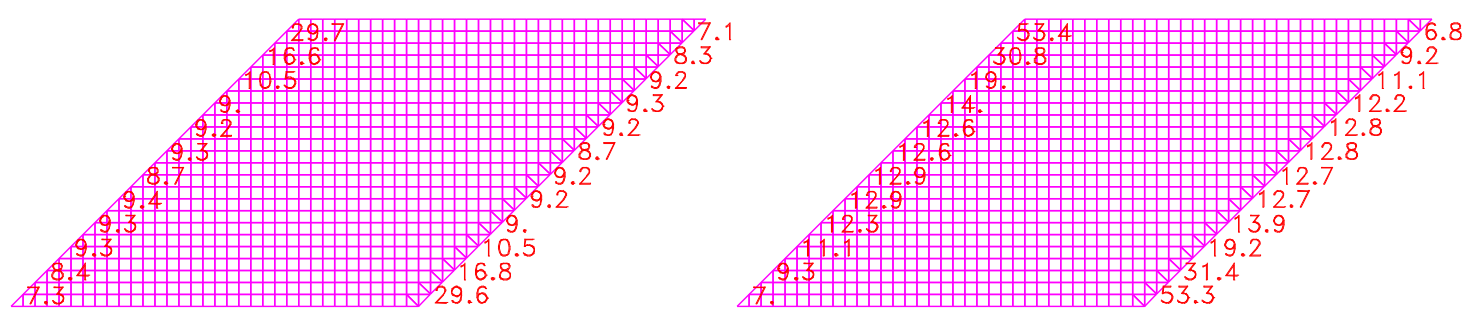


\section{Solicitaç̃es das lajes com $50^{\circ}$ de esconsidade}

\section{Momentos Fletores}

Permanente:

Longitudinal $(\mathrm{x})$
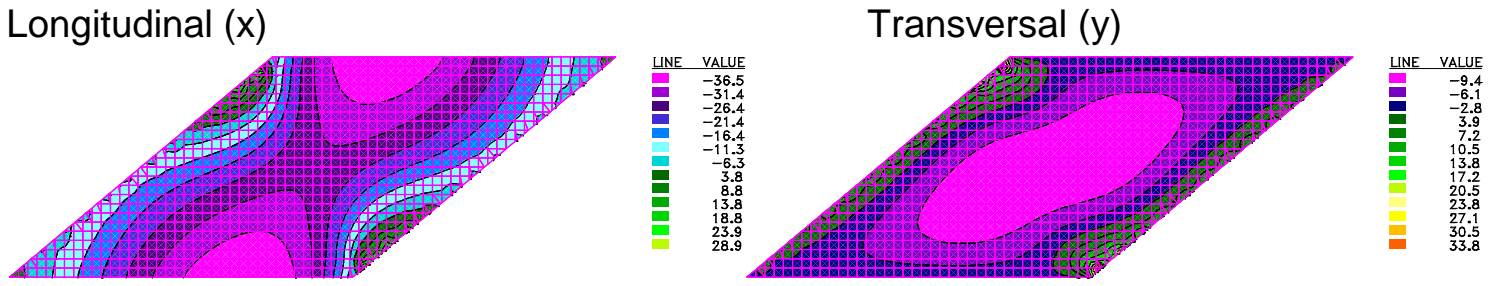

Longitudinal Mínimo (x)
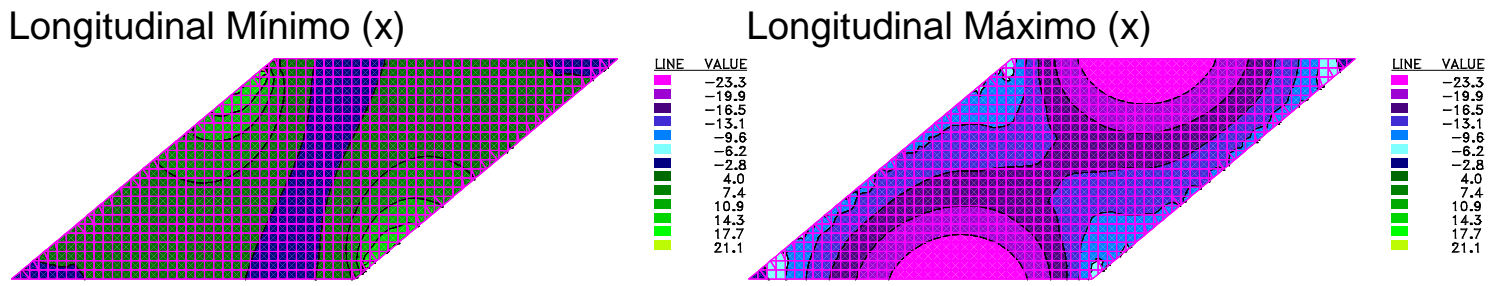

Transversal Mínimo (y)
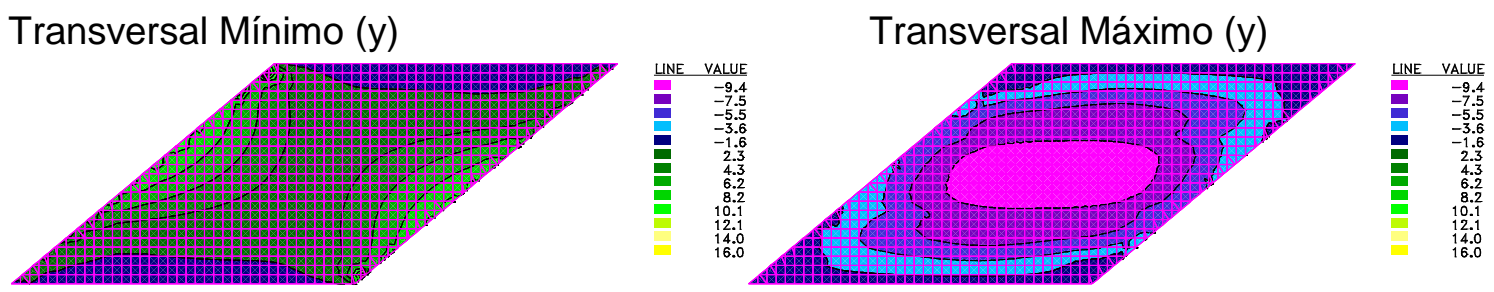

\section{Reações nos Apoios}

Permanentes

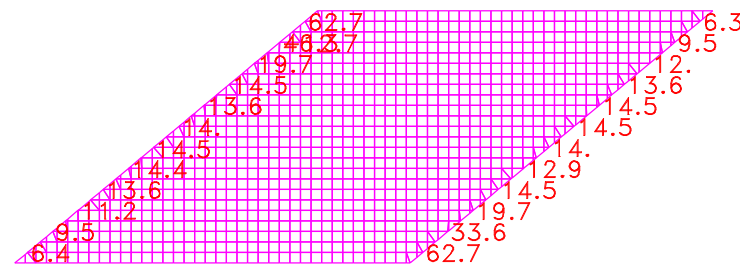

Envoltória das acidentais

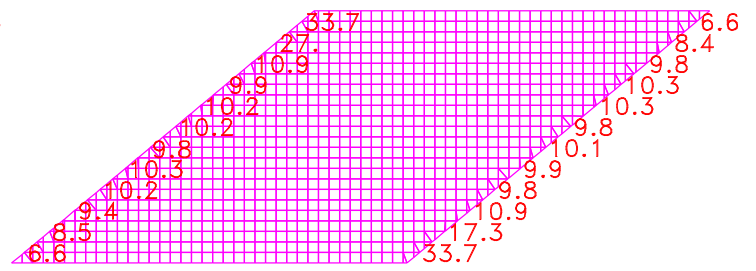


Solicitaç̃es das lajes com $55^{\circ}$ de esconsidade

\section{Momentos Fletores}

Permanente:

Longitudinal $(\mathrm{x})$
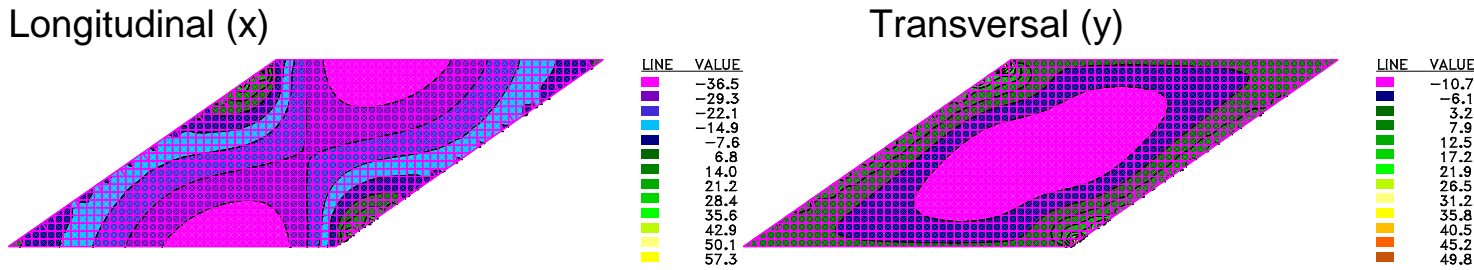

Longitudinal Mínimo (x)

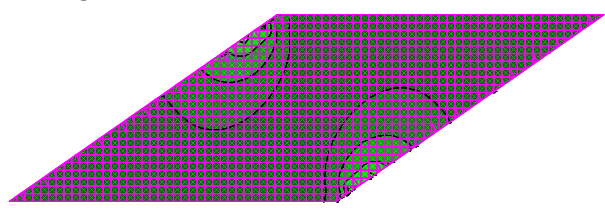

Longitudinal Máximo (x)
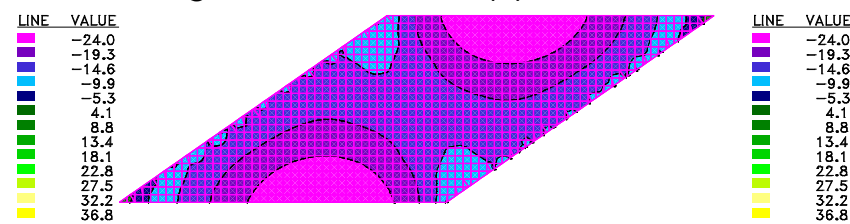

Transversal Mínimo (y)
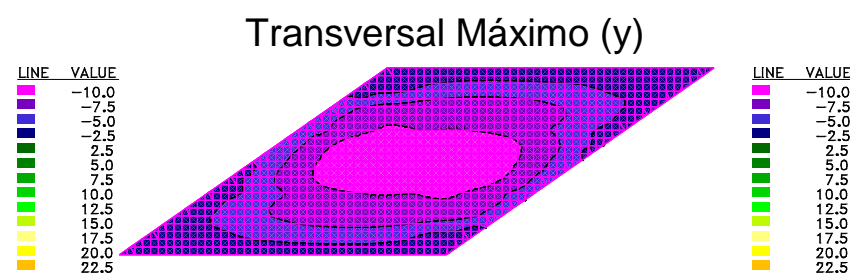

Reações nos Apoios

Permanentes

Envoltória das acidentais
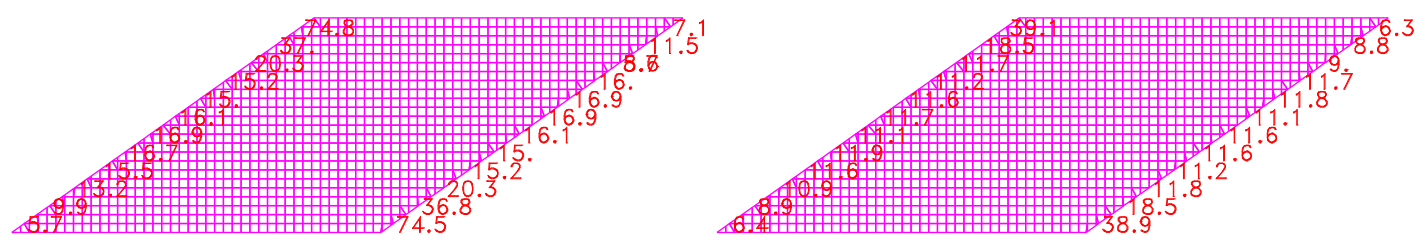

Forças Cortantes 


\section{Solicitaç̃es das lajes com $60^{\circ}$ de esconsidade}

\section{Momentos Fletores}

Permanente:

Longitudinal $(x)$

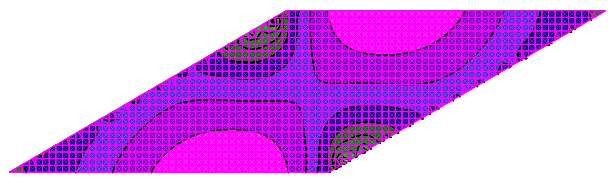

Longitudinal Mínimo (x)

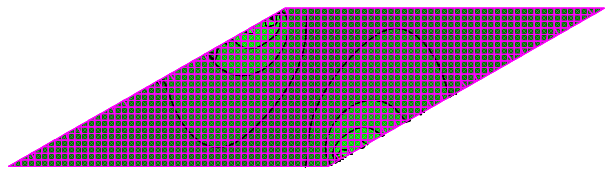

Transversal Mínimo (y)

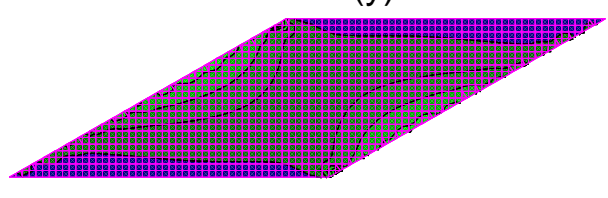

Transversal (y)

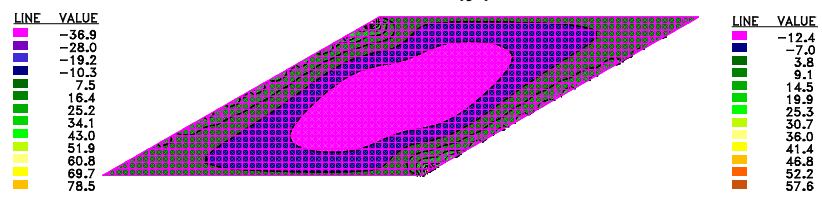

Longitudinal Máximo (x)

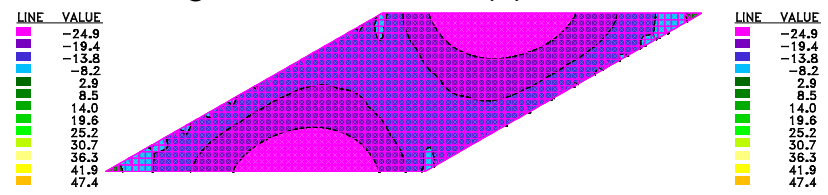

Transversal Máximo (y)

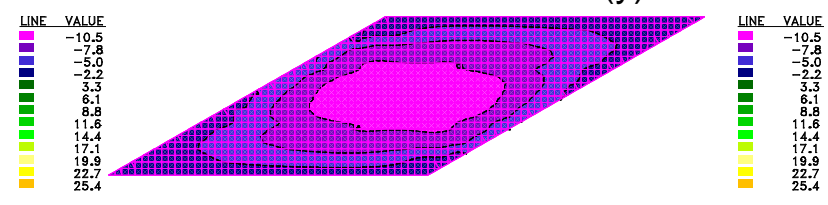

Reações nos Apoios

Permanentes

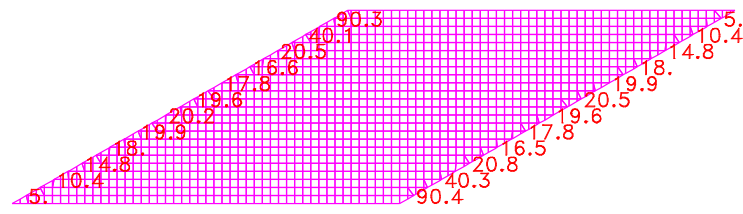

Envoltória das acidentais

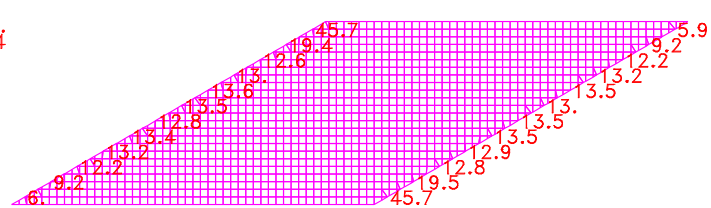




\section{ANEXO D - GRELHA - TRANSVERSINA ESCONSA}

\section{Solicitações nas Grelhas com $0^{\circ}$ de esconsidade}

Longarina

Momento Fletor

Permanente

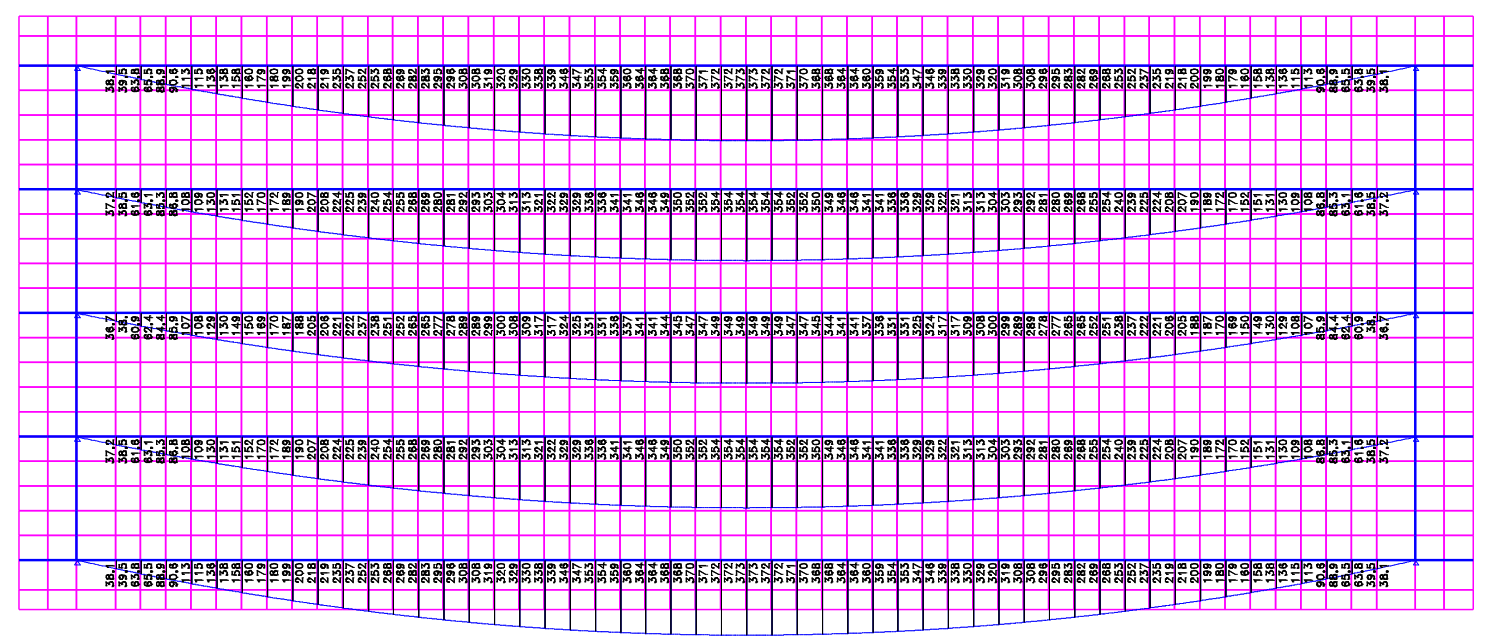

Móvel - Envoltória

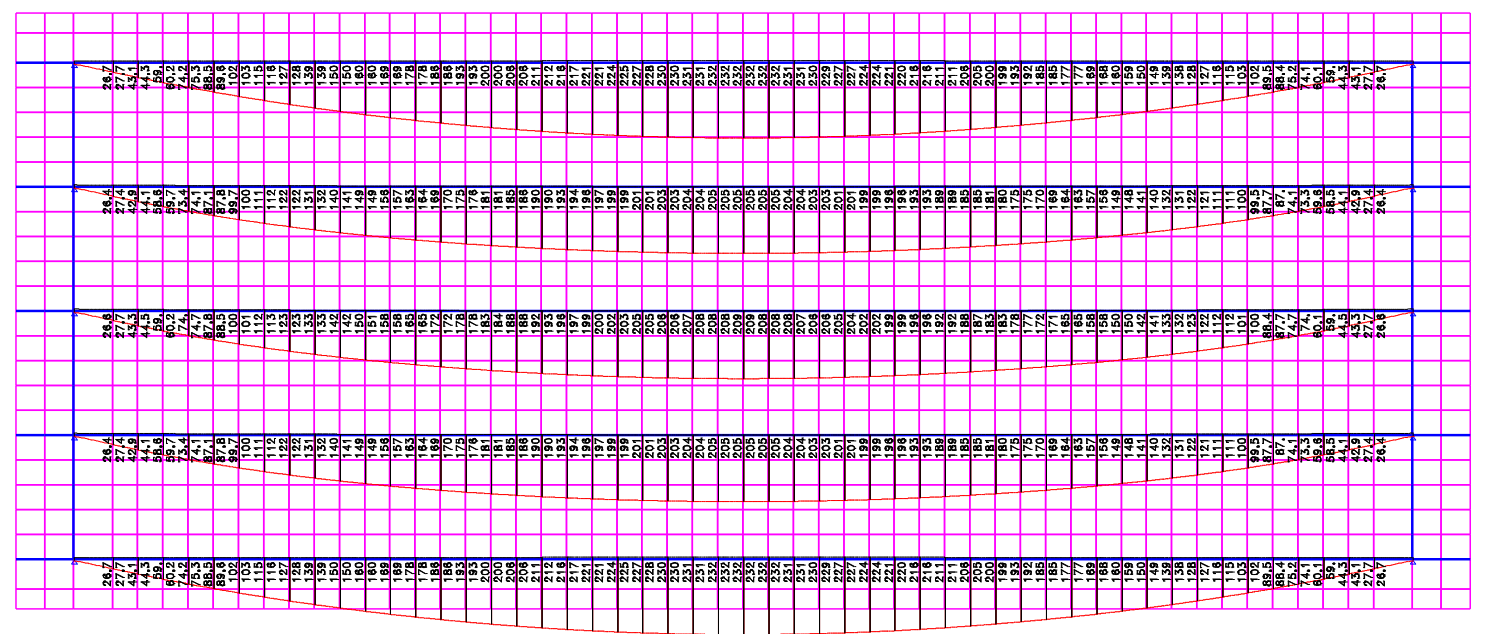


Força Cortante

Permanente

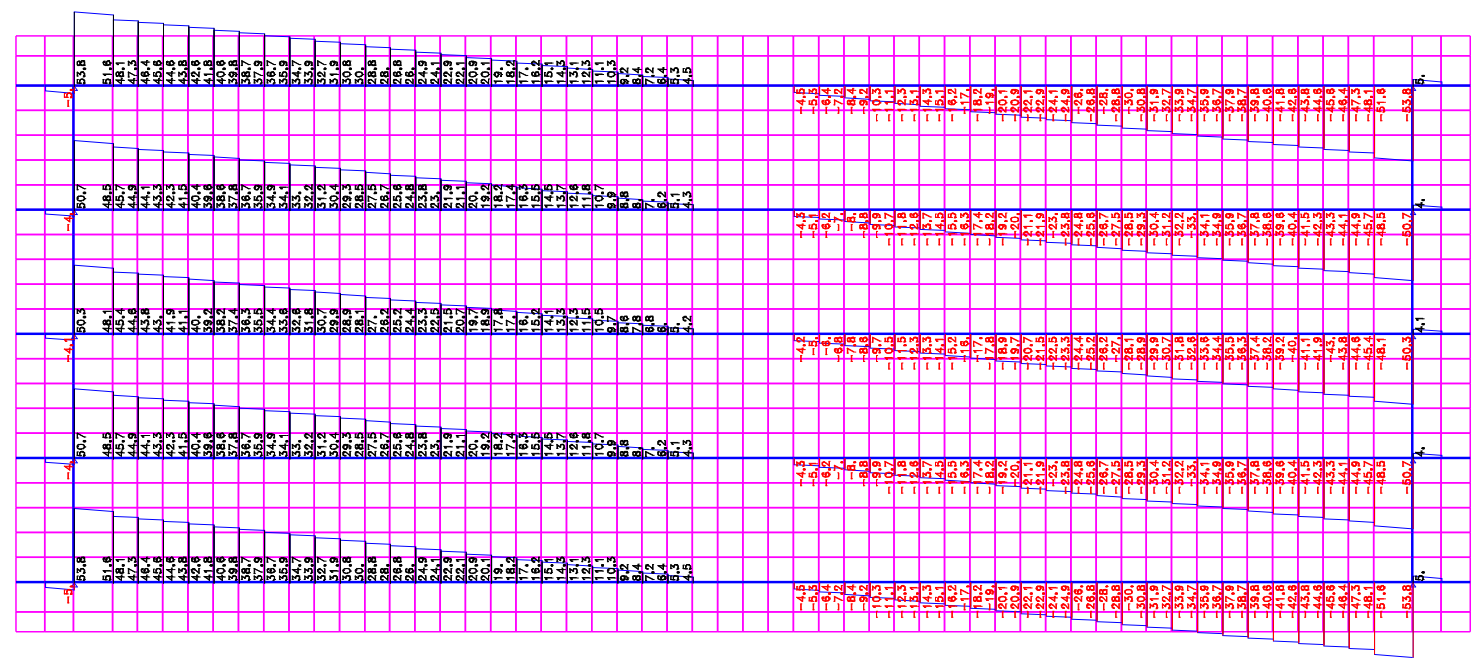

Móvel - Envoltória

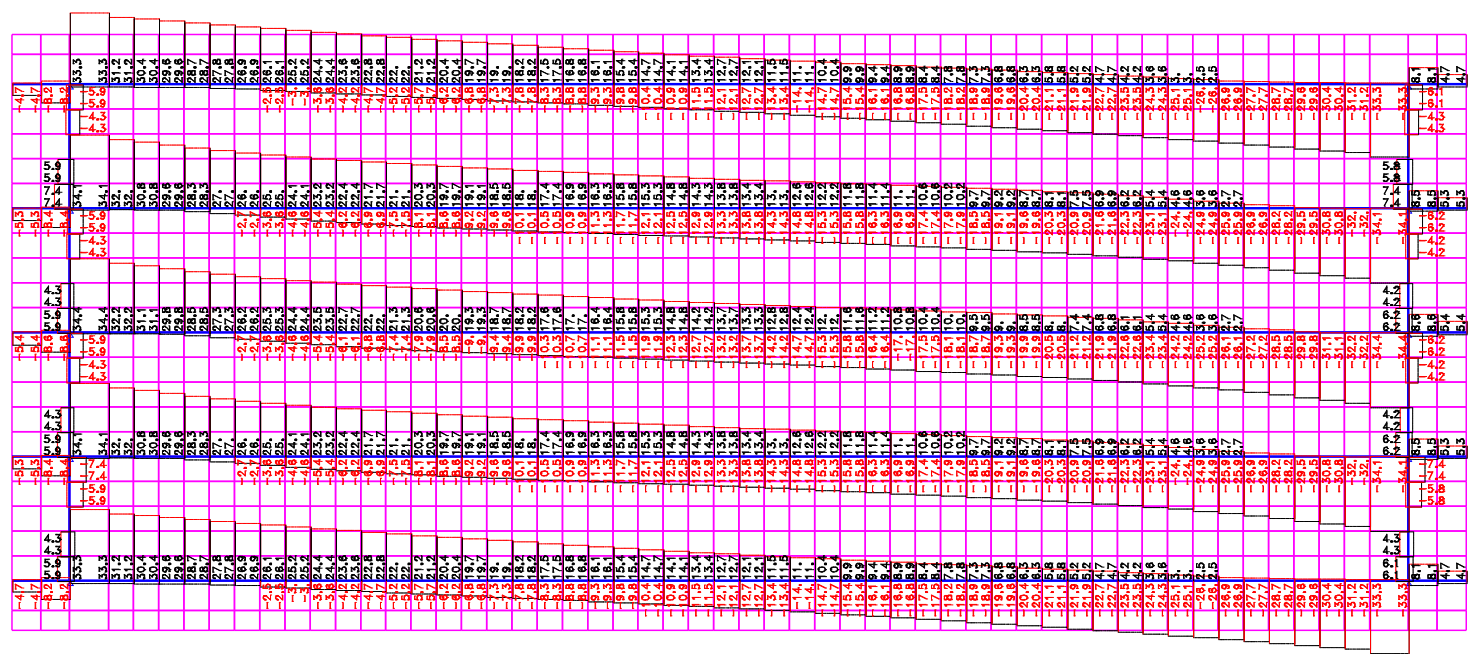


Reações nos Apoios

Permanente

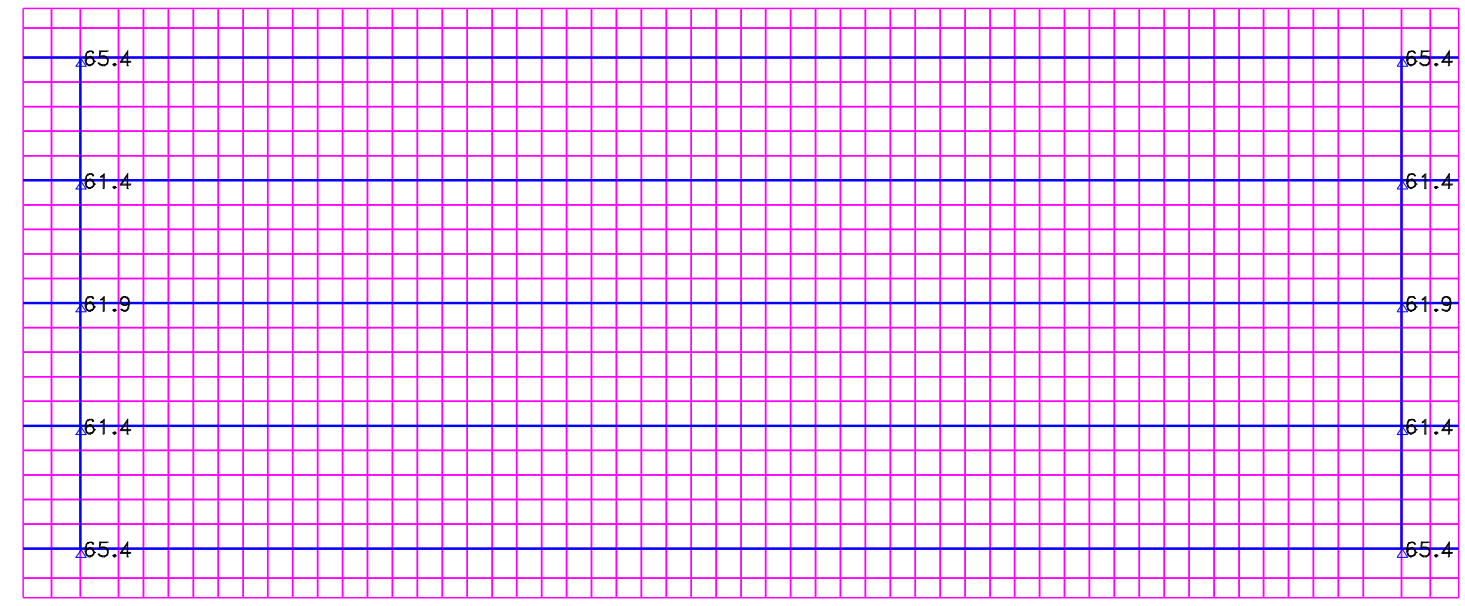

Móvel - Envoltória

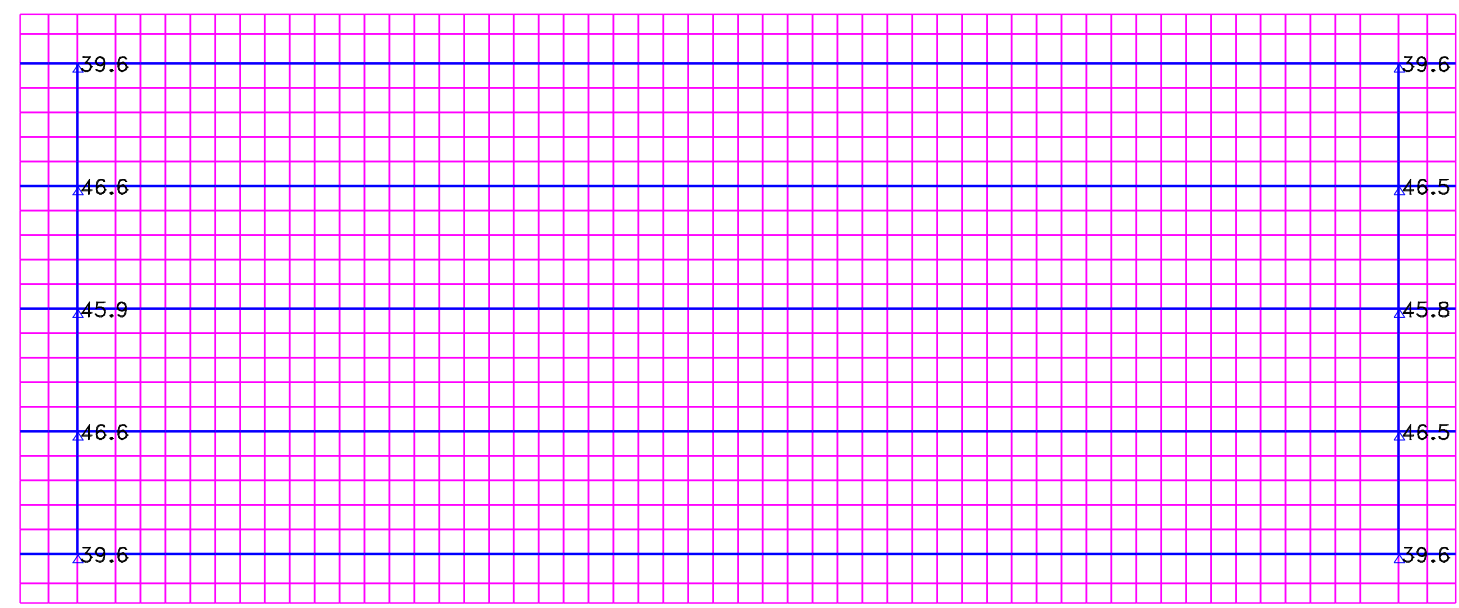


Solicitações nas Grelhas com $15^{\circ}$ de esconsidade

Longarina

Momento Fletor

Permanente

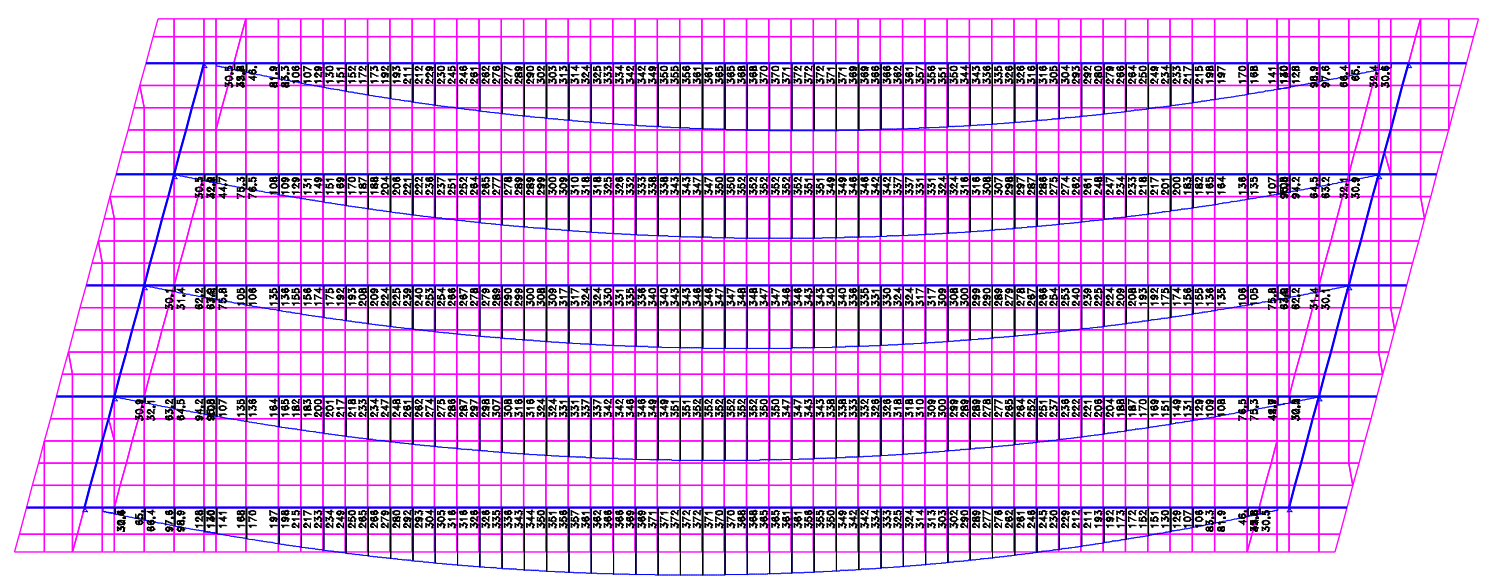

Móvel - Envoltória

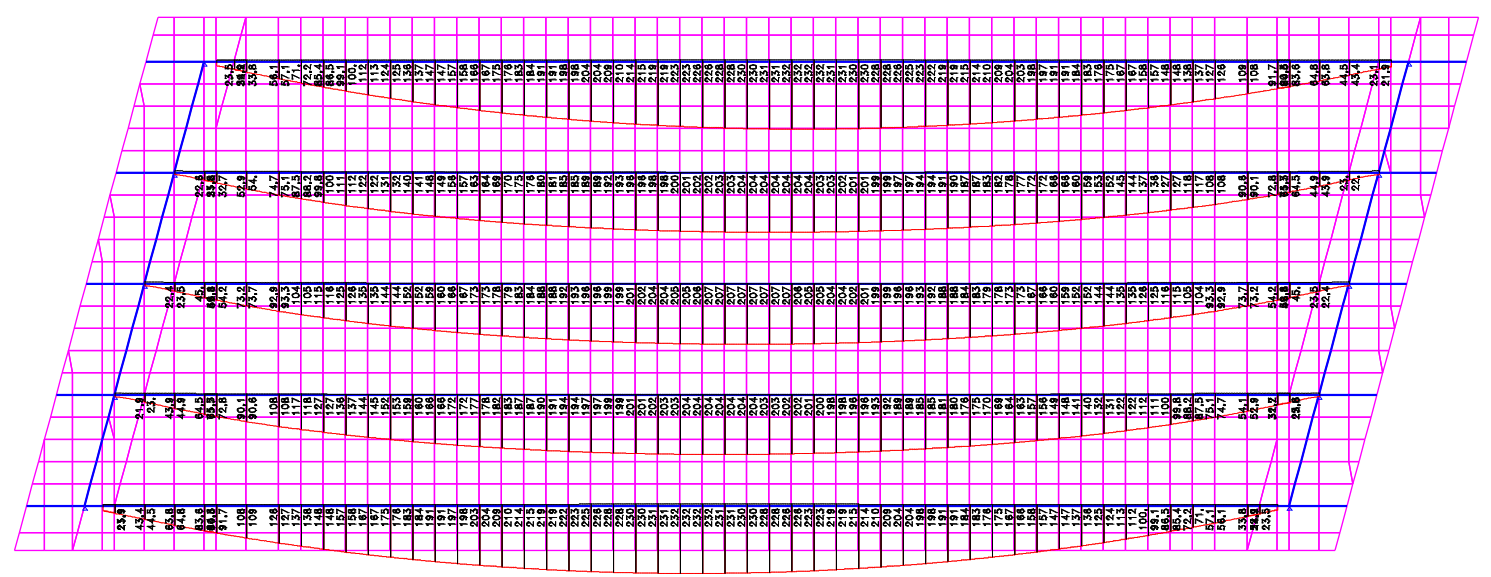

Força Cortante

Permanente

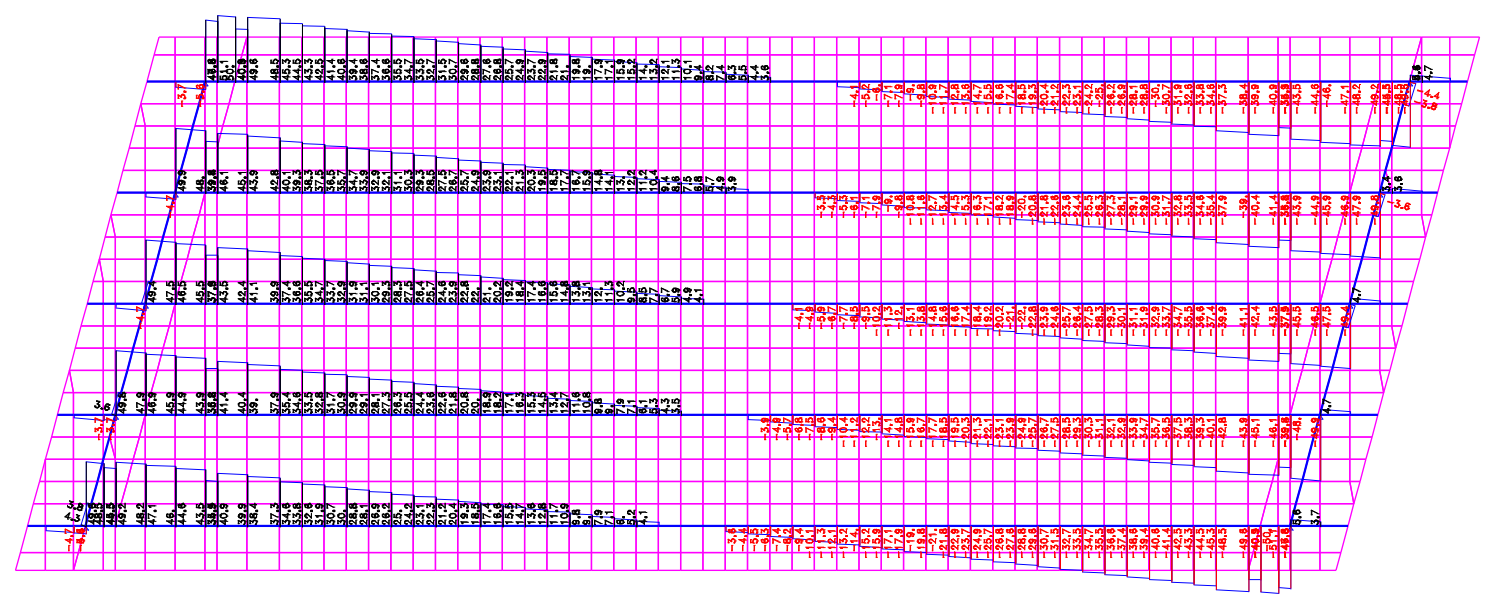


Móvel - Envoltória

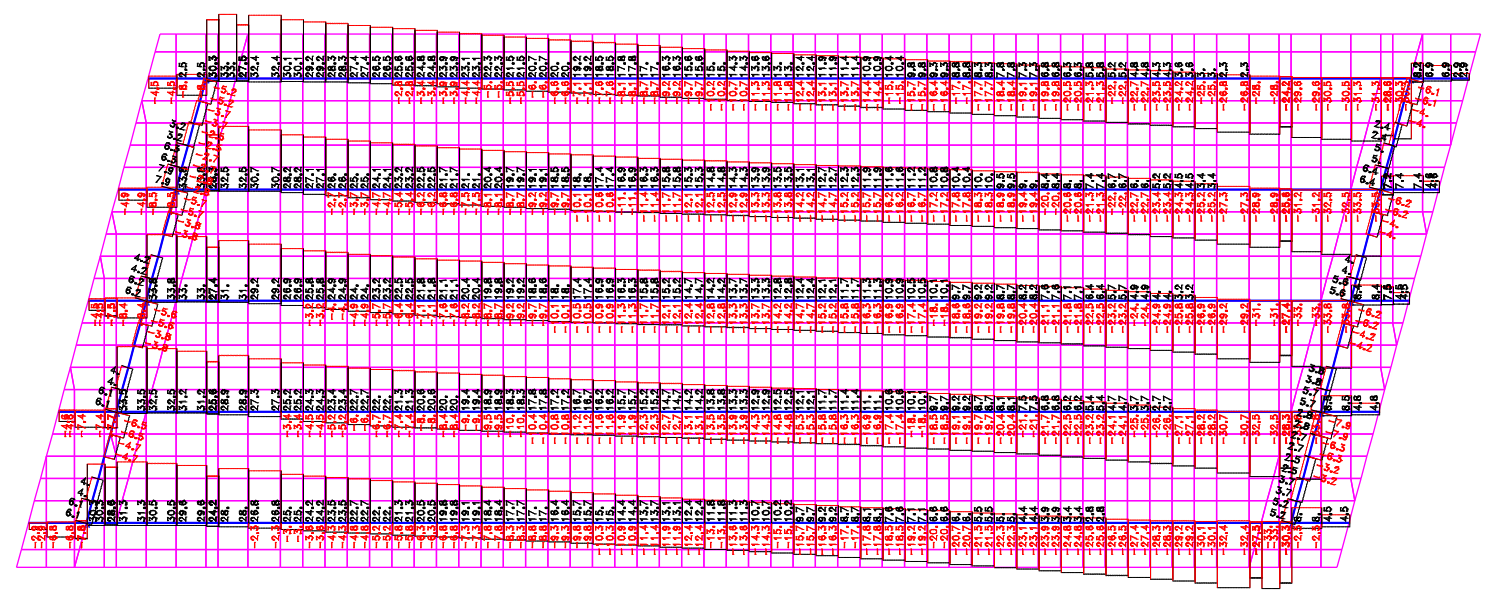

Torção

Permanente

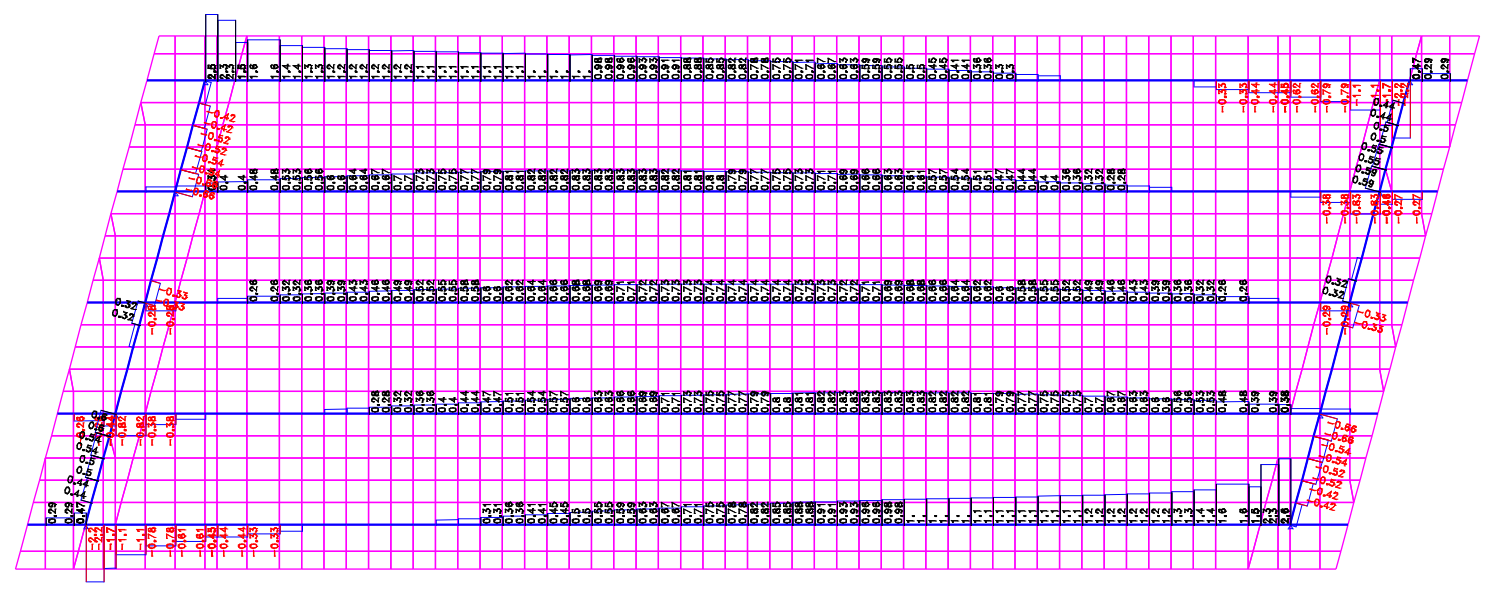

Móvel - Envoltória

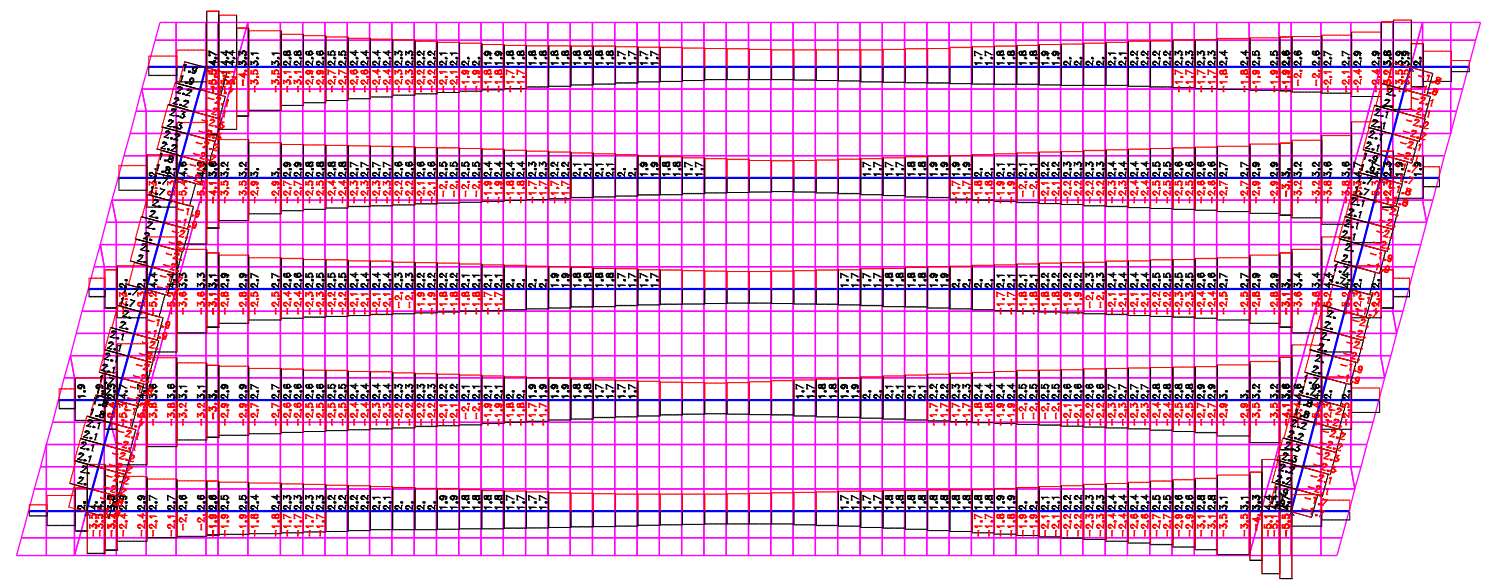


Reações nos Apoios

Permanente

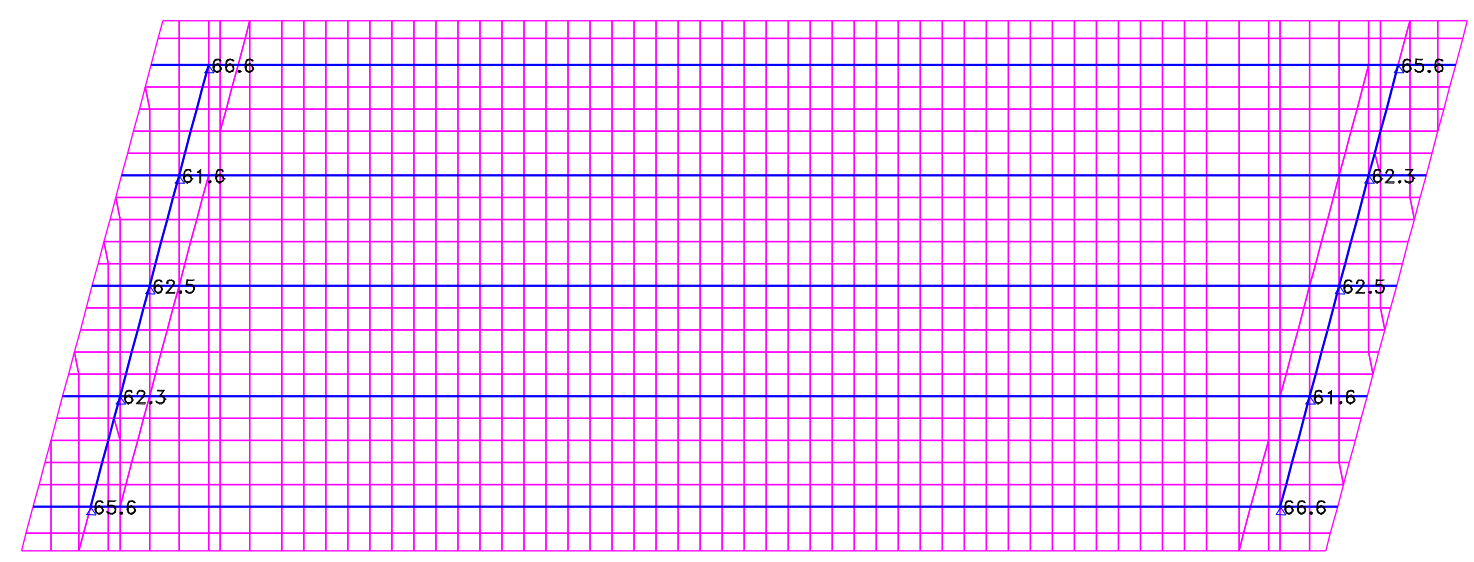

Móvel - Envoltória

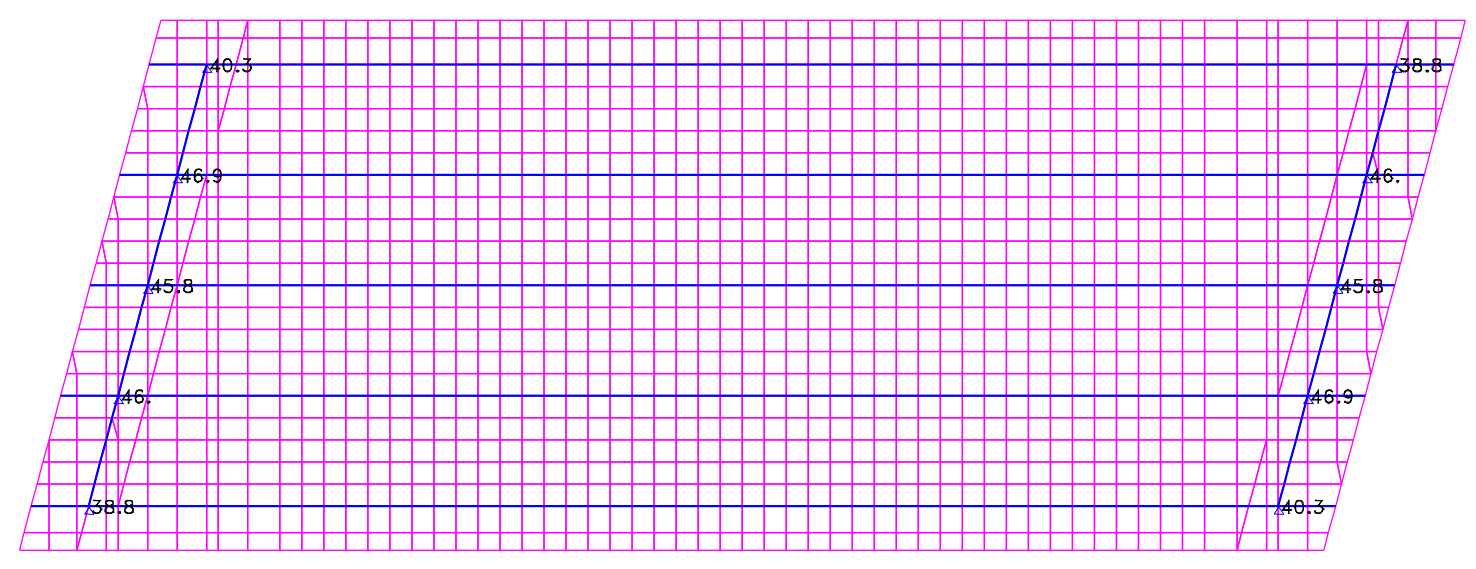


Solicitações nas Grelhas com $30^{\circ}$ de esconsidade

Longarina

Momento Fletor

Permanente

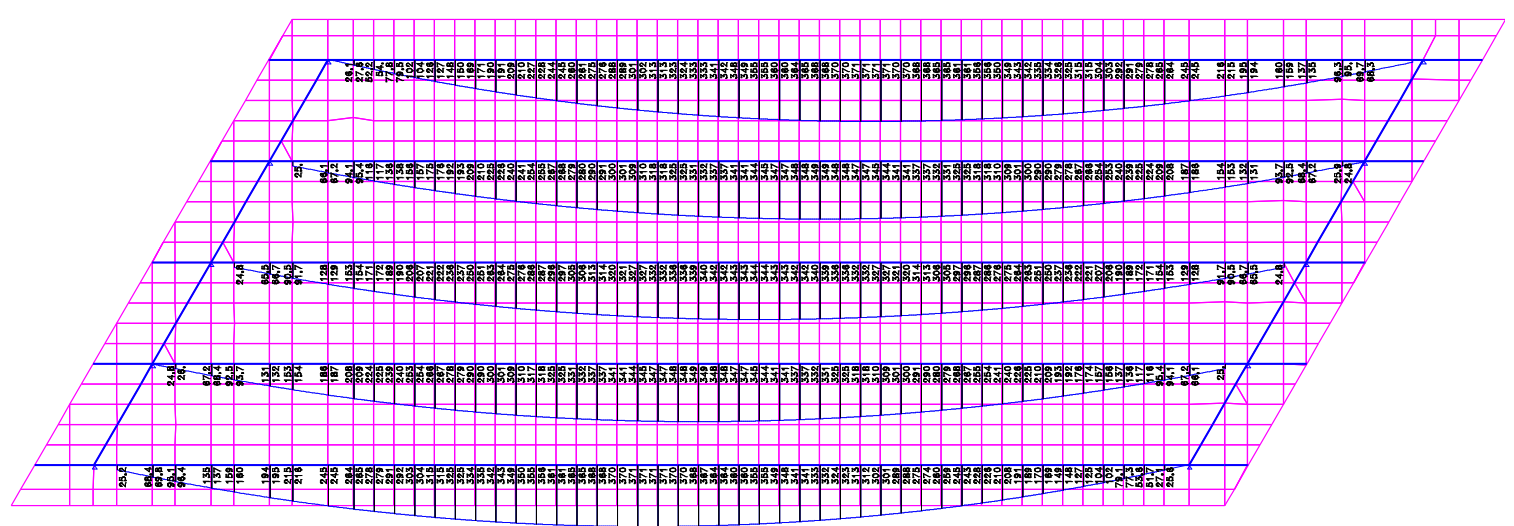

Móvel - Envoltória

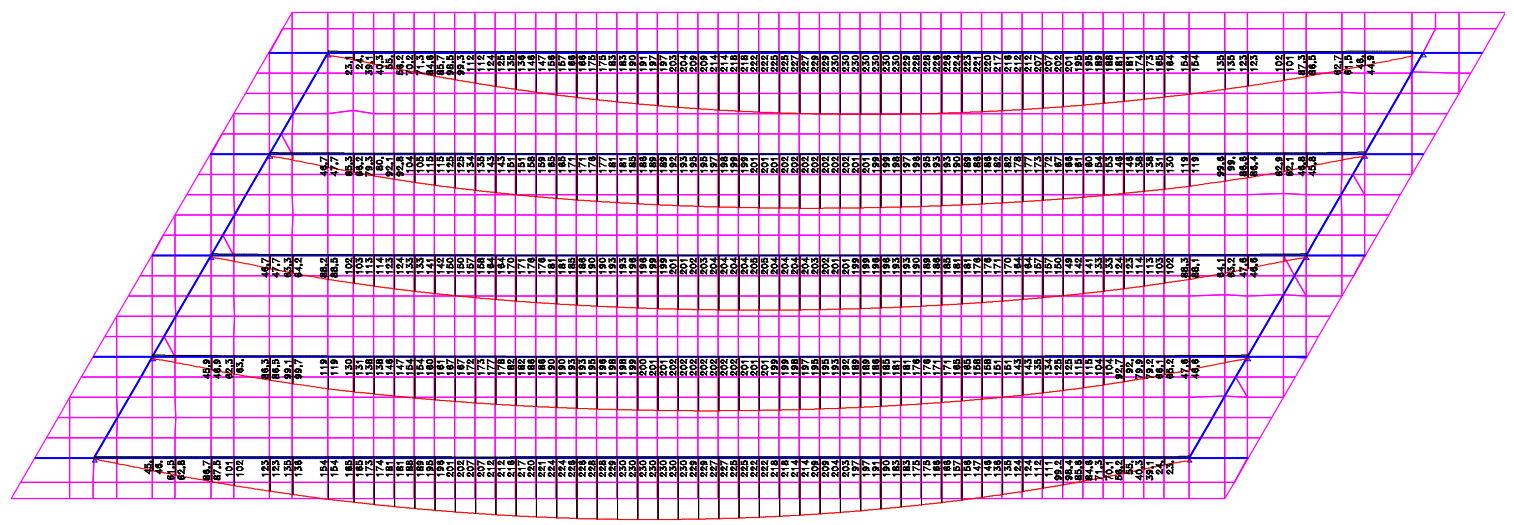

Força Cortante

Permanente

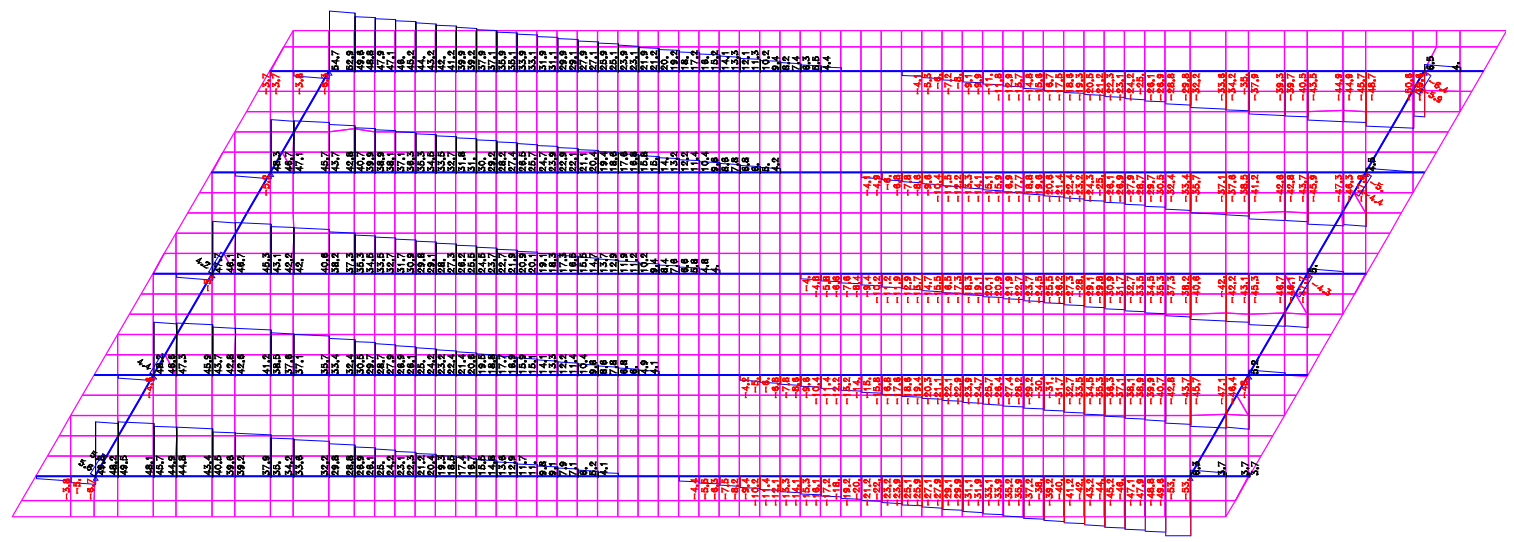


Móvel - Envoltória

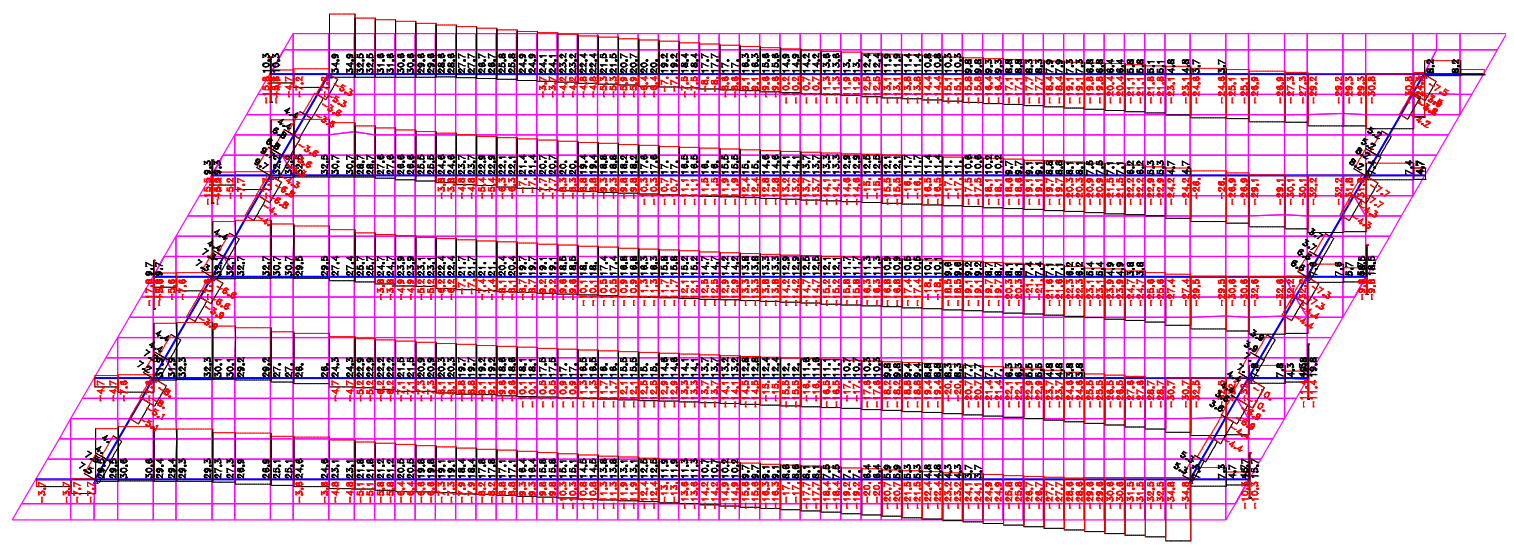

Torção

Permanente

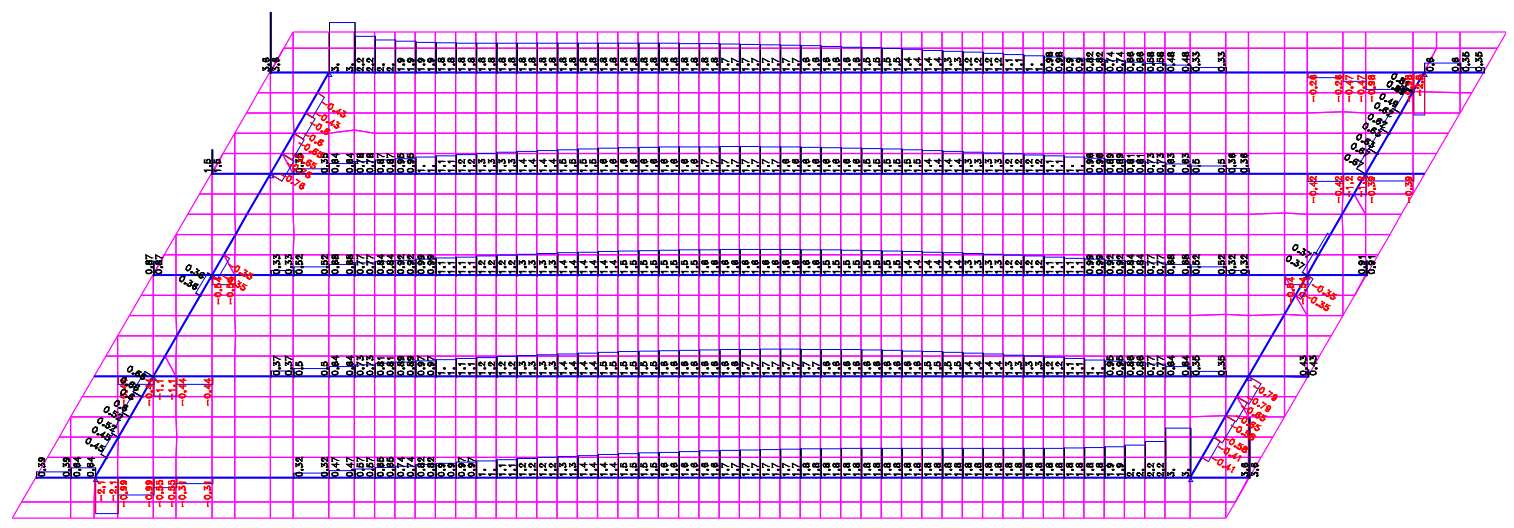

Móvel - Envoltória

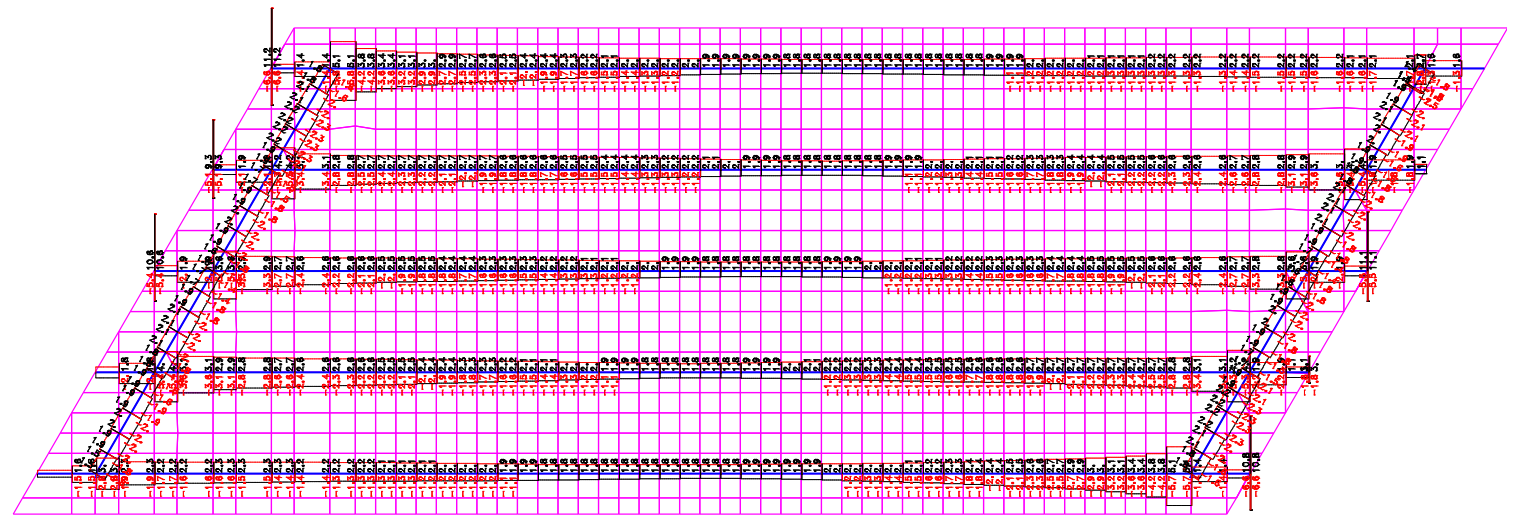


Reações nos Apoios

Permanente

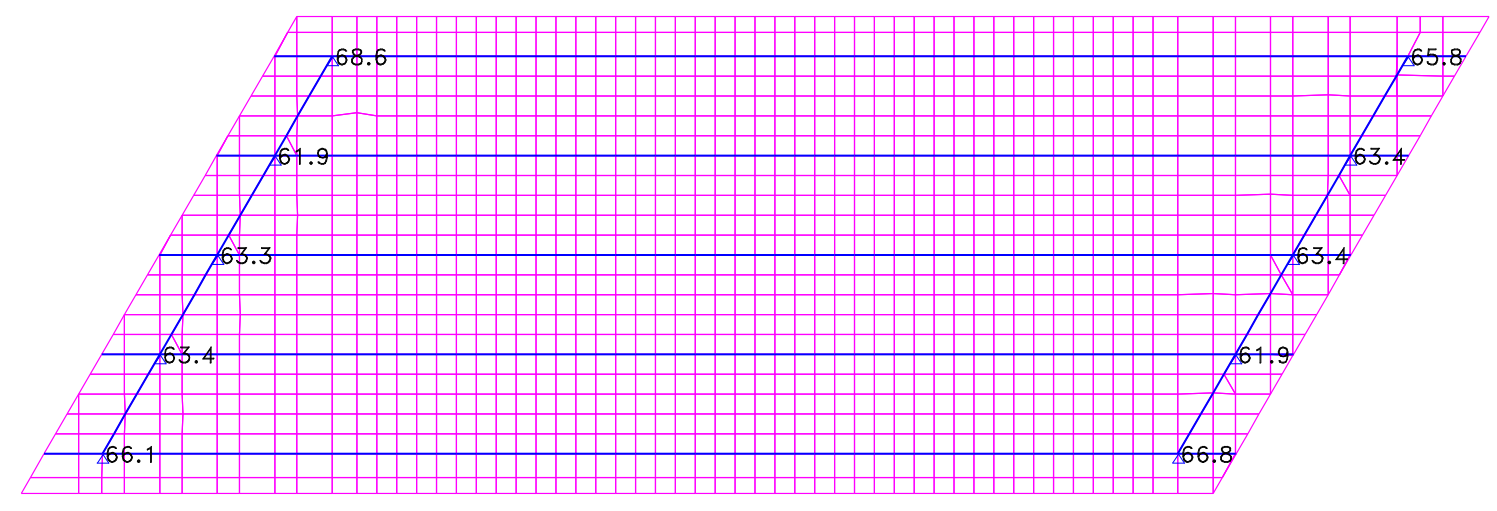

Móvel - Envoltória

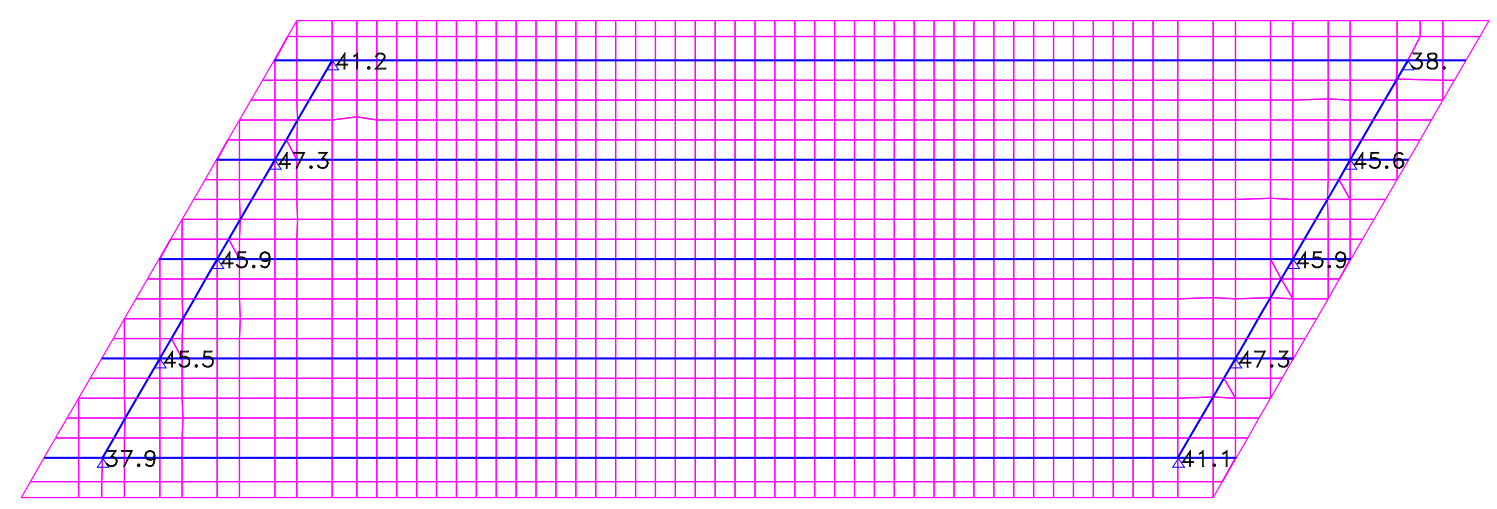




\section{Solicitações nas Grelhas com $45^{\circ}$ de esconsidade}

Longarina

Momento Fletor

Permanente

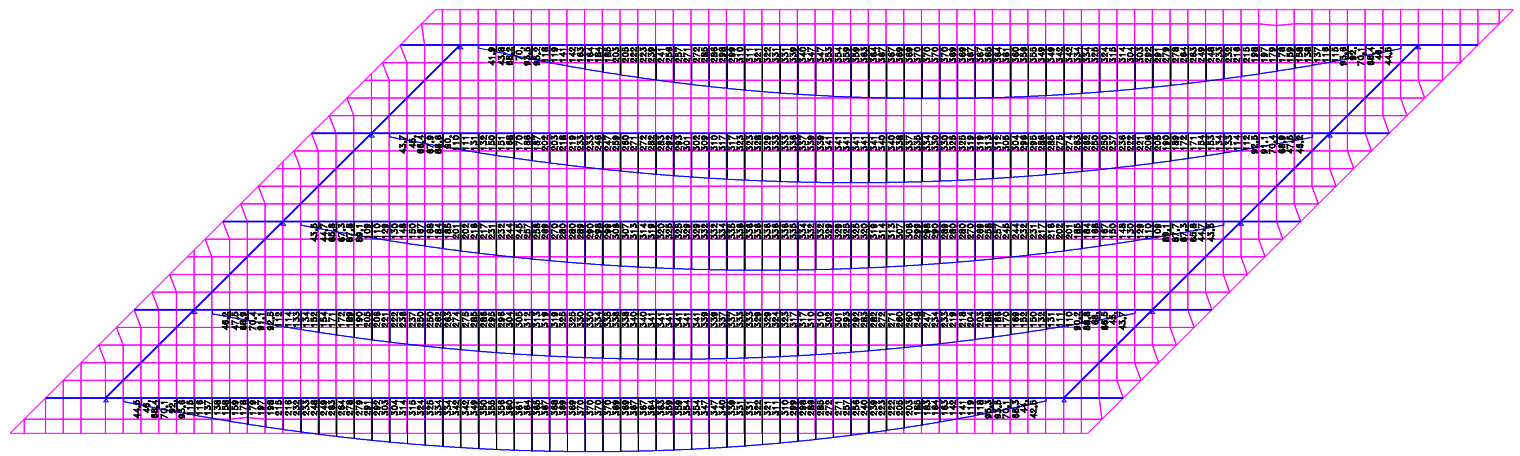

Móvel - Envoltória

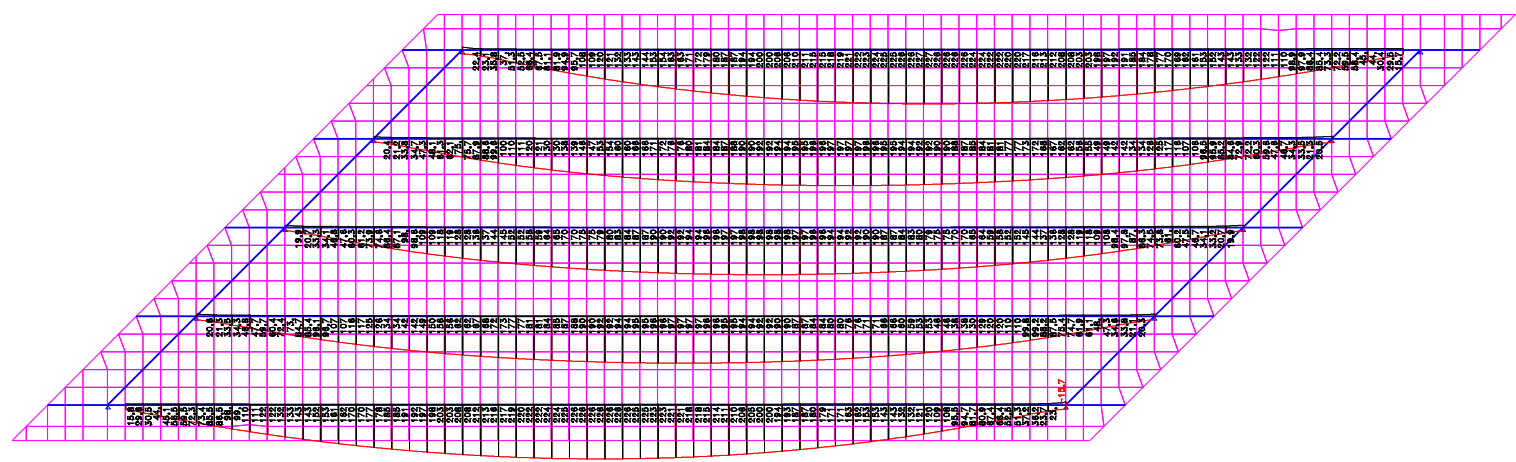

Força Cortante

Permanente

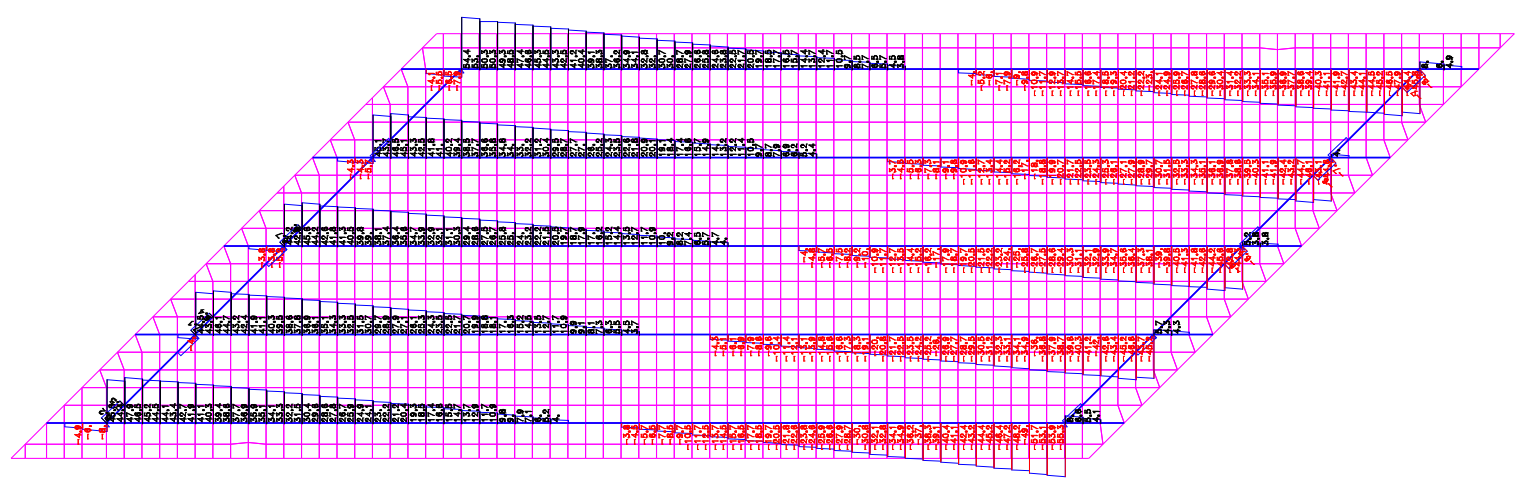

Móvel - Envoltória

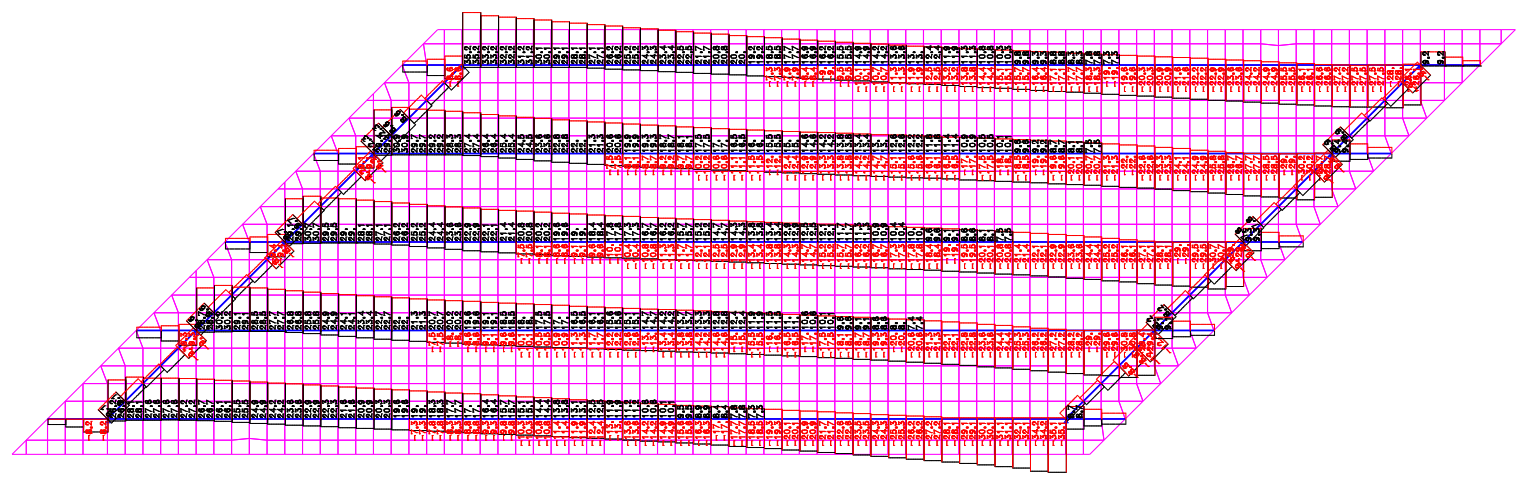


Torção

Permanente

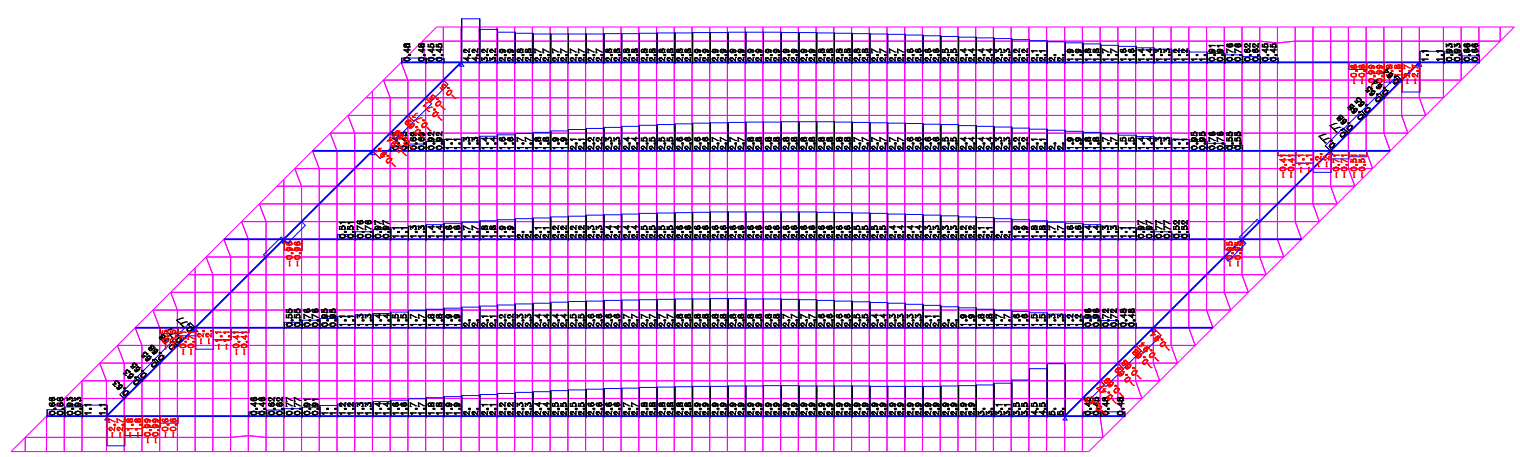

\section{Móvel - Envoltória}

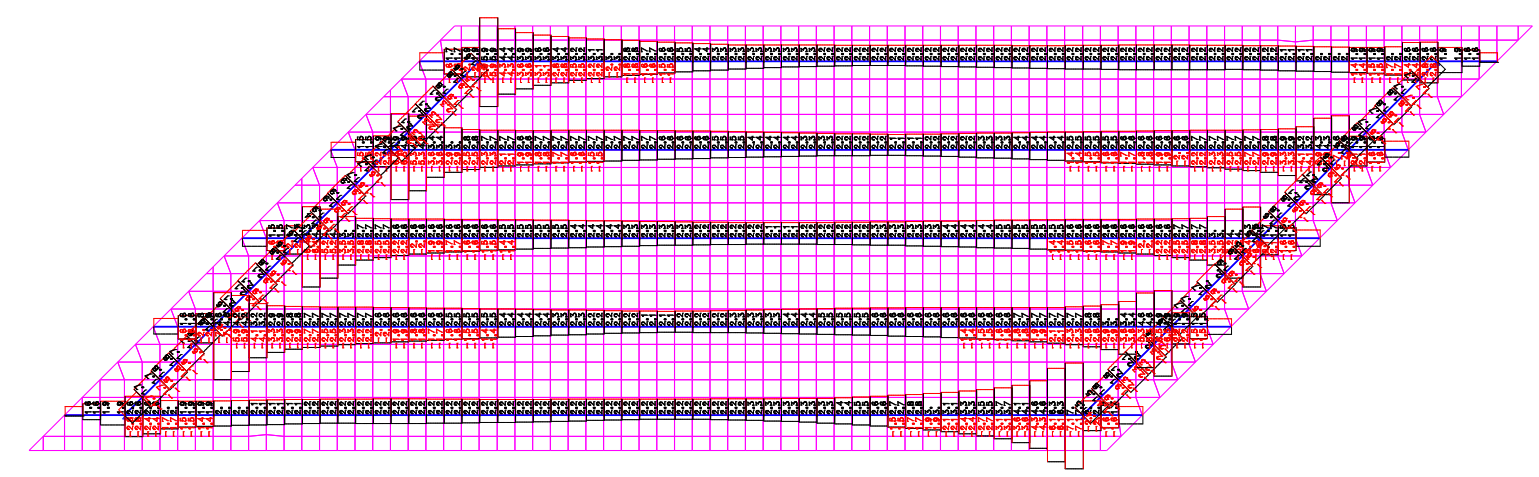

\section{Reações nos Apoios}

Permanente

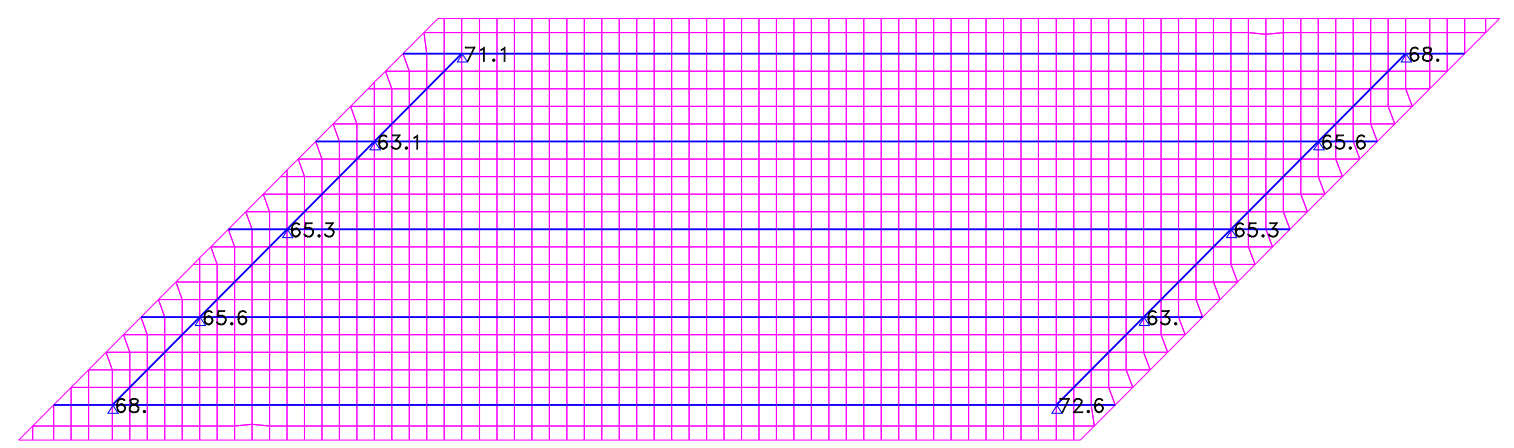

Móvel - Envoltória

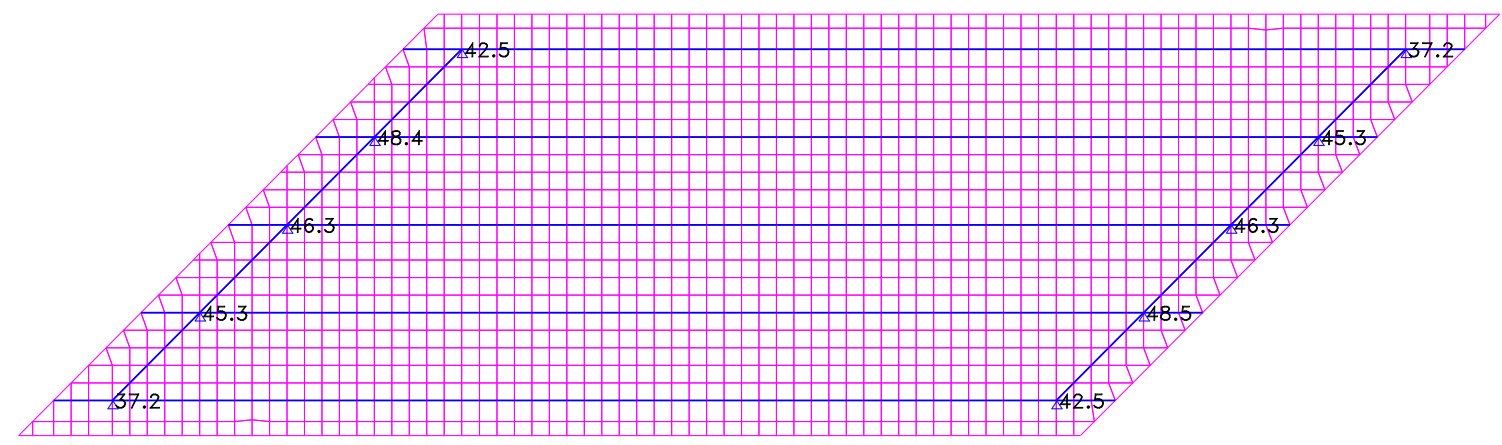


Solicitações nas Grelhas com $60^{\circ}$ de esconsidade

Longarina

Momento Fletor

Permanente

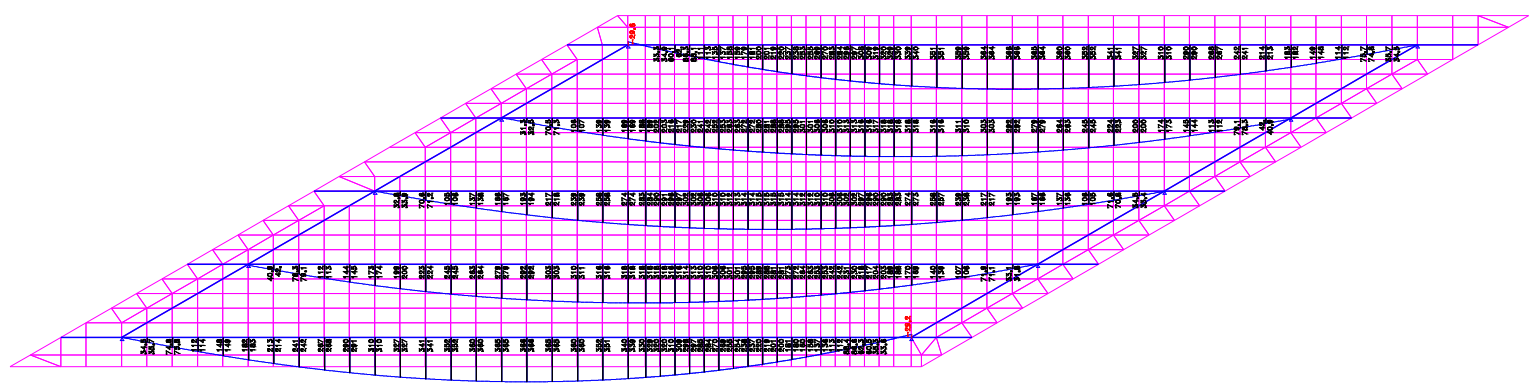

Móvel - Envoltória

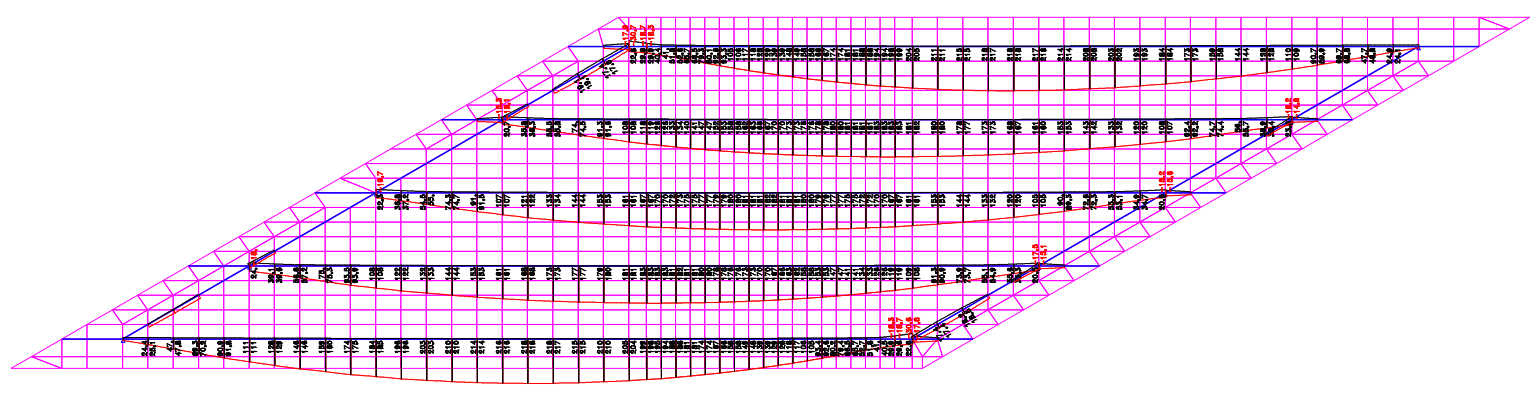

Força Cortante

Permanente

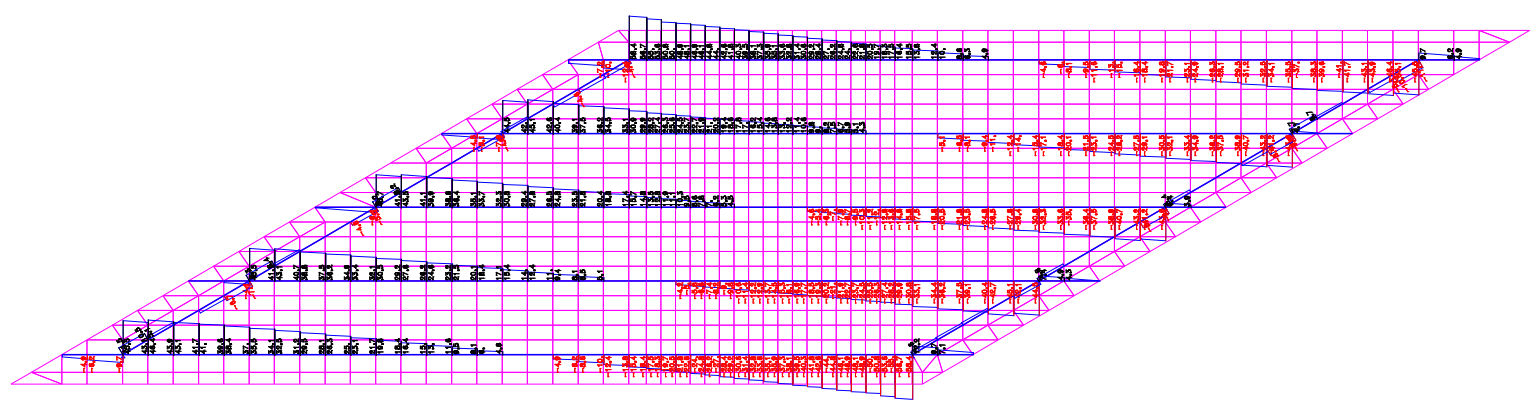


Móvel - Envoltória

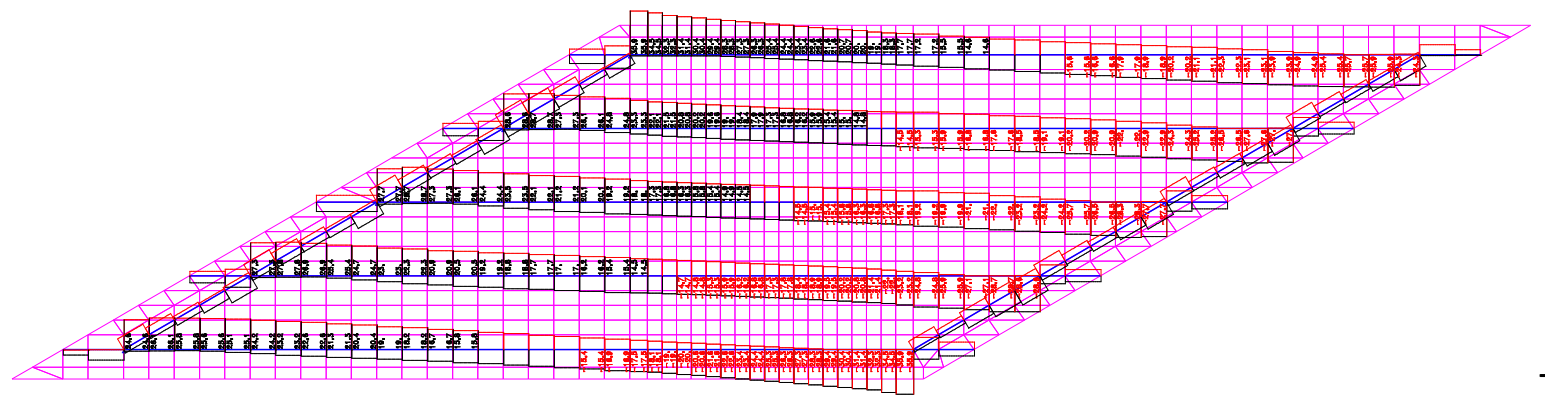

rção

Permanente

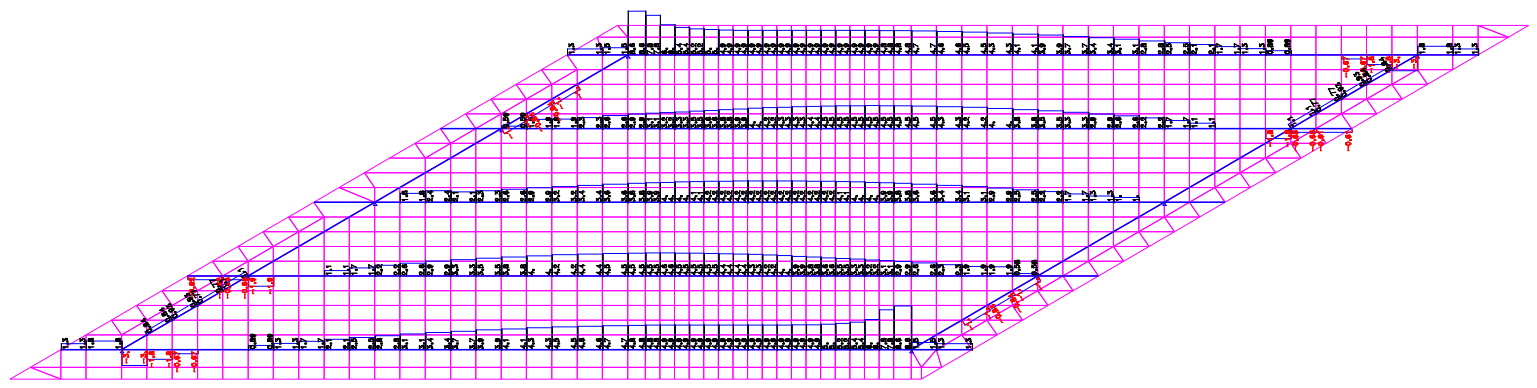

Móvel - Envoltória

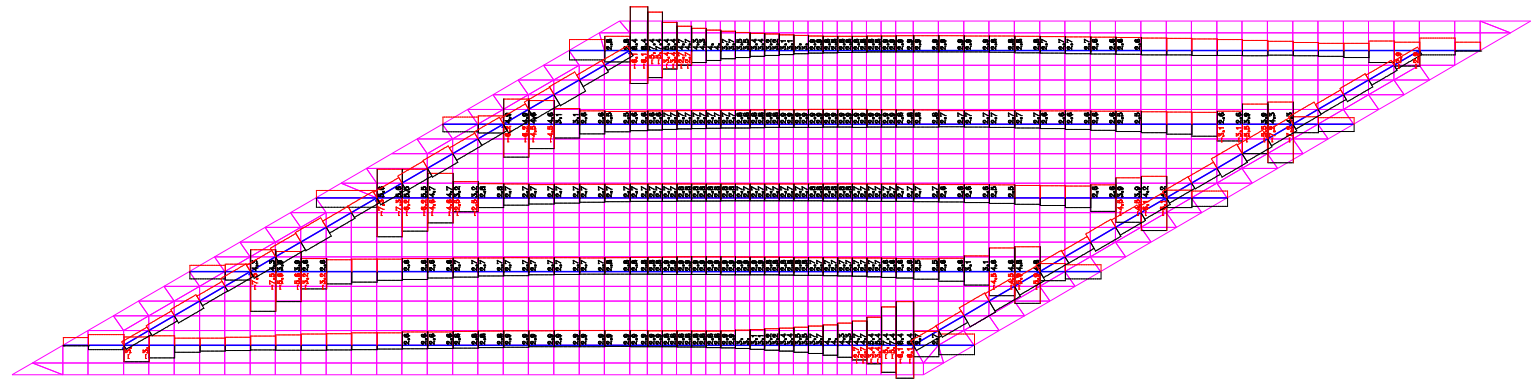


Reações nos Apoios

Permanente

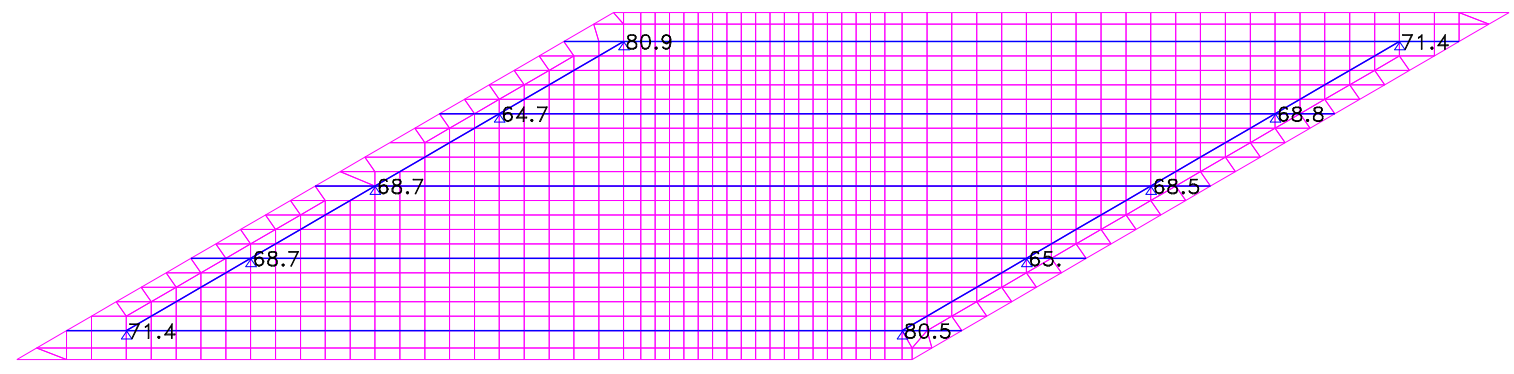

Móvel - Envoltória

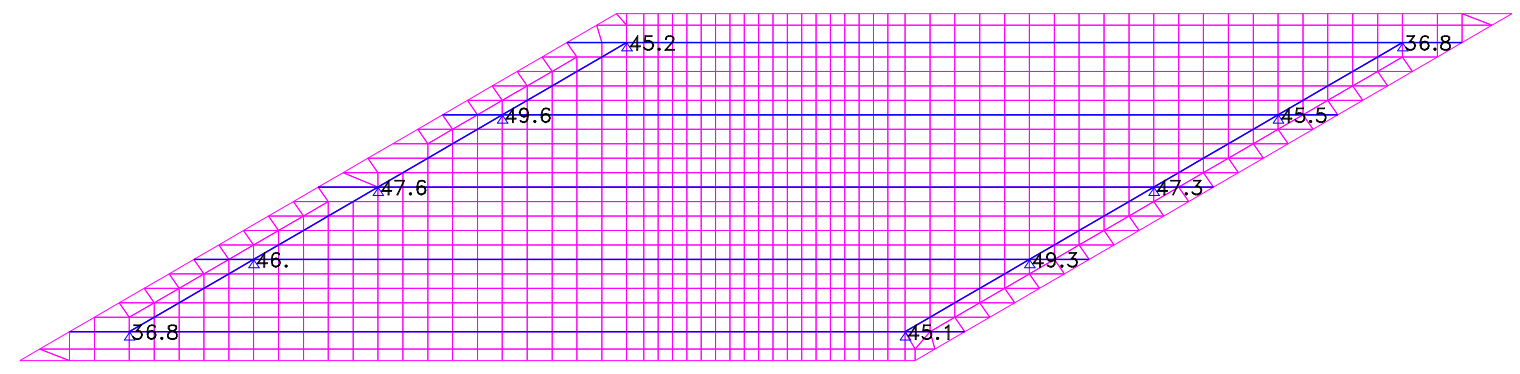


Solicitações nas Grelhas com $60^{\circ}$ de esconsidade - APOIOS FLEXÍVEIS

Longarina

Momento Fletor

Permanente

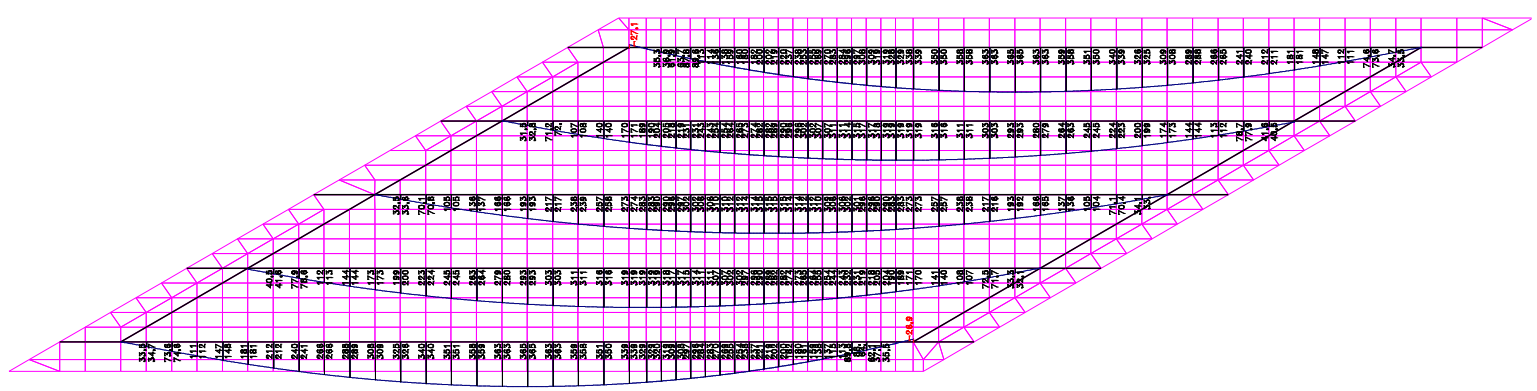

Móvel - Envoltória

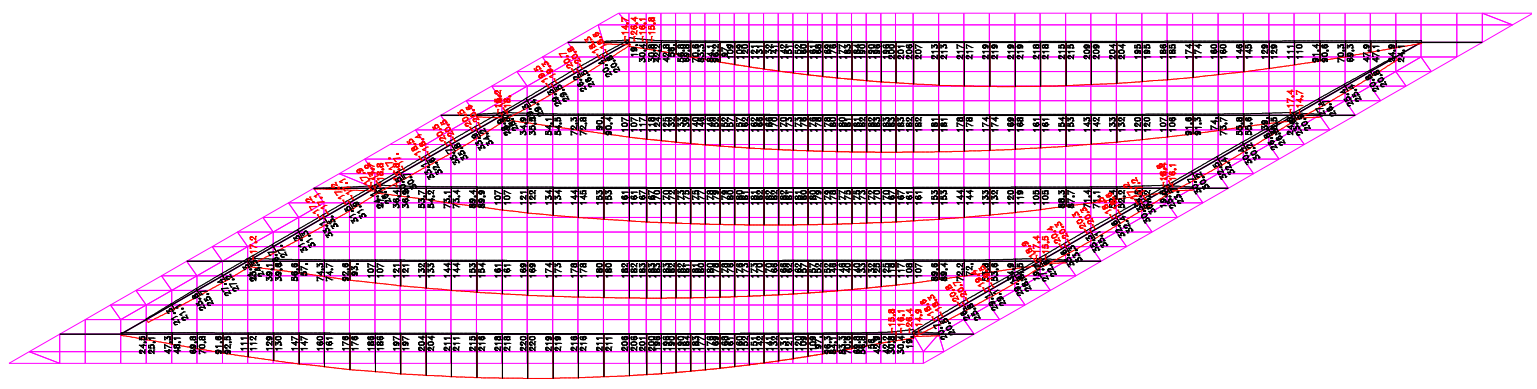

Força Cortante

Permanente

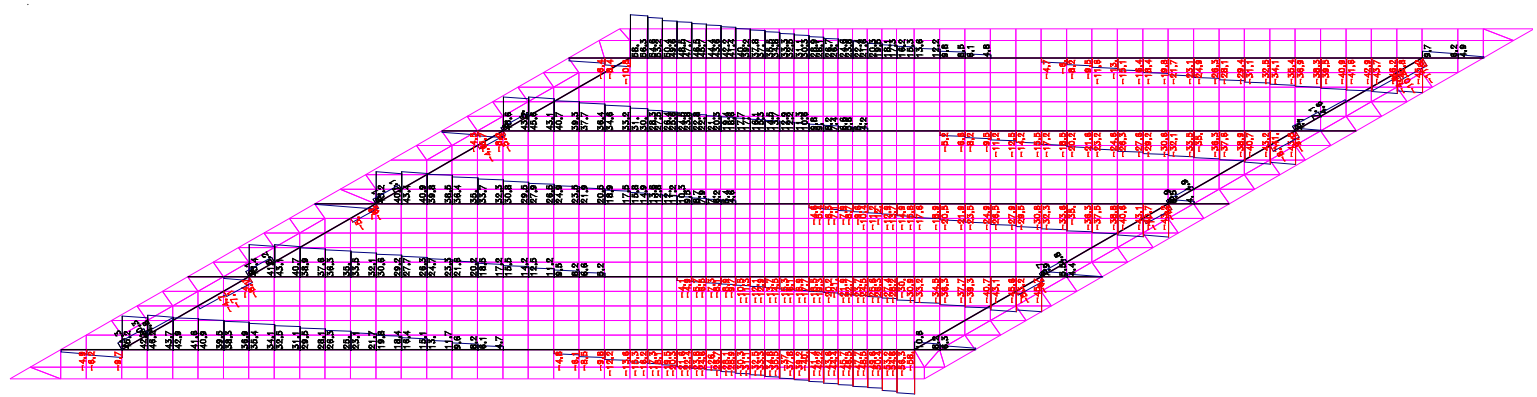

Móvel - Envoltória

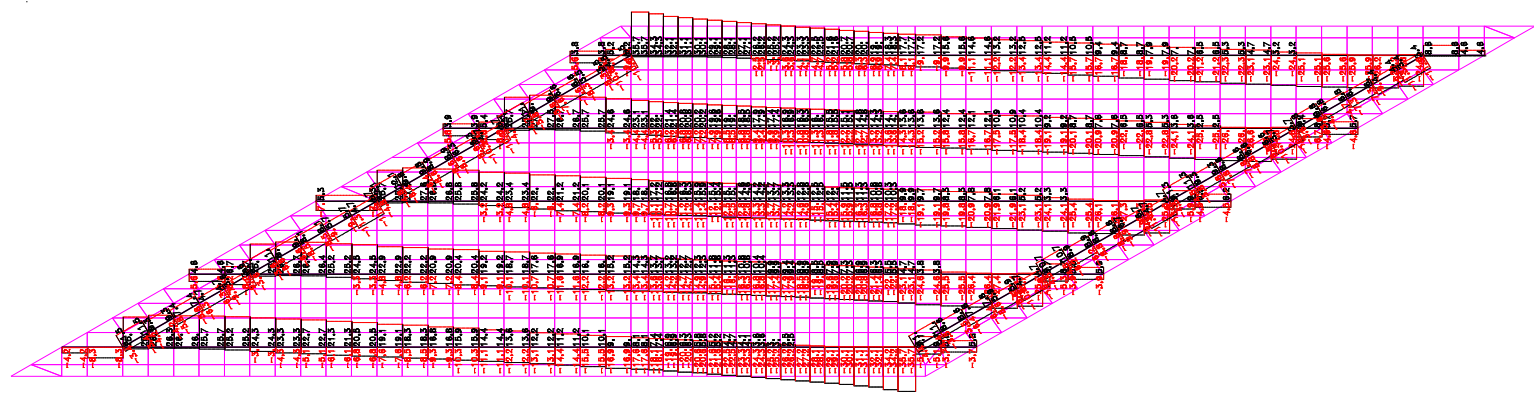


Torção

Permanente

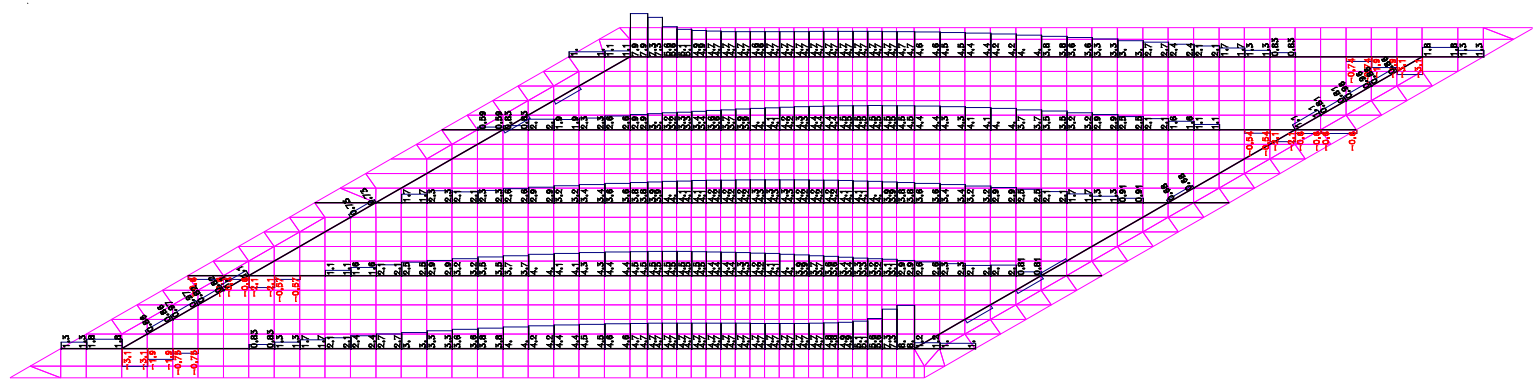

Móvel - Envoltória

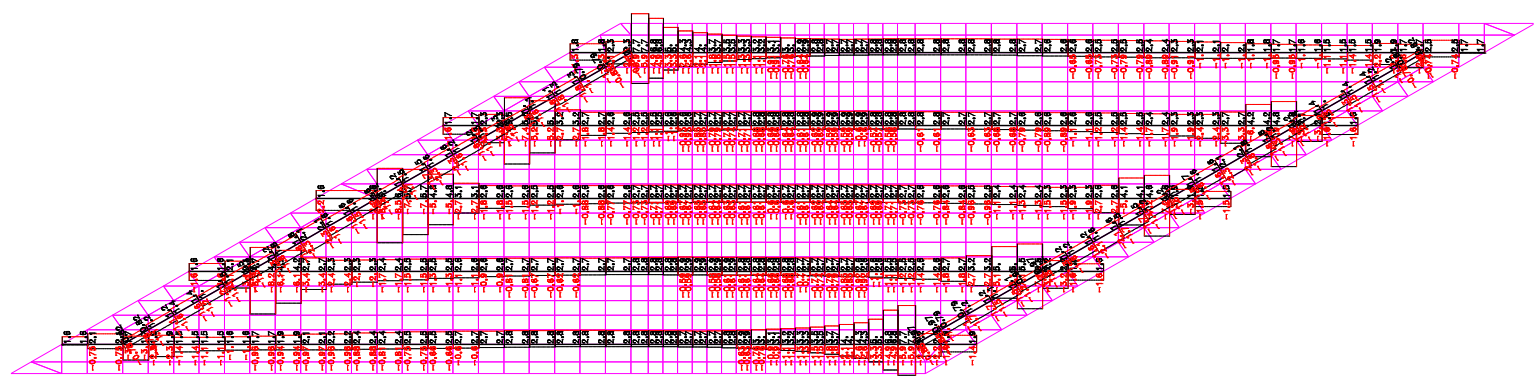

Reações nos Apoios

Permanente

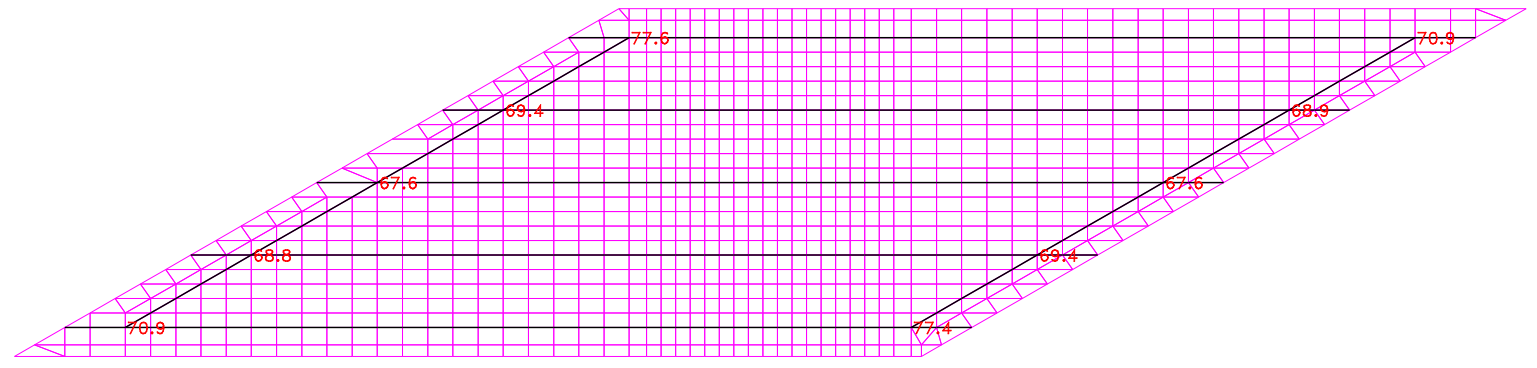

Móvel - Envoltória

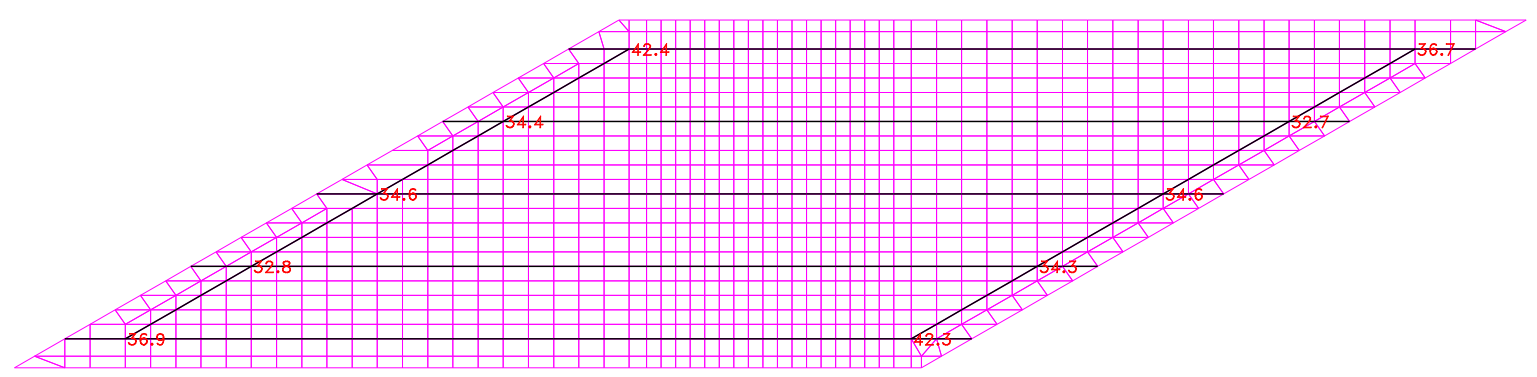




\section{ANEXO E - GRELHA - TRANSVERSINA NORMAL A}

\section{LONGARINA}

Solicitações nas Grelhas com $15^{\circ}$ de esconsidade

Longarina

Momento Fletor

Permanente

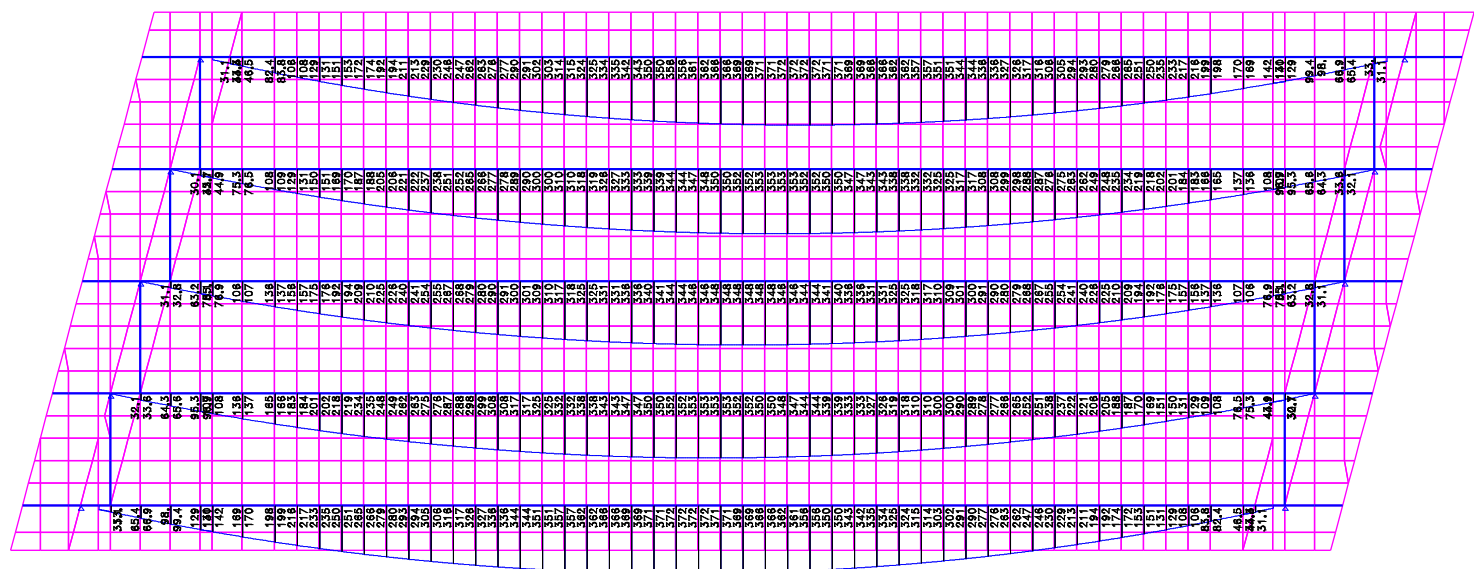

Móvel - Envoltória

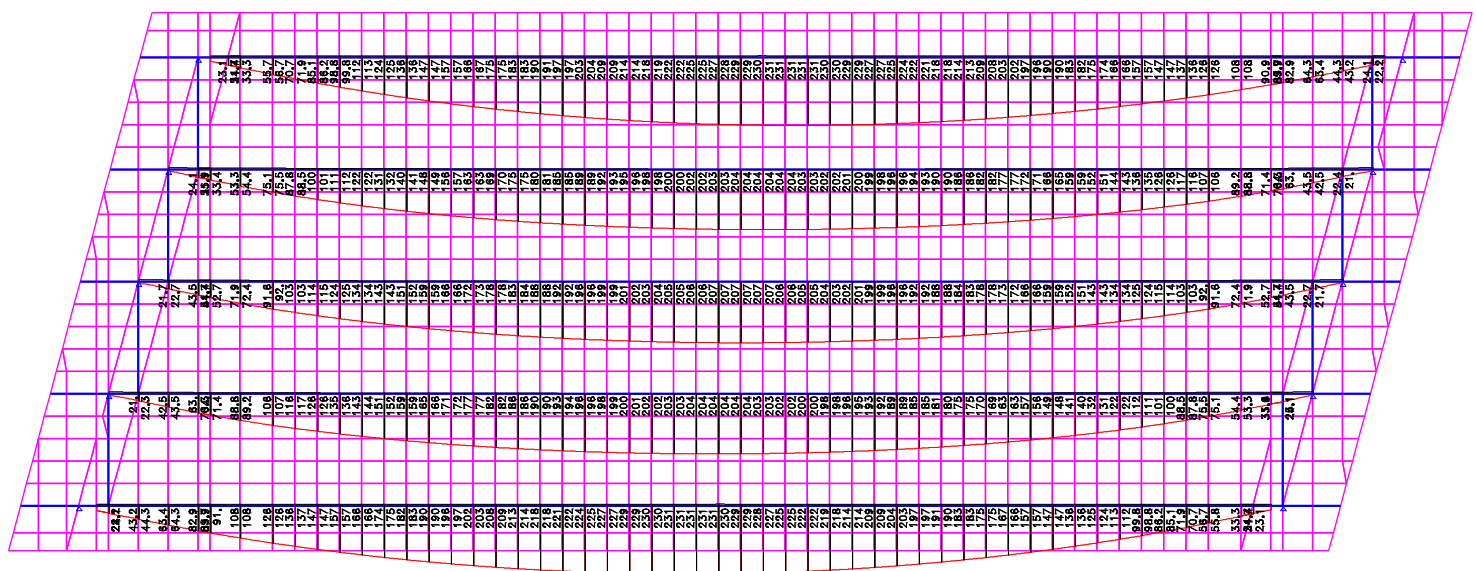


Força Cortante

Permanente

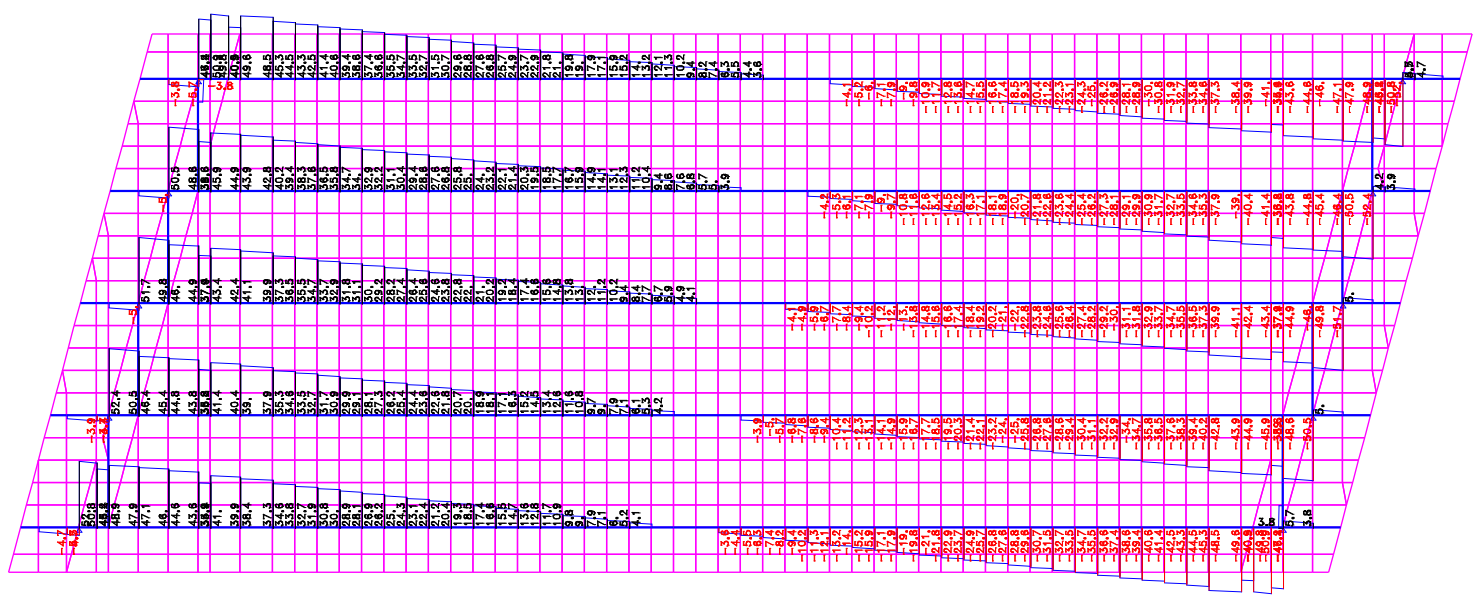

Móvel - Envoltória

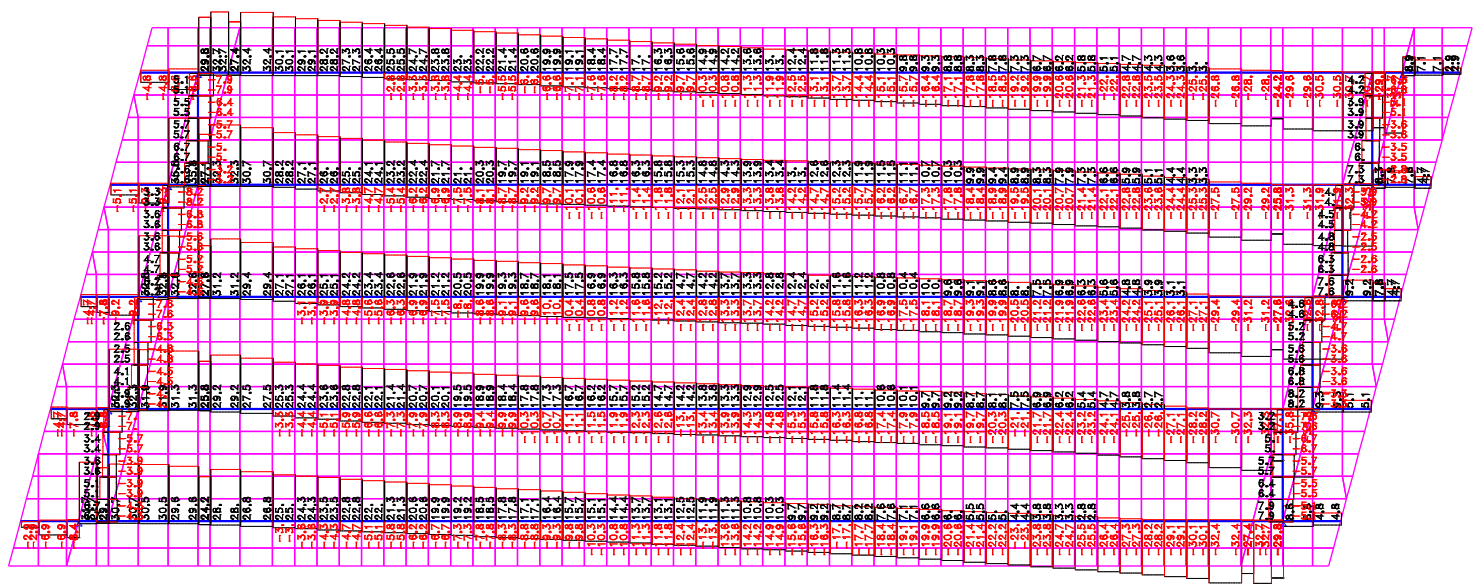


Torção

Permanente

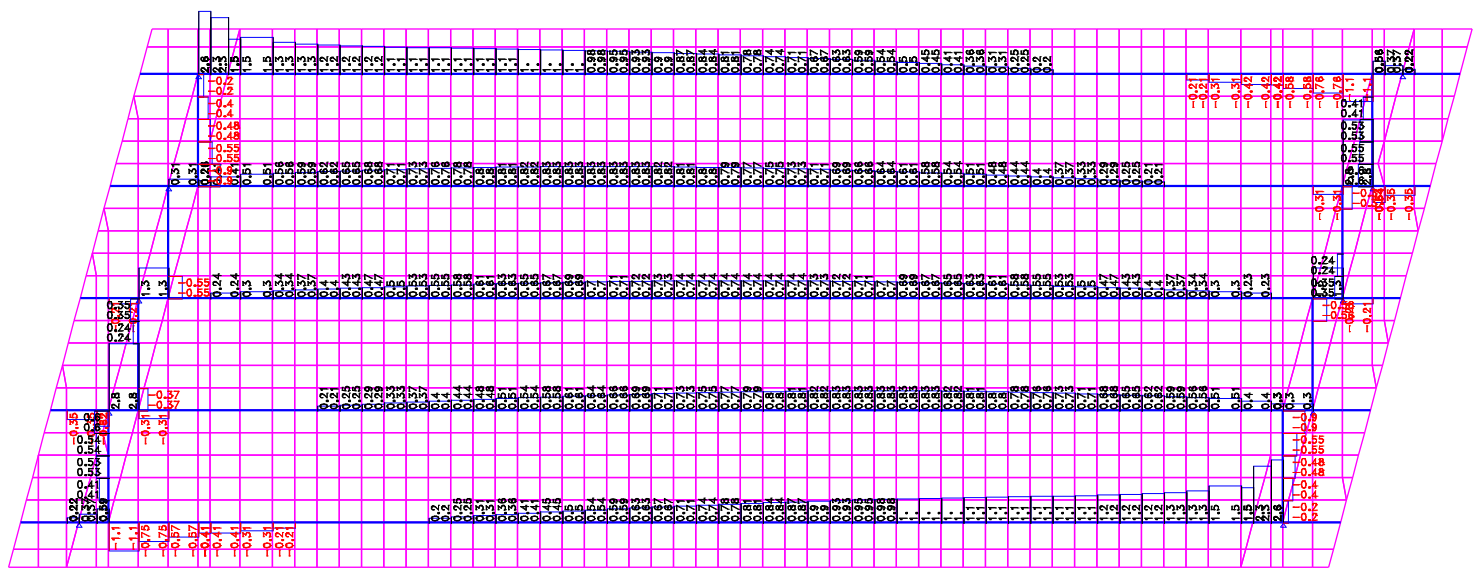

Móvel - Envoltória

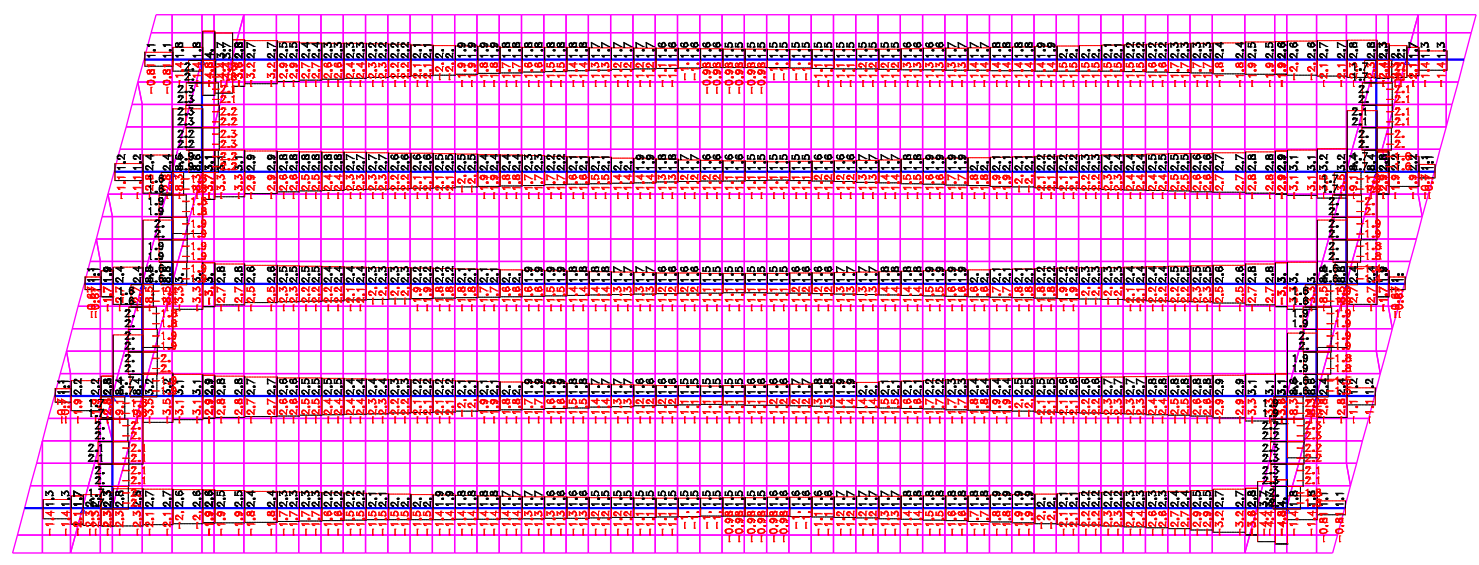


Reações nos Apoios

Permanente

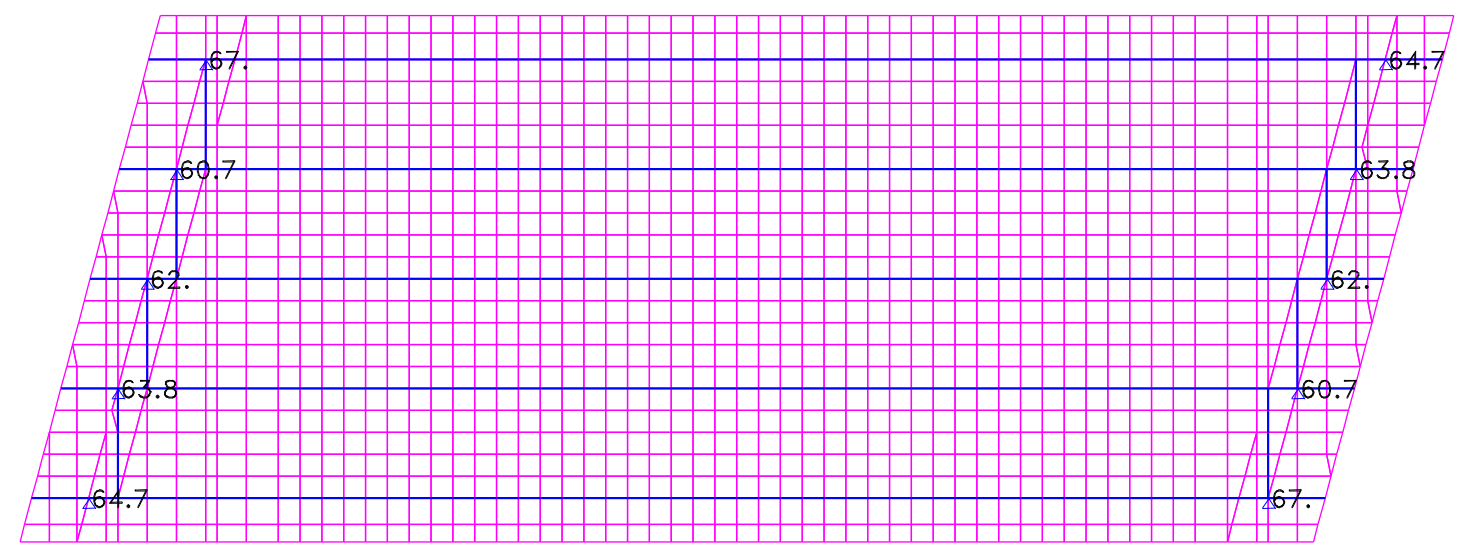

\section{Móvel - Envoltória}

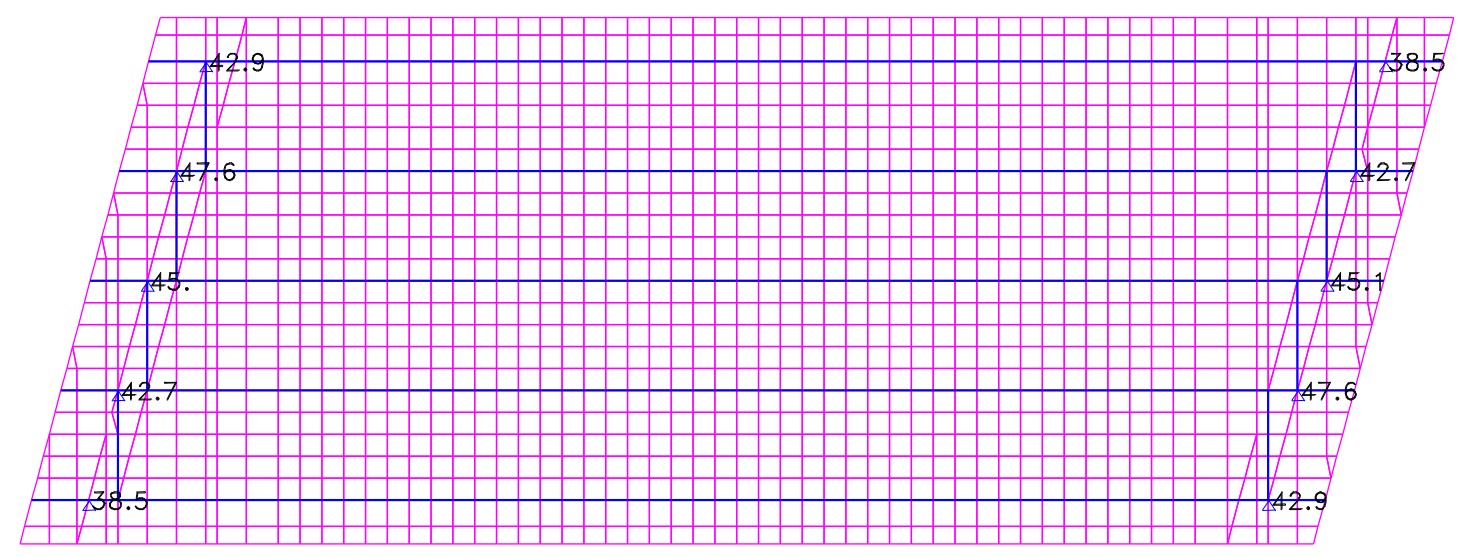


Solicitações nas Grelhas com $30^{\circ}$ de esconsidade

Longarina

Momento Fletor

Permanente

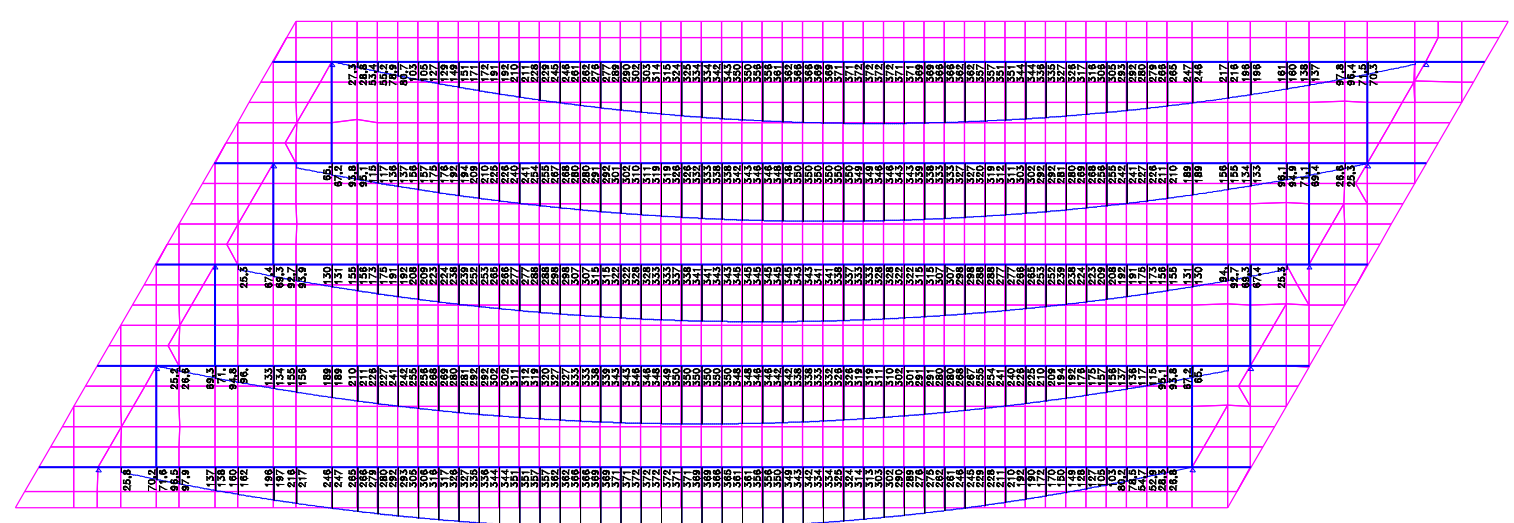

Móvel - Envoltória

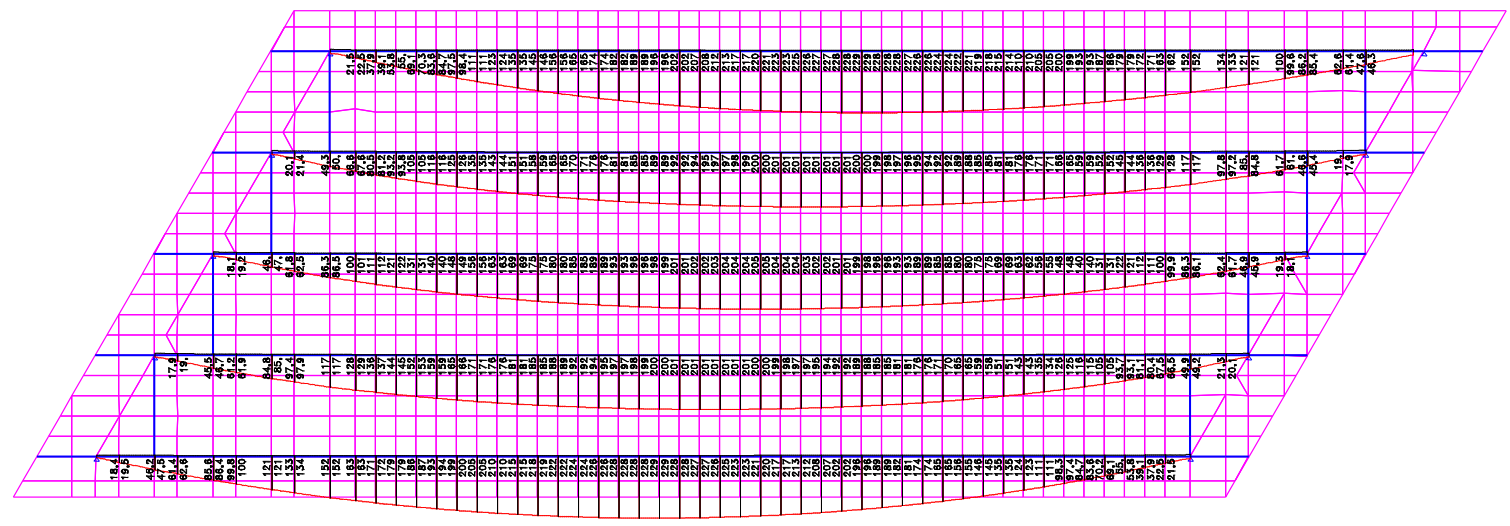

Força Cortante

Permanente

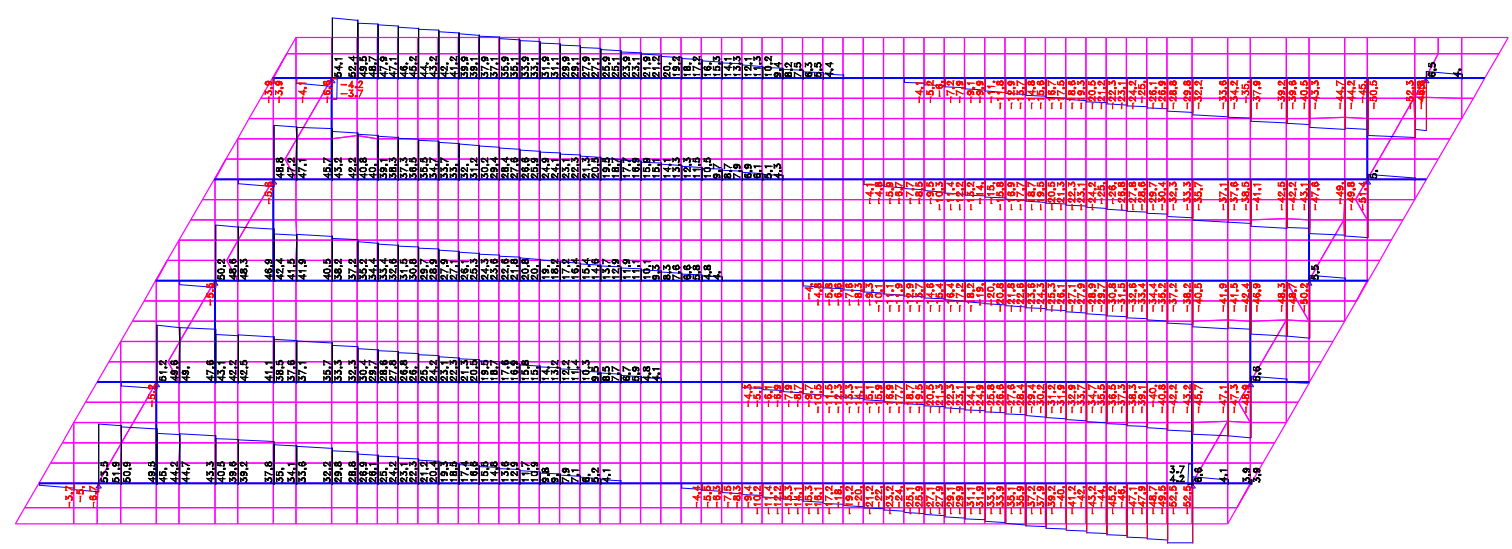


Móvel - Envoltória

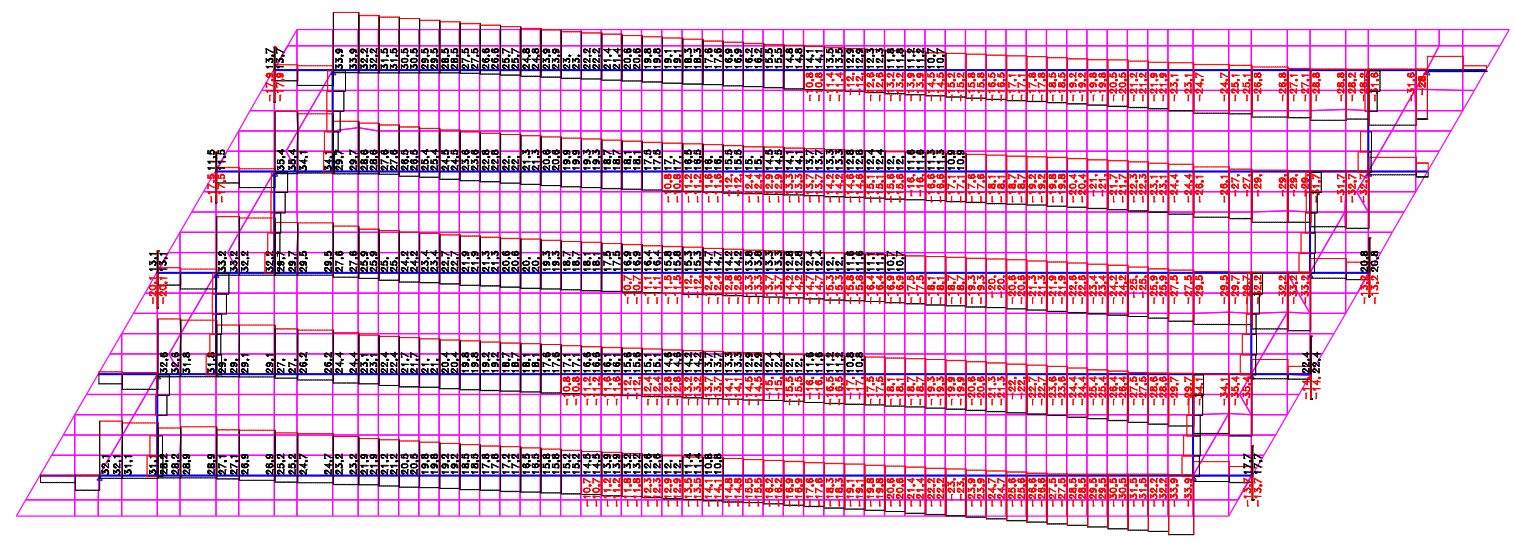

Torção

Permanente

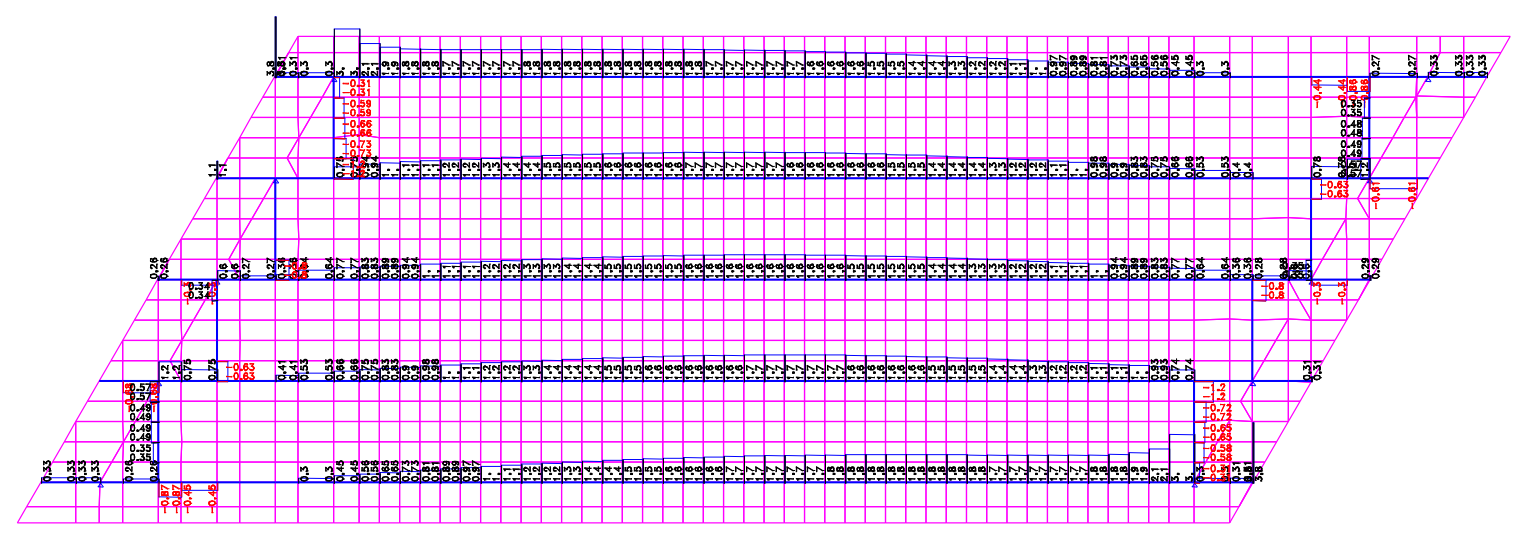

Móvel - Envoltória

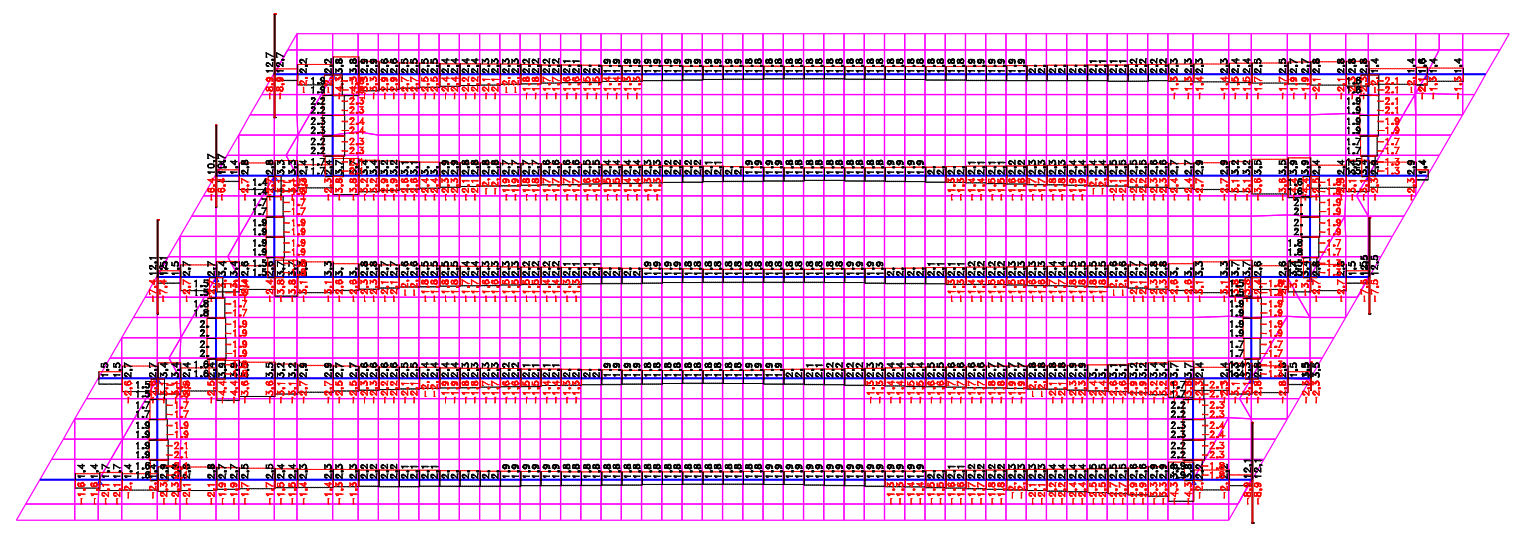


Reações nos Apoios

Permanente

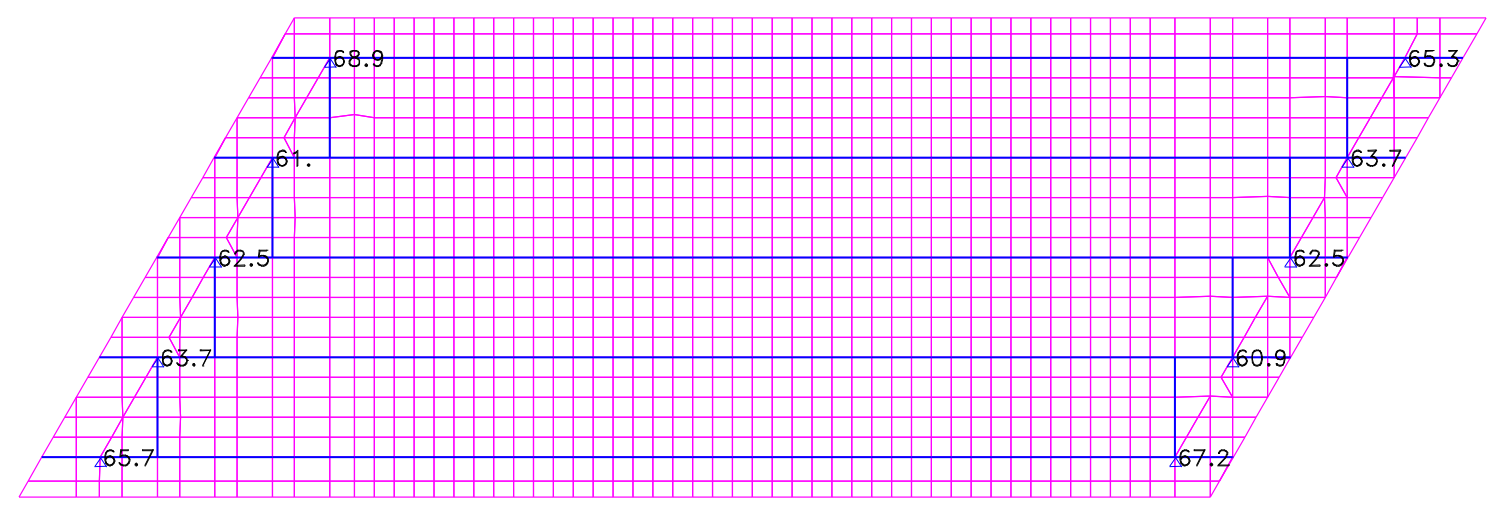

Móvel - Envoltória

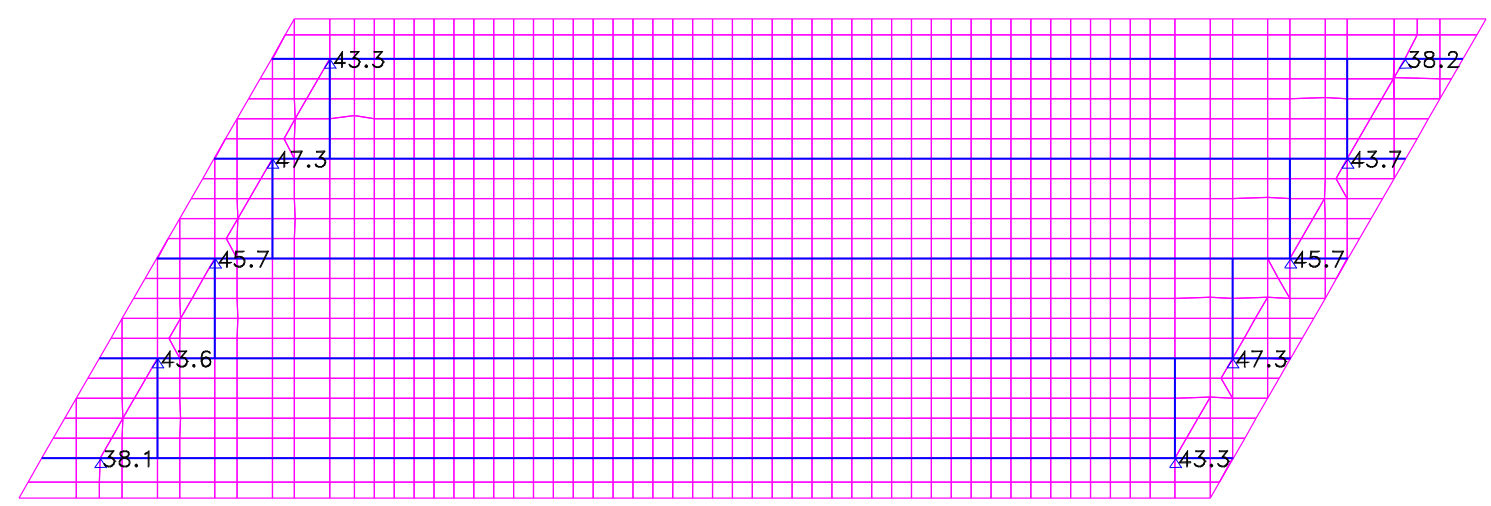




\section{Solicitações nas Grelhas com $45^{\circ}$ de esconsidade}

\section{Longarina}

Momento Fletor

Permanente

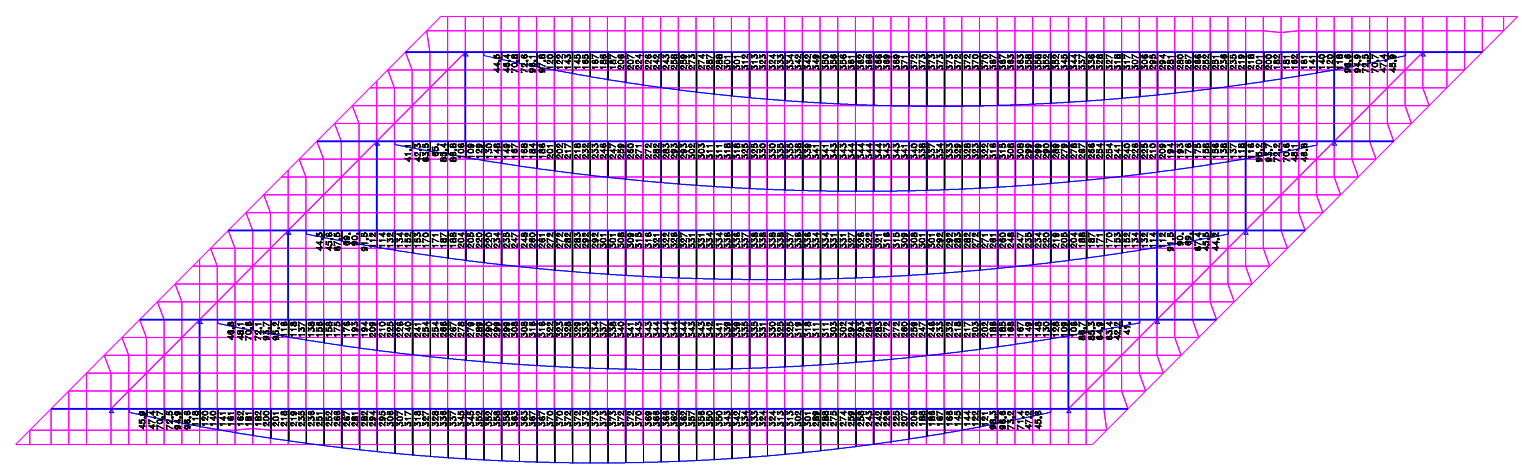

Móvel - Envoltória

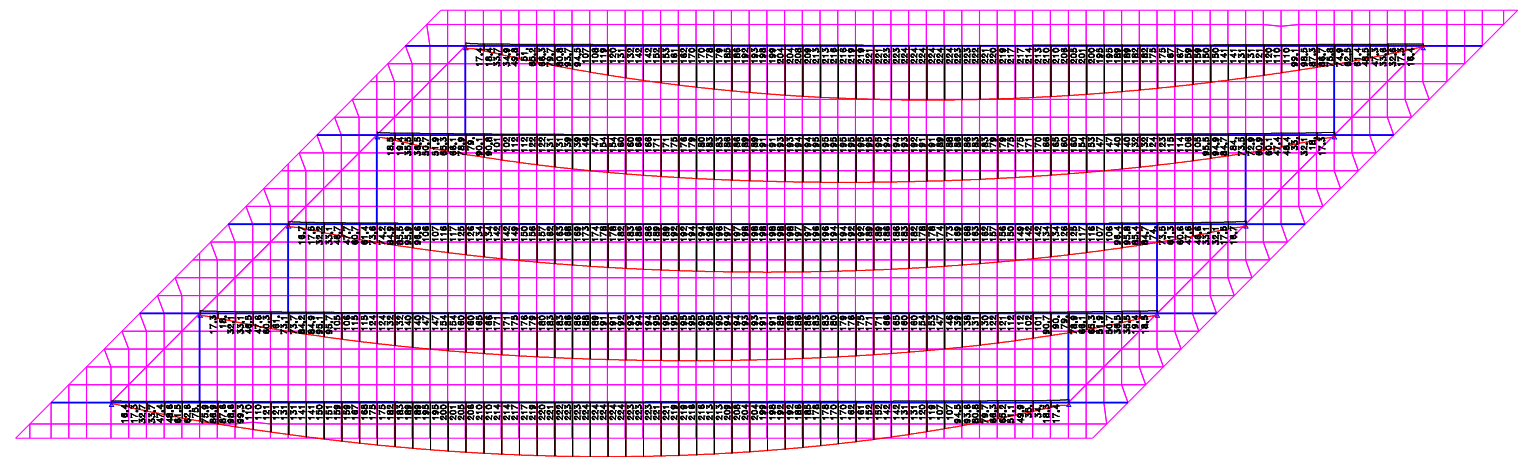

Força Cortante

Permanente

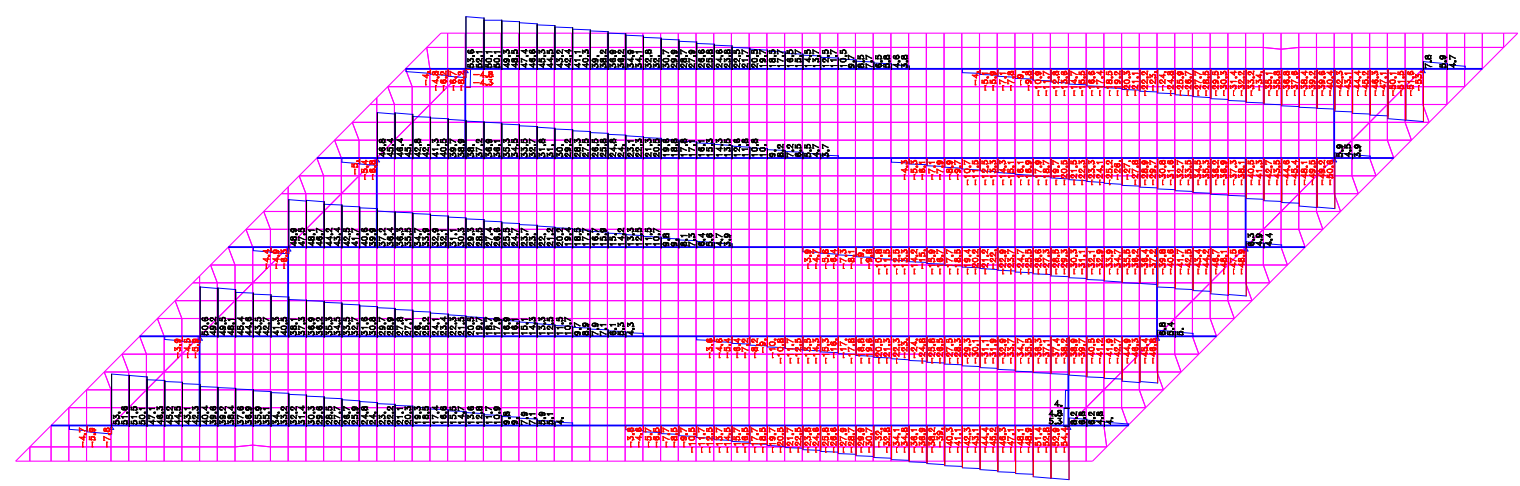

Móvel - Envoltória

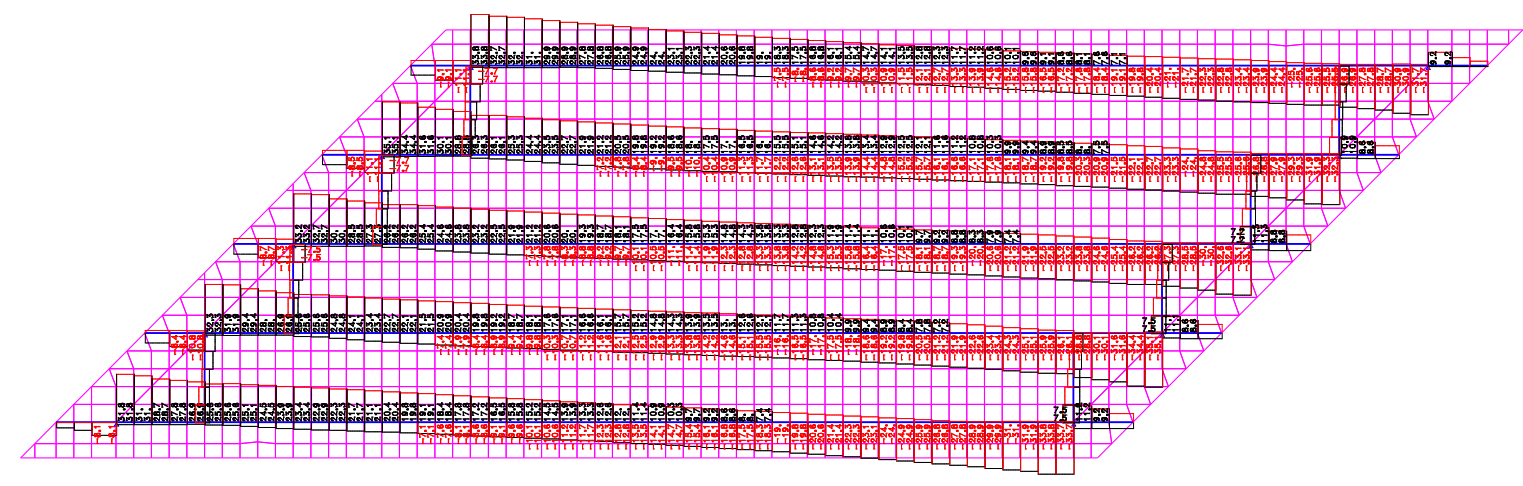


Torção

Permanente

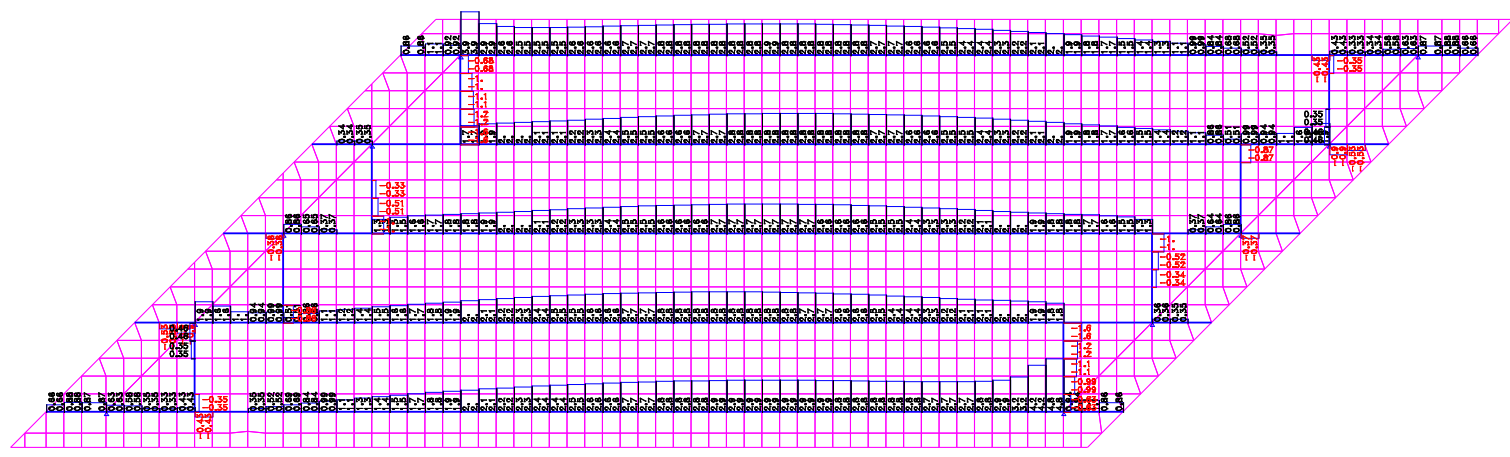

Móvel - Envoltória

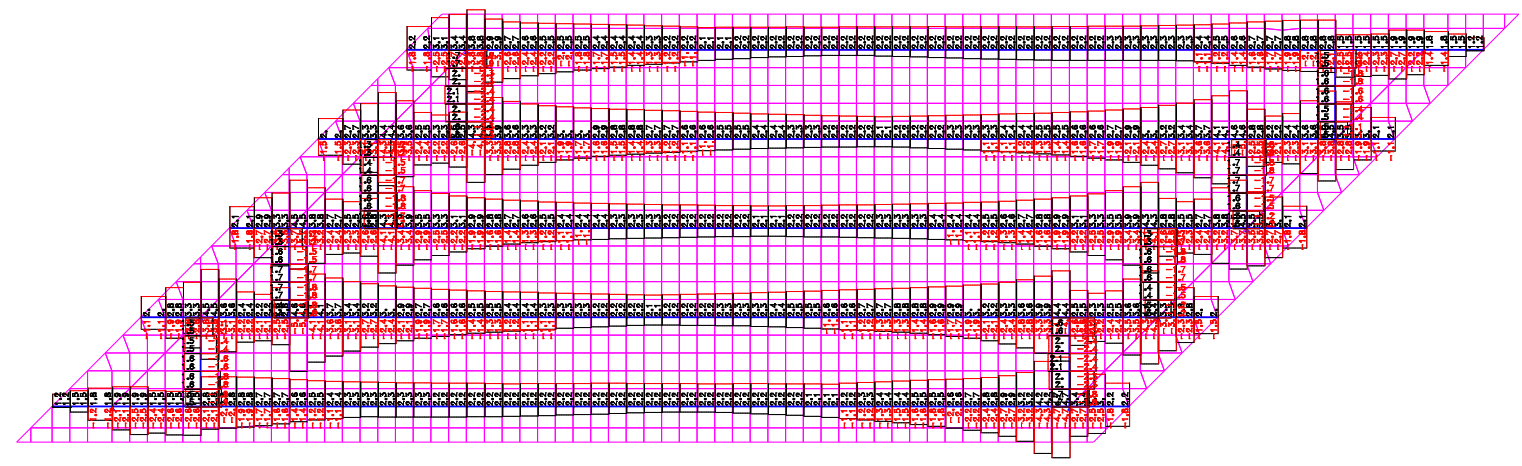

Reações nos Apoios

Permanente

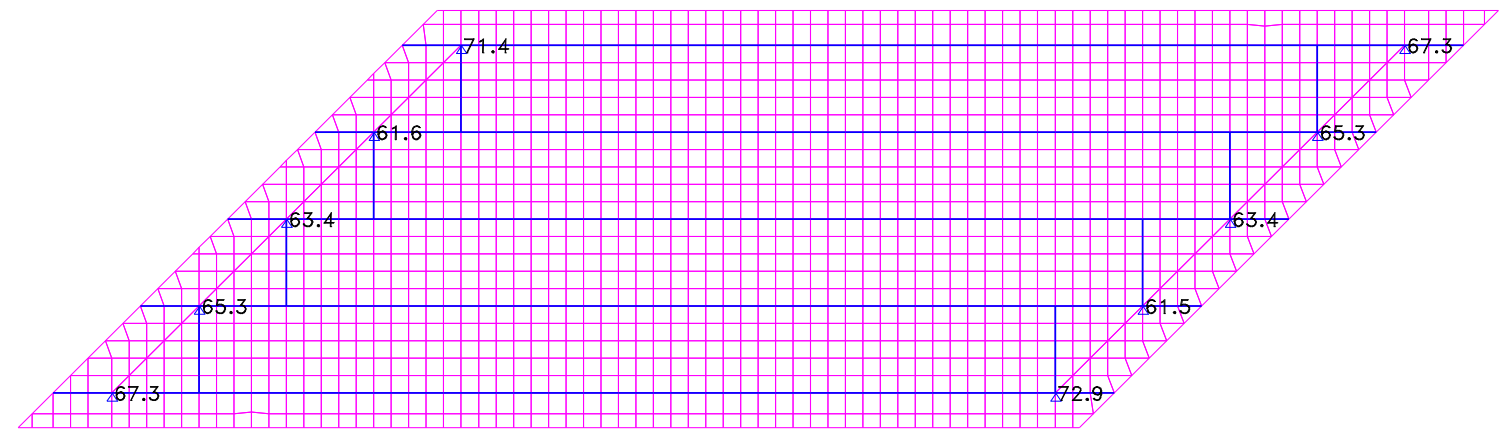

Móvel - Envoltória

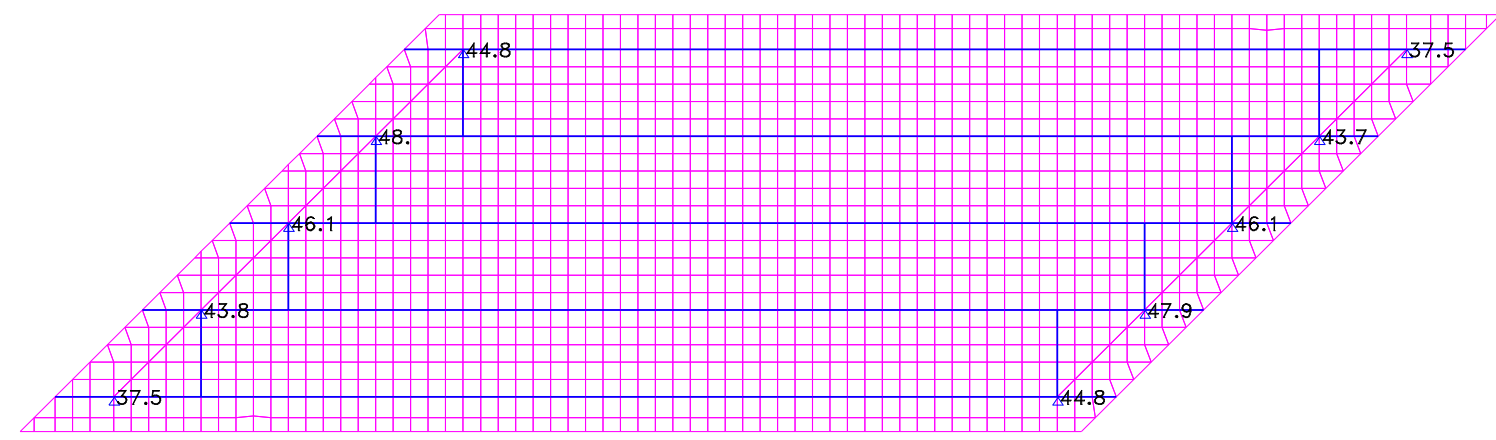


Solicitações nas Grelhas com $60^{\circ}$ de esconsidade

Longarina

Momento Fletor

Permanente

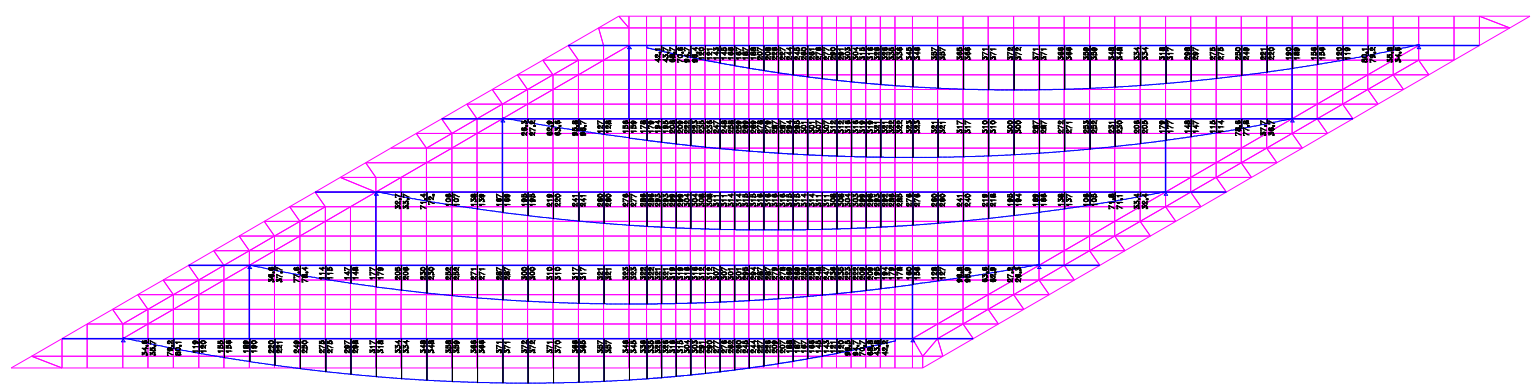

Móvel - Envoltória

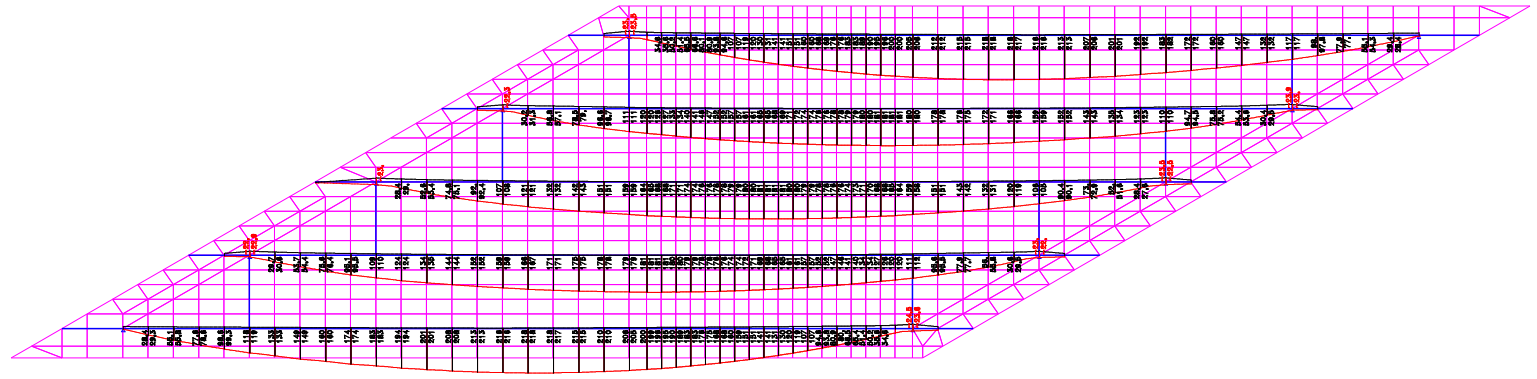

Força Cortante

Permanente

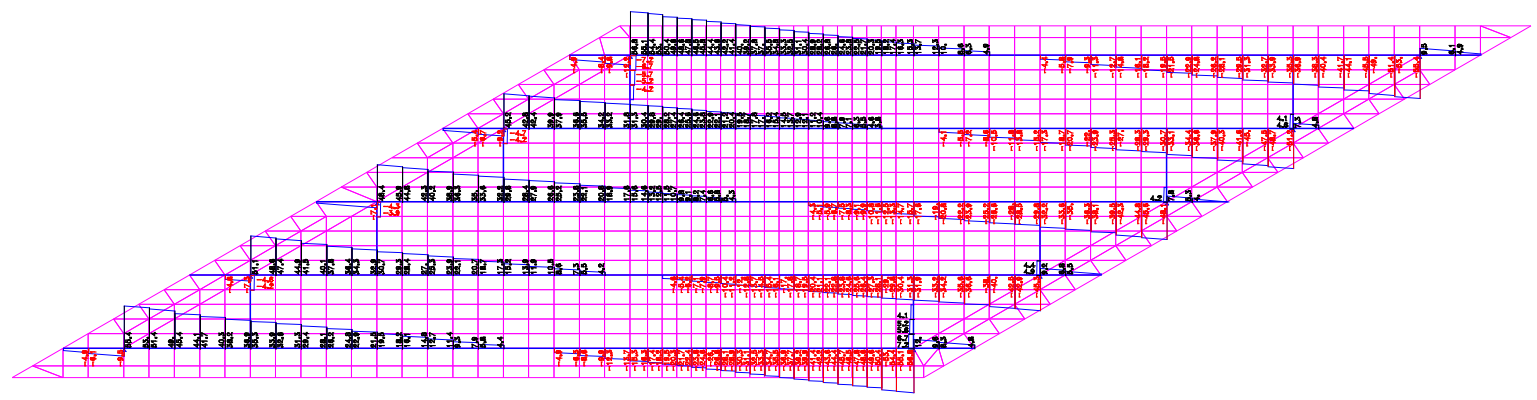

Móvel - Envoltória

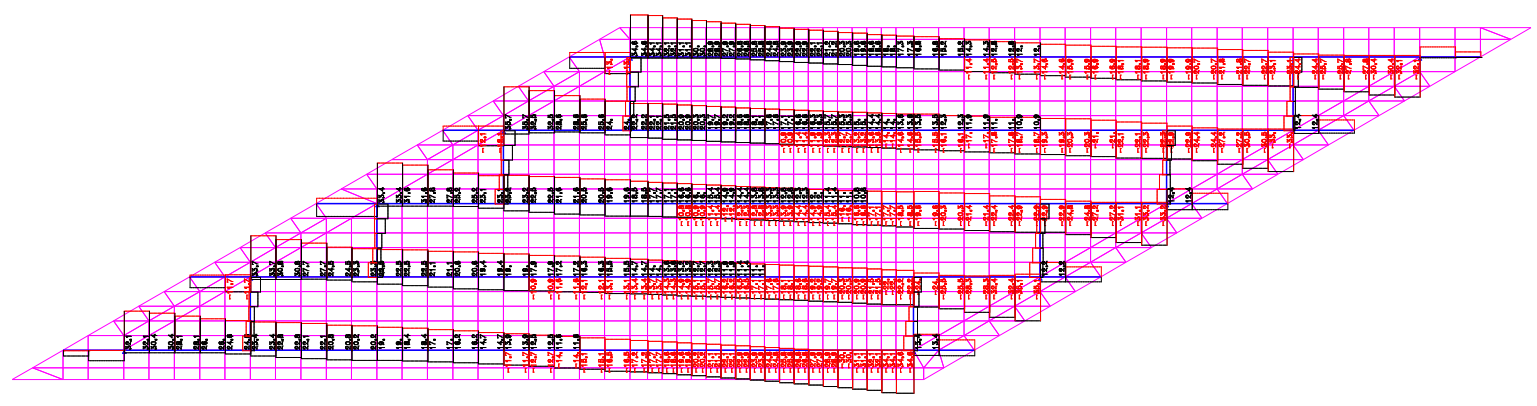


Torção

Permanente

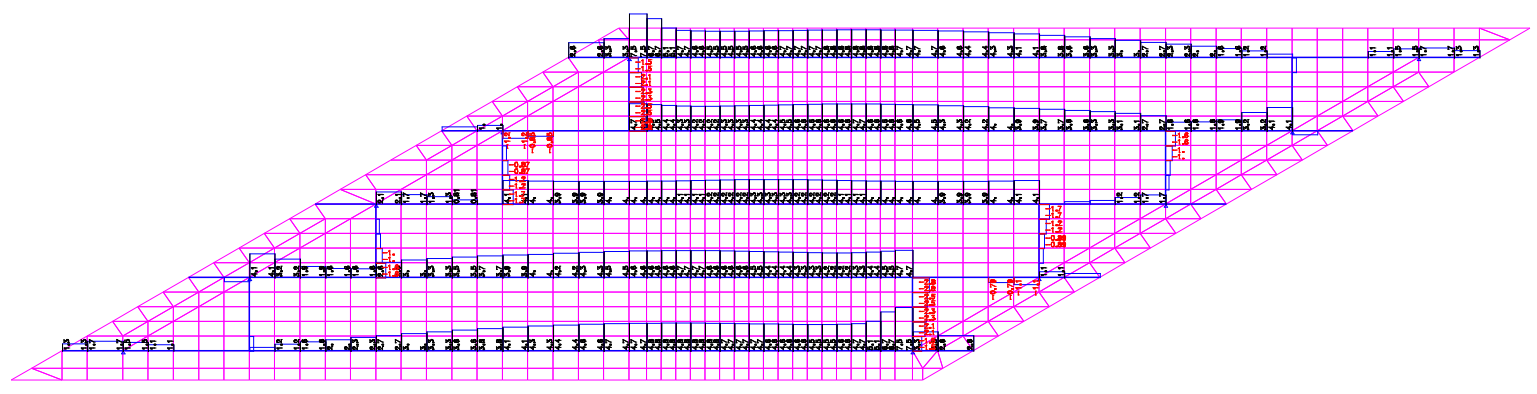

Móvel - Envoltória

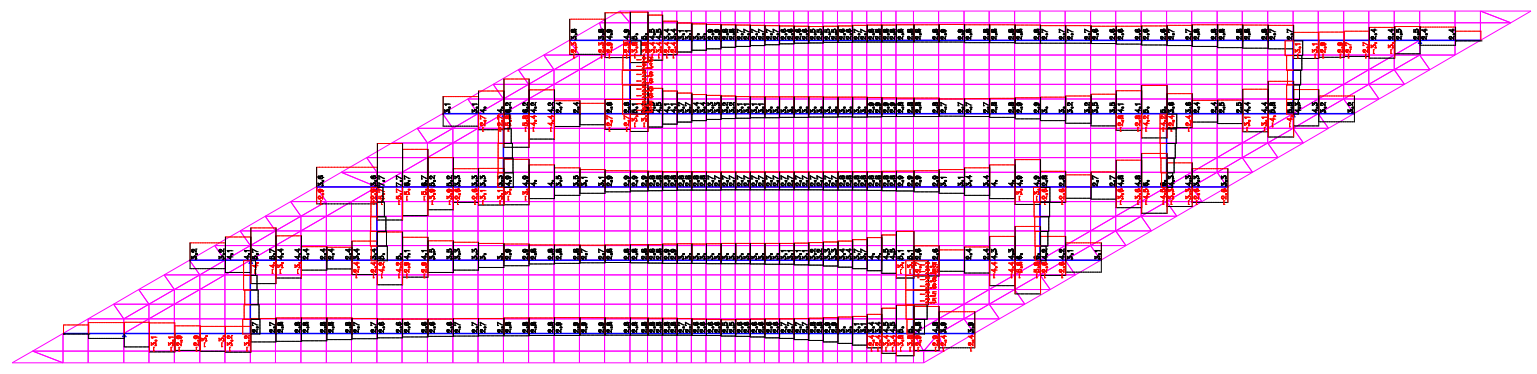

Reações nos Apoios

Permanente

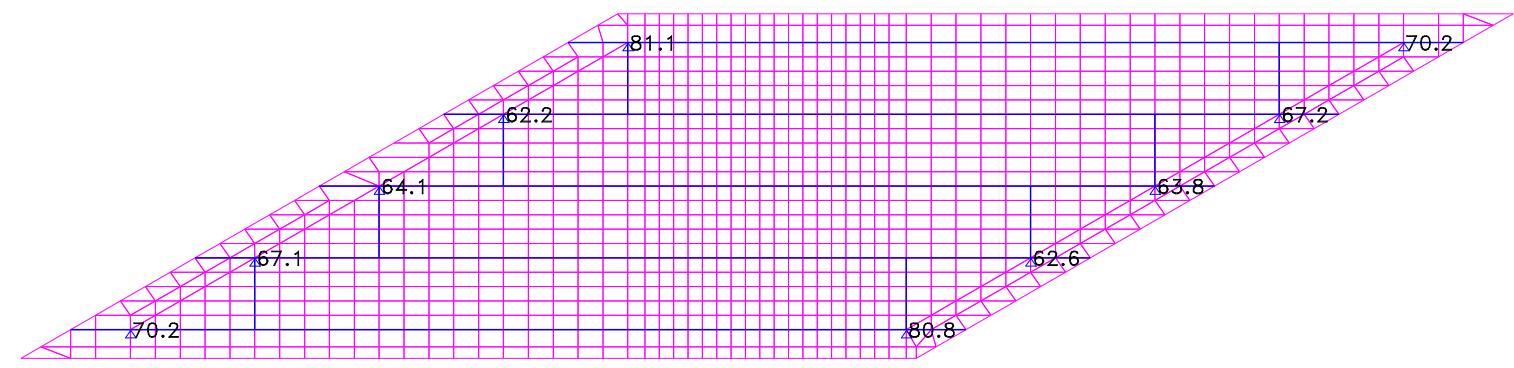

Móvel - Envoltória

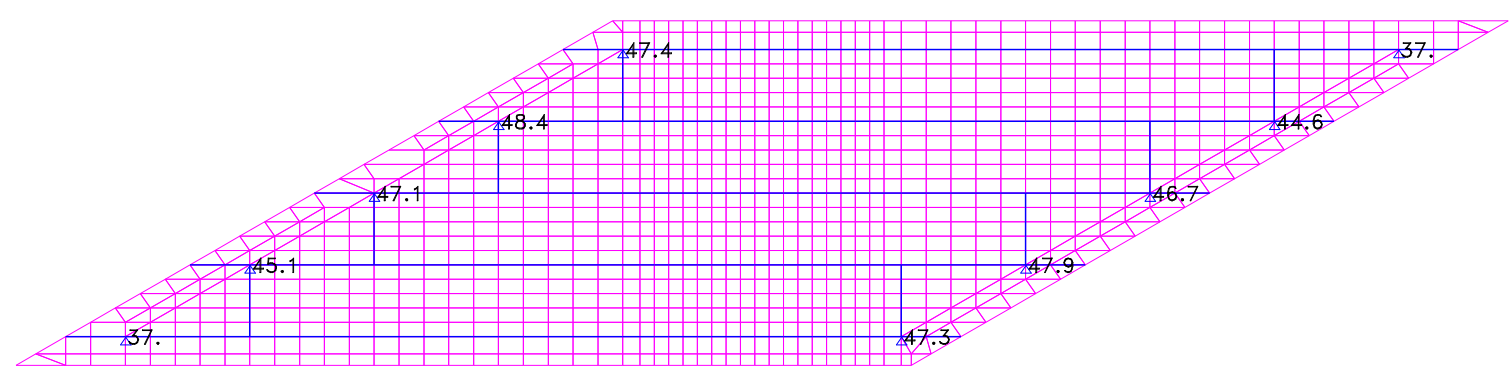




\section{ANEXO $\mathbf{F}$ - GRELHA - SEM TRANSVERSINAS \\ Solicitações nas Grelhas com $0^{\circ}$ de esconsidade}

Longarina

Momento Fletor

Permanente

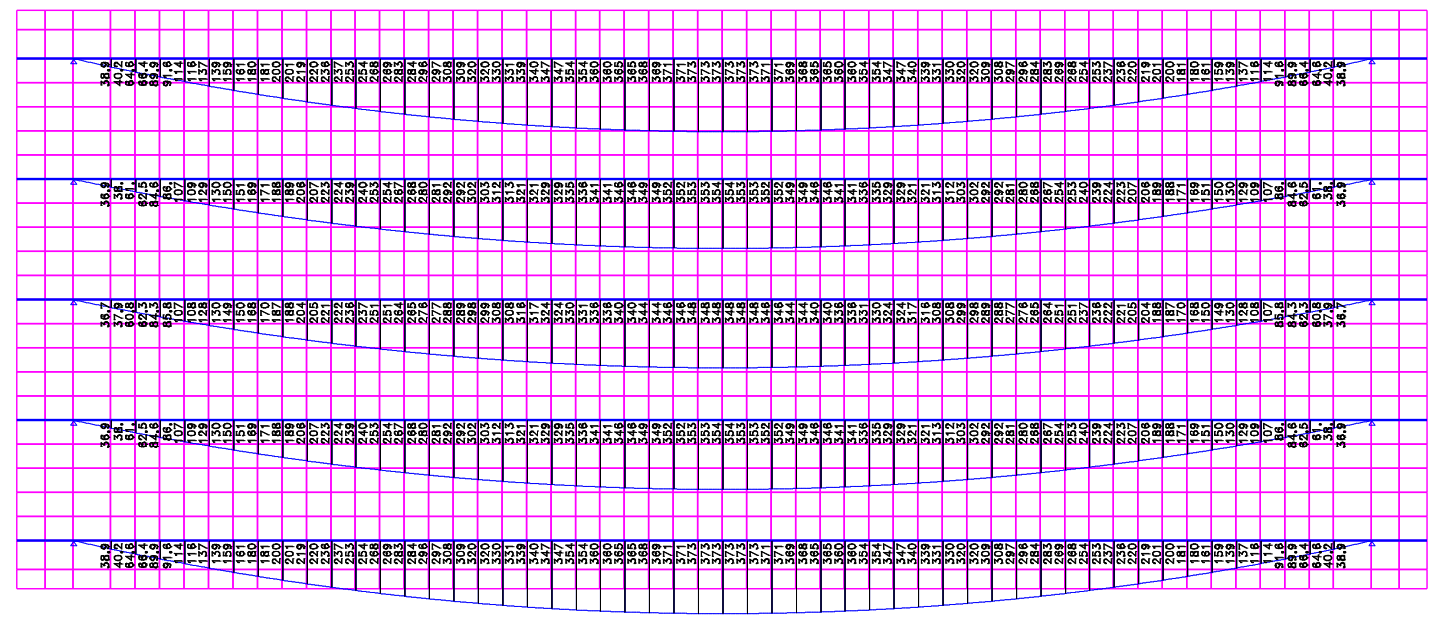

Móvel - Envoltória

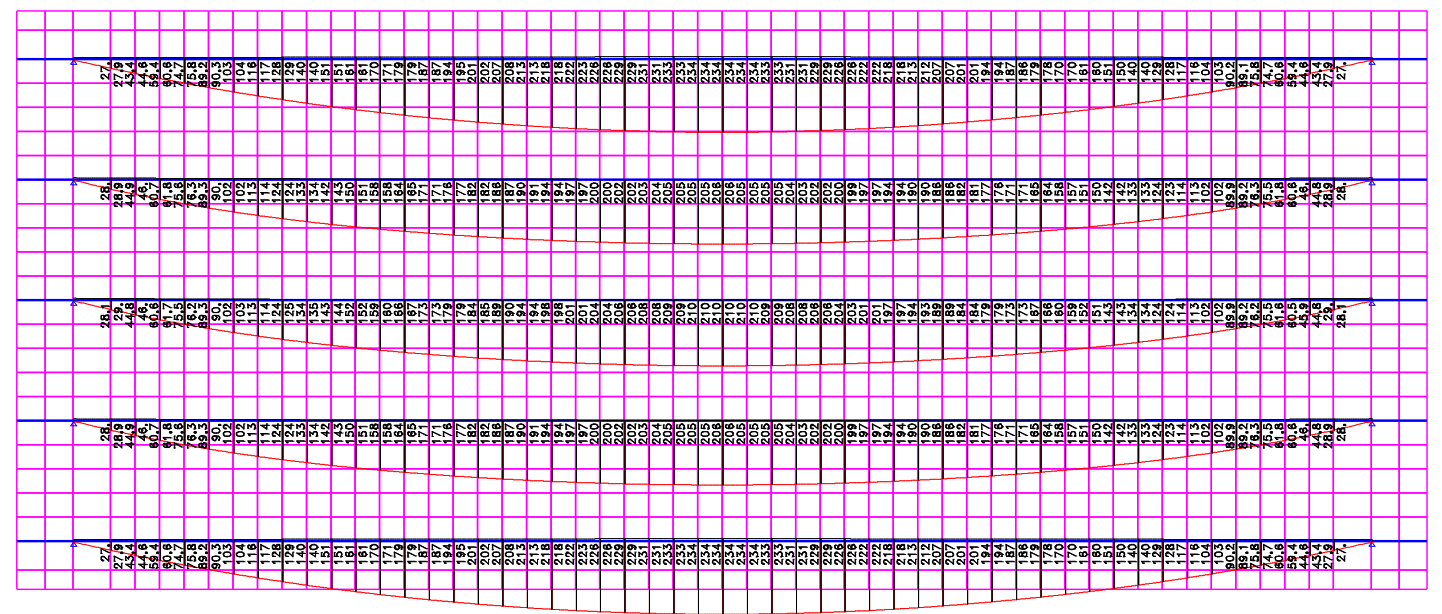

Força Cortante

Permanente

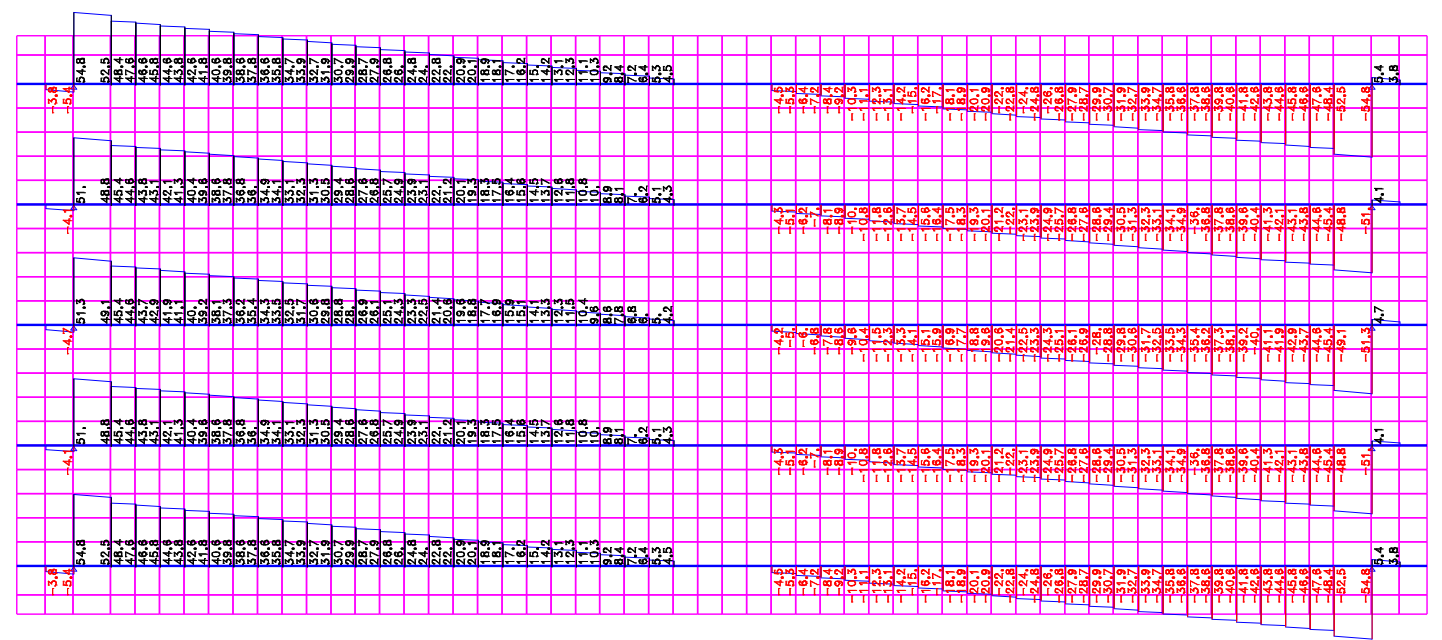


Móvel - Envoltória

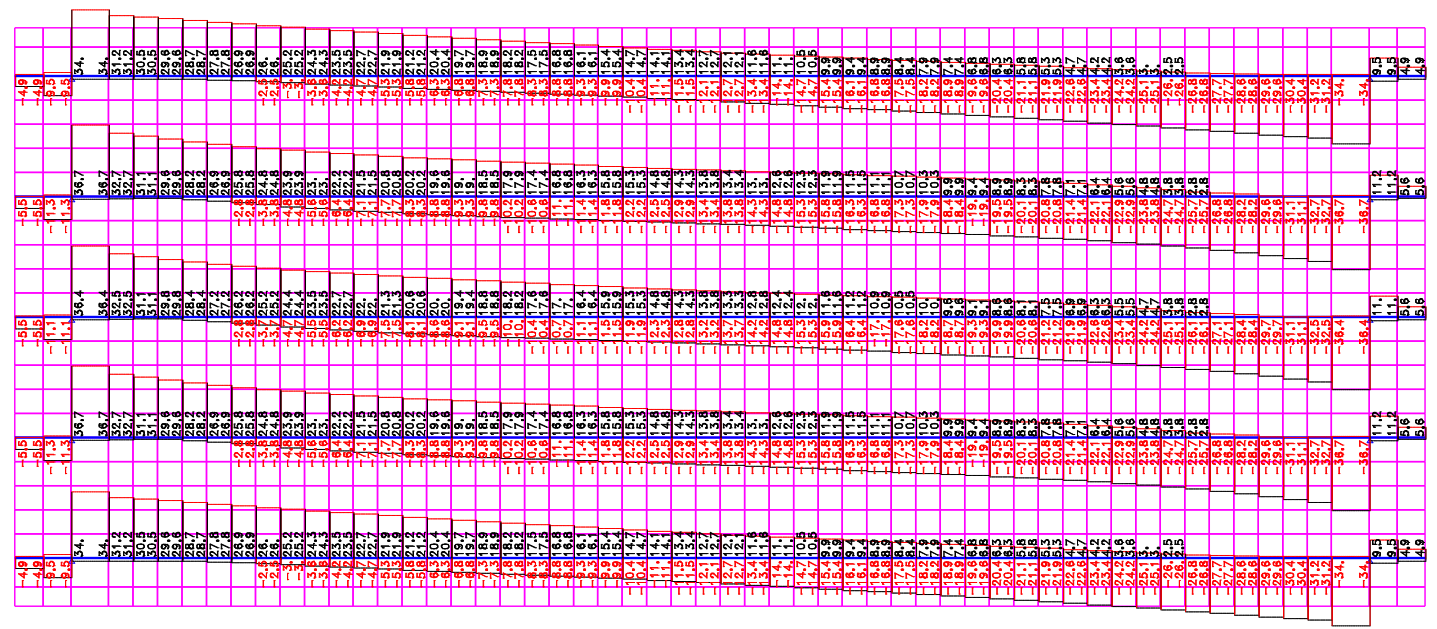

Torção

Permanente

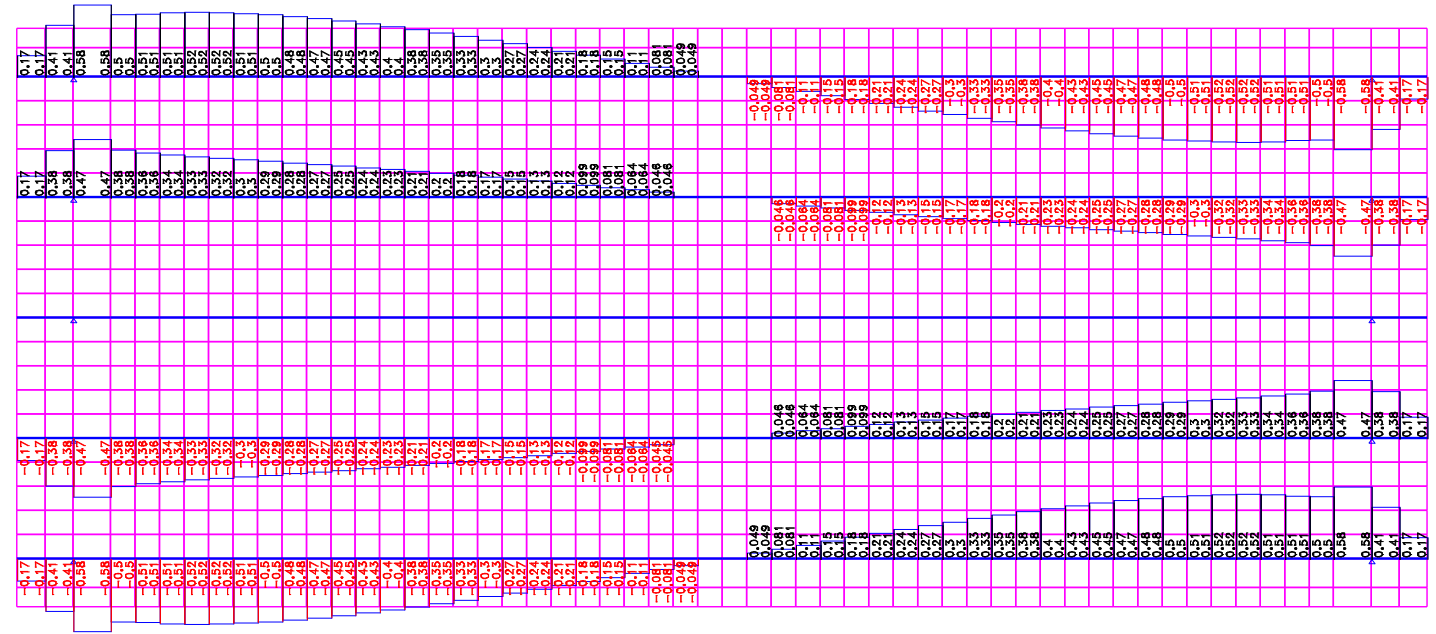

\section{Móvel - Envoltória}

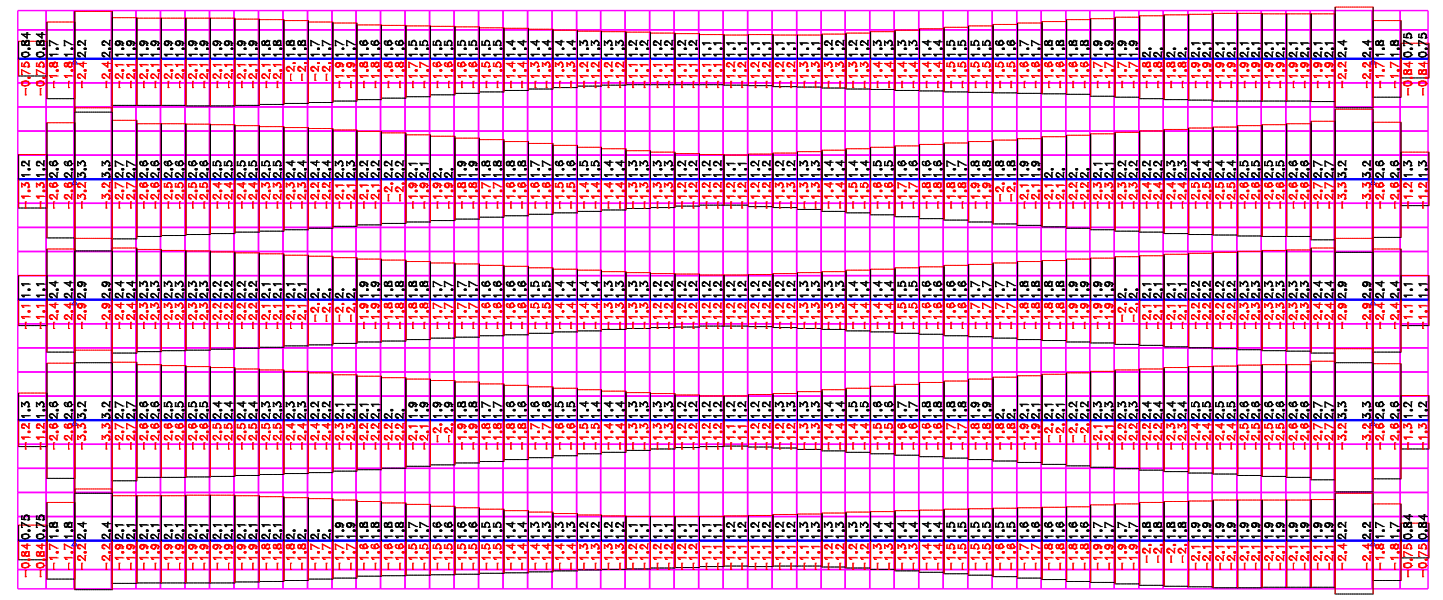


Reações nos Apoios

Permanente

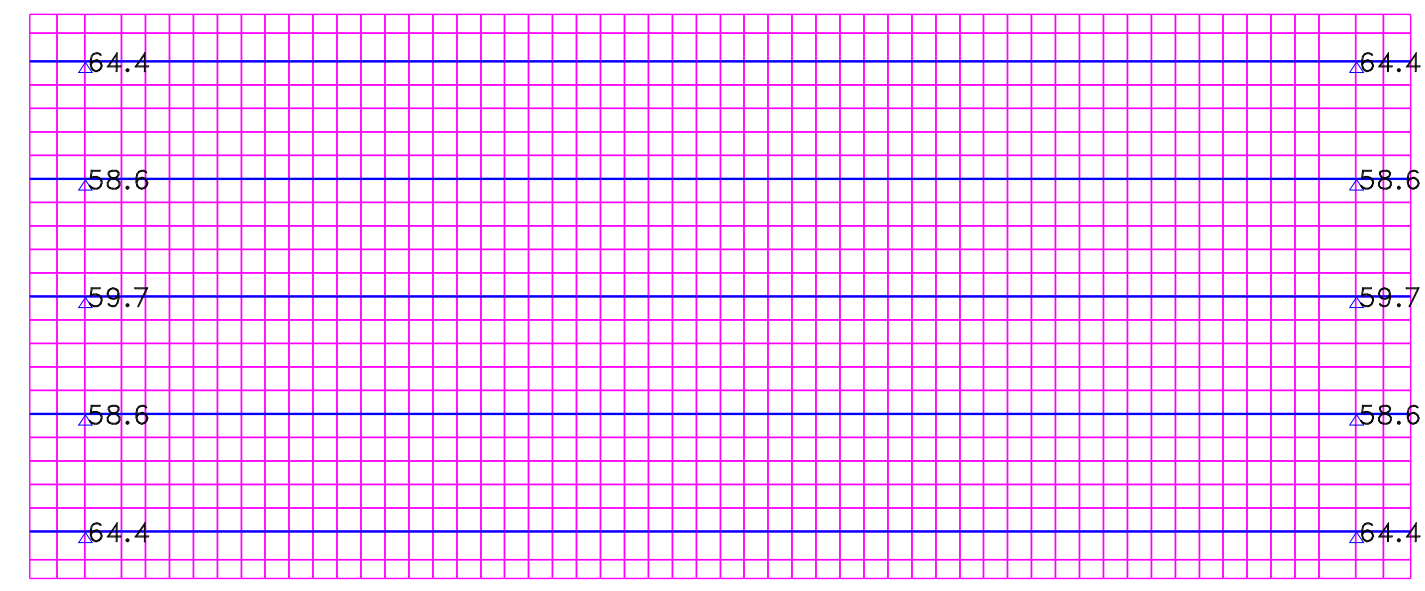

Móvel - Envoltória

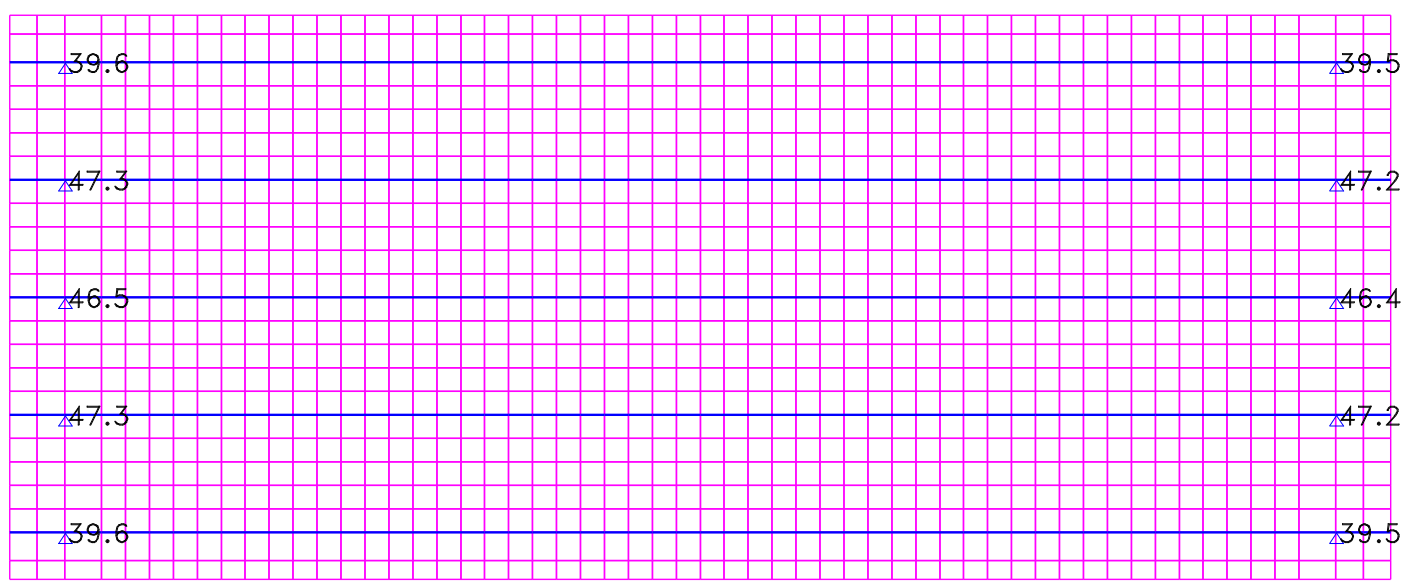


Solicitações nas Grelhas com $15^{\circ}$ de esconsidade

Longarina

Momento Fletor

Permanente

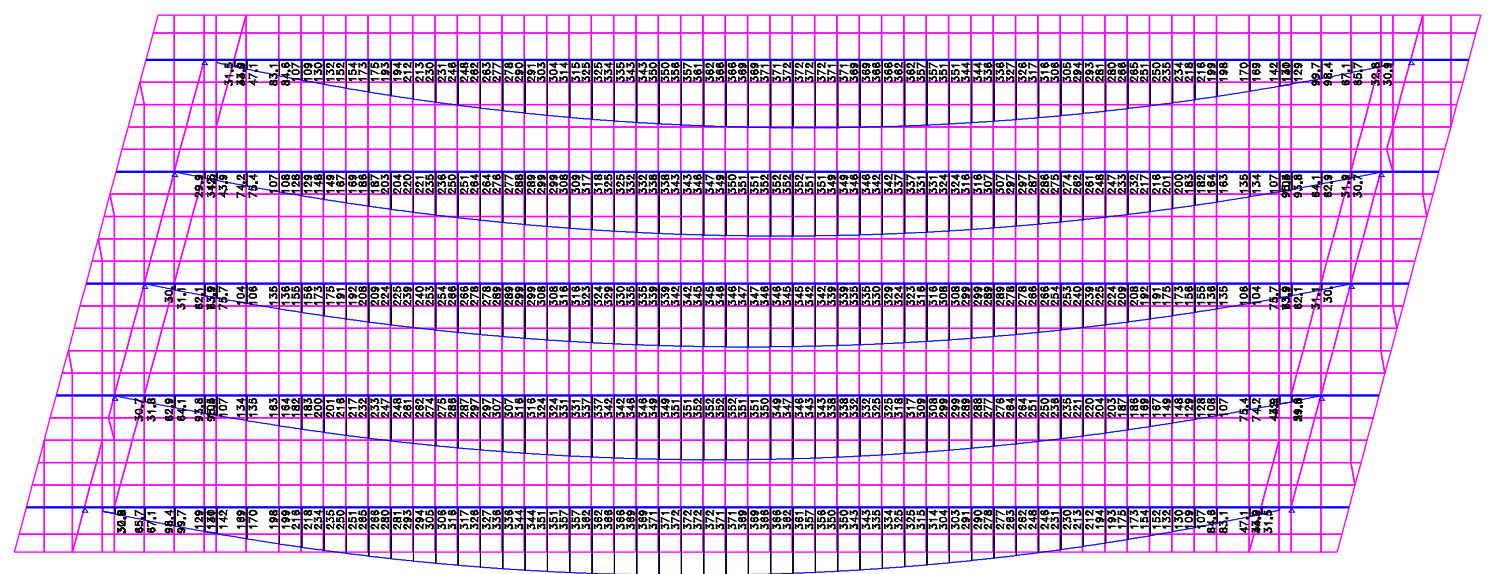

Móvel - Envoltória

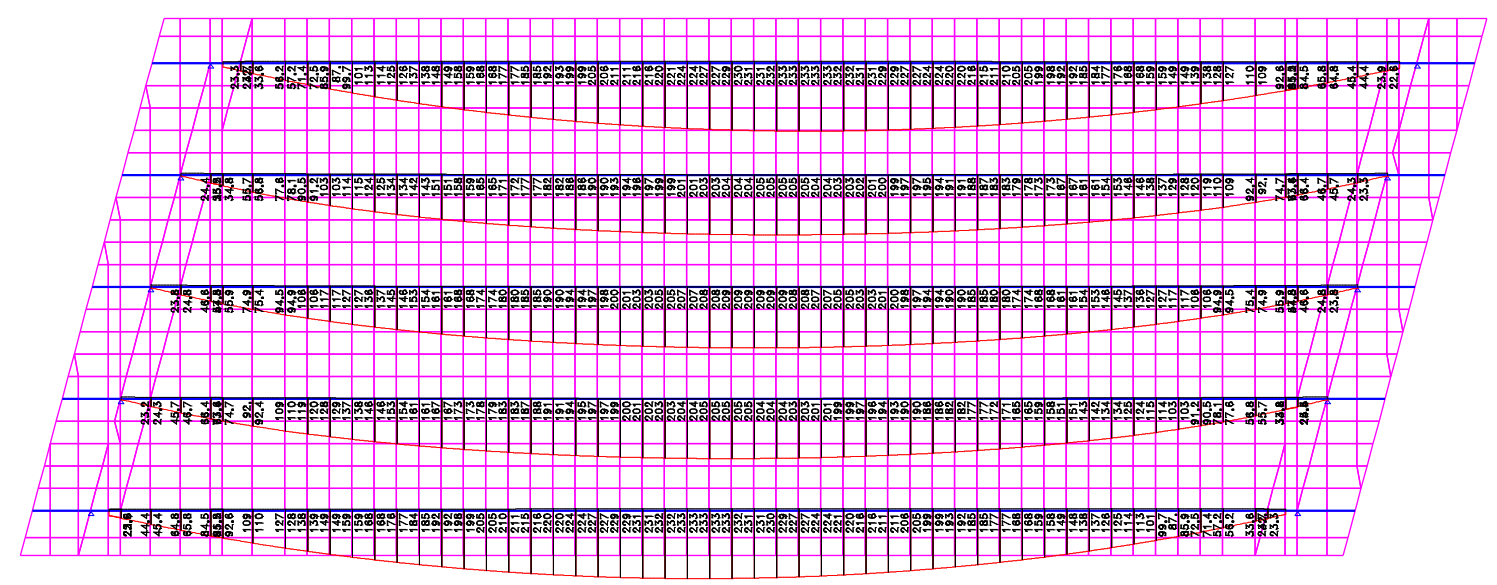

Força Cortante

Permanente

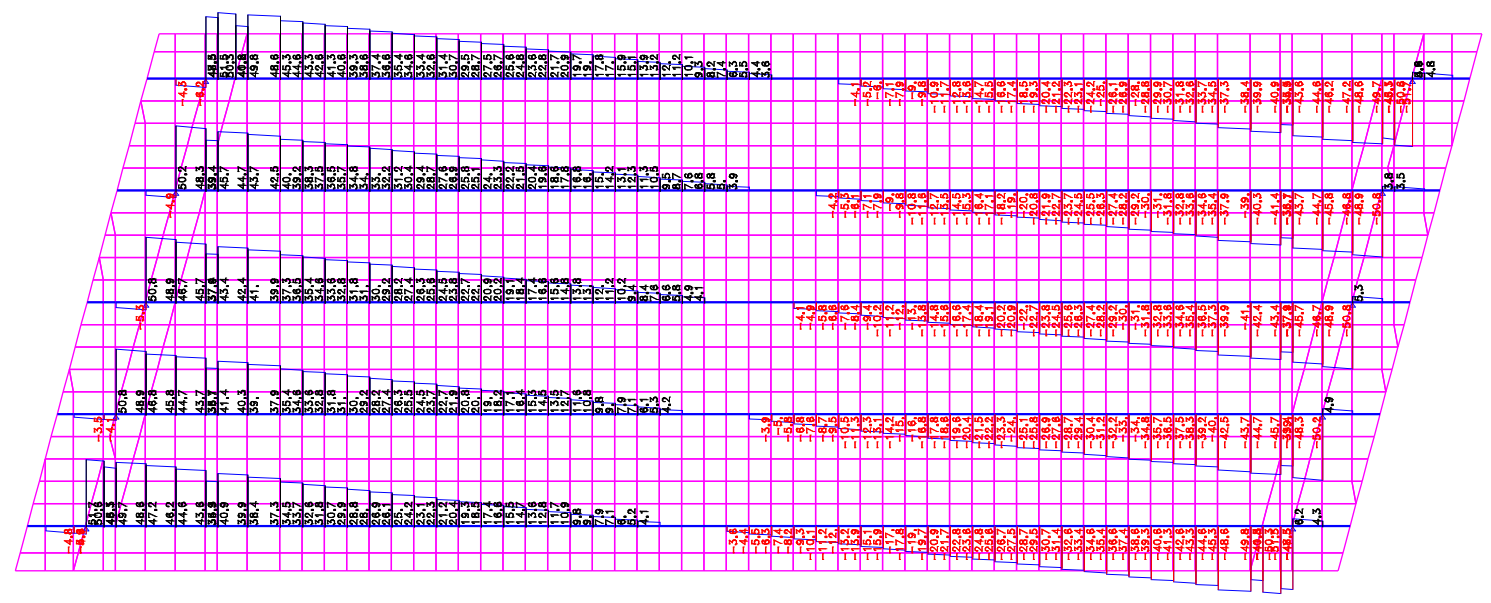


Móvel - Envoltória

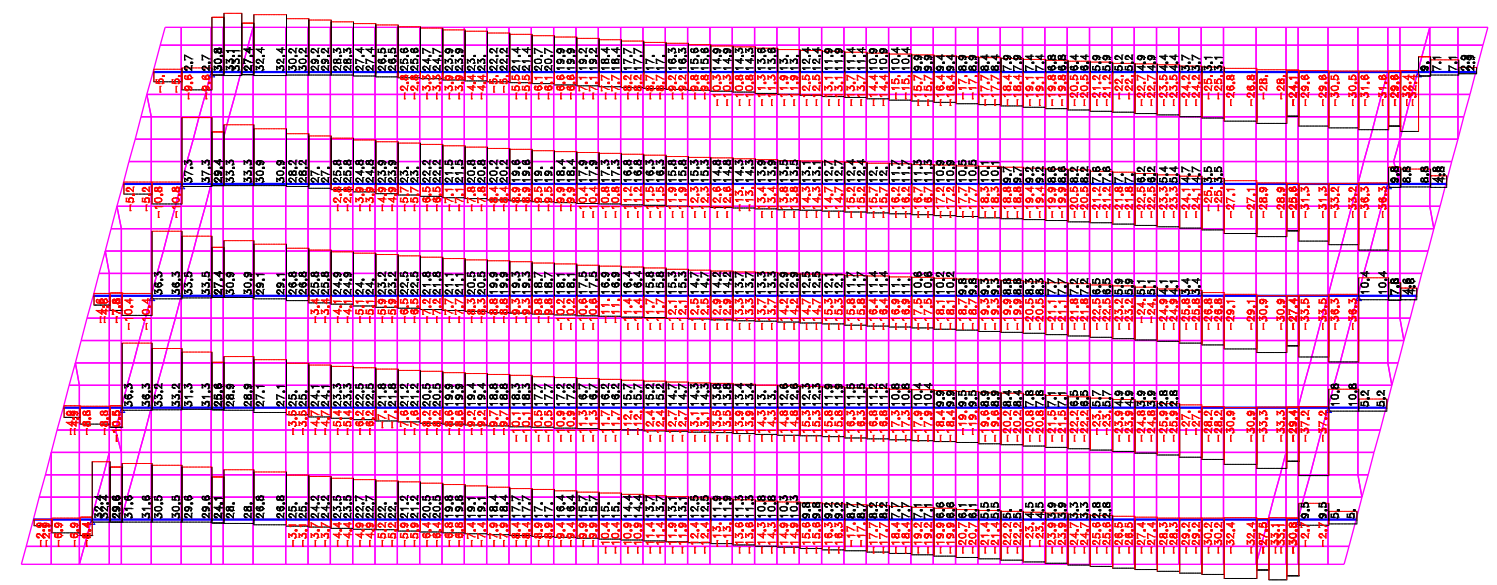

Torção

Permanente

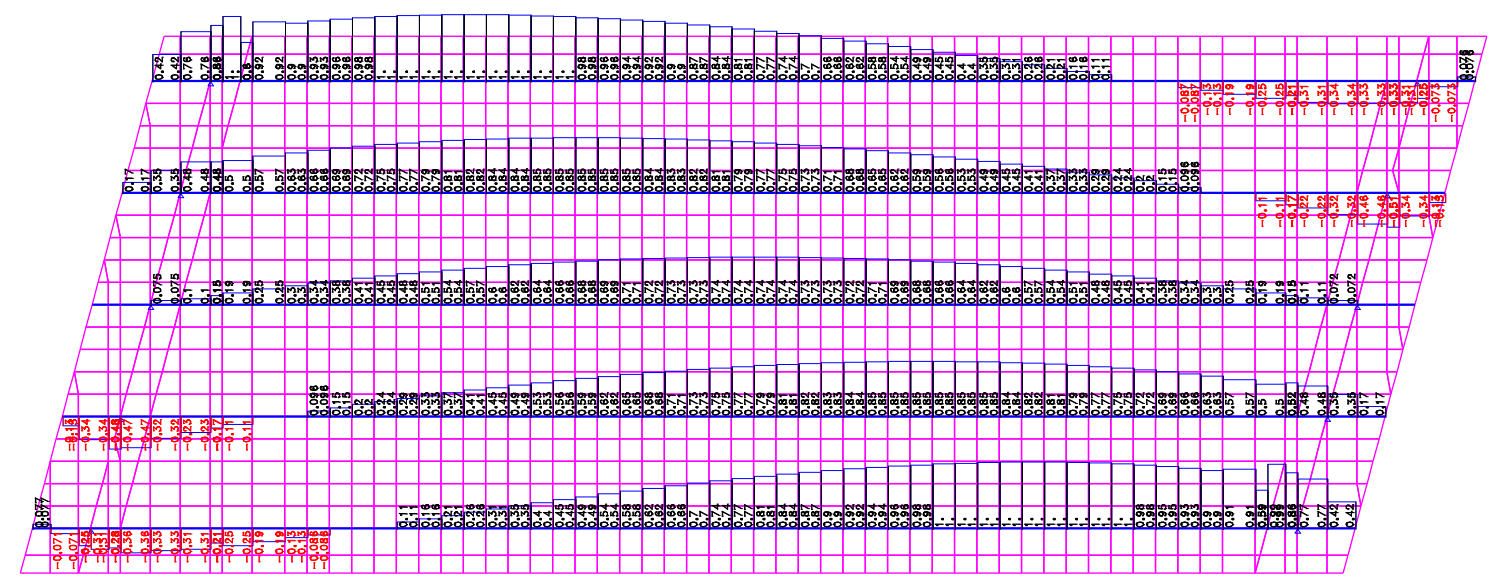

\section{Móvel - Envoltória}

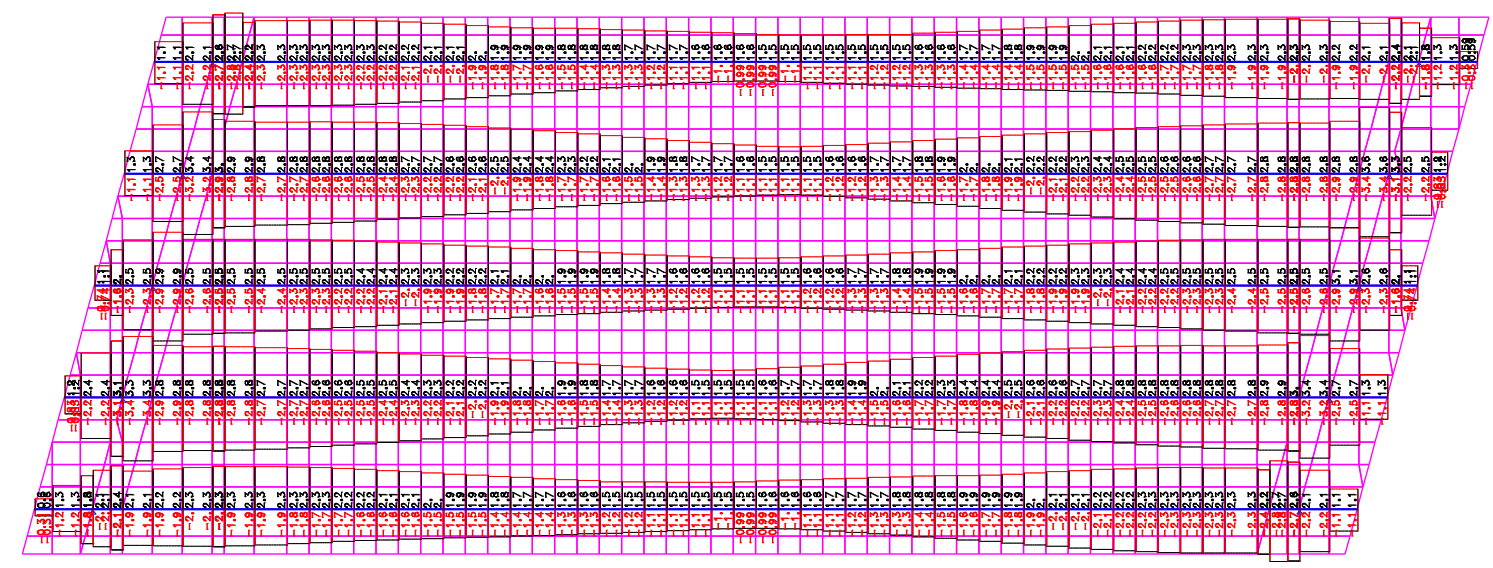


Reações nos Apoios

Permanente

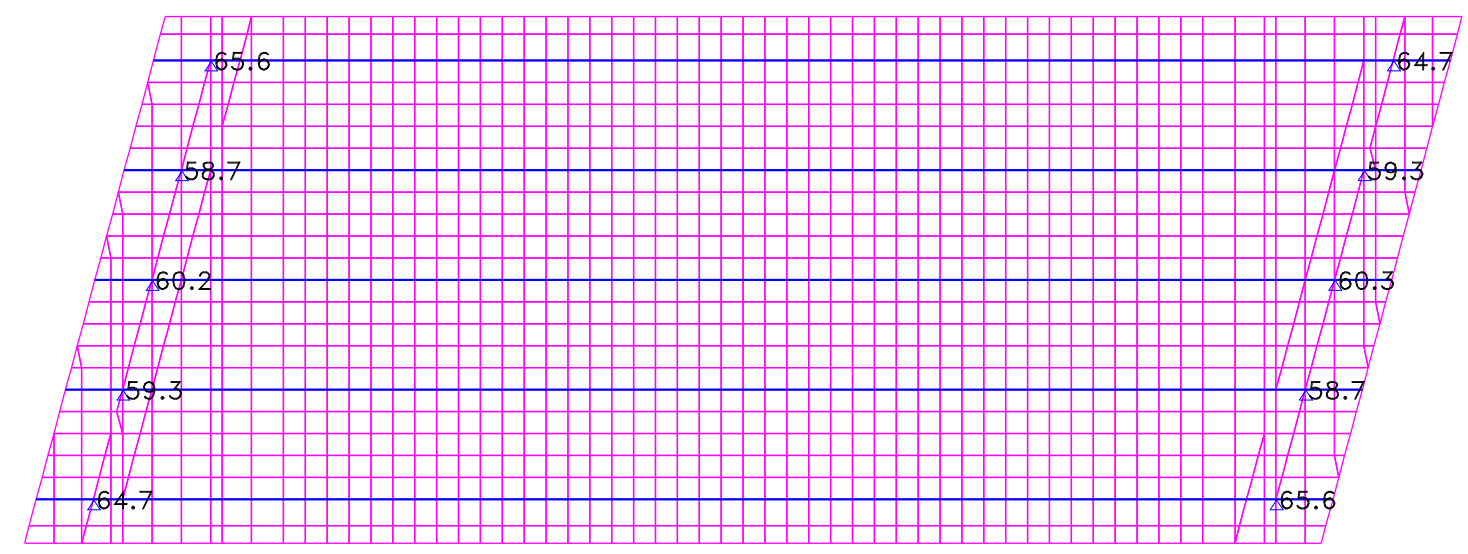

Móvel - Envoltória

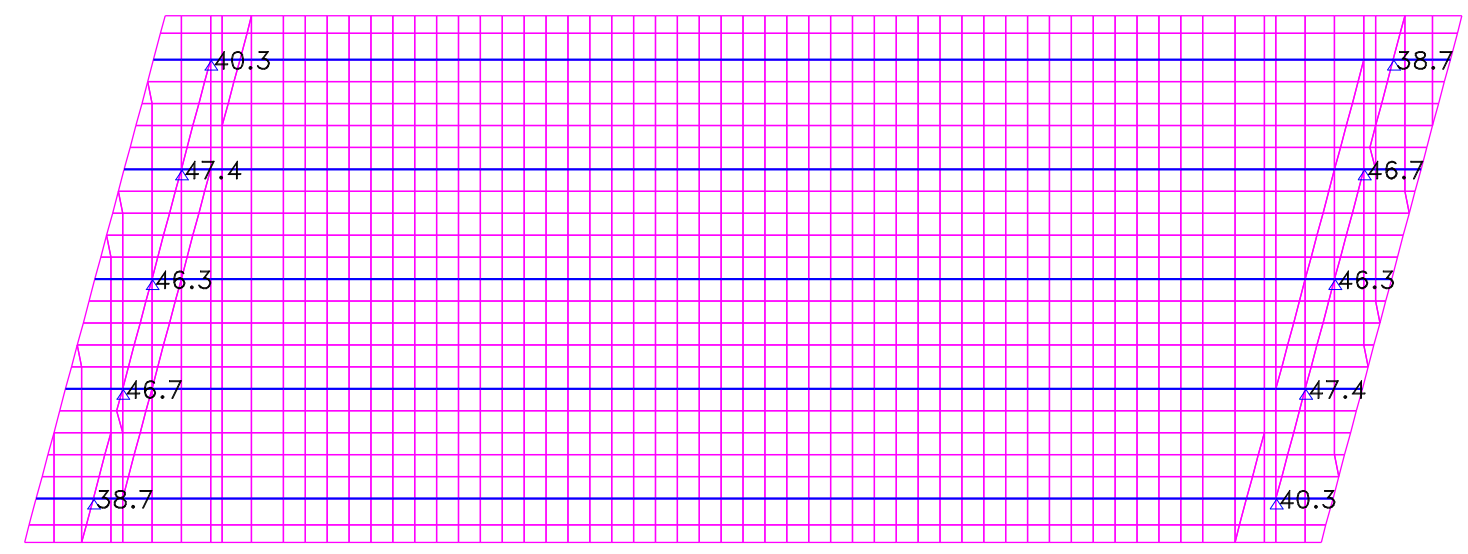


Solicitações nas Grelhas com $30^{\circ}$ de esconsidade

Longarina

Momento Fletor

Permanente

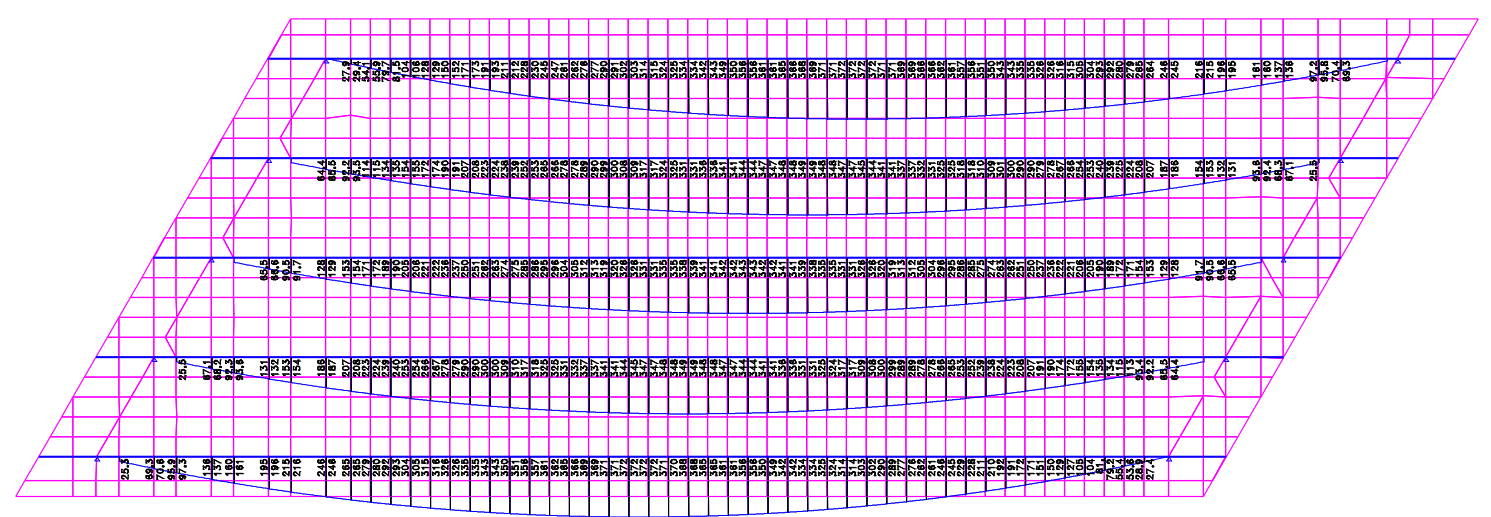

Móvel - Envoltória

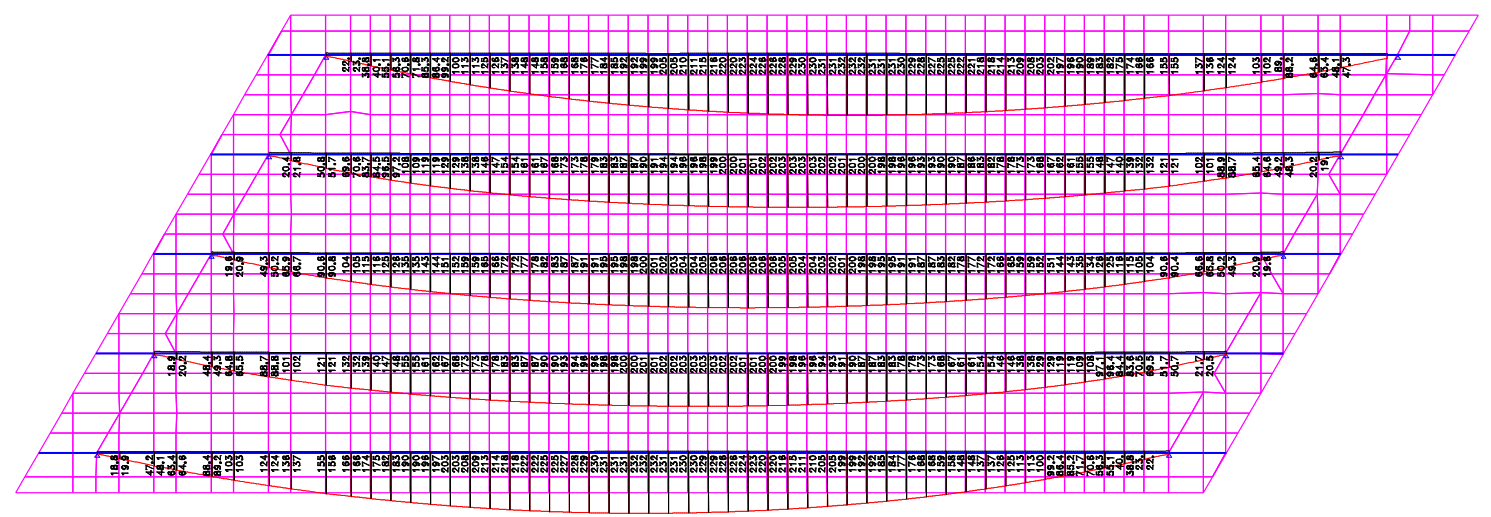

Força Cortante

Permanente

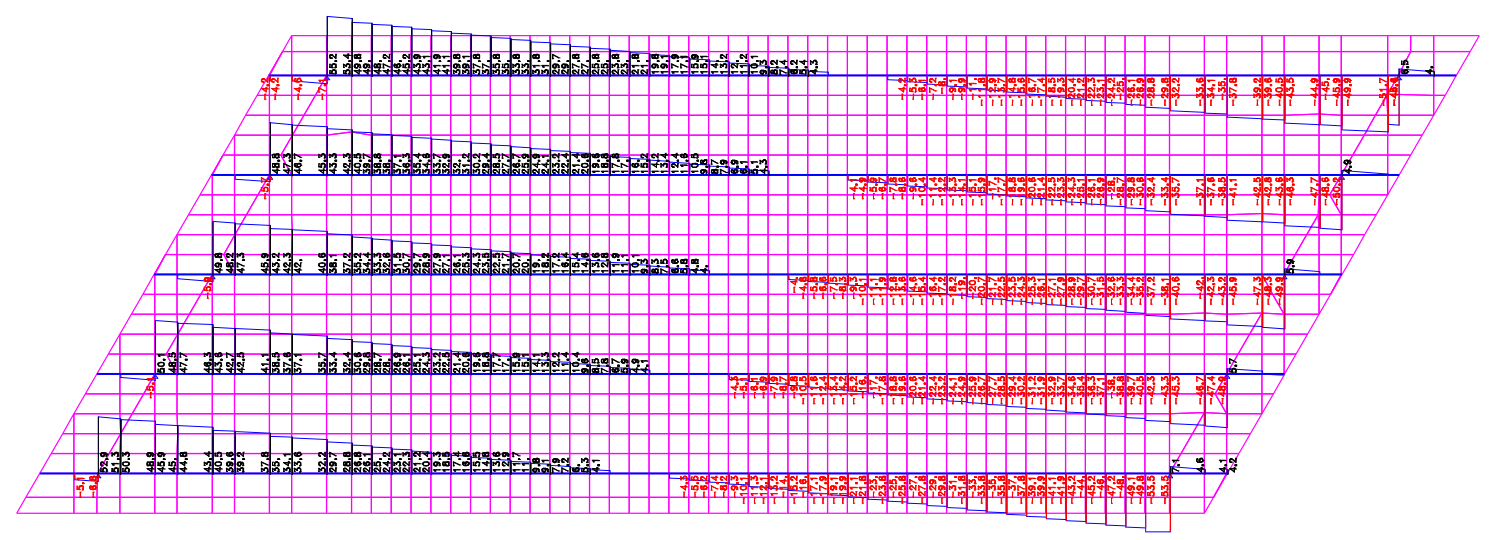


Móvel - Envoltória

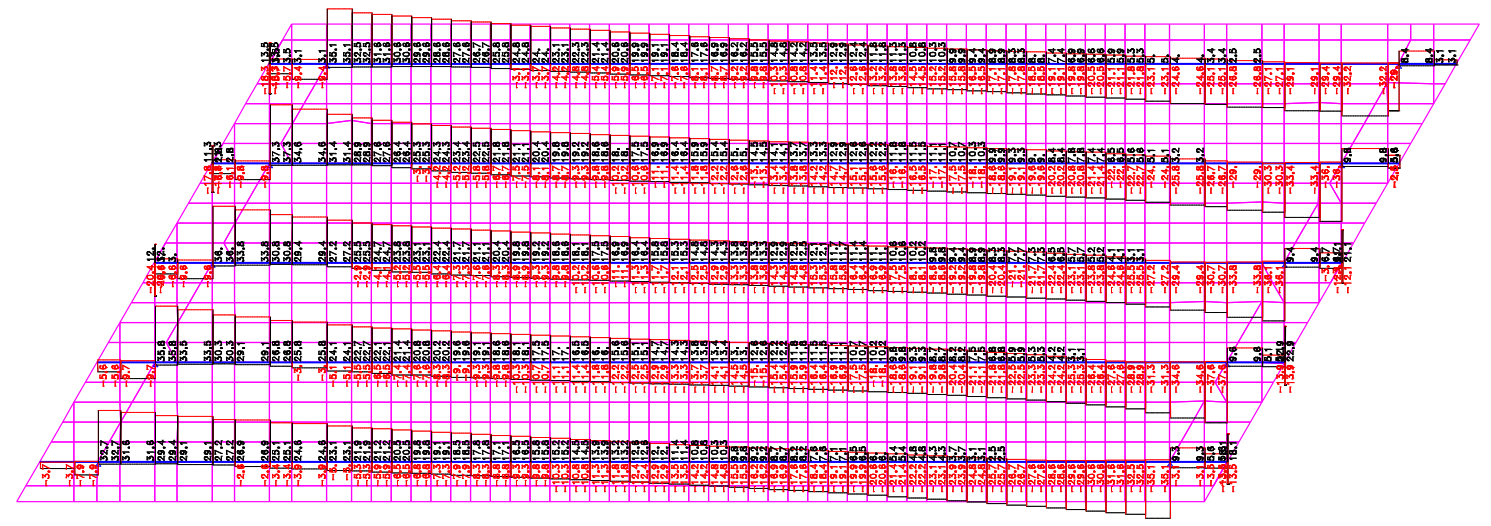

Torção

Permanente

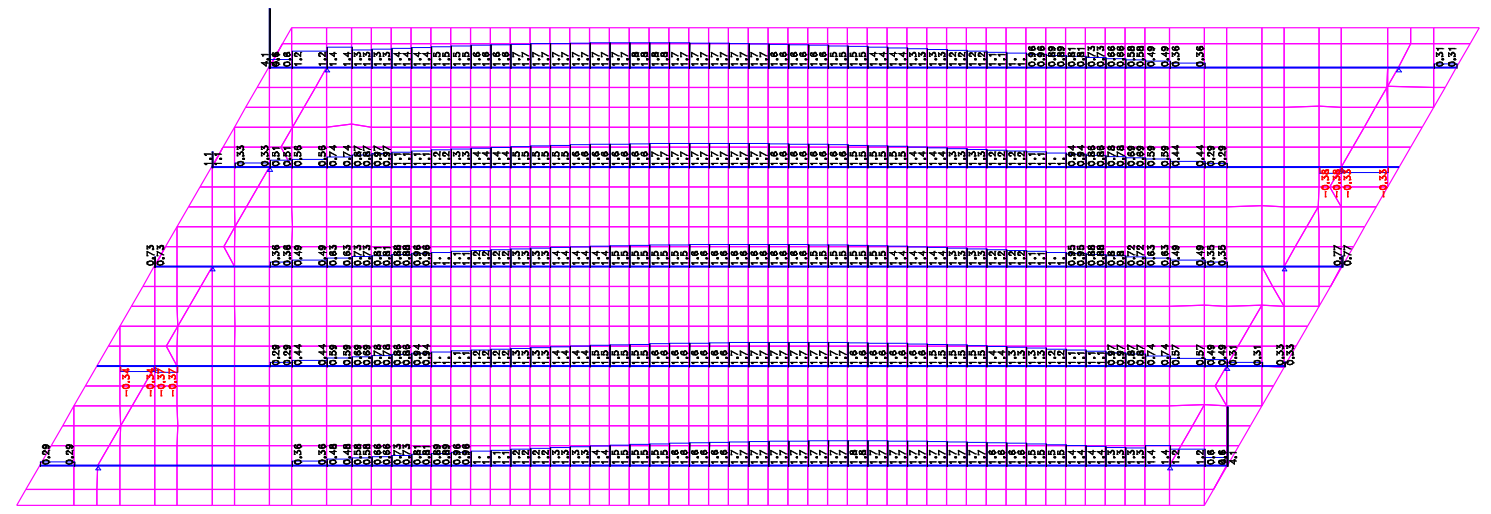

Móvel - Envoltória

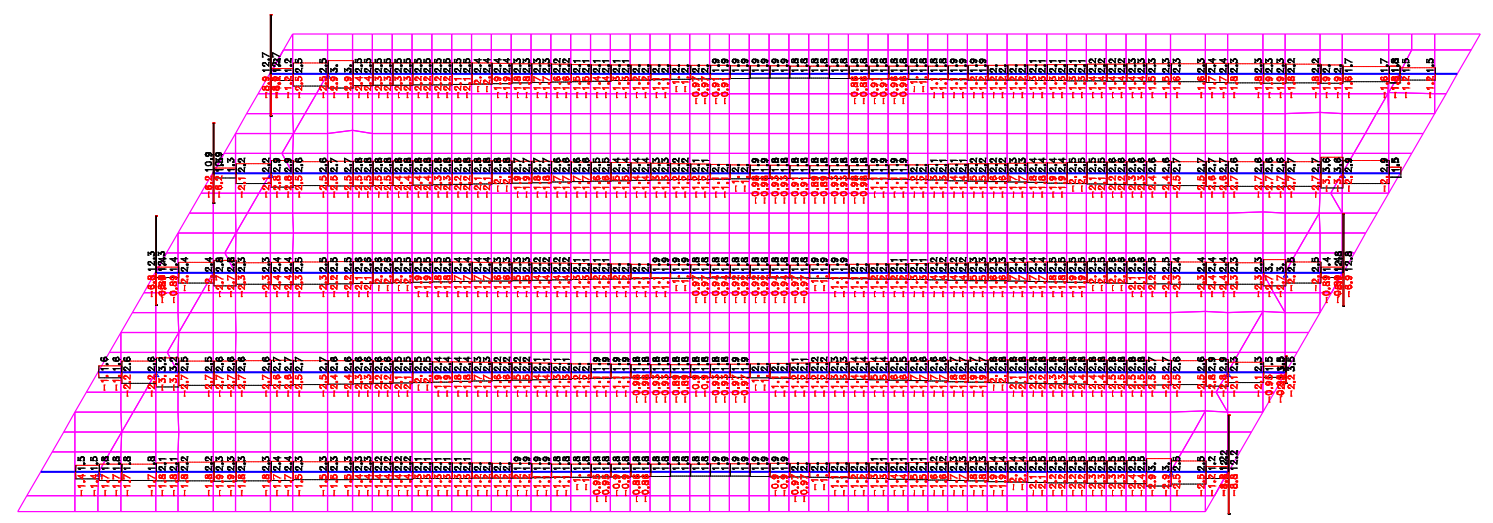


Reações nos Apoios

Permanente

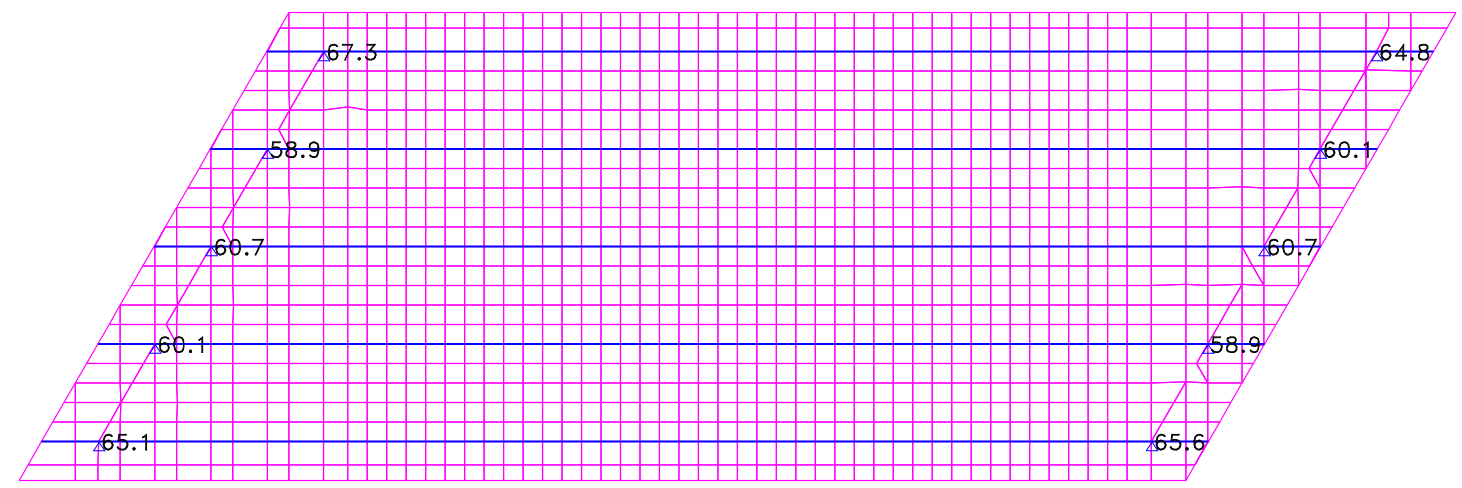

Móvel - Envoltória

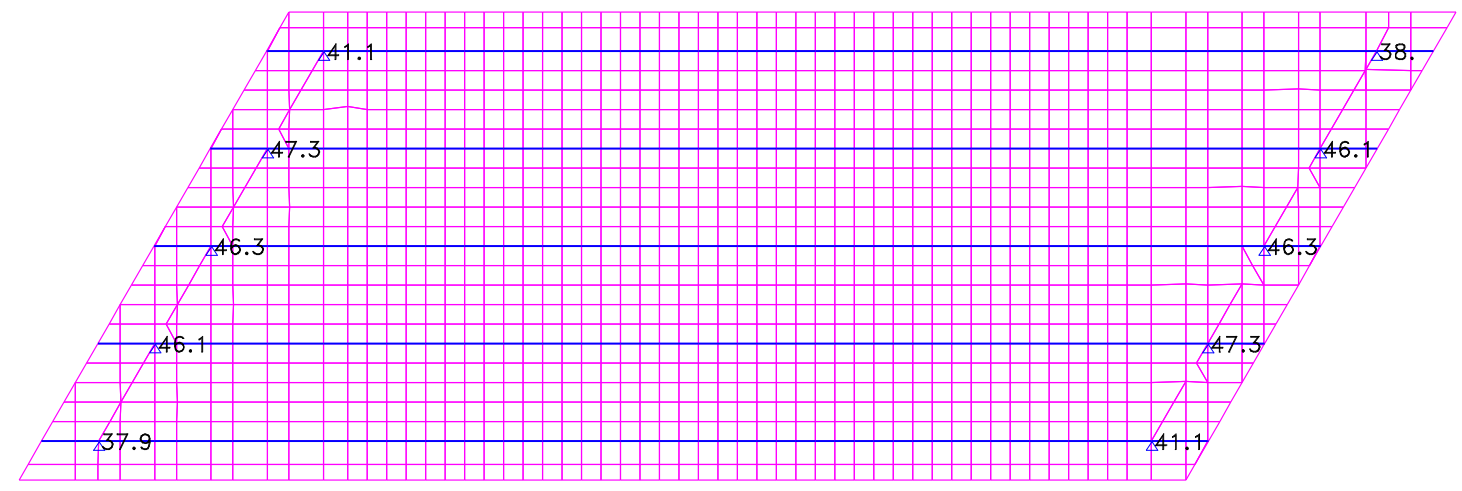


Solicitações nas Grelhas com $45^{\circ}$ de esconsidade

Longarina

Momento Fletor

Permanente

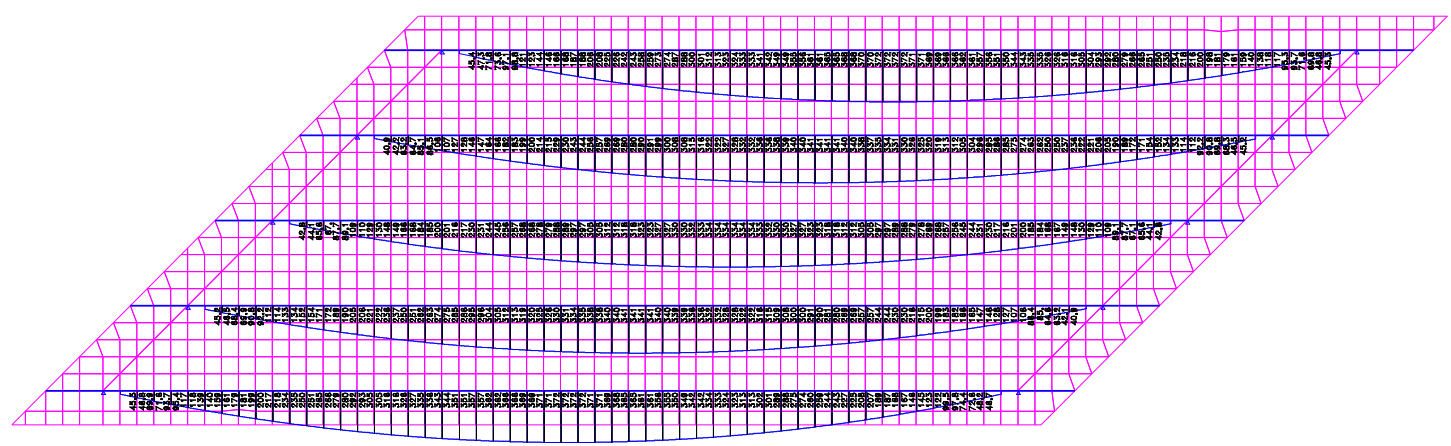

Móvel - Envoltória

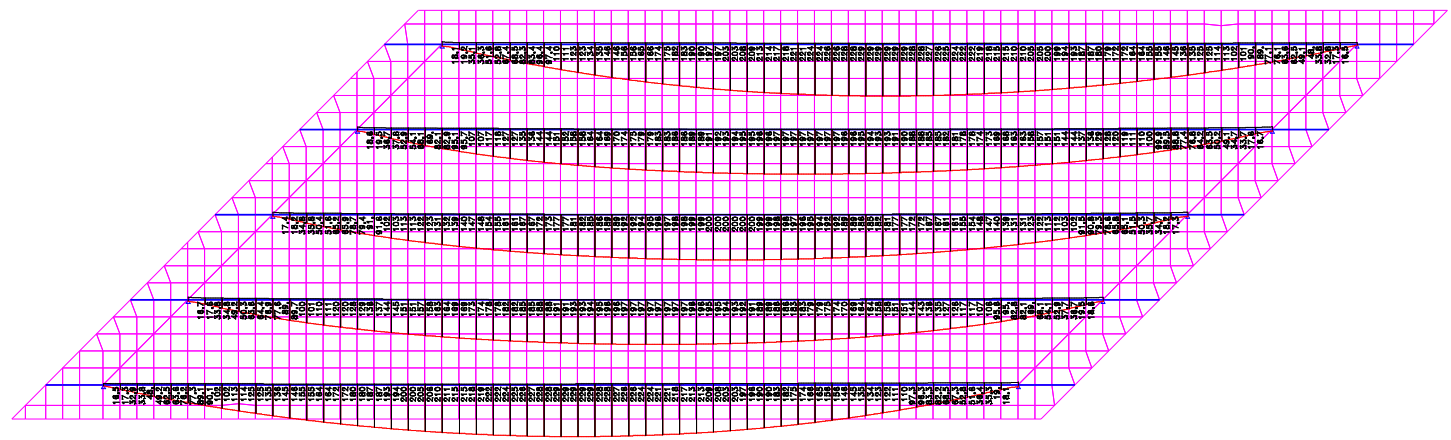

Força Cortante

Permanente

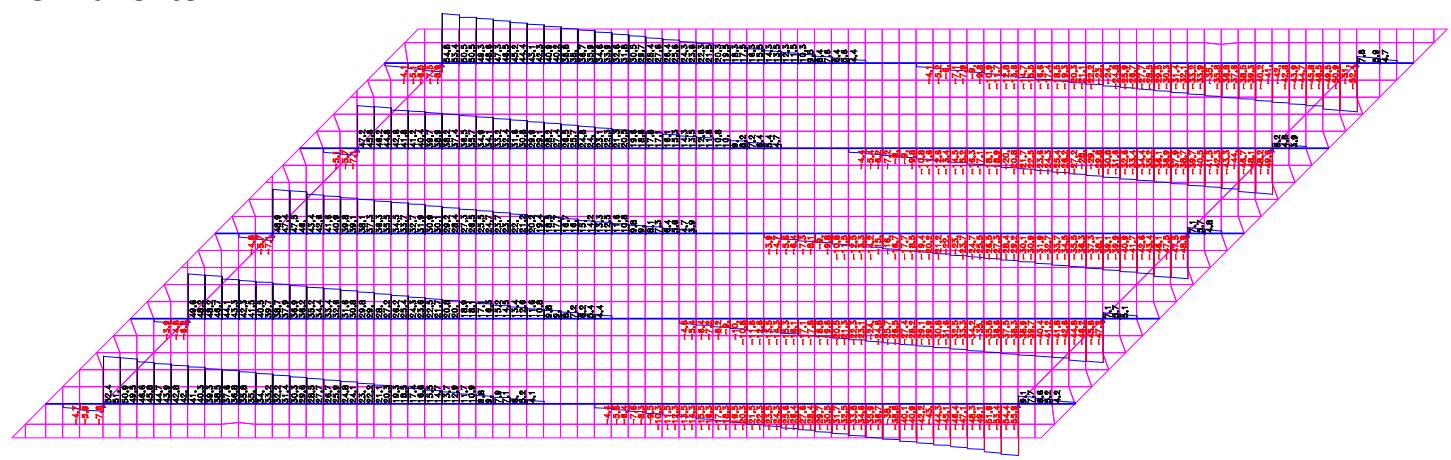




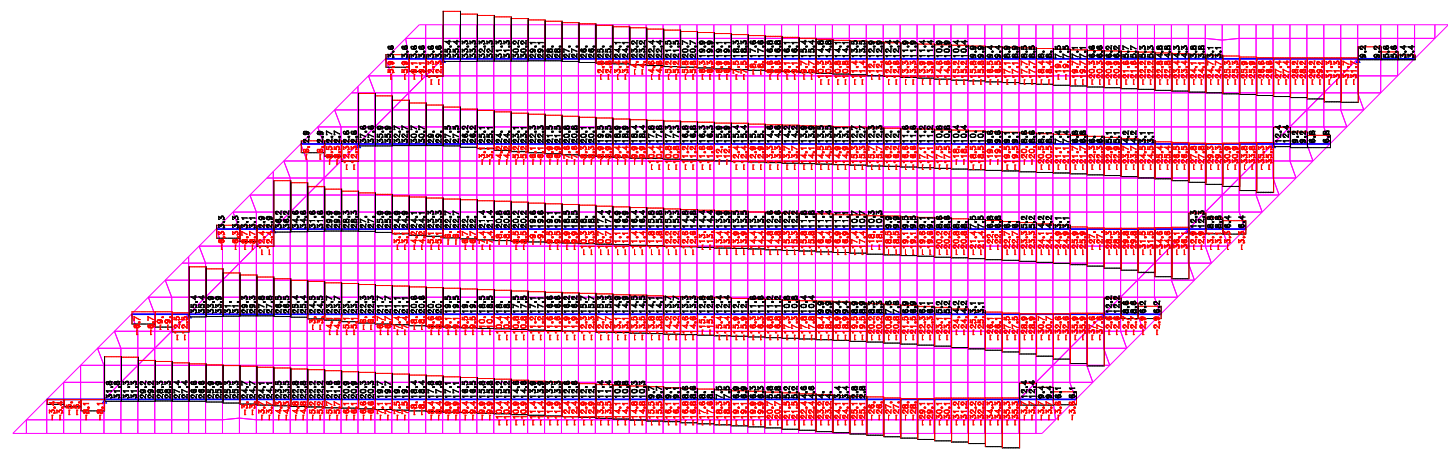

\section{Permanente}

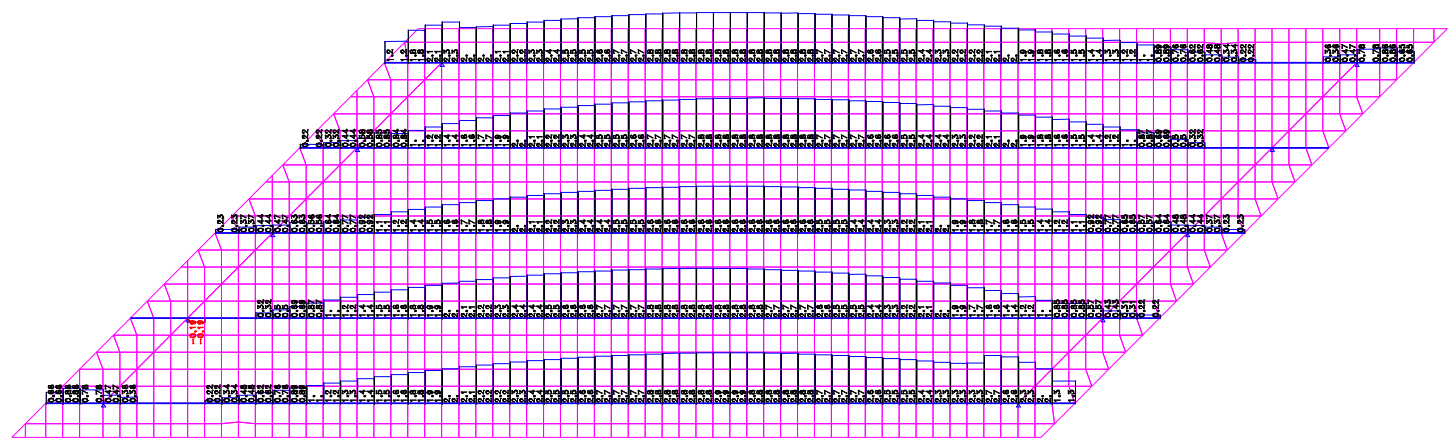

\section{Móvel - Envoltória}

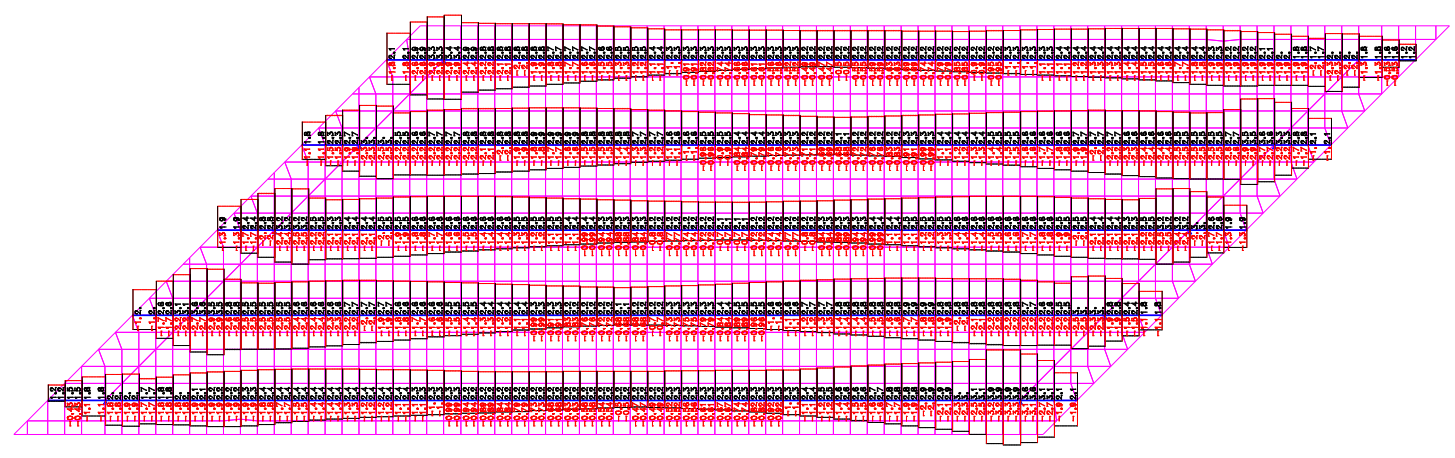


Reações nos Apoios

Permanente

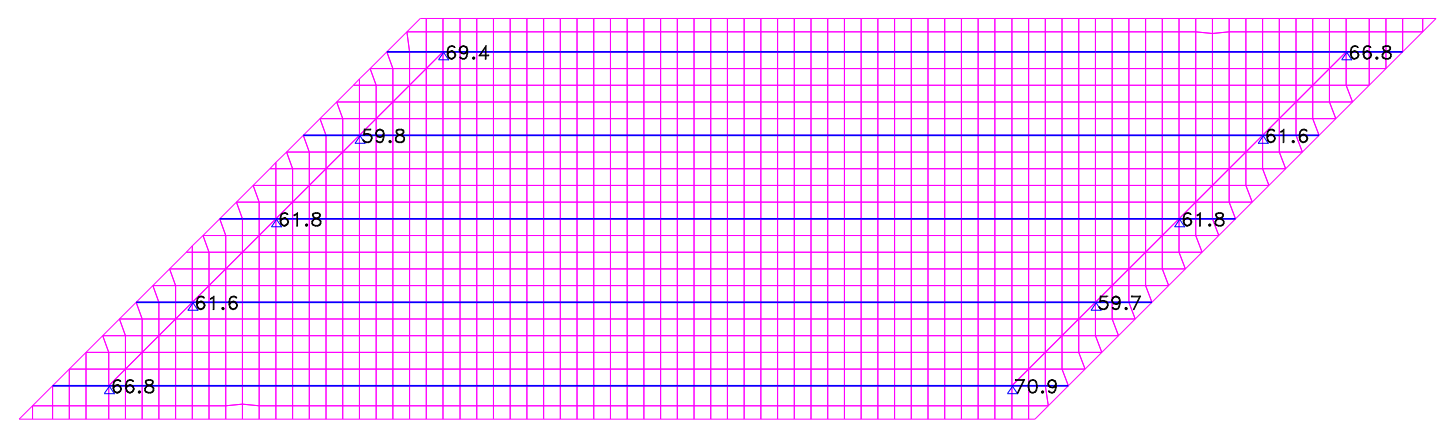

Móvel - Envoltória

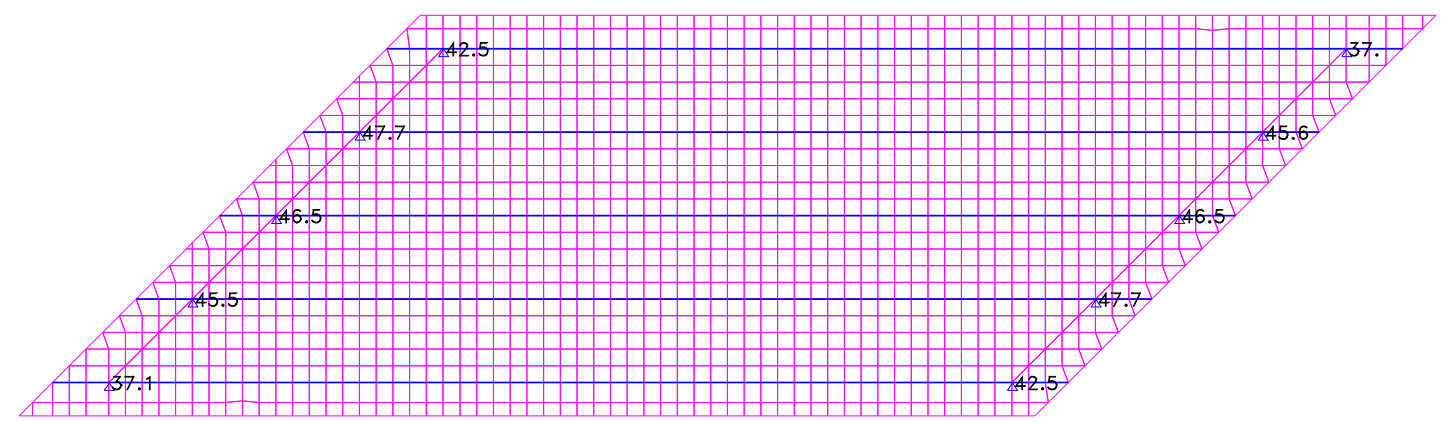


Solicitações nas Grelhas com $60^{\circ}$ de esconsidade

Longarina

Momento Fletor

Permanente

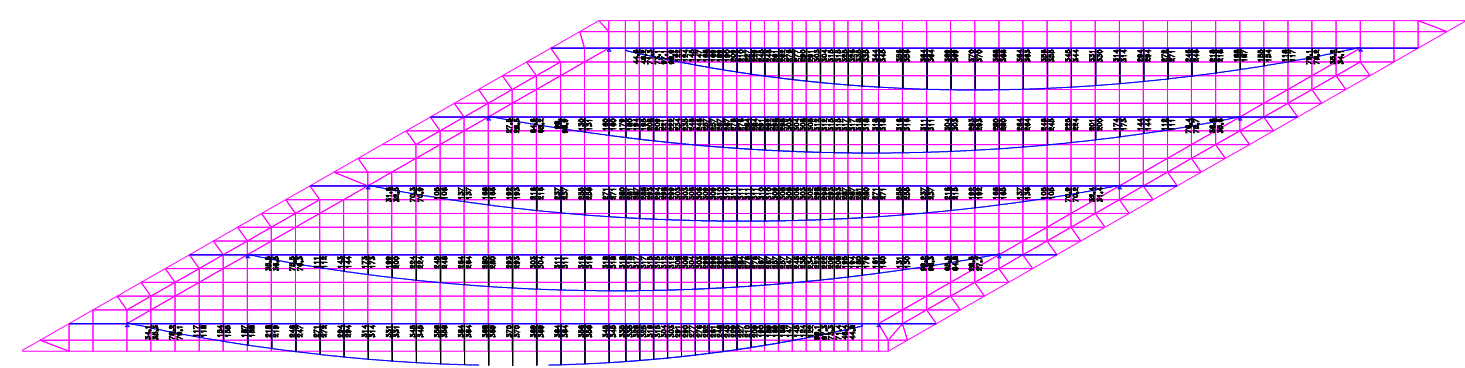

Móvel - Envoltória

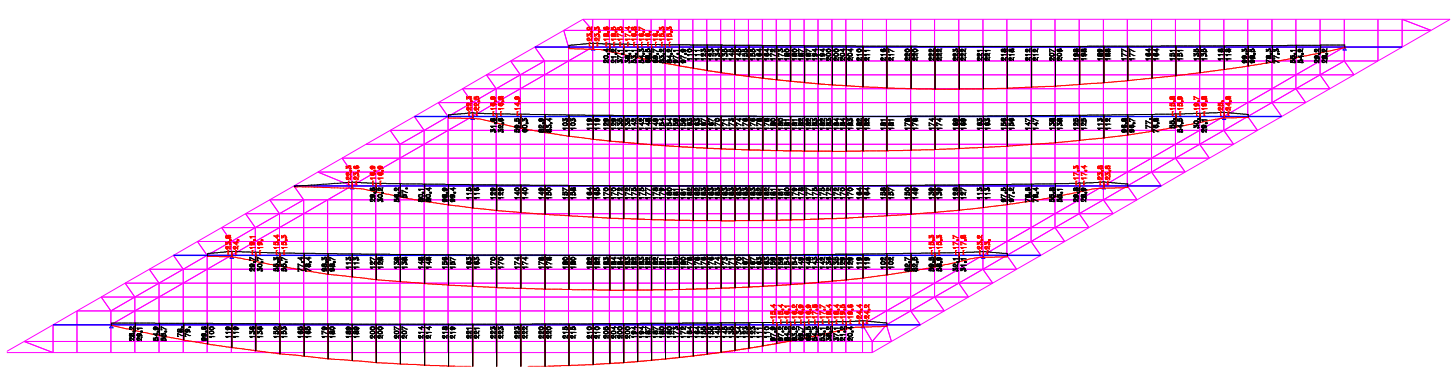

Força Cortante

Permanente

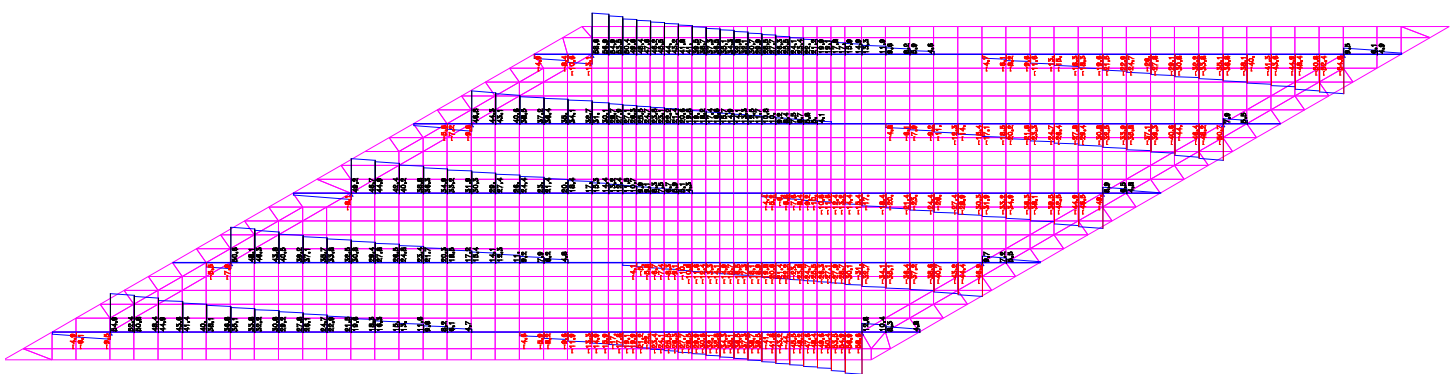


Móvel - Envoltória

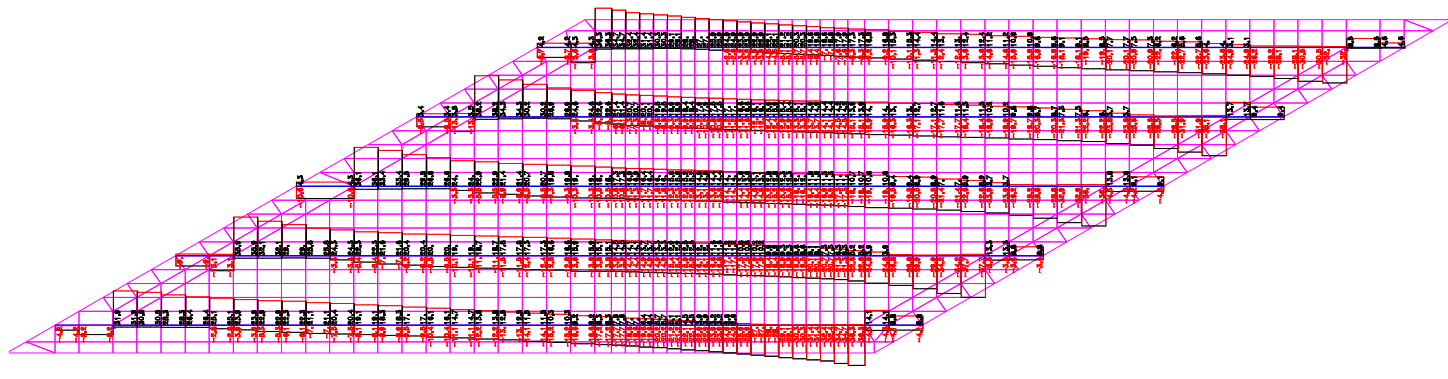

Permanente

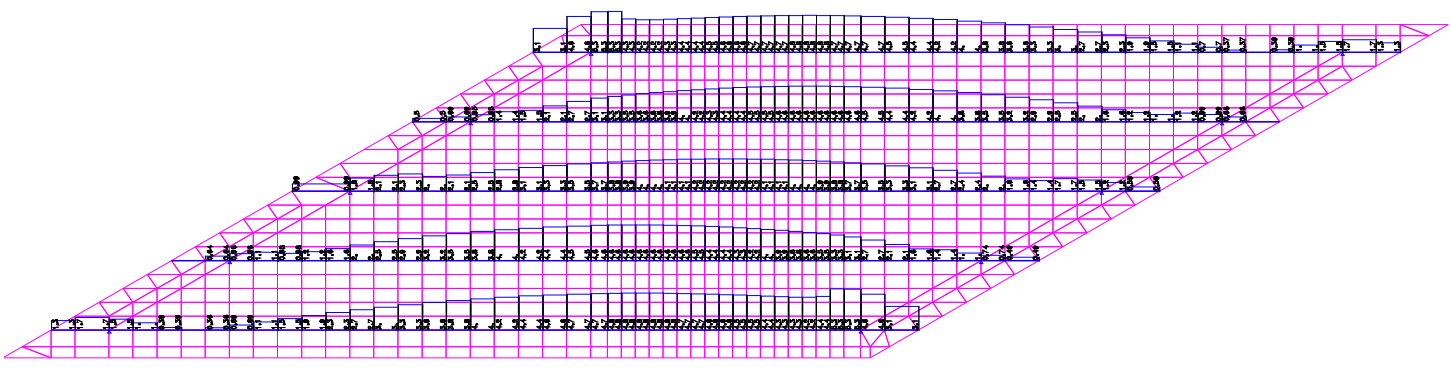

Móvel - Envoltória

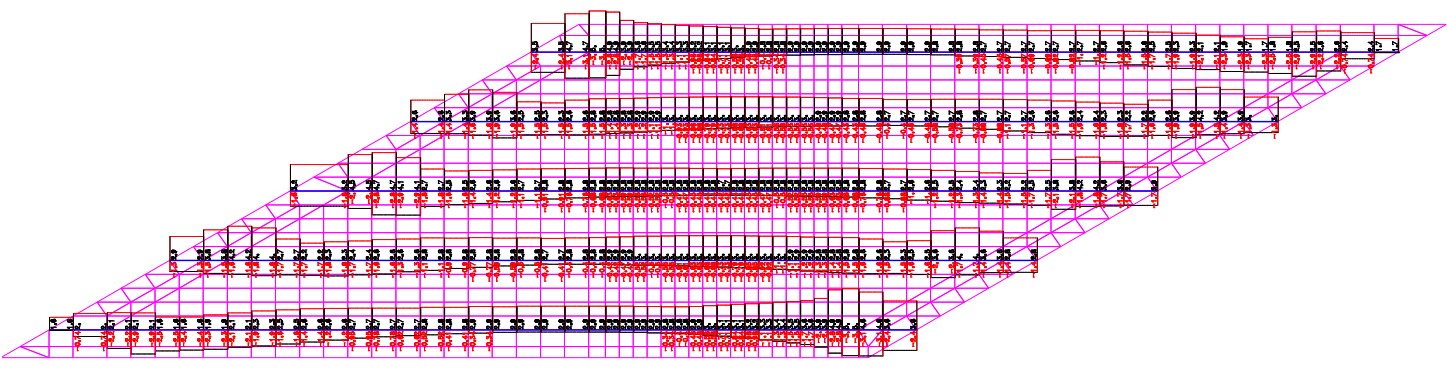


Reações nos Apoios

Permanente

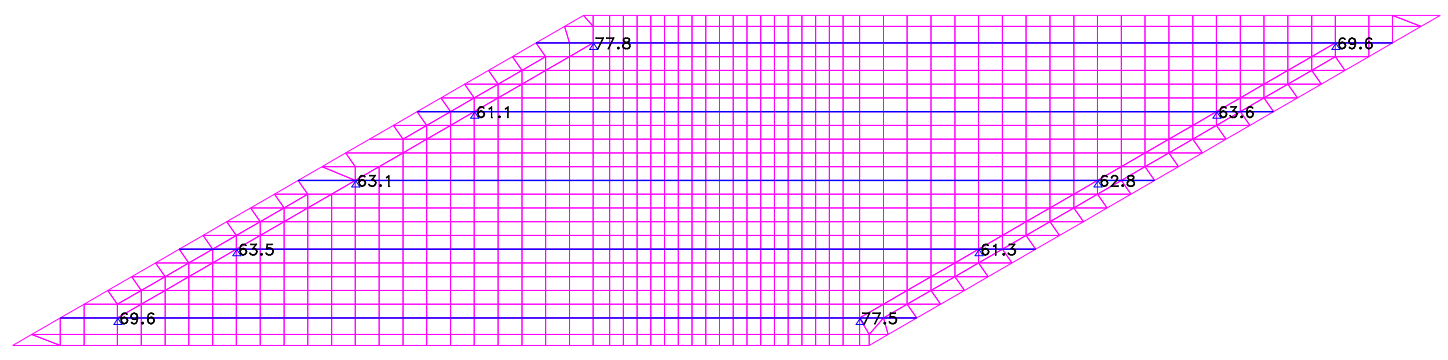

Móvel - Envoltória

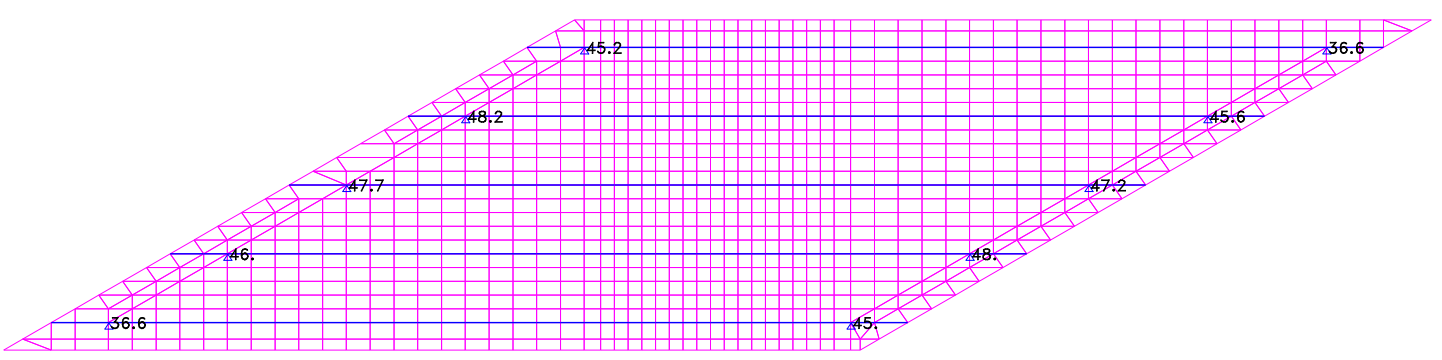

